\title{
PROPOSTA PARA A ESTIMATIVA DA RESISTÊNCIA À COMPRESSÃO UNIAXIAL IN SITU DE CAMADAS DE CARVÃO COM A UTILIZAÇÃO DE GEOFÍSICA
}

\section{CLOVIS GONZATTI}

Tese apresentada à Escola de Engenharia de São Carlos, da Universidade de São Paulo, como parte dos requisitos para obtenção do Título de Doutor em Geotecnia.

ORIENTADOR: Prof. Dr. Tarcísio Barreto Celestino

São Carlos

2007 


\section{AUTORIZO A REPRODUÇÃO E DIVULGAÇÃO TOTAL OU PARCIAL DESTE TRABALHO, POR QUALQUER MEIO CONVENCIONAL OU ELETRÔNICO, PARA FINS DE ESTUDO E PESQUISA, DESDE QUE CITADA A FONTE.}

Ficha catalográfica preparada pela Seção de Tratamento da Informação do Serviço de Biblioteca - EESC/USP

Gonzatti, Clovis

G643p Proposta para a estimativa da resistência à compressão uniaxial in situ de camadas de carvão com a utilização de geofísica / Clovis Gonzatti ; orientador Tarcísio Barreto Celestino. -- São Carlos, 2007.

Tese (Doutorado-Programa de Pós-Graduação e Área de Concentração em Geotecnia) -- Escola de Engenharia de São Carlos da Universidade de São Paulo, 2007.

1. Carvão - resistência. I. Título. 


\section{FOLHA DE JULGAMENTO}

Candidato: Engenheiro CLOVIS GONZATTI

Tese defendida e julgada em 08/02/2008 perante a Comissão Julgadora:

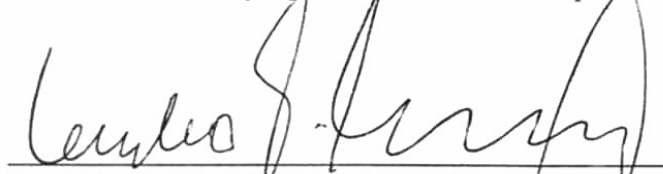

Prof. Dr. TARCISIO BARRETO CELESPINO (Orientador)

(Escola de Engenharia de São Carlos/USP)

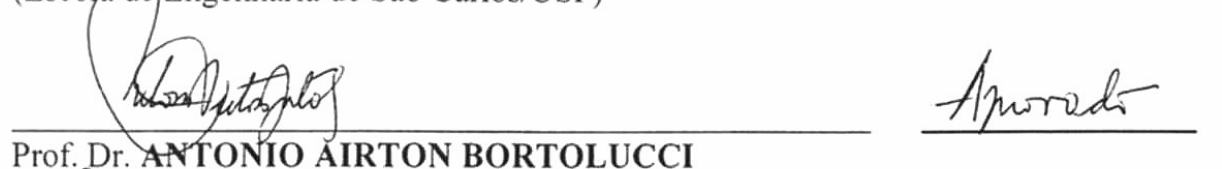

Prof. Dr. ANTONIO AIRTON BORTOLUCCI

(Escola de Engenharia de São Carlos/USP)

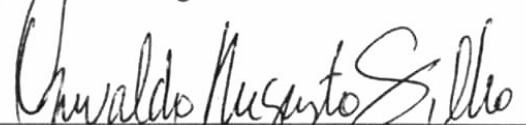

Prof. Dr. OSWALDO AUGUSTO FILHO

(Escola de Engenharia de São Carlos/USP)

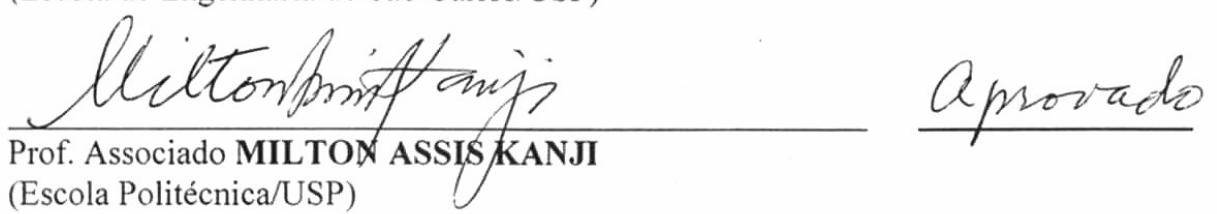

(Escola Politécnica/USP)

PYof. Dr. JOSÉ LINS ROLIM FILHO

(Universidade Federal de Pernambuco/UFPE)
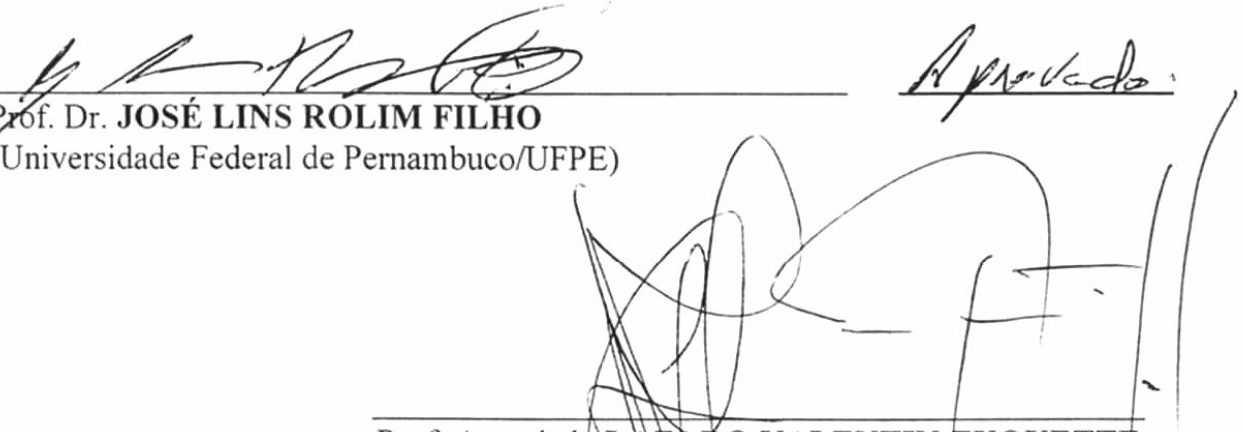

Prof. Associado LAZARO VALENTIN ZUQUETTE

Coordenador de Programa-de Pós-Graduação em Geotecnia

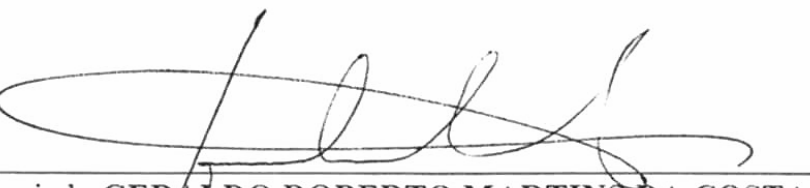

Prof. Associado GERALDO ROBERTO MARTINSD̀DA COSTA Presidente da Comissão da Pós-Graduação da EESC 
- 
Aos meus pais, Mário e Vicença, por sempre acreditarem no valor da educação.

À minha esposa, Carla Giane, pela parceria indestrutível. 


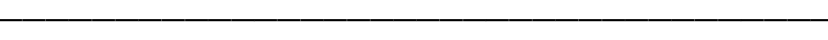




\section{Agradecimentos}

À CIENTEC - Fundação de Ciência e Tecnologia do Estado do Rio Grande do Sul, de Porto Alegre - RS, e à Carbonífera Metropolitana S/A, de Criciúma - SC. Este trabalho foi viabilizado pelo apoio incondicional dessas empresas, através do Termo de Cooperação Técnica e Termo Aditivo $\mathrm{N}^{0} 1$, celebrados em 30 de maio de 2001.

À Carbonífera Belluno LTDA. e à Minageo LTDA. pelo fornecimento de amostras, disponibilização dos resultados de laboratório e apoio logístico para a realização de levantamentos geofísicos nas Minas Morozini Norte e Santa Augusta Norte, respectivamente.

Aos recursos humanos da área de mecânica e tecnologia de rochas do Departamento de Geotecnia da CIENTEC, porque foram os co-idealizadores, apoiadores incondicionais e críticos propositivos.

Aos recursos humanos da Carbonífera Metropolitana S/A, pela disposição constante e espírito cooperativo.

Ao Eng. Édison Douglas Montedo (in memorium), pelo seu espírito incentivador enquanto esteve conosco. 


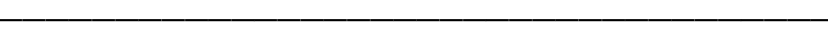




\section{Sumário}

Lista de Figuras v v

Lista de Tabelas xiii

Lista de Abreviaturas $\quad$ xix

Lista de Símbolos/Variáveis xix

Resumo xxiii

Abstract Xxv

1 Introdução 1

2 Revisão da Literatura 5

2.1 Introdução 5

2.2 Métodos de Dimensionamento de Pilares 6

2.3 Métodos Utilizados para a Determinação da Resistência In Situ 13

$\begin{array}{lll}2.3 .1 & \text { Introdução } & 13\end{array}$

2.3.2 Efeito Escala em Materiais Rochosos 14

2.3.3 Técnicas Diretas para a Determinação da Resistência In Situ de 22 Camadas de Carvão

2.3.3.1 Ensaios de Compressão Uniaxial em Laboratório 25

2.3.3.2 Ensaios de Compressão Triaxial em Laboratório 33

2.3.3.3 Ensaios de Compressão Uniaxial In Situ 36

2.3.4 Abordagem Geomecânica na Definição da Resistência In Situ $\quad 44$

2.3.4.1 Uso de Classificações Geomecânicas Associadas a Critérios $\quad 46$ de Ruptura

2.3.4.2 Uso da Velocidade de Propagação de Ondas 54

2.3.5 Estimativa da Resistência In Situ a Partir da Análise de Casos de 56 Ruptura de Pilares

3 Aspectos Geológicos dos Jazimentos de Carvão no 63 Brasil

3.1 Introdução 63

3.2 Classificação das Bacias 63

3.3 Aspectos da Geologia Regional e Local 64

$\begin{array}{lll}\text { 3.3.1 Camada Bonito } & 67\end{array}$

3.3.2 Camada Irapuá 68

3.4 Fatores Geológicos que Afetam a Lavra de Carvão 69 


\section{Ensaios de Laboratório e Investigações In Situ}

4.1 Ensaios para a Determinação do Efeito Escala na Resistência à

Compressão Uniaxial do Carvão da Camada Bonito - Mina Fontanella

4.1.1 Extração das Amostras, Preparação dos Corpos-de-Prova e Execução dos Ensaios

4.1.2 Resultados Obtidos 74

4.1.3 Discussão dos Resultados dos Ensaios para Determinação do 79 Efeito Escala na Resistência à Compressão Uniaxial no Carvão da Camada Bonito - Mina Fontanella

Teor de cinzas 79

Velocidade de propagação da onda ultra-sônica 80

Deformabilidade 83

Resistência à compressão uniaxial

4.2 Ensaios para a Determinação da Envoltória de Resistência do Carvão da Camada Bonito - Mina Fontanella

4.2.1 Preparação dos Corpos-de-Prova e Execução dos Ensaios

4.2.2 Resultados Obtidos

4.3 Ensaios para a Determinação da Resistência à Compressão Uniaxial 94 do Carvão da Camada Irapuá - Minas Morozini Norte e Santa Augusta Norte

4.3.1 Extração das Amostras, Preparação dos Corpos-de-Prova e 94 Execução dos Ensaios

4.3.2 Resultados Obtidos

4.4 Mapeamento Estrutural da Camada de Carvão Bonito na Mina Fontanella

4.4.1 Introdução 97

4.4.2 Execução das Medições 98

4.4.3 Tratamento dos Dados de Campo 104

4.4.4 Resultados Obtidos 105

4.4.4.1 Orientação das Fraturas 105

$\begin{array}{lll}\text { 4.4.4.2 } & \text { Freqüência de Fraturas } & 107\end{array}$

$\begin{array}{lll}\text { 4.4.4.3 Persistência das Fraturas } & 107\end{array}$

4.4.4.4 Características dos Contatos Entre os Planos das Fraturas 113

4.4.5 Discussão dos Resultados do Mapeamento Estrutural 113

4.5 Investigações In Situ nas Camadas de Carvão Utilizando Geofísica 116 de Refração 
4.5.1 Equipamentos Utilizados e Procedimentos de Execução 116 Adotados

Técnica de Perfilagem

Técnica de Radiação

4.5.2 Levantamentos na Mina Fontanella 120

4.5.2.1 Resultados Obtidos 121

4.5.3 Levantamentos na Mina Morozini Norte 126

4.5.3.1 Resultados Obtidos 127

4.5.4 Levantamentos na Mina Santa Augusta Norte 129

4.5.4.1 Resultados Obtidos 130

4.5.5 Dificuldades e Limitações do Método de Levantamento nos 132 Casos Estudados

4.5.6 Discussão dos Resultados dos Levantamentos Geofísicos 132

4.6 Estudos em Laboratório Sobre a Influência da Tensão e da Água na 135

Velocidade de Propagação de Ondas

4.6.1 Introdução 135

4.6.2 Ensaios para a Determinação da Influência da Tensão na 135 Velocidade de Propagação da Onda Ultra-Sônica

4.6.2.1 Execução dos Ensaios 136

4.6.2.2 Resultados Obtidos 137

Carvão Bonito - Mina Fontanella 137

Carvão Irapuá - Mina Morozini Norte 141

Carvão Irapuá - Mina Santa Augusta Norte 143

4.6.2.3 Discussão dos Resultados 145

Percurso da onda paralelo aos planos de estratificação do 145 carvão

Percurso da onda perpendicular aos planos de estratificação do carvão

4.6.2.4 Fator de Correção da Velocidade de Ondas Sísmicas Medidas In Situ para a Condição de Tensão de Ensaio em Laboratório (Tensão $\cong 0$ )

4.6.3 Ensaios para a Determinação da Influência do Grau de 148 Saturação na Velocidade de Propagação da Onda Ultra-Sônica

4.6.3.1 Execução dos Ensaios 148

$\begin{array}{lll}\text { 4.6.3.2 Resultados Obtidos } & 150\end{array}$

4.6.3.3 Discussão dos Resultados 150 
4.6.3.4 Fator de Correção da Velocidade de Ondas Sísmicas Medidas In Situ para a Condição de Umidade Natural em Laboratório (Grau de Saturação $\cong 0$ )

5 Estimativa da Resistência In Situ da Camada de Carvão Bonito na Mina Fontanella Utilizando Diferentes Técnicas

5.1 Introdução

5.2 Aplicação dos Diferentes Métodos para a Estimativa da Resistência In Situ

5.2.1 Critério de Ruptura de Hoek-Brown

5.2.2 Critério de Wilson

5.2.3 Critérios de Ruptura de Ramamurthy, Bieniawski Genérico e Sheorey

5.2.4 Critério de Kalamaras

5.2.5 Critério de Palmstrøm 159

5.2.6 Lei do Efeito Escala de GADDY 161

5.2.7 Retro-Análise de Caso de Ruptura de Pilares na Mina Fontanella 162

5.3 Discussão dos Resultados de $S_{1}$ Obtidos Segundo as Diferentes 162

Técnicas para a Estimativa da Resistência In Situ

\section{Metodologia para a Estimativa da Resistência In Situ de Camadas de Carvão Utilizando Geofísica}

6.1 Introdução

6.2 Descrição da Metodologia

6.3 Estimativas das Resistências In Situ $\left(\mathrm{S}_{1}\right)$ para os Casos Estudados

6.4 Análise dos Resultados

6.4.1 Camada de Carvão Bonito - Mina Fontanella 170

6.4.2 Camada de Carvão Irapuá - Minas Morozini Norte e Santa 172 Augusta Norte

\section{Conclusão}

8 Recomendações

9 Referências Bibliográficas

Anexo 1 - Detalhes dos Procedimentos Adotados nos Ensaios para a Determinação do Efeito Escala na Resistência à Compressão Uniaxial do Carvão da Camada Bonito - Mina Fontanella

Anexo 2 - Tratamento dos Dados dos Levantamentos Estruturais Realizados na Camada de Carvão Bonito - Mina Fontanella 


\section{Lista de Figuras}

Figura 2.1 - Métodos para a determinação do comportamento mecânico de maciços rochosos (adaptado de NATAU, 1990)

Figura 2.2 - Concepções propostas para a expressão do efeito escala (adaptado de PROTODIAKONOV \& KOIFMAN, 1967)

Página

15

17

Figura 2.3 - Resultados de ensaios de compressão uniaxial in situ sobre o carvão da camada Witbank - África do Sul (adaptado de BIENIAWSKI, 1968a).

Figura 2.4 - Efeito escala na resistência à compressão uniaxial de rocha intacta (adaptado de HOEK \& BROWN, 1980a)

Figura 2.5 - Efeito do volume na resistência à compressão uniaxial de diferentes tipos de rocha (dados compilados de LAMA \& GONANO, 1976 e KACZYNSKI, 1986 - adaptado de BANDIS, 1990)

Figura 2.6 - Variação das propriedades da rocha com o aumento da dimensão da amostra (adaptado de GOMES, 1993)

Figura 2.7 - Diagrama idealizado para a transição entre uma amostra intacta e in situ representativa de carvão (adaptado de TRUEMAN \& MEDHURST, 1994)

Figura 2.8 - Resultados de ensaios de compressão uniaxial em laboratório e in situ com materiais da camada de carvão $11 \mathrm{~F}$ da Mina Charqueadas no RS (MIDÉA et al., 1985)

Figura 2.9 - Resultados de ensaios de compressão uniaxial em laboratório em in situ com materiais da camada de carvão Barro Branco da jazida Sul-Catarinense (adaptado de CIENTEC, 1990; ZORZI et al., 1998; AGOSTINI et al., 2002).

Figura 2.10 - Configurações utilizadas para a realização de ensaios de compressão uniaxial in situ sobre grandes amostras (adaptado de VAN HEERDEN, 1975)

Figura 2.11 - Curva "tensão x deformação" obtida em ensaio in situ em corpo-de-prova com relação largura/altura $=2$, no carvão da camada Usutu - África do Sul. Nos histogramas, distribuição das tensões nas diferentes fases de carregamento (WAGNER, 1974, adaptado de JAEGER \& COOK, 1977).

Figura 2.12 - Perfil litológico típico dos corpos-de-prova ensaiados in situ nas camadas brasileiras I1F e Barro Branco (AGOSTINI et al., 2002)

Figura 2.13 - Detalhe do corpo-de-prova ensaiado in situ na camada de carvão Barro Branco, após a ruptura (AGOSTINI et al., 2002) 
Figura 2.14 - Influência da tensão axial $(P c)$ e da abertura da fratura (b) na determinação da velocidade de propagação de ondas sônicas. a) estudos em rochas como granito e diorito (adaptado de TANIMOTO \& IKEDA, 1983); b) estudos sobre arenito (adaptado de WU et al., 1991)

Figura 2.15 - Variação da resistência do pilar em função da sua 62 geometria ( $\mathrm{h}_{\text {constante }}=2 \mathrm{~m}$ ), segundo diferentes equações propostas: a) para os carvões da ÁFRICA DO SUL; b) para os carvões da AUSTRÁLIA

Figura 3.1 - Mapa geológico do sul do Brasil com a indicação das bacias carboníferas conhecidas. Bacia IX = Sul-Catarinense (COSTA, 2000)

Figura 3.2 - Mapa de localização com a indicação, em azul, da área de concessão da Mina Fontanella (COSTA, 2000)

Figura 3.3 - Perfil estratigráfico típico da formação Rio Bonito (COSTA, 2000)

Figura 3.4 - Perfil típico da camada de carvão Bonito (COSTA, 2000)

Figura 3.5 - Perfis típicos da camada Irapuá nas áreas das Minas Morozini Norte (região de Rio Maina) e Santa Augusta Norte (região de Criciúma) - (adaptado de CIENTEC, 1990)

Figura 4.1 - Pontos de coleta de amostras de carvão da camada Bonito, na Mina Fontanella.

Figura 4.2 - Corpos-de-prova cúbicos utilizados nos estudos do efeito escala no carvão da camada Bonito, da Mina Fontanella.

Figura 4.3 - Resultados das determinações do teor de umidade nos corpos-de-prova após os ensaios, para os diferentes tamanhos de corpos-de-prova ensaiados.

Figura 4.4 - Resultados das determinações do teor de cinzas, para os diferentes tamanhos de corpos-de-prova ensaiados.

Figura 4.5 - Resultados das determinações da massa específica aparente, para os diferentes tamanhos de corpos-de-prova ensaiados.

Figura 4.6a - Resultados das determinações da velocidade de propagação da onda ultra-sônica (onda $P$ ), para os diferentes tamanhos de corpos-de-prova ensaiados.

Figura 4.6b - Resultados das determinações da velocidade de propagação da onda ultra-sônica (onda P), para os diferentes tamanhos de corpos-de-prova ensaiados.

Figura 4.6c - Resultados das determinações da velocidade de propagação da onda ultra-sônica (onda $P$ ), para os diferentes tamanhos de corpos-de-prova ensaiados. 
Figura 4.7a - Curvas "tensão $x$ deformação" típicas obtidas em ensaios com amostras provenientes dos pontos de amostragem $1 \mathrm{e}$ 4, em corpos-de-prova com diferentes tamanhos Carregamento na direção perpendicular à estratificação da camada.

Figura 4.7b - Curvas "tensão $x$ deformação" típicas obtidas em ensaios com amostras provenientes dos pontos de amostragem $2 \mathrm{e}$ 3 , em corpos-de-prova com diferentes tamanhos Carregamento na direção perpendicular à estratificação da camada.

Figura 4.8 - Resultados das determinações do módulo de deformabilidade médio na direção perpendicular à estratificação da camada, para os diferentes tamanhos de corpos-de-prova ensaiados.

Figura 4.9 - Resultados das determinações da resistência à compressão uniaxial, determinada na direção perpendicular à estratificação da camada, para os diferentes tamanhos de corpos-de-prova ensaiados.

Figura 4.10 - Relação entre o teor de cinzas e a massa específica aparente, para corpos-de-prova cúbicos de carvão de diferentes tamanhos.

Figura 4.11 - Variação das velocidades de propagação da onda ultrasônica medidas na direção dos 3 eixos dos corpos-de-prova cúbicos de carvão com dimensões entre $5 \mathrm{~cm}$ e $30 \mathrm{~cm}$.

Figura 4.12 - Comportamento da velocidade de propagação da onda ultra-sônica, ponderada nas direções de determinação paralelas aos planos de estratificação, em função do tamanho dos corpos-de-prova.

Figura 4.13 - Correlação entre o módulo de deformabilidade médio e a velocidade de propagação da onda ultra-sônica ponderada nas direções de determinação paralelas aos planos de estratificação, para corpos-de-prova cúbicos de carvão de diferentes tamanhos.

Figura 4.14a - Correlação entre o módulo de deformabilidade médio e a resistência à compressão uniaxial, determinados na direção perpendicular à estratificação da camada, para corpos-de-prova cúbicos de carvão de diferentes tamanhos.

Figura 4.14b - Função ajustada para a correlação entre o módulo de deformabilidade médio e a resistência à compressão uniaxial, determinados na direção perpendicular à estratificação da camada, para corpos-de-prova cúbicos de carvão de diferentes tamanhos - Dados de todos os pontos de amostragem agrupados. 
Figura 4.15 - Resultados do módulo de deformabilidade médio em corpos-de-prova cúbicos com a dimensão do lado entre $5 \mathrm{~cm}$ e $10 \mathrm{~cm}$, nos diferentes pontos de amostragem.

Figura 4.16 - Resultados de resistência à compressão uniaxial de corpos-de-prova cúbicos com a dimensão do lado entre $5 \mathrm{~cm}$ e $10 \mathrm{~cm}$, nos diferentes pontos de amostragem.

Figura 4.17a - Correlação entre a resistência à compressão uniaxial e a velocidade da onda ultra-sônica ponderada nas direções de determinação paralelas aos planos de estratificação, para corpos-de-prova cúbicos de diferentes tamanhos.

Figura 4.17b - Funções ajustadas para a correlação entre a resistência à compressão uniaxial e a velocidade da onda ultra-sônica ponderada nas direções de determinação paralelas aos planos de estratificação, para corpos-de-prova cúbicos de diferentes tamanhos.

Figura 4.18 - Resultados de ensaios de compressão diametral, uniaxial e triaxial em corpos-de-prova cilíndricos de carvão da camada Bonito da Mina Fontanella.

Figura 4.19 - Localização das amostras de carvão da camada Irapuá coletadas na Mina Morozini Norte (Fonte: Relatório de Ensaio 19774/66293 - CARBONÍFERA BELLUNO LTDA).

Figura 4.20 - Localização das amostras de carvão da camada Irapuá coletadas na Mina Santa Augusta Norte (Fonte: Relatório de Ensaio 19997/66354 - MINAGEO LTDA).

Figura 4.21 - Detalhe da iluminação utilizada para a realização do mapeamento.

Figura 4.22 - Janela de mapeamento das fraturas, definida pela altura da camada de carvão e comprimento da linha de referência. a) Detalhe de fratura que atravessa a camada de carvão; b) Fratura mapeada a partir da projeção da linha da fratura sobre a linha de referência.

Figura 4.23 - No centro, a linha horizontal de referência (em amarelo) para a determinação da distância aparente entre as fraturas. Notar detalhe da marcação das fraturas (pontilhado branco) para facilitar a medição da orientação e características das fraturas.

Figura 4.24a - Localização do Ponto 1 (P1) de coleta de amostras de 102 carvão para ensaios em laboratório $(A)$, linhas de levantamento estrutural (em vermelho), levantamento com geofísica na periferia do pilar (em azul) e levantamento com geofísica no interior do pilar (em verde), na Mina Fontanella (Fonte: Carbonífera Metropolitana S.A.). 
Figura 4.24b - Localização do Ponto 4 (P4) de coleta de amostras de carvão para ensaios em laboratório (A), linhas de levantamento estrutural (em vermelho), levantamento com geofísica na periferia do pilar (em azul) e levantamento com geofísica no interior do pilar (em verde), na Mina Fontanella (Fonte: Carbonífera Metropolitana S.A.).

Figura 4.24c - Localização do Ponto 2 (P2) de coleta de amostras de carvão para ensaios em laboratório (A), linhas de levantamento estrutural (em vermelho), levantamento com geofísica na periferia do pilar (em azul) e levantamento com geofísica no interior do pilar (em verde), na Mina Fontanella (Fonte: Carbonífera Metropolitana S.A.).

Figura 4.24d - Localização do Ponto 3 (P3) de coleta de amostras de carvão para ensaios em laboratório (A), linhas de levantamento estrutural (em vermelho), levantamento com geofísica na periferia do pilar (em azul) e levantamento com geofísica no interior do pilar (em verde), na Mina Fontanella (Fonte: Carbonífera Metropolitana S.A.).

Figura 4.25 - a) Orientações das famílias presentes nos locais P1 e P4;

b) Orientação média dos planos que representam as famílias presentes nos locais P1 + P4 agrupados - Projeção no hemisfério inferior.

Figura 4.26 - a) Orientações das famílias presentes nos locais P2 e P3;

b) Orientação média dos planos que representam as famílias presentes nos locais P2 + P3 agrupados - Projeção no hemisfério inferior.

Figura 4.27 - Comportamento da média móvel do espaçamento aparente entre as fraturas, em função da área (pontos agrupados) e da direção das linhas de levantamento na camada Bonito, na Mina Fontanella.

Figura 4.28 - Histogramas de freqüência das persistências de todas as fraturas medidas nos 4 pontos de amostragem.

Figura 4.29 - Resultados dos levantamentos efetuados no que se refere à rugosidade (JRC), grau de alteração, abertura e presença de água nos planos de descontinuidades, nas duas áreas de estudo (área $14 \equiv \mathrm{P} 1+\mathrm{P} 4$; área $23 \equiv \mathrm{P} 2+\mathrm{P} 3$ ).

Figura 4.30 - Relação entre a resistência de laboratório (CPs cúbicos com lado entre $5 \mathrm{~cm}$ e $10 \mathrm{~cm}$ ) e a freqüência de fraturas nos diferentes locais de estudo na camada de carvão Bonito, na Mina Fontanella.

Figura 4.31 - Relação entre os RQDs calculados teoricamente (RQDteórico) e determinados diretamente através de sondagens horizontais (RQDmedido), em função da freqüência de fraturas na camada de carvão Bonito, na Mina Fontanella. 
Figura 4.32 - Equipamento utilizado nos levantamentos geofísicos.

Figura 4.33 - Geofone fixado na rocha. No detalhe, cavidade feita para a inserção do pino com a pasta de gesso para a solidarização do geofone na rocha.

Figura 4.34 - Geração manual do sismo com marreta de $5 \mathrm{~kg}$.

Figura 4.35 - Técnica de perfilagem - Disposição típica dos geofones e dos pontos de geração do sismo no pilar.

Figura 4.36 - Técnica de radiação - Disposição típica dos geofones e dos pontos de geração dos sismos no pilar de carvão.

Figura 4.37a - Técnica de perfilagem - Sismogramas obtidos na linha $1 \mathrm{~A}$ do Ponto 1, na Mina Fontanella. Linha com 12 geofones.

Figura 4.37b - Técnica de perfilagem - Relação "distância x tempo de chegada da primeira onda" composta a partir dos sismogramas obtidos na linha $1 \mathrm{~A}$ do Ponto 1 , na camada Bonito, na Mina Fontanella.

Figura 4.38a - Técnica de perfilagem - Sismogramas obtidos na linha 1 do Ponto 3, na Mina Fontanella. Linha com 12 geofones. Geração do sismo no início da linha (a), no meio da linha (b) e no final da linha (c).

Figura 4.38b - Técnica de perfilagem - Relação "distância x tempo de chegada da primeira onda" composta a partir dos sismogramas obtidos na linha $1 \mathrm{~A}$ do Ponto 3 , na camada Bonito, na Mina Fontanella.

Figura 4.39 - Disposição dos geofones com a indicação dos pontos de geração dos sismos no levantamento por radiação, em pilar de carvão da camada Irapuá, na Mina Morozini Norte.

Figura 4.40a - Técnica de perfilagem + radiação - Sismograma obtido na Mina Morozini Norte. Linha de perfilagem com 6 geofones (1 a 6) num lado do pilar. Demais geofones distribuídos nos outros lados do pilar. Geração do sismo no início da linha de perfilagem, ao lado do geofone 1.

Figura 4.40b - Técnica de perfilagem - Relação "distância x tempo de chegada da primeira onda" composta a partir dos sismogramas obtidos na camada Irapuá, na Mina Morozini Norte.

Figura 4.41 - Disposição dos geofones com a indicação dos pontos de geração dos sismos no levantamento por radiação, em pilar de carvão da camada Irapuá, na Mina Santa Augusta Norte.

Figura 4.42a - Técnica de perfilagem + radiação - Sismograma obtido na Mina Santa Augusta Norte. Linha de perfilagem com 6 geofones (7 a 12). Demais geofones (1 a 6 ) distribuídos nos outros dois lados do pilar. Geração do sismo no início da linha de perfilagem, ao lado do geofone 12. 
Figura 4.42b - Técnica de perfilagem - Relação "distância x tempo de chegada da primeira onda" composta a partir dos sismogramas obtidos na camada Irapuá, na Mina Santa Augusta Norte.

Figura 4.43 - Correlação entre a velocidade de propagação de ondas sísmicas corrigida e a freqüência aparente média de fraturas na camada de carvão Bonito, na Mina Fontanella.

Figura 4.44a - Configuração do ensaio com aplicação da carga e 138 medição da velocidade de propagação da onda ultrasônica na direção perpendicular aos planos da estratificação do carvão. No detalhe, geofones de $1 \mathrm{MHz}$ acoplados ao corpo-de-prova.

Figura 4.44b - Configuração do ensaio com aplicação da carga na direção perpendicular aos planos de estratificação do carvão e medição da velocidade de propagação da onda ultra-sônica na direção paralela. No detalhe, geofones de $200 \mathrm{kHz}$ acoplados ao corpo-de-prova.

Figura 4.45a - Variação percentual da velocidade de propagação da onda ultra-sônica em função da variação da tensão uniaxial - Carvão da camada Bonito da Mina Fontanella.

Figura 4.45b - Variação percentual da velocidade de propagação da onda ultra-sônica em função da variação da tensão uniaxial - Carvão da camada Bonito da Mina Fontanella.

Figura 4.46a - Variação percentual da velocidade de propagação da 142 onda ultra-sônica em função da variação da tensão uniaxial - Carvão da camada Irapuá da Mina Morozini Norte.

Figura 4.46b - Variação percentual da velocidade de propagação da onda ultra-sônica em função da variação da tensão uniaxial - Carvão da camada Irapuá da Mina Morozini Norte.

Figura 4.47a - Variação percentual da velocidade de propagação da onda ultra-sônica em função da variação da tensão uniaxial - Carvão da camada Irapuá da Mina Santa Augusta Norte.

Figura 4.47b - Variação percentual da velocidade de propagação da onda ultra-sônica em função da variação da tensão uniaxial - Carvão da camada Irapuá da Mina Santa Augusta Norte.

Figura 4.48 - Curvas típicas de variação percentual da velocidade ultrasônica em função da variação da tensão uniaxial aplicada na rocha. 
Figura 4.49 - Variação máxima esperada para a velocidade ultra-sônica quando a rocha é submetida a tensões uniaxiais elevadas, para carvões com diferentes velocidades ultra-sônicas determinadas sob tensão $\cong 0$. Nota: os dados com elipse não foram considerados na regressão.

Figura 4.50 - Variação máxima esperada para a velocidade ultra-sônica em função da resistência à compressão uniaxial. Nota: os dados com elipse não foram considerados na regressão.

Figura 4.51 - Imersão dos corpos-de-prova de carvão em água à 149 temperatura ambiente, durante o estudo da influência do grau de saturação na velocidade da onda ultra-sônica no carvão da camada Bonito da Mina Fontanella.

Figura 4.52 - Variação percentual da velocidade de propagação da onda ultra-sônica, medida na direção paralela aos planos de estratificação do carvão, em função do grau de saturação do carvão.

Figura 4.53 - Variação percentual máxima da velocidade de propagação da onda ultra-sônica na condição saturada ( $\mathrm{Si}=100 \%$ ), em função da velocidade medida no corpo-de-prova na condição seca $(\mathrm{Si}=0 \%)$. Nota: os dados com elipse não foram considerados na regressão.

Figura 5.1 - Ajuste do modelo de GADDY (1956) aos resultados de laboratório para a estimativa da resistência in situ da camada Bonito na Mina Fontanella. Notar os valores sugeridos para a resistência in situ para outras camadas de carvão brasileiras

Figura 6.1 - Comportamento do fator de correção da resistência de laboratório para a condição in situ (linha cheia), em função da variação do "fator geofísico".

Figura 6.2 - Valores de resistência in situ estimados para a camada de carvão Bonito, de acordo com as diferentes técnicas utilizadas, em função da densidade de fraturas observada nos diferentes locais (P1, P2, P3 e P4) estudados na Mina Fontanella.

Figura 6.3 - Valores de resistência in situ estimados para a camada de carvão Irapuá, de acordo com a nova metodologia (Minas Morozini Norte e Santa Augusta Norte), e o valor médio sugerido por ZORZI et al. (1991). 


\section{Lista de Tabelas}

Página

Tabela 2.1 - Valores do expoente " $\alpha$ " na função do efeito escala obtidos para diferentes camadas de carvão no mundo

Tabela 2.2 - Valores sugeridos para o tamanho crítico para a estimativa da resistência in situ de camadas de carvão

Tabela 2.3 - Valores de coesão (c) e ângulo de atrito (o) de carvões dos EUA e Ingleses (adaptado de ATKINSON \& KO, 1977 e WILSON, 1972)

Tabela 2.4 - Síntese dos resultados de ensaios in situ em diferentes camadas carbonosas do mundo.

Tabela 2.5 - Síntese dos resultados de ensaios in situ em camadas carbonosas do RS e SC (AGOSTINI et al., 2002)

Tabela 2.6 - Comparativo entre as diferentes classificações geomecânicas (adaptado de OJIMA, 1982)

30

35

Tabela 2.7 - Síntese das funções de cálculo da resistência de pilares de carvão e dos valores de resistência característica para as camadas da Índia, África do Sul e Austrália, estabelecidos a partir de sucessivos estudos de casos de pilares colapsados e não colapsados

Tabela 3.1 - Reservas conhecidas de carvão da camada Bonito na Bacia Sul-Catarinense (adaptado de ABORRAGE \& LOPES, 1986)

Tabela 4.1 - Quantitativos de ensaios efetivamente realizadas com amostras de cada um dos pontos de amostragem na camada Bonito, na Mina Fontanella.

Tabela 4.2 - Estatística descritiva da velocidade de propagação da onda ultra-sônica, medida nas 3 direções dos corpos-de-prova cúbicos de carvão, com dimensões entre $5 \mathrm{~cm}$ e $30 \mathrm{~cm}$.

Tabela 4.3 - Estatística descritiva das velocidades de propagação da onda ultra-sônica medidas nos corpos-de-prova cúbicos de carvão, na faixa de tamanho entre $5 \mathrm{~cm}$ e $10 \mathrm{~cm}$.

Tabela 4.4 - Estatística descritiva do módulo de deformabilidade médio em corpos-de-prova cúbicos com a dimensão do lado entre $5 \mathrm{~cm}$ a $10 \mathrm{~cm}$.

Tabela 4.5 - Estatística descritiva da resistência à compressão uniaxial em corpos-de-prova cúbicos com a dimensão do lado entre $5 \mathrm{~cm}$ a $10 \mathrm{~cm}$. 
Tabela 4.6a - Matriz de p proveniente da aplicação de teste de semelhança entre médias (duas a duas) da resistência à compressão uniaxial de corpos-de-prova cúbicos com a dimensão do lado entre $5 \mathrm{~cm}$ a $10 \mathrm{~cm}$ - teste LSD -

Tabela 4.6b - Resultados da aplicação de teste de comparação múltipla de médias para a resistência à compressão uniaxial de corpos-de-prova cúbicos com a dimensão do lado entre $5 \mathrm{~cm}$ a $10 \mathrm{~cm}$ - método de Bonferroni ao nível de confiança de $95 \%$ -

Tabela 4.7 - Resultados das análises de regressão para a determinação do efeito escala na resistência do carvão da camada Bonito, na Mina Fontanella.

Tabela 4.8 - Estatística descritiva dos parâmetros determinados no carvão da camada Irapuá da Mina Morozini Norte, em corpos-de-prova cúbicos com a dimensão do lado entre $5 \mathrm{~cm}$ e $7 \mathrm{~cm}$ (Amostras - Fase 2).

Tabela 4.9 - Estatística descritiva dos parâmetros determinados no carvão da camada Irapuá da Mina Santa Augusta Norte, em corpos-de-prova cúbicos com a dimensão do lado entre $5 \mathrm{~cm}$ e $6 \mathrm{~cm}$.

Tabela 4.10 - Síntese dos quantitativos realizados para o mapeamento estrutural da camada de carvão Bonito na Mina Fontanella.

Tabela 4.11 - Orientações médias definidas para representar as famílias de descontinuidades presentes nas duas áreas de levantamento na camada de carvão Bonito, na Mina Fontanella.

Tabela 4.12 - Freqüências aparentes médias de fraturas por metro, individualizadas por linha de levantamento, nos 4 pontos de levantamento na camada Bonito, na Mina Fontanella.

Tabela 4.13 - Freqüências aparentes médias de fraturas por metro, individualizadas por direção das linhas de levantamento, nas duas áreas de estudo (Área 14 - pontos 1 e 4; Área 23 - pontos 2 e 3) na camada Bonito, na Mina Fontanella.

Tabela 4.14a - Síntese das persistências e freqüências de fraturas por área, computadas em cada linha nos pontos 1 e 4 de levantamento estrutural na camada de carvão Bonito, na Mina Fontanella.

Tabela 4.14b - Síntese das persistências e freqüências de fraturas por área, computadas em cada linha nos pontos 2 e 3 de levantamento estrutural na camada de carvão Bonito, na Mina Fontanella. 
Tabela 4.15a - Técnica de perfilagem - Velocidades de propagação de ondas sísmicas medidas nos diferentes pontos de levantamento na camada de carvão Bonito, na Mina Fontanella.

Tabela 4.15b - Técnica de radiação - Velocidades de propagação de ondas sísmicas medidas nos diferentes pontos de levantamento na camada de carvão Bonito, na Mina Fontanella.

Tabela 4.16a - Técnica de perfilagem - Velocidades de propagação de ondas sísmicas medidas na camada de carvão Irapuá, na Mina Morozini Norte.

Tabela 4.16b - Técnica de radiação - Velocidades de propagação de ondas sísmicas medidas na camada de carvão Irapuá, na Mina Morozini Norte.

Tabela 4.17a - Técnica de perfilagem - Velocidades de propagação de ondas sísmicas medidas na camada de carvão Irapuá, na Mina Santa Augusta Norte.

Tabela 4.17b - Técnica de radiação - Velocidades de propagação de ondas sísmicas medidas na camada de carvão Irapuá, na Mina Santa Augusta Norte.

Tabela 4.18 - Síntese das velocidades de ondas sísmicas medidas nas diferentes minas estudadas.

Tabela 4.19a - Características dos corpos-de-prova para estudo da influência da tensão uniaxial na velocidade de propagação da onda ultra-sônica medida na direção perpendicular aos planos de estratificação, no carvão da camada Bonito, na Mina Fontanella.

Tabela 4.19b - Características dos corpos-de-prova para estudo da influência da tensão uniaxial na velocidade de propagação da onda ultra-sônica medida na direção paralela aos planos de estratificação, no carvão da camada Bonito.

Tabela 4.20 - Características dos corpos-de-prova usados nos estudos da influência da tensão uniaxial na velocidade de propagação da onda ultra-sônica medida nas direções paralela e perpendicular aos planos de estratificação, no carvão da camada Irapuá da Mina Morozini Norte (Amostras - Fase 1).

Tabela 4.21 - Características dos corpos-de-prova usados nos estudos da influência da tensão uniaxial na velocidade de propagação da onda ultra-sônica medida nas direções paralela e perpendicular aos planos de estratificação, no carvão da camada Irapuá da Mina Santa Augusta Norte. 
Tabela 4.22 - Valores do fator F1 a serem utilizados para correção da velocidade de propagação de ondas sísmicas medidas in situ sob diferentes níveis de tensão, para a condição de tensão de ensaio em laboratório (tensão $\cong 0$ ).

Tabela 4.23 - Valores do fator F2 a serem utilizados para correção da velocidade de propagação de ondas sísmicas medidas in situ sob diferentes condições de umidade, para a condição de umidade natural em laboratório (grau de saturação $\cong 0$ ).

Tabela 5.1 - Resistência in situ (S1) da camada de carvão Bonito, na 155 Mina Fontanella, estimada segundo o critério de ruptura de Hoek-Brown (HOEK et al., 2002).

Tabela 5.2 - Resistência in situ (S1) da camada de carvão Bonito, na Mina Fontanella, estimada segundo WILSON (1983).

Tabela 5.3a - RMR da camada de carvão Bonito segundo BIENIAWSKI (1974).

Tabela 5.3b - Resistência in situ (S1) da camada de carvão Bonito, na Mina Fontanella, estimada utilizando o critério de ruptura de RAMAMURTHY (1986).

Tabela 5.4a - RMR da camada de carvão Bonito segundo BIENIAWSKI (1989).

Tabela 5.4b - Resistência in situ (S1) da camada de carvão Bonito, na Mina Fontanella, estimada utilizando o critério de ruptura "Bieniawski genérico".

Tabela 5.5a - RMR da camada de carvão Bonito segundo BIENIAWSKI (1976).

Tabela 5.5b - Resistência in situ (S1) da camada de carvão Bonito, na Mina Fontanella, estimada utilizando o critério de ruptura de SHEOREY (1997).

Tabela 5.6 - Resistências in situ (S1) da camada de carvão Bonito, na Mina Fontanella, estimadas utilizando os critérios de ruptura de RAMAMURTHY (1986), "Bieniawski genérico" e SHEOREY (1997), considerando o RQDmedido determinado a partir de sondagens horizontais.

Tabela 5.7a - RMR da camada de carvão Bonito segundo a classificação geomecânica de KALAMARAS (1993).

Tabela 5.7b - Resistência in situ (S1) da camada de carvão Bonito, na Mina Fontanella, estimada utilizando a classificação geomecânica de KALAMARAS (1993).

Tabela 5.8a - Estimativas da resistência in situ (S1), com Vb calculado a partir da freqüência média de fraturas por metro das famílias. 
Tabela 5.8b - Estimativas da resistência in situ (S1), com Vb calculado com base na freqüência aparente média de fraturas por metro determinada unidirecionalmente.

Tabela 5.8c - Valores estimados para a resistência in situ (S1), com Vb calculado a partir do índice Jv.

Tabela 5.8d - Média dos valores de resistência in situ (S1), segundo o critério de Palmstrøm, obtidos para os diferentes locais de estudo na camada Bonito, na Mina Fontanella.

Tabela 6.1 - Condições geométricas das escavações e de umidade observadas nos locais de levantamentos nas diferentes minas estudadas.

Tabela 6.2 - Resistências in situ (S1) estimadas para as camadas de carvão Bonito, na Mina Fontanella, e Irapuá, nas Minas Morozini Norte e Santa Augusta Norte.

Tabela 6.3 - Fatores de segurança calculados segundo os diferentes métodos de dimensionamento para as condições presentes na camada de carvão Bonito, na Mina Fontanella, e Irapuá, nas Minas Morozini Norte e Santa Augusta Norte. 


\section{Lista de Abreviaturas}

CIENTEC Fundação de Ciência e Tecnologia do Estado do Rio Grande do Sul - Brasil.

CPRM Companhia de Pesquisa e Lavras Minerais - Brasil.

CMRS Central Mining Research Station - Índia.

DNPM Departamento Nacional da Produção Mineral - Brasil.

IPT Instituto de Pesquisas Tecnológicas do Estado de São Paulo Brasil.

ISRM International Society for Rock Mechanics.

NIOSHI National Institute for Occupational Safety and Health - EUA.

USBM United States Bureau of Mines - EUA.

\section{Lista de Símbolos/Variáveis}

$\mathrm{Na}$ lista a seguir não estão contemplados os símbolos/variáveis presentes no Capítulo 2 - Revisão da Literatura. Neste capítulo, especificamente, os símbolos/variáveis foram mantidos de acordo com as definições apresentadas nos trabalhos originais dos autores consultados.

$\lambda$

$\lambda \mathrm{a}$

Absorçãoi

Absorçãomáx

$\mathrm{B}_{\text {gal }}$

$\beta$

$c^{\prime}, \phi^{\prime}$

$E_{m}$

$\mathrm{F}$

$F_{1}$

$\mathrm{F}_{2}$

FS
Freqüência média de fraturas (fraturas $/ m$ ).

Freqüência aparente média de fraturas (fraturas $/ \mathrm{m}$ ).

Absorção de água ao longo do tempo de imersão (\%).

Absorção de água após 72 horas de imersão (\%).

Largura da galeria $(m)$.

Fator forma dos blocos de acordo com o critério de Palmstrøm.

Coesão e ângulo de atrito interno, respectivamente, estimados para o maciço rochoso $(\mathrm{MPa})$ e $\left(^{\circ}\right)$.

Módulo de deformabilidade médio na direção perpendicular aos planos de estratificação do carvão (GPa).

Fator de correção da resistência de laboratório para a condição in situ de acordo com o critério de Wilson.

Fator de correção da velocidade de propagação de ondas sísmicas em função da tensão vertical in situ.

Fator de correção da velocidade de propagação de ondas sísmicas em função das condições de umidade.

Fator de segurança. 
GSI

$\mathrm{h}_{\text {cam }}$

$\mathrm{H}_{\text {cam }}$

jL, jR, jA

JP

Jv

kl

L, D, P, H

$m_{i}, m_{b}$

r

$\rho_{a}$

$\mathrm{RMi}$

RMR

$\mathrm{RMR}_{\text {camada }}$

$R Q D$

$\mathrm{RQD}_{\text {medido }}$

$R Q D_{\text {teórico }}$

$S$

s, a

$\mathrm{S}_{1}$

$S_{i}$

$\sigma_{1}, \sigma_{3}$
Geological Strength Index de acordo com o critério de HoekBrown.

Altura da camada minerada $(\mathrm{m})$.

Profundidade da camada minerada $(m)$.

Fatores que representam a persistência, rugosidade e grau de alteração das juntas, respectivamente, de acordo com 0 critério de Palmstrøm.

fator de redução da resistência de acordo com o critério de Palmstrøm.

Densidade de fraturas por volume (fraturas $/ \mathrm{m}^{3}$ ).

Fator de correlação entre a freqüência de juntas unidimensional e tridimensional de acordo com o critério de Palmstrøm.

Largura (ou dimensão do lado do corpo-de-prova cúbico), diâmetro, profundidade e altura do corpo-de-prova, respectivamente $(\mathrm{m})$.

Constantes do critério de ruptura de Hoek-Brown para rocha intacta e para o maciço rochoso, respectivamente.

Coeficiente de correlação.

Massa específica aparente $\left(\mathrm{g} / \mathrm{cm}^{3}\right)$.

Rock Mass index de acordo com o critério de Palmstrøm (MPa).

Rock Mass Rating da classificação de Bieniawski.

RMR da camada de carvão.

Rock Quality Designation da classificação de Deere (\%).

RQD determinado diretamente a partir de sondagens horizontais (\%).

RQD calculado a partir da freqüência de fraturas de acordo com a expressão proposta por PRIEST \& HUDSON (1976) (\%)

Erro padrão.

Constantes do critério de ruptura de Hoek-Brown para rocha intacta.

Resistência in situ da camada de carvão (MPa).

Grau de saturação aparente ao longo do tempo de imersão (\%).

Tensões principais maior e menor, respectivamente (MPa). 


\begin{tabular}{|c|c|}
\hline$\sigma_{\text {c.cilindro }}$ & $\begin{array}{l}\text { Resistência à compressão uniaxial de corpo-de-prova } \\
\text { cilíndrico com carregamento na direção perpendicular aos } \\
\text { planos de estratificação do carvão, corrigida para a relação } \\
\text { altura/diâmetro }=1(\mathrm{MPa}) \text {. }\end{array}$ \\
\hline$\sigma_{\text {c.cubo }}$ & $\begin{array}{l}\text { resistência à compressão uniaxial de corpo-de-prova cúbico } \\
\text { com carregamento na direção perpendicular aos planos de } \\
\text { estratificação do carvão (MPa). }\end{array}$ \\
\hline$\sigma_{\mathrm{ci}}$ & Resistência à compressão uniaxial da rocha intacta (MPa). \\
\hline$\sigma_{v}$ & Tensão vertical in situ (MPa). \\
\hline $\mathrm{V}_{\text {altura }}=\mathrm{V}_{\text {perp }}$ & $\begin{array}{l}\text { velocidade de propagação da onda ultra-sônica longitudinal na } \\
\text { direção da altura do corpo-de-prova ou velocidade de } \\
\text { propagação da onda ultra-sônica longitudinal medida na } \\
\text { direção perpendicular aos planos de estratificação do carvão } \\
(\mathrm{km} / \mathrm{s}) \text {. }\end{array}$ \\
\hline Variação $V_{\text {perp }}$ & $\begin{array}{l}\text { Variação da velocidade de propagação da onda ultra-sônica } \\
\text { longitudinal medida na direção perpendicular aos planos de } \\
\text { estratificação do carvão (\%). }\end{array}$ \\
\hline Variação $_{\text {pond.par }}$ & $\begin{array}{l}\text { Variação da velocidade de propagação da onda ultra-sônica } \\
\text { longitudinal ponderada nas direções de determinação } \\
\text { paralelas aos planos de estratificação do carvão (\%). }\end{array}$ \\
\hline $\mathrm{Vb}$ & Volume dos blocos $\left(\mathrm{m}^{3}\right)$ \\
\hline VER & Volume Elementar Representativo \\
\hline$V_{\text {largura }}$ & $\begin{array}{l}\text { Velocidade de propagação da onda ultra-sônica longitudinal na } \\
\text { direção da largura do corpo-de-prova ou paralela aos planos } \\
\text { de estratificação do carvão (km/s). }\end{array}$ \\
\hline $\mathrm{V}_{\mathrm{par} \text { (tensão } \cong 0)}$ & $\begin{array}{l}\text { Velocidade de propagação da onda ultra-sônica longitudinal } \\
\text { medida na direção paralela aos planos de estratificação do } \\
\text { carvão, na condição de tensão uniaxial de ensaio } \cong 0(\mathrm{~km} / \mathrm{s}) \text {. }\end{array}$ \\
\hline$V_{\text {perp (tensão } \cong 0)}$ & $\begin{array}{l}\text { Velocidade de propagação da onda ultra-sônica longitudinal } \\
\text { medida na direção perpendicular aos planos de estratificação } \\
\text { do carvão, na condição de tensão uniaxial de ensaio } \cong 0 \\
(\mathrm{~km} / \mathrm{s}) \text {. }\end{array}$ \\
\hline$V_{\text {pond.par }}$ & $\begin{array}{l}\text { Velocidade de propagação da onda ultra-sônica longitudinal } \\
\text { ponderada nas direções de determinação paralelas aos planos } \\
\text { de estratificação do carvão }(\mathrm{km} / \mathrm{s}) \text {. }\end{array}$ \\
\hline$V_{\text {pond.par.seca }}$ & $\begin{array}{l}\text { Velocidade de propagação da onda ultra-sônica longitudinal } \\
\text { ponderada nas direções de determinação paralelas aos planos } \\
\text { de estratificação do carvão com o corpo-de-prova na condição } \\
\text { seca }(\mathrm{km} / \mathrm{s}) \text {; }\end{array}$ \\
\hline
\end{tabular}




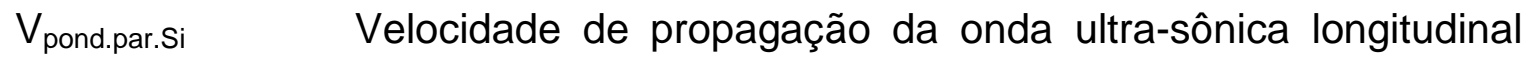
ponderada nas direções de determinação paralelas aos planos de estratificação do carvão com o corpo-de-prova sob diferentes graus de saturação aparente $S_{i}(\mathrm{~km} / \mathrm{s})$.

$V_{\text {profundidade }}$

$\mathrm{V}_{\mathrm{s} 1}$

$V_{s 1}^{\prime}$ e V's2

$\mathrm{V}_{\mathrm{s} 2}$ Velocidade de propagação da onda ultra-sônica longitudinal na direção da profundidade do corpo-de-prova ou paralela aos planos de estratificação do carvão $(\mathrm{km} / \mathrm{s})$.

Velocidade média medida com o sismo gerado no início da linha de levantamento $(\mathrm{km} / \mathrm{s})$.

Velocidades médias medidas com o sismo gerado no meio da linha de levantamento, nas direções do final da linha $\left(V^{\prime}{ }_{1}\right)$ e do início da linha $\left(\mathrm{V}_{2}{ }_{2}\right)$, respectivamente $(\mathrm{km} / \mathrm{s})$.

Velocidade média medida com o sismo gerado no final da linha de levantamento $(\mathrm{km} / \mathrm{s})$.

$\mathrm{V}_{\text {sld }} \quad$ Velocidade média computada com distâncias de percurso da onda sísmica maior que $75 \%$ da dimensão do lado do pilar $(\mathrm{km} / \mathrm{s})$.

$\mathrm{V}_{\mathrm{st}} \quad$ Velocidade média considerando todos os geofones localizados a mais de $1,0 \mathrm{~m}$ de distância do ponto de geração do sismo $(\mathrm{km} / \mathrm{s})$.

$V_{\text {tensãovvarível }}$

Velocidade de propagação da onda ultra-sônica longitudinal medida na direção perpendicular aos planos de estratificação do carvão, nas diferentes tensões uniaxiais de ensaio $(\mathrm{km} / \mathrm{s})$.

W Teor de umidade (\%).

$\mathrm{W}_{1}$ e $\mathrm{W}_{2}$ Dimensões de projeto do lado menor e do lado maior do pilar, respectivamente $(\mathrm{m})$. 


\section{Resumo}

A arte de dimensionar pilares em minas subterrâneas de carvão tem sido objeto de pesquisa há mais de 100 anos no mundo inteiro. A maioria dos métodos de dimensionamento de pilares para a lavra segundo o método "câmara e pilares" se vale de parâmetros de resistência e geométricos das camadas de carvão. A resistência in situ da camada de carvão $\left(S_{1}\right)$ é um desses parâmetros.

No Brasil, na Bacia Carbonífera Sul-Catarinense, uma nova camada de carvão, a Bonito, passou a ser minerada em volume considerável a partir da década de 1990. A sua resistência in situ ainda hoje é uma incógnita.

Tendo como campo experimental a camada de carvão Bonito presente na Mina Fontanella, no município de Treviso - SC, foram desenvolvidos diferentes estudos de laboratório e em subsolo, visando à caracterização mecânica, estrutural e geofísica dessa camada. Adicionalmente, foram realizadas investigações sobre uma segunda camada de carvão, a Irapuá, já relativamente conhecida, presente em outras duas minas na mesma bacia carbonífera.

Os estudos realizados serviram de base para a proposição de uma nova metodologia para a estimativa da resistência à compressão uniaxial in situ de camadas de carvão $\left(S_{1}\right)$, levando em consideração a resistência de laboratório e informações geofísicas de laboratório e in situ.

Com o uso da nova metodologia, são propostos valores de resistência à compressão uniaxial in situ da camada de carvão Bonito, para diferentes condições geológico-estruturais observadas na Mina Fontanella, e para a camada Irapuá, nas minas Morozini Norte e Santa Augusta Norte. 


\begin{abstract}
Researchers in all over the world have spent a lot of time in developing techniques for pillar design in coal underground mines that use room and pillar method. Almost all the available methods are based on strength and geometric parameters of the coal seam. One of the most important is the coal seam in situ strength $\left(\mathrm{S}_{1}\right)$.

In Brazil, at Sul-Catarinense Carboniferous basin, a new coal seam (Bonito seam) is being mined since the last decade. Many instability problems have occured during mining. The coal seam strength is not very well known so far.

Using the Bonito seam present at Fontanella mine in Treviso - SC, different studies were performed in laboratory and in situ. In adition, another coal seam, Irapuá, was also studied.

The compilation of data at different sites was used to propose a new approach to estimates of the in situ uniaxial compressive strength of coal seams $\left(S_{1}\right)$ using three parameters. The uniaxial compressive strength and compressional wave ultra sonic velocity are determined in laboratory using small samples, while seismic velocity is measured in large scale conditions directly at the coal seam in situ.

Using the new approach, values for in situ strength at Fontanella mine are proposed and also for two mines at Irapuá coal seam, Morozini Norte and Santa Augusta Norte.
\end{abstract}




\section{Introdução}

O desenvolvimento da lavra de carvão em jazidas cada vez mais profundas, associado à necessidade de incremento das condições de segurança nas operações em subsolo, tem levado as empresas mineradoras a investir maiores quantidades de recursos em estudos de caracterização geomecânica dos maciços onde serão abertas as novas minas.

Tomando como condição de contorno a legislação brasileira atual, que exige a manutenção das escavações subterrâneas abertas, mesmo após a lavra, para não ocasionar problemas ambientais em superfície, torna-se imperioso um melhor conhecimento da capacidade de suporte das estruturas de sustentação das minas (pilares de carvão). Esse conhecimento é necessário para que a lavra se desenvolva sob condições de segurança recomendáveis para operações a maiores profundidades que as praticadas atualmente. Além disso, pode otimizar recuperação da jazida, considerando as novas condições geométricas da camada de carvão, mais espessas e com coberturas da ordem de $300 \mathrm{~m}$ ou mais.

Com a crise energética rondando o País, novas usinas térmicas estão em vias de serem viabilizadas, algumas previstas para serem instaladas junto às futuras minas, utilizando como combustível o carvão mineral. A Mina Fontanella constituise numa das futuras minas subterrâneas a serem explotadas, com uma vida útil estimada em 25 anos. Um dos pontos críticos para a viabilização da lavra nesta mina, na camada Bonito, passa pela determinação da sua resistência in situ, para que as estruturas de sustentação da mina (pilares) possam ser projetadas com mais segurança. Esse foi o motivo principal para o desenvolvimento dessa pesquisa.

Motivaram, também, os estudos ora desenvolvidos, o fato de 3 minas terem sido abertas na última década, na camada de carvão Bonito, com a ocorrência de problemas de ruptura de pilares. Numa delas o resultado foi catastrófico, com o fechamento integral das aberturas existentes.

Considerando os aspectos acima expostos, este projeto de pesquisa estabeleceu como objetivos principais:

a) propor uma nova metodologia para a estimativa da resistência in situ de camadas de carvão, levando em consideração os seguintes parâmetros: resistência à compressão uniaxial e - velocidade de ondas ultra-sônicas, determinadas em laboratório, e - velocidade de ondas sísmicas, medida in situ;

b) estimar a resistência in situ da camada Bonito para as diferentes condições geológico-estruturais presentes na área acessível da Mina Fontanella. 
Para a consecução dos objetivos propostos, foram desenvolvidas atividades com diferentes abordagens, quais sejam:

a) ensaios de laboratório para da determinação da resistência do carvão da camada Bonito, da Mina Fontanella;

b) mapeamento geotécnico para a determinação dos padrões geológicoestruturais característicos da camada de carvão Bonito, presentes na Mina Fontanella;

c) ensaios de laboratório para determinação da resistência do carvão da camada Irapuá presente nas minas Morozini Norte e Santa Augusta Norte;

d) levantamentos geofísicos in situ para determinar a velocidade de propagação de ondas sísmicas na camada de carvão Bonito, na Mina Fontanella, e na camada Irapuá, nas minas Morozini Norte e Santa Augusta Norte.

Num primeiro momento foi desenvolvida uma extensa pesquisa na literatura nacional e internacional, com o intuito de conhecer as diferentes técnicas utilizadas para a definição da resistência in situ de camadas de carvão. Adicionalmente, foram buscados subsídios para auxiliar na proposição de uma metodologia nova para a estimativa da resistência in situ de camadas de carvão. A consolidação desse trabalho está relatada no Capítulo 2 - Revisão da Literatura.

No Capítulo 3 - Geologia da Camada de Carvão Bonito são apresentados os vários aspectos geológicos e estruturais pertinentes às camadas de carvão presentes na Bacia Sul-Catarinense, com ênfase na camada Bonito, tendo em vista ser essa camada o campo experimental principal para desenvolvimento da pesquisa. São apresentadas sinteticamente as características das bacias carboníferas existentes na região Sul do Brasil, a geologia regional e local e, finalmente, destacados os vários aspectos intervenientes na lavra de carvão.

As atividades experimentais desenvolvidas nesta pesquisa são apresentadas no Capítulo 4 - Ensaios de Laboratório e Investigações In Situ. As atividades desenvolvidas em laboratório e in situ nas diferentes minas são amplamente detalhadas. São descritas as atividades de campo para a amostragem do carvão da camada Bonito, na Mina Fontanella, o processo de preparação dos corpos-deprova e a execução das diferentes modalidades de ensaios em laboratório, assim como os resultados obtidos. Ainda, são apresentados os estudos realizados com carvão da camada Irapuá, procedentes de duas outras minas estudadas. No que tange ao levantamento estrutural realizado em subsolo na Mina Fontanella, são descritos os procedimentos utilizados para o mapeamento das descontinuidades presentes na camada de carvão, o tratamento estatístico aplicado nos dados de campo para a definição dos padrões estruturais observados nos diferentes locais amostrados na mina, assim como são apresentados os resultados qualitativos e quantitativos sobre as principais famílias de descontinuidades. Finalmente, são descritas as atividades de prospecção geofísica, destacando-se a técnica adotada, os equipamentos utilizados e os resultados relativos às velocidades de propagação de ondas sísmicas obtidos nas 3 minas de carvão estudadas: Fontanella, Morozini Norte e Santa Augusta Norte. 
O Capítulo 5 - Estimativa da Resistência In Situ da Camada de Carvão Bonito na Mina Fontanella Utilizando Diferentes Técnicas, trata da integração dos resultados provenientes das 3 linhas de trabalho adotadas no principal sítio de desenvolvimento dessa pesquisa, a camada de carvão Bonito da Mina Fontanella. São discutidas as diferentes técnicas disponíveis para estimar a resistência in situ de maciços rochosos em geral e, em especial, maciços carbonosos. Com base nos resultados dos ensaios de laboratório e do levantamento estrutural, são feitas estimativas para a resistência in situ da camada Bonito. Os resultados provenientes da aplicação dessas diferentes técnicas serviram de balizamento para as estimativas da resistência in situ da camada Bonito na mina Fontanella feitas com base na nova metodologia proposta para estimar a resistência in situ de camadas de carvão.

No Capítulo 6 - Metodologia para a Estimativa da Resistência In Situ de Camadas de Carvão Utilizando Geofísica, são apresentadas as premissas adotadas e o modelo para estimar a resistência in situ de camadas de carvão, a partir da resistência e velocidade ultra-sônica de laboratório e velocidade de ondas sísmicas in situ. Também, são apresentadas as verificações do modelo proposto, através da computação dos fatores de segurança nos locais estudados (4 áreas na camada Bonito, na Mina Fontanella em Treviso - SC e 2 áreas na camada Irapuá, uma na Mina Morozini Norte, em Treviso - SC e outra na Mina Santa Augusta Norte, em Criciúma - SC), considerando as resistências estimadas segundo o novo método.

Embora baseado num número restrito de casos práticos, no Capítulo 7 são apresentadas as conclusões sobre as estimativas de resistência para a camada de carvão Bonito, na Mina Fontanella, e Irapuá, para as minas Morozini Norte e Santa Augusta Norte. Finalmente, no Capítulo 8, são discutidos aspectos julgados passíveis de estudos complementares, visando à melhoria e ao refinamento da metodologia proposta para a estimativa da resistência in situ de camadas de carvão. 


\section{Revisão da Literatura}

\subsection{Introdução}

A determinação da resistência in situ de maciços em geral, e em especial, de camadas de carvão, não é tarefa fácil, haja vista a quantidade de acidentes com o colapso total ou parcial de áreas mineradas em subsolo.

No Brasil, os estudos mais importantes foram realizados a partir da década de 1980. À época, várias camadas de carvão encontravam-se em explotação. As mais importantes foram estudadas em diferentes graus de detalhe.

Cada vez que uma nova camada de carvão entra na pauta da mineração, velhos problemas ocorrem, entre eles o colapso de pilares. Embora a causa nunca seja uma única variável, o fato é que o desconhecimento da resistência in situ, parâmetro empregado na maioria dos métodos de dimensionamento de pilares, é um dos fatores principais causadores desses problemas.

Tendo como premissa básica a necessidade de manutenção dos pilares íntegros por longo período, mesmo após a lavra, para não ocasionar problemas ambientais em superfície, torna-se imperioso um melhor conhecimento da capacidade de suporte das estruturas de sustentação das minas (pilares de carvão).

O caso da camada de carvão Bonito é atual e a determinação da sua resistência está na pauta das pesquisas sobre essa camada da bacia carbonífera SulCatarinense. Trata-se de uma camada espessa (cerca de $4 \mathrm{~m}$ ) e que possui características estruturais muito próprias, além de que esta camada está situada sob coberturas superiores a $300 \mathrm{~m}$.

Propor uma nova metodologia para a estimativa da resistência in situ de camadas de carvão é o desafio teórico. Determinar a resistência da camada Bonito na Mina Fontanella é o desafio prático.

Para auxiliar no alcance dos objetivos propostos nessa pesquisa, são abordados os estudos já desenvolvidos no mundo sobre os seguintes temas principais:

a) técnicas para o dimensionamento de pilares em minas de carvão para a lavra pelo método de câmaras e pilares;

b) técnicas para a determinação da resistência in situ de rochas carbonosas;

c) emprego de geofísica para a caracterização mecânica de maciços rochosos;

d) técnicas indiretas para a determinação da resistência in situ de rochas carbonosas. 


\subsection{Métodos de Dimensionamento de Pilares}

A tarefa de dimensionar os pilares em minas subterrâneas de carvão, que utilizam o método de lavra "câmaras e pilares", tem tomado grande quantidade de tempo dos pesquisadores e consumido grandes somas de recursos financeiros para pesquisa no mundo inteiro, ao longo do século passado.

A adoção do método de lavra por câmaras e pilares pressupõe a abertura de galerias, de onde é extraído o carvão, e a manutenção de pilares entre essas galerias, cuja função é a sustentação das rochas da cobertura, acima da camada de carvão. No caso do Brasil, a legislação exige que as estruturas de sustentação devem ser resistentes o suficiente para manter o teto estável não somente durante as atividades de lavra, oferecendo segurança aos trabalhadores e equipamentos, mas também, no longo prazo, para que a cobertura permaneça intacta, evitando a ocorrência de subsidência e os danos ambientais associados na superfície.

No Brasil, o método de lavra por câmaras e pilares se constitui no método empregado em praticamente $100 \%$ das minas subterrâneas de carvão. Isso se deve, principalmente, pelas orientações governamentais aplicadas pelo órgão responsável pela fiscalização da mineração no Brasil, o DNPM - Departamento Nacional da Produção Mineral, no sentido da restrição da lavra com recuperação parcial de pilares, técnica antigamente empregada em muitas minas de Santa Catarina, ou recuperação total, quando empregados os métodos de frentes largas (longwall) ou frentes estreitas (shortwall).

O cálculo da dimensão adequada para os pilares é feito confrontando-se, de um lado, a tensão que deverá ser imposta ao pilar quando da abertura das galerias e, de outro, a resistência que o pilar oferece, adotando-se um fator de segurança maior que 1 para compensar a incerteza na determinação dessas duas variáveis, o qual é definido da seguinte forma:

$$
F S=\frac{\sigma_{p}}{\sigma_{v}}
$$

onde: $\sigma_{p}=$ resistência média do pilar;

$\sigma_{\mathrm{v}}=$ tensão média aplicada no pilar.

A resistência do pilar, definida pela carga máxima suportada por unidade de área, é dependente de pelo menos três elementos básicos:

- resistência in situ do carvão que forma o pilar;

- forma do pilar;

- propriedades mecânicas das rochas encaixantes.

Para a determinação da resistência do pilar estão disponíveis diferentes modelos matemáticos, com diferentes formas, normalmente estabelecidos a partir de estudos em laboratório, ensaios in situ ou a partir do tratamento estatístico de casos reais. 
As primeiras proposições são provenientes de países com maior tradição na mineração subterrânea de carvão a África do Sul, EUA, Índia e Inglaterra.

A primeira proposta feita para as condições específicas dos carvões presentes no Sul do Brasil foi apresentada em 1991 (ZORZl et al., 1991).

Embora não seja o objetivo deste trabalho discutir as técnicas para o cálculo da resistência do pilar, um pequeno apanhado da vasta literatura disponível mostra a existência de um número muito grande de funções matemáticas disponíveis para uso. Duas famílias de funções, potência e linear, no entanto abarcam praticamente todas as proposições até então apresentadas.

A maioria das propostas empíricas para o cálculo da resistência dos pilares, $\sigma_{p}$, são expressões do tipo:

$$
\sigma_{p}=S_{1} * \frac{W^{\beta}}{h^{\alpha}}
$$

ou

$$
\sigma_{p}=S_{1} *\left(A+B * \frac{W}{h}\right)
$$

onde: $\mathrm{S}_{1}=$ resistência característica da camada de carvão, que em última análise, pode ser traduzida como a resistência à compressão uniaxial in situ da camada de carvão;

$\alpha, \beta, \mathrm{A}$ e $\mathrm{B}=$ constantes definidas dependendo do autor proponente e da camada de carvão considerada;

$\mathrm{W}$ = dimensão do lado do pilar;

$\mathrm{h}=$ altura ou espessura da camada minerada.

A resistência característica da camada de carvão $\left(S_{1}\right)$ varia de acordo com as características específicas de cada jazimento. Esse parâmetro está presente em todas as equações de cálculo da resistência do pilar propostas por diferentes autores ao longo dos últimos 100 anos.

Entre as formulações mais conhecidas e utilizadas, são destacadas as seguintes, relacionadas na ordem cronológica de proposição:

a) BAUSHINGER (1876) apud LOGIE \& MATHESON (1982) foi um dos pioneiros a desenvolver uma equação que contemplava o "efeito forma" na resistência da rocha:

$$
\sigma_{\text {prisma }}=\sigma_{c} *\left[0,778+0,222 *\left(\frac{W}{h}\right)\right]
$$

onde: $\sigma_{\text {prisma }}=$ resistência à compressão de um corpo-de-prova prismático;

$\sigma_{\mathrm{c}}=$ resistência à compressão uniaxial de um prisma em que $\mathrm{W}=\mathrm{h}$ (cubo);

W = dimensão lateral mínima;

$\mathrm{h}=$ altura do prisma. 
Conforme poderá ser visto adiante, a equação proposta por este autor, de certa maneira, serviu de base para muitas equações de cálculo da resistência do pilar, que foram sugeridas por diferentes autores no mundo inteiro ao longo do tempo.

b) BUNTING (1911) foi o primeiro nos EUA a propor uma equação empírica para o cálculo da resistência do pilar:

$S_{p}=S_{1} *\left[0,7+0,3 *\left(\frac{W}{h}\right)\right]$

onde: $S_{p}=$ resistência do pilar;

$\mathrm{S}_{1}=$ resistência característica da camada de carvão, determinada a partir da análise de casos de ruptura de pilares;

$\mathrm{W}=$ largura do pilar;

$\mathrm{h}=$ altura do pilar.

Deve ser destacado que o conceito básico, até hoje, é utilizado por alguns autores, apesar de quase um século da sua proposição. Além disso, já à época o autor prevenia quanto ao uso dos resultados de laboratório diretamente em projeto, devido à existência dos efeitos do "tamanho" e da "forma" dos corposde-prova na resistência dos materiais rochosos ensaiados.

c) ZERN (1926) apud TSUR-LAVIE \& DENEKAMP (1982a) 15 anos depois de BUNTING (1911) propôs outra função para a computação da resistência do pilar:

$S_{p}=S_{1} *\left(\frac{W}{h}\right)^{0,5}$

onde: $S_{p}=$ resistência do pilar;

$\mathrm{S}_{1}=$ resistência característica da camada de carvão.

d) HOLLAND \& GADDY (1956) apud HOLLAND (1962a e 1962b), a partir de ensaios em laboratório desenvolvidos por GADDY (1956), propuseram uma variação da equação de ZERN (1926) para a resistência do pilar:

$S_{p}=k * \frac{W^{0,5}}{h}$

onde: $S_{p}=$ resistência do pilar;

$\mathrm{k}$ = constante característica da camada de carvão, determinada a partir de ensaios de compressão uniaxial em cubos com a dimensão do lado variando entre $2,5 \mathrm{~cm}$ e $10 \mathrm{~cm}$, calculada pela seguinte equação: $k=\sigma_{c} * S^{0,5}$ onde $\sigma_{\mathrm{c}}=$ é a resistência à compressão uniaxial de um corpo-de-prova cúbico;

$\mathrm{S}=$ dimensão do lado do corpo-de-prova cúbico ensaiado. 
e) SALAMON (1967) e SALAMON \& MUNRO (1967), a partir do tratamento estatístico de casos reais de pilares colapsados e estáveis na África do Sul, propuseram outra variação da equação de ZERN (1926) para a resistência do pilar:

$$
S_{p}=S_{1} * \frac{W^{0,46}}{h^{0,66}}
$$

onde: $S_{p}=$ resistência do pilar;

$\mathrm{S}_{1}=$ resistência à compressão uniaxial de um cubo de carvão com lado igual a 1 pé $(30,4 \mathrm{~cm})$.

Em 1996 SALAMON et al. (1996), analisando dados da África do Sul e da Austrália, propuseram pequenas modificações tanto para o valor de $S_{1}$ como para as constantes do efeito forma.

Esse ainda é o método oficialmente aceito no Brasil, embora haja empresas já adotando a proposta feita por ZORZI et al. (1991) para os jazimentos de carvão brasileiros.

f) OBERT \& DUVALL (1967), baseado em resultados de ensaios de laboratório, propuseram uma função para o cálculo da resistência do pilar que, na forma, se constitui na mesma equação proposta por BAUSHINGER (1876):

$$
S_{p}=S_{1} *\left[0,778+0,222 *\left(\frac{W}{h}\right)\right]
$$

onde: $S_{p}=$ resistência do pilar;

$S_{1}=$ resistência à compressão uniaxial do carvão determinada a partir de ensaios em laboratório com corpos-de-prova cúbicos. Uma versão modificada dessa equação sugere a adoção da resistência estimada para a condição in situ ou a partir de ensaios em corposde-prova cúbicos com dimensão igual ou superior a 1,5m.

É importante ressaltar que a forma originalmente proposta para a determinação de $S_{1}$ não considera o efeito escala. Como conseqüência, a resistência da camada tende a ser superestimada, o que tem levado a adoção de fatores de segurança elevados ( $F S>3$ ) para compensar a diferença entre a resistência em laboratório e a in situ.

Uma equação igual foi sugerida por SKELLY et al. (1977) baseada em resultados de ensaios em laboratório e in situ, nos USA.

g) BIENIAWSKI (1968a) na África do Sul, tendo como base ensaios in situ em grandes amostras, introduziu o conceito de tamanho "crítico", cujo significado é o tamanho do corpo-de-prova a partir do qual a resistência se mantém constante. A equação proposta pelo mesmo incorporou este conceito no cálculo da resistência do pilar, no entanto, apresenta a mesma forma que a proposta por BUNTING (1911):

$$
S_{p}=S_{1} *\left[0,645+0,355 *\left(\frac{W}{h}\right)\right]
$$

onde: $S_{p}=$ resistência do pilar; 
$\mathrm{S}_{1}=$ resistência in situ da camada de carvão definida como a resistência à compressão uniaxial de um cubo de tamanho crítico, ou seja, cerca de 1,5m (BIENIAWSKI, 1968a, 1968b, 1968c e 1981). Esse valor foi reduzido para um valor entre $0,9 \mathrm{~m}$ e $1,0 \mathrm{~m}$ (HUSTRULID, 1976; BIENIAWSKI, 1982, 1983 e 1984).

Após estudos realizados na Pensilvânia essa equação foi ajustada, então, para as condições norte-americanas.

h) WILSON (1972) na Inglaterra, introduziu um novo conceito para a determinação da resistência do pilar. O conceito do núcleo elástico, como é conhecido, já havia sido observado também por outros pesquisadores (LABASSE, 1949 e WALKER, 1955 apud LOGIE \& MATHESON, 1982). O autor parte da premissa de que o pilar possui uma zona periférica, delimitada pelo ponto em que se verifica o pico de tensão no pilar e a parede da galeria, na qual a rocha sofre ruptura, porém, ainda possui resistência ("yield zone"). A partir dessa zona (casca externa) em direção ao centro do pilar, a rocha permanece praticamente intacta e a sua resistência tende a obedecer às leis da teoria da elasticidade. Esse comportamento do interior do pilar, associado ao confinamento proporcionado pela zona de rocha fraturada na periferia, forma o núcleo do pilar ("pillar core). Dependendo das dimensões do pilar, o núcleo do pilar pode desenvolver resistências tão elevadas a ponto de torná-lo praticamente indestrutível.

Dentro do conceito de Wilson, pelo menos 3 aspectos merecem destaque no processo de cálculo da resistência do pilar: a importância dada às rochas encaixantes (rochas do teto e do piso), a mensuração da zona periférica do pilar que atinge a ruptura e a incorporação do efeito do confinamento no cálculo da resistência da parcela interna do pilar.

Na sua forma mais genérica, a função de cálculo da resistência do pilar é dada pela seguinte expressão:

$S_{p}=\sigma_{1 e}+\sigma_{1 p}$

onde: $\mathrm{S}_{\mathrm{p}}=$ resistência do pilar;

$\sigma_{1 \mathrm{e}}=$ resistência da zona elástica (núcleo) do pilar;

$\sigma_{1 p}=$ resistência da zona plastificada do pilar.

Os detalhes do equacionamento para o cálculo da resistência do pilar podem ser vistos em WILSON (1983).

i) PANEK (1980) propôs uma função para a estimativa da resistência do pilar baseada na teoria da similitude. $O$ autor incorpora, na sua proposição, as propriedades mecânicas das encaixantes (atrito e rigidez), as quais desempenham papel importante na resistência do pilar. A equação básica partindo da resistência de laboratório em corpos-de-prova com as mesmas relações geométricas dos futuros pilares, possui a seguinte conformação:

$$
S_{p}=S_{l a b} *\left(\frac{E_{r}}{E_{s}}\right)^{c 4} *\left(\frac{E_{f}}{E_{s}}\right)^{c 5} *\left(\frac{\mu_{c r}}{\mu_{c s}}\right)^{c 6} *\left(\frac{\mu_{c f}}{\mu_{c s}}\right)^{c 7} *\left(\frac{\nu_{s}}{\nu_{r}}\right)^{c 8} *\left(\frac{\nu_{s}}{\nu_{f}}\right)^{c 9}
$$


onde: $S_{p}=$ resistência do pilar;

$S_{\text {lab }}=$ resistência conhecida de laboratório;

$E_{r}, E_{f}$ e $E_{s}=$ módulo de Young da rocha encaixante do teto, da rocha encaixante do piso e do aço, respectivamente;

$\mu_{\mathrm{cr}}, \mu_{\mathrm{cf}}$ e $\mu_{\mathrm{cs}}=$ coeficiente de atrito entre o carvão e a encaixante do teto, entre o carvão e a encaixante do piso e entre o carvão e o aço, respectivamente;

$v_{r}, v_{f}$ e $v_{s}=$ coeficiente de Poisson da encaixante do teto, da encaixante do piso e do aço, respectivamente;

$\mathrm{C}_{4}, \mathrm{C}_{5}, \mathrm{C}_{6}, \mathrm{C}_{7}, \mathrm{C}_{8}$ e $\mathrm{C}_{9}=$ constantes determinadas por métodos estatísticos.

j) SINGH (1980), apresentou uma proposta capaz de contemplar o efeito tempo (indiretamente) na resistência dos pilares. Para isso, o autor introduziu uma constante adicional à equação proposta por SALAMON \& MUNRO (1967) que leva em consideração o comportamento da curva "tensão x deformação" durante a ruptura do carvão. A equação utilizada para o cálculo da resistência do pilar, válida para a relação $W / h \leq 8$, é assim definida:

$$
S_{p}=S_{1} * K * \frac{W^{0,46}}{h^{0,66}}
$$

onde: $S_{p}=$ resistência do pilar;

$\mathrm{S}_{1}=$ resistência in situ do carvão resultante de ensaios em cubos com lado igual a $30 \mathrm{~cm}$.

$\mathrm{K}=$ constante variando de 0,6 a 0,8 . Esse fator é obtido nas curvas "tensão x deformação" de ensaios de compressão uniaxial. Corresponde ao nível de tensão, em relação à tensão de ruptura, em que o comportamento da curva passa a ser não linear.

k) HUSTRULID \& SWANSON (1981) apud LOGIE \& MATHESON (1982) a partir de uma análise detalhada das proposições feitas por outros investigadores para o cálculo da resistência do pilar, apresentaram uma equação procurando incorporar os melhores aspectos de cada método, sugerindo a seguinte expressão:

$$
S_{p}=\frac{k}{h^{0,5}} *\left(\frac{W}{h}\right)^{0,5}
$$

onde: $S_{p}=$ resistência do pilar;

$\mathrm{k}=$ constante característica da camada de carvão baseada em ensaios de laboratório ou in situ, calculada pela seguinte equação: $k=\sigma_{c} * L^{0,5}$, onde:

$\sigma_{\mathrm{c}}=$ é a resistência à compressão uniaxial in situ ou de laboratório determinada sobre uma amostra cúbica; 


$$
\begin{aligned}
\mathrm{L}=\text { dimensão do lado da amostra que deu origem a } \sigma_{\mathrm{c}} ; \\
\mathrm{h}=\text { altura do pilar, constante em } 0,9 \mathrm{~m} \text { para camadas de carvão com } \\
\text { espessura superior a esse valor. }
\end{aligned}
$$

I) ZORZI et al. (1991) foram os primeiros pesquisadores a propor um método de dimensionamento de pilares aplicável aos jazimentos de carvão presentes no Sul do Brasil. Duas equações são sugeridas para o cálculo da resistência do pilar de carvão, definidas a partir de estudos em laboratório e in situ nas principais camadas de carvão em explotação à época:

- encaixantes menos resistentes que a camada de carvão e pilares com a relação $\mathrm{W} / \mathrm{h}$ > 8,5:

$$
S_{p}=S_{1} *\left(\frac{W}{h}\right)^{0,46} * f d * f t * f e
$$

- pilares com a relação $\mathrm{W} / \mathrm{h} \leq 8,5$ :

$$
S_{p}=S_{1} *\left[0,778+0,222 *\left(\frac{W}{h}\right)\right] * f d * f t * f e
$$

onde: $S_{p}=$ resistência do pilar;

$S_{1}=$ resistência in situ da camada de carvão. A partir dos estudos realizados foram sugeridas as resistências características das três principais camadas de carvão em explotação no Brasil, Barro Branco e Irapuá em SC e I ${ }_{1} F$ no RS;

$\mathrm{fd}, \mathrm{ft}$ e fe $=$ fatores de redução da resistência em função do método de desmonte, da ação do tempo e da mudança de esbeltez do pilar, respectivamente.

Essa metodologia não se preocupou em propor uma outra equação de cálculo da resistência, mas apresentar alternativas objetivas e seguras que permitissem otimizar o processo de dimensionamento dos pilares a partir do conhecimento de determinadas variáveis, como a técnica usada no desmonte, a vida útil prevista para o pilar e a estabilidade do teto com o passar dos anos. Também, é um dos raros métodos propostos que no dimensionamento do pilar leva em consideração, tanto a resistência da camada de carvão como a das rochas encaixantes.

m) GALVIN \& HEBBLEWHITE (1995) apud SALAMON et al. (1996), após estudos de casos de ruptura em minas da Austrália, propuseram para as condições daquele país a seguinte equação para o cálculo da resistência do pilar válida para a relação $\mathrm{W} / \mathrm{h} \leq 5$ :

$$
S_{p}=S_{1} * \frac{W^{0,46}}{h^{0,66}}
$$

onde: $S_{p}=$ resistência do pilar;

$\mathrm{S}_{1}=$ resistência característica das camadas de carvão australianas, igual a $7,4 \mathrm{MPa}$. 
Nos últimos anos, análises sobre um maior número de casos de ruptura de pilares na Austrália levou a proposição de mudanças na resistência característica da camada e leves alterações na forma das equações.

A observação das diferentes propostas para a computação da resistência de pilares mostra claramente que não existe uma única função aplicável a todas as camadas de carvão.

Diferentes condições geológicas e estruturais onde estão localizadas as camadas de carvão, características estruturais e composicionais dessas camadas e os tipos de rochas encaixantes presentes nos jazimentos de carvão, possivelmente são os fatores mais influentes no comportamento mecânico das estruturas em subsolo, exigindo tratamento diferenciado na determinação da resistência dos pilares entre uma camada e outra.

Com aplicação voltada para a mineração de minerais metálicos, HEDLEY \& GRANT (1972) fizeram ajustes na função proposta por SALAMON \& MUNRO (1967), para a computação da resistência de pilares de rochas duras. Esse método foi ajustado por POTVIN et al. (1989) para a otimização das dimensões dos pilares, levando em conta a função e vida útil requerida para o pilar. MARTIN \& MAYBEE (2000) sumarizam uma série de equações propostas por vários autores para o cálculo da resistência de pilares em minas abertas em rochas duras. A maioria delas possui forma muito semelhante às equações até então apresentadas para o cálculo da resistência de pilares de carvão, como as de GREENWALD et al. (1939), STEART (1954) e SALAMON \& MUNRO (1967), entre outros. A diferença mais marcante está associada ao efeito escala, onde se observa que no carvão esse efeito tende a ser maior que em rochas duras. Uma outra abordagem para a verificação da estabilidade de pilares em minas metálicas foi proposta por Lunder (1994) e modificada por Mah (1995) apud PAKALNIS \& VONGPAISAL. A estabilidade dos pilares é verificada com base em duas variáveis, uma representada pela relação entre a tensão medida no centro do pilar e a resistência à compressão uniaxial da rocha intacta, e outra pela relação entre a largura e a altura do pilar. Essas relações são representadas graficamente e definidas regiões de pilares estáveis, instáveis e colapsados. A menção suscinta dessas propostas foi julgada oportuna apenas para efeito ilustrativo dos diferentes métodos de dimensionamento de pilares. $\mathrm{O}$ seu detalhamento não é levado a efeito, uma vez que o foco da pesquisa desenvolvida neste trabalho está intimamente associado à mineração de carvão.

\subsection{Métodos Utilizados para a Determinação da Resistência In Situ}

\subsubsection{Introdução}

As rochas carbonosas, possivelmente, estão entre as mais difíceis de serem estudadas, em função das grandes variações geológicas observadas num mesmo jazimento. Essas variações podem ser representadas por descontinuidades de grande porte e natureza diversa (fraturas, falhas, intrusões), pela presença de estruturas numa escala bem menor, destacando-se as inclusões de minerais não carbonosos (nódulos de pirita, lentes/camadas de carbonato concentrado, por exemplo), e por pequenas descontinuidades intrínsecas desse tipo de rocha ("cleats"). Tanto a composição heterogênea do pacote carbonoso, representada 
muitas vezes por intercalações de carvão e material estéril, como as estruturas presentes nesse pacote, são fatores que influenciam na resistência e deformabilidade, inclusive com maior ênfase do que em outros tipos litológicos (TRUEMAN \& MEDHURST, 1994).

A escolha da técnica mais adequada para a determinação (estimativa) da resistência de um maciço rochoso depende de uma série de fatores distintos, que podem ser de ordem econômica, operacional e tecnológica, entre outros. As limitações tecnológicas para a obtenção, preparação e ensaio das amostras, possivelmente tenham sido os maiores problemas transpostos pelos primeiros pesquisadores que buscavam entender o comportamento mecânico dos maciços rochosos onde estavam localizadas as atividades mineiras.

Por vezes, mesmo com os avanços tecnológicos disponíveis, a escassez de recursos é o maior limitante para a execução de determinado tipo de estudo. Esse fator impede que informações possam ser antecipadas num projeto de engenharia, pelo simples fato de que amostras de rocha não são coletadas e/ou estudos in situ não são realizados.

Em outras situações, a impossibilidade de acesso e obtenção de materiais rochosos em quantidades desejáveis torna impossível a realização de estudos com confiabilidade estatística capazes de permitir o bom entendimento do ambiente em que serão desenvolvidas as atividades em subsolo.

À medida que novos avanços tecnológicos foram implementados, melhores condições foram propiciadas para que estudos mais aprofundados do ponto de vista científico pudessem ser realizados. BIENIAWSKI (1981) sugere diferentes técnicas que podem ser adotadas para a estimativa da resistência in situ dos carvões, como a determinação do efeito escala a partir de ensaios de laboratório, a realização de ensaios in situ, o uso de geofísica, o emprego do método de PROTODYAKONOV (1965) ou a utilização do critério de resistência de HOEK \& BROWN (1980), por exemplo. Essas técnicas e outras serão discutidas adiante, tendo em vista a importância para a realização da pesquisa proposta neste trabalho.

A Figura 2.1 apresenta um fluxograma, proposto por NATAU (1990), com as principais alternativas e caminhos que podem ser utilizados para a determinação do comportamento mecânico de maciços rochosos (resistência e deformabilidade), que em última análise, são as informações de interesse direto na elaboração dos projetos de engenharia inseridos em maciços rochosos.

\subsubsection{Efeito Escala em Materiais Rochosos}

No âmbito do Comitê de Estudos do Efeito Escala em Mecânica de Rochas da ISRM - International Society for Rock Mechanics, tem sido observado experimentalmente que um conjunto de amostras com diferentes tamanhos provenientes de um mesmo universo apresenta distribuições estatísticas com diferentes parâmetros (média, desvio padrão, por exemplo) para uma mesma propriedade da rocha. Adicionalmente, um conjunto de amostras de uma mesma rocha ou de um mesmo maciço rochoso quando submetida a carregamento em condições similares, apresenta características não constantes, mas dependentes da dimensão da amostra. Essa variação é denominada de efeito escala (CUNHA, 1990 e 1992). 


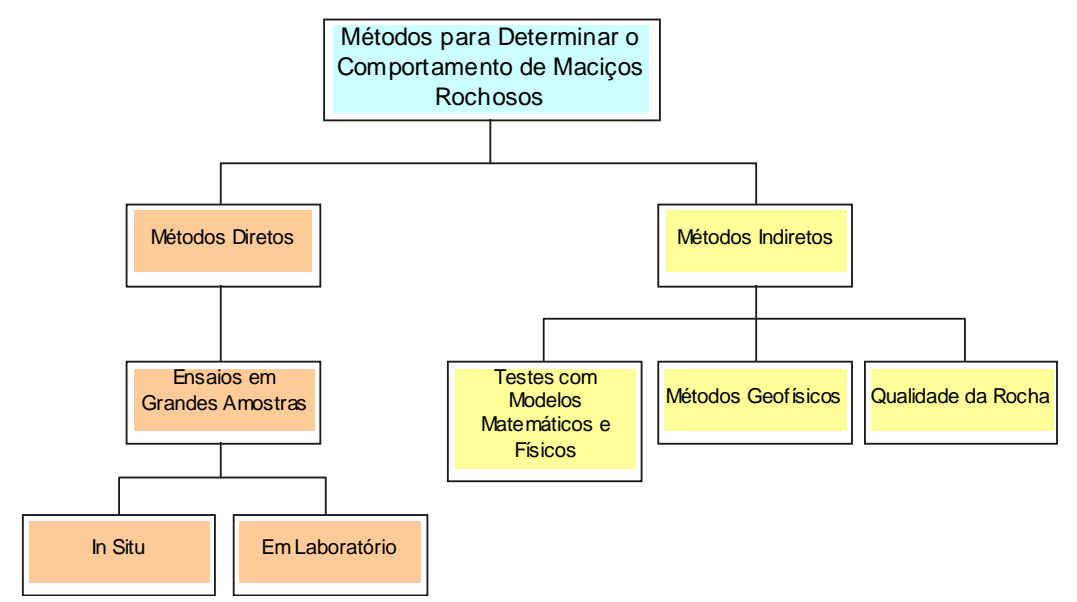

Figura 2.1 - Métodos para a determinação do comportamento mecânico de maciços rochosos (adaptado de NATAU, 1990).

O efeito de escala na resistência de materiais rochosos tem sido observado em diferentes modalidades de ensaios, além da compressão uniaxial, como na compressão diametral, carga pontual, cisalhamento direto, ensaios de deformabilidade e capacidade de carga (HEUZE, 1980; BRACE, 1981; TSURLAVIE \& DENEKAMP, 1982b; CUNHA, 1990; BANDIS, 1990). WEILBULL (1952) observou o mesmo fenômeno em outros materiais diferentes de rocha.

O fenômeno do efeito escala, que permanece ainda não decifrado integralmente até hoje, já havia sido observado há quase 100 anos atrás. Estudando antracitos e carvões betuminosos do EUA, DANIELS \& MOORE (1907) estão entre os primeiros estudiosos do assunto a observar que a resistência de corpos-de-prova cúbicos diminui à medida que o tamanho aumenta. Esses autores observaram, também, o chamado "efeito forma" na resistência, o qual se reflete na queda da resistência à medida que um corpo-de-prova (ou um pilar) se torna mais esbelto (mais magro). Já à época, os autores alertavam sobre o fato de que a determinação da resistência deve levar em consideração esses aspectos (tamanho e forma), associados a outros fatores como o grau de sanidade da rocha, a presença de descontinuidades ("cleats"), a existência de camadas de estéril no meio do carvão e a direção de aplicação da carga em relação à orientação dos planos de estratificação da rocha.

A "teoria do elo mais fraco" de WEILBULL (1939) apud TSUR-LAVIE \& DENEKAMP (1982a), propunha que a ruptura ocorre devido à distribuição estatística das descontinuidades (planos de fraqueza) ou à não homogeneidade da amostra. Segundo o autor, o número de descontinuidades aumenta, assim como a probabilidade da ruptura, à medida que o volume da amostra aumenta. Esta teoria foi criticada severamente por BROWN (1971), por ser usada indiscriminadamente para explicar o efeito escala na resistência à compressão, sugerindo a sua não aplicação devido às suas limitações, já que ela havia sido desenvolvida baseada exclusivamente em ensaios de tração. Embora ainda contestada como explicação física para o efeito escala, até hoje muitos resultados experimentais ainda podem ser explicados por essa teoria.

Já na década de 1940, TUCKER (1945) discutia a precisão dos resultados de resistência em função da variação da dimensão da amostra em concreto. 
Observou que a dispersão dos resultados é tanto menor quanto maior for a dimensão da amostra. Amparado em estudos estatísticos o autor propôs uma regra básica para a definição do número de ensaios requeridos para determinado tamanho de corpo-de-prova, de acordo com a seguinte função:

$$
x\left(d_{2}\right)=x\left(d_{1}\right) * \frac{1}{\left(\frac{d_{2}}{d_{1}}\right)^{2}}
$$

onde: $\mathrm{x}\left(\mathrm{d}_{2}\right)=$ número de ensaios requeridos para corpos-de-prova com a dimensão $\mathrm{d}_{2}$;

$x\left(d_{1}\right)=$ número de ensaios realizados em corpos-de-prova com a dimensão $\mathrm{d}_{1}$;

$d_{1}$ e $d_{2}=$ dimensão dos corpos-de-prova de menor e maior tamanho, respectivamente.

Comportamento semelhante, porém, baseado em estudos experimentais com materiais rochosos foi observado por vários outros pesquisadores (SINGH, 1980 e HERGET, 1988 apud CUNHA, 1990).

PROTODIAKONOV \& KOIFMAN (1967) sugerem algumas explicações para o decréscimo da resistência da rocha com o aumento do volume da amostra ensaiada, ilustradas na Figura 2.2: o "efeito do volume" e o "efeito da superfície". Para esses autores, quanto maior o volume da amostra, maior é a probabilidade da presença de algum distúrbio na rocha (fratura, fissura, inclusão) e menor é a resistência. Outro aspecto que tende a influenciar na resistência é o fato de que, normalmente, somente amostras de boa qualidade (com pequenos defeitos) permitem a obtenção de corpos-de-prova de pequenas dimensões. Nesses casos, os resultados de resistência são maiores que em corpos-de-prova de grandes dimensões, que incorporam no seu volume pequenos e grandes defeitos (curva 1). Já o efeito de superfície está associado aos danos impostos pelo processo de preparação do material para ensaio. BANDIS (1990) associa ainda a esse efeito os danos superficiais nos corpos-de-prova ocasionados pela alteração dos minerais da rocha. Os efeitos negativos desses problemas superficiais na qualidade da rocha são tanto maiores quanto menores forem os corpos-de-prova. O resultado é a diminuição da resistência à medida que o tamanho dos corposde-prova decresce (curva 2). A presença simultânea dessas duas formas de influência na resistência da rocha pode ocasionar, muitas vezes, o cancelamento do efeito de cada uma individualmente e o resultado é a constância da resistência, independentemente da dimensão do corpo-de-prova ensaiado (curva 3). BARTON (1990) sugere que a existência do efeito escala se deve, além dos aspectos já elencados, ao condicionamento e às dificuldades na amostragem, o que tende a prejudicar a análise estatística dos resultados.

BIENIAWSKI (1968b) por seu lado, reporta um extenso estudo realizado na África do Sul com amostras da camada de carvão Witbank. Esse autor foi um dos primeiros a estudar o efeito escala na resistência à compressão uniaxial no carvão a partir de ensaios em corpos-de-prova cúbicos com dimensões compreendidas numa larga faixa, de aproximadamente $2 \mathrm{~cm}$ até $2 \mathrm{~m}$, conforme 
visto na Figura 2.3. Para ele, o decréscimo da resistência em função do aumento do tamanho dos corpos-de-prova está associado à maior probabilidade de existirem mais descontinuidades nos corpos-de-prova maiores do que nos de menor dimensão.

EINSTEIN et al. (1970) estudando uma mistura de gesso em corpos-de-prova de pequenas dimensões (cilindros de até $5 \mathrm{~cm}$ de diâmetro e prismas de até $5 \mathrm{~cm} x$ $10 \mathrm{~cm}$ de lado na base, na relação altura/diâmetro $\cong 2$ ), buscaram lançar as bases para o entendimento dos mecanismos que governam o decréscimo da resistência com o aumento da dimensão do corpo-de-prova. Segundo esses autores, à época três diferentes aproximações eram usadas pelos pesquisadores para explicar o efeito escala:

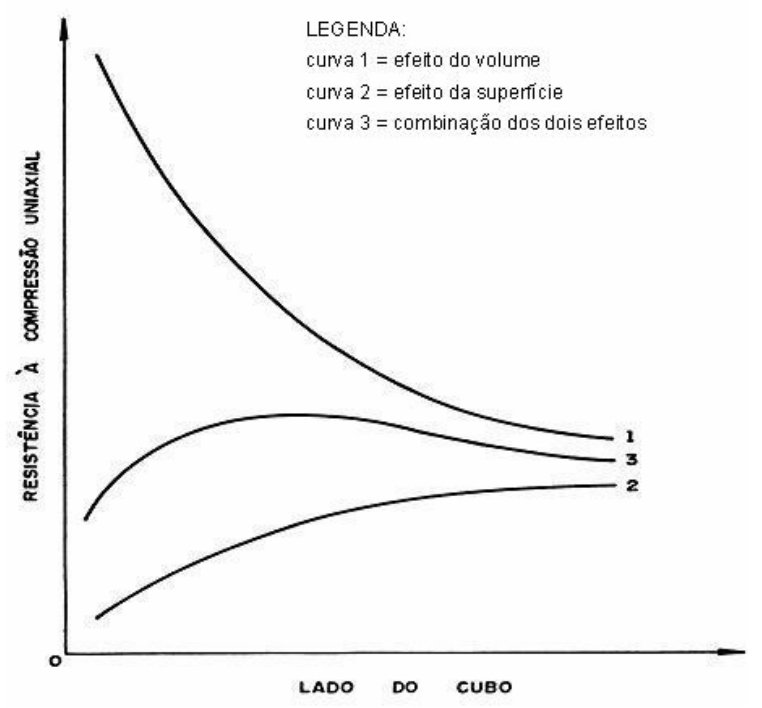

Figura 2.2 - Concepções propostas para a expressão do efeito escala (adaptado de PROTODIAKONOV \& KOIFMAN, 1967).

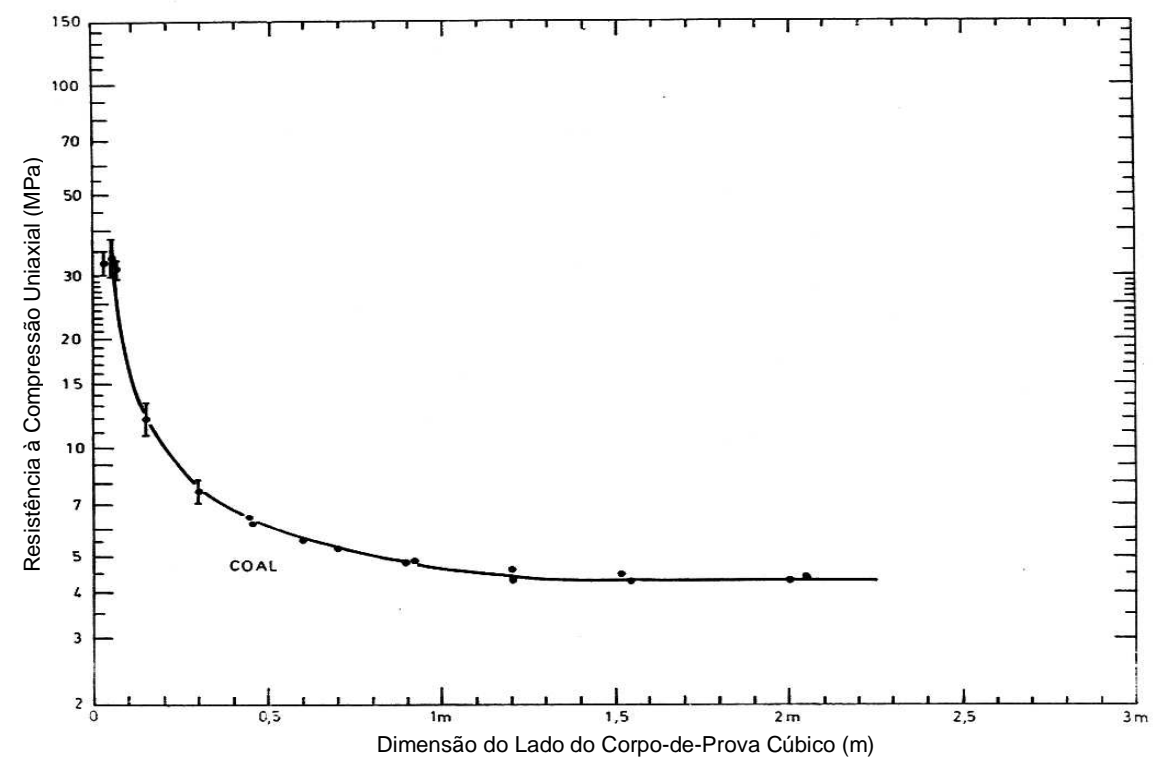

Figura 2.3 - Resultados de ensaios de compressão uniaxial in situ sobre o carvão da camada Witbank - África do Sul (adaptado de BIENIAWSKI, 1968a). 
- a estatística, segundo a qual a queda da resistência está associada à distribuição dos planos de fraqueza, sua orientação, geometria e localização na amostra;

- a mecânica, que explica a queda de resistência com o aumento do volume da amostra a partir da energia de deformação armazenada, a qual é liberada durante a propagação de fraturas. Isso ocorre em maior escala nas amostras de maior dimensão porque quanto maior a amostra maior é a quantidade de energia de deformação disponível;

- a empírica, que se baseia em estudos experimentais.

A partir da observação do efeito escala nos seus experimentos, esses autores sugerem que as duas aproximações, estatística e mecânica, conjuntamente explicam esse efeito, uma vez que a dimensão das amostras afeta tanto a distribuição da população de descontinuidades como a quantidade de energia de deformação armazenada.

HODGSON \& COOK (1970) observaram efeito escala praticamente desprezível em estudos de dois tipos litológicos de comportamento frágil (quartzito e xisto), quando ensaiados sob condições de tensão uniforme (compressão uniaxial). Sugerem, então, que a variação da resistência não está associada à estrutura da rocha, mas à variabilidade da matriz rochosa. Já a conclusões bem diferentes chegaram PRATT et al. (1972), que estudaram o efeito escala sobre rochas vulcânicas intrusivas (diorito e granodiorito) não fraturadas, a partir de ensaios de compressão uniaxial em amostras com dimensões variando entre $11 \mathrm{~cm} \mathrm{e} 30 \mathrm{~cm}$ em laboratório e $30 \mathrm{~cm}$ e $2,7 \mathrm{~m}$ in situ, aproximadamente. Observaram uma redução da resistência da ordem de 10 vezes com o incremento do tamanho da amostra. Esses autores concordam com a observação de BIENIAWSKI (1968a, 1968b, 1968c e 1969) feita a partir de ensaios de compressão uniaxial in situ sobre amostras cúbicas ou prismáticas com o lado da base variando entre $30 \mathrm{~cm}$ e $2 \mathrm{~m}$, de que existe um limite de tamanho de amostra a partir do qual a resistência se mantém constante.

HOEK \& BROWN (1980a) após analisar dados de ensaios de compressão uniaxial de diferentes casos na literatura, inclusive alguns em que não foi observado nenhum efeito da variação do tamanho da amostra na resistência, acreditam que o efeito escala está presente na maioria das rochas. Apresentam um conjunto de resultados de ensaios de compressão uniaxial em rocha intacta, onde a resistência de cada tipo litológico foi normalizada para a resistência média de corpos-de-prova de $50 \mathrm{~mm}$ de diâmetro. A Figura 2.4 mostra os dados compilados, bem como uma função matemática para explicar o feito escala em amostras com dimensões entre $10 \mathrm{~mm}$ e $200 \mathrm{~mm}$.

BARTON (1987) apud CUNHA (1990) baseado em dados experimentais propõe algo semelhante, ou seja:

$\left(\frac{\sigma_{c}}{\sigma_{c 50}}\right)=\left(\frac{50}{d}\right)^{0,22}$

onde: $\sigma_{\mathrm{c}}=$ resistência à compressão uniaxial do corpo-de-prova com diâmetro d;

$\sigma_{c 50}=$ resistência à compressão uniaxial de corpo-de-prova com diâmetro $50 \mathrm{~mm}$. 


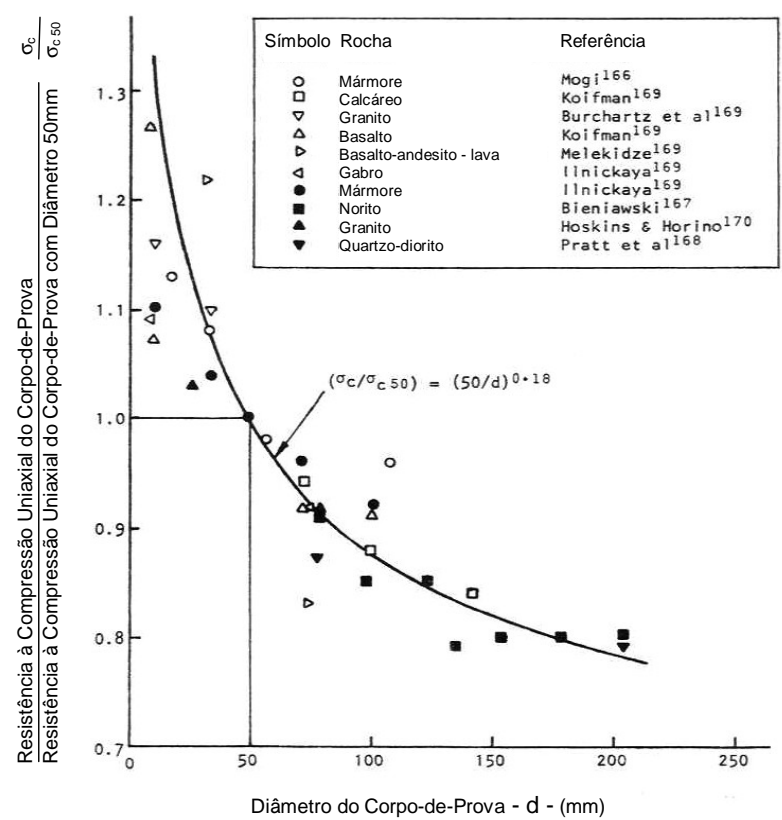

Figura 2.4 - Efeito escala na resistência à compressão uniaxial de rocha intacta (adaptado de HOEK \& BROWN, 1980a).

BRACE (1981) apresenta uma série de resultados e discute o efeito escala associado a diferentes propriedades da rocha. Este autor observa que determinadas rochas, especialmente as de baixa resistência, apresentam grande redução na resistência em função do aumento do volume e que corpos-de-prova com dimensões superiores a $1 \mathrm{~m}$, nessas rochas, tendem a apresentar resistência constante.

BANDIS (1990) também elenca várias pesquisas realizadas e mostra que o efeito do tamanho da amostra se pronuncia em várias propriedades mecânicas da rocha, ou seja, não somente na resistência à compressão uniaxial, mas também na resistência à tração indireta, na resistência ao cisalhamento e, com menor intensidade, na deformabilidade (módulo de elasticidade). Ensaios de laboratório associados a ensaios in situ têm revelado significativa variação na resistência devido ao efeito da variação do volume de rocha ensaiada. Observa, também, que o efeito escala depende do tipo de rocha ensaiada, como pode ser visto na Figura 2.5. Esse autor, além de concordar com as hipóteses sugeridas anteriormente para explicar o decréscimo da resistência em função do aumento do tamanho da amostra, acrescenta ainda os "efeitos mecânicos", os quais estão relacionados à energia de deformação armazenada no corpo-de-prova durante o processo de compressão.

CUNHA (1990) destaca além da dimensão da amostra, outros aspectos que influenciam na determinação das diferentes propriedades dos maciços rochosos. Para ele, o local de ensaio ou da coleta das amostras (presença de heterogeneidade), a orientação da determinação das propriedades (influência da anisotropia), fatores desconhecidos ou fenômenos de alguma relevância como a fluência, o efeito da variação da temperatura e o efeito combinado desses fatores também são importantes. 


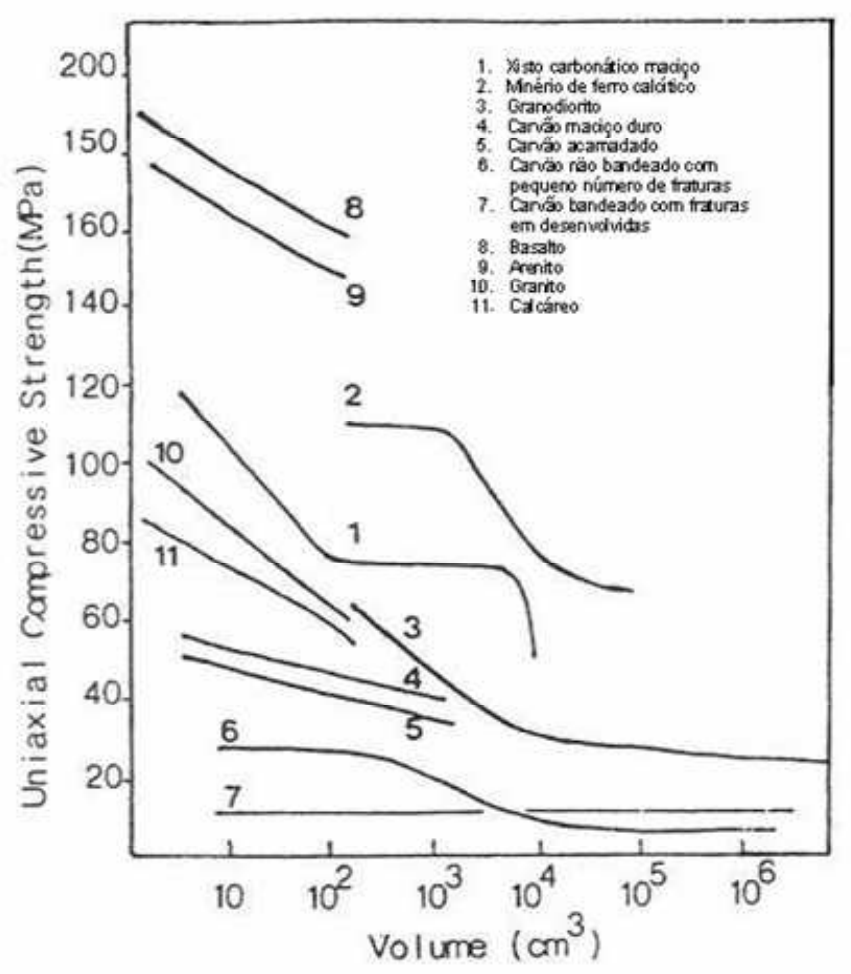

Figura 2.5 - Efeito do volume na resistência à compressão uniaxial de diferentes tipos de rocha (dados compilados de LAMA \& GONANO, 1976 e KACZYNSKI, 1986 - adaptado de BANDIS, 1990).

Para rochas intactas, o efeito escala é devido à heterogeneidade mineralógica. Isso geralmente ocorre numa escala bastante reduzida. À medida que o tamanho da amostra aumenta, o efeito escala se deve, além da heterogeneidade, ao conjunto de descontinuidades macroscópicas presentes na rocha. Tomando-se o efeito escala como a única variável a ser estudada, mantidas as demais constantes, é necessário que se defina o menor volume a partir do qual não ocorrem variações nas propriedades de um maciço rochoso. Esse volume o autor define como o VER - Volume Elementar Representativo e pode variar de acordo com o maciço e a propriedade em consideração. Algo semelhante a esse conceito já fora proposto por SANDER (1930) apud NATAU (1990), quando eram dados os primeiros passos no sentido do estabelecimento de um modelo teórico para explicar o efeito escala. Para esse autor, o estudo do efeito escala na resistência de maciços rochosos deve levar em conta os seguintes aspectos:

- a área de estudo considerada;

- o menor volume necessário para representar as características do maciço rochoso e;

- os elementos básicos (por exemplo, a estrutura cristalina, minerais componentes dos grãos, fraturas, falhas, tectônica), os quais dependem da área considerada.

Enquanto os estudos apontam para a necessidade da utilização de amostras que incorporem o maior número possível de elementos presentes no maciço, alguns autores, com base em estudos de laboratório sobre rochas duras, tem enfatizado 
a necessidade da determinação da resistência da rocha intacta (sem descontinuidades) como ponto de partida para a definição da resistência do maciço rochoso (SILVA \& BORN, 1993 e SILVA \& HENNIES, 1993). Essa abordagem, porém, parece ir de encontro à abordagem mais realista do problema da determinação do efeito escala em rochas, que considera de fundamental importância a determinação da resistência da rocha associada a uma hierarquização, por exemplo, das estruturas geológicas de onde as amostras foram extraídas para ensaio. Não parece uma abordagem aplicável aos jazimentos carbonosos, onde a presença de descontinuidades é indiscutível, por estarem presentes em grande quantidade e com características muito variáveis.

São bastante conhecidas as dificuldades para a representação das condições de um maciço rochoso apenas com amostras de pequeno porte, mesmo adotando-se as melhores técnicas de extração e acondicionamento, para a posterior realização dos estudos em laboratório. Conforme BANDIS (1990), as questões mais difíceis de serem respondidas e que são discutidas no âmbito do Comitê de Estudos do Efeito Escala em Mecânica de Rochas da ISRM dizem respeito:

- ao tamanho ótimo da amostra a partir do qual a resistência não mais sofre variação;

- às relações que podem ser estabelecidas com segurança para explicar a variação da resistência quando somente dimensões abaixo da considerada ótima são utilizadas;

- e às relações capazes de conjugar as informações geradas a partir de ensaios de laboratório e ensaios in situ para a determinação da resistência de maciços que contém descontinuidades.

Ao longo das últimas décadas, um grande número de pesquisadores têm dedicado tempo e grandes esforços, no mundo inteiro, ao estudo do efeito escala na resistência à compressão uniaxial de diferentes materiais rochosos e, em especial, de rochas carbonosas. Rochas brandas, onde poderiam ser enquadradas as rochas carbonosas, apresentam variações de resistência da ordem de 2 a 5 vezes (NATAU (1990)), podendo chegar até 10 vezes em função da variação do tamanho da amostra (BRACE, 1981; BANDIS, 1990). TRUEMAN \& MEDHURST (1994), com base numa ampla revisão de dados da literatura e BARON \& YANG (1992) baseados em estudos de laboratório, são enfáticos em afirmar que a resistência à compressão uniaxial de rochas carbonosas é mais sensível à variação do tamanho da amostra que em outros tipos litológicos, tornando muito mais difícil a estimativa da sua resistência na condição in situ. Com base na grande quantidade de estudos já realizados, PARISEAU (1975) sugere que o efeito escala não deve ser o mesmo para qualquer condição geológica, o que significa dizer que a aplicação dos modelos existentes não necessariamente podem ser os mais adequados quando novos jazimentos são explotados. Como decorrência das incertezas que ainda persistem na definição da mecânica que governa o efeito escala, não raramente tem sido adotados modelos empíricos para expressar a variação da resistência com o aumento do volume da amostra. Esses modelos normalmente tem sido baseados em ensaios nas escalas de laboratório $e$ in situ e analisados conjuntamente ou individualmente, fazendo-se extrapolações para a estimativa da resistência in situ. 


\subsubsection{Técnicas Diretas para a Determinação da Resistência In Situ de Camadas de Carvão}

Na década de 1960, DENKHAUS (1962), numa revisão crítica do conhecimento sobre a resistência de pilares de minas de carvão definiu duas escolas de pensamento para a abordagem da resistência de pilares de carvão: a baseada em ensaios de grande porte e a escola de ensaios em laboratório. Segundo o autor, os ensaios em larga escala são sem dúvida a maneira mais direta de determinar a resistência de um maciço rochoso, porém, a mais custosa.

Independentemente da escola de pensamento escolhida pelos diferentes pesquisadores no mundo ao longo do tempo, tanto o processo de amostragem como a preparação dos espécimens para a realização dos ensaios são fatores que contribuem sensivelmente para o sucesso de qualquer estudo visando à determinação das propriedades mecânicas de um maciço rochoso.

A representatividade das amostras em relação a um determinado maciço rochoso é fator preponderante para a aplicação dos resultados nas obras de engenharia. A princípio não existe um tamanho único de amostra capaz de representar um determinado maciço, tendo em vista a sua heterogeneidade e a presença de estruturas diversas. Geralmente o tamanho ideal (teórico) esbarra na limitada capacidade operacional dos equipamentos disponíveis tanto para a extração como para a realização dos ensaios de caracterização.

Em se tratando de estudos de efeito escala, a amostragem ganha maior importância ainda, tendo em vista a necessidade de grandes amostras para representar o maciço. Amostras de dimensões maiores tendem a sofrer danos mais facilmente e, associado ao fato de normalmente contemplarem maior número de descontinuidades, apresentam menor resistência que amostras de menor porte (BARTON, 1990). Parte da queda da resistência, nesse caso, pode estar associada à menor qualidade da amostra de grande porte, devido aos danos impostos durante a coleta e não às fraquezas naturais da rocha. CUNHA (1990, 1992) sugere que há uma tendência em amostrar os materiais de zonas de pior qualidade ou de zonas que sejam mais facilmente acessíveis. Esses aspectos tendem a condicionar a qualidade da amostra, distanciando-a da representatividade desejável do maciço rochoso.

Uma discussão qualitativa dos aspectos pertinentes à representatividade da amostra para contemplar o efeito escala em laboratório é apresentada por GOMES (1993), cujo modelo esquemático do efeito escala em função do tamanho da amostra é apresentado na Figura 2.6. Para o autor, o fato de resultarem valores de resistência em pequenas amostras muito baixos (área hachurada na Figura 2.6) e próximos da condição de ensaios in situ (Vi), significa que essas amostras já incorporaram aqueles fatores que tendem a reduzir a resistência nas grandes amostras. Como primeiro passo para definir a representatividade da amostra, o autor sugere que os corpos-de-prova ensaiados sejam descritos abordando-se os aspectos mais relevantes (heterogeneidade, morfologia, reologia, composição), bem como sejam analisados criteriosamente aqueles resultados presentes na área hachurada da Figura 2.6 (menor resistência). A pergunta que permanece não respondida é: serão esses resultados, de menor resistência, equivalentes à condição de ensaios in situ? 


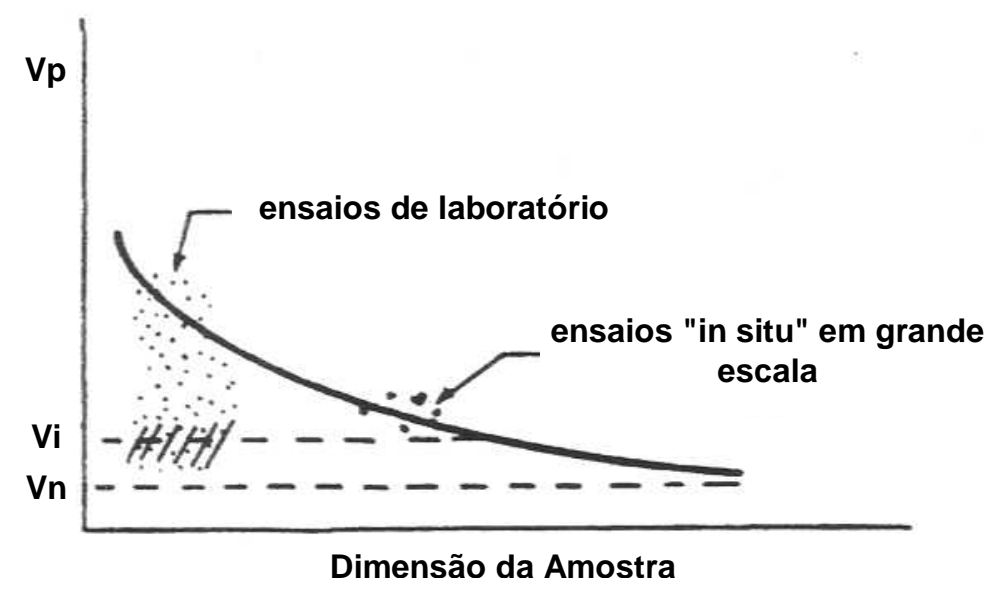

Figura 2.6 - Variação das propriedades da rocha (Vp) com o aumento da dimensão da amostra (adaptado de GOMES, 1993).

Uma vez definidos o local de amostragem, a dimensão mínima da amostra, a quantidade de amostras necessárias, a técnica de extração passa a ser de fundamental importância, tendo em vista que dela dependerá muito a qualidade das amostras que serão levadas ao laboratório ou mesmo ensaiadas in situ. Várias experiências tem mostrado as enormes dificuldades para a execução do trabalho de separação das amostras do maciço rochoso.

Uma outra luz para a seleção do tamanho mínimo de amostra é a utilização do conceito de VARGA (1993) de maciço quase homogêneo, segundo o qual o tamanho da amostra estudada deverá ser muito maior que o tamanho do elemento heterogêneo. Esse autor apresenta uma conceituação de homogeneidade do maciço, relacionando tamanho do maciço estudado (Lm) e o tamanho do elemento heterogêneo (Le). Define três classes de maciço:

a) maciço quase homogêneo: quando $L m>$ Le;

b) maciço com efetiva heterogeneidade: $L m>L e$;

c) maciço heterogêneo: $L m<$ Le.

Já levando em conta as características composicionais e estruturais do carvão, TRUEMAN \& MEDHURST (1994) propuseram uma idealização de maciço rochoso para representar a transição entre uma amostra de rocha intacta de carvão (sem descontinuidades) e a condição in situ, em função do aumento do tamanho da amostra, como ilustra a Figura 2.7. Dessa proposição pode-se extrair aspectos importantes a serem considerados no processo de amostragem, ou seja, a necessidade de conhecimento prévio da geologia da jazida, da distribuição e dimensão dos componentes estruturais presentes para a definição dos locais mais apropriados e a quantidade de amostra para representar o maciço.

$\mathrm{Na}$ condição de inexistência de acesso direto à camada de carvão, amostras de menor dimensão são coletadas através de sondagens rotativas, em campanhas com a finalidade específica de obter material para estudos geomecânicos na fase de projeto. Normalmente amostras com diâmetro não superior a $15 \mathrm{~cm}$ são coletadas (o diâmetro NX - 54mm é o mais utilizado). 


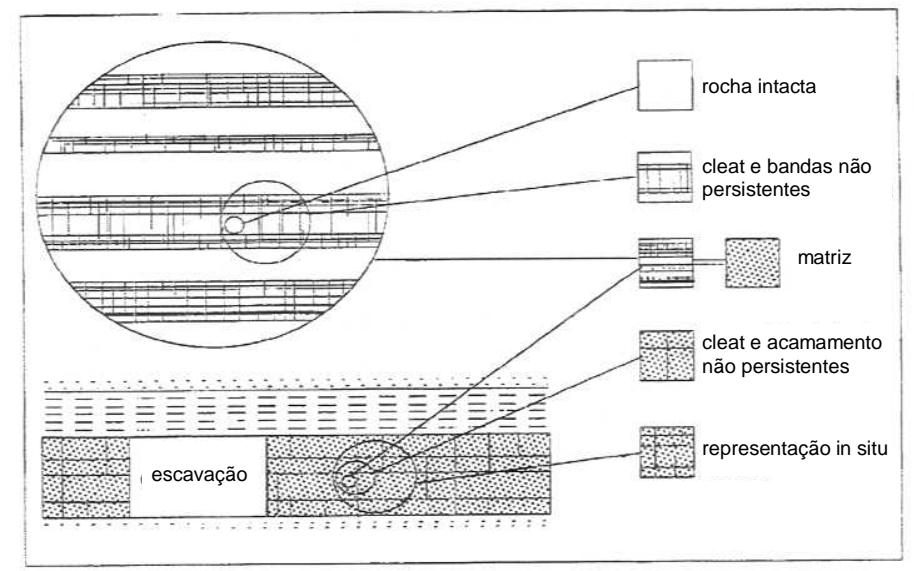

Figura 2.7 - Diagrama idealizado para a transição entre uma amostra intacta e in situ representativa de carvão (adaptado de TRUEMAN \& MEDHURST, 1994).

Quando é possível o acesso direto à camada, amostras de maior dimensão têm sido coletadas ou preparadas normalmente sem o uso de explosivos, nas frentes de lavra, em galerias especialmente desenvolvidas ou nos cantos de pilares. São utilizados equipamentos mecânicos ou manuais de diferentes portes e, em muitos casos, especialmente adaptados para tais tarefas como por exemplo, cortadeira universal, moto-serra com corrente de vídea, perfuratrizes, ferramentas manuais (GREENWALD et al., 1939; BIENIAWSKI, 1969; LAMA, 1970; BIENIAWSKI \& VAN HEERDEN, 1975; CYRUL, 1984; MIDÉA et al., 1985; CIENTEC, 1990 e 1996 e AGOSTINI et al., 2002).

Independentemente da técnica empregada para a coleta das amostras, uma grande preocupação que se faz presente é a conservação do material, visto ser o carvão uma rocha bastante suscetível aos processos de alteração devido à ação do ambiente. É freqüente a utilização de parafina, filme plástico ou material similar para proteger a rocha da ação dos agentes ambientais oxidantes (danosos à rocha) e da perda ou ganho de umidade. Esses cuidados, além de uma técnica adequada quando do transporte das amostras, são fatores por demais importantes para a manutenção da integridade da rocha, sob pena de comprometer todo o trabalho posterior de preparação dos corpos-de-prova e ensaio propriamente dito. Já no que tange ao processo de preparação dos espécimens para ensaio em laboratório, observa-se que as técnicas evoluiram muito nas últimas décadas, especialmente a partir da incorporação de equipamentos utilizados na indústria metal-mecânica (tornos de precisão, retíficas de superfícies cilíndricas e de superfícies planas, utilizando ferramentas diamantadas) adaptados para as condições de trabalho com materiais friáveis. Embora esse tipo de assunto não renda grandes dividendos do ponto de vista científico, alguns pesquisadores têm dedicado grandes esforços no sentido de consolidar as suas experiências, relatando as técnicas que apresentaram sucesso ou mesmo aquelas que não resultaram em bom aproveitamento das amostras de rochas friáveis, entre elas e em especial o carvão.

Vários autores têm reportado os enormes problemas envolvidos no processo de coleta e preparação das amostras. Numa tentativa de fazer frente às dificuldades 
no processo de preparação das amostras, EVANS et al. (1961a) utilizaram o expediente de envolver o carvão com cimento e após efetuar os cortes até a conformação final do corpo-de-prova.

ATKINSON \& CASSAPI (1983) relatam uma experiência de adaptação de uma furadeira radial, utilizada originalmente para metais, para a extração de testemunhos cilíndricos a partir de blocos de carvão. Trata-se de um equipamento que apresenta uma série de virtudes para a realização desse tipo de sondagem, como a alta rigidez da estrutura, o elevado torque e a grande flexibilidade para a variação da velocidade de rotação da broca. Para os autores, os aspectos mais importantes para o sucesso na extração de testemunhos cilíndricos de rocha friável estão relacionados à velocidade de rotação do mandril, da ordem de 1000 revoluções/minuto, e aos baixíssimos níveis de vibração da máquina.

HARPALANI (1988) por sua vez, faz uma revisão das técnicas empregadas nas últimas 3 décadas para a preparação de corpos-de-prova de carvão. Métodos que utilizam o congelamento não apresentaram bons resultados para carvão, embora funcionem com outros tipos de rocha. Esse autor cita uma técnica de envolvimento da amostra de carvão por concreto, utilizada por GAWUGA (1979), porém, observa que foram verificadas muitas quebras nos testemunhos durante 0 processo de preparação. Já a técnica empregada por ele próprio consistiu, basicamente na utilização de torno e retífica com extremo cuidado, sempre trabalhando a seco. Embora com bons resultados, uma grande inconveniência é a enorme quantidade de tempo dispendido: 6 horas para cada corpo-de-prova de $3,81 \mathrm{~cm}$ (diâmetro) x 7,62cm (altura). Estudos realizados pela Fundação de Ciência e Tecnologia (CIENTEC) com amostras de carvões brasileiros, na década de 1980 e o início da década de 1990 (CIENTEC, 1990 e 1996), fizeram o uso de técnicas e equipamentos normalmente empregados na preparação de amostras de rocha (serras diamantadas de diferentes diâmetros, torno, lixadeira). Num dos estudos, mais de 1200 corpos-de-prova cúbicos e prismáticos foram preparados e ensaiados. Os maiores problemas sempre estiveram associados às freqüentes quebras do material durante o processo de corte e ao acabamento (baixo rendimento e perda da amostra) e às dificuldades de manutenção da integridade das amostras após a coleta devido à grande tendência à alteração desse tipo de rocha.

St GEORGE (1995 e 1997) relata experiência obtida estudando o carvão da camada Kupakupa da Nova Zelândia, em que observou o quanto crítico é o processo de coleta da amostra e de preparação dos espécimens, especialmente a perda de umidade. Tal constatação levou o autor a estudar especificamente a relação entre o teor de umidade e a resistência do carvão.

\subsubsection{Ensaios de Compressão Uniaxial em Laboratório}

Geralmente, quando há disponibilidade de amostra, seja ela obtida pelo acesso direto à camada de carvão ou mesmo pelo acesso indireto, através de sondagens, a realização de ensaios de compressão uniaxial utilizando corpos-deprova cúbicos com dimensões variando de alguns centímetros até algumas dezenas de centímetros, tem sido uma alternativa bastante empregada para a estimativa da resistência do maciço. Essa técnica, apesar da larga utilização, ainda é motivo de discussões e de controvérsias para a definição da resistência 
característica das camadas de carvão $\left(S_{1}\right)$, em função das limitações na representação das condições estruturais do maciço.

DANIELS \& MOORE (1907) estão entre os primeiros pesquisadores a relatar estudos em laboratório com carvões dos EUA, visando à determinação da sua resistência para fins de dimensionamento dos pilares em minas subterrâneas. Carvões de 12 minas foram ensaiados utilizando corpos-de-prova cúbicos com dimensões do lado variando de $5 \mathrm{~cm}$ a $15 \mathrm{~cm}$ e prismas com o lado da base entre $5 \mathrm{~cm}$ e $10 \mathrm{~cm}$ e altura de 10 a $30 \mathrm{~cm}$ (relação altura/diâmetro = 2 a 3). Apesar das enormes limitações dos equipamentos tanto para a preparação dos espécimens como para a ruptura à compressão, ainda assim, resultados importantes foram obtidos mostrando que a resistência decresce em função do aumento do tamanho da amostra (efeito escala) e do aumento da relação altura/diâmetro da amostra (efeito forma). Esses autores observaram, ainda, que a estrutura do material (presença de "cleats"), a composição heterogênea da amostra (intercalações de carvão e estéril) e a direção do carregamento em relação aos planos de acamamento tendem a influenciar na resistência final do carvão.

Ainda nos EUA, RICE (1929) e LAVALL \& HOLLAND (1937) observaram em estudos sobre os carvões do Illinois, Pennsylvania e da West Virginia o mesmo tipo de comportamento, ou seja, o decréscimo da resistência em função do aumento da dimensão de corpos-de-prova cúbicos.

STEART (1954), com base em ensaios de laboratório em pequenas amostras e através de observações em subsolo, e GADDY (1956), estudando várias camadas de carvão americanas individualmente, observaram que 0 comportamento da resistência é inversamente proporcional ao tamanho da amostra. Ambos sugeriram a seguinte função genérica para explicar esse comportamento:

$$
\sigma_{C}=\frac{k}{D^{\alpha}}
$$

onde: $\sigma_{\mathrm{c}}=$ resistência a compressão uniaxial;

$\mathrm{k}=$ constante dependente das características físicas de cada camada de carvão;

D = dimensão da amostra cúbica ensaiada;

$\alpha=$ coeficiente correspondente ao efeito escala para a camada de carvão estudada.

Segundo esses autores, os resultados obtidos sugerem que $\alpha=0,5$ representa razoavelmente o comportamento médio desse fator para as diferentes camadas estudadas. MARK \& BARTON (1997) sugerem que esse modelo com $\alpha=0,5$, só é aplicável para camadas de carvão com elevado grau de fraturamento.

Sobre carvões Ingleses, EVANS \& POMEROY (1958) e EVANS et al. (1961a, 1961 b e 1961c) realizaram uma grande quantidade de ensaios de compressão uniaxial, utilizando corpos-de-prova cúbicos, com o lado da base variando entre $0,3 \mathrm{~cm}$ e $5,4 \mathrm{~cm}$, e prismáticos com os lados da base variando entre $1,3 \mathrm{~cm}$ e $5 \mathrm{~cm}$ e a altura entre $1,3 \mathrm{~cm}$ e $5,4 \mathrm{~cm}$. Foram estudados dois carvões com características diferentes: o da camada Barnsley Hards, relativamente uniforme, e o da camada 
Deep Duffryn, bastante friável e com planos de fraqueza bem definidos. As principais constatações dizem respeito ao decréscimo da resistência média em função do aumento do tamanho da amostra (efeito escala). No entanto, o aspecto mais importante parece estar associado à grande variabilidade da resistência do carvão em corpos-de-prova de mesma dimensão. Esse fato em especial, levou os autores a concluir que a resistência do carvão não deve ser descrita por um valor absoluto, mas em termos estatísticos. Algumas críticas a essa pesquisa foram anotadas por HUSTRULID (1976) e BARON (1983). Para o primeiro, as dimensões reduzidas de parte dos corpos-de-prova utilizados (da ordem de $0,3 \mathrm{~cm}$ ) tornam a execução do trabalho muito difícil e, por conseqüência, os resultados questionáveis. Para o segundo, essas pequenas dimensões $(<<2,5 \mathrm{~cm})$ possuem somente sentido do ponto de vista acadêmico, e não prático. Essa crítica se aplica ainda mais aos estudos de MILLARD et al. (1955) que chegaram a trabalhar com corpos-de-prova de dimensões microscópicas.

A Tabela 2.1 apresenta uma síntese dos resultados obtidos em uma grande quantidade de pesquisas realizadas por diferentes autores sobre os materiais carbonosos, os quais obedecem à lei anteriormente definida.

Esses vários autores, em última análise, buscaram através da realização de ensaios em laboratório com corpos-de-prova cúbicos de diferentes dimensões, definir com maior clareza a lei que explicava o comportamento da resistência do carvão em função do aumento da dimensão da amostra, ou seja, o efeito escala nas diferentes camadas de carvão. De outra parte, o comportamento preconizado pela lei de STEART (1954) e GADDY (1956) não ocorre indefinidamente, ou seja, existe um tamanho de amostra a partir do qual a resistência varia muito pouco. Esse limite corresponde à dimensão ("tamanho crítico") a partir da qual, para efeitos práticos, a resistência do carvão permanece constante. A determinação dessa dimensão foi um dos grandes avanços para efeitos de projeto. Várias sugestões de tamanho crítico foram apresentadas por diferentes pesquisadores, conforme pode ser visto na Tabela 2.2.

Uma abordagem um pouco diferente para a definição da resistência in situ do carvão a partir de ensaios em laboratório foi apresentada por PANEK (1980). Partindo da reavaliação de uma grande quantidade de resultados de resistência do carvão na literatura, utilizando os conceitos da teoria da similitude, o autor propôs uma função para prever a resistência in situ a partir de ensaios de laboratório. Considerando que os efeitos do atrito e da rigidez dos pratos de aço das prensas são influentes na determinação da resistência, o autor sugere a substituição dos mesmos pelos materiais presentes no teto e no piso da camada de carvão. Sugerem, também, a realização de ensaios com corpos-de-prova de diferentes tamanhos e formas, esta última preferencialmente semelhante a dos pilares a serem projetados. No entanto, maior atenção deve ser dada ao efeito escala, visto que esse efeito parece ser diferente, dependendo das características dos materiais constituintes do pilar. 
Tabela 2.1 - Valores do expoente " $\alpha$ " na função do efeito escala $\sigma_{C}=\frac{k}{D^{\alpha}}$ obtidos para diferentes camadas de carvão no mundo.

\begin{tabular}{|c|c|c|c|}
\hline Denominação da camada de carvão & Expoente " $\alpha "$ & Condições em que " $\alpha$ " foi determinado & Referência \\
\hline Llanderbie (Inglaterra) & 0,44 & \multirow{3}{*}{$\begin{array}{l}\text { Definido a partir de mais de } 200 \text { ensaios em laboratório em corpos-de- } \\
\text { prova com dimensões desde microscópicas (massa da ordem de } 10 \\
\mathrm{~g} \text { ) até cubos com lado de aproximadamente } 9 \mathrm{~cm} \text {. }\end{array}$} & \multirow{3}{*}{ MILLARD et al. (1955). } \\
\hline Betteshanger (Inglaterra) & 0,47 & & \\
\hline Langwith (Inglaterra) & 0,53 & & \\
\hline Pittsburgh (USA) & 0,53 & $\begin{array}{l}\text { Definido a partir de } 109 \text { ensaios em laboratório e in situ em cubos com } \\
\text { lado entre } 5,4 \mathrm{~cm} \text { e } 163 \mathrm{~cm} \text {. }\end{array}$ & \multirow{5}{*}{ GADDY (1956). } \\
\hline Clintwood (USA) & 0,46 & $\begin{array}{l}\text { Definido a partir de } 88 \text { ensaios em laboratório em cubos com lado } \\
\text { entre } 5,4 \mathrm{~cm} \text { e } 18 \mathrm{~cm} \text {. }\end{array}$ & \\
\hline Pocahontas $\mathrm{N}^{\circ} 4$ (USA) & 0,42 & $\begin{array}{l}\text { Definido a partir de } 80 \text { ensaios em laboratório em cubos com lado } \\
\text { entre } 5,4 \mathrm{~cm} \text { e } 18 \mathrm{~cm} \text {. }\end{array}$ & \\
\hline Harlan (USA) & 0,55 & $\begin{array}{l}\text { Definido a partir de } 76 \text { ensaios em laboratório em cubos com lado } \\
\text { entre } 5,4 \mathrm{~cm} \text { e } 18 \mathrm{~cm} \text {. }\end{array}$ & \\
\hline Taggart-Marker (USA) & 0,49 & $\begin{array}{l}\text { Definido a partir de } 60 \text { ensaios em laboratório em cubos com lado } \\
\text { entre } 5,4 \mathrm{~cm} \text { e } 18 \mathrm{~cm} \text {. }\end{array}$ & \\
\hline Pocahontas $\mathrm{N}^{\circ} 3$ (USA) & 0,21 & $\begin{array}{l}\text { Definido a partir de } 155 \text { ensaios em laboratório em cilindros com } \\
\text { diâmetro entre } 2,5 \mathrm{~cm} \text { e } 30,5 \mathrm{~cm} \text { e relação altura/diâmetro entre } 0,5 \text { e } 2 \text {, } \\
\text { associados a } 2 \text { ensaios in situ em escala real com pilares de } 18,85 \mathrm{~m} \text {. }\end{array}$ & SKELLY et al. (1977). \\
\hline Deep Duffryn (Inglaterra) & 0,32 & $\begin{array}{l}\text { Definido a partir de } 511 \text { ensaios em laboratório em cubos com lado } \\
\text { entre } 6,3 \mathrm{~cm} \text { e } 5,4 \mathrm{~cm} \text {. O carvão apresenta características friáveis e com } \\
\text { muitos planos de fraqueza bem definidos. }\end{array}$ & $\begin{array}{l}\text { EVANS \& POMEROY (1958), EVANS } \\
\text { et al. (1961a). }\end{array}$ \\
\hline Barnsley Hards (Inglaterra) & 0,17 & $\begin{array}{l}\text { Definido a partir de } 827 \text { ensaios em laboratório em cubos com lado } \\
\text { entre } 0,3 \mathrm{~cm} \text { e } 4 \mathrm{~cm} \text {. O carvão apresenta características homogêneas. }\end{array}$ & $\begin{array}{l}\text { EVANS \& POMEROY (1958), EVANS } \\
\text { et al. (1961a). }\end{array}$ \\
\hline Witbank (África do Sul) & 0,39 & $\begin{array}{l}\text { Definido a partir de ensaios em laboratório e in situ em cubos com lado } \\
\text { entre } 2,5 \mathrm{~cm} \text { e } 200 \mathrm{~cm} \text {. }\end{array}$ & $\begin{array}{l}\text { BIENIAWSKI \& VAN HEERDEN } \\
\text { (1975). }\end{array}$ \\
\hline- & 0,5 & $\begin{array}{l}\text { Resistência teórica baseada no conceito do balanço de energia, } \\
\text { derivada para ruptura à tração. }\end{array}$ & FAIRHURST (1973). \\
\hline- & 0,5 & Baseado nos resultados obtidos por Bieniawski na África do Sul. & HUSTRULID (1976). \\
\hline - & 0,5 & $\begin{array}{l}\text { Baseado em dados da literatura sobre carvões de várias partes do } \\
\text { mundo. }\end{array}$ & $\begin{array}{l}\text { BARON (1983), BARON \& YANG } \\
\text { (1992). }\end{array}$ \\
\hline
\end{tabular}

Continua ... 
Continuação ...

\begin{tabular}{|c|c|c|c|}
\hline Denominação da camada de carvão & Expoente " $\alpha "$ & Condições em que " $\alpha$ " foi determinado & Referência \\
\hline $\mathrm{I}_{1} \mathrm{~F}($ Brasil-RS) & 0,42 & $\begin{array}{l}\text { Resultados de ensaios em laboratório em cubos com dimensões entre } \\
5 \mathrm{~cm} \text { e } 45 \mathrm{~cm} \text { e } 1 \text { ensaio in situ com lado igual a } 100 \mathrm{~cm} \text {. } \\
\end{array}$ & MIDÉA et al. (1985). \\
\hline $\mathrm{I}_{1} \mathrm{~F}$ (Brasil-RS) & 0,5 & $\begin{array}{l}\text { Resultados de ensaios em laboratório em cubos com dimensões entre } \\
5,3 \mathrm{~cm} \text { e } 29,8 \mathrm{~cm} \text { e } 2 \text { ensaios in situ com lado entre } 80 \mathrm{~cm} \text { e } 90 \mathrm{~cm} \text {. }\end{array}$ & \multirow{3}{*}{ CIENTEC (1990). } \\
\hline I (Brasil-RS) & 0,5 & $\begin{array}{l}\text { Resultados de ensaios em laboratório em cubos com dimensões entre } \\
2,3 \mathrm{~cm} \text { e } 19,5 \mathrm{~cm} \text {. }\end{array}$ & \\
\hline Chico Lomã (Brasil-RS) & 0,5 & $\begin{array}{l}\text { Resultados de ensaios em laboratório em cubos com dimensões entre } \\
2,4 \mathrm{~cm} \text { e } 14,2 \mathrm{~cm} \text {. }\end{array}$ & \\
\hline Blind Canyon (USA) & 0,54 & $\begin{array}{l}\text { Baseado em } 126 \text { dados da literatura em corpos-de-prova com a } \\
\text { relação largura/altura = } 1 \text { e dimensão máxima de } 29,5 \mathrm{~cm} \text {. }\end{array}$ & \multirow{10}{*}{ MARK \& BARTON (1996) } \\
\hline Clintwood (USA) & 0,31 & $\begin{array}{l}\text { Baseado em } 88 \text { dados da literatura em corpos-de-prova com a relação } \\
\text { largura/altura }=1 \text { e dimensão máxima de } 18 \mathrm{~cm} \text {. }\end{array}$ & \\
\hline Elkhorn (USA) & 0,55 & $\begin{array}{l}\text { Baseado em } 69 \text { dados da literatura em corpos-de-prova com a relação } \\
\text { largura/altura = } 1 \text { e dimensão máxima de } 16 \mathrm{~cm} .\end{array}$ & \\
\hline Harlan (USA) & 0,29 & $\begin{array}{l}\text { Baseado em } 129 \text { dados da literatura em corpos-de-prova com a } \\
\text { relação largura/altura =1 e dimensão máxima de } 18 \mathrm{~cm} \text {. }\end{array}$ & \\
\hline Herrin $N^{\circ} 6$ (USA) & 0,38 & $\begin{array}{l}\text { Baseado em } 150 \text { dados da literatura em corpos-de-prova com a } \\
\text { relação largura/altura }=1 \text { e dimensão máxima de } 34,5 \mathrm{~cm} \text {. }\end{array}$ & \\
\hline Taggart-Marker (USA) & 0,45 & $\begin{array}{l}\text { Baseado em } 60 \text { dados da literatura em corpos-de-prova com a relação } \\
\text { largura/altura = } 1 \text { e dimensão máxima de } 18 \mathrm{~cm} \text {. }\end{array}$ & \\
\hline Pittsburgh (USA) & 0,52 & $\begin{array}{l}\text { Baseado em } 272 \text { dados da literatura em corpos-de-prova com a } \\
\text { relação largura/altura = } 1 \text { e dimensão máxima de } 22,9 \mathrm{~cm} \text {. }\end{array}$ & \\
\hline Pocahontas $N^{\circ} 3$ (USA) & 0,03 & $\begin{array}{l}\text { Baseado em } 140 \text { dados da literatura em corpos-de-prova com a } \\
\text { relação largura/altura = } 1 \text { e dimensão máxima de } 29,5 \mathrm{~cm} \text {. }\end{array}$ & \\
\hline Pocahontas $\mathrm{N}^{\circ} 4$ (USA) & 0,13 & $\begin{array}{l}\text { Baseado em } 74 \text { dados da literatura em corpos-de-prova com a relação } \\
\text { largura/altura }=1 \text { e dimensão máxima de } 18 \mathrm{~cm} \text {. }\end{array}$ & \\
\hline Upper Banner (USA) & 0,29 & $\begin{array}{l}\text { Baseado em } 78 \text { dados da literatura em corpos-de-prova com a relação } \\
\text { largura/altura }=1 \text { e dimensão máxima de } 20,8 \mathrm{~cm} \text {. }\end{array}$ & \\
\hline
\end{tabular}


Tabela 2.2 - Valores sugeridos para o tamanho crítico para a estimativa da resistência in situ de camadas de carvão.

\begin{tabular}{|c|c|c|}
\hline $\begin{array}{l}\text { Tamanho Crítico } \\
\text { para a Estimativa } \\
\text { da Resistência In } \\
\text { Situ do Carvão } \\
\text { (m) }\end{array}$ & $\begin{array}{c}\text { Base de Informações para a } \\
\text { Proposição }\end{array}$ & Referência \\
\hline 1,6 & $\begin{array}{l}\text { Ensaios em laboratório e in situ em } \\
\text { corpos-de-prova com o lado } \\
\text { variando entre } 5,4 \mathrm{~cm} \text { e } 163 \mathrm{~cm} \text {. }\end{array}$ & GADDY (1956). \\
\hline 1,5 a 1,8 & $\begin{array}{l}\text { Ensaios em laboratório em corpos- } \\
\text { de-prova cilíndricos com diâmetro } \\
\text { entre } 2,5 \mathrm{~cm} \text { e } 30,5 \mathrm{~cm} \text { e ensaios in } \\
\text { situ em pilares na escala real com } \\
18,85 \mathrm{~m} \text { de lado. }\end{array}$ & SKELLY et al. (1977). \\
\hline 1,6 & Análise de dados da literatura. & $\begin{array}{l}\text { BARON (1983) e BARON \& } \\
\text { YANG (1992). }\end{array}$ \\
\hline 1,5 & $\begin{array}{l}\text { Ensaios em laboratório e in situ em } \\
\text { corpos-de-prova com o lado } \\
\text { variando entre } 2,5 \mathrm{~cm} \text { e } 200 \mathrm{~cm} \text {. }\end{array}$ & $\begin{array}{l}\text { BIENIAWSKI (1968a, 1968b, } \\
\text { 1968c, 1969 e 1981) e } \\
\text { BIENIAWSKI \& VAN } \\
\text { HEERDEN (1975). }\end{array}$ \\
\hline 0,9 a 1,0 & Análise de dados da literatura. & $\begin{array}{l}\text { BIENIAWSKI (1982, } 1983 \text { e } \\
\text { 1984). }\end{array}$ \\
\hline 0,9 & Análise de dados da literatura. & HUSTRULID (1976). \\
\hline 1,4 & $\begin{array}{l}\text { Ensaios em laboratório em corpos- } \\
\text { de-prova cúbicos com o lado } \\
\text { variando entre } 5 \mathrm{~cm} \text { e } 45 \mathrm{~cm} \text { e } \\
\text { ensaio in situ em corpo-de-prova } \\
\text { com lado igual a } 100 \mathrm{~cm} \text { na camada } \\
\text { de carvão } \mathrm{I}_{1} \mathrm{~F} \text { do RS no Brasil. } \\
\text { Resultados não conclusivos pelos } \\
\text { autores. }\end{array}$ & MIDÉA et al. (1985). \\
\hline$>2^{\# \#}$ & $\begin{array}{l}\text { Ensaios em laboratório em corpos- } \\
\text { de-prova cilíndricos com diâmetro } \\
\text { entre } 2,5 \mathrm{~cm} \text { e } 30,5 \mathrm{~cm} \text { em } 4 \\
\text { diferentes camadas de carvão do } \\
\text { Brasil e ensaios in situ em corpos- } \\
\text { de-prova com lado entre } 70 \mathrm{~cm} \text { e } \\
90 \mathrm{~cm} \text { em } 2 \text { camadas. }\end{array}$ & CIENTEC (1990). \\
\hline
\end{tabular}

\# Sugerido para camadas de carvão homogêneas (I, $\mathrm{l}_{1} \mathrm{~F}$ e Chico Lomã - Brasil-RS), cujo efeito escala pode ser expresso pela função raiz quadrada.

\#\# Indicado para a camada Barro Branco - Brasil-SC. 
O IPT - Instituto de Pesquisas Tecnológicas do Estado de São Paulo (MIDEA et al., 1985), no início da década de 80 , desenvolveu um primeiro trabalho em que foram realizados ensaios de laboratório com cubos de 5 a $45 \mathrm{~cm}$ de lado e um único ensaio in situ com corpo-de-prova com $1 \mathrm{~m}^{3}$, cujos resultados podem ser vistos na Figura 2.8, na Mina de Charqueadas, no Rio Grande do Sul. Foi uma uma primeira tentativa de determinar a resistência in situ da camada de carvão denominada $\mathrm{I}_{1} \mathrm{~F}$. Embora tenham feito uma estimativa do que poderia ser adotado como a resistência in situ $\left(S_{1}\right)$ da camada de carvão $\mathrm{I}_{1} \mathrm{~F}(8,26 \mathrm{MPa})$, esse dado não é sugerido como conclusivo. Devido à pequena quantidade de ensaios, esses autores se limitaram a discutir a importância da necessidade de estudos geomecânicos para as camadas de carvão brasileiras. Os resultados, no entanto, permitiram constatar que as camadas brasileiras não necessariamente se comportam, do ponto de vista de resistência, como as camadas estrangeiras, as quais tem servido de base para o dimensionamento dos pilares no Brasil. $O$ mesmo IPT desenvolveu, também, na época, estudos sobre a camada Barro Branco, em Santa Catarina, porém, com poucos resultados práticos para o dimensionamento de pilares para as minas subterrâneas daquela jazida.

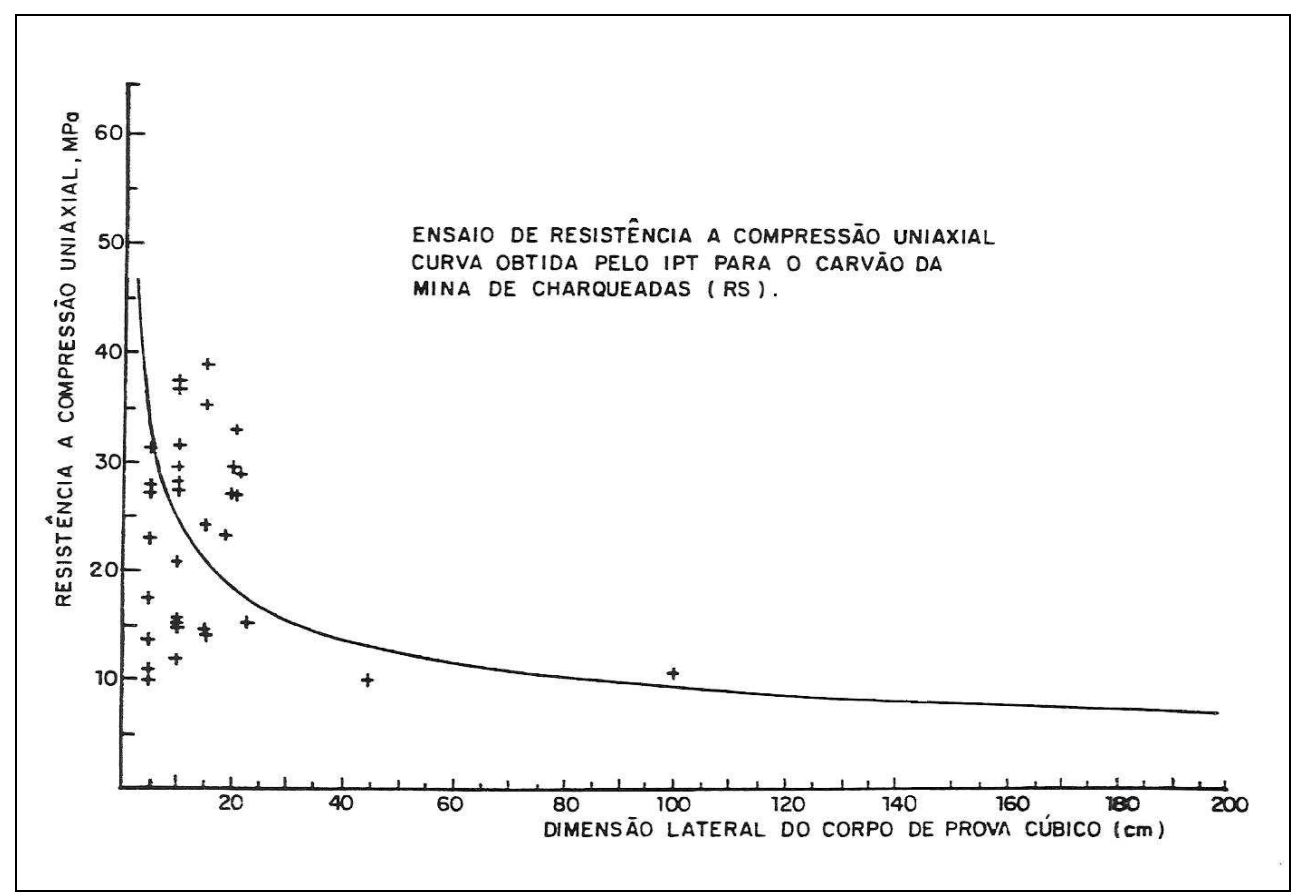

Figura 2.8 - Resultados de ensaios de compressão uniaxial em laboratório e in situ com materiais da camada de carvão $\mathrm{I}_{1} \mathrm{~F}$ da Mina Charqueadas no RS (MIDÉA et al., 1985).

Observando que as pesquisas relacionadas à resistência na maioria dos casos se concentravam apenas na determinação da resistência do carvão propriamente dito, UNRUG et al. (1986) procuraram introduzir o conceito de "resistência da camada de carvão". Utilizaram para difundir essa idéia estudos sobre os tipos litológicos diferentes do carvão (material estéril) presentes nas camadas de carvão Coalburg e Warfield dos USA. Seus argumentos decorreram da observação de que a camada de carvão não é homogênea, ou seja, não é 
constituída somente de carvão mas de uma seqüência de leitos de carvão e material estéril, e que a resistência desses diferentes materiais pode variar muito. Ensaios de compressão uniaxial, com mais de 200 corpos-de-prova cúbicos de $5 \mathrm{~cm}$ de lado, provenientes de todas as litologias presentes na camada, foram realizados. Os resultados mostraram variações na resistência entre os materiais de até 5 vezes. Ficou clara para os autores, a necessidade da ponderação entre as resistências dos vários materiais presentes ao longo do perfil da camada de carvão, para a definição da resistência in situ a ser utilizada em projeto.

Preocupação semelhante foi adotada pela CIENTEC (1990) na definição da resistência característica de cada uma das camadas de carvão do Sul do Brasil. Isso se deveu à grande heterogeneidade presente em algumas delas, especialmente na camada Barro Branco, a mais importante minerada em subsolo no estado de Santa Catarina. Os primeiros estudos com materiais carbonosos realizados pela CIENTEC foram feitos a partir da década de 1980. Com ênfase na caracterização geomecânica das jazidas carboníferas do Sul do Brasil, o estudo abrangeu as mais importantes camadas de carvão em mineração à época, além de outras potencialmente mineráveis, e as camadas encaixantes das camadas de carvão em que havia minas em operação. Esses estudos foram o primeiro grande passo para a definição da resistência in situ das camadas de carvão $I_{1} F$ (jazida de Charqueadas, no Rio Grande do Sul) e Barro Branco e Irapuá (jazida SulCatarinense), o estabelecimento de modelos geológicos básicos para as jazidas brasileiras de carvão, além da proposição de uma metodologia de dimensionamento de pilares aplicada às condições dos jazimentos do Sul do Brasil (ZORZI et al., 1991). A resistência de quatro camadas de carvão (I, l ${ }_{1} \mathrm{~F}$ e Chico Lomã no RS e Barro Branco em SC) foi estudada a partir da realização de 1238 ensaios em laboratório com corpos-de-prova cúbicos com a dimensão do lado entre $2,5 \mathrm{~cm}$ e $31 \mathrm{~cm}$, além de um conjunto de 5 ensaios in situ os quais serão abordados adiante. Os resultados serviram para mostrar claramente que as camadas de carvão brasileiras não possuem as mesmas características de resistência das Sul-Africanas, as quais serviam até então como parâmetro de balizamento para o dimensionamento dos pilares.

A variabilidade da resistência encontrada nos materiais (carvão, siltito e brecha) da camada Barro Branco, visto na Figura 2.9, serviu, também, para mostrar as grandes dificuldades que acompanham o manejo de materiais com características estruturais e litológicas como as que possuem os carvões brasileiros. Apontam para a necessidade de incorporação de elementos adicionais, além da resistência dos corpos-de-prova, para permitir uma análise mais segura e mais realista dos maciços rochosos onde são abertas as minas em subsolo.

Num trabalho de síntese de dados da literatura, MARK \& BARTON (1996), após compilar os resultados de mais de 4000 ensaios realizados sobre mais de 60 camadas de carvão dos USA, discutem a validade do uso de resultados de ensaios de laboratório. Com base no fato de que o efeito escala assume comportamento diverso, dependendo da camada analisada, os autores sugerem a não utilização de resultados de ensaios de compressão uniaxial quando utilizado o método de dimensionamento de pilares ARMPS - Analysis of Retreat Mining Pillar Stability para as camadas de carvão dos EUA. 


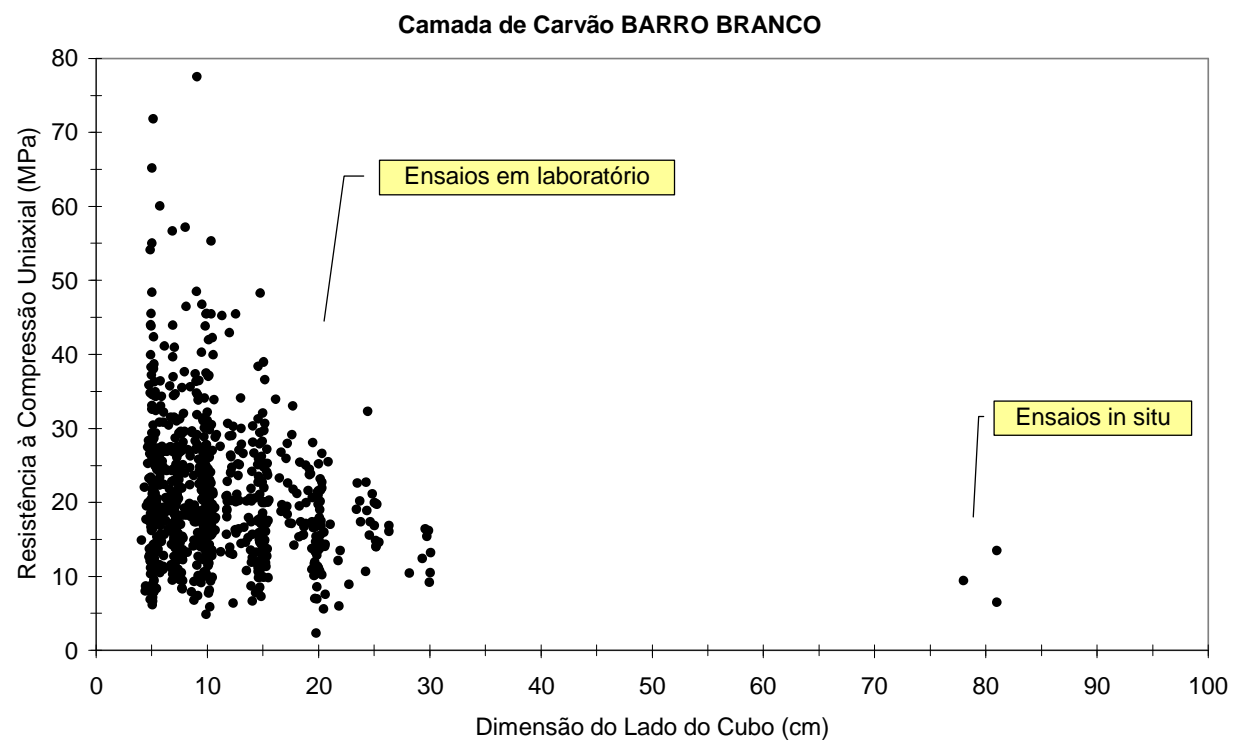

Figura 2.9 - Resultados de ensaios de compressão uniaxial em laboratório em in situ com materiais da camada de carvão Barro Branco da jazida Sul-Catarinense (adaptado de CIENTEC, 1990; ZORZI et al., 1998; AGOSTINI et al., 2002).

Para os carvões da Nova Zelândia, St GEORGE (1995 e 1997) apresenta resultados de resistência obtidos a partir de ensaios em laboratório sobre amostras de rocha intacta nas dimensões que variam de $1,6 \mathrm{~cm}$ a $6,4 \mathrm{~cm}$. Resistências entre $1,2 \mathrm{MPa}$ e $28,7 \mathrm{MPa}$ foram observadas, o que denota uma grande variabilidade. Além de uma boa descrição petrográfica, foram determinados também outros índices capazes de serem correlacionados com a resistência à compressão uniaxial, como o índice de carga pontual, dureza ao impacto e moabilidade. Esses índices serviram de certa forma para explicar e balizar as resistências determinadas diretamente através dos ensaios de compressão uniaxial. Embora o autor objetivasse explicar o efeito das estruturas na resistência das camadas de carvão, os resultados mal permitiram que o autor comentasse sobre a necessidade de novos estudos no sentido de entender as estruturas da rocha e os mecanismos que controlam a resistência do maciço.

\subsubsection{Ensaios de Compressão Triaxial em Laboratório}

A utilização dessa modalidade de ensaio visa a estudar o comportamento do material rochoso sob confinamento, condição que ocorre na região central dos pilares. O resultado desse tipo de estudo é o estabelecimento da envoltória de resistência do material, seja via algum critério de ruptura já consolidado no meio científico, seja através do desenvolvimento de critério específico para o material em estudo.

Diferentes critérios de ruptura têm sido propostos nos últimos anos por diferentes autores. Segundo KALAMARAS \& BIENIAWSKI (1993 e 1995) os seguintes critérios de ruptura são indicados para aplicação em maciços rochosos de carvão: o proposto por BIENIAWSKI (1974), o de HOEK \& BROWN (1980a e 1980b), o de RAMAMURTHY (1986) e o de CARTER et al. (1991). Para o estabelecimento da 
envoltória de resistência do material na condição in situ, no entanto, primeiro devem ser estabelecidas as constantes típicas de cada camada de carvão que atendam às necessidades do critério de ruptura. Finalmente, essas constantes devem ser corrigidas para a condição in situ, via uma classificação geomecânica ou alguma outra técnica que contemple a influência das descontinuidades na resistência do maciço rochoso.

Vários estudos, com diferentes camadas de carvão no mundo, tem sido desenvolvidos na direção da determinação do comportamento do carvão sob confinamento em laboratório. Pesquisa realizada por HOBBS (1960 e 1964) sobre 9 camadas de carvão da Inglaterra mostrou não haver grandes diferenças entre elas quando submetidas a tensões confinantes de $35 \mathrm{MPa}$, embora a resistência à compressão uniaxial variasse 14 vezes entre a camada mais e a menos resistente. Também observou que os resultados podem ser bem representados pelos critérios de ruptura de Mohr-Coulomb e de Griffth. Esse tipo de estudo permite de um lado a comparação relativa entre as resistências de diferentes camadas de carvão, porém, possui uma grande limitação de uso na prática de engenharia pelo fato de não contemplar a correção da envoltória de resistência para a condição in situ. Estudos semelhantes foram levados a efeito por ATKINSON \& KO (1977), que reportam uma série de ensaios triaxiais realizados sobre carvões betuminosos de 6 Estados dos EUA. Para as condições de confinamento adotadas ( 0 a $10 \mathrm{MPa}$, aproximadamente), foram determinados os parâmetros básicos da envoltória de resistência de pico e residual, coesão (c) e ângulo de atrito $(\phi)$ do critério de resistência de Mohr-Coulomb, para cada uma das camadas estudadas. Os resultados são sintetizados na Tabela 2.3. Para efeitos de comparação, nesse quadro são apresentadas, também, as características de resistência de carvões Ingleses. As limitações desses resultados, porém, residem no fato de que servem essencialmente para efeitos de comparação entre diferentes camadas de carvão. Os autores são categóricos ao alertar que, devido à natureza do carvão, amostras com pequenas dimensões devem ser evitadas, tendo em vista a forte influência do efeito escala na sua resistência.

MEDHURST et al. (1995) e MEDHURST \& BROWN (1996) levaram a efeito uma série de ensaios de compressão triaxial em amostras com diâmetro variando de $6,1 \mathrm{~cm}$ a $30 \mathrm{~cm}$ do carvão da camada Moura DU da Austrália. Enfatizam a importância da descrição detalhada do carvão utilizado nos ensaios como forma de facilitar a análise dos resultados quando amostras de diferentes locais numa jazida são utilizadas. Para contornar as variações litológicas na jazida, os autores utilizaram como critério de homogeinização dos resultados uma classificação das amostras segundo o teor de carvão brilhante. Embora baseados numa pequena quantidade de ensaios com as amostras de maior porte e em ensaios sob baixíssimas tensões confinantes (menores que 1,0MPa no caso das amostras de maior porte), os autores propõem uma envoltória de resistência do maciço rochoso de carvão utilizando o critério de ruptura de Hoek-Brown com as seguintes constantes: $\sigma_{\mathrm{c}}=25,80 \mathrm{MPa}, \mathrm{m}=2,93, \mathrm{~s}=0,075, \mathrm{a}=0,65$ na função $\sigma_{1}=\sigma_{3}+\sigma_{c} *\left(\frac{m^{*} \sigma_{3}}{\sigma_{c}}+s\right)^{a}$, sugerindo uma resistência do maciço rochoso da ordem de $\sigma_{\mathrm{c} \text { in situ }}=4,8 \mathrm{MPa}$. 
Tabela 2.3 - Valores de coesão (c) e ângulo de atrito $(\phi)$ de carvões dos EUA e Ingleses (adaptado de ATKINSON \& KO, 1977 e WILSON, 1972).

\begin{tabular}{|c|c|c|c|c|}
\hline Camada de Carvão País & $\begin{array}{l}\mathrm{C}_{\text {intacta }} \\
(\mathrm{MPa})\end{array}$ & $\begin{array}{c}\phi_{\text {intacta }} \\
\left({ }^{\circ}\right)\end{array}$ & $\begin{array}{l}\mathrm{C}_{\text {residual }} \\
(\mathrm{MPa})\end{array}$ & $\begin{array}{c}\phi_{\text {residual }} \\
\quad\left({ }^{\circ}\right)\end{array}$ \\
\hline Beehive EUA & 3,14 & 47,2 & 1,92 & 38,70 \\
\hline Bruceton EUA & 2,51 & 53,5 & 2,09 & 42,80 \\
\hline Decker EUA & 8,72 & 32,2 & 4,39 & 28,40 \\
\hline Federal $\mathrm{N}^{\circ} 2^{\text {EUA }}$ & 3,26 & 47,4 & 2,89 & 37,90 \\
\hline Hanna EUA & 1,54 & 50,0 & - & - \\
\hline York Canyon EUA & 0,50 & 56,7 & - & - \\
\hline Pentremawr Inglaterra & 7,43 & 40,6 & - & - \\
\hline Deep Duffryn Inglaterra & 1,87 & 33,9 & - & - \\
\hline Oakdale Inglaterra & 1,53 & 33,0 & - & - \\
\hline Cwmtillery Inglaterra & 3,38 & 36,3 & - & - \\
\hline Rossington Inglaterra & 15,20 & 30,0 & - & - \\
\hline Rossington Inglaterra & 6,06 & 37,5 & - & - \\
\hline Teversal Inglaterra & 3,85 & 39,0 & - & - \\
\hline Markham Inglaterra & 5,82 & 35,2 & - & - \\
\hline Linby Inglaterra & 5,17 & 40,6 & - & - \\
\hline
\end{tabular}

A observação dos resultados apresentados, de um lado, mostra claramente que boa parte das deduções são decorrentes mais da prática de engenharia dos autores do que da tendência dos resultados disponíveis. De outro, porém, se consideramos as enormes dificuldades para a realização de ensaios triaxiais com amostras de carvão de grande porte (na escala de laboratório), esse estudo possivelmente tenha sido um dos mais completos para a determinação do efeito escala através de ensaios de compressão triaxial.

Trabalhando com uma grande quantidade de dados da literatura YANG (1991) e BARRON \& YANG (1992) desenvolveram um modelo capaz de definir uma envoltória de resistência do carvão in situ, segundo o critério de ruptura de Hoek \& Brown, utilizando resultados de ensaios triaxiais em laboratório. Para comprovar a aplicabilidade da proposição esses últimos pesquisadores utilizaram carvão da Mina Whitewood, do Canadá. Os ensaios triaxiais foram realizados em corpos-deprova com diâmetro entre 5,6 a $6,8 \mathrm{~cm}$ e altura entre 8 e 12cm. O tratamento dos resultados permitiu a estimativa da resistência à compressão uniaxial de laboratório, $\sigma_{\mathrm{c}}=65,6 \mathrm{MPa}$, e das constantes para a condição in situ daquela camada, $m=0,034, s=0,028$ e $a=0,5$. A resistência in situ foi estimada em $\sigma_{c}$ in situ $=10,98 \mathrm{MPa}$. Embora acreditem ser a proposição promissora, os autores são enfáticos em apontar algumas limitações do modelo, especialmente a relacionada à definição da constante $s=0,028$ para os maciços rochosos de carvão. 


\subsubsection{Ensaios de Compressão Uniaxial In Situ}

Não são freqüentes os estudos sobre a resistência e deformabilidade de rochas carbonosas que têm incluído a realização de ensaios de compressão uniaxial in situ. Os vários estudos levados a efeito pelos diferentes autores, em várias partes do mundo, mostraram que trabalhar in situ com amostras de grande porte (volumes da ordem de $1 \mathrm{~m}^{3}$ ) é tarefa muito difícil e muito custosa, por envolver uma quantidade de recursos humanos maior que em laboratório, uma infraestrutura pesada e especialmente projetada para esse tipo de trabalho, dificuldades enormes para a preparação dos espécimens para ensaio, além da adequação das operações de produção da mina para atender às necessidades das equipes envolvidas com a preparação e execução dos ensaios.

A realização de ensaios in situ, por ser em pequeno número e, normalmente, estatisticamente não representativos, não é garantia de bons resultados para a determinação da resistência in situ da rocha, uma vez que nem sempre é possível incorporar todas as características e peculiaridades da rocha no corpo-de-prova ensaiado. Não obstante as dificuldades para a execução e as limitações dos resultados fornecidos, vários autores (BIENIAWSKI \& VAN HEERDEN, 1975; VAN HEERDEN, 1976 e AGOSTINI et al., 2002) têm observado que ensaios in situ são extremamente úteis para a determinação da resistência das camadas de carvão, porque possibilitam o acesso direto às condições mais próximas da realidade do maciço rochoso. Outra vantagem do emprego da técnica de ensaios in situ em comparação com a condição de laboratório, é a possibilidade da manutenção da amostra nas condições ambientais de origem, fato por demais importante em se tratando de um material altamente suscetível à alteração quando retirado do ambiente natural.

Os primeiros ensaios in situ em materiais carbonosos remontam ao final da década de 1930, nos EUA. GREENWALD et al. (1939 e 1941) foram os primeiros autores a reportar resultados de ensaios in situ em amostras de carvão. Esses autores realizaram 12 ensaios na camada Pittsburgh caracterizada pela presença de "cleats" em grande quantidade, numa mina experimental do USBM - United States Bureau of Mines (atual NIOSHI - National Institute for Occupational Safety and Health). Foram ensaiados corpos-de-prova com dimensões da base variando entre $50 \mathrm{~cm}$ e $1,3 \mathrm{~m}$ e altura envolvendo parcial ou integralmente a camada, entre $74 \mathrm{~cm}$ e $1,61 \mathrm{~m}$. A relação base/altura variou de 0,5 a 1,7 , aproximadamente. Os corpos-de-prova foram moldados ao longo do processo de avanço de uma galeria especialmente aberta para os ensaios. $O$ acabamento dos corpos-de-prova foi feito sem o uso de explosivos. Macacos hidráulicos (duas unidades no máximo) com até 750 toneladas de capacidade de carga foram utilizados para a ruptura dos corpos-de-prova. Não obstante a pouca representatividade estatística, devido à quantidade limitada do número de ensaios, os resultados permitiram que os autores propusessem, à época, uma função para a determinação da resistência do carvão em pilares quadrados, aplicável à camada Pittsburgh. Até então, somente estudos de laboratório haviam sido realizados. Problemas como a cravação do corpo-de-prova no piso devido à baixa resistência desse material, com a conseqüente perda do ensaio, estão entre os vários problemas vivenciados pelos autores para levar adiante as suas pesquisas. 
No início da década de 1960, LAMA (1966 e 1970) desenvolveu estudos sobre carvões na Polônia, com o intuito de explicar problemas de ruptura explosiva ("rock burst") em minas de carvão. Duas camadas de carvão com espessura entre 1,8 e $2 \mathrm{~m}$ foram selecionadas para estudo: a camada $A$, com uma estrutura de bandas bem definidas, composta por intercalações de clarênio, vitrênio e durênio (cerca de 75\%) e a camada B, com bandeamento menos pronunciado de clarênio, vitrênio e durênio (82\%). Ambas as camadas possuiam pelo menos duas direções de clivagem bem pronunciadas. Os ensaios in situ foram realizados em corposde-prova de base quadrada com lado igual $65 \mathrm{~cm}$ e altura de $1,6 \mathrm{~m}$, aproximadamente, num total de 20 ensaios. Metade das amostras foi ensaiada à compressão uniaxial na condição totalmente livre lateralmente, metade na condição de apenas um lado livre (restrição lateral em 3 lados). Os resultados, tanto de resistência como de deformabilidade, mostraram forte influência da presença das descontinuidades, embora o autor não atribua à densidade de descontinuidades o maior peso, mas à distribuição das tensões que ocorre nas fraturas durante a ruptura. Comparando os resultados das duas camadas, observou que a resistência foi maior na camada com maior densidade de clivagem. Considerando os resultados obtidos também a partir de ensaios em laboratório, o autor conclui que, com segurança, somente ensaios in situ podem prover informações seguras quanto à resistência para serem usadas em projeto.

Já BIENIAWSKI (1968a, 1968b, 1968c e 1969) foi um dos precursores na realização de ensaios in situ para a determinação da resistência do carvão da camada Witbank na África do Sul. O autor destaca como vantagens da realização de ensaios in situ a eliminação de fatores danosos à conservação das amostras ensaiadas (variação de temperatura e umidade), além de enfatizar a importância de ensaiar amostras de grande porte, tão grandes quanto possível, para melhor representar a realidade do maciço. Uma síntese dos resultados de mais de 60 ensaios in situ pode ser visto na Figura 2.3.

Os ensaios foram realizados sobre corpos-de-prova cúbicos, ou prismáticos de base quadrada, com as dimensões da base acima de $2 \mathrm{~cm}$ até $2 \mathrm{~m}$ e relação largura/altura variando entre 0,5 a 3,3. Os resultados deram origem a uma fórmula para a estimativa da resistência in situ de pilares nas minas Sul Africanas, bem como permitiram a definição da resistência característica da camada Witbank. Os resultados provenientes de ensaios em grandes amostras serviram de base para justificar a indicação de um tamanho crítico da ordem de $1,5 \mathrm{~m}$. $\mathrm{O}$ arranjo básico da montagem dos ensaios nas amostras de maior porte pode ser visto na Figura 2.10a.

Também na África do Sul, COOK et al. (1970) e VAN HEERDEN (1975) desenvolveram uma série de ensaios de compressão uniaxial in situ em grandes amostras de carvão das camadas Usutu e New Largo, respectivamente. Os primeiros autores adotaram uma técnica de ensaio em que os contatos entre 0 carvão/encaixantes (piso e teto) permaneceram intactos, conforme Figura 2.10b, permitindo a manutenção do confinamento exercido pelas encaixantes (quando essas são mais resistentes que o carvão) sobre a camada de carvão. Além dessa configuração diferente da utilizada por Bieniawski, foi adotado um procedimento de ensaio em que o controle do processo de ruptura é feito por taxa de deformação constante. 

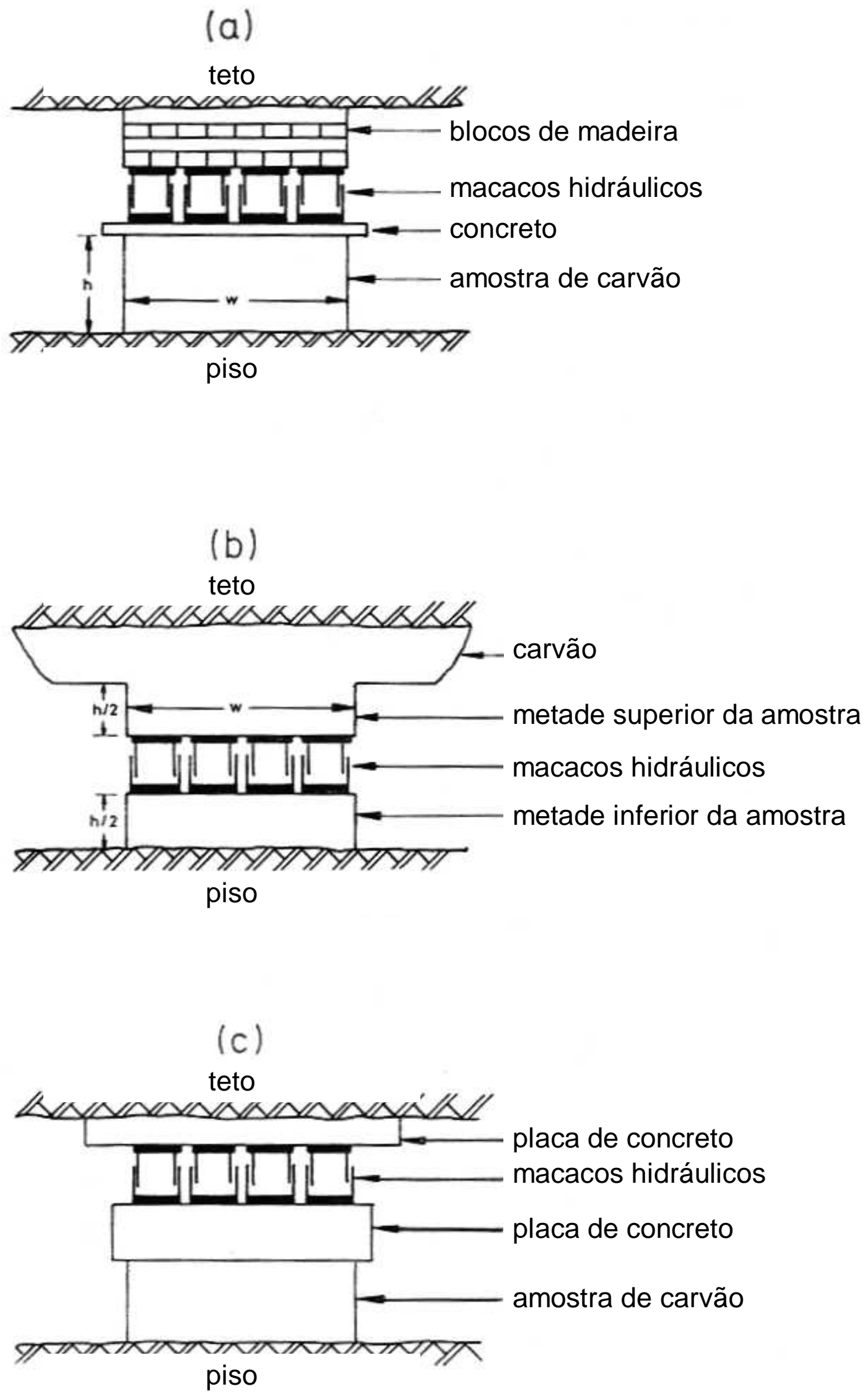

Figura 2.10 - Configurações utilizadas para a realização de ensaios de compressão uniaxial in situ sobre grandes amostras (adaptado de VAN HEERDEN, 1975). 
Esse procedimento permitiu a determinação completa da curva tensão $x$ deformação do ensaio. São reportados resultados de 10 ensaios em corpos-deprova de base quadrada com o lado variando de $0,8 \mathrm{~m}$ a $1,5 \mathrm{~m}$ e a relação largura/altura 0,2 e 1,6, aproximadamente. A técnica utilizada pelos autores tinha como limitação a capacidade de carga insuficiente quando ensaiados corpos-deprova muito achatados. Por sua vez, VAN HEERDEN (1975) aproveitou os avanços obtidos pelas experiências anteriores e adotando uma configuração de ensaio como mostra a Figura 2.10c, executou 10 ensaios em corpos-de-prova de base quadrada com o lado igual a $1,4 \mathrm{~m}$ e alturas variando entre $0,4 \mathrm{~m}$ e $1,2 \mathrm{~m}$ (largura/altura $=1,1$ a 3,4). Comparando os resultados das diferentes camadas Sul Africanas até então obtidos a partir de ensaios em cubos com dimensões entre $1,4 \mathrm{~m}$ e $2 \mathrm{~m}$, incluindo resultados obtidos sobre a camada Usutu por WAGNER (1974), o autor concluiu que a função de BIENIAWSKI (1968a) permite expressar a resistência de um pilar de carvão de qualquer uma das camadas, tendo como variável apenas o efeito forma (relação largura/altura do pilar), desde que adotada a resistência característica $\left(S_{1}\right)$ específica de cada camada determinada a partir de ensaios em amostras cúbicas com o lado medindo pelo menos $1,5 \mathrm{~m}$.

WAGNER (1974), adotando uma técnica de ensaio semelhante à de COOK et al. (1970), ou seja, carregamento com taxa de deformação constante e mantendo a camada de carvão solidária às encaixantes, obteve resultados muito úteis no que se refere ao comportamento pós-ruptura do carvão e à distribuição das tensões durante a ruptura em função da forma do corpo-de-prova, como mostra a Figura 2.11. Nessa figura, observa-se claramente a maior capacidade de carga no miolo do corpo-de-prova, devido ao efeito do confinamento proporcionado pelo material da periferia, algo semelhante ao que se observa nos pilares na escala real. Esse autor realizou 30 ensaios in situ em corpos-de-prova de base quadrada e retangular, com dimensões variando entre $0,6 \mathrm{~m}$ e $2 \mathrm{~m}$ e relação largura/altura de 0,6 a 2,2 no carvão da camada Usutu da África do Sul. Além dos aspectos associados à resistência e à deformabilidade do carvão, importantes informações sobre a atividade micro-sísmica foram registradas, algo relativamente novo a época. Embora o autor não tenha obtido resultados que pudessem expressar claramente o efeito escala, uma estimativa da resistência in situ da camada é sugerida. No que tange à deformabilidade, não foi observada variação em função da variação das dimensões dos espécimens testados.

Um caso que pode ser classificado como extremo em termos de escala de ensaio in situ, é relatado por WANG et al. (1976) e SKELLY et al. (1977). Esses autores realizaram, na camada de carvão Pocahontas $n^{\circ} 3$ (USA), dois ensaios na escala real, utilizando pilares de $24,3 \mathrm{~m}$ de largura por $1,78 \mathrm{~m}$ de altura. $O$ ensaio consistiu na redução gradativa das dimensões dos pilares até cerca de $8 \mathrm{~m}$. A ruptura ocorreu com os pilares medindo aproximadamente $19 \mathrm{~m}$. Os resultados mostraram, de um lado, as limitações de alguns modelos de dimensionamento de pilares para aquela camada de carvão e, de outro, permitiram aferir a previsão da resistência característica da camada a partir de ensaios na escala de laboratório. 


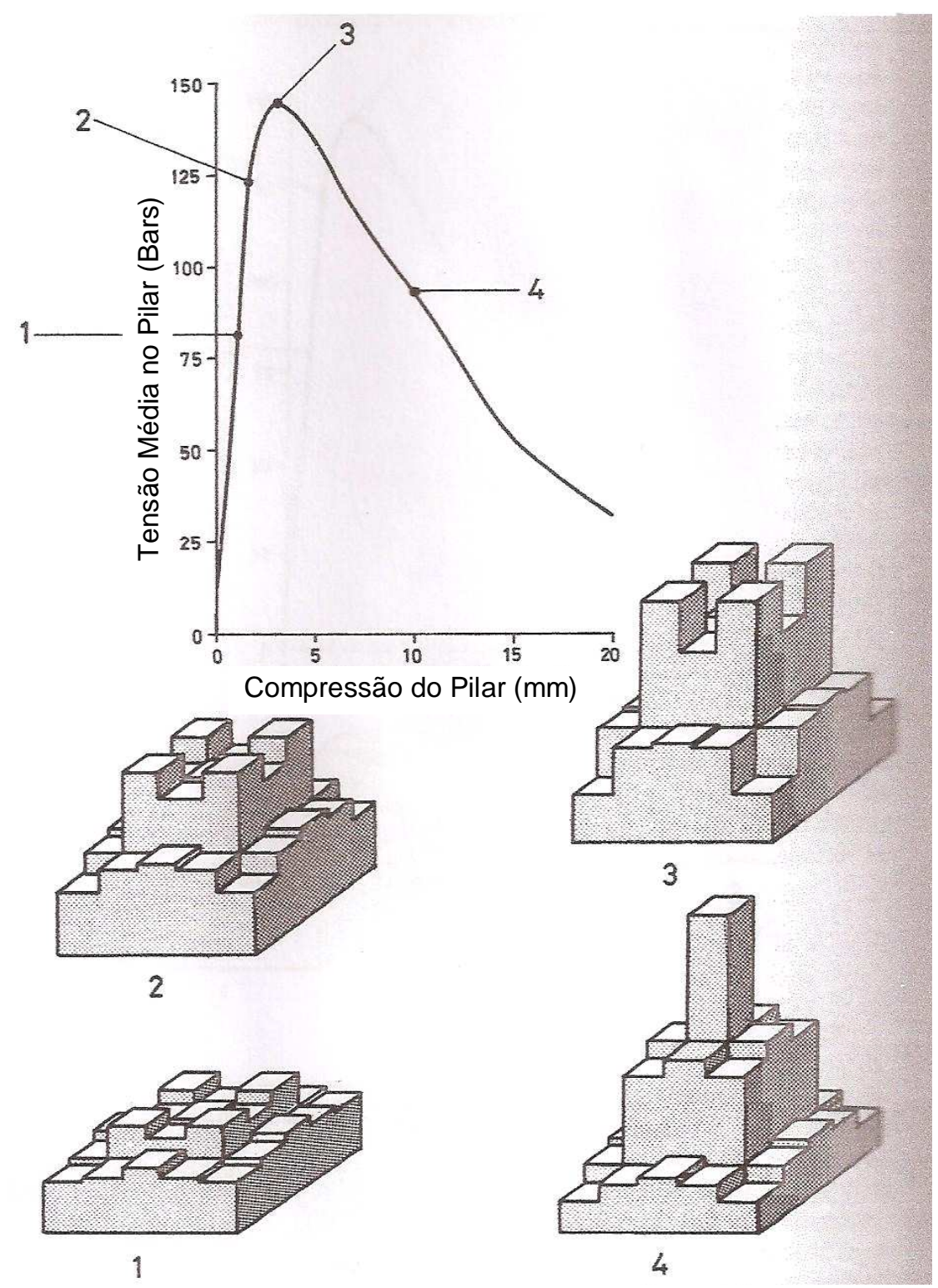

Figura 2.11 - Curva "tensão x deformação" obtida em ensaio in situ em corpo-de-prova com relação largura/altura $=2$, no carvão da camada Usutu - África do Sul. Nos histogramas, distribuição das tensões nas diferentes fases de carregamento (WAGNER, 1974, adaptado de JAEGER \& COOK, 1977).

Na Polônia, CYRUL (1984) descreve a realização de um único ensaio de compressão em carvão, num corpo-de-prova cúbico de $1,5 \mathrm{~m}$ de lado. Este autor destaca a rica instrumentação utilizada para o monitoramento das deformações durante a ruptura, capaz de melhor explicar o comportamento de uma amostra cujas características marcantes são a forte laminação e a heterogeneidade. Com as informações obtidas sobre as deformações que ocorrem durante o processo de ruptura, o autor sugere que a determinação da resistência seja feita utilizando como critério a deformação máxima e não simplesmente a carga máxima dividida pela área da seção transversal do corpo-e-prova.

A Tabela 2.4 apresenta uma síntese de 50 ensaios in situ realizados por vários pesquisadores, distribuídos em diferentes camadas de carvão no mundo. 
Tabela 2.4 - Síntese dos resultados de ensaios in situ em diferentes camadas carbonosas do mundo.

\begin{tabular}{|c|c|c|c|c|c|c|}
\hline Camada (País) & $\mathrm{CP}$ & $\begin{array}{c}\mathrm{L} \\
(\mathrm{cm})\end{array}$ & $\begin{array}{c}\mathrm{H} \\
(\mathrm{cm})\end{array}$ & $\begin{array}{c}\sigma_{\mathrm{c}} \\
(\mathrm{MPa})\end{array}$ & $\begin{array}{c}E \\
(\mathrm{MPa})\end{array}$ & Referência \\
\hline \multirow{10}{*}{ Pittsburgh (USA) } & 2 & 79 & 157 & 3,51 & - & \multirow{5}{*}{ GREENWALD et al. (1939). } \\
\hline & 4 & 121 & 161 & 4,21 & - & \\
\hline & 5 & 81 & 78 & 6,46 & - & \\
\hline & 6 & 82 & 81 & 6,21 & - & \\
\hline & 7 & 162 & 161 & 4,88 & - & \\
\hline & 8 & 108 & 77 & 7,37 & - & \multirow{5}{*}{ GREENWALD et al. (1941). } \\
\hline & 9 & 52 & 75 & 6,32 & - & \\
\hline & 10 & 53 & 76 & 6,67 & - & \\
\hline & 11 & 131 & 77 & 8,43 & - & \\
\hline & 12 & 31 & 74 & 5,62 & - & \\
\hline \multirow{19}{*}{ Witbank (África do Sul) } & 1 & 61 & 122 & 4,21 & 5,06 & \multirow{19}{*}{ BIENIAWSKI (1969). } \\
\hline & 2 & 61 & 91 & 4,61 & - & \\
\hline & 3 & 61 & 61 & 5,62 & - & \\
\hline & 4 & 91 & 91 & 4,99 & 4,42 & \\
\hline & 5 & 91 & 61 & 6,28 & - & \\
\hline & 6 & 122 & 122 & 4,64 & 4,49 & \\
\hline & 7 & 122 & 91 & 5,31 & - & \\
\hline & 8 & 122 & 61 & 6,77 & - & \\
\hline & 9 & 152 & 152 & 4,58 & 2,95 & \\
\hline & 10 & 152 & 122 & 4,76 & - & \\
\hline & 11 & 152 & 91 & 5,26 & - & \\
\hline & 12 & 152 & 61 & 6,67 & - & \\
\hline & 13 & 203 & 203 & 4,56 & 3,72 & \\
\hline & 14 & 203 & 122 & 5,66 & - & \\
\hline & 15 & 203 & 91 & 6,05 & - & \\
\hline & 16 & 203 & 61 & 9,71 & - & \\
\hline & 17 & 91 & 91 & 11,42 & 2,72 & \\
\hline & 18 & 91 & 91 & 11,21 & 8,50 & \\
\hline & 19 & 91 & 91 & 11,11 & 2,19 & \\
\hline 504 (Polônia) & 1 & 150 & 150 & 18,80 & - & CYRUL (1984). \\
\hline \multirow{8}{*}{ I (Índia) } & 1 & 65 & 163 & 7,18 & - & \multirow{8}{*}{ LAMA (1970). } \\
\hline & 2 & 65 & 163 & 6,50 & - & \\
\hline & 3 & 65 & 163 & 6,75 & - & \\
\hline & 4 & 65 & 163 & 7,00 & - & \\
\hline & 1 & 66 & 165 & 11,50 & - & \\
\hline & 2 & 66 & 165 & 11,10 & - & \\
\hline & 3 & 66 & 165 & 11,00 & - & \\
\hline & 4 & 66 & 165 & 11,95 & - & \\
\hline
\end{tabular}

LEGENDA:

$\mathrm{CP}=$ corpo-de-prova; $\mathrm{H}=$ altura; $\mathrm{L}=$ comprimento; $\sigma_{\mathrm{c}}=$ resistência à compressão uniaxial com carregamento na direção perpendicular aos planos de estratificação do carvão; $\mathrm{E}=$ módulo de elasticidade, com carregamento na direção perpendicular aos planos de estratificação do carvão.

Continua ... 
Continuação ...

\begin{tabular}{|c|c|c|c|c|c|c|}
\hline Camada (País) & $\mathrm{CP}$ & $\begin{array}{c}\mathrm{L} \\
(\mathrm{cm})\end{array}$ & $\begin{array}{c}\mathrm{H} \\
(\mathrm{cm})\end{array}$ & $\begin{array}{c}\sigma_{\mathrm{c}} \\
(\mathrm{MPa})\end{array}$ & $\begin{array}{c}\mathrm{E} \\
(\mathrm{MPa})\end{array}$ & Referência \\
\hline \multirow{10}{*}{ New Largo (África do Sul) } & 1 & 141 & 124 & 14,82 & 3,71 & \multirow{10}{*}{ VAN HEERDEN (1975) } \\
\hline & 2 & 142 & 123 & 16,69 & 4,59 & \\
\hline & 3 & 143 & 112 & 14,22 & 4,52 & \\
\hline & 4 & 139 & 106 & 15,14 & 3,33 & \\
\hline & 5 & 141 & 76 & 19,02 & 3,75 & \\
\hline & 6 & 138 & 65 & 19,40 & 4,26 & \\
\hline & 7 & 137 & 49 & 20,26 & 3,86 & \\
\hline & 8 & 142 & 51 & 20,58 & 3,62 & \\
\hline & 9 & 140 & 43 & 22,78 & 3,95 & \\
\hline & 10 & 139 & 41 & 25,05 & 4,29 & \\
\hline Pocahontas No. 3 (USA) & $A$ & 1884 & 177 & 20,36 & 2,11 & WANG et al. (1976). \\
\hline
\end{tabular}

Também no Brasil os ensaios in situ foram de grande relevância para o estabelecimento da resistência característica das camadas de carvão. Sobre o carvão da camada de carvão $I_{1} F$, MIDÉA et al. (1985) realizaram um único ensaio em corpo-de-prova cúbico com lado igual a $1 \mathrm{~m}$. Tal feito foi realizado a partir da mobilização de equipamento com capacidade de carga da ordem de 12MN. A resistência do corpo-de-prova foi de aproximadamente 10,8MPa.. Embora do ponto de vista estatístico o resultado seja pouco representativo, este foi o primeiro ensaio in situ realizado sobre amostras de carvão no Brasil.

Os ensaios in situ realizados pela CIENTEC foram nas camadas $\mathrm{l}_{1} \mathrm{~F}$ e Barro Branco (CIENTEC, 1990; ZORZI et al., 1998 e AGOSTINI et al., 2002). Essas duas camadas possuem características estruturais bastante distintas, conforme mostra a Figura 2.12, onde a primeira possivelmente representa a camada de carvão mais homogênea dentre as várias presentes nas jazidas brasileiras e a segunda a mais heterogênea do ponto de vista composicional. Utilizando estruturas de carga com capacidade variando entre $9 \mathrm{MN}$ e $12 \mathrm{MN}$, conforme Figura 2.13, foram ensaiados dois corpos-de-prova na camada $\mathrm{l}_{1} \mathrm{~F}$ e três na camada Barro Branco. Ensaiando ora a metade inferior da camada, ora a metade superior, segundo esses pesquisadores, foi a forma de melhor representar o perfil integral das camadas de carvão e as suas variações em termos de resistência devido às suas características estruturais e litológicas diversas. A Tabela 2.5 apresenta uma síntese dos resultados de resistência à compressão uniaxial e deformabilidade dos ensaios realizados in situ nessas duas importantes camadas de carvão.

Os resultados de uma grande quantidade de ensaios na escala de laboratório, conforme destacado anteriormente, conjugados com os da realização de 5 ensaios in situ deram origem às constantes características de resistência in situ $\left(S_{1}\right)$ de duas camadas de carvão: $I_{1} F=6,80 \mathrm{MPa}$, Barro Branco $=7,12 \mathrm{MPa}$ (ZORZI et al., 1991). 


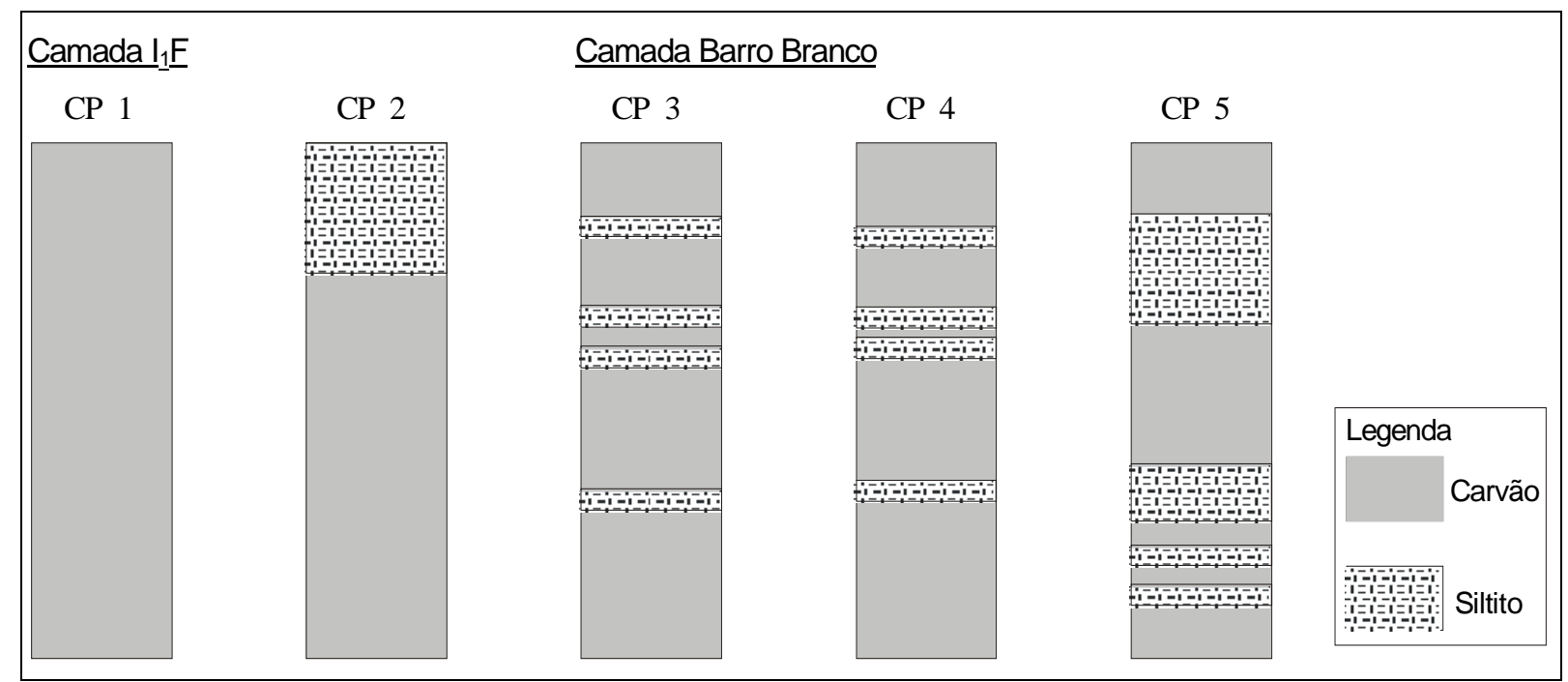

Figura 2.12 - Perfil litológico típico dos corpos-de-prova ensaiados in situ nas camadas brasileiras $\mathrm{I}_{1} \mathrm{~F}$ e Barro Branco (AGOSTINI et al., 2002).

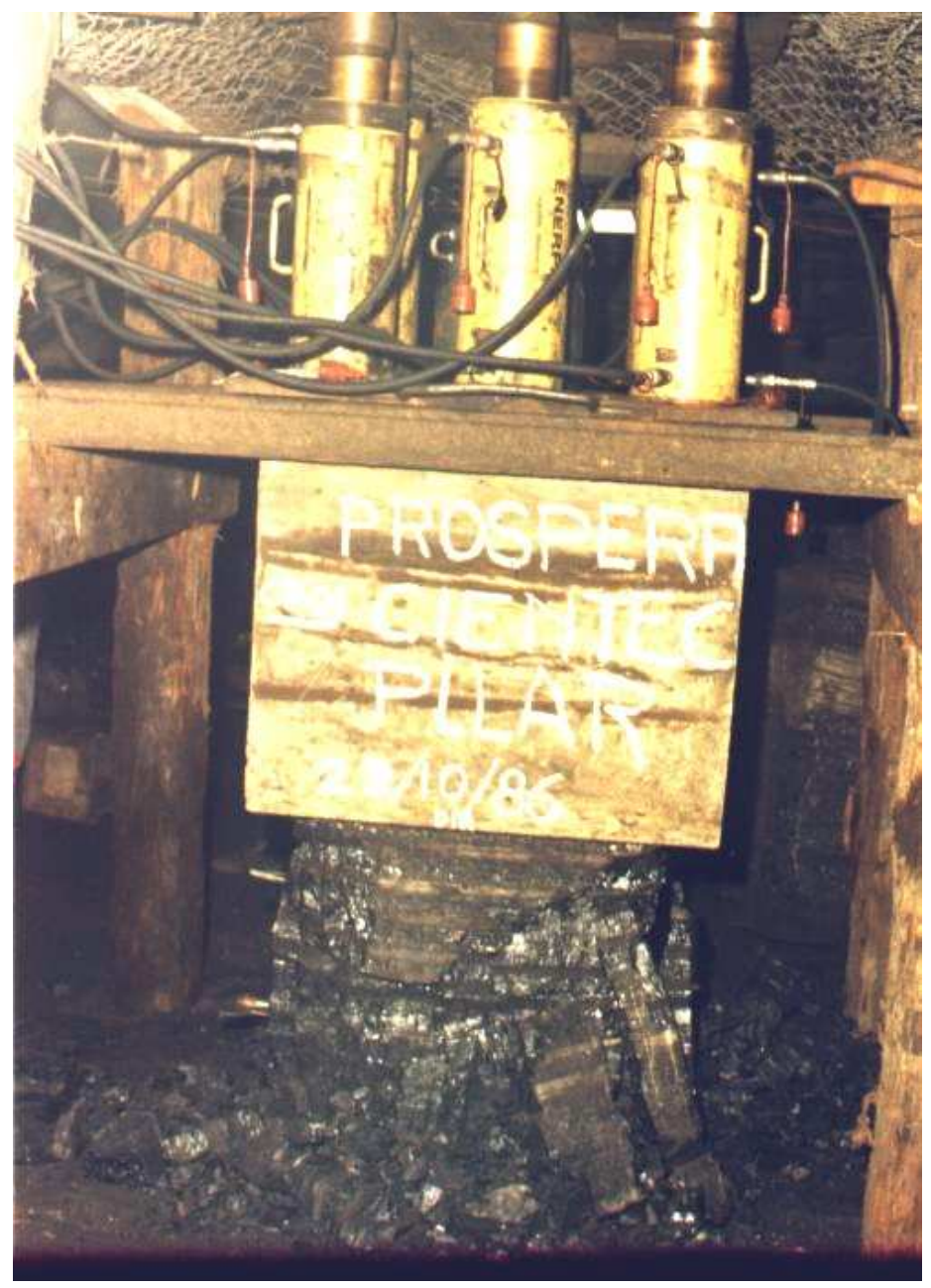

Figura 2.13 - Detalhe do corpo-de-prova ensaiado in situ na metade inferior da camada de carvão Barro Branco, após a ruptura (AGOSTINI et al., 2002). 
Tabela 2.5 - Síntese dos resultados de ensaios in situ em camadas carbonosas do RS e SC realizados pela CIENTEC (AGOSTINI et al., 2002).

\begin{tabular}{|c|c|c|c|c|c|c|c|}
\hline $\begin{array}{l}\text { Camada de } \\
\text { Carvão }\end{array}$ & $\begin{array}{c}\text { Mina } \\
\text { (Estado) }\end{array}$ & $\mathrm{CP}$ & $\begin{array}{c}\mathrm{L} \\
(\mathrm{cm})\end{array}$ & $\begin{array}{c}\mathrm{H} \\
(\mathrm{cm})\end{array}$ & $\begin{array}{c}\sigma_{\mathrm{c}} \\
(\mathrm{MPa})\end{array}$ & $\begin{array}{c}\mathrm{E}_{\mathrm{m}} \\
(\mathrm{GPa})\end{array}$ & $v_{m}$ \\
\hline $\mathrm{I}_{1} \mathrm{~F}$ - metade inferior & \multirow{2}{*}{$\begin{array}{c}\text { Charqueadas } \\
\text { (Brasil-RS) }\end{array}$} & 1 & 90 & 90 & 13,4 & 7,62 & 0,40 \\
\hline $\mathrm{l}_{1} \mathrm{~F}$ - metade superior & & 2 & 81 & 79 & 8,6 & 9,55 & - \\
\hline \multirow{2}{*}{$\begin{array}{l}\text { Barro Branco - metade } \\
\text { inferior }\end{array}$} & \multirow{3}{*}{$\begin{array}{l}\text { A-Sangão } \\
\text { (Brasil-SC) }\end{array}$} & 3 & 81 & 80 & 13,5 & 5,32 & 0,12 \\
\hline & & 4 & 78 & 76 & 9,4 & 6,77 & 0,21 \\
\hline $\begin{array}{l}\text { Barro Branco - metade } \\
\text { superior }\end{array}$ & & 5 & 81 & 79 & 6,5 & 1,83 & 0,18 \\
\hline
\end{tabular}

LEGENDA:

$\mathrm{CP}=$ corpo-de-prova; $\mathrm{H}=$ altura; $\mathrm{L}=$ comprimento; $\mathrm{P}=$ profundidade; $\sigma_{\mathrm{c}}=$ resistência à compressão uniaxial com carregamento na direção perpendicular aos planos de estratificação do carvão; $E_{m}, v_{m}=$ módulo de elasticidade médio e coeficiente de Poisson médio, respectivamente, com carregamento na direção perpendicular aos planos de estratificação do carvão.

No início da década de 1990, outra pesquisa foi desenvolvida na jazida SulCatarinense para estudar a resistência da camada Irapuá (CIENTEC, 1996). A resistência in situ foi estimada a partir de ensaios de laboratório em corpos-deprova com dimensões entre 5 e $30 \mathrm{~cm}$ e corroborada por retro-análise de um caso de ruptura na própria mina onde se realizou o estudo (Mina A-Sangão). Os resultados apontaram para a mesma resistência característica média de 5,27MPa, sugerida por ZORZI et al. (1991).

\subsubsection{Abordagem Geomecânica na Definição da Resistência In Situ}

Muito tem sido discutido sobre os métodos tradicionais de determinação da resistência de materiais rochosos, baseados no enforque estritamente mecânico. De outra parte, já vem de muito tempo a certeza de que a rocha não pode ser considerada como um meio contínuo e que a resistência é, na sua maior parte, influenciada pela resistência das suas descontinuidades, as quais podem ser representadas por micro-fissuras não visíveis, fissuras, fraturas, falhas, planos de acamamento, etc..

Nas jazidas de carvão brasileiras, variações litológicas dentro de uma mesma camada de carvão são freqüentes, descontinuidades de natureza diversa não são facilmente identificáveis e quantificáveis, variações estruturais consideráveis ocorrem ao longo de uma mesma mina, enfim, uma quantidade de características geológicas diferentes podem estar presentes numa mesma jazida. A abordagem exclusivamente de engenharia na determinação da resistência de rochas carbonosas, na melhor das hipóteses, resulta na determinação da resistência média da camada de carvão, quando são amostrados vários pontos de uma jazida, ou da resistência de uma parcela muito localizada, quando as amostras provêm de uma zona restrita da jazida. Esquecer a influência dos fatores geológicos nesse tipo de jazimento pode significar ora superestimar a resistência 
do maciço (a favor da segurança mas com perdas na recuperação da jazida), ora subestimar a resistência, tendo como conseqüência, nesse caso, a possibilidade de ocorrência de colapso das estruturas de sustentação (pilares de carvão).

Como visto até então, os vários estudos apresentados baseiam-se quase que estritamente numa abordagem mecânica de engenharia. A consideração de aspectos geológicos no processo de determinação da resistência do maciço ainda foi pouco desbravado pelos pesquisadores, possivelmente devido às enormes dificuldades para a caracterização estrutural dos maciços fraturados, especialmente, de rochas carbonosas.

Os aspectos geológicos intervenientes na resistência do carvão têm sido destacados por uma outra vertente de pesquisadores há mais de meio século. Reconhecem a necessidade de uma abordagem global no processo de estimativa da resistência do maciço rochoso, o que significa incluir além da abordagem de engenharia a geológica. PROTODIAKONOV (1965) foi um dos primeiros pesquisadores a propor a utilização desse conceito para explicar o efeito escala em rochas carbonosas. Esse autor procura, inicialmente, explicar a origem das descontinuidades nas rochas carbonosas, que podem ser do tipo:

a) acamamento devido à deposição sistemática de sedimentos;

b) clivagens perpendiculares ao acamamento devido à contração da rocha durante o processo de perda de água;

c) fraturas originadas por esforços de cisalhamento devido à tectônica.

Como decorrência da presença dos diferentes tipos de descontinuidades, ensaios de laboratório em pequenas amostras tendem a apresentar uma grande variabilidade nos resultados. Os valores máximos estão associados a amostras praticamente livres de descontinuidades e os mínimos associados à presença de muitas descontinuidades. A medida que o tamanho da amostra aumenta, o número de descontinuidades aumenta e a resistência tende a diminuir. Como a probabilidade de uma amostra não conter descontinuidades é muito pequena, a variabilidade dos resultados tende a ser menor uma vez que não haverá amostra livre de descontinuidade. Conceitualmente, já à época, esse autor sugeria algumas técnicas para a avaliação do estado de fraturamento do maciço rochoso, utilizáveis individualmente ou em conjunto, quais sejam:

a) estudo geológico observando o comportamento estrutural e textural da rocha;

b) avaliação baseada em índices de consumo de explosivos, taxa de descarga de gás em furos de sondagem e pelas dimensões do material obtido pelo desmonte com explosivos;

c) estudo geométrico, computando a frequência das fraturas e a orientação espacial das mesmas;

d) avaliação baseada no grau de cominuição durante o processo de britagem do carvão;

e) através de ensaios em modelos reduzidos, de tamanhos e formas diversas, com materiais equivalentes para investigar o efeito do fraturamento na resistência in situ; 
f) métodos físicos, baseados na taxa de expulsão do metano da rocha, na taxa de filtragem de diferentes gases através do carvão, na condutividade elétrica ou na velocidade de propagação de ondas ultra-sônicas.

VARGA (1993) também é partidário da necessidade de uma abordagem não estritamente de engenharia para a caracterização da resistência do maciço rochoso, apontando para a necessidade de hierarquização das estruturas geológicas que influenciam diferentemente a resistência do maciço rochoso, como forma de facilitar o entendimento e a interpretação dos resultados de ensaios. Para o autor, no entanto, o tamanho do elemento heterogêneo não é a única causa do efeito escala. As condições das descontinuidades presentes (orientação, rugosidade, preenchimentos) também possuem a sua parcela de influência.

\subsubsection{Uso de Classificações Geomecânicas Associadas a Critérios de Ruptura}

Esse tipo de associação é recente e vem preencher uma lacuna ainda aberta no que se refere ao transporte da resistência de laboratório para a condição in situ de camadas de carvão. Dadas às características estruturais muito especiais do carvão, estima-se que a resistência à compressão uniaxial da rocha intacta representa não mais do que $15 \%$ da resistência do maciço rochoso. O restante da resistência estaria associada aos defeitos da rocha, representados pelas suas descontinuidades, de origem e com características variadas.

As classificações geomecânicas constituem-se em métodos empíricos, desenvolvidos com base na experiência prática de cada um dos proponentes, que utilizam uma série de critérios objetivos e bem definidos, capazes de proporcionar informações qualitativas e quantitativas sobre a resistência e deformabilidade de determinado maciço rochoso. Foram desenvolvidas inicialmente para auxiliar no dimensionamento do sistema de suporte de túneis, levando em consideração não somente a resistência mecânica da rocha intacta mas, também, as características das descontinuidades presentes na rocha. Foi a maneira encontrada para que a comunicação entre engenheiros e geólogos, sobre a qualidade e comportamento mecânico de determinado maciço rochoso, pudesse ser entendida por todos, mesmo quando operando em maciços com diferentes condições geológicas.

Com o passar do tempo e com os novos avanços, as informações resultantes da classificação do maciço rochoso passaram a ser utilizadas para as mais diversas finalidades, como projeto do sistema de suporte em aberturas subterrâneas, projeto de estabilização de taludes a céu aberto, definição do sistema de desmonte da rocha, entre as mais importantes aplicações. As principais propostas de classificação de maciços, bem como os critérios sobre os quais elas se baseiam podem ser vistos na Tabela 2.6. 
Tabela 2.6 - Comparativo entre as diferentes classificações geomecânicas (adaptado de OJIMA, 1982).

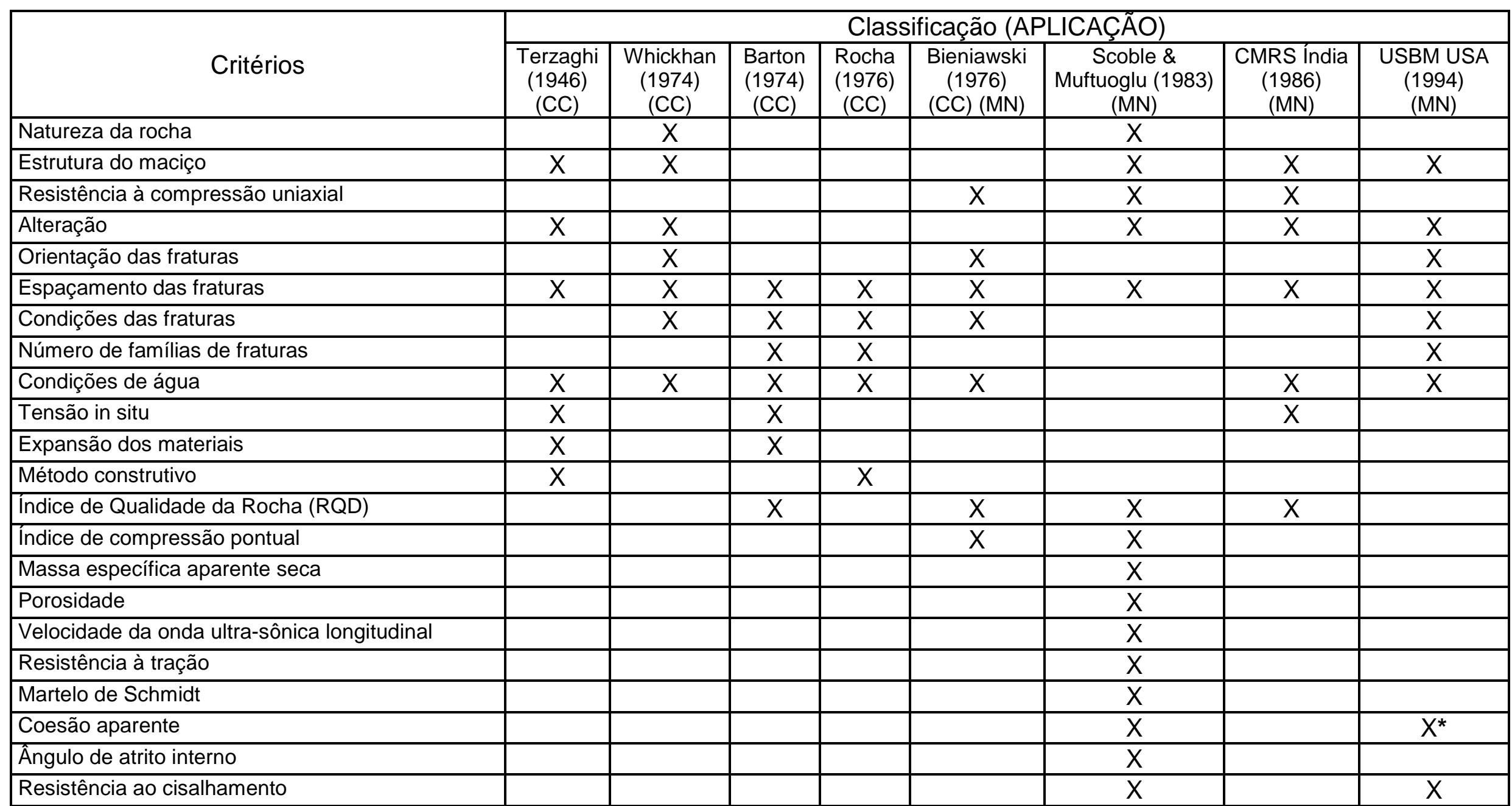

LEGENDA:

CC = construção civil (túneis); MN = mineração; USBM - United States Bureau of Mines; CMRS - Central Mining Research Station.

* planos de estratificação. 
Embora sua proposta não fosse exatamente uma classificação geomecânica do maciço, WILSON (1983) foi um dos primeiros pesquisadores na área de carvão a sugerir que os resultados de resistência obtidos em laboratório levassem em consideração aspectos estruturais do maciço carbonoso, antes de serem utilizados no dimensionamento dos pilares das minas subterrâneas. Para ele, os valores de laboratório deveriam sofrer uma correção do tipo:

$$
\sigma_{\text {insitu }}=\frac{\sigma_{\text {lab. }}}{F}
$$

onde: $\sigma_{\text {in situ }}=$ resistência do maciço rochoso;

$\sigma_{\text {lab. }}=$ resistência de laboratório;

$\mathrm{F}=$ fator de correção da resistência de laboratório para a condição in situ, em função das características estruturais do maciço rochoso.

$O$ autor sugere valores para $F$ que vão desde 1 , para zonas de rocha maciça desprovida de descontinuidades, 4 para rochas com muitas juntas, 5 para rochas com clivagem intensa como o carvão, até 6 ou 7 para maciços em zonas de falha.

A grande limitação dessa escala é a subjetividade envolvida na definição das diferentes classes estruturais de maciço, especialmente as intermediárias, já que a cada fator está associada uma condição geológica definida apenas qualitativamente. Ainda assim, essa abordagem não deixa de ser atrativa, por ser uma solução bastante prática quando estão disponíveis somente informações a partir de estudos de laboratório, especialmente se consideramos que em jazidas de carvão a presença de diferentes condições geológicas é muito comum, devido às condições de formação das mesmas e às grandes extensões em área abrangidas pela jazidas.

Ainda no início da década de 1980, HOEK \& BROWN (1980a e 1980b) propuseram um critério de ruptura com o objetivo de melhor descrever 0 comportamento da rocha intacta nas condições de confinamento das obras de engenharia, tentar explicar a anisotropia da resistência devido aos planos de descontinuidades e, mesmo que numa primeira aproximação, prover alguma indicação da resistência de maciços rochosos com várias famílias de descontinuidades. A função genérica proposta para representar a envoltória de resistência, já reportada anteriormente, é a seguinte:

$$
\sigma_{1}=\sigma_{3}+\sigma_{c} *\left(\frac{m * \sigma_{3}}{\sigma_{c}}+s\right)^{a}
$$

onde: $\sigma_{1}$ e $\sigma_{3}=$ tensões principais na ruptura obtidos a partir de ensaios de compressão triaxial;

$\sigma_{\mathrm{c}}=$ resistência à compressão uniaxial da rocha intacta;

$\mathrm{m}$ e $\mathrm{s}=$ constantes dependentes das propriedades da rocha e do grau de fraturamento da mesma antes de ser submetida ao processo de ruptura;

$a=0,5$ na versão original (valores diferentes de 0,5 passaram a ser atribuídos a partir de 1994). 
Para a estimativa das constantes $m$ e de $s$ de cada tipo e condição de maciço rochoso os autores sugeriram o uso das classificações geomecânicas de BIENIAWSKI (1976) e de BARTON et al. (1974). Já a resistência à compressão uniaxial in situ $\left(\sigma_{\mathrm{c}}\right.$ in situ) podia ser obtida fazendo-se $\sigma_{3}=0$ e $s$ definido para as condições de fraturamento, condições das superfícies das descontinuidades e grau de alteração do maciço rochoso. Os dados práticos associados ao critério de ruptura abrangiam os mais diferentes tipos de rocha, exceto rochas carbonosas. Para este tipo de rocha, BIENIAWSKI \& BAUER (1982) sugeriram uma série de valores de $m$ e $s$ para diferentes classes de maciços de carvão, com base em estudos sobre os carvões dos EUA. Esses dados de certa forma foram contestados por HOEK \& BROWN (1982) com o argumento de que o carvão ensaiado não necessariamente seria rocha intacta. Avanços e refinamentos ao critério de ruptura foram propostos pelos próprios autores ou por outros pesquisadores ao longo do tempo, no sentido de aperfeiçoar as estimativas de $m$ e de $s$ e, por conseqüência, de $\sigma_{c}$ in situ (WOOD, 1991; HOEK, 1983 e 1990; UCAR, 1986; BROWN \& HOEK, 1988; LONDE, 1988; HOEK \& BROWN, 1988 e HOEK et al., 1992). Somente em 1994 os primeiros dados relativos ao carvão, ainda que para a rocha intacta, foram apresentados por HOEK (1994). Também foi proposta uma função mais geral para o critério de ruptura e um novo índice, o GSI Geological Strength Index, capaz de suprir as limitações impostas pelas simplificações assumidas inicialmente e pelos métodos utilizados na estimativa das constantes $\mathrm{m}$, s e a, especialmente para maciços rochosos muito pobres (elevado grau de fraturamento). Esse novo índice, aperfeiçoado por HOEK \& BROWN (1997) e HOEK et al. (2002), consiste num sistema, em substituição às classificações geomecânicas tradicionais, capaz de expressar as condições estruturais e o estado das superfícies das descontinuidades presentes no maciço, permitindo a redução da resistência de laboratório para diferentes condições geológicas. A partir desses novos avanços, $\sigma_{\mathrm{c}}$ in situ passou a ser estimado a partir dos parâmetros coesão $\left(c^{\prime}\right)$ e ângulo de atrito $(\phi)$ do critério de Mohr-Coulomb do maciço rochoso, através da seguinte expressão:

$\sigma_{\text {cin situ }}=\frac{2 * c^{\prime *} \cos \varphi^{\prime}}{1-\operatorname{sen} \varphi}$

Uma das limitações desse critério é a elevada sensibilidade do parâmetro $\sigma_{c}$ in situ à parcela da envoltória de Hoek-Brown utilizada para fazer a equivalência ao critério de Mohr-Coulomb e definir os parâmetros $c$ e $\phi$ in situ. Ainda assim, é um dos poucos critérios de ruptura que melhor tem explicado o comportamento dos materiais rochosos.

Critérios de ruptura semelhantes para a estimativa da resistência de maciços rochosos fraturados foram propostos por RAMAMURTHY (1986), KALAMARAS e BIENIAWSKI (1993) e SHEOREY et al. (1997). Para esses autores, a resistência à compressão uniaxial do maciço deve ser estimada a partir da resistência de laboratório corrigida por um fator escala baseado no índice RMR da classificação geomecânica de Bieniawski. O critério utilizado para o cálculo da resistência in situ difere muito pouco de autor para autor, a não ser pelo valor de RMR que varia em função da versão da classificação de Bieniawski utilizada para a sua computação. A relação empírica proposta por RAMAMURTHY (1986) para estimar a resistência à compressão uniaxial in situ é a seguinte: 


$$
\sigma_{c m}=\sigma_{c} * \exp ^{\left(\frac{R M R-100}{18,75}\right)}
$$

onde $\sigma_{c}=$ resistência à compressão uniaxial da rocha intacta (MPa);

RMR baseado na classificação de BIENIAWSKI (1974).

O critério denominado de "Bieniawski genérico", baseado em BIENIAWSKI (1974) e sugerido por KALAMARAS e BIENIAWSKI (1993), define a resistência de maciços carbonosos através da seguinte expressão:

$$
\sigma_{c m}=\sigma_{c} * \exp ^{\left(\frac{R M R-100}{24}\right)}
$$

onde $\sigma_{c}=$ resistência à compressão uniaxial de laboratório determinada sobre corpos-de-prova com diâmetro de $25 \mathrm{~mm}$ e relação altura/diâmetro $=2$ $(\mathrm{MPa})$;

RMR baseado na classificação de BIENIAWSKI (1989).

Já o critério proposto por SHEOREY (1997) é definido como:

$$
\sigma_{c m}=\sigma_{c} * \exp ^{\left(\frac{R M R-100}{20}\right)}
$$

onde $\sigma_{\mathrm{c}}=$ resistência à compressão uniaxial da rocha intacta (MPa);

RMR baseado na classificação de BIENIAWSKI (1976).

Talvez as maiores limitações dos critérios de Ramamurthy e Sheorey para a estimativa da resistência de camadas de carvão seja a utilização da classificação de Bieniawski na sua concepção original para túneis, a qual não contempla as particularidades específicas de maciços carbonosos e a sua importância na resistência do pilar. O critério de Sheorey, especificamente, não é o mais recomendado quando a orientação das descontinuidades constitui fator importante na estabilidade do maciço. Esse autor sugere, nesses casos, o uso de um critério de ruptura anisotrópico. Considerando as características estruturais da camada de carvão Bonito, parece prudente que os resultados decorrentes da sua utilização nesse estudo sejam tomados com certa reserva.

Uma outra abordagem geomecânca para a definição da resistência in situ de camadas de carvão foi proposta por KALAMARAS (1993) e refinada por KALAMARAS \& BIENIAWSKI (1993 e 1995). Essa proposta, conceitual, para maciços carbonosos foi uma adaptação do sistema RMR - Rock Mass Rating de BIENIAWSKI (1973). Embora ainda não embasada em dados práticos, os autores discutem os vários aspectos estruturais intervenientes na resistência específicos para maciços carbonosos, como a presença de "cleats", a hierarquia e a orientação das descontinuidades e a heterogeneidade das camadas caracterizada pela intercalação de camadas com diferentes patamares de resistências. Contemplam, ainda, no escopo da classificação os procedimentos a serem seguidos visando a determinação da resistência in situ do carvão quando são utilizados métodos empíricos de dimensionamento de pilares.

TRUEMAN et al. (1992) avaliando as especifidades associadas aos maciços de rochas carbonosas, como a anisotropia e a existência de descontinuidades horizontais que normalmente não apresentam maiores problemas para a 
estabilidade dos pilares, já haviam sugerido o uso dessa classificação para inferir as propriedades de resistência do carvão in situ, porém, com alguns ajustes na direção de medição do índice RMR.

Num curto espaço de tempo as seguintes funções, análogas à proposta por LAUBSCHER (1984), foram sugeridas para a resistência in situ da camada de carvão:

a) $\sigma_{M}=\frac{0,6 *(R M R-A) * \sigma_{c}}{85}$

proposta em 1993,

onde: $\sigma_{M}=$ resistência à compressão uniaxial do maciço rochoso;

$\sigma_{\mathrm{c}}=$ resistência à compressão uniaxial obtida em laboratório a partir de corpos-de-prova com 2,5cm de diâmetro e 5,0cm de altura;

$A=$ peso atribuído pela classificação geomecânica em função do valor da resistência à compressão uniaxial de laboratório.

b) $\sigma_{M}=\frac{0,5 *(R M R-15) * \sigma_{c}}{85}$

proposta em 1995;

c) $\sigma_{M}=20 * R M R$

onde $\sigma_{M}$ é dado em libra/polegada quadrada. Essa expressão é indicada para carvões que não possuem a resistência da rocha intacta definida com confiabilidade.

Não é preciso ir muito longe para observar o quanto de incerteza existe na determinação da resistência in situ do carvão com base em classificações geomecânicas. Não se pode, no entanto, deixar de considerar o quanto esse tipo de aproximação pode ajudar na determinação da resistência in situ quando associada a outras técnicas menos empíricas e mais diretas. É importante destacar que esse tipo de ferramenta ainda tem sido pouco explorado no Brasil.

Com o decorrer dos anos, outros pesquisadores começaram a transformar esses conceitos em algo mais prático, ou seja, buscaram a quantificação da influência dos aspectos geológicos no cômputo final da resistência in situ da rocha.

No rumo da quantificação da influência das descontinuidades na resistência do maciço rochoso, PALMSTR $\varnothing \mathrm{M}$ (1982, 1985 e 1996a) sugeriu a utilização da freqüência de juntas por unidade de volume (Jv) como o parâmetro mais representativo para expressar o grau de fraturamento de um maciço. $\mathrm{Na}$ realidade, esse parâmetro foi um aperfeiçoamento da aproximação proposta por ANON (1977) do espaçamento entre juntas em três dimensões. Palmstrøm considera Jv mais apropriado que o RQD - Rock Quality Designation (DEERE, 1963) e que o espaçamento linear entre juntas proposto por PRIEST \& HUDSON (1976 e 1981). Na prática, o parâmetro Jv dependendo da forma como é determinado, tende a minorar os defeitos existentes nos parâmetros que tratam o grau de fraturamento do maciço através de uma medida unidirecional. Esse tipo de medida, dependendo de fatores como a orientação e qualidade da execução da sondagem, no caso do RQD, ou a orientação e extensão da linha de levantamento das fraturas, no caso da medida do espaçamento entre juntas, pode 
se tornar muito grosseira ou imprecisa. No meio da década de 1990, o mesmo PALMSTR $\varnothing M(1995,1996 b, 1996$ c e 1997), amparado em estudos de laboratório e uma pequena quantidade de ensaios in situ sobre rochas duras, propôs o índice RMi - Rock Mass index, cuja principal característica é a redução da resistência da rocha intacta a partir da ponderação dos diferentes aspectos estruturais que reconhecidamente interferem na resistência do maciço. Esse índice parece ser muito promissor, tendo em vista a sua objetividade para uso em projetos de engenharia de rochas. Representa a resistência à compressão uniaxial in situ e é expresso pela seguinte função:

$$
R M i=\sigma_{c} * J P
$$

onde: $\mathrm{RMi}$ = índice que representa a resistência à compressão uniaxial do maciço rochoso;

$\sigma_{\mathrm{c}}=$ resistência à compressão uniaxial da rocha intacta determinada sobre corpos-de-prova com diâmetro de 50mm (MPa);

$\mathrm{JP}=$ coeficiente de redução da resistência que representa o tamanho dos blocos individualizados pelas juntas (descontinuidades) e as características dessas juntas (persistência, grau de alteração e rugosidade), definido por:

$$
J P=0,2 * \sqrt{j C} * V b^{D} ; j C=j L * j R / j A ; D=0,37 * j C^{-0,2}, \text { sendo: }
$$

$\mathrm{Vb}=$ volume dos blocos formados pela interseção das famílias de juntas presentes no maciço $\left(\mathrm{m}^{3}\right)$;

$\mathrm{jC}=$ fator que expressa as condições das juntas;

$\mathrm{jL}=$ fator persistência das juntas;

$\mathrm{j} R$ = fator rugosidade das juntas;

$\mathrm{j} A$ = fator grau de alteração das superfícies das juntas.

Embora a função possa assumir uma condição relativamente complexa do ponto de vista físico, o fato é que todas as variáveis incorporadas ao modelo são largamente conhecidas e já consolidadas no âmbito da geologia de engenharia, o que facilita por demais a sua determinação no campo e o seu uso. O resultado dessa proposta parece, ainda, atender a uma demanda enorme por objetividade quando são utilizadas informações geológicas associadas às propriedades mecânicas do maciço. Vem atender a carência de objetividade contida na proposta de WILSON (1983), por exemplo, em que o tipo de maciço rochoso era definido apenas qualitativamente.

Com 0 intuito de atender demandas de parâmetros de resistência e deformabilidade dos modelos numéricos, REDDISH \& STACE (1999) discutem conceitualmente, para os carvões Ingleses, as ligações entre uma classificação geomecânica e os parâmetros de entrada para simulações utilizando modelos numéricos. Algo importante a ser destacado nesse conceito é a ratificação da importância, dada por vários autores, para algumas características típicas dos maciços carbonosos, como a presença de descontinuidades tipo "cleats", planos de acamamento e fissibilidade do carvão. 
Uma abordagem semelhante à utilizada por Palmstrøm, porém, desenvolvida sobre jazimentos de carvão, é apresentada por ESTERHUIZEN (1995). Em estudo envolvendo camadas de carvão da África do Sul, o autor propõe a utilização de classificação geomecânica dos maciços, a partir de detalhado mapeamento estrutural das camadas de carvão, para a correção da resistência característica da camada. A exemplo de VARGAS (1983), porém, com avanços muito objetivos e práticos, o autor caracterizou e hierarquizou os diferentes tipos de descontinuidades presentes nas camadas de carvão (cleats, slikensides, fraturas), obtendo como resultado padrões de maciço cuja resistência in situ poderia ser determinada (estimada) a partir da aplicação do critério de resistência de HOEK \& BROWN (1980). Em outra pesquisa, o mesmo ESTERHUIZEN (2000), apoiado em ensaios de laboratório sobre amostras contendo juntas e simulações numéricas para a avaliação da influência das juntas e da geometria dos pilares na sua resistência final, propôs uma função para o cálculo da resistência do pilar com a seguinte forma básica:

$\sigma_{p j}=\sigma_{p i} * e^{-0,017 *\left(F_{1}+F_{2}+\ldots F_{n}\right)}$

onde $\sigma_{\mathrm{pj}}=$ resistência de um pilar contendo juntas;

$\sigma_{\mathrm{pi}}=$ resistência de um pilar sem juntas;

$F_{1}, F_{2}, \ldots F_{n}=$ fator junta para cada uma das famílias de juntas presentes na camada de carvão, definido por:

$F=\frac{10 *\left(\frac{W}{h}\right)^{-0,5} *\left(1-e^{-0,23^{*} h^{*} J_{f}}\right)}{n * \tan (\phi)}$ onde:

$\mathrm{W}=$ largura do pilar $(\mathrm{m})$;

$\mathrm{h}=$ altura do pilar $(\mathrm{m})$;

$J_{f}=$ freqüência de juntas por metro;

$\mathrm{n}$ = parâmetro que expressa a orientação das juntas em relação à direção de carregamento do pilar;

$\Phi=$ ângulo de atrito entre as juntas $\left(^{\circ}\right)$.

$\mathrm{Na}$ expressão proposta, a resistência característica da camada de carvão está implícita na $\sigma_{\mathrm{p} i}$. Isso significa que é necessário que se determine a resistência característica da camada de carvão in situ e se adote alguma função conhecida para determinar a resistência do pilar numa condição sem juntas. Ainda assim, não se pode desprezar, a exemplo da proposta de Palmstrøm, a objetividade em contemplar o efeito das juntas na redução da resistência da rocha que forma 0 pilar de sustentação da mina. 


\subsubsection{Uso da Velocidade de Propagação de Ondas}

A utilização de geofísica como ferramenta adicional para a classificação do maciço rochoso tem recebido maior atenção nas últimas décadas por vários pesquisadores.

$\mathrm{O}$ uso da velocidade da onda compressional (onda $\mathrm{P}$ ) tem sido feito por meio de correlações para definir classes de maciços, propriedades mecânicas da rocha, espessura de fraturamento na periferia de escavações e permeabilidade, por exemplo. De outra parte, é sabido que a velocidade sísmica depende de uma série de fatores incluindo a composição química e mineralógica da rocha, tamanho dos grãos, grau de cimentação, porosidade, teor de umidade, grau de alteração, entre outros fatores (DARRACOTT \& ORR, 1976). YOUNG \& HILL (1986) e KAHRAMAN (2001) citam, ainda, as condições de alteração das fraturas, tipo do material e espessura de preenchimento, freqüência e orientação das fraturas como outros fatores influentes na velocidade de propagação de ondas.

A influência desses e outros fatores foi estudada em laboratório por TANIMOTO \& IKEDA (1983), estes últimos, utilizando rochas duras, como riolito e granito. Esses autores simularam a presença de fraturas na rocha separando, com um corte paralelo às bases, os corpos-de-prova cilíndricos em duas metades. As fraturas foram construídas a partir da interposição entre as metades de materiais com espessuras variáveis. Assim, estudaram o efeito do preenchimento, da abertura das fraturas e da tensão axial aplicada para o fechamento das fraturas, na velocidade de propagação de ondas sísmicas. Tensões axiais de até 3MPa foram empregadas no estudo. Os resultados mostraram haver pouca influência da freqüência de fraturas na velocidade. Porém, para fins práticos de homogeinização das velocidades de ondas medidas em laboratório e in situ, o aspecto mais importante observado nesse estudo parece estar associado à influência da tensão na determinação da velocidade.

Dentro da mesma linha de avaliação da importância da tensão axial na determinação velocidade ultra-sônica, KING (1983 e 1984) e WU et al. (1991) reportam resultados de laboratório, também obtidos sobre rochas do tipo ígneas, metamórficas e sedimentares, de baixa deformabilidade e alta resistência. Acréscimos na velocidade ultra-sônica entre $4 \%$ e $25 \%$, para tensões de até $10 \mathrm{MPa}$, foram observados. As Figuras 2.14a e 2.14b apresentam casos onde foram medidas as variações da velocidade ultra-sônica para tensões axiais até $40 \mathrm{MPa}$. Esse mesmo autor estudou a influência do grau de saturação na velocidade ultra-sônica da onda $\mathrm{P}$. Observou variações máximas de velocidade (amostra saturada), em relação à velocidade na condição seca, entre $8 \%$ e 13\%, dependendo do nível de tensão a que a rocha estava submetida.

Uma série de correlações entre a velocidade da onda $\mathrm{P}$ e o grau de fraturamento, representado pela freqüência de fraturas por metro e RQD, o módulo de deformabilidade dinâmico e a quantidade de suporte em túneis, é apresentada por SJØGREN et al. (1979). A abrangência do estudo envolveu uma grande quantidade de litologias de rochas duras de diferentes lugares da Noruega, com velocidades variando entre $3,0 \mathrm{~km} / \mathrm{s}$ e $5,5 \mathrm{~km} / \mathrm{s}$. As medidas foram realizadas utilizando sísmica de refração tanto in situ como em laboratório. 


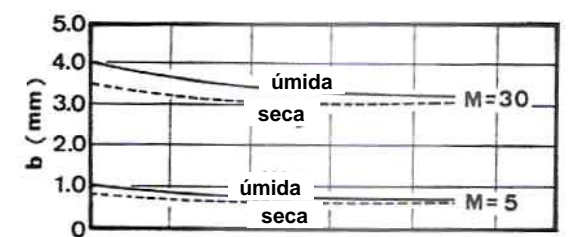

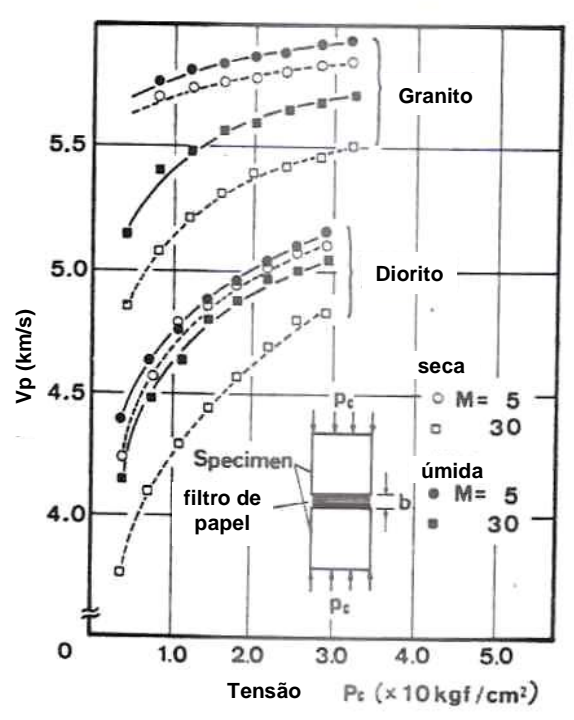

a)

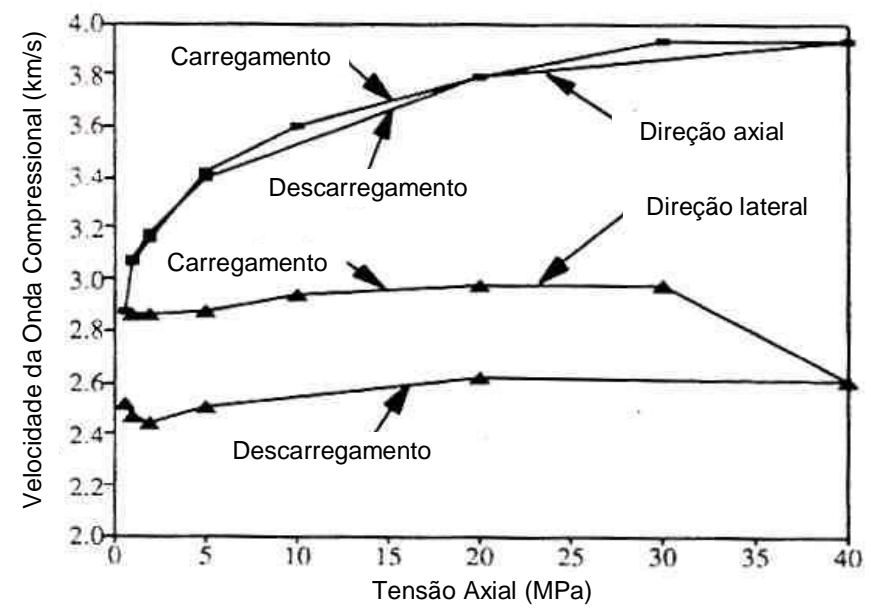

b)

Figura 2.14 - Influência da tensão axial $(\mathrm{Pc})$ e da abertura da fratura (b) na determinação da velocidade de propagação de ondas ultra-sônicas (Vp). a) estudos em rochas como granito e diorito (adaptado de TANIMOTO \& IKEDA, 1983); b) estudos sobre arenito (adaptado de WU et al., 1991).

KAHRAMAN (2001) procurou relacionar a velocidade da onda $P$ não somente com a freqüência de fraturas, mas também com a resistência da rocha através do ensaio com o martelo de Schmidt. COON \& MERRITT (1970) sugerem a utilização do quadrado da relação entre a velocidade de ondas medida em laboratório e in situ como um índice de qualidade do maciço rochoso (dividem em 5 classes), embora tenham consciência das limitações do índice para a estimativa da deformabilidade do maciço.

$\mathrm{Na}$ mesma direção dos estudos anteriores e com a atenção voltada para a aplicação em túneis, BARTON (2000 e 2002) apresenta uma série de correlações entre a velocidade da onda $\mathrm{P}$ e propriedades mecânicas do maciço rochoso, adicionando a velocidade como mais um elemento na sua classificação geomecânica, além dos já conhecidos em uso. Este autor chama a atenção para alguns aspectos interferentes na determinação da velocidade da onda $P$, observando um incremento da velocidade com o aumento da profundidade e da tensão in situ. Sugere uma função de correlação entre a deformabilidade do maciço e a velocidade da seguinte forma:

$$
E_{\text {maciço }}=10 * 10^{\left(\frac{V p-3,5}{3}\right)}
$$

onde: $\mathrm{E}_{\text {maciço }}=$ módulo de deformabilidade do maciço $(\mathrm{GPa})$;

$\mathrm{Vp}=$ velocidade da onda $\mathrm{P}(\mathrm{km} / \mathrm{s})$. 
Com o intuito de identificar a zona danificada na periferia de pilares de carvão em painéis de longwall, BHATTACHARYYA \& BELLEZA (1986) aplicaram a técnica de sísmica de refração. Conseguiram identificar claramente duas zonas no pilar, a zona periférica fraturada e a zona central do pilar intacto. Um fato que chamou a atenção foi o fato da velocidade de laboratório ser inferior a velocidade in situ da zona de rocha intacta. Os autores atribuem isso ao estado de tensão in situ, conforme observado por BARTON (2002) mais recentemente.

Do ponto de vista da escala de avaliação, as técnicas de sísmica de campo tem como vantagens sobre as técnicas de laboratório o fato de trabalhar com as condições reais do maciço em estudo, comparada com a escala reduzida das amostras de laboratório. O uso de parâmetros geofísicos para a estimativa das propriedades mecânicas de maciços rochosos, no entanto, não deve desconsiderar a importância dos aspectos acima mencionados para efeitos de homogeinização das velocidades in situ e de laboratório.

\subsubsection{Estimativa da Resistência In Situ a Partir da Análise de Casos de Ruptura de Pilares}

A utilização de informações sobre casos de sucesso e de insucesso na prática de dimensionamento de pilares em minas de carvão tem sido outra alternativa para a determinação da resistência das camadas mineradas. Se por um lado os resultados seriam a melhor amostra da realidade de uma mina, por outro lado, são indiscutíveis as dificuldades e limitações para a sua aplicação.

Casos de ruptura ou insucessos, não obstante os problemas inerentes a sua ocorrência, uma vez que significam o acontecimento de algum tipo de desastre, constituem uma das mais importantes fontes de informação sobre a real resistência dos pilares de carvão, desde que devidamente caracterizados.

As maiores dificuldades decorrem da quase impossibilidade de atendimento de algumas condições desejáveis para permitir uma boa análise, quais sejam: a área colapsada deve ser relativamente grande (SALAMON, 1967) com dimensões pelo menos iguais a profundidade, de modo a permitir que a teoria da área tributária possa ser usada no cômputo da carga sobre o pilar; a área deve ser livre de estruturas geológicas que introduzam elementos não comuns nas áreas mineradas; os pilares devem possuir dimensões regulares; a espessura de cobertura deve ser constante (St. GEORGE, 1995). SALAMON et al. (1996) engrossam a lista de características necessárias para a análise de uma área colapsada. Esses autores incluem outros aspectos qualitativos, como a garantia de que o colapso da área se deu devido à ruptura dos pilares efetivamente e não do teto ou do piso, a necessidade de que a ruptura não tenha ocorrido logo após a formação dos pilares, entre os aspectos que devem ser levados em consideração para utilização do caso como dado válido.

As vantagens decorrentes do uso dessa técnica residem no fato de que, tanto o efeito escala, como o efeito forma, estão representados pelas constantes que são determinadas a partir de pilares nas dimensões reais, assim como as condições de contato teto-camada-piso. Esses mesmos autores são enfáticos, no entanto, em destacar um dos aspectos ainda limitadores do método, que é a definição da população de dados e a função de distribuição capaz de representar os fatores de segurança críticos. 
Um dos primeiros trabalhos representativos nessa linha de pesquisa, visando à determinação da resistência de pilares de carvão, foi desenvolvido por SALAMON \& MUNRO (1967) e SALAMON (1967) sobre várias camadas de carvão da África do Sul, mineradas nos estados de Transvaal e Orange Free. Esses autores basearam suas conclusões em 125 casos de pilares colapsados, sendo 27 coapsados e 98 não colapsados, localizados entre $20 \mathrm{~m}$ e $220 \mathrm{~m}$ de profundidade, aproximadamente, ocorridos até 1966. A partir de tratamento estatístico e utilizando o método da máxima probabilidade, foi proposto um dos mais conhecidos métodos para dimensionamento de pilares em minas de carvão, onde a constante característica $S_{1}$ das camadas Sul-Africanas analisadas foi definida em 7,17MPa. Esse valor representa a resistência de um cubo de carvão com 30,4cm de lado, para uma condição de camada "média" e condições geológicas "médias" da África do Sul. Ainda hoje o DNPM - Departamento Nacional da Produção Mineral e muitas empresas mineradoras de carvão no Brasil utilizam esse método de dimensionamento de pilares. Em 1982, observando que a função originalmente proposta não contemplava os enormes ganhos de resistência do pilar para relações largura/altura do pilar $(\mathrm{W} / \mathrm{h})>5$, o mesmo SALAMON (1982) apud SALAMON \& WAGNER (1985) sugeriu uma equação alternativa capaz de levar em conta os ganhos maiores de resistência quando a forma do pilar é mais achatada. Essa função foi testada por MADDEN (1991) utilizando rocha arenítica como material de ensaio, com resultados que confirmam a proposição de Salamon. Já a incorporação de mais 17 casos de pilares de carvão, que entraram em colapso entre 1968 e 1988, ao banco de dados de Salamon e Munro, resultou numa função de cálculo da resistência do pilar muito semelhante à original sugerida para as camadas Sul Africanas.

GALVIN \& HEBBLEWHITE (1995) apud GALVIN et al. (1999), após estudos de casos de ruptura em minas da Austrália, propuseram a primeira equação empírica para o cálculo da resistência do pilar para aquele País, válida para pilares achatados e não achatados, muito semelhante à usada na África do Sul. Mais tarde, analisando 19 casos de pilares colapsados e 16 de pilares não colapsados em carvões da Austrália, nos estados de New South Wales e Queensland, SALAMON et al. (1996) e GALVIN et al. (1999) chegaram a resultados muito semelhantes aos registrados para as minas Sul-Africanas, recomendando para os carvões australianos a mesma função (com as mesmas constantes) utilizada na África do Sul para a computação da resistência do pilar.

As primeiras sugestões de modificação na proposta original de Salamon e Munro vieram em 1993. Especificamente na camada de carvão Vaal Basin da África do Sul, VAN der MERWE (1993) observou uma série de casos de ruptura quando o dimensionamento dos pilares foi executado considerando a resistência característica originalmente proposta por Salamon e Munro para as camadas Sul Africanas. Para fazer frente a esses problemas o autor sugere a redução da resistência característica de $7,2 \mathrm{MPa}$ para $4,5 \mathrm{MPa}$ na expressão original de cálculo da resistência do pilar. Com base na reanálise dos dados originais de Salamon e Munro associados a novos casos de ruptura após 1966, excetuando os da camada Vaal Basin que deve ser tratada independentemente das demais, VAN der MERWE (1999) propôs uma nova equação de cálculo da resistência do pilar para as camadas Sul Africanas. O mesmo VAN der MERWE (2002), após incluir no banco de dados de Salamon e Munro novos casos de ruptura ocorridos 
após 1966, sugere uma terceira equação, desta vez distinguindo as camadas Sul Africanas em dois grandes grupos: camadas de carvão de baixa resistência e camadas de resistência normal. SALAMON et al. (1996) após estudar exaustivamente os casos de ruptura da África do Sul e Austrália propuseram uma série de funções dependendo dos dados considerados nas análises.

A observação da evolução das equações de cálculo da resistência de pilares na África do Sul mostra que, dependendo do período em que foi desenvolvida e, por conseqüência, da quantidade de dados utilizada, as funções foram sendo paulatinamente modificadas. A resistência do pilar calculada por cada uma das diferentes equações, no entanto, pouco diferem entre si, exceto no caso da função indicada para pilares com a relação $\mathrm{W} / \mathrm{H}>5$ e no caso das camadas de baixa resistência, conforme apontado por VAN der MERWE (1993).

Em 1980 o CMRS - Central Mining Research Station da Índia (SINGH, 1980) propôs uma revisão da equação de Salamon \& Munro para a utilização nas minas indianas. Após observarem que o comportamento da curva tensão $x$ deformação do carvão, a partir de 60 a $80 \%$ da tensão de ruptura, não é mais elástica, sugeriram um fator de correção da resistência in situ da camada de carvão. Assim, a resistência característica da camada deve ser multiplicada por um fator de correção que varia entre 0,6 e 0,8 para que o pilar tenha vida útil maior.

SHEOREY et at. (1986) apresentaram uma proposta para o cálculo da resistência de pilares de carvão baseada num novo critério de ruptura para camadas de carvão. O fator de correção da resistência de laboratório para a condição in situ é definido pela expressão $0,66 * \sigma_{c} * h^{-0,35}$ onde $\sigma_{c}$ é a resistência de um cubo de $30 \mathrm{~cm}$ de lado e h é a altura da camada minerada. Para os autores, a resistência do pilar depende não somente da resistência da camada, mas também da profundidade da camada minerada. Adotando o mesmo procedimento estatístico dos pesquisadores da África do Sul, SHEOREY et at. (1987) sugeriram equação de cálculo da resistência de pilares de carvão semelhante, com base num conjunto de 23 casos de ruptura e 20 casos de sucesso documentados nas minas da Índia. $\mathrm{Na}$ equação proposta, a resistência à compressão uniaxial é determinada sobre corpos-de-prova cúbicos de $2,5 \mathrm{~cm}$ de lado. Nessa função, a parcela $0,27 * \sigma_{c} * h^{-0,36}$ representa o efeito escala para a estimativa da resistência característica da camada de carvão minerada. Mais tarde, o mesmo SHEOREY (1992) propôs alguns refinamentos para o cálculo da resistência do pilar, levando em consideração, além da resistência do carvão, a tensão in situ. MOHAN et al. (2001) propuseram uma função semelhante para a computação da resistência do pilar nas camadas indianas, baseando-se no modelamento numérico desses mesmos casos de pilares estáveis e colapsados.

A Tabela 2.7 apresenta uma síntese das equações de cálculo da resistência de pilares de carvão, propostas para as camadas de carvão da Índia, África do Sul e da Austrália, juntamente com as constantes características de cada camada de carvão, que foram sugeridas em função dos vários estudos realizados ao longo do tempo. As Figuras 2.15a e 2.15b mostram o comportamento da resistência das equações com formato "potência", sugeridas para os carvões da África do Sul e da Austrália, respectivamente. 
As diversas experiências apresentadas mostram condições vigentes nas áreas onde os estudos foram realizados diferentes entre si, o que dificulta a sua transposição para outros locais sem os devidos ajustes. O uso indiscriminado dessas equações no cálculo da resistência de pilares fora das condições sob as quais foram determinadas, portanto, pode resultar em situações nada desejáveis do ponto de vista de segurança. Nunca deve ser esquecido que cada uma dessas funções representa condições médias das camadas e dos locais (países) de onde se originaram.

Tabela 2.7 - Síntese das funções de cálculo da resistência de pilares de carvão e dos valores de resistência característica para camadas da Índia, África do Sul e Austrália, estabelecidos a partir de sucessivos estudos de casos de pilares colapsados e não colapsados.

\begin{tabular}{|c|c|c|c|}
\hline \multicolumn{4}{|c|}{ Base de Dados: Índia } \\
\hline $\begin{array}{c}\text { Função Geral para o Cálculo da } \\
\text { Resistência do Pilar }\end{array}$ & $\begin{array}{c}\sigma_{\mathrm{c}} \\
(\mathrm{MPa})\end{array}$ & $\begin{array}{l}\text { Camada de Carvão } \\
\text { Aplicável }\end{array}$ & Referência \\
\hline$S_{p}=\sigma_{c} * K * \frac{W^{0,46}}{h^{0,66}}$ & $\sigma_{\mathrm{c}(30 \mathrm{~cm})}$ & $\begin{array}{l}\text { Não especificadas. } \\
\text { Aparentemente, válida para } \\
\text { todas as camadas. }\end{array}$ & \multirow[b]{2}{*}{ SINGH (1980). } \\
\hline$S_{p}=R_{s} * \sigma_{c} * K * h^{-0,2}$ & $\sigma_{\mathrm{c}(30 \mathrm{~cm})}$ & $\begin{array}{l}\text { Não especificadas. } \\
\text { Aparentemente, válida para } \\
\text { todas as camadas e para } \\
\text { pilares com a relação } \\
\qquad \mathrm{W} / \mathrm{h} \geq 8 .\end{array}$ & \\
\hline $\begin{array}{c}S_{p}=0,66 * \sigma_{c} * h^{-0,35}+\ldots \\
\ldots+5 *\left[\gamma * H *\left(1-e^{-1,5 * W / D}\right)\right]^{0,8}\end{array}$ & $\sigma_{\mathrm{c}(30 \mathrm{~cm})}$ & $\begin{array}{l}\text { Não especificadas. } \\
\text { Aparentemente, válida para } \\
\text { todas as camadas. }\end{array}$ & SHEOREY et al. (1986). \\
\hline $\begin{array}{c}S_{p}=0,27 * \sigma_{c} * h^{-0,36}+\frac{H}{160} *\left(\frac{W}{h}-1\right) \\
\text { Ou na sua versão simplificada: } \\
S_{p}=0,27 * \sigma_{c} * h^{-0,36} * \sqrt{\frac{W}{h}}\end{array}$ & $\sigma_{\mathrm{c}(2,5 \mathrm{~cm})}$ & $\begin{array}{l}\text { Não especificadas. } \\
\text { Aparentemente, válida para } \\
\text { todas as camadas. }\end{array}$ & SHEOREY et al. (1987). \\
\hline$S_{p}=0,27 * \sigma_{c} * h^{-0,36}+\frac{H}{150} *\left(0,6+\frac{150}{H}\right)\left(\frac{W}{h}-1\right)$ & $\sigma_{\mathrm{c}(2,5 \mathrm{~cm})}$ & $\begin{array}{l}\text { Não especificadas. } \\
\text { Aparentemente, válida para } \\
\text { todas as camadas. }\end{array}$ & SHEOREY (1992). \\
\hline$S_{p}=0,27 * \sigma_{c} * h^{-0,36}+\left(\frac{H}{250}+1\right) *\left(\frac{W}{h}-1\right)$ & $\sigma_{\mathrm{c}(2,5 \mathrm{~cm})}$ & $\begin{array}{l}\text { Não especificadas. } \\
\text { Aparentemente, válida para } \\
\text { todas as camadas. }\end{array}$ & MOHAN et al. (2001). \\
\hline
\end{tabular}

NOTAS: a) $S_{p}=$ resistência do pilar $(\mathrm{MPa})$; $\sigma_{\mathrm{c}}=$ resistência à compressão uniaxial de um corpo-deprova cúbico ( $\mathrm{MPa}) ; \mathrm{K}=$ fator de correção da resistência à compressão uniaxial variando entre 0,6 e 0,$8 ; \mathrm{W}=$ largura do pilar $(\mathrm{m}) ; \mathrm{h}=$ altura do pilar $(\mathrm{m})$;

b) $\sigma_{\mathrm{c}(30 \mathrm{~cm})}$ e $\sigma_{\mathrm{c}(2,5 \mathrm{~cm})}=$ resistência à compressão uniaxial de um corpo-de-prova cúbico com lado igual a $30 \mathrm{~cm}$ e $2,54 \mathrm{~cm}$, respectivamente (MPa);

c) $\mathrm{H}=$ profundidade da camada de carvão minerada $(\mathrm{m}) ; \mathrm{D}=$ fator dependente da profundidade e da rigidez da cobertura, podendo variar entre 25 e $120(\mathrm{~m}) ; \gamma=$ tensão unitária da rocha $(\mathrm{MPa} / \mathrm{m}) ; \mathrm{R}_{\mathrm{s}}=5$ para $\mathrm{W} / \mathrm{h}$ entre 8 e 10 e $R_{\mathrm{s}}=6$ para W/h entre $11 \mathrm{e}$ 12. 
continuação . . .

\begin{tabular}{|c|c|c|c|}
\hline \multicolumn{4}{|c|}{ Base de Dados: África do Sul } \\
\hline $\begin{array}{l}\text { Função Geral para o Cálculo da Resistência } \\
\text { do Pilar }\end{array}$ & $\begin{array}{c}\mathrm{S}_{1} \\
(\mathrm{MPa})\end{array}$ & $\begin{array}{l}\text { Camada de Carvão } \\
\text { Aplicável }\end{array}$ & Referência \\
\hline$S_{p}=S_{1} * \frac{W^{0,46}}{h^{0,66}}$ & 7,17 & Todas as camadas. & $\begin{array}{l}\text { SALAMON (1967)e } \\
\text { SALAMON \& MUNRO } \\
\text { (1967). }\end{array}$ \\
\hline $\begin{array}{l}\quad S_{p}=S_{1} * R o^{b} * V^{a} *\left\{\frac{b}{\varepsilon} *\left[\left(\frac{R}{R o}\right)^{\varepsilon}-1\right]+1\right\} \\
\text { Ou numa forma trabalhada, com as constantes } \\
\quad \text { definidas conforme notas abaixo: } \\
S_{p}=\frac{S_{1} * 2,5985}{W^{0,1334} * h^{0,0667}} *\left\{0,2373 *\left[\left(\frac{W}{5^{*} h}\right)^{2,5}-1\right]+1\right\}\end{array}$ & 7,17 & $\begin{array}{l}\text { Todas as camadas para } \\
\text { pilares com a relação } \\
\qquad \mathrm{W} / \mathrm{h} \geq 5\end{array}$ & $\begin{array}{c}\text { SALAMON \& WAGNER } \\
\text { (1985). }\end{array}$ \\
\hline$S_{p}=S_{1} * \frac{W^{0,63}}{h^{0,78}}$ & 5,24 & Todas as camadas. & MADDEN (1991). \\
\hline$S_{p}=S_{1} * \frac{W^{0,46}}{h^{0,66}}$ & 4,5 & Camada Vaal Basin. & $\begin{array}{l}\text { VAN der MERWE } \\
\text { (1993). }\end{array}$ \\
\hline$S_{p}=S_{1} * \frac{W^{0,81}}{h^{0,76}}$ & 4,0 & Camada Vaal Basin. & $\begin{array}{l}\text { VAN der MERWE } \\
\text { (1999). }\end{array}$ \\
\hline \multirow[b]{2}{*}{$S_{p}=S_{1} * \frac{W}{h}$} & 1,5 & $\begin{array}{l}\text { Camadas de baixa } \\
\text { resistência (Vaal Basin e } \\
\text { Klip River). }\end{array}$ & \multirow[b]{2}{*}{$\begin{array}{l}\text { VAN der MERWE } \\
\text { (2002). }\end{array}$} \\
\hline & 3,5 & $\begin{array}{l}\text { Camadas de resistência } \\
\text { normal (Witbank, South } \\
\text { Rand, Ultrecht, Spring- } \\
\text { Witbank e camadas do } \\
\text { estado Orange Free). }\end{array}$ & \\
\hline$S_{p}=S_{1} * \frac{W^{0,42}}{h^{0,6}}$ & 6,88 & $\begin{array}{l}\text { Todas as camadas para } \\
\text { pilares quadrados com a } \\
\text { relação } \mathrm{W} / \mathrm{h} \leq 5 .\end{array}$ & \multirow{3}{*}{ SALAMON et al. (1996). } \\
\hline$S_{p}=\frac{S_{1} * 2,3784}{W^{0,116} * h^{0,058}} *\left\{0,215 *\left[\left(\frac{W}{5^{*} h}\right)^{2,5}-1\right]+1\right\}$ & 6,88 & $\begin{array}{l}\text { Todas as camadas para } \\
\text { pilares quadrados com a } \\
\text { relação } W / h>5\end{array}$ & \\
\hline$S_{p}=S_{1} *\left(0,69+0,31 * \frac{W}{h}\right)$ & 5,60 & $\begin{array}{l}\text { Válida para todas as } \\
\text { camadas. }\end{array}$ & \\
\hline
\end{tabular}

NOTA: $\mathrm{S}_{1}=$ resistência característica da(s) camada(s) de carvão $(\mathrm{MPa}) ; \mathrm{V}=$ volume do pilar definido como: $W^{2 *} h\left(m^{3}\right) ; R=W / h ; R o=5 ; a=-0,0667 ; b=0,5933 ; \varepsilon=2,5$;

continua . . . 
continuação . . .

\begin{tabular}{|c|c|c|c|}
\hline \multicolumn{4}{|c|}{ Base de Dados: Austrália } \\
\hline $\begin{array}{c}\text { Função Geral para o Cálculo da } \\
\text { Resistência do Pilar }\end{array}$ & $\begin{array}{c}\mathrm{S}_{1} \\
(\mathrm{MPa})\end{array}$ & $\begin{array}{l}\text { Camada de Carvão } \\
\text { Aplicável }\end{array}$ & Referência \\
\hline$S_{p}=S_{1} * \frac{W^{0,51}}{h^{0,84}}$ & 8,6 & $\begin{array}{l}\text { Camadas dos estados de } \\
\text { New South Wales e } \\
\text { Queensland para pilares } \\
\text { quadrados com a relação } \\
\text { W/h } \leq 5 .\end{array}$ & \multirow{2}{*}{ SALAMON et al. (1996). } \\
\hline$S_{p}=\frac{S_{1} * 3,2141}{W^{0,220} * h^{0,110}} *\left\{0,290 *\left[\left(\frac{W}{5 * h}\right)^{2,5}-1\right]+1\right\}$ & 8,6 & $\begin{array}{l}\text { Camadas dos estados de } \\
\text { New South Wales e } \\
\text { Queensland para pilares } \\
\text { quadrados com a relação } \\
\text { W/h>5. }\end{array}$ & \\
\hline$S_{p}=S_{1} * \frac{W^{0,46}}{h^{0,66}}$ & 7,4 & $\begin{array}{l}\text { Válida para todas as } \\
\text { camadas para pilares } \\
\text { quadrados com a relação } \\
\mathrm{W} / \mathrm{h} \leq 5 .\end{array}$ & \multirow{3}{*}{ GALVIN et al. (1999). } \\
\hline$S_{p}=\frac{S_{1} * 2,5984}{W^{0,133} * h^{0,067}} *\left\{0,237 *\left[\left(\frac{W}{5 * h}\right)^{2,5}-1\right]+1\right\}$ & 7,4 & $\begin{array}{c}\text { Válida para todas as } \\
\text { camadas para pilares } \\
\text { quadrados com a relação } \\
\qquad \mathrm{W} / \mathrm{h}>5 \text {. }\end{array}$ & \\
\hline$S_{p}=S_{1} *\left(0,64+0,36 * \frac{W}{h}\right)$ & 5,36 & $\begin{array}{l}\text { Válida para todas as } \\
\text { camadas. }\end{array}$ & \\
\hline \multicolumn{4}{|c|}{ Base de Dados: África do Sul e Austrália } \\
\hline$S_{p}=S_{1} * \frac{W^{0,5}}{h^{0,7}}$ & 6,88 & $\begin{array}{l}\text { Recomendada para as } \\
\text { camadas tanto da África do } \\
\text { Sul como da Austrália, para } \\
\text { pilares quadrados com a } \\
\text { relação } \mathrm{W} / \mathrm{h} \leq 5 \text {. }\end{array}$ & \multirow{3}{*}{ SALAMON et al. (1996). } \\
\hline$S_{p}=\frac{S_{1} * 2,7701}{W^{0,133} * h^{0,066}} *\left\{0,253 *\left[\left(\frac{W}{5 * h}\right)^{2,5}-1\right]+1\right\}$ & 6,88 & $\begin{array}{l}\text { Recomendada para as } \\
\text { camadas tanto da África do } \\
\text { Sul como da Austrália para } \\
\text { pilares quadrados com a } \\
\text { relação } W / h>5 .\end{array}$ & \\
\hline$S_{p}=S_{1} *\left(0,63+0,37 * \frac{W}{h}\right)$ & 5,41 & $\begin{array}{l}\text { Válida para todas as } \\
\text { camadas. }\end{array}$ & \\
\hline
\end{tabular}




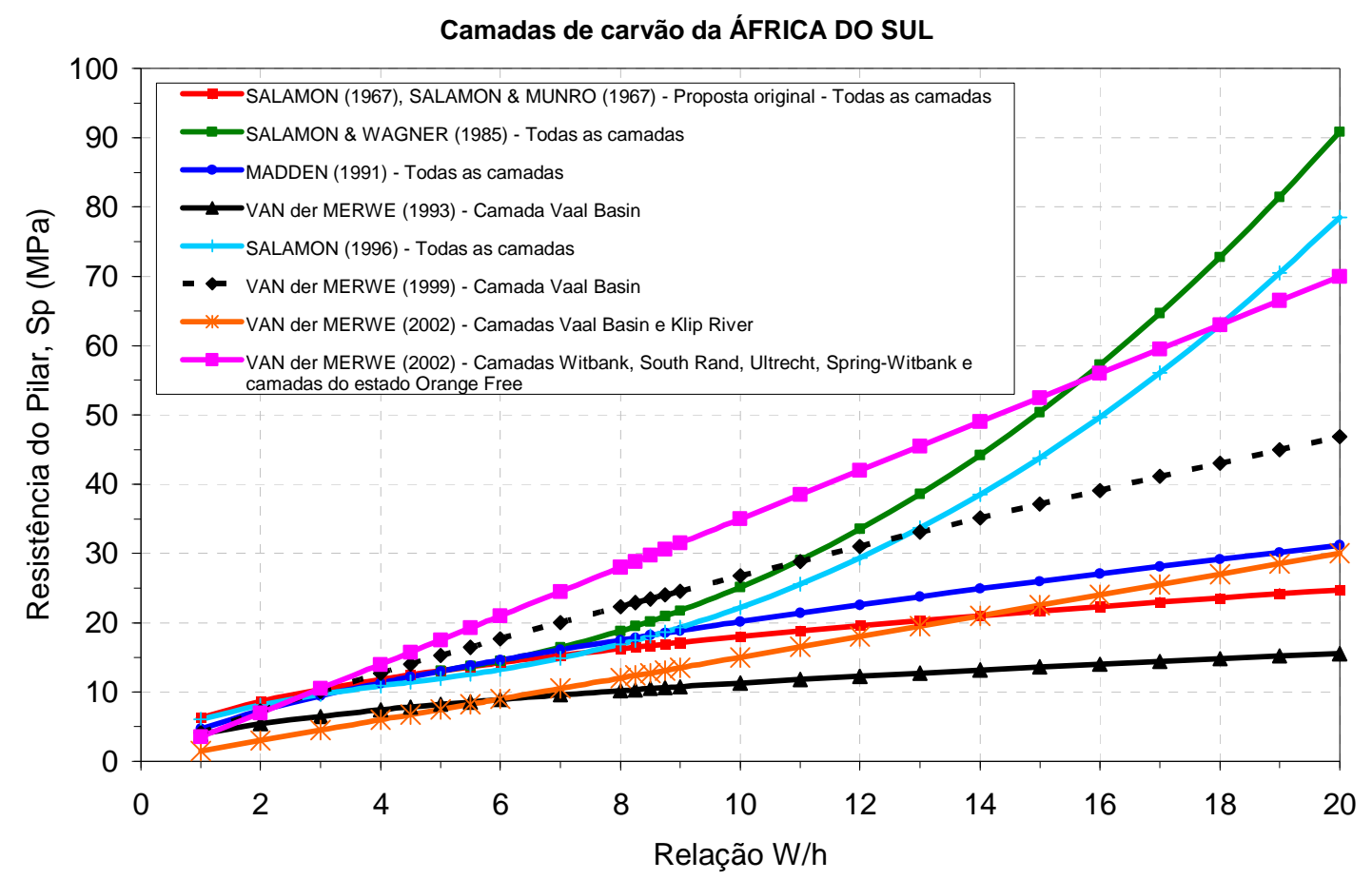

a)

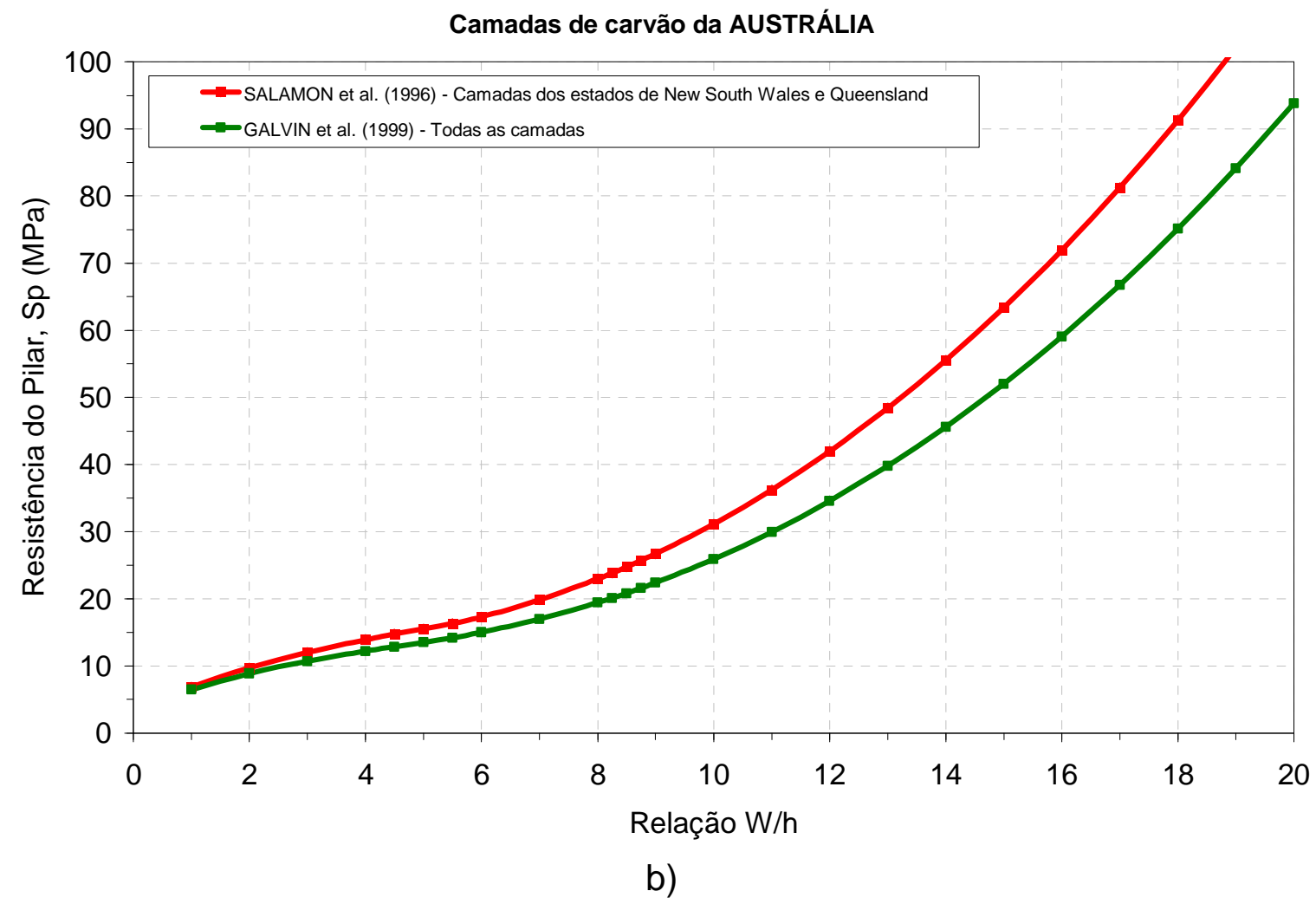

Figura 2.15 - Variação da resistência do pilar em função da sua geometria $\left(\mathrm{h}_{\text {constante }}\right.$ $=2 \mathrm{~m}$ ), segundo diferentes equações propostas: a) para os carvões da ÁFRICA DO SUL; b) para os carvões da AUSTRÁLIA. 


\section{Aspectos Geológicos dos Jazimentos de Carvão no Brasil}

\subsection{Introdução}

A abordagem de aspectos geológicos neste trabalho está concentrada na camada de carvão Bonito, por ser essa camada, na Mina Fontanella dentro da Bacia SulCatarinense, o campo experimental fundamental para o desenvolvimento desta pesquisa.

Sobre a camada Irapuá são apresentadas informações genéricas, haja vista a sua pequena participação no fornecimento de dados para a consecução dos objetivos desse trabalho.

Os tópicos apresentados adiante têm por base os trabalhos desenvolvidos pela CPRM - Companhia de Pesquisa e Lavras Minerais (ABORRAGE \& LOPES, 1986), a síntese da geologia aplicada à lavra de carvão em subsolo apresentada em CIENTEC - Fundação de Ciência e Tecnologia (1990) e a geologia geral apresentada no projeto de avaliação das reservas de carvão da Mina Fontanella (COSTA, 2000).

\subsection{Classificação das Bacias}

As bacias carboníferas são bastante variáveis quanto à sua estrutura geológica e apresentam vários tipos de classificação. Uma das mais aceitas está relacionada ao ambiente deposicional. Essa classificação auxilia na identificação dos processos geológicos que condicionaram a formação dos depósitos carboníferos e suas implicações na estruturação do pacote sedimentar. Desta forma, as bacias são divididas em límnicas e parálicas.

As bacias límnicas são aquelas interiorizadas nos continentes, sem influência marinha, e possuem extensão limitada. O número e a espessura das camadas de carvão e sedimentos associados variam grandemente em curtas distâncias.

Já as bacias parálicas bordejam os mares e estão sujeitas a incursões marinhas. Nessas bacias, os jazimentos carboníferos possuem sedimentos marinhos, são de grande porte, com grandes espessuras e as camadas de carvão possuem continuidade lateral.

$\mathrm{Na}$ jazidas de Santa Catarina a deposição da matéria orgânica vegetal que originou os carvões ocorreu em ambientes transicionais, com influências ora marinhas, ora continentais. Não existe ainda uma definição clara quanto ao tipo de bacia que originou os carvões nessa região do País. Algumas camadas associam-se a depósitos fluviais, como é o caso provavelmente da camada 
Irapuá, enquanto as demais, incluindo a camada Bonito, estão associadas provavelmente a ambiente marinho.

\subsection{Aspectos da Geologia Regional e Local}

Nos jazimentos carboníferos conhecidos no Brasil, a matéria carbonosa é encontrada desde a fase do linhito até o antracito. O linhito tem suas ocorrências mais importantes localizadas no setor ocidental do estado do Amazonas e na Bacia do Jatobá em Pernambuco. Já as reservas de carvão betuminoso e subbetuminoso estão distribuídas pelo extremo sul do País, na região leste da bacia do Paraná, distribuídas pelos estados do Paraná, Santa Catarina e Rio Grande do Sul. Enquanto os linhitos do Norte e Nordeste são considerados sem interesse econômico ainda, os jazimentos de carvão com os seus diferentes "ranks", são objeto de atividade mineira desde o início do século XIX no sul do Brasil.

$\mathrm{Na}$ Bacia do Paraná, as reservas de carvão estão localizadas na sua porção sudeste, conhecida por ser uma grande bacia sedimentar gonduânica intracratônica. Esta bacia se estende do centro ao sul do Brasil e inclui parte dos países Paraguai, Uruguai e Argentina, como pode ser visto na Figura 3.1. No Brasil, os estados de Santa Catarina e Rio Grande do Sul são os que contemplam as maiores jazidas com potencial de lavra subterrânea.

A concessão da Mina Fontanella, de propriedade da Carbonífera Metropolitana S.A., está localizada na porção norte da bacia carbonífera Sul-Catarinense, englobando áreas dos municípios de Treviso, Lauro Müller e Siderópolis. A Figura 3.2 mostra a localização da área de concessão onde se localiza a Mina Fontanella.

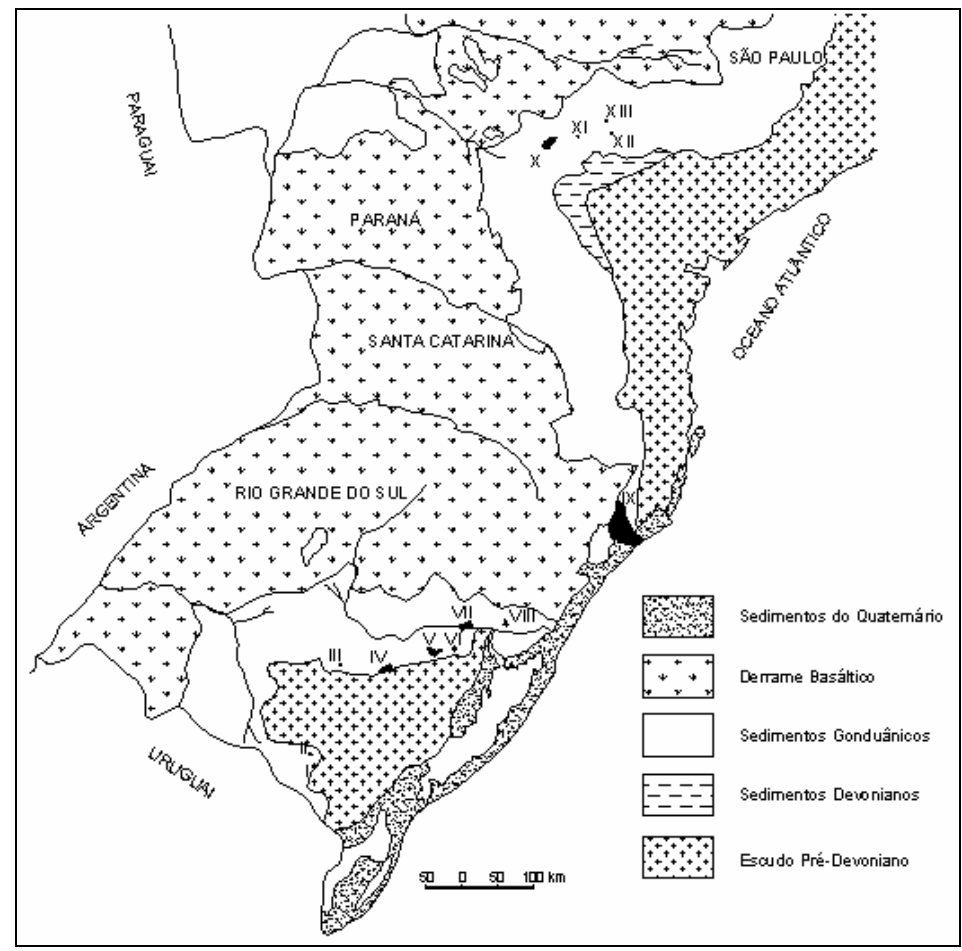

Figura 3.1 - Mapa geológico do sul do Brasil com a indicação das bacias carboníferas conhecidas. Bacia IX = Sul-Catarinense (COSTA, 2000). 


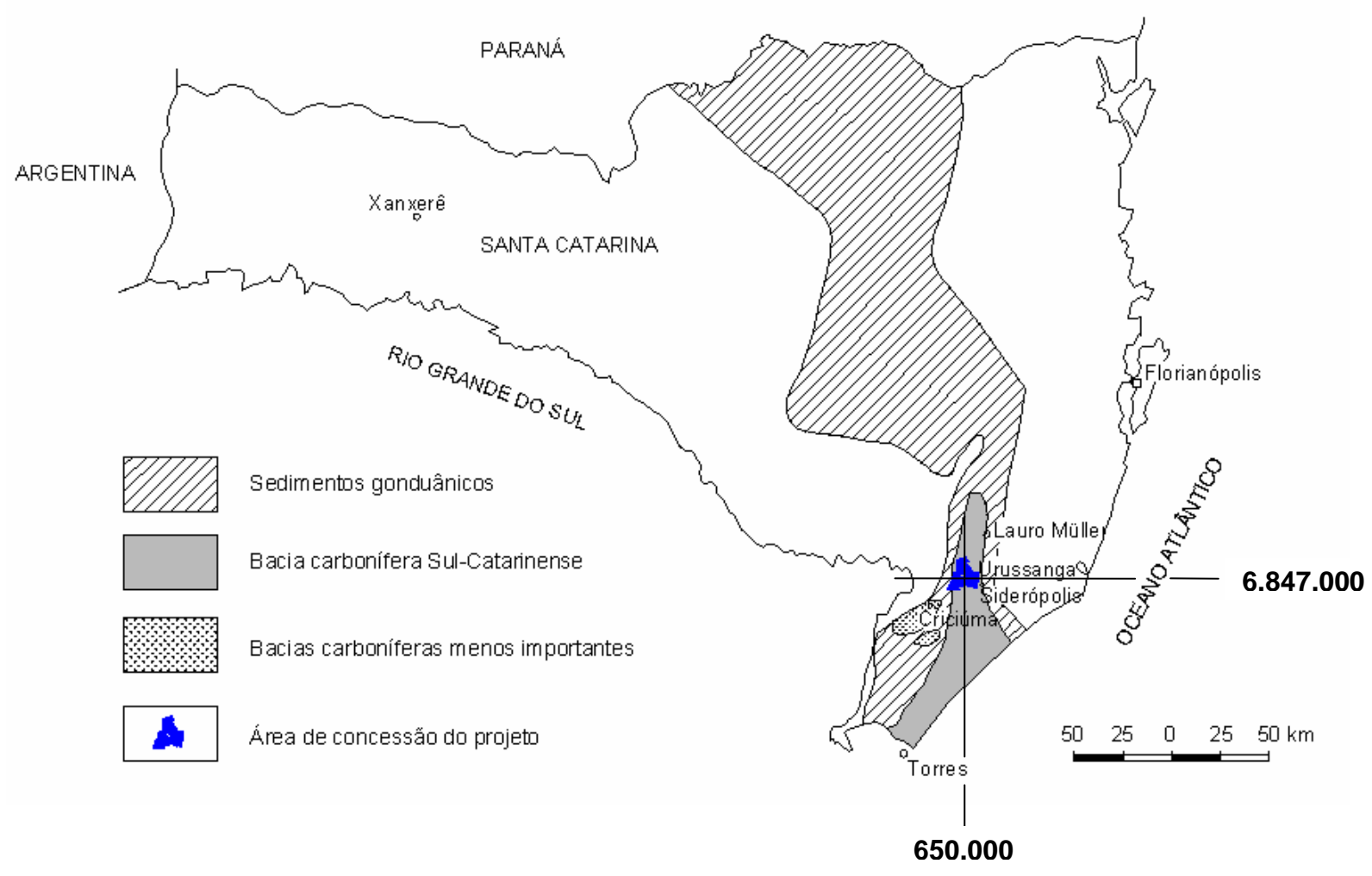

Figura 3.2 - Mapa de localização com a indicação, em azul, da área de concessão da Mina Fontanella (adaptado de COSTA, 2000).

Estratigraficamente, a camada de carvão Bonito situa-se dentro da Formação Rio Bonito. Trata-se da formação mais antiga aflorante na área, sendo esta também a formação que hospeda as camadas de carvão economicamente mais importantes. Esta formação pode ser descrita em três diferentes porções:

- Rio Bonito Inferior: é composta por uma seqüência de arenitos e siltitos micáceos acinzentados, menos freqüentemente folhelhos cinza-escuros com camadas de carvão. Em termos de espessura, varia de $20 \mathrm{~m}$ a $60 \mathrm{~m}$;

- Rio Bonito Intermediário: nesta porção estão presentes siltitos acinzentados a esverdeados com leitos estreitos de mica e geralmente compactos. Com menos freqüência aparecem intercalações de camadas de arenitos da mesma cor;

- Rio Bonito Superior: esta seqüência possui uma espessura variando de $50 \mathrm{~m}$ a $90 \mathrm{~m}$. É nesta parcela da formação que estão localizadas as camadas de carvão com maior valor econômico. São freqüentes, ainda, arenitos compactos de cor cinza-claro.

$\mathrm{Na}$ Figura 3.3 pode ser vista a distribuição das camadas de carvão e das rochas encaixantes de cada uma dessas camadas, de maior ou menor importância econômica. A camada de carvão Bonito (Inferior e Superior) está localizada cerca de $70 \mathrm{~m}$ abaixo da camada Barro Branco que, atualmente, ainda se constitui na camada de carvão de maior volume em explotação. De ocorrência restrita, entre essas duas camadas encontra-se a camada Irapuá. 


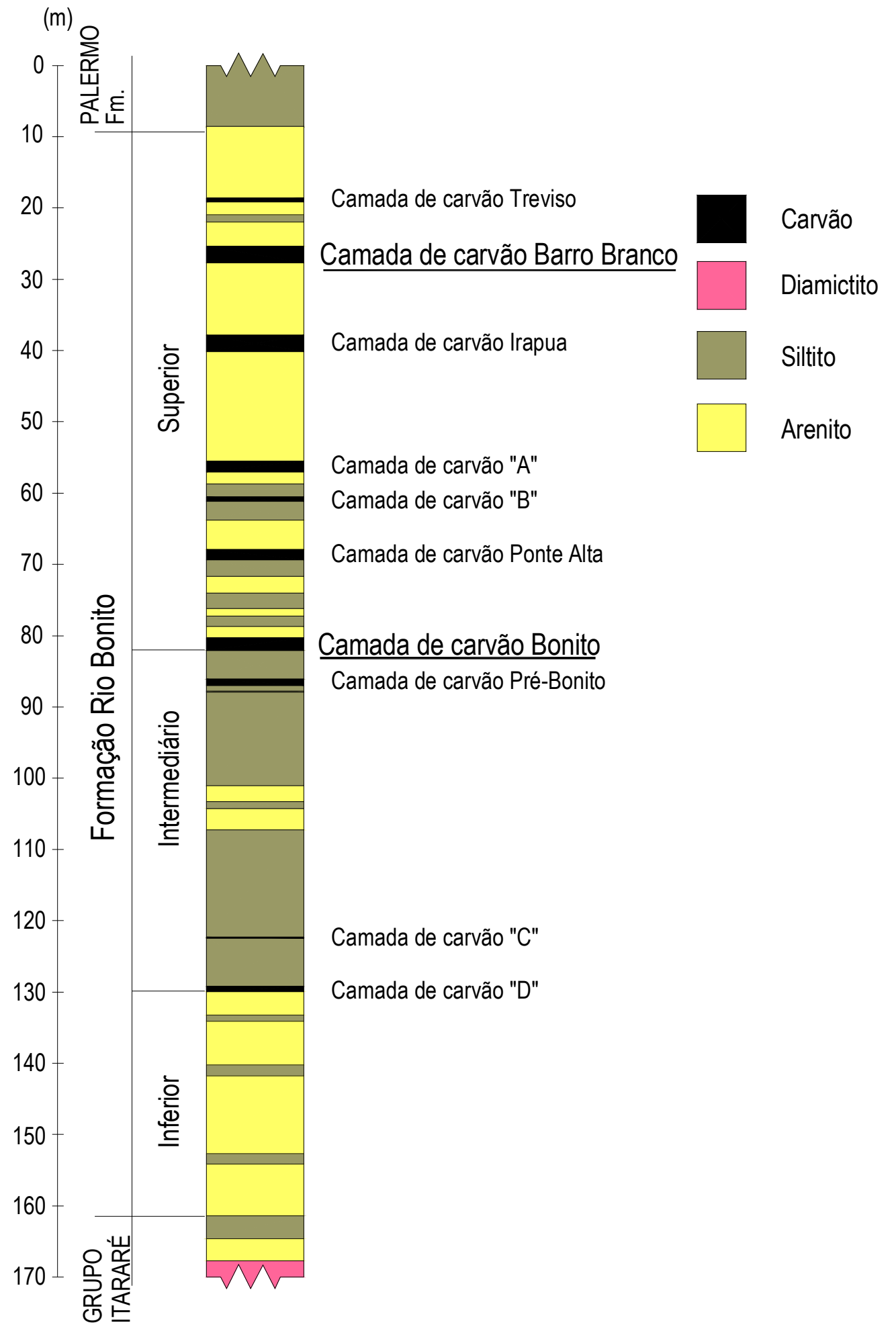

Figura 3.3 - Perfil estratigráfico típico da formação Rio Bonito (COSTA, 2000). 


\subsubsection{Camada Bonito}

A camada Bonito (Inferior) presente na Mina Fontanella é composta basicamente por camadas de carvão fosco e folhelho carbonoso, contendo intercalações de pequenas camadas de siltito e argilito. Observa-se, ainda, no meio da camada, concreções de calcário, as quais se constituem em inclusões com características de resistência e deformabilidade totalmente diferentes do restante da camada de carvão.

Um perfil típico dessa camada de carvão pode ser visto na Figura 3.4. Já as reservas de carvão da camada Bonito computadas até 1986 são apresentadas na Tabela 3.1.

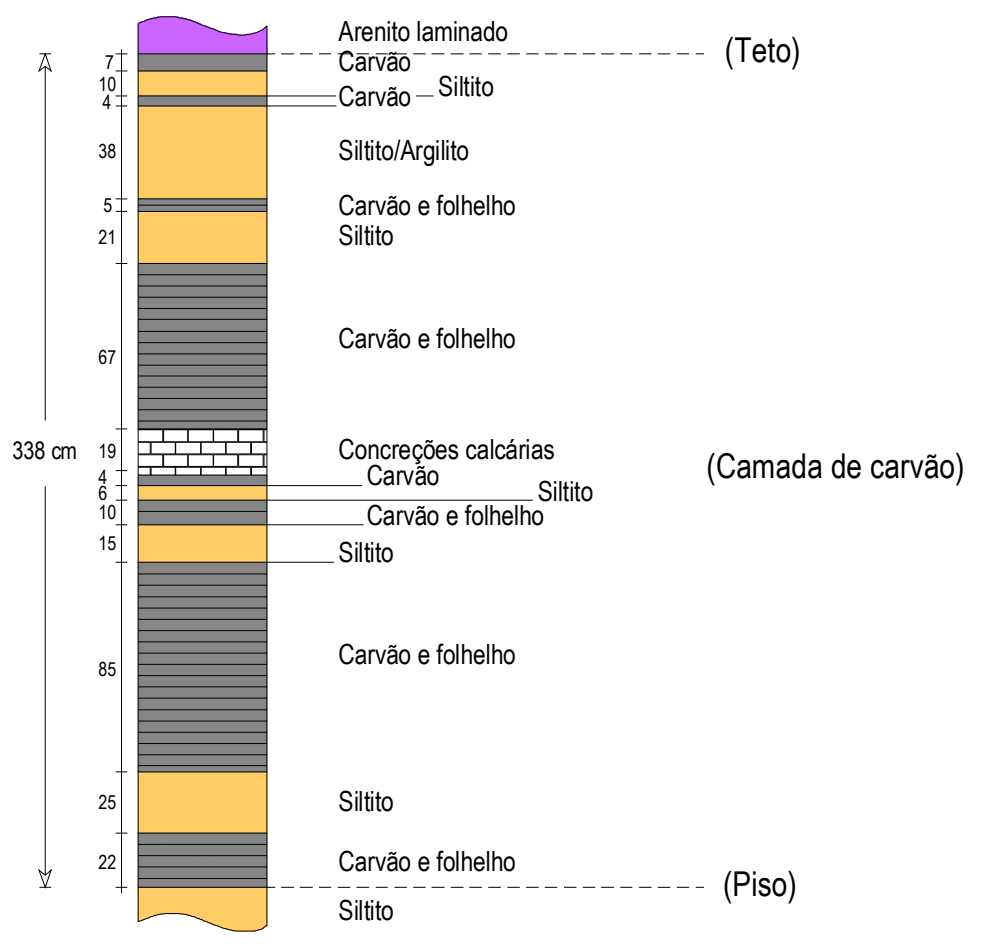

Figura 3.4 - Perfil típico da camada de carvão Bonito (Inferior) na Mina Fontanella (COSTA, 2000).

Tabela 3.1 - Reservas conhecidas de carvão da camada Bonito na Bacia Sul-Catarinense (adaptado de ABORRAGE \& LOPES, 1986).

\begin{tabular}{|c|c|c|c|c|c|}
\hline \multirow{2}{*}{ Camada } & \multicolumn{5}{|c|}{ Cobertura } \\
\hline & $<50 m$ & $50 \mathrm{~m}$ a $300 \mathrm{~m}$ & $300 \mathrm{~m}$ a $800 \mathrm{~m}$ & $>800 \mathrm{~m}$ & Total \\
\hline Bonito (Superior) & $4,0 * 10^{6} t$ & $41,7^{*} 10^{6} \mathrm{t}$ & $250,1 * 10^{6} t$ & - & $295,8 * 10^{6} t$ \\
\hline Bonito (Inferior) & $344,0^{*} 10^{6} t$ & $605,7^{*} 10^{6} t$ & $354,7^{\star} 10^{6} t$ & $242,3^{*} 10^{6} t$ & $1547,4^{*} 10^{6} \mathrm{t}$ \\
\hline Pré-Bonito Superior & - & $34,7^{*} 10^{6} \mathrm{t}$ & $181,3^{*} 10^{6} \mathrm{t}$ & - & $216,0 * 10^{6} t$ \\
\hline Pré-Bonito Inferior & - & - & $197,8^{*} 10^{6} \mathrm{t}$ & - & $197,8^{*} 10^{6} t$ \\
\hline
\end{tabular}

\footnotetext{
" Camada de interesse econômico;

\#\# Camada de interesse econômico na Mina Fontanella e estudada neste trabalho.
} 


\subsubsection{Camada Irapuá}

A camada Irapuá é de ocorrência restrita e apresenta em planta uma forma de cordão, composto por segmentos isolados, sem uma continuidade aparente. Em perfil mostra um formato de calha de fundo achatado, onde a camada se adelgaça para um ou os dois flancos. No interior das minas esta forma fica bem marcada em alguns locais, pelas mudanças no mergulho do plano do piso ou teto da camada de carvão, chegando a $10^{\circ}$ de mergulho e variações de mais de $1 \mathrm{~m}$ de espessura.

Os contatos da camada de carvão com os arenitos do piso e teto são bruscos, formando planos de partição bem definidos. Esta forma de calha está associada à possível deposição da turfa em paleocanais. A Figura 3.5 apresenta um perfil médio da camada, representativo do que se encontra nas minas Morozini Norte e Santa Augusta Norte.

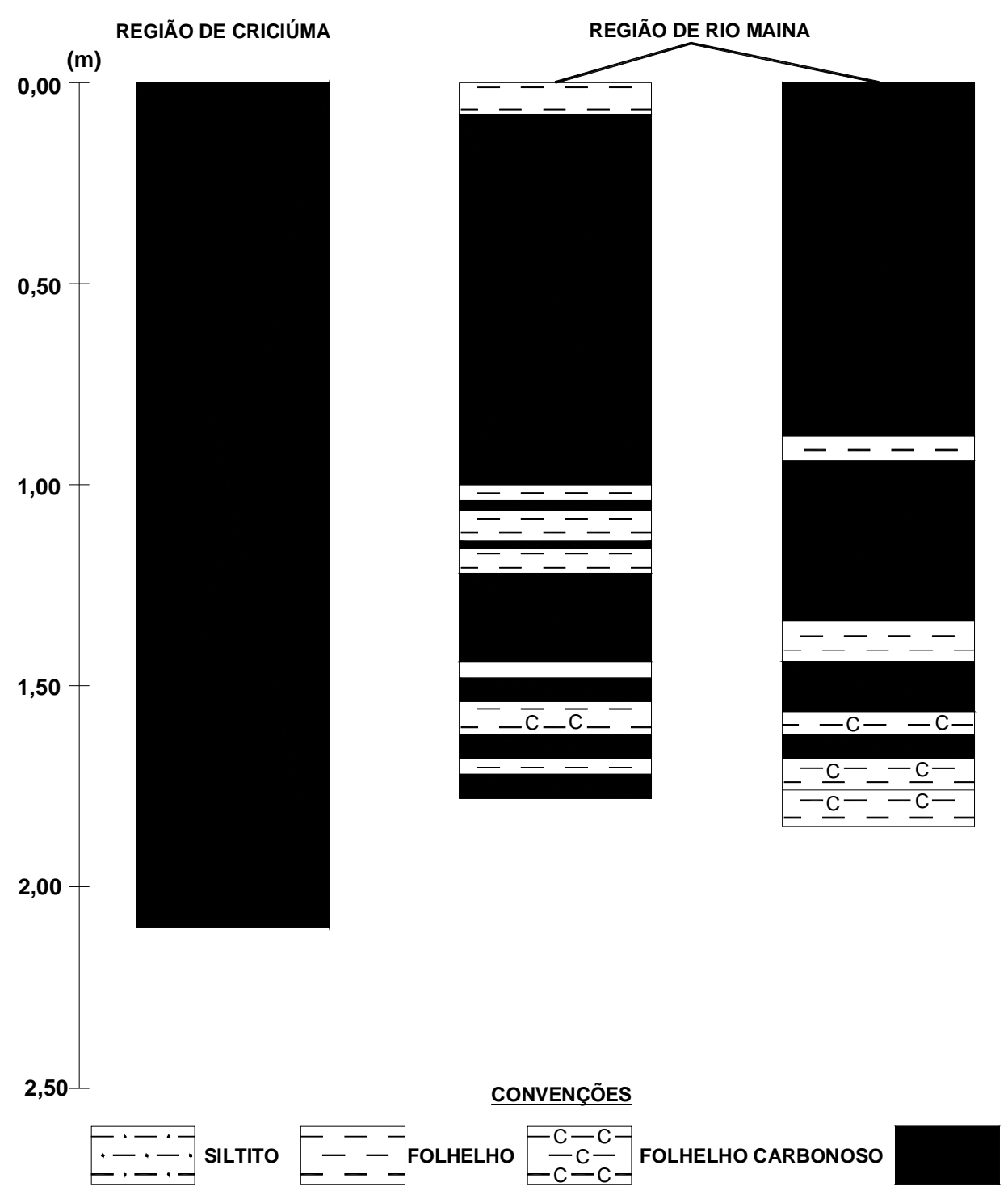

CARVÃO

Figura 3.5 - Perfis típicos da camada Irapuá nas Minas Morozini Norte - região de Rio Maina - e Santa Augusta Norte - região de Criciúma - (adaptado de CIENTEC, 1990). 


\subsection{Fatores Geológicos que Afetam a Lavra de Carvão}

O conhecimento das feições geológicas associadas aos jazimentos carboníferos é de fundamental importância na implementação ou desenvolvimento da lavra. Essas feições podem ter sido geradas antes, durante ou após a deposição da turfa que deu origem à formação das camadas de carvão. A natureza de cada uma delas vai depender da evolução da bacia carbonífera ao longo da sua história. Os principais fatores geológicos que interferem nas condições mecânicas da camada de carvão podem ser sintetizados da seguinte forma:

- litológicos: é importante o conhecimento sobre a existência de intercalações de materiais inorgânicos, sua posição na camada, espessura, além da composição da matéria orgânica que compõe o carvão e o seu grau de carbonificação. Conhecimento sobre os sedimentos que compõem o pacote acima (capa) e abaixo (lapa) da camada são desejáveis, especificamente os tipos de sedimentos, número de estratos, suas espessuras e variações composicionais, tanto lateral como verticalmente;

- estruturais e geométricos: os fatores estruturais relacionam-se com o arranjo e distribuição das camadas de carvão e das encaixantes, além dos efeitos dos processos diagenéticos e tectônicos como falhas, fraturas, fissuras, dobras, que atuaram sobre o pacote sedimentar. É importante que esses fatores sejam definidos local e regionalmente. Especificamente sobre a camada de carvão, é necessária a determinação da espessura média da camada, bem como suas variações dentro da jazida, a profundidade e o mergulho. Para o caso dos falhamentos, é importante a determinação dos tipos de falhas presentes, dos rejeitos apresentados, dos preenchimentos nos planos de falha e das condições de fraturamento nas proximidades das falhas (zonas de falhas). Sistemas de fraturas devem ter seus espaçamentos, persistência e orientações medidos. A presença dessas superfícies de fraqueza na camada de carvão representa um papel importante na resistência e estabilidade das estruturas de sustentação das escavações em subsolo. Outras descontinuidades ligadas à tectônica rígida são os "slikensides", ou lisos, como são designados no ambiente mineiro em subsolo. Esse tipo de descontinuidade possui baixíssima resistência ao cisalhamento e se constitui numa das descontinuidades mais perigosas quando se trata da segurança dos trabalhadores em subsolo e da estabilidade de pilares ou do teto nas minas de carvão;

- magmáticos: freqüentemente, em jazimentos carboníferos, as rochas sedimentares e as camadas de carvão são atravessadas por rochas magmáticas, formando diques ou "sills". É importante definir a posição espacial dentro da jazida, a extensão, espessura, a orientação e a zona da camada de carvão afetada termicamente. No caso dos "sills", a formação de placas de grande extensão lateral tende a criar condições muito especiais em termos de distribuição das tensões durante e após a lavra;

- hidrogeológicos: do ponto de vista hidrogeológico é importante o conhecimento e a localização dos aqüíferos que porventura possam existir na coluna de rochas sedimentares, tanto acima quanto abaixo da camada de carvão a ser minerada. Deve-se determinar a espessura e as características das rochas portadoras da água, bem como a posição do lençol freático em relação à camada de carvão. 


\section{Ensaios de Laboratório e Investigações In Situ}

As atividades práticas apresentadas neste trabalho tiveram como principal fonte de informações e materiais para ensaios em laboratório a Mina Fontanella, da Carbonífera Metropolitana S/A, localizada no município de Treviso-SC. A mina possui uma área relativamente grande para o acesso direto à camada de carvão Bonito e encontra-se atualmente em explotação. O método de lavra empregado é o de "câmaras e pilares". A condição de acesso direto às estruturas em subsolo tornou possível a extração de amostras de carvão de grande porte utilizadas em estudos de laboratório. Nos mesmos locais de extração das amostras, foram realizados estudos geológico-estruturais, através do mapeamento direto das descontinuidades presentes na camada de carvão, além de medidas de velocidade de propagação de ondas sísmicas com o emprego de sísmica de refração.

Outras duas minas foram objeto de estudos experimentais complementares, in situ e em laboratório, porém, limitados. Na Mina Morozini Norte, de propriedade da Carbonífera Belluno LTDA., localizada no município de Treviso-SC, as atividades consistiram de investigações geofísicas in situ e ensaios de laboratório em pequenas amostras da camada de carvão Irapuá. Investigações análogas foram realizadas na Mina Santa Augusta Norte, de propriedade da MINAGEO LTDA., localizada no município de Criciúma-SC, também sobre o carvão da camada Irapuá. Nas duas minas a lavra é realizada pelo método de "câmaras e pilares".

Todos os trabalhos de laboratório foram desenvolvidos no Laboratório de Mecânica e Tecnologia de Rochas da CIENTEC - Fundação de Ciência e Tecnologia do Estado do Rio Grande do Sul, com exceção das determinações do teor de cinzas no carvão, que foram realizadas pelo Laboratório de Ensaios em Combustíveis, também da CIENTEC.

\subsection{Ensaios para a Determinação do Efeito Escala na Resistência à Compressão Uniaxial do Carvão da Camada Bonito - Mina Fontanella}

\subsubsection{Extração das Amostras, Preparação dos Corpos-de-Prova e Execução dos Ensaios}

A coleta de amostras de carvão da camada Bonito, na Mina Fontanella, procurou representar tanto quanto possível, diferentes condições geológicas na área já minerada da mina. Esses locais estão indicados na Figura 4.1. Dois pontos de amostragem foram localizados em painéis de lavra que estavam em operação a época da coleta das amostras (2003) e dois nas proximidades de galerias abertas 2,5 anos antes, aproximadamente. 


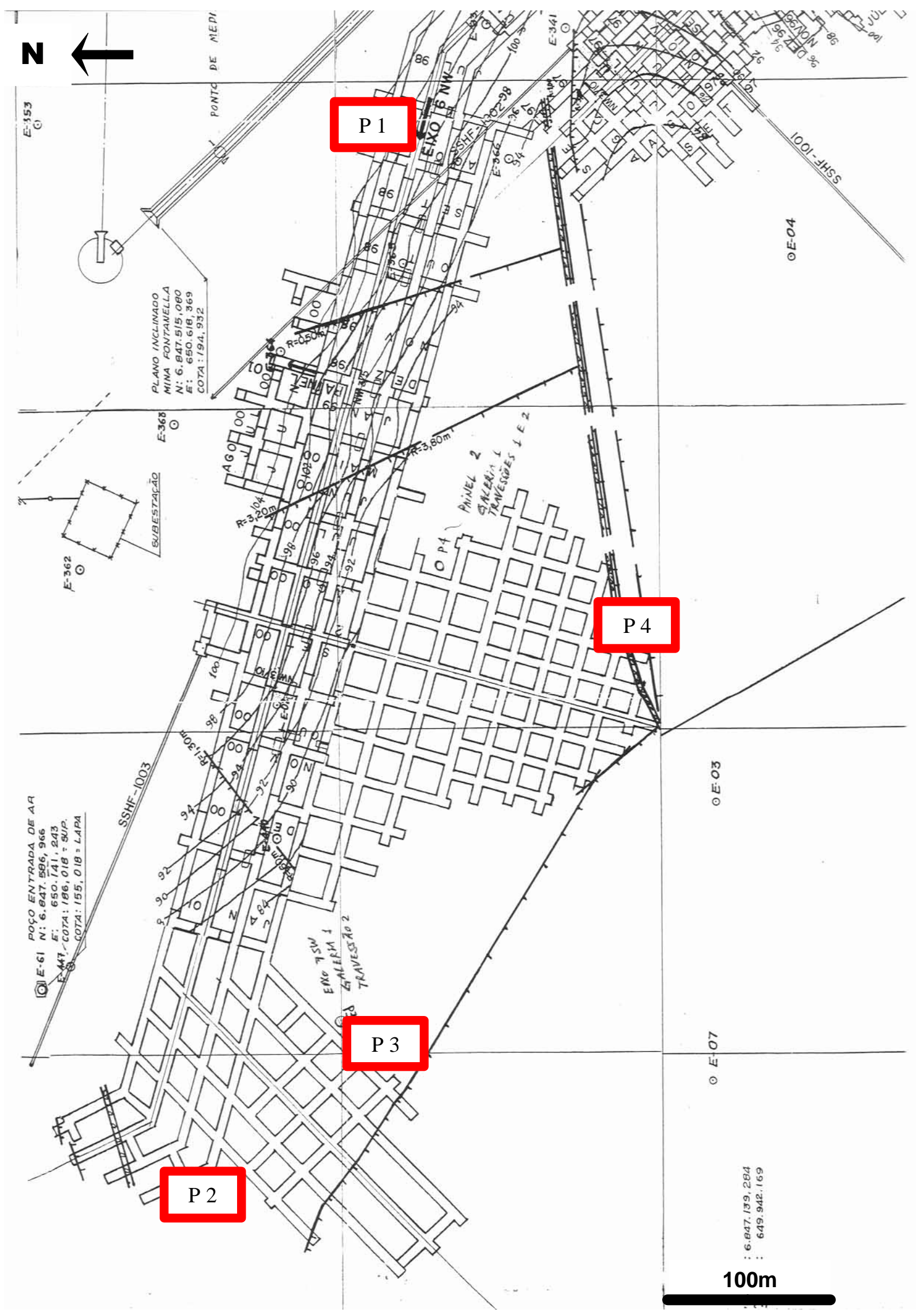

Figura 4.1 - Pontos de coleta de amostras de carvão da camada Bonito, na Mina Fontanella (Fonte da planta: Carbonífera Metropolitana S/A). 
A extração das amostras do maciço foi feita utilizando desmonte mecânico, empregando-se uma cortadeira universal para a separação dos blocos do maciço. Cerca de $8 \mathrm{~m}^{3}$ (12 toneladas) de material foram coletados e transportados ao laboratório para a realização dos ensaios.

A preparação dos corpos-de-prova foi realizada com o uso de serras diamantadas de diferentes portes e retíficas. O acabamento dos corpos-de-prova, assim como a ruptura, seguiu as especificações recomendadas pela ISRM (1999) para ensaios de compressão uniaxial com determinação da curva "tensão $\mathrm{x}$ deformação" pós-ruptura.

No total, foram preparados 78 corpos-de-prova cúbicos, com as dimensões do lado variando entre $5 \mathrm{~cm}$ e $30 \mathrm{~cm}$, conforme pode ser visto na Tabela 4.1. A Figura 4.2 mostra corpos-de-prova com diferentes dimensões antes da ruptura.

Tabela 4.1 - Quantitativos de ensaios efetivamente realizadas com amostras de cada um dos pontos de amostragem na camada Bonito, na Mina Fontanella.

\begin{tabular}{|c|c|c|}
\hline $\begin{array}{c}\text { Ponto de } \\
\text { Amostragem }\end{array}$ & $\begin{array}{l}\text { Dimensão do Lado dos } \\
\text { Corpos-de-Prova Cúbicos }\end{array}$ & Quantidade \\
\hline \multirow{4}{*}{1} & $5 \mathrm{~cm}$ a $10 \mathrm{~cm}$ & 20 \\
\hline & $10 \mathrm{~cm}$ a $20 \mathrm{~cm}$ & 5 \\
\hline & $20 \mathrm{~cm}$ a $30 \mathrm{~cm}$ & 1 \\
\hline & Total de ensaios no ponto 1 & 26 \\
\hline \multirow{4}{*}{2} & $5 \mathrm{~cm}$ a $10 \mathrm{~cm}$ & 6 \\
\hline & $10 \mathrm{~cm}$ a $20 \mathrm{~cm}$ & 4 \\
\hline & $20 \mathrm{~cm}$ a $30 \mathrm{~cm}$ & 2 \\
\hline & Total de ensaios no ponto 2 & 12 \\
\hline \multirow{4}{*}{3} & $5 \mathrm{~cm}$ a $10 \mathrm{~cm}$ & 13 \\
\hline & $10 \mathrm{~cm}$ a $20 \mathrm{~cm}$ & 6 \\
\hline & $20 \mathrm{~cm}$ a $30 \mathrm{~cm}$ & 6 \\
\hline & Total de ensaios no ponto 3 & 25 \\
\hline \multirow{4}{*}{4} & $5 \mathrm{~cm}$ a $10 \mathrm{~cm}$ & 10 \\
\hline & $10 \mathrm{~cm}$ a $20 \mathrm{~cm}$ & 5 \\
\hline & $20 \mathrm{~cm}$ a $30 \mathrm{~cm}$ & - \\
\hline & Total de ensaios no ponto 4 & 15 \\
\hline
\end{tabular}

Previamente à ruptura dos corpos-de-prova, foram determinadas a massa específica aparente e a velocidade de propagação de ondas ultra-sônicas longitudinais nas 3 direções do cubo, de acordo com os métodos específicos sugeridos para cada ensaio (ISRM, 1979a e 1978a, respectivamente). Os teores de umidade e de cinzas foram determinados após a ruptura, de acordo com a ISRM (1979a) e a ABNT NBR 8289 (1983), respectivamente.

A ruptura dos corpos-de-prova à compressão uniaxial foi feita utilizado um sistema de carregamento MTS 816 servo-controlado, com capacidade de carga de 2,0MN. Diferentes tipos de extensômetros foram utilizados para a medição das 
deformações nos corpos-de-prova durante a ruptura, dependendo do tamanho do corpo-de-prova. Em todos os ensaios o carregamento foi aplicado na direção perpendicular aos planos de estratificação do carvão.

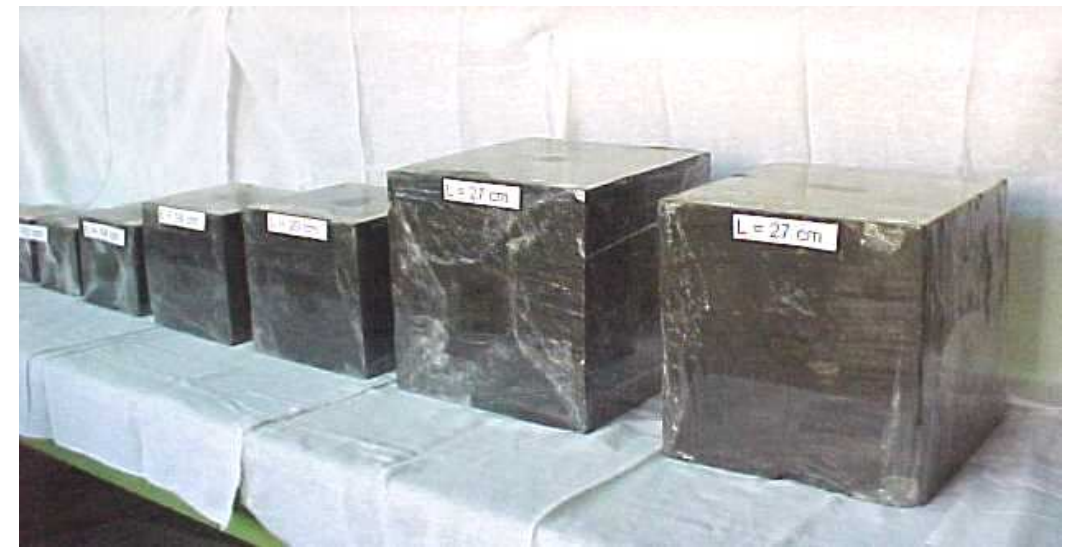

Figura 4.2 - Corpos-de-prova cúbicos utilizados nos estudos do efeito escala no carvão da camada Bonito, da Mina Fontanella.

No Anexo 1 são apresentados detalhes do processo de coleta das amostras, características do perfil da camada de carvão nos locais amostrados e as técnicas empregadas para a preparação dos espécimens. Aspectos composicionais e estruturais dos corpos-de-prova são descritos, assim como são apresentados os equipamentos e os procedimentos operacionais utilizados nos ensaios de compressão uniaxial em laboratório.

\subsubsection{Resultados Obtidos}

Os resultados relativos às diferentes propriedades determinadas, em função do tamanho dos corpos-de-prova, são apresentados na forma gráfica, individualizados por ponto $(\mathrm{P})$ de amostragem.

Nas Figuras 4.3, 4.4 e 4.5 podem ser vistos o teor de umidade, o teor de cinzas e os índices físicos dos corpos-de-prova ensaiados.

As determinações da velocidade de propagação da onda ultra-sônica compressional (onda P), medidas na direção dos três eixos do corpo-de-prova, largura, profundidade e altura, são apresentadas nas Figuras 4.6a, 4.6b e 4.6c, respectivamente.

Nas Figuras $4.7 \mathrm{a}$ e $4.7 \mathrm{~b}$ podem ser vistos comportamentos típicos da curva "tensão x deformação" observados no carvão dos diferentes locais amostrados. Como as deformações foram medidas nos próprios corpos-de-prova, nem sempre foi possível monitorar adequadamente as deformações até a ruptura. Normalmente, as tensões limites das curvas representam mais de $80 \%$ da tensão de ruptura. A Figura 4.8, por sua vez, apresenta os módulos de deformabilidade estático em função da dimensão do lado do corpo-de-prova cúbico.

Já os resultados de resistência à compressão uniaxial, em função da variação do tamanho dos corpos-de-prova, podem ser vistos na Figura 4.9. 


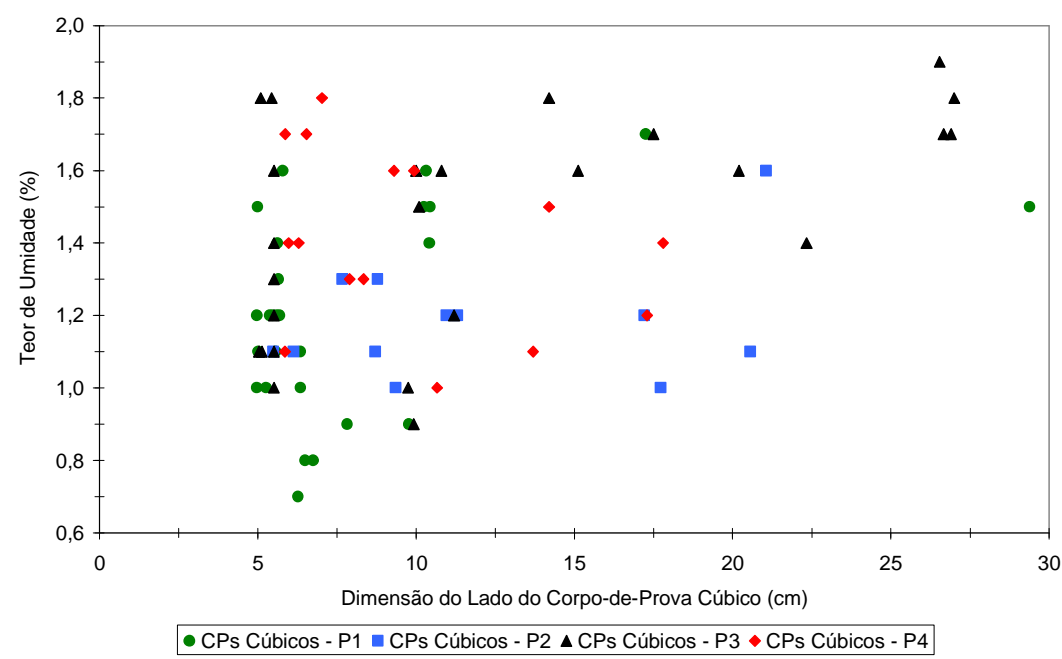

Figura 4.3 - Resultados das determinações do teor de umidade nos corpos-de-prova após os ensaios, para os diferentes tamanhos de corpos-de-prova ensaiados.

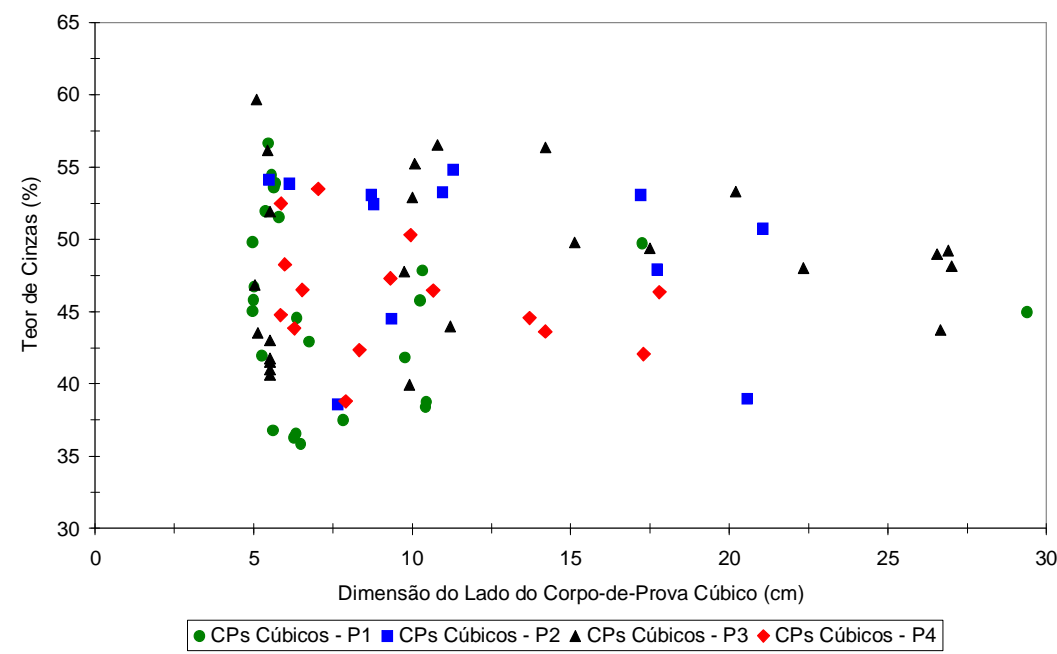

Figura 4.4 - Resultados das determinações do teor de cinzas, para os diferentes tamanhos de corpos-de-prova ensaiados.

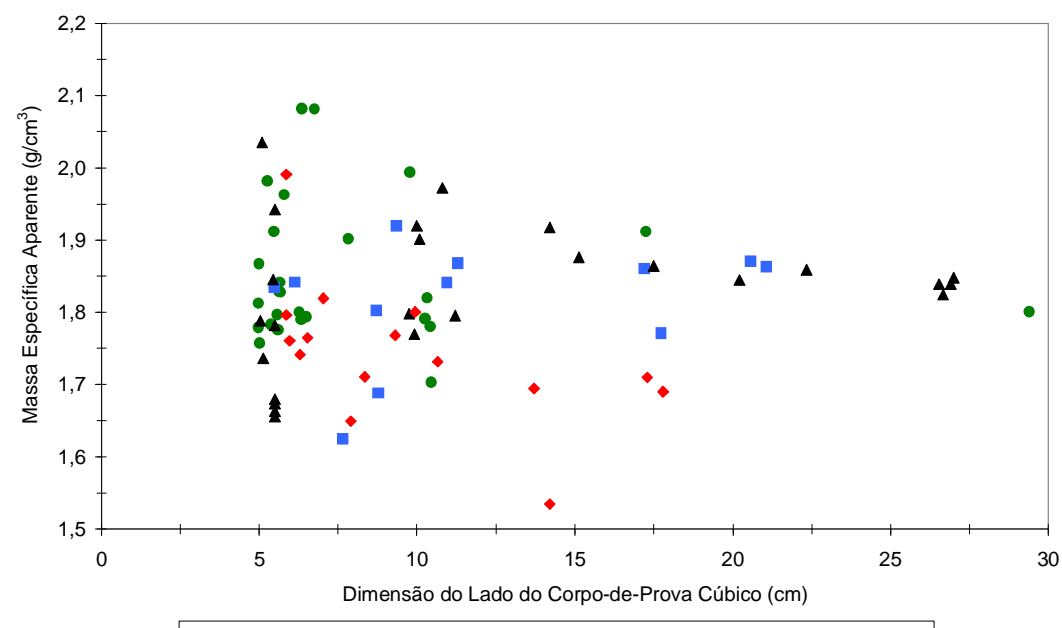

- CPs Cúbicos - P1 a CPs Cúbicos - P2 \ CPs Cúbicos - P3 • CPs Cúbicos - P4

Figura 4.5 - Resultados das determinações da massa específica aparente, para os diferentes tamanhos de corpos-de-prova ensaiados. 


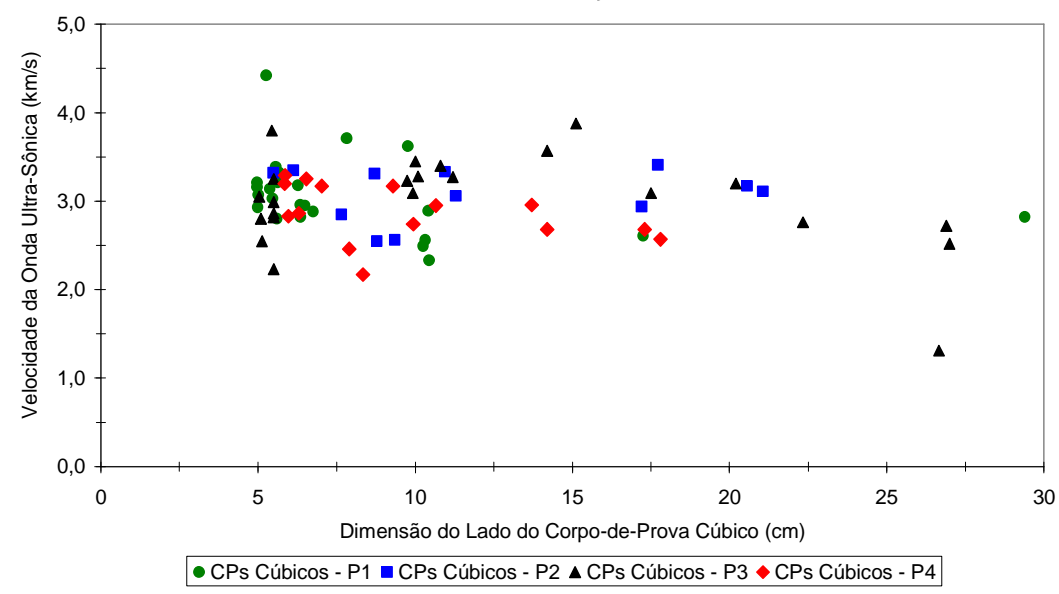

Figura 4.6a - Resultados das determinações da velocidade de propagação da onda ultrasônica (onda P), para os diferentes tamanhos de corpos-de-prova ensaiados.

Velocidade da Onda Ultra-Sônica na Direção da PROFUNDIDADE - Paralela à Estratificação -

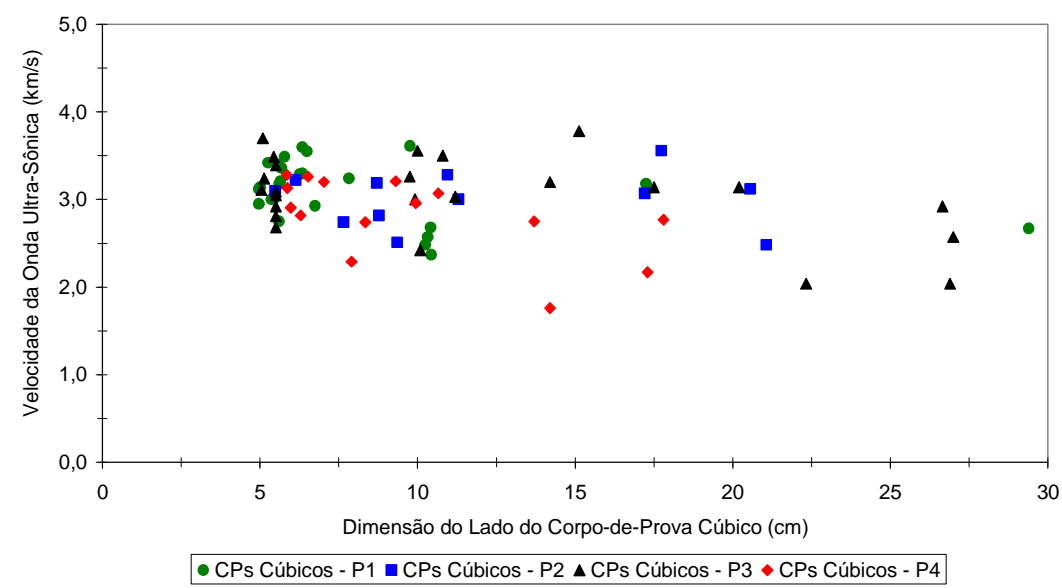

Figura 4.6b - Resultados das determinações da velocidade de propagação da onda ultrasônica (onda P), para os diferentes tamanhos de corpos-de-prova ensaiados.

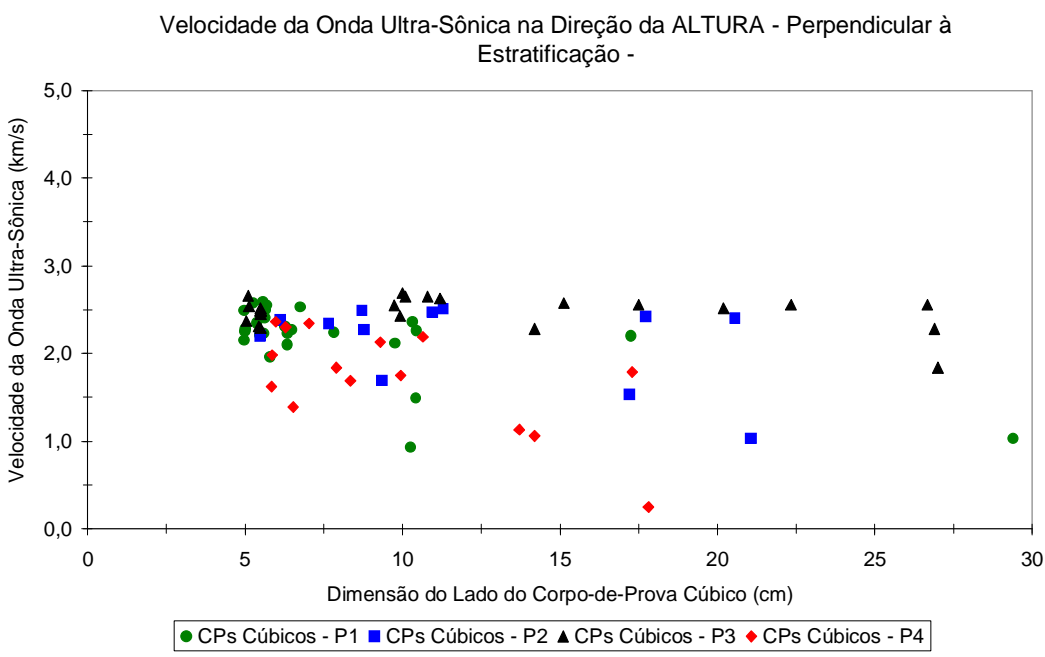

Figura 4.6c - Resultados das determinações da velocidade de propagação da onda ultrasônica (onda P), para os diferentes tamanhos de corpos-de-prova ensaiados. 
Curvas tensão x deformação obtidas com carvão da camada Bonito - Pontos 1 e 4.

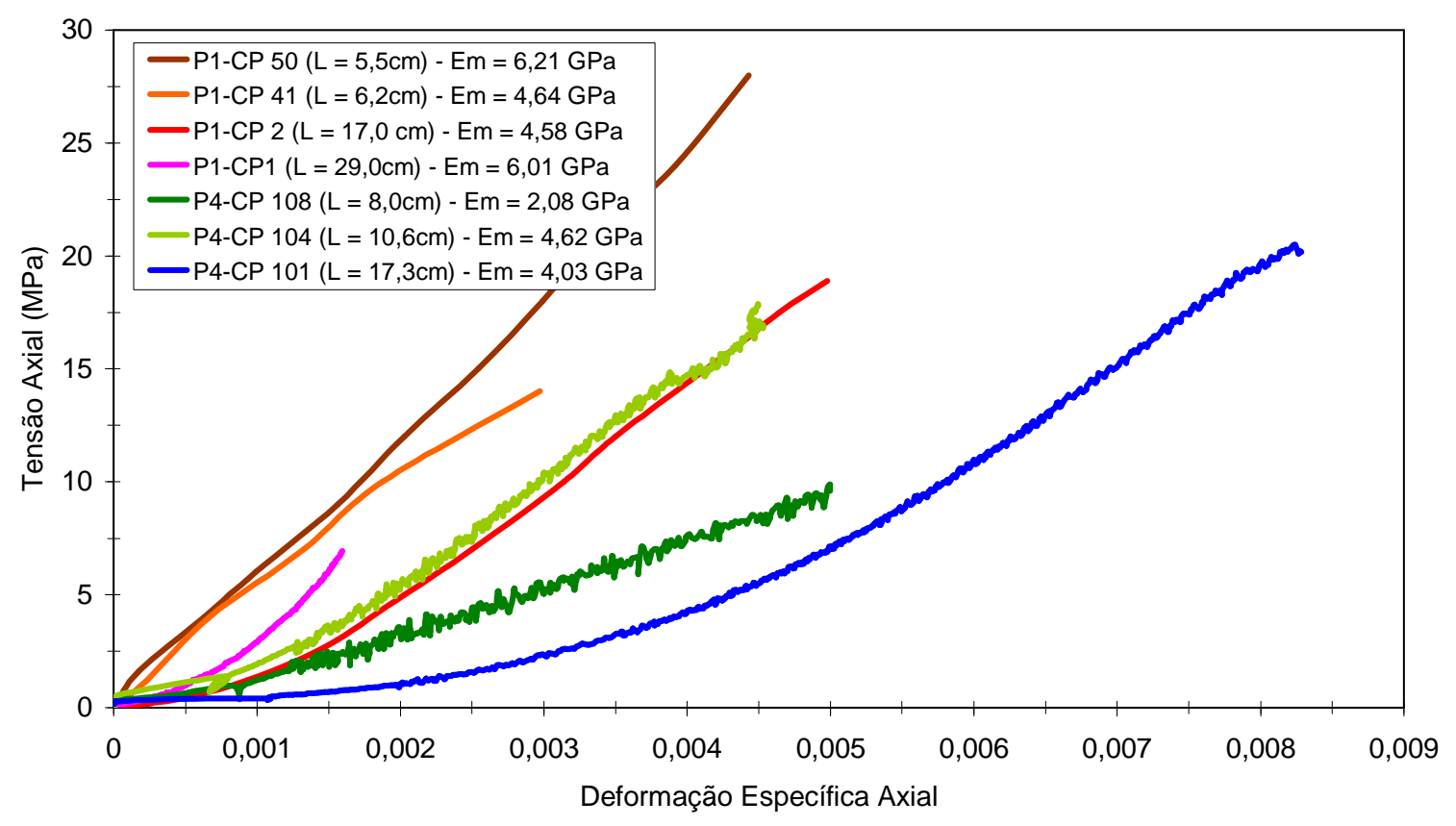

Figura 4.7a - Curvas "tensão x deformação" típicas obtidas em ensaios com amostras provenientes dos pontos de amostragem 1 e 4, em corpos-de-prova com diferentes tamanhos - Carregamento na direção perpendicular à estratificação da camada.

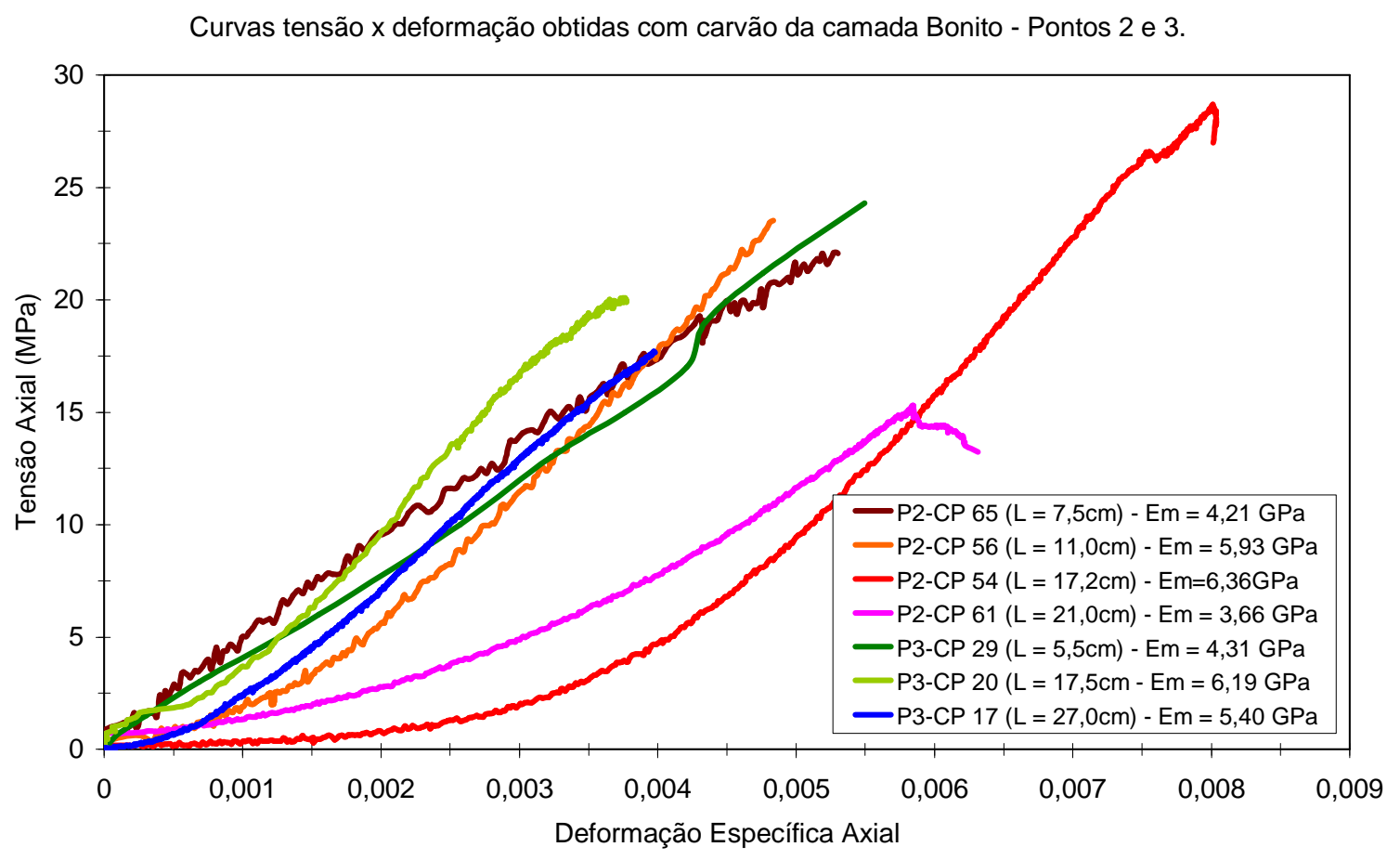

Figura 4.7b - Curvas "tensão $x$ deformação" típicas obtidas em ensaios com amostras provenientes dos pontos de amostragem 2 e 3 , em corpos-de-prova com diferentes tamanhos - Carregamento na direção perpendicular à estratificação da camada. 


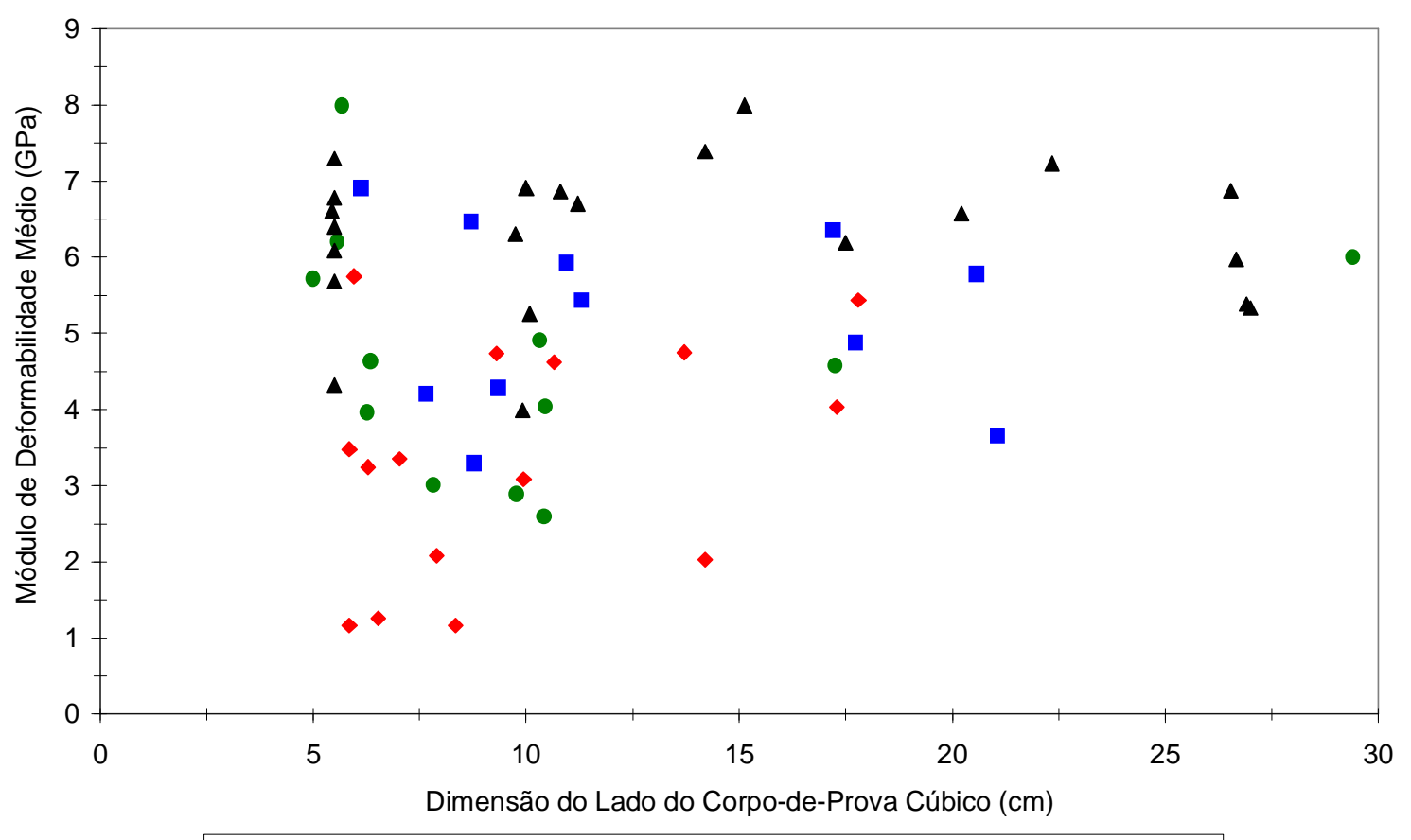

- CPs Cúbicos - P1 •CPs Cúbicos - P2 ^ CPs Cúbicos - P3 • CPs Cúbicos - P4

Figura 4.8 - Resultados das determinações do módulo de deformabilidade médio na direção perpendicular à estratificação da camada, para os diferentes tamanhos de corpos-de-prova ensaiados.

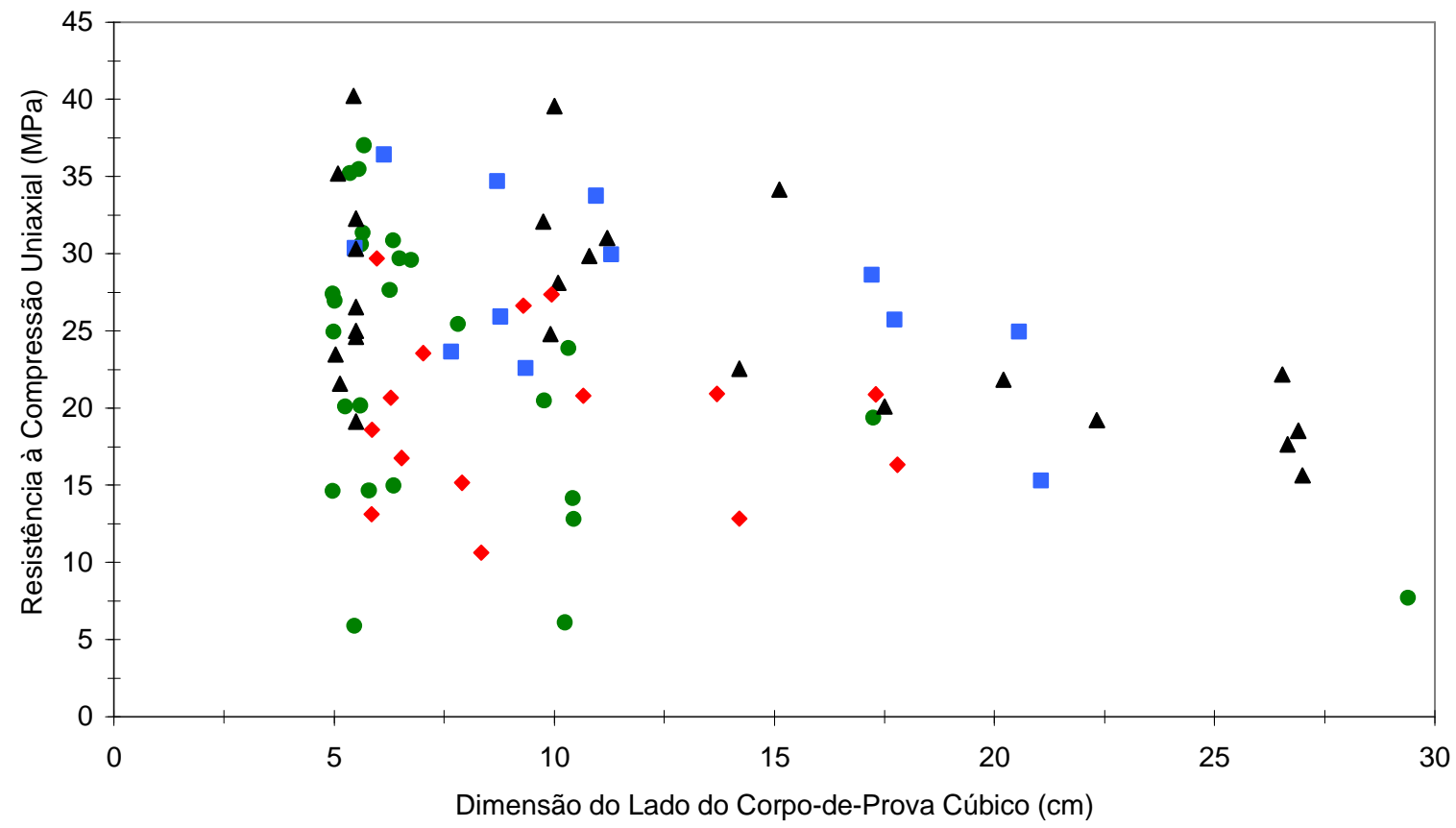

- CPs Cúbicos - P1 — CPs Cúbicos - P2 ^ CPs Cúbicos - P3 • CPs Cúbicos - P4

Figura 4.9 - Resultados das determinações da resistência à compressão uniaxial, determinada na direção perpendicular à estratificação da camada, para os diferentes tamanhos de corpos-de-prova ensaiados. 


\subsubsection{Discussão dos Resultados dos Ensaios para Determinação do Efeito Escala na Resistência à Compressão Uniaxial no Carvão da Camada Bonito - Mina Fontanella}

A avaliação qualitativa e quantitativa dos resultados obtidos para as diversas propriedades físicas e mecânicas estudadas mostra alguns aspectos bastante claros, os quais são discutidos a seguir.

\section{Teor de cinzas}

O teor de cinzas (Figura 4.4) e a massa específica aparente (Figura 4.5) não apresentam nenhuma correlação com o tamanho dos corpos-de-prova, embora seja visível a dispersão bem maior de ambas as variáveis nos espécimens de menor dimensão. Isso se deve à presença de inclusões de outros materiais (piritas, carbonatos) e a intercalações de material estéril (siltitos) com camadas de carvão. Nos corpos-de-prova de maiores dimensões essa sucessão de camadas é bem representada, enquanto nos de menor dimensão, ora pode predominar uma composição mais siltosa, ora uma composição mais carbonosa. Esse comportamento parece independer do ponto de amostragem na Mina Fontanella.

De outra parte, como era de se esperar, existe uma boa correlação entre esses dois índices, conforme Figura 4.10. Os dados circundados pela elipse estão associados a corpos-de-prova (CPs 34, 39 a 47, 55, 63 e 114 - ver códigos de descrição) com grande quantidade de pirita, a qual aumenta fortemente o valor da massa específica aparente, mascarando a influência do teor de cinzas.

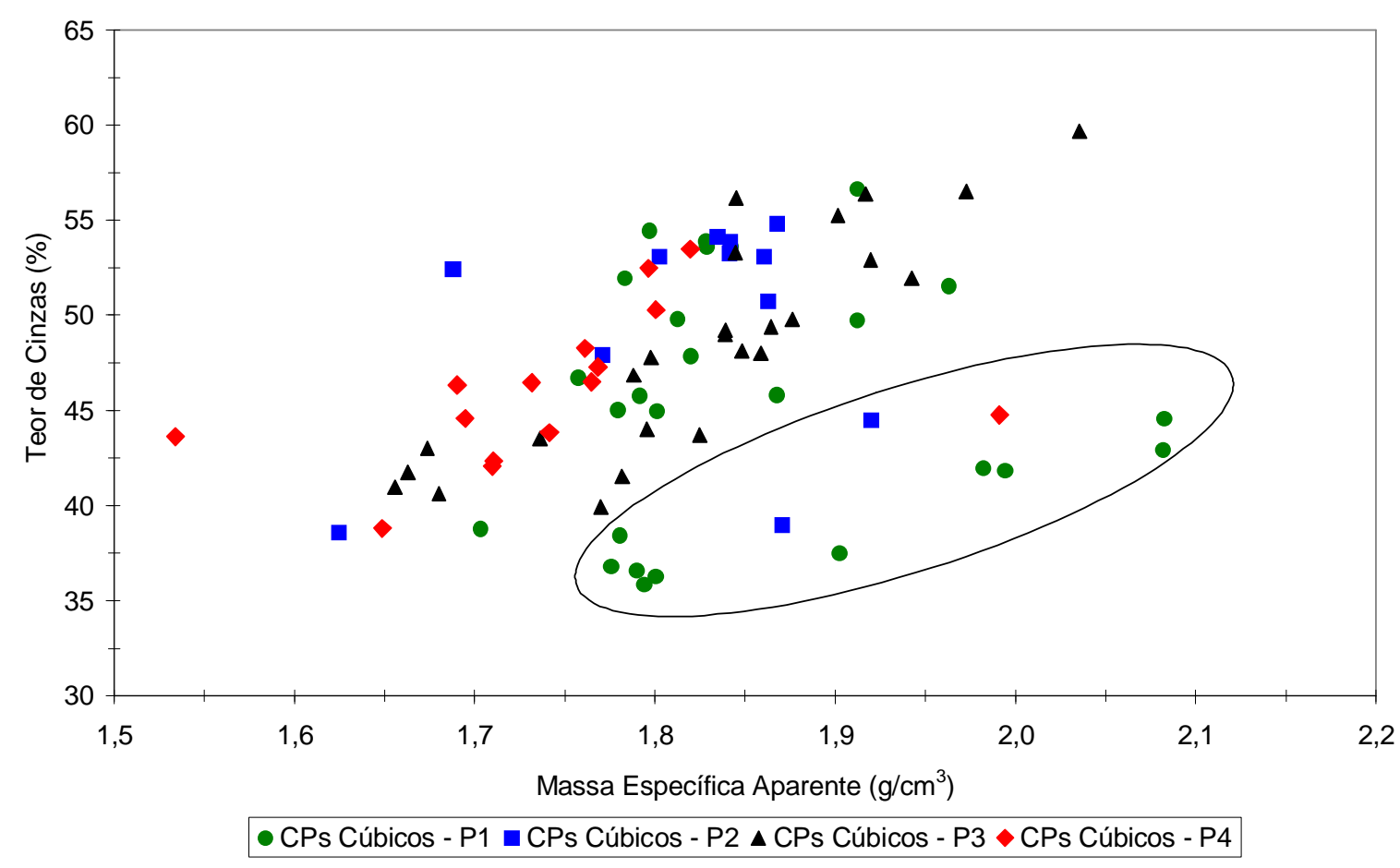

Figura 4.10 - Relação entre o teor de cinzas e a massa específica aparente, para corposde-prova cúbicos de carvão de diferentes tamanhos. 


\section{Velocidade de propagação da onda ultra-sônica}

A velocidade ultra-sônica mostrou-se fortemente influenciada pelas fraturas presentes nos corpos-de-prova, porém, de forma variada dependendo da direção de medição. A velocidade medida na direção perpendicular aos planos de estratificação do carvão (Figura 4.6c) se mostrou bem menor, sendo, na média, cerca de $30 \%$ inferior às velocidades medidas nas outras duas direções paralelas à estratificação (Figuras 4.6a e 4.6b). Isso pode ser explicado pelo fato de que a onda que se propaga na direção perpendicular aos planos de estratificação do carvão, sempre sofre a atenuação dessas descontinuidades. Como esses planos se repetem com uma freqüência aproximadamente constante, a atenuação independe da dimensão do corpo-de-prova. Já as ondas que viajam nas direções paralelas aos planos de estratificação (na direção da largura ou da profundidade), sofrem a atenuação quase que exclusivamente das fraturas perpendiculares ou inclinadas em relação aos planos da estratificação.

Os resultados apresentados na forma de diagramas de caixas da Figura 4.11 mostram bem esse comportamento. Nesta representação, os dados estão divididos em quatro áreas de igual freqüência. A caixa retangular engloba a metade central dos valores. No interior da caixa o símbolo ( $\square$ ) indica o valor da mediana da amostra. A linha vertical que parte da extremidade inferior da caixa, se estende do primeiro quartil até o menor valor situado dentro de 1,5 vezes o intervalo interquartil. A linha vertical que parte da extremidade superior da caixa, se estende do terceiro quartil até o maior valor situado dentro de 1,5 vezes o intervalo interquartil. Valores que se situam entre 1,5 a 3 vezes 0 intervalo interquartil, a partir dos respectivos quartis, são plotados como o símbolo (o) e designados de "outliers". Os valores que se situam além de 3 intervalos interquartil, abaixo do primeiro quartil e acima do terceiro quartil, são plotados com o símbolo (ж) e denominados de "extremos".

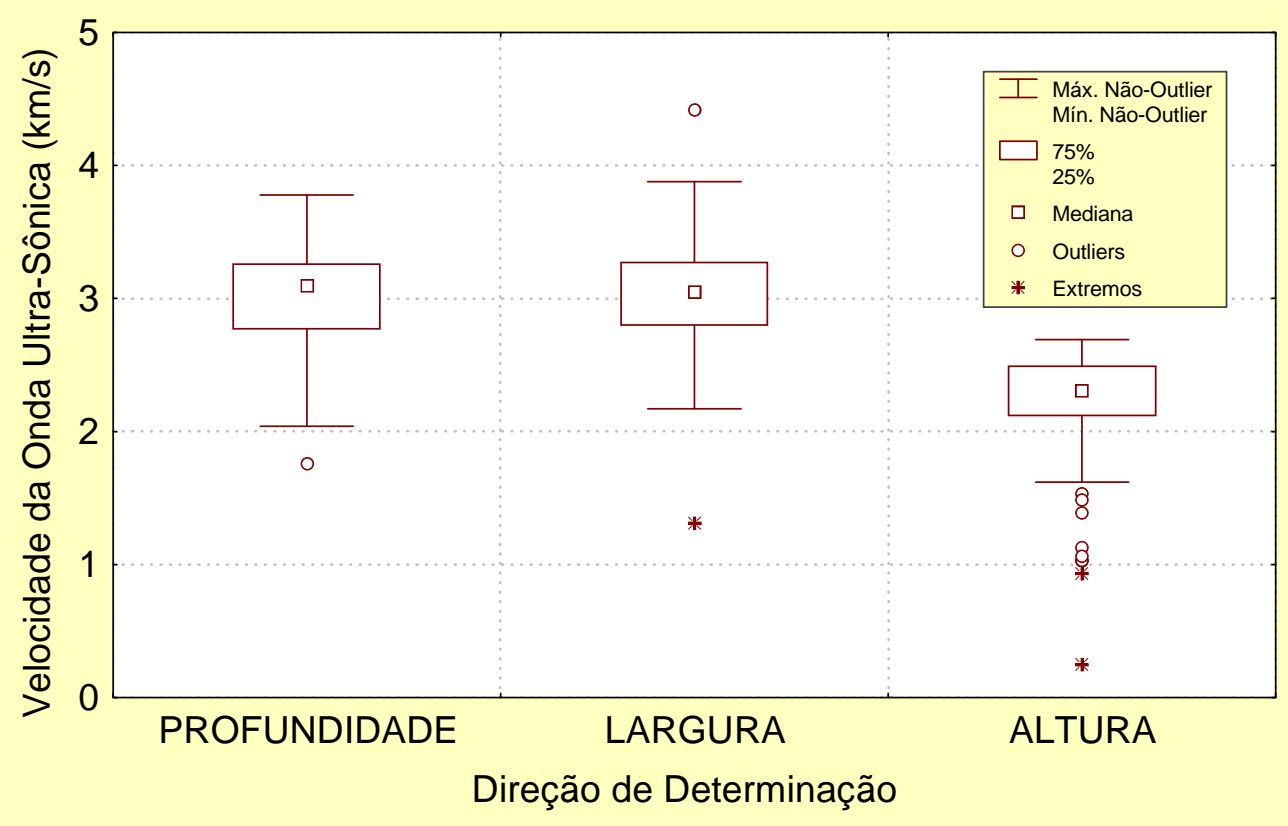

Figura 4.11 - Variação das velocidades de propagação da onda ultra-sônica medidas na direção dos 3 eixos dos corpos-de-prova cúbicos de carvão com dimensões entre $5 \mathrm{~cm}$ e $30 \mathrm{~cm}$. 
A Tabela 4.2 apresenta uma síntese dos parâmetros estatísticos da velocidade de propagação de ondas nas três direções de determinação.

Tabela 4.2 - Estatística descritiva da velocidade de propagação da onda ultra-sônica, medida nas 3 direções dos corpos-de-prova cúbicos de carvão, com dimensões entre $5 \mathrm{~cm}$ e $30 \mathrm{~cm}$.

\begin{tabular}{|l|c|c|c|c|c|c|}
\hline $\begin{array}{c}\text { Direção de } \\
\begin{array}{c}\text { Determinação da } \\
\text { Velocidade }\end{array}\end{array}$ & $\mathrm{N}$ & $\begin{array}{c}\text { Média } \\
(\mathrm{km} / \mathrm{s})\end{array}$ & $\begin{array}{c}\text { Mediana } \\
(\mathrm{km} / \mathrm{s})\end{array}$ & $\begin{array}{c}\text { Mínimo } \\
(\mathrm{km} / \mathrm{s})\end{array}$ & $\begin{array}{c}\text { Máximo } \\
(\mathrm{km} / \mathrm{s})\end{array}$ & $\begin{array}{c}\text { Desvio } \\
\text { Padrão } \\
(\mathrm{km} / \mathrm{s})\end{array}$ \\
\hline $\mathrm{V}_{\text {largura }}$ & 77 & 3,01 & 3,10 & 1,76 & 3,78 & 0,40 \\
\hline $\mathrm{V}_{\text {profundidade }}$ & 77 & 3,01 & 3,05 & 1,31 & 4,42 & 0,43 \\
\hline $\mathrm{V}_{\text {altura }}=\mathrm{V}_{\text {perp }}$ & 77 & 2,17 & 2,31 & 0,25 & 2,69 & 0,48 \\
\hline
\end{tabular}
LEGENDA:

$\mathrm{V}_{\text {largura }}, \mathrm{V}_{\text {profundidade }} \mathrm{e} \mathrm{V}_{\text {altura }}=$ velocidades de propagação da onda ultra-sônica longitudinal nas direções da largura, profundidade (ou paralelas aos planos de estratificação do carvão) e altura (ou perpendicular aos planos de estratificação do carvão) do corpo-de-prova, respectivamente; $\mathrm{N}$ = número de observações.

Quando as velocidades são analisadas em conjunto num mesmo corpo-de-prova, observa-se que em muitos casos a velocidade determinada numa das direções paralelas difere enormemente da outra. Isso ocorre quando os planos das fraturas são aproximadamente paralelos à face do corpo-de-prova paralela à direção de propagação da onda. Aquela onda que se propaga na direção "paralela" à fratura tende a não ser atenuada pela fratura, enquanto aquela que viaja na direção "perpendicular" ou "inclinada" em relação à fratura sofre forte atenuação. As fraturas inclinadas em relação aos planos de estratificação podem atenuar uma ou mesmo as duas velocidades medidas na direção paralela a esses planos, além de impor uma atenuação ainda maior na onda que se propaga na direção perpendicular à estratificação.

Para a determinação da velocidade média na direção paralela à estratificação a velocidade ultra-sônica foi ponderada da seguinte forma:

$$
V_{\text {pond.par }}=\left(V_{\text {larg ura }} * V_{\text {profundidade }}\right)^{0,5}
$$

onde: $V_{\text {pond.par }}=$ velocidade de propagação da onda ultra-sônica longitudinal ponderada nas direções de determinação paralelas aos planos de estratificação do carvão $(\mathrm{km} / \mathrm{s})$.

$$
\begin{aligned}
V_{\text {largura }} \text { e } V_{\text {profundidade }}= & \text { velocidades de propagação da onda ultra-sônica } \\
& \text { longitudinal nas direções da largura e profundidade } \\
& \text { do corpo-de-prova, respectivamente }(\mathrm{km} / \mathrm{s}) .
\end{aligned}
$$

Os resultados da análise estatística descritiva da velocidade da onda ultra-sônica em corpos-de-prova na faixa de tamanho entre $5 \mathrm{~cm}$ e $10 \mathrm{~cm}$ são apresentados na Tabela 4.3.

São observados, também, indicativos do efeito escala nas velocidades de propagação da onda ultra-sônica medidas nas duas direções paralelas aos planos de estratificação do carvão (Figuras 4.6a e 4.6b - velocidades individualizadas).

Já quando a velocidade é ponderada, esse efeito se mostra bem mais visível, o que era de se esperar, uma vez que a probabilidade de haver um maior número de descontinuidades (além dos planos de estratificação) é muito maior à medida 
que o tamanho dos corpos-de-prova aumenta, como mostra a Figura 4.12. O mesmo não pode ser dito sobre a velocidade medida na direção perpendicular aos planos de estratificação (Figura 4.30c).

Tabela 4.3 - Estatística descritiva das velocidades de propagação da onda ultra-sônica medidas nos corpos-de-prova cúbicos de carvão, na faixa de tamanho entre $5 \mathrm{~cm}$ e $10 \mathrm{~cm}$.

\begin{tabular}{|c|c|c|c|c|c|c|c|}
\hline $\begin{array}{c}\text { Local de } \\
\text { Amostragem }\end{array}$ & $\begin{array}{c}\text { Direção de } \\
\text { Determinação } \\
\text { da Velocidade }\end{array}$ & $\mathrm{N}$ & $\begin{array}{c}\text { Média } \\
(\mathrm{km} / \mathrm{s})\end{array}$ & $\begin{array}{c}\text { Mediana } \\
(\mathrm{km} / \mathrm{s})\end{array}$ & $\begin{array}{c}\text { Mínimo } \\
(\mathrm{km} / \mathrm{s})\end{array}$ & $\begin{array}{c}\text { Máximo } \\
(\mathrm{km} / \mathrm{s})\end{array}$ & $\begin{array}{c}\text { Desvio } \\
\text { Padrão } \\
(\mathrm{km} / \mathrm{s})\end{array}$ \\
\hline \multirow{3}{*}{ P1 } & $\mathrm{V}_{\text {perp }}$ & 20 & 2,32 & 2,28 & 1,96 & 2,59 & 0,18 \\
\cline { 2 - 8 } & $\mathrm{V}_{\text {pond.par }}$ & 20 & 3,22 & 3,21 & 2,77 & 3,89 & 0,25 \\
\hline \multirow{2}{*}{ P4 } & $\mathrm{V}_{\text {perp }}$ & 10 & 1,94 & 1,91 & 1,39 & 2,36 & 0,34 \\
\cline { 2 - 8 } & $\mathrm{V}_{\text {pond.par }}$ & 10 & 2,95 & 3,03 & 2,37 & 3,26 & 0,33 \\
\hline \multirow{2}{*}{ P2 } & $\mathrm{V}_{\text {perp }}$ & 6 & 2,23 & 2,31 & 1,69 & 2,49 & 0,28 \\
\cline { 2 - 8 } & $\mathrm{V}_{\text {pond.par }}$ & 6 & 2,96 & 3,00 & 2,54 & 3,28 & 0,33 \\
\hline \multirow{2}{*}{ P3 } & $\mathrm{V}_{\text {perp }}$ & 12 & 2,47 & 2,49 & 2,29 & 2,66 & 0,11 \\
\cline { 2 - 8 } & $\mathrm{V}_{\text {pond.par }}$ & 13 & 3,08 & 3,08 & 2,55 & 3,64 & 0,30 \\
\hline
\end{tabular}

\section{LEGENDA:}

$\mathrm{V}_{\text {perp }}=$ velocidade de propagação da onda ultra-sônica longitudinal na direção perpendicular aos planos de estratificação do carvão; $V_{\text {pond.par }}=$ velocidade de propagação da onda ultra-sônica longitudinal ponderada nas direções de determinação paralelas aos planos de estratificação do carvão; $\mathrm{N}$ = número de observações.

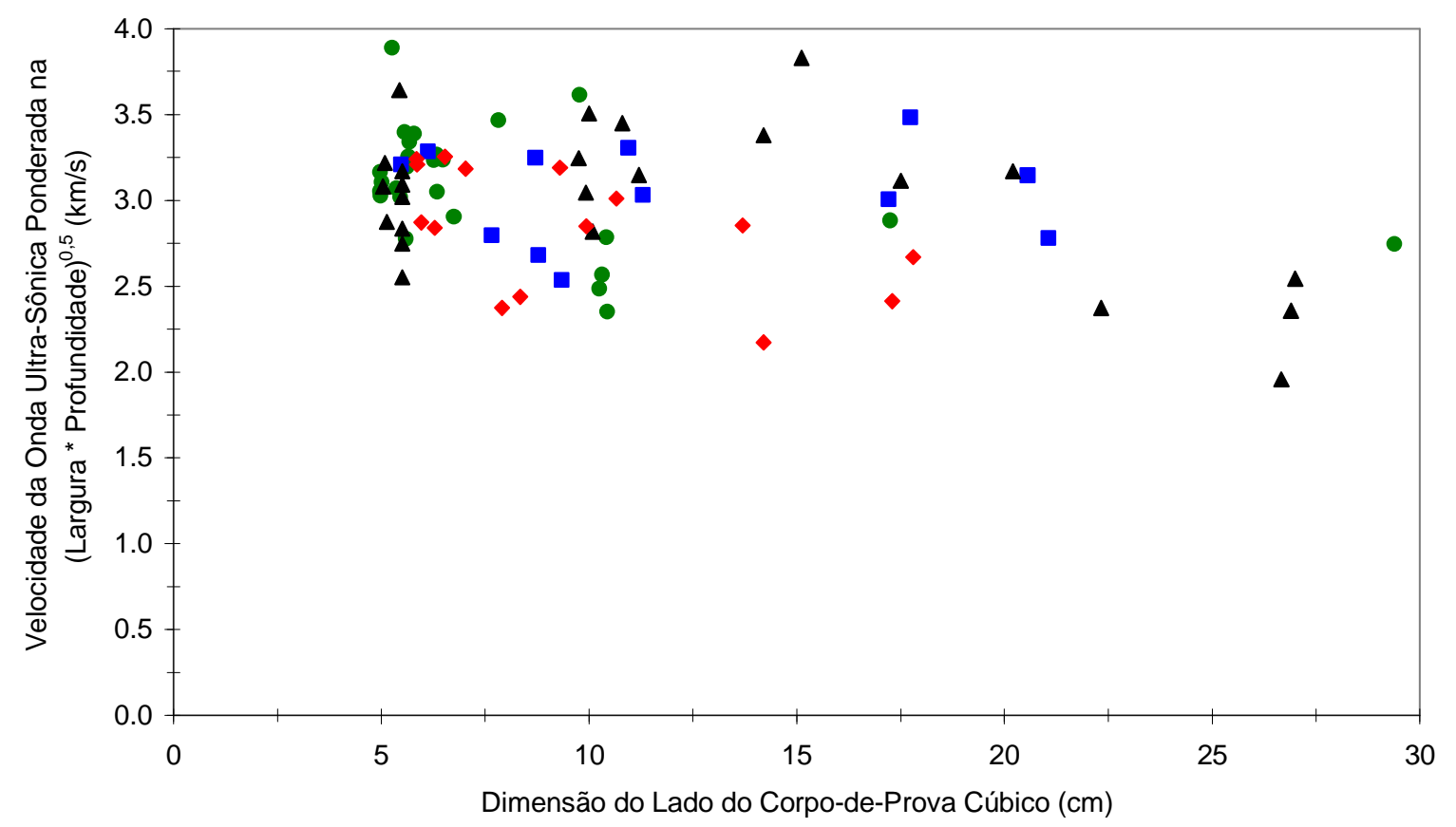

CPs Cúbicos - P1 —CPs Cúbicos - P2 ^ CPs Cúbicos - P3 • CPs Cúbicos - P4

Figura 4.12 - Comportamento da velocidade de propagação da onda ultra-sônica, ponderada nas direções de determinação paralelas aos planos de estratificação, em função do tamanho dos corpos-de-prova. 


\section{Deformabilidade}

Em termos de deformabilidade, não se observa correlação com a variação do tamanho dos corpos-de-prova (Figura 4.8) para os dados dos locais P1 e P4. Os resultados dos locais P2 e P3 mostram uma leve tendência de diminuição com o aumento do tamanho dos corpos-de-prova. Nota-se, de outra parte, que o carvão dos pontos 2 e 3 de amostragem apresenta módulos de deformabilidade mais elevados, além de menor variabilidade, que os dos pontos 1 e 4 . A explicação para esse comportamento pode estar associada ao maior grau de fraturamento do maciço encontrado nos pontos 1 e 4, como será visto adiante, do que se verifica nos pontos 2 e 3 . Outro aspecto a ser observado são as correlações existentes entre o módulo e a velocidade ultra-sônica (ponderada nas 2 direções paralelas à estratificação) e entre o módulo e a resistência à compressão uniaxial.

A relação com a velocidade ultra-sônica ponderada nas duas direções paralela à estratificação do carvão é apresentada na Figura 4.13. Os dados assinalados com as elipses podem ser considerados fora do contexto, porque os corpos-de-prova apresentam algum tipo de anomalia considerável e devidamente identificada. Os dados do ponto 1 de amostragem, identificados pela elipse em verde, e dois dados do ponto 4 (elipse vermelha) possuem elevada quantidade de pirita, além de fraturas fechadas. O resultado é uma velocidade ultra-sônica muito elevada, devido à alta densidade da rocha e à pequena atenuação ocasionada pelas fraturas. Por outro lado, a deformabilidade (e a resistência, como será visto adiante) é fortemente afetada para baixo, devido às fraturas e à presença de inclusões rígidas (nódulos de pirita) dispersos na massa carbonosa. Já os dados indicados pela elipse preta possuem a velocidade ponderada fortemente afetada por fraturas paralelas à direção de carregamento.

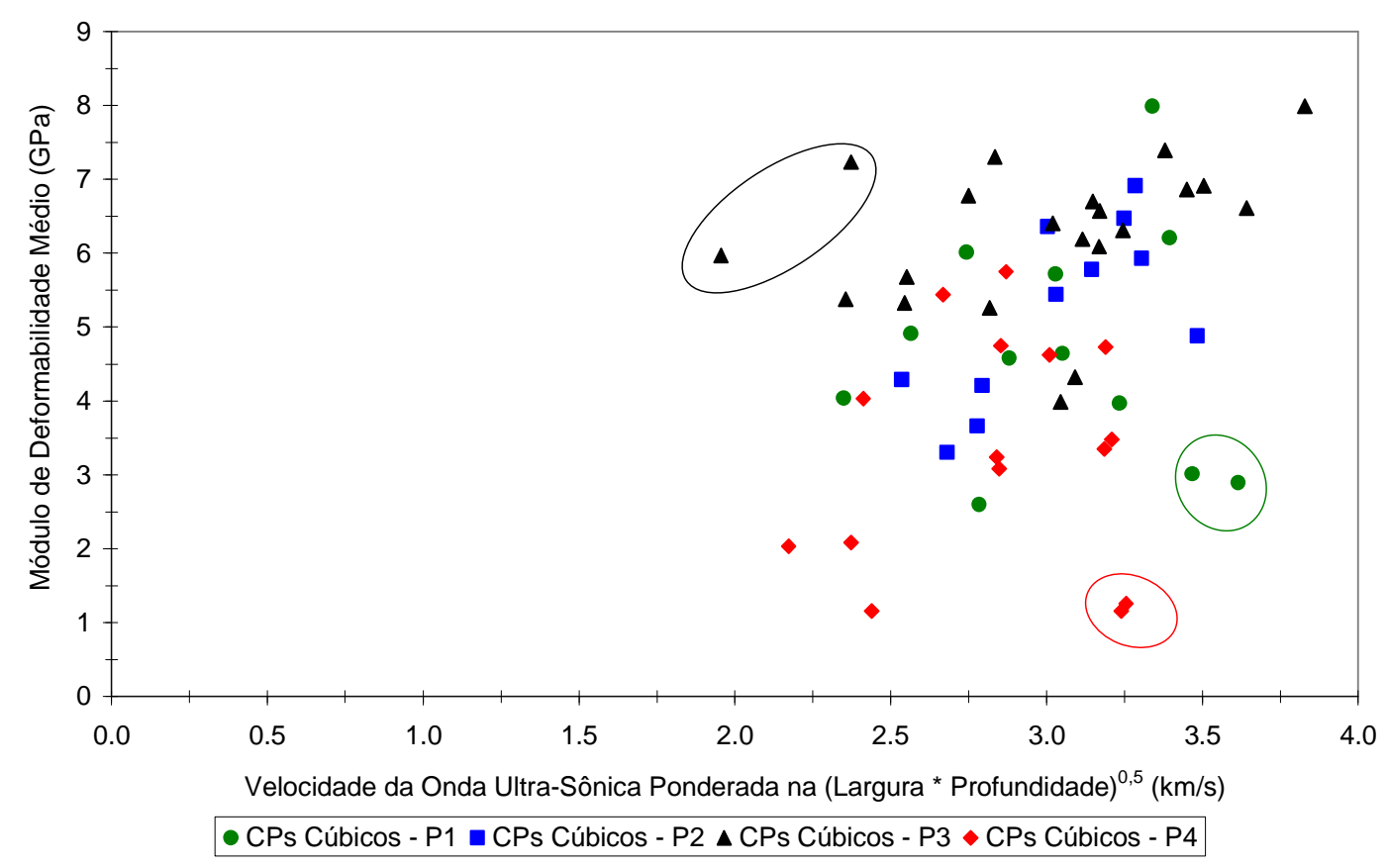

Figura 4.13 - Correlação entre o módulo de deformabilidade médio e a velocidade de propagação da onda ultra-sônica ponderada nas direções de determinação paralelas aos planos de estratificação, para corpos-de-prova cúbicos de carvão de diferentes tamanhos. 
$\mathrm{Na}$ Figura 4.14a pode ser vista a correlação existente entre o módulo de deformabilidade médio e a resistência à compressão uniaxial. $O$ valor indicado pela elipse se refere a um corpo-de-prova com fratura inclinada, sobre a qual ocorreu a ruptura. Notadamente, a resistência foi fortemente influenciada pela presença dessa descontinuidade, o que não ocorreu com o módulo.

O patamar de módulo correspondente a $5 \mathrm{GPa}$, aproximadamente, conforme indicado pela linha tracejada, parece separar bem os grupos de dados dos locais P1-P4 e P2-P3. Para os materiais estudados, a relação média entre o módulo de deformabilidade e a resistência à compressão uniaxial é da ordem de 200, conforme indicado na Figura 4.14b. O baixo coeficiente de correlação pode ser explicado pela heterogeneidade do material ensaiado e, principalmente, pela presença de diferentes tipos de descontinuidades (planos de estratificação perpendiculares ao carregamento, fraturas com orientações diversas), que influenciam de forma específica cada uma das variáveis consideradas.

$\mathrm{Na}$ Tabela 4.4 são apresentados os resultados da estatística descritiva do módulo para os corpos-de-prova na faixa de tamanho entre $5 \mathrm{~cm}$ e $10 \mathrm{~cm}$. Esses mesmos resultados podem ser vistos graficamente nos diagramas de caixas na Figura 4.15 .

\section{Resistência à compressão uniaxial}

Do ponto de vista da resistência à compressão uniaxial, que é o objetivo principal dessa pesquisa, além da correlação com a deformabilidade já observada acima, pelo menos duas outras relações são de fundamental importância dentro dos objetivos desse trabalho: a relação entre a resistência e o tamanho dos corposde-prova (efeito escala) e a relação entre a resistência e a velocidade da onda ultra-sônica.

A Tabela 4.5 apresenta a estatística descritiva da resistência na faixa de tamanho de corpo-de-prova entre $5 \mathrm{~cm}$ e $10 \mathrm{~cm}$, enquanto na Figura 4.16 esses resultados são exibidos através dos diagramas de caixas.

Nas Tabelas 4.6a e 4.6b são apresentados resultados de dois diferentes testes estatísticos de semelhança entre médias. O parâmetro utilizado para comparação foi a resistência obtida nos diferentes locais de amostragem da camada Bonito na Mina Fontanella. Os resultados do teste de intervalos LSD - Least Significant Differences, expressos pelo índice $p$ na Tabela 4.6a, mostram que a resistência do local P4 é diferente da resistência dos locais P2 e P3 (ver valores de $p$ menores que 0,05). O teste de Bonferroni (Tabela 4.6b), por sua vez, mostra que quando os locais de amostragem são tratados indidualmente, somente as amostras dos locais P4 e P3 são diferentes (locais que não pertencem ao mesmo Grupo Homogêneo). Já quando os locais de amostragem são agrupados por proximidade espacial na mina $(\mathrm{P} 1+\mathrm{P} 4$ e $\mathrm{P} 2+\mathrm{P} 3)$, o teste mostra que as resistências médias desses dois grupos são diferentes. 


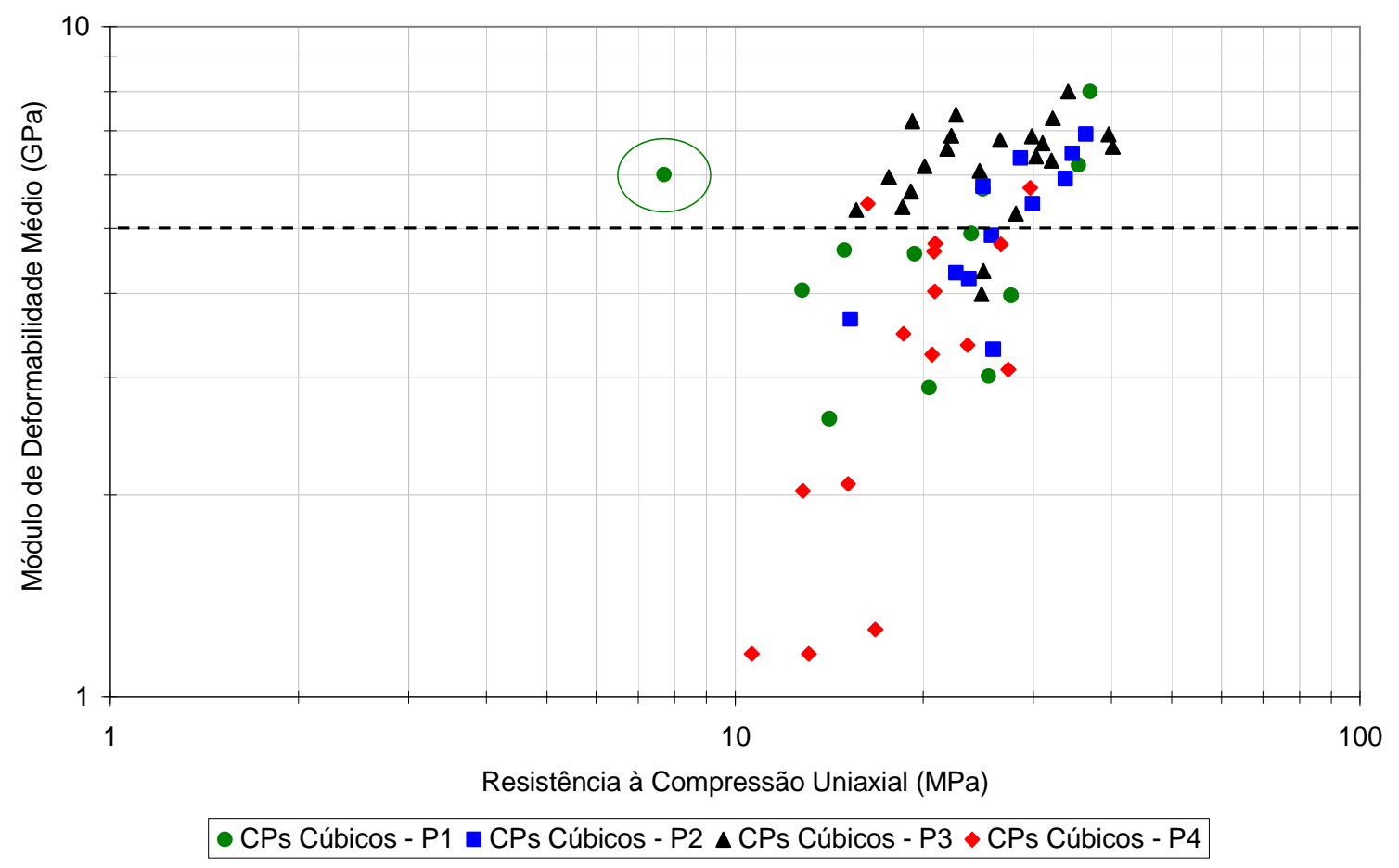

Figura 4.14a - Correlação entre o módulo de deformabilidade médio e a resistência à compressão uniaxial, determinados na direção perpendicular à estratificação da camada, para corpos-de-prova cúbicos de carvão de diferentes tamanhos.

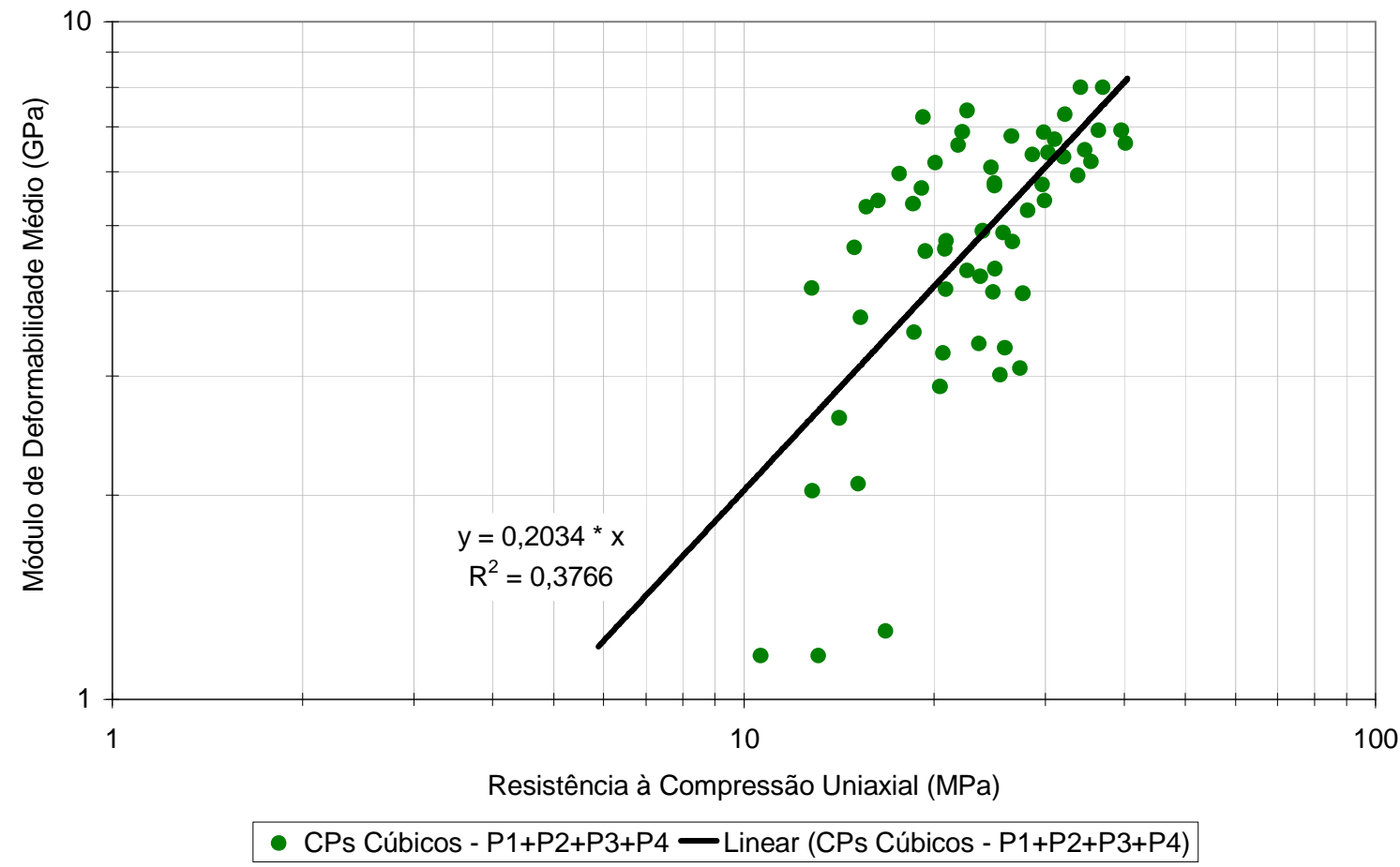

Figura 4.14b - Função ajustada para a correlação entre o módulo de deformabilidade médio e a resistência à compressão uniaxial, determinados na direção perpendicular à estratificação da camada, para corpos-de-prova cúbicos de carvão de diferentes tamanhos - Dados de todos os pontos de amostragem agrupados. 
Tabela 4.4 - Estatística descritiva do módulo de deformabilidade médio em corpos-deprova cúbicos com a dimensão do lado entre $5 \mathrm{~cm}$ a $10 \mathrm{~cm}$.

\begin{tabular}{|c|c|c|c|c|c|c|}
\hline $\begin{array}{c}\text { Local de } \\
\text { Amostragem }\end{array}$ & $\mathrm{N}$ & $\begin{array}{c}\text { Média } \\
(\mathrm{MPa})\end{array}$ & $\begin{array}{c}\text { Mediana } \\
(\mathrm{MPa})\end{array}$ & $\begin{array}{c}\text { Mínimo } \\
(\mathrm{MPa})\end{array}$ & $\begin{array}{c}\text { Máximo } \\
(\mathrm{MPa})\end{array}$ & $\begin{array}{c}\text { Desvio Padrão } \\
(\mathrm{MPa})\end{array}$ \\
\hline $\mathrm{P} 1$ & 7 & 4,92 & 4,64 & 2,89 & 7,99 & 1,85 \\
\hline $\mathrm{P} 4$ & 10 & 2,93 & 3,16 & 1,16 & 5,75 & 1,55 \\
\hline $\mathrm{P} 2$ & 5 & 5,04 & 4,29 & 3,30 & 6,91 & 1,57 \\
\hline $\mathrm{P} 3$ & 10 & 6,04 & 6,36 & 3,99 & 7,30 & 1,09 \\
\hline
\end{tabular}

LEGENDA:

$\mathrm{N}$ = número de ensaios.

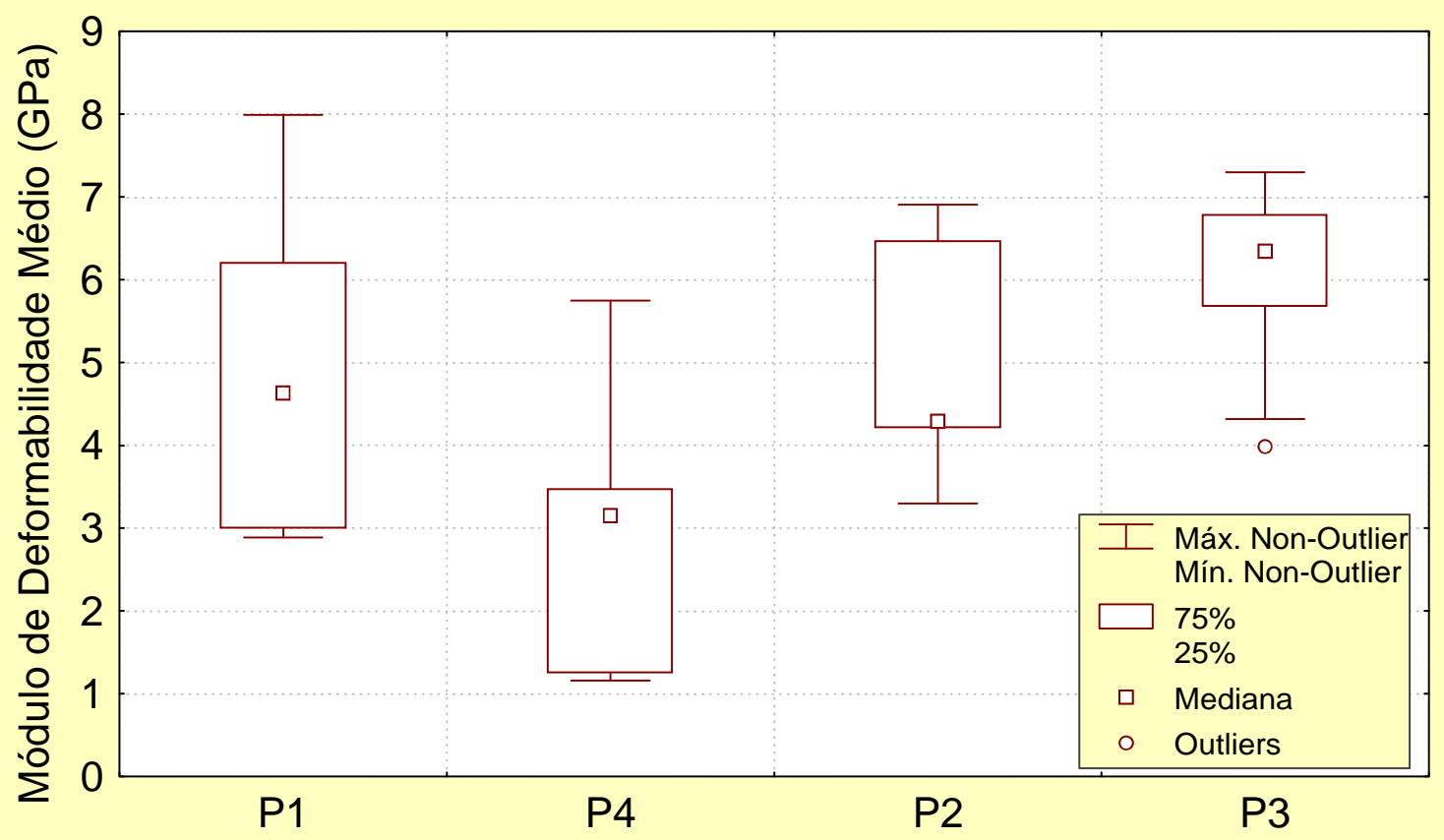

Local de Amostragem

Figura 4.15 - Resultados do módulo de deformabilidade médio em corpos-de-prova cúbicos com a dimensão do lado entre $5 \mathrm{~cm}$ e $10 \mathrm{~cm}$, nos diferentes pontos de amostragem. 
Tabela 4.5 - Estatística descritiva da resistência à compressão uniaxial em corpos-deprova cúbicos com a dimensão do lado entre $5 \mathrm{~cm}$ a $10 \mathrm{~cm}$.

\begin{tabular}{|c|c|c|c|c|c|c|}
\hline $\begin{array}{c}\text { Local de } \\
\text { Amostragem }\end{array}$ & $\mathrm{N}$ & $\begin{array}{c}\text { Média } \\
(\mathrm{MPa})\end{array}$ & $\begin{array}{c}\text { Mediana } \\
(\mathrm{MPa})\end{array}$ & $\begin{array}{c}\text { Mínimo } \\
(\mathrm{MPa})\end{array}$ & $\begin{array}{c}\text { Máximo } \\
(\mathrm{MPa})\end{array}$ & $\begin{array}{c}\text { Desvio Padrão } \\
(\mathrm{MPa})\end{array}$ \\
\hline $\mathrm{P} 1$ & 20 & 25,15 & 27,17 & 5,88 & 37,02 & 8,18 \\
\hline P4 & 10 & 20,22 & 19,61 & 10,64 & 29,69 & 6,46 \\
\hline P2 & 6 & 28,92 & 28,11 & 22,57 & 36,42 & 5,80 \\
\hline P3 & 13 & 28,82 & 26,53 & 19,11 & 40,23 & 6,71 \\
\hline
\end{tabular}

LEGENDA:

$\mathrm{N}=$ número de ensaios.

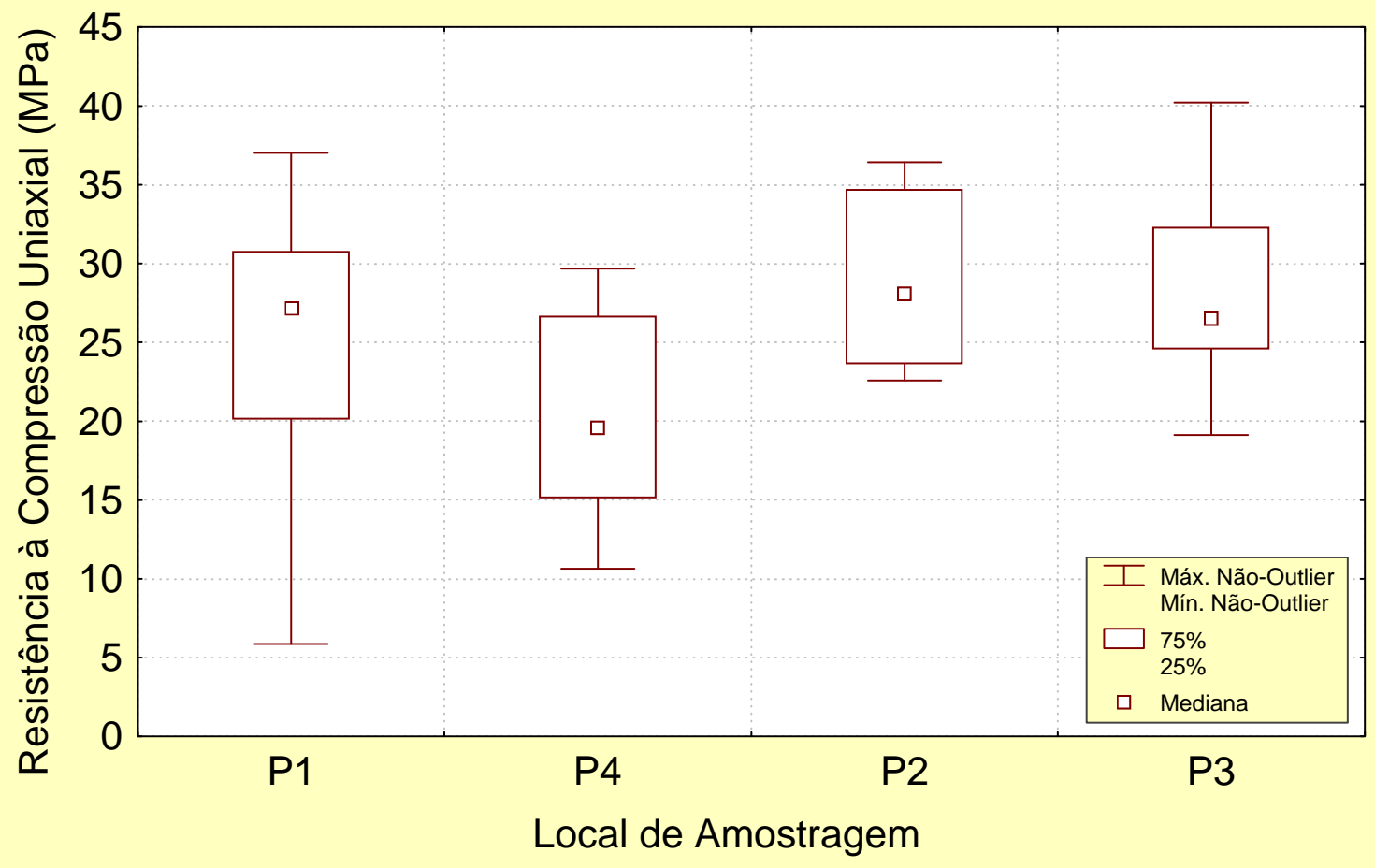

Figura 4.16 - Resultados de resistência à compressão uniaxial de corpos-de-prova cúbicos com a dimensão do lado entre $5 \mathrm{~cm}$ e $10 \mathrm{~cm}$, nos diferentes pontos de amostragem. 
Tabela 4.6a - Matriz de $p$ proveniente da aplicação de teste de semelhança entre médias (duas a duas) da resistência à compressão uniaxial de corpos-de-prova cúbicos com a dimensão do lado entre $5 \mathrm{~cm}$ a $10 \mathrm{~cm}$ - teste LSD -.

\begin{tabular}{|c|c|c|c|c|}
\cline { 2 - 5 } \multicolumn{1}{c|}{} & \multicolumn{4}{c|}{$p$} \\
\hline Local de Amostragem & P1 & P4 & P2 & P3 \\
\hline P1 & - & - & - & - \\
\hline P4 & 0,0837 & - & - & - \\
\hline P2 & 0,2685 & $\mathbf{0 , 0 2 4 4}$ & - & - \\
\hline P3 & 0,1611 & $\mathbf{0 , 0 0 7 0}$ & 0,9777 & - \\
\hline
\end{tabular}

Nota: valores em negrito significam amostras diferentes ao nível de significância de $5 \%$.

Tabela 4.6b - Resultados da aplicação de teste de comparação múltipla de médias para a resistência à compressão uniaxial de corpos-de-prova cúbicos com a dimensão do lado entre $5 \mathrm{~cm}$ a $10 \mathrm{~cm}$ - método de Bonferroni ao nível de confiança de $95 \%$ -

\begin{tabular}{|c|c|c|c|}
\hline \multicolumn{4}{|c|}{ Comparativo de médias entre os locais de amostragem individualizados: } \\
\hline Local de Amostragem & $\begin{array}{l}\text { Número de } \\
\text { Observações }\end{array}$ & $\begin{array}{l}\text { Média } \\
(\mathrm{MPa})\end{array}$ & $\begin{array}{c}\text { Grupos } \\
\text { Homogêneos }\end{array}$ \\
\hline P4 & 10 & 20,22 & $\mathbf{X}$ \\
\hline P1 & 20 & 25,15 & $\mathbf{X} \mathbf{X}$ \\
\hline $\mathrm{P} 2$ & 6 & 28,92 & $\mathbf{X X}$ \\
\hline P3 & 13 & 28,82 & $\mathbf{x}$ \\
\hline Contraste & Diferença & \multicolumn{2}{|c|}{ +/- Limites } \\
\hline $\mathrm{P} 1-\mathrm{P} 2$ & $-3,7745$ & \multicolumn{2}{|c|}{9,2976} \\
\hline P1 - P3 & $-3,6764$ & \multicolumn{2}{|c|}{7,1162} \\
\hline $\mathrm{P} 1-\mathrm{P} 4$ & 4,9305 & \multicolumn{2}{|c|}{7,7361} \\
\hline P2 - P3 & 0,0981 & \multicolumn{2}{|c|}{9,8584} \\
\hline $\mathrm{P} 2-\mathrm{P} 4$ & 8,7050 & \multicolumn{2}{|c|}{10,3148} \\
\hline P3 - P4 & ${ }^{\#} 8,6069$ & \multicolumn{2}{|c|}{8,4017} \\
\hline \multicolumn{4}{|c|}{ Comparativo de médias entre os locais de amostragem agrupados: } \\
\hline Local de Amostragem & $\begin{array}{l}\text { Número de } \\
\text { Observações }\end{array}$ & $\begin{array}{l}\text { Média } \\
(\mathrm{MPa})\end{array}$ & $\begin{array}{c}\text { Grupos } \\
\text { Homogêneos }\end{array}$ \\
\hline $\mathrm{P} 1+\mathrm{P} 4$ & 30 & 23,51 & $\mathbf{X}$ \\
\hline $\mathrm{P} 2+\mathrm{P} 3$ & 19 & 28,86 & $\mathbf{x}$ \\
\hline Contraste & Diferença & \multicolumn{2}{|c|}{ +/- Limites } \\
\hline $\mathrm{P} 1+\mathrm{P} 4-\mathrm{P} 2+\mathrm{P} 3$ & ${ }^{\#}-5,3509$ & \multicolumn{2}{|c|}{4,3183} \\
\hline
\end{tabular}

\# denota diferença estatisticamente significativa entre as médias dos locais de amostragem para o nível de confiança de $95 \%$. 
Os resultados estatísticos e a observação do conjunto de dados de resistência em função do tamanho dos corpos-de-prova, conforme Figura 4.9, permitem os seguintes comentários:

- os resultados de resistência dos pontos de amostragem 1 e 4 são geralmente inferiores aos dos pontos 2 e 3 , em praticamente todas as dimensões de corpos-de-prova;

- a resistência varia entre $5 \mathrm{MPa}$ e $40 \mathrm{MPa}$ na faixa de tamanho dos corpos-deprova entre $5 \mathrm{~cm}$ e $10 \mathrm{~cm}$. Os testes comparativos entre as médias de resistência, nos diferentes pontos amostrados, indicam que existe diferença entre os locais P1 e P4 (especialmente o P4) e os locais P2 e P3.

Tendo presente as limitações de quantidade de ensaios no local de amostragem $\mathrm{P} 2$, os resultados indicativos de semelhança de deformabilidade e resistência entre pontos de amostragem, obtidos a partir das análises estatísticas descritiva e testes de semelhança entre as médias de resistência, as características estruturais da camada de carvão observadas nos diferentes pontos de amostragem (ver Item 4.4 adiante) e a posição espacial dos locais amostrados, a análise do efeito escala na resistência do carvão Bonito da Mina Fontanella foi feita considerando os dados reunidos da seguinte forma:

- agrupados em dois subconjuntos: um composto pelos dados dos pontos 1 e $4 \mathrm{e}$ outro pelos dados dos pontos 2 e 3 ;

- um único conjunto com os dados de todos os pontos de amostragem.

$\mathrm{Na}$ Tabela 4.7 podem ser vistos os resultados da aplicação dos diferentes modelos de regressão utilizados nas análises do efeito escala na resistência à compressão uniaxial. Essas análises, especificamente, foram realizadas com o auxílio do software CurveExpert 1.38. Para cada conjunto de dados deve ser notado que ao modelo "potência" foi adicionada uma análise de regressão em que a constante "b" foi definida com igual a 0,5 . Esse modelo corresponde à proposta de GADDY (1956) para expressar o efeito escala da camada de carvão Pittsburgh dos EUA.

Os parâmetros indicadores do ajuste do modelo aos dados são assim definidos pelo software:

Erro Padrão, $S=\sqrt{\frac{\sum_{i=1}^{n_{\text {tadase }}}\left(y_{i}-f\left(x_{i}\right)\right)^{2}}{n_{\text {dados }}-n_{\text {parâmetros }}}}$

Coeficiente de correlação, $r=\sqrt{\frac{S_{t}-S_{r}}{S_{t}}}$

onde $\left.S_{t}=\sum_{i=1}^{n_{\text {tadas }}(}\left(\bar{y}-y_{i}\right)\right)^{2}$

e $S_{r}=\sum_{i=1}^{n_{\text {nadase }}}\left(y_{i}-f\left(x_{i}\right)\right)^{2}$ 
Tabela 4.7 - Resultados das análises de regressão para a determinação do efeito escala na resistência do carvão da camada Bonito, na Mina Fontanella.

\begin{tabular}{|c|c|c|c|c|c|}
\hline $\begin{array}{c}\text { Local de } \\
\text { Amostragem }\end{array}$ & Modelo de Regressão & a & $b$ & $\begin{array}{c}\text { Coeficiente de } \\
\text { Correlação, } \\
\text { r }\end{array}$ & $\begin{array}{c}\text { Erro } \\
\text { Padrão, } \\
\text { S }\end{array}$ \\
\hline \multirow{6}{*}{$P 1+P 4$} & \multirow{2}{*}{$\begin{array}{c}\text { Potência } \\
\sigma_{\text {c.cubo }}=a^{*} L^{b}\end{array}$} & 58,333 & $-0,5^{\#}$ & - & 7,43 \\
\hline & & 46,731 & $-0,384$ & 0,40 & 7,47 \\
\hline & $\begin{array}{l}\text { Potência modificado } \\
\qquad \sigma_{\text {c.cubo }}=a^{*} b^{L}\end{array}$ & 29,433 & 0,963 & 0,40 & 7,48 \\
\hline & $\begin{array}{c}\text { Exponencial } \\
\sigma_{\text {c.cubo }}=a * e^{\left(b^{*} L\right)}\end{array}$ & 29,433 & $-0,038$ & 0,40 & 7,48 \\
\hline & $\begin{array}{l}\text { Exponencial modificado } \\
\sigma_{c . c u b o}=a^{*} e^{(b / L)}\end{array}$ & 13,775 & 3,137 & 0,39 & 7,53 \\
\hline & $\begin{array}{c}\text { Recíproco } \\
\sigma_{\text {c.cubo }}=1 /(a * L+b)\end{array}$ & 0,0020 & 0,0303 & 0,40 & 7,47 \\
\hline \multirow{6}{*}{$\mathrm{P} 2+\mathrm{P} 3$} & \multirow{2}{*}{$\begin{array}{c}\text { Potência } \\
\sigma_{\text {c.cubo }}=a^{*} L^{b}\end{array}$} & 79,689 & $-0,5^{\#}$ & - & 7,26 \\
\hline & & 41,800 & $-0,193$ & 0,47 & 5,81 \\
\hline & $\begin{array}{l}\text { Potência modificado } \\
\sigma_{\text {c.cubo }}=a^{*} b^{L}\end{array}$ & 33,391 & 0,981 & 0,55 & 5,51 \\
\hline & $\begin{array}{c}\text { Exponencial } \\
\sigma_{\text {c.cubo }}=a^{*} e^{\left(b^{*} L\right)}\end{array}$ & 33,391 & $-0,019$ & 0,55 & 5,51 \\
\hline & $\begin{array}{l}\text { Exponencial modificado } \\
\qquad \sigma_{c . \text { cubo }}=a^{*} e^{(b / L)}\end{array}$ & 22,471 & 1,524 & 0,38 & 6,09 \\
\hline & $\begin{array}{c}\text { Recíproco } \\
\sigma_{\text {c.cubo }}=1 /(a * L+b)\end{array}$ & na & na & na & na \\
\hline \multirow{6}{*}{$\begin{array}{l}\text { Todos os } \\
\text { dados } \\
\text { agrupados }\end{array}$} & \multirow{2}{*}{$\begin{array}{c}\text { Potência } \\
\sigma_{c . c u b o}=a^{*} L^{b}\end{array}$} & 67,273 & $-0,5^{\#}$ & - & 8,21 \\
\hline & & 35,475 & $-0,181$ & 0,29 & 7,49 \\
\hline & $\begin{array}{c}\text { Potência modificado } \\
\sigma_{c . c u b o}=a^{*} b^{L}\end{array}$ & 28,384 & 0,983 & 0,31 & 7,43 \\
\hline & $\begin{array}{c}\text { Exponencial } \\
\sigma_{\text {c.cubo }}=a^{*} e^{\left(b^{*} L\right)}\end{array}$ & 28,384 & $-0,017$ & 0,31 & 7,43 \\
\hline & $\begin{array}{c}\text { Exponencial modificado } \\
\sigma_{c . c u b o}=a^{*} e^{(b / L)}\end{array}$ & 19,694 & 1,538 & 0,26 & 7,55 \\
\hline & $\begin{array}{c}\text { Recíproco } \\
\sigma_{\text {c.cubo }}=1 /(a * L+b)\end{array}$ & 0,0007 & 0,0346 & 0,31 & 7,44 \\
\hline
\end{tabular}

\section{LEGENDA:}

$\sigma_{\text {c.cubo }}=$ resistência à compressão uniaxial de corpo-de-prova cúbico com carregamento na direção perpendicular aos planos de estratificação do carvão (MPa);

$\mathrm{L}=$ dimensão do lado do corpo-de-prova cúbico $(\mathrm{cm})$;

na = não aplicado;

\# coeficiente proposto por GADDY (1956) para o carvão da camada Pittsburgh dos EUA. 
$\mathrm{Na}$ relação entre a resistência à compressão uniaxial e a velocidade de propagação da onda ultra-sônica, conforme visto na Figura 4.17a, uma parcela dos dados possui explicação plausível para a sua localização relativamente fora dos padrões (dados envolvidos pela elipse pontilhada). Nesses corpos-de-prova, havia a presença de fraturas paralelas ou inclinadas em relação à direção de carregamento, além de muita pirita em alguns deles. Esses aspectos tendem a afetar de forma diferenciada a resistência e a velocidade sônica. Fraturas localizadas abaixo do meio da face do corpo-de-prova ou fraturas fechadas (paralelas ou inclinadas) praticamente não afetam a velocidade sônica, porém, interferem negativamente na resistência.

Por outro lado, a velocidade do corpo-de-prova identificado pela elipse cheia sofreu forte influência das fraturas. Como são fraturas paralelas à direção da carga a resistência foi afetada em menor proporção. Nos ensaios que apresentaram baixíssima resistência (parte inferior da elipse tracejada), foi notável a influência das fraturas inclinadas pré-existentes nos corpos-de-prova. Esse conjunto de aspectos explica a grande dispersão dos dados nessa relação.

$\mathrm{Na}$ Figura $4.17 \mathrm{~b}$ é feita uma tentativa de correlacionar essas duas variáveis estudadas em laboratório, utilizando-se todos os resultados. Com visto, o ajuste da função potência (assim como outras funções) se mostrou muito pobre. Assim, essa correlação deve ser tomada não mais do que indicativa de tendência. Um aspecto a ser considerado nesses dados é o fato de que as velocidades em laboratório foram determinadas sob condições não confinadas, ou seja, com as amostras tendo experimentado o relaxamento das tensões in situ. $\mathrm{O}$ seu uso em conjunto com a velocidade sísmica medida in situ deve ser precedida da aplicação de algum fator de homogeinização entre as velocidades medidas em laboratório (ondas ultra-sônicas) e in situ (ondas sísmicas). 


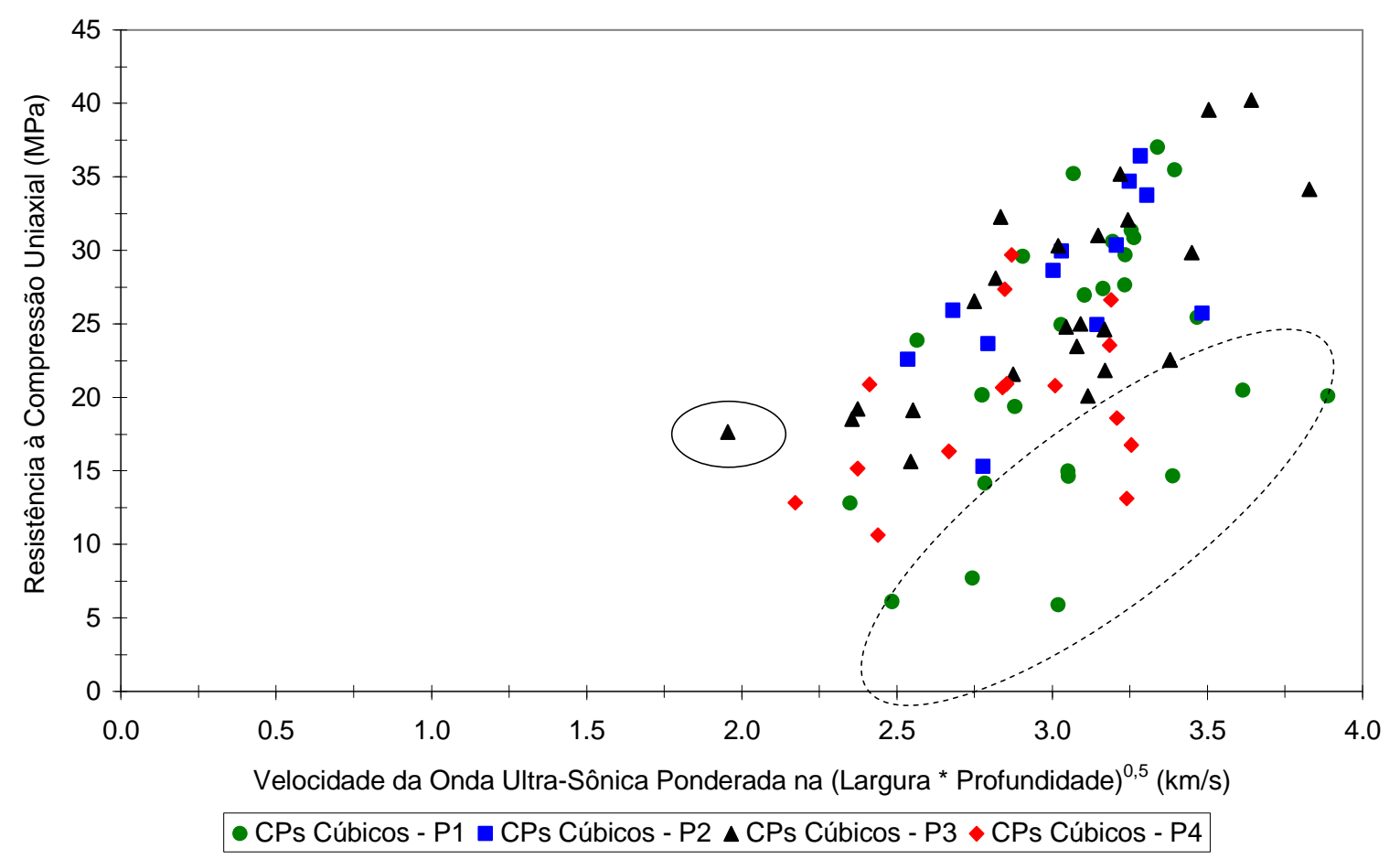

Figura 4.17a - Correlação entre a resistência à compressão uniaxial e a velocidade da onda ultra-sônica ponderada nas direções de determinação paralelas aos planos de estratificação, para corpos-de-prova cúbicos de diferentes tamanhos.

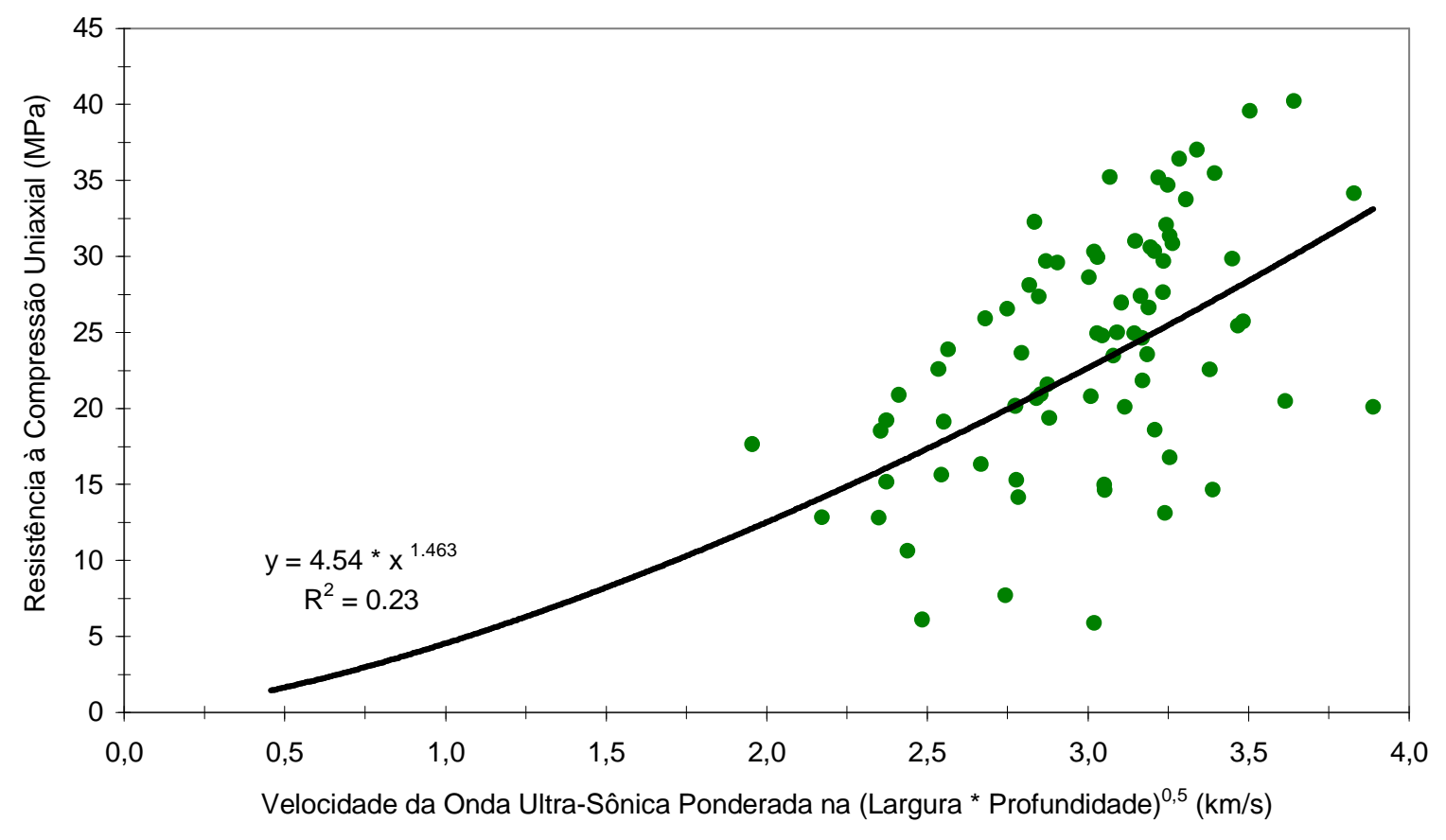

Figura 4.17b - Funções ajustadas para a correlação entre a resistência à compressão uniaxial e a velocidade da onda ultra-sônica ponderada nas direções de determinação paralelas aos planos de estratificação, para corpos-de-prova cúbicos de diferentes tamanhos. 


\subsection{Ensaios para a Determinação da Envoltória de Resistência do Carvão da Camada Bonito - Mina Fontanella}

\subsubsection{Preparação dos Corpos-de-Prova e Execução dos Ensaios}

Para a definição da envoltória de resistência do carvão foi utilizado o material proveniente do ponto 3 de amostragem. No total, 24 corpos-de-prova cilíndricos, com diâmetro de $54 \mathrm{~mm}$, foram preparados a partir de testemunhos de sondagem extraídos dos blocos de carvão. A geometria e o acabamento dos corpos-deprova, assim como a ruptura, seguiu os procedimentos sugeridos pela ISRM (1978b, 1979b e 1983), de acordo com a modalidade de ensaio realizada.

Os ensaios de compressão uniaxial ( $N=7$ ensaios) e compressão triaxial $(\mathrm{N}=11)$ foram realizados na mesma prensa utilizada nos ensaios em cubos. Em ambas as modalidades de ensaio a aplicação da tensão principal maior foi feita perpendicularmente aos planos de estratificação do carvão. Para os ensaios triaxiais utilizou-se uma câmara triaxial de Hoek. Em 8 corpos-de-prova adotou-se o procedimento de ensaio multiestágio. As tensões confinantes aplicadas variaram entre $2,5 \mathrm{MPa}$ e $10,5 \mathrm{MPa}$.

Os ensaios de compressão diametral $(N=6)$ foram realizados numa prensa Losenhausen com capacidade de carga de $100 \mathrm{kN}$. A resistência à tração foi determinada paralelamente aos planos de estratificação do carvão.

\subsubsection{Resultados Obtidos}

Os resultados, em termos de tensões principais maior $\left(\sigma_{1}\right)$ e menor $\left(\sigma_{3}\right)$, das diferentes modalidades de ensaios, juntamente com a envoltória de resistência, são apresentados na Figura 4.18. Os parâmetros da envoltória de resistência da rocha intacta - resistência à compressão uniaxial $\left(\sigma_{\mathrm{ci}}\right)$ e as constantes $\left(\mathrm{m}_{\mathrm{i}}\right),(\mathrm{s})$ e (a) - foram calculados segundo o critério de ruptura de Hoek-Brown - edição 2002 (HOEK et al., 2002), utilizando o programa RocLab 1.0.

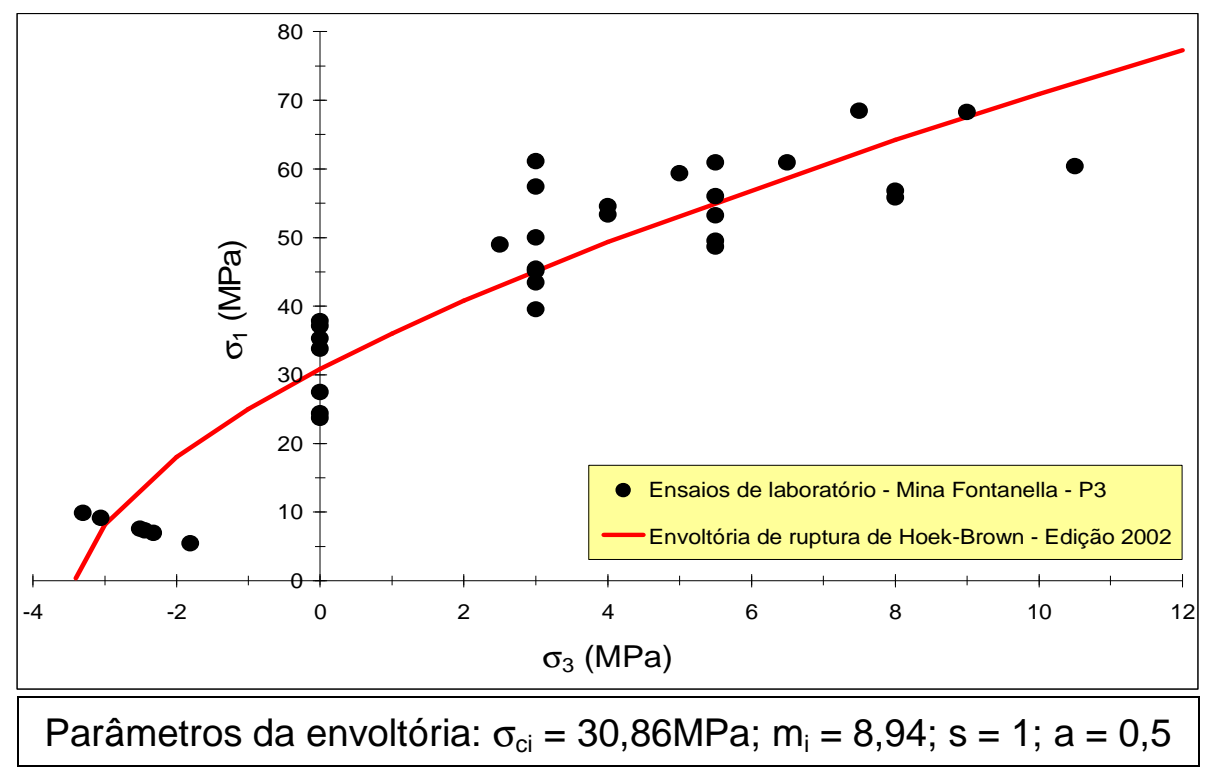

Figura 4.18 - Resultados de ensaios de compressão diametral, uniaxial e triaxial em corpos-de-prova cilíndricos de carvão da camada Bonito da Mina Fontanella. 


\subsection{Ensaios para a Determinação da Resistência à Compressão Uniaxial do Carvão da Camada Irapuá - Minas Morozini Norte e Santa Augusta Norte}

\subsubsection{Extração das Amostras, Preparação dos Corpos-de-Prova e Execução dos Ensaios}

As amostras do carvão da camada Irapuá utilizadas nos ensaios de compressão uniaxial foram fornecidas pelas próprias empresas mineradoras. Os blocos de carvão, com volume de aproximadamente $0,03 \mathrm{~m}^{3}$, foram coletados nos seguintes locais das minas:

- Mina Morozini Norte: diretamente da rafa (material desmontado) junto às frentes de lavra em operação no mês de junho de 2006 (Amostras - Fase 1) e da lateral de pilares recém conformados no mês de agosto de 2006 (Amostras Fase 2), nas proximidades dos furos de sondagem 1777 e 1776, respectivamente, conforme mostra Figura 4.19;

- Mina Santa Augusta Norte: próximo das frentes de lavra, na Galeria 3 do Eixo NW-01, Travessão 5, conforme indicado na Figura 4.20.

Os perfis típicos da camada Irapuá, nessas duas minas, podem ser vistos no Capítulo 3, na Figura 3.5.

Após a extração, as amostras receberam proteção com filme plástico e/ou parafina para evitar a ação da umidade. Em seguida foram transportadas ao laboratório para a realização dos ensaios.

Os materiais coletados na Fase 1 de amostragem na Mina Morozini Norte, foram utilizados somente para estudos complementares sobre a influência da tensão e da água na determinação da velocidade de propagação de ondas. Esses estudos são apresentados em detalhe no Item 4.6, adiante.

É importante salientar, também, que na Mina Morozini Norte o método de desmonte do carvão é por explosivos, enquanto na Mina Santa Augusta Norte o desmonte é feito com minerador contínuo.

Para a determinação da resistência à compressão uniaxial foram preparados corpos-de-prova cúbicos, com dimensão do lado entre $5 \mathrm{~cm}$ e $7 \mathrm{~cm}$. $O$ acabamento dos corpos-de-prova, assim como a medição das deformações axiais durante a ruptura, seguiu os procedimentos sugeridos pela ISRM (1979b) para ensaios de compressão uniaxial.

As determinações da massa específica aparente (ISRM, 1979a) e da velocidade da onda ultra-sônica nas 3 direções dos corpos-de-prova (ISRM, 1978a), foram feitas previamente à ruptura à compressão uniaxial. Os teores de umidade (ISRM, 1979a) foram determinados após a ruptura.

Para a ruptura utilizou-se o mesmo sistema de carga MTS 816 empregado nos ensaios do carvão da camada Bonito. A aplicação da carga foi feita na direção perpendicular aos planos de estratificação do carvão.

Durante a ruptura, medições de deformações axiais foram realizadas com extensômetros modelo MTS, numa faixa de medição ("gage length") de $25 \mathrm{~mm}$. 


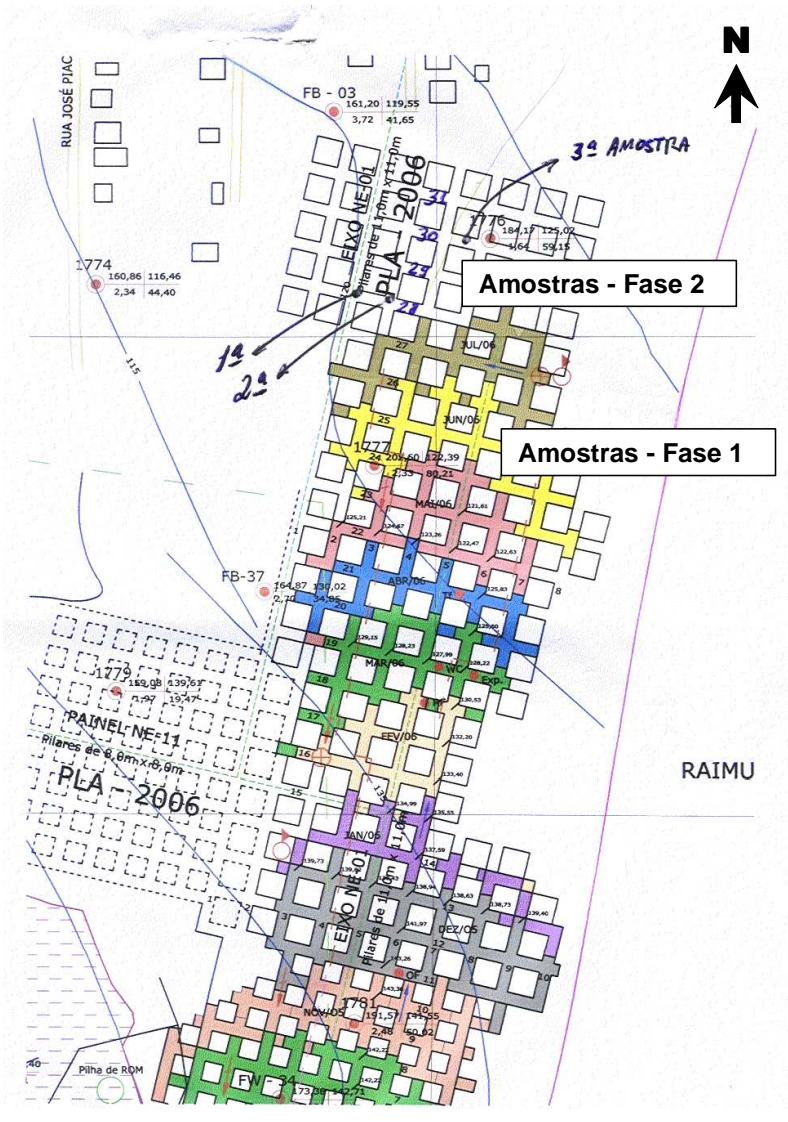

Figura 4.19 - Localização das amostras de carvão da camada Irapuá coletadas na Mina Morozini Norte (Fonte: Relatório de Ensaio 19774/66293 - CARBONÍFERA BELLUNO LTDA).

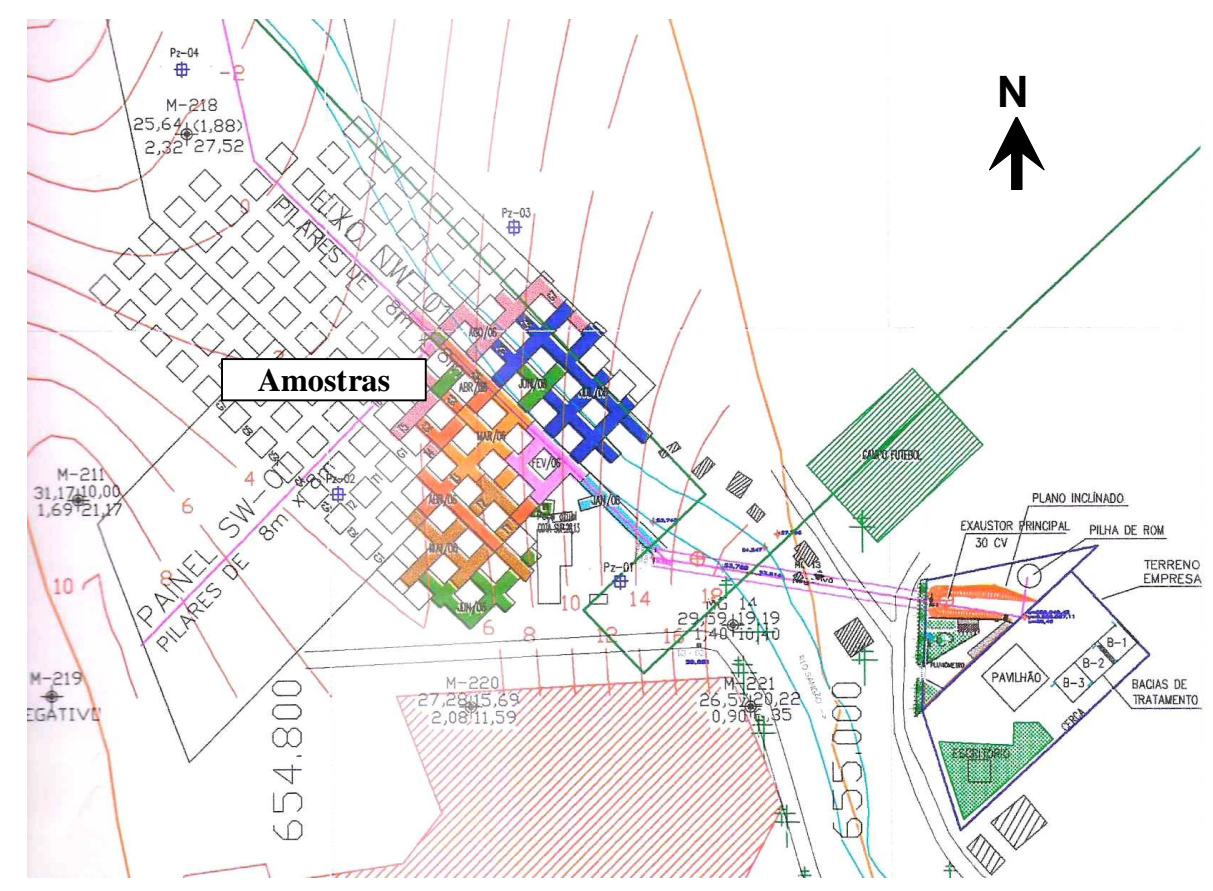

Figura 4.20 - Localização das amostras de carvão da camada Irapuá coletadas na Mina Santa Augusta Norte (Fonte: Relatório de Ensaio 19997/66354 - MINAGEO LTDA). 


\subsubsection{Resultados Obtidos}

Devido às variações de composição observadas na camada Irapuá, devidamente representadas nas amostras provenientes da Mina Morozini Norte, a análise estatística foi feita individualizando-se as litologias carvão e folhelho carbonoso. Os resultados são apresentados na Tabela 4.8.

A estatística descritiva dos resultados de resistência à compressão uniaxial, juntamente com os índices físicos e a deformabilidade do material ensaiado da Mina Santa Augusta Norte, pode ser vista na Tabela 4.9.

Tabela 4.8 - Estatística descritiva dos parâmetros determinados no carvão da camada Irapuá da Mina Morozini Norte, em corpos-de-prova cúbicos com a dimensão do lado entre $5 \mathrm{~cm}$ e $7 \mathrm{~cm}$ (Amostras - Fase 2).

\begin{tabular}{|c|c|c|c|c|c|c|}
\hline \multicolumn{7}{|c|}{ Carvão } \\
\hline Parâmetro & $\mathrm{N}$ & Média & Mediana & Mínimo & Máximo & Desvio Padrão \\
\hline W (\%) & 9 & 0,7 & 0,7 & 0,4 & 1,0 & 0,13 \\
\hline$\rho_{a}\left(\mathrm{~g} / \mathrm{cm}^{3}\right)$ & 9 & 1,85 & 2,00 & 1,45 & 1,69 & 0,06 \\
\hline $\mathrm{V}_{\text {perp }}(\mathrm{km} / \mathrm{s})$ & 9 & 2,17 & 2,16 & 2,06 & 2,34 & 0,09 \\
\hline $\mathrm{V}_{\text {pond.par }}(\mathrm{km} / \mathrm{s})$ & 9 & 2,65 & 2,66 & 2,48 & 2,86 & 0,12 \\
\hline $\mathrm{E}_{\mathrm{m}}(\mathrm{GPa})$ & 9 & 3,58 & 3,58 & 2,97 & 4,30 & 0,42 \\
\hline$\sigma_{\text {c.cubo }}(\mathrm{MPa})$ & 9 & 16,74 & 17,72 & 12,33 & 18,75 & 2,30 \\
\hline \multicolumn{7}{|c|}{ Folhelho Carbonoso } \\
\hline Parâmetro & $\mathrm{N}$ & Média & Mediana & Mínimo & Máximo & Desvio Padrão \\
\hline W (\%) & 16 & 0,7 & 0,7 & 0,4 & 0,9 & 0,14 \\
\hline$\rho_{a}\left(g / \mathrm{cm}^{3}\right)$ & 16 & 2,04 & 2,03 & 1,96 & 2,20 & 0,05 \\
\hline$V_{\text {perp }}(\mathrm{km} / \mathrm{s})$ & 16 & 2,44 & 2,43 & 2,26 & 2,70 & 0,12 \\
\hline $\mathrm{V}_{\text {pond.par }}(\mathrm{km} / \mathrm{s})$ & 16 & 3,34 & 3,34 & 3,01 & 3,71 & 0,19 \\
\hline $\mathrm{E}_{\mathrm{m}}(\mathrm{GPa})$ & 14 & 4,26 & 4,60 & 1,56 & 6,71 & 1,33 \\
\hline$\sigma_{\text {c.cubo }}(\mathrm{MPa})$ & 16 & 18,56 & 19,47 & 10,01 & 27,96 & 3,88 \\
\hline
\end{tabular}

LEGENDA:

$\sigma_{\text {c.cubo }}=$ resistência à compressão uniaxial de corpo-de-prova cúbico com carregamento na direção perpendicular aos planos de estratificação do carvão; $N=$ número de ensaios; $\rho_{a}=$ massa específica aparente; $V_{\text {perp }}=$ velocidade de propagação da onda ultra-sônica longitudinal medida na direção perpendicular aos planos de estratificação do carvão; $V_{\text {pond.par }}=$ velocidade de propagação da onda ultrasônica longitudinal ponderada nas direções de determinação paralelas aos planos de estratificação do carvão; $E_{m}=$ módulo de deformabilidade médio na direção perpendicular aos planos de estratificação do carvão; $\mathrm{W}$ = umidade da amostra após o ensaio.

NOTA: fonte parcial dos dados: Relatório de Ensaio 19774/66293 - CARBONÍFERA BELLUNO LTDA. 
Tabela 4.9 - Estatística descritiva dos parâmetros determinados no carvão da camada Irapuá da Mina Santa Augusta Norte, em corpos-de-prova cúbicos com a dimensão do lado entre $5 \mathrm{~cm}$ e $6 \mathrm{~cm}$.

\begin{tabular}{|c|c|c|c|c|c|c|}
\hline Parâmetro & $\mathrm{N}$ & Média & Mediana & Mínimo & Máximo & Desvio Padrão \\
\hline $\mathrm{W}(\%)$ & 14 & 0,5 & 0,5 & 0,3 & 0,9 & 0,2 \\
\hline$\rho_{\mathrm{a}}\left(\mathrm{g} / \mathrm{cm}^{3}\right)$ & 14 & 1,53 & 1,53 & 1,47 & 1,64 & 0,05 \\
\hline $\mathrm{V}_{\text {perp }}(\mathrm{km} / \mathrm{s})$ & 14 & 2,04 & 2,08 & 1,53 & 2,27 & 0,21 \\
\hline $\mathrm{V}_{\text {pond.par }}(\mathrm{km} / \mathrm{s})$ & 14 & 2,69 & 2,68 & 2,19 & 3,05 & 0,23 \\
\hline $\mathrm{E}_{\mathrm{m}}(\mathrm{GPa})$ & 14 & 3,16 & 3,06 & 1,95 & 4,23 & 0,68 \\
\hline$\sigma_{\text {c.cubo }}(\mathrm{MPa})$ & 14 & 28,33 & 29,25 & 19,54 & 36,62 & 5,45 \\
\hline
\end{tabular}

LEGENDA:

$\sigma_{\text {c.cubo }}=$ resistência à compressão uniaxial de corpo-de-prova cúbico com carregamento na direção perpendicular aos planos de estratificação do carvão; $N=$ número de ensaios; $\rho_{a}=$ massa específica aparente; $\mathrm{V}_{\text {perp }}=$ velocidade de propagação da onda ultra-sônica longitudinal medida na direção perpendicular aos planos de estratificação do carvão; $V_{\text {pond.par }}=$ velocidade de propagação da onda ultrasônica longitudinal ponderada nas direções de determinação paralelas aos planos de estratificação do carvão; $\mathrm{E}_{\mathrm{m}}=$ módulo de deformabilidade médio na direção perpendicular aos planos de estratificação do carvão; $\mathrm{W}$ = umidade da amostra após o ensaio.

NOTA: fonte parcial dos dados: Relatório de Ensaio 19997/66354 - MINAGEO LTDA.

\subsection{Mapeamento Estrutural da Camada de Carvão Bonito na Mina Fontanella}

\subsubsection{Introdução}

O mapeamento estrutural na camada Bonito da Mina Fontanella teve como objetivos dar subsídios aos estudos para a determinação da resistência in situ por meio de classificações geomecânicas.

Também, visou prover informações que pudessem facilitar a interpretação dos resultados de resistência obtidos em laboratório, bem como os resultados dos levantamentos geofísicos, descritos adiante, efetuados nos diferentes locais de estudo.

Dentro desse contexto, são apresentadas as atividades desenvolvidas durante o mapeamento das estruturas, as técnicas de tratamento dos dados, juntamente com os resultados sobre as principais famílias de descontinuidades presentes na camada Bonito, na Mina Fontanella. Para alguns dos parâmetros estudados os detalhes são apresentados no Anexo 2. 


\subsubsection{Execução das Medições}

O levantamento das fraturas presentes na camada de carvão foi realizado nos mesmos locais onde foram coletadas as amostras para ensaios de laboratório. Para a locação dos pontos, levaram-se em consideração os seguintes aspectos:

a) os pontos deveriam ficar o mais próximo possível de onde foram extraídas as amostras de carvão para ensaios em laboratório;

b) acesso seguro ao local, visto que em algumas galerias onde poderiam ser realizados os trabalhos havia problemas de instabilidade do teto.

Para facilitar os trabalhos de medição da orientação das fraturas, foram utilizados 2 holofotes de 1000 watts de potência para a iluminação do local, como mostra a Figura 4.21. Esse tipo de iluminação foi de fundamental importância, uma vez que permitiu uma visão global das áreas a serem mapeadas na parede do pilar, além de possibilitar a identificação mais fácil dos planos das fraturas.

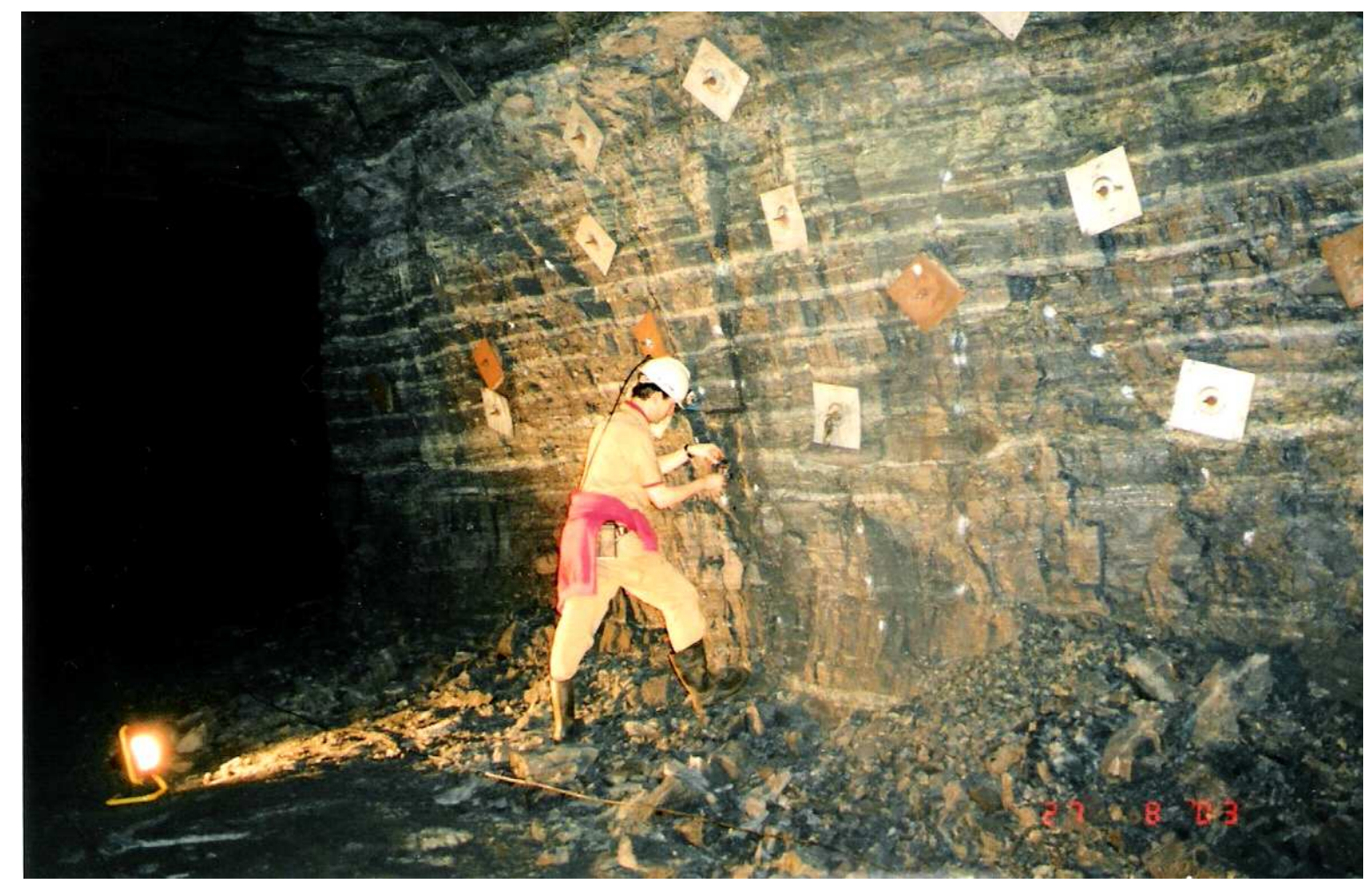

Figura 4.21 - Detalhe da iluminação utilizada para a realização do mapeamento.

A técnica adotada foi a de mapeamento das fraturas em janelas na parede dos pilares, seguindo-se os procedimentos gerais sugeridos pela ISRM (1978c) para a caracterização de descontinuidades em maciços rochosos. Os instrumentos utilizados consistiram de uma bússola para medir a orientação das fraturas e uma trena flexível de $50 \mathrm{~m}$ para a determinação da distância aparente entre as fraturas ao longo da linha de referência no meio da janela.

Em todos os pontos de levantamento foram definidas janelas nas duas direções das aberturas (na direção do avanço da lavra - galerias e na direção 
perpendicular às galerias - travessões), com comprimento mínimo equivalente à dimensão do lado do pilar e altura igual à espessura da camada minerada no local (entre 3,0m e 3,4m).

Em alguns locais (Pontos 1 e 3, por exemplo), quando o mapeamento foi feito ao longo da galeria, foi possível estabelecer janelas com comprimento de até $50 \mathrm{~m}$.

Já na direção dos travessões, para tomar medidas numa extensão maior, quando possível foram mapeados pelo menos 2 travessões seguidos. A adoção dessa sistemática (longas extensões numa mesma direção) permitiu a obtenção de informações ao longo de uma linha relativamente comprida em relação ao espaçamento entre as fraturas.

Para o mapeamento, propriamente dito, após a definição do tamanho da janela de amostragem, como mostra o desenho da Figura 4.22, foram adotados os seguintes procedimentos:

a) definição de uma linha de referência na meia altura do pilar (cerca de 1,6m acima do piso da galeria), através da extensão da trena na parede da galeria, conforme mostra a Figura 4.23. Essa linha serviu de base para a determinação do afastamento aparente entre fraturas;

b) identificação de todas as fraturas com persistência superior a 0,5m. A adoção dessa persistência de "corte" foi feita a partir do mapeamento das fraturas no Ponto 1. Nesse local, onde a parede do pilar se apresentava lisa, é bastante visível que as fraturas com persistência menor que $0,5 \mathrm{~m}$ geralmente correspondem aos "cleats". A persistência de corte teve como objetivo, também, a filtragem das fraturas não naturais do maciço, aquelas provocadas pelo desmonte da rocha por explosivos;

c) determinação da posição da descontinuidade na linha de referência na janela. Fraturas que não atravessavam a linha de referência (fratura $b$ na Figura 4.22) foram projetadas até a linha e mapeadas normalmente;

d) determinação da orientação da descontinuidade adotando-se a sistemática "direção do mergulho" e "mergulho";

e) levantamento de informações sobre a persistência, rugosidade, presença de água, condições de alteração das paredes da descontinuidade, abertura das fraturas, preenchimento e o coeficiente de rugosidade (JRC).

As medições realizadas foram distribuídas em 18 janelas numa área de $960 \mathrm{~m}^{2}$ de paredes de galerias, totalizando 267 fraturas mapeadas. Cada ponto de levantamento demandou cerca de 1,5 dias de trabalho. A Tabela 4.10 apresenta uma síntese dos quantitativos realizados durante o mapeamento estrutural da camada Bonito na Mina Fontanella.

Os fragmentos de mapas das Figuras 4.24a a 4.24d mostram a localização das linhas de levantamento estrutural em vermelho. 


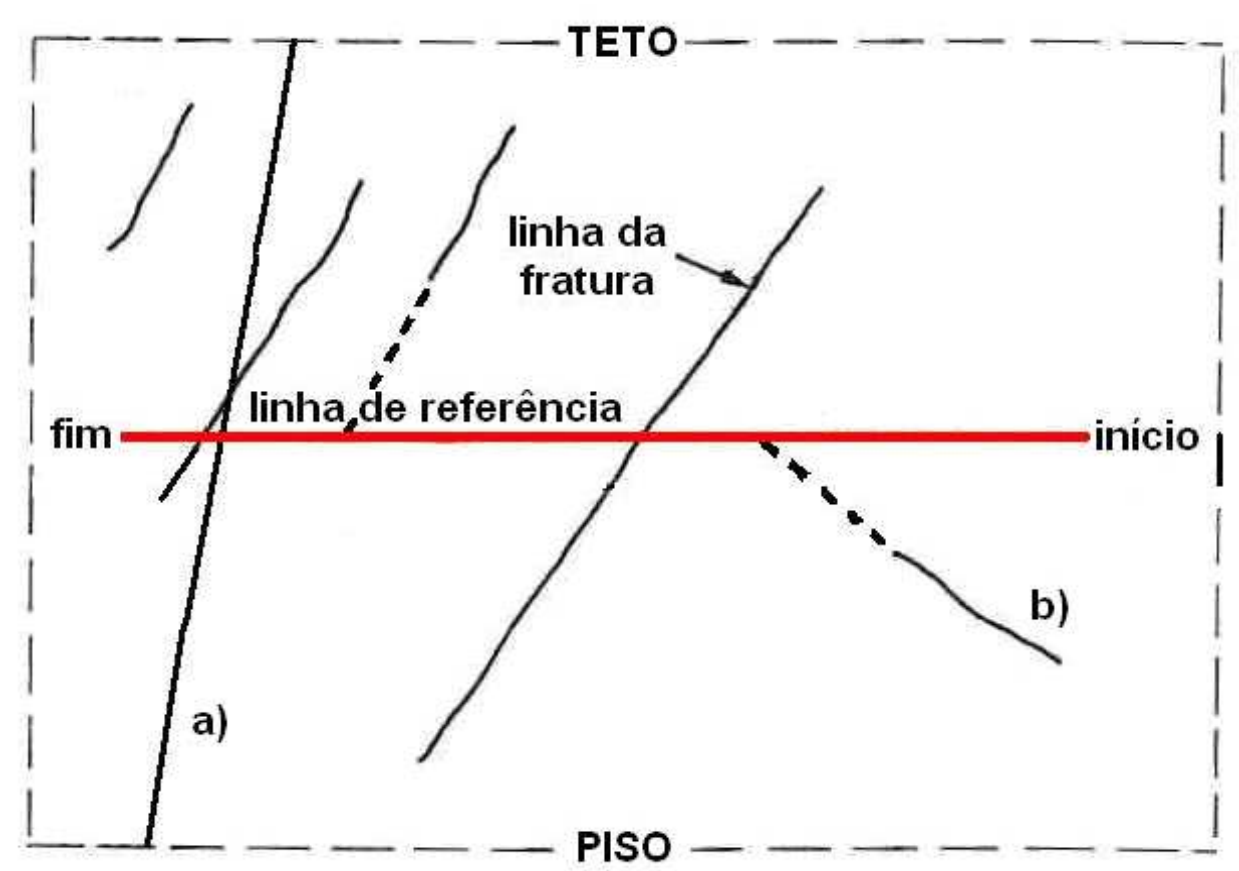

Figura 4.22 - Janela de mapeamento das fraturas, definida pela altura da camada de carvão e comprimento da linha de referência. a) Detalhe de fratura que atravessa a camada de carvão; b) Fratura mapeada a partir da projeção da linha da fratura sobre a linha de referência.

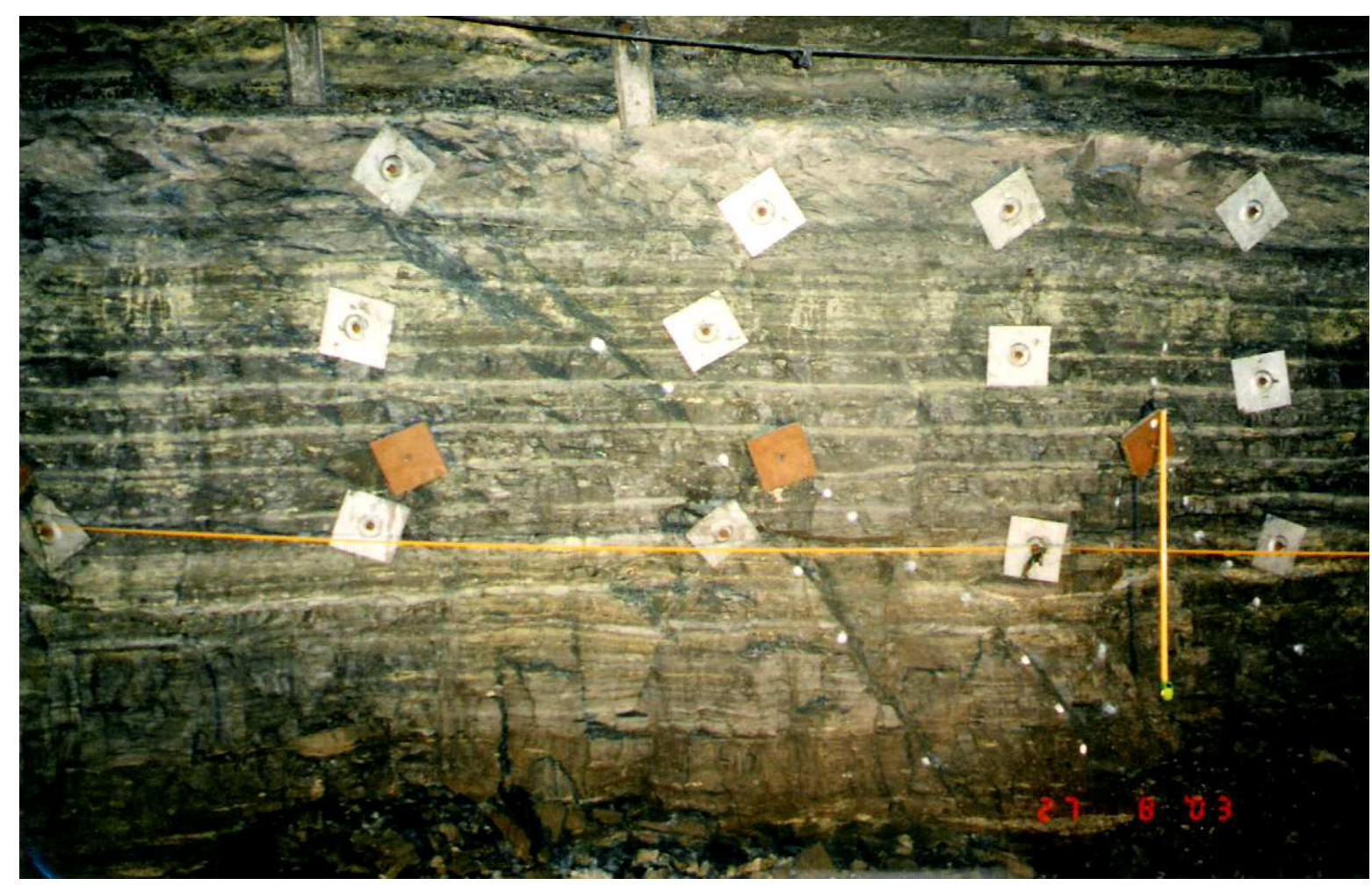

Figura 4.23 - No centro, a linha horizontal de referência (em amarelo) para a determinação da distância aparente entre as fraturas. Notar detalhe da marcação das fraturas (pontilhado branco) para facilitar a medição da orientação e características das fraturas. 
Tabela 4.10 - Síntese dos quantitativos realizados para o mapeamento estrutural da camada de carvão Bonito na Mina Fontanella.

\begin{tabular}{|c|c|c|c|c|c|c|}
\hline \multicolumn{3}{|c|}{ Localização da Janela } & \multirow{3}{*}{$\begin{array}{c}\begin{array}{c}\text { Direção da Linha } \\
\text { de Medição / } \\
\text { Inclinação } \\
\left({ }^{\circ}\right)\end{array} \\
106 \text { / } 00\end{array}$} & \multirow{3}{*}{$\begin{array}{c}\text { Comprimento } \\
\text { da Linha } \\
(\mathrm{m})\end{array}$} & \multirow{3}{*}{$\begin{array}{c}\begin{array}{c}\text { Área da } \\
\text { Janela } \\
\left(\mathrm{m}^{2}\right)\end{array} \\
40,1\end{array}$} & \multirow{3}{*}{$\begin{array}{c}\text { Número de } \\
\text { Medidas } \\
\text { Realizadas } \\
25\end{array}$} \\
\hline \multicolumn{2}{|c|}{$\begin{array}{l}\text { Local/Linha } \\
\text { de } \\
\text { Medição }\end{array}$} & Endereço na Mina & & & & \\
\hline \multirow{6}{*}{$\mathrm{P} 1$} & $\mathrm{~L} 1$ & $\begin{array}{c}\text { Eixo 6NW - G4, entre } \\
\text { T2 e T1, lado } \\
\text { esquerdo }\end{array}$ & & & & \\
\hline & L2 & $\begin{array}{c}\text { Eixo 6NW - G4, entre } \\
\text { T2 e T1, lado } \\
\text { esquerdo }\end{array}$ & $106 / 00$ & 11,5 & 39,4 & 8 \\
\hline & L3 & $\begin{array}{c}\text { Eixo 6NW - T2 entre } \\
\text { G4 e G3, lado } \\
\text { esquerdo }\end{array}$ & $196 / 10$ & 20,4 & 70,0 & 10 \\
\hline & $\mathrm{L} 4$ & $\begin{array}{c}\text { Eixo 6NW - G4, entre } \\
\text { T3 e T2, lado } \\
\text { esquerdo }\end{array}$ & $106 / 00$ & 13,5 & 46,3 & 16 \\
\hline & L5 & $\begin{array}{c}\text { Eixo 6NW - T3, entre } \\
\text { G4 e G3, lado } \\
\text { esquerdo }\end{array}$ & $196 / 10$ & 15,9 & 54,5 & 10 \\
\hline & \multicolumn{3}{|c|}{ Totais } & 73,0 & 250,4 & 69 \\
\hline \multirow{6}{*}{$\mathrm{P} 4$} & $\mathrm{~L} 1$ & $\begin{array}{c}\text { Eixo 6NW - Painel } \\
\text { 2SW - T6, entre G0 e } \\
\text { G1, lado esquerdo }\end{array}$ & $286 / 00$ & 15,1 & 51,3 & 14 \\
\hline & L2 & $\begin{array}{c}\text { Eixo 6NW - Painel } \\
\text { 2SW - T6, entre G1 e } \\
\text { G2, lado direito }\end{array}$ & $286 / 00$ & 12,0 & 40,8 & 20 \\
\hline & L3 & $\begin{array}{c}\text { Eixo 6NW - Painel } \\
\text { 2SW - G1 entre T6 e } \\
\text { T5, lado direito }\end{array}$ & $016 / 00$ & 15,0 & 51,0 & 21 \\
\hline & $\mathrm{L} 4$ & $\begin{array}{c}\text { Eixo 6NW - Painel } \\
\text { 2SW - G1, entre T5 e } \\
\text { T4, lado esquerdo }\end{array}$ & $016 / 00$ & 14,3 & 48,6 & 12 \\
\hline & L5 & $\begin{array}{c}\text { Eixo } 6 N W \text { - Pinel 2SW } \\
\text { - T6, entre G2 e G3, } \\
\text { lado direito }\end{array}$ & $286 / 00$ & 11,0 & 37,4 & 12 \\
\hline & \multicolumn{3}{|c|}{ Totais } & 67,4 & 229,2 & 79 \\
\hline \multirow{6}{*}{$\mathrm{P} 2$} & $\mathrm{~L} 1$ & $\begin{array}{l}\text { Eixo 8NW - G2, entre } \\
\text { T0 e T1, lado direito }\end{array}$ & $286 / 10$ & 14,5 & 44,9 & 18 \\
\hline & L2 & $\begin{array}{l}\text { Eixo 8NW - G2, entre } \\
\text { T1 e T2, lado direito }\end{array}$ & $335 / 00$ & 18,6 & 57,7 & 11 \\
\hline & L3 & $\begin{array}{l}\text { Eixo 8NW - T0 entre } \\
\text { G2 e G3, lado direito }\end{array}$ & $046 / 05$ & 12,7 & 39,4 & 9 \\
\hline & $\mathrm{L} 4$ & $\begin{array}{l}\text { Eixo 8NW - T0, entre } \\
\text { G3 e G4, lado direito }\end{array}$ & $046 / 05$ & 12,8 & 40,0 & 10 \\
\hline & L5 & $\begin{array}{l}\text { Eixo 8NW - G4, entre } \\
\text { T1 e T0, lado direito }\end{array}$ & $106 / 00$ & 15,0 & 46,5 & 6 \\
\hline & \multicolumn{3}{|c|}{ Totais } & 73,6 & 228,2 & 55 \\
\hline \multirow{4}{*}{ P3 } & $\mathrm{L} 1$ & $\begin{array}{c}\text { Eixo 7SW - G1, entre } \\
\text { T2 e T1/T0, lado } \\
\text { direito }\end{array}$ & $046 / 05$ & 51,3 & 155,4 & 34 \\
\hline & $\mathrm{L} 2$ & $\begin{array}{l}\text { Eixo 7SW - T2, entre } \\
\text { G1 e G2, lado direito }\end{array}$ & $316 / 00$ & 13,2 & 40,0 & 17 \\
\hline & L3 & $\begin{array}{l}\text { Eixo 7SW - T2 entre } \\
\text { G2 e G3, lado direito }\end{array}$ & $316 / 00$ & 18,6 & 56,4 & 13 \\
\hline & \multicolumn{3}{|c|}{ Totais } & 83,1 & 251,8 & 64 \\
\hline
\end{tabular}

Nota $1: \mathrm{P} 1, \mathrm{P} 2, \ldots=$ pontos de levantamento $1,2 \ldots ; \mathrm{L} 1, \mathrm{~L} 2, \ldots=$ linhas de levantamento $1,2 \ldots$ Nota 2: Altura da galeria: $\mathrm{P} 1=3,4 \mathrm{~m} ; \mathrm{P} 4=3,4 \mathrm{~m} ; \mathrm{P} 2=3,1 \mathrm{~m} ; \mathrm{P} 3=3,0 \mathrm{~m}$. 


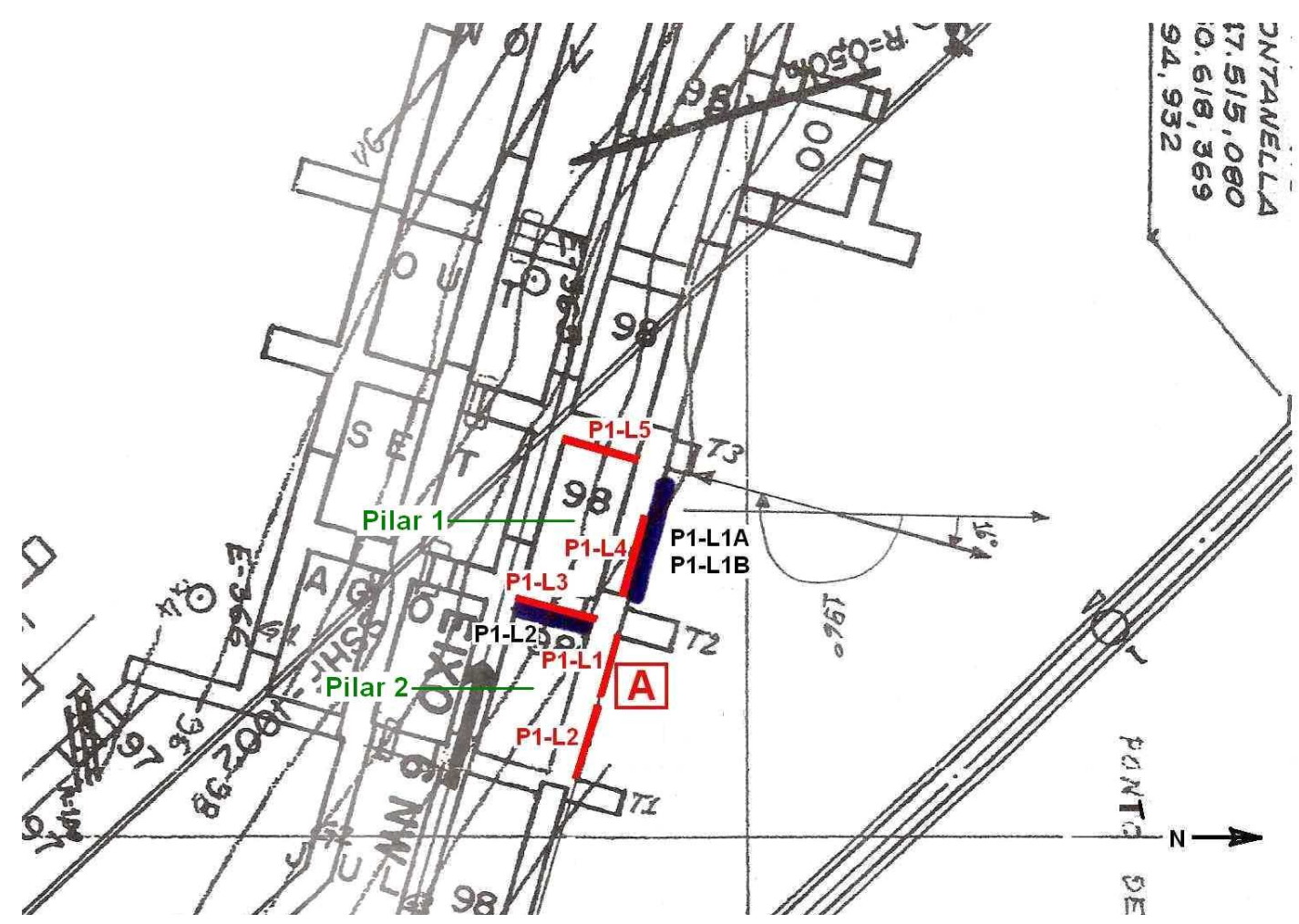

Figura 4.24a - Localização do Ponto 1 (P1) de coleta de amostras de carvão para ensaios em laboratório $(A)$, linhas de levantamento estrutural (em vermelho), levantamento com geofísica na periferia do pilar (em azul) e levantamento com geofísica no interior do pilar (em verde), na Mina Fontanella (Fonte da planta: Carbonífera Metropolitana S/A).

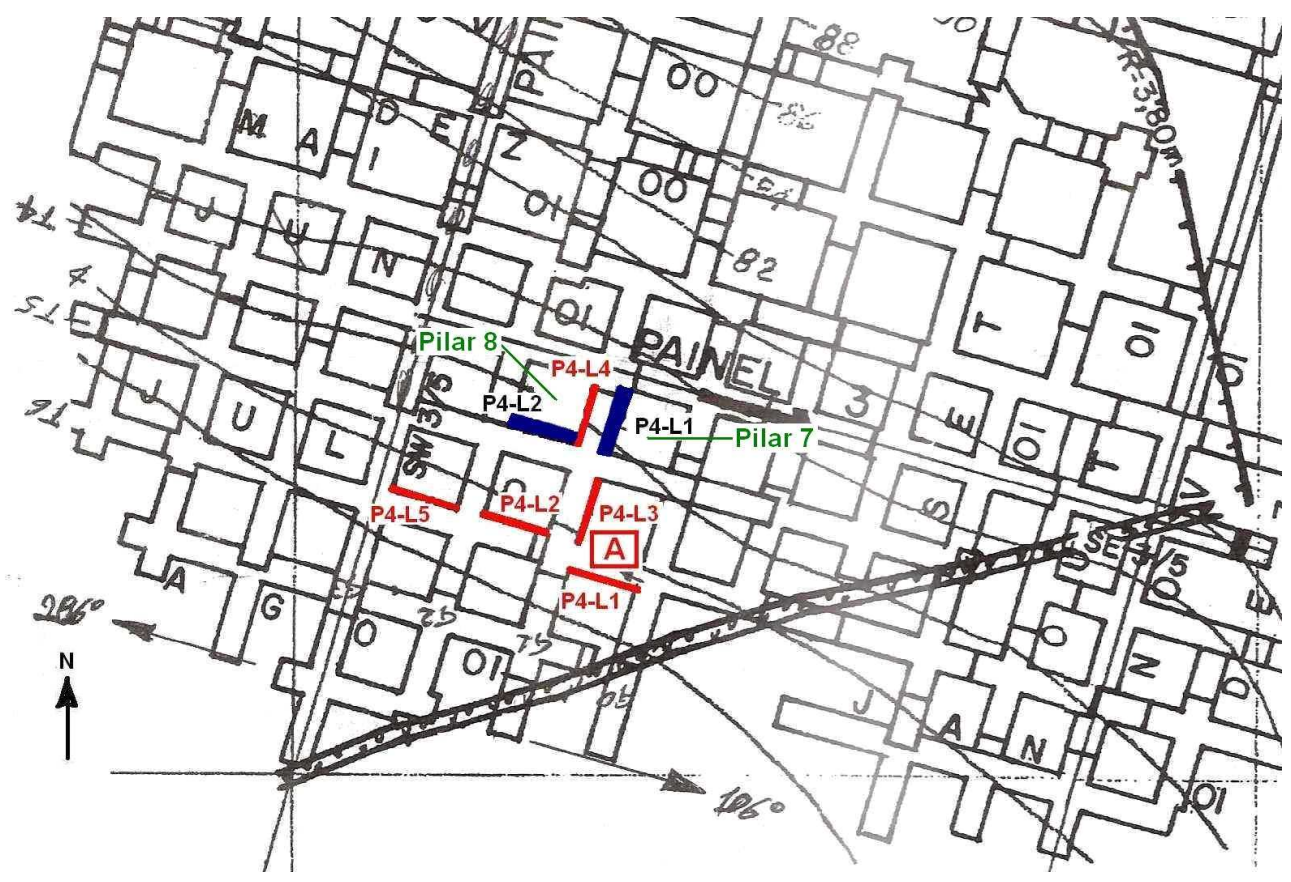

Figura 4.24b - Localização do Ponto 4 (P4) de coleta de amostras de carvão para ensaios em laboratório $(A)$, linhas de levantamento estrutural (em vermelho), levantamento com geofísica na periferia do pilar (em azul) e levantamento com geofísica no interior do pilar (em verde), na Mina Fontanella (Fonte da planta: Carbonífera Metropolitana S/A). 


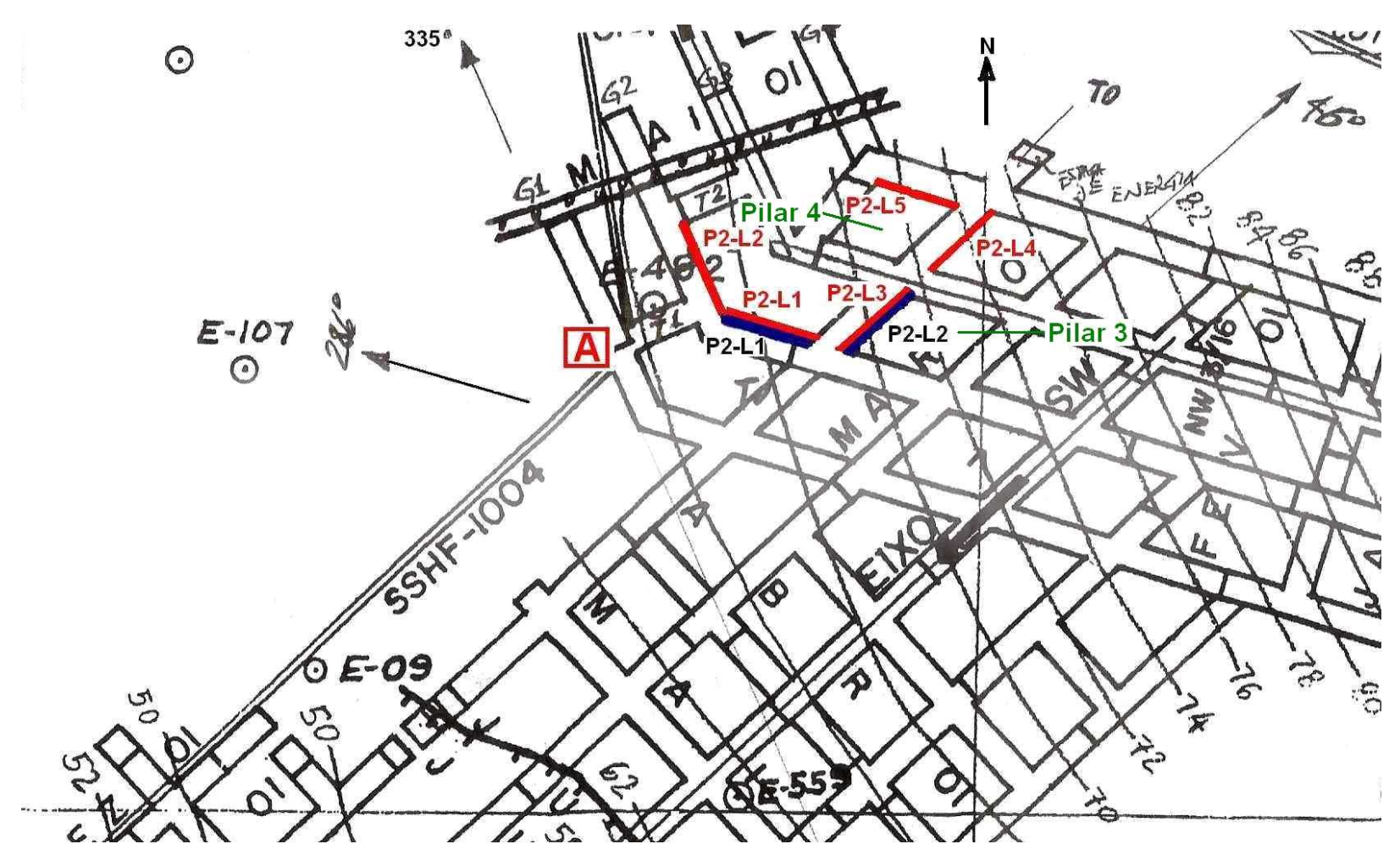

Figura 4.24c - Localização do Ponto 2 (P2) de coleta de amostras de carvão para ensaios em laboratório (A), linhas de levantamento estrutural (em vermelho), levantamento com geofísica na periferia do pilar (em azul) e levantamento com geofísica no interior do pilar (em verde), na Mina Fontanella (Fonte da planta: Carbonífera Metropolitana S/A).

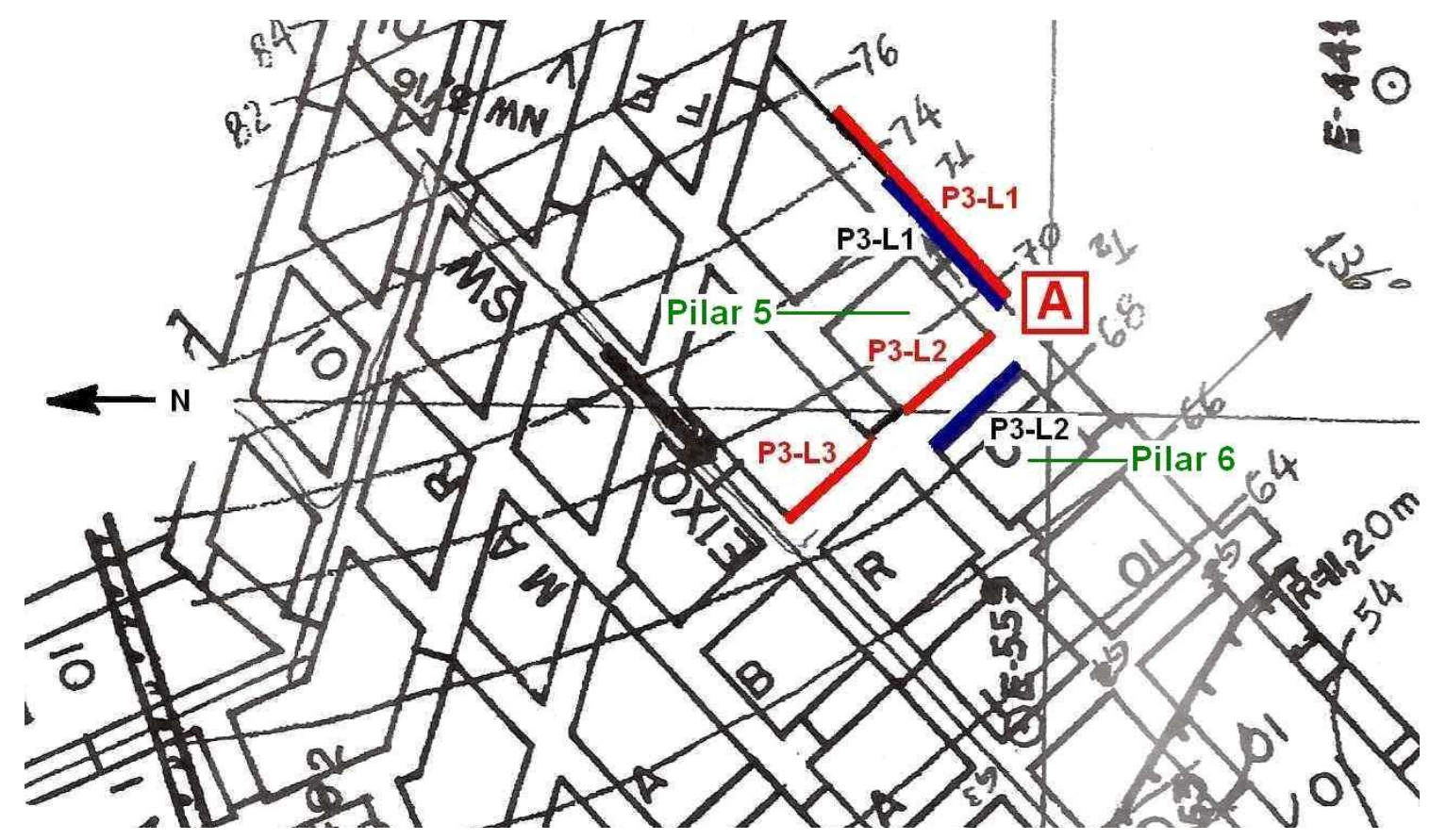

Figura 4.24d - Localização do Ponto 3 (P3) de coleta de amostras de carvão para ensaios em laboratório (A), linhas de levantamento estrutural (em vermelho), levantamento com geofísica na periferia do pilar (em azul) e levantamento com geofísica no interior do pilar (em verde), na Mina Fontanella (Fonte da planta: Carbonífera Metropolitana S/A). 


\subsubsection{Tratamento dos Dados de Campo}

As medidas de orientação das fraturas (direção do mergulho e mergulho) foram tratadas com o auxílio de diagramas de rosetas dos planos das fraturas, diagramas de isolinhas dos pólos das fraturas e diagramas de densidade de pólos. A identificação das principais famílias de descontinuidades foi feita com o auxílio do programa para análise estatística de descontinuidades GESAP, versão 2.0.

Diferentes procedimentos foram adotados para a computação da freqüência média entre descontinuidades. As alternativas adotadas foram as seguintes:

- alternativa 1: considerando cada uma das linhas de levantamento, em cada ponto de levantamento, individualmente;

- alternativa 2: considerando os pontos de levantamento agrupados dois a dois, em função da proximidade na área de estudo. Adicionalmente, como nas linhas de levantamento mais curtas algumas famílias não foram suficientemente representadas e, considerando que algumas famílias definidas inicialmente constituem-se em variações de uma mesma família, duas ou mais famílias foram agrupadas e consideradas como uma única família;

- alternativa 3: considerando cada linha de levantamento individualmente, porém, sem fazer distinção entre as famílias de fraturas.

Na prática, nessa alternativa de análise, todas as fraturas observadas na linha de levantamento são consideradas como pertencentes a uma "única" família. Desta forma, as linhas de levantamento podem ser consideradas "longas" comparadas com o espaçamento aparente médio entre fraturas. Para compensar a forte influência da direção das linhas de levantamentos, além da análise individual por linha de levantamento, as linhas de um mesmo local nas diferentes direções, foram agrupadas e analisadas conjuntamente. A freqüência aparente média de fraturas por metro $(\lambda a)$ foi calculada com base na expressão proposta por PRIEST \& HUDSON (1981):

$$
\lambda a=\frac{1}{\frac{\sum_{i=1}^{N-1} X_{i}}{N-1}}(\text { fraturas } / m)
$$

onde: $\frac{\sum_{i=1}^{N-1} X_{i}}{N-1}=$ espaçamento aparente médio entre fraturas adjacentes;

$X_{i}=$ distância medida entre duas fraturas adjacentes ao longo da linha de levantamento $(\mathrm{m})$;

$\mathrm{N}=$ número de fraturas observadas.

No Anexo 2, são apresentados em detalhe os procedimentos utilizados para o tratamento das medidas de descontinuidades no que se refere à identificação das principais famílias e à computação do espaçamento entre as descontinuidades. 


\subsubsection{Resultados Obtidos}

\subsubsection{Orientação das Fraturas}

Após a avaliação global das famílias mapeadas, foram definidas 3 famílias para representar o conjunto das descontinuidades nas duas áreas formadas pelo agrupamento dos pontos de levantamento mais próximos entre si. Embora numa das áreas uma quarta família pudesse ser considerada, com mergulho vertical, para efeitos práticos julgou-se oportuno agrupá-la a uma das famílias inclinadas que também possui grande representatividade na camada.

A Tabela 4.11 apresenta a síntese com orientação das famílias. Nas Figuras 4.25 e 4.26 podem ser vistas todas as famílias de descontinuidades identificadas nos locais de levantamento agrupados dois a dois, assim como as famílias representativas das descontinuidades nesses locais.

Tabela 4.11 - Orientações médias definidas para representar as famílias de descontinuidades presentes nas duas áreas de levantamento na camada de carvão Bonito, na Mina Fontanella.

\begin{tabular}{|c|c|c|c|c|}
\hline $\begin{array}{c}\text { Área de } \\
\text { Levantamento }\end{array}$ & Família & $\begin{array}{l}\text { Direção do } \\
\text { Mergulho } \\
\text { (o) }\end{array}$ & $\begin{array}{c}\text { Mergulho } \\
\text { (o) }\end{array}$ & $\begin{array}{l}\text { Ângulo Formado } \\
\text { entre as Famílias } \\
\text { (o) }\end{array}$ \\
\hline \multirow{3}{*}{$\begin{array}{c}14 \\
(\mathrm{P} 1+\mathrm{P} 4)\end{array}$} & $\mathrm{F} 1 \mathrm{~m}$ & 115 & 42 & \multirow{3}{*}{$\begin{array}{l}F 1 m \text { e } F 2 m=103 \\
F 1 m \text { e } F 3 m=54 \\
F 2 m \text { e } F 3 m=134\end{array}$} \\
\hline & $\mathrm{F} 2 \mathrm{~m}$ & 289 & 55 & \\
\hline & F3m & 078 & 89 & \\
\hline \multirow{3}{*}{$\begin{array}{l}23 \\
+P 3)\end{array}$} & F1m' & 268 & 50 & \multirow{3}{*}{$\begin{array}{l}F 1 m^{\prime} \text { e } F 2 m^{\prime}=73 \\
F 1 m^{\prime} \text { e } F 3 m^{\prime}=68 \\
F 2 m^{\prime} \text { e } F 3 m^{\prime}=108\end{array}$} \\
\hline & $\mathrm{F} 2 \mathrm{~m}^{\prime}$ & 355 & 65 & \\
\hline & F3m' & 168 & 43 & \\
\hline
\end{tabular}




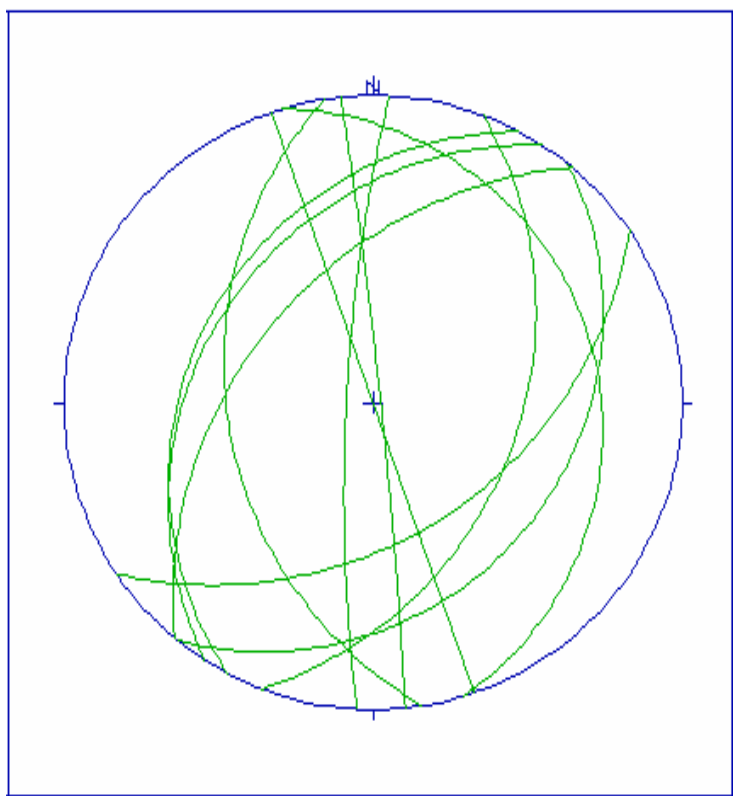

a)

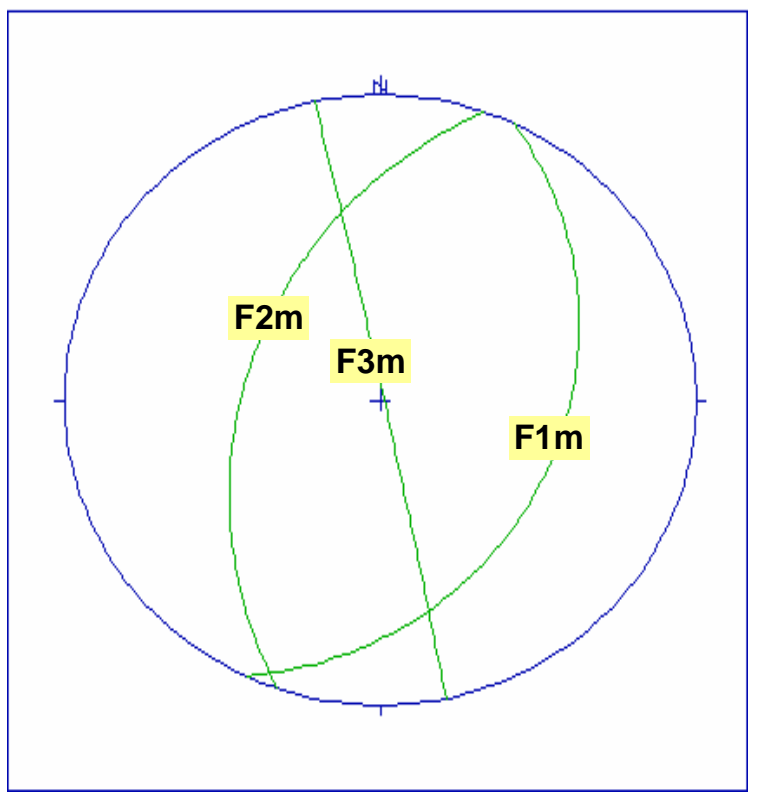

b)

Figura 4.25 - a) Orientações das famílias presentes nos locais P1 e P4; b) Orientação média dos planos que representam as famílias presentes nos locais P1 + P4 agrupados Projeção no hemisfério inferior.

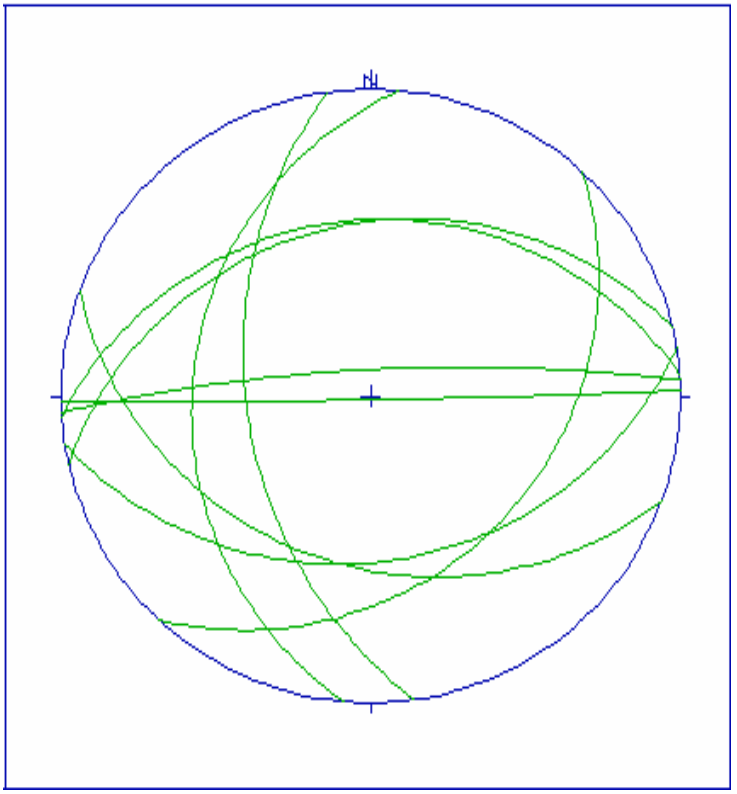

a)

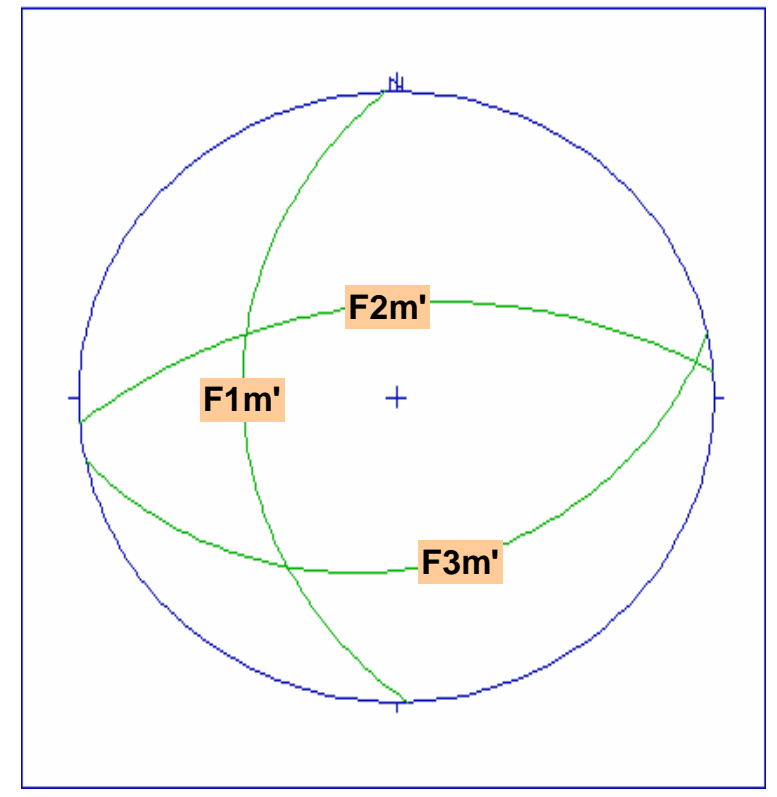

b)

Figura 4.26 - a) Orientações das famílias presentes nos locais P2 e P3; b) Orientação média dos planos que representam as famílias presentes nos locais P2 + P3 agrupados Projeção no hemisfério inferior. 


\subsubsection{Freqüência de Fraturas}

Os resultados das análises segundo as diferentes alternativas adotadas podem ser vistos no Anexo 2.

Neste capítulo são apresentados apenas os resultados provenientes da alternativa 3 de análise, em que foram calculadas as freqüências aparentes médias de fraturas por metro individualizadas por linha e por local de levantamento.

Os resultados podem ser vistos na Tabela 4.12. Nessa tabela também são apresentados valores de RQD - Rock Quality Designation. $O R Q D_{\text {teórico }}$ foi calculado a partir da freqüência de fraturas com persistência maior que $0,5 \mathrm{~m}$, enquanto $\circ R Q D_{\text {medido }}$ foi determinado diretamente a partir de sondagens horizontais (6 furos no total).

Uma outra avaliação foi feita agrupando-se as linhas com a mesma orientação (ou orientação semelhante) em cada área de estudo. Assim, foram formadas em cada uma das áreas de levantamento duas linhas de levantamento com direções perpendiculares ou aproximadamente perpendiculares entre si. Os resultados das freqüências aparentes de fraturas por metro são apresentados na Tabela 4.13.

Já na Figura 4.27 pode ser visto o comportamento da média móvel do espaçamento aparente, em função do número de medidas realizadas, calculada para cada direção de levantamento nas duas áreas.

\subsubsection{Persistência das Fraturas}

A medição da persistência das fraturas foi feita por faixa de comprimentos, de maneira a tornar o processo de levantamento mais rápido e abrangente (maior número de linhas, maiores áreas). Para tanto, foram definidas três classes de persistência, considerando as seguintes faixas de comprimentos:

- classe 1 - persistência entre $0,5 \mathrm{~m}$ e 1,0m;

- classe 2 - persistência entre 1,0m e 3,0m, normalmente na metade inferior ou na metade superior da camada de carvão;

- classe 3 - persistência entre 3,0m e 10,0m, ao longo de toda a camada.

Para a computação do comprimento total de fraturas observado em cada ponto de levantamento, adotaram-se as seguintes dimensões médias em função da classe de persistência:

- classe 1 - 0,75m;

- classe 2 - 2,0m;

- classe 3 - ponto $1=4,9 \mathrm{~m}$; ponto $2=4,4 \mathrm{~m}$; ponto $3=4,3 \mathrm{~m}$; ponto $4=4,8 \mathrm{~m}$. Corresponde ao comprimento do traço de uma fratura inclinada de $45^{\circ}$, que atravessa a camada do piso ao teto da galeria.

Nas Tabelas $4.14 \mathrm{a}$ e $4.14 \mathrm{~b}$ podem ser vistas as persistências das fraturas observadas em cada linha nos 4 pontos de levantamento, normalizadas pela área das janelas de observação. Já os resultados relativos à distribuição de cada classe de persistência podem ser observados nos histogramas de freqüência da Figura 4.28. 
Tabela 4.12 - Freqüências aparentes médias de fraturas por metro, individualizadas por linha de levantamento, nos 4 pontos de levantamento na camada Bonito, na Mina Fontanella.

\begin{tabular}{|c|c|c|c|c|c|}
\hline $\begin{array}{c}\text { Local de } \\
\text { Levantamento }\end{array}$ & $\begin{array}{c}\text { Linha de } \\
\text { Levantamento }\end{array}$ & $\begin{array}{c}\text { Direção da } \\
\text { Linha de } \\
\text { Levantamento } \\
\text { (o) }\end{array}$ & $\begin{array}{r}\text { Freqi } \\
\text { Aparente } \\
\text { Fratur } \\
\text { (fratu }\end{array}$ & $\begin{array}{l}\text { cia } \\
\text { édia de } \\
\lambda \mathrm{a} \\
\text { /m) }\end{array}$ & $\begin{array}{c}R Q D_{\text {teórico }}{ }^{\#}\left(R Q D_{\text {medido }}{ }^{\# \#}\right) \\
(\%)\end{array}$ \\
\hline \multirow{5}{*}{$\mathrm{P} 1$} & $\mathrm{~L} 1$ & 106 & $2,05(25)$ & \multirow{5}{*}{$\begin{array}{l}1,02 \\
(69)\end{array}$} & \multirow{5}{*}{$90(30)$} \\
\hline & $\mathrm{L} 2$ & 106 & $0,61(8)$ & & \\
\hline & L3 & 196 & $0,69(10)$ & & \\
\hline & L4 & 106 & $1,11(16)$ & & \\
\hline & L5 & 196 & $0,69(10)$ & & \\
\hline \multirow{5}{*}{ P4 } & L1 & 286 & $1,49(14)$ & \multirow{5}{*}{$\begin{array}{l}1,37 \\
(79)\end{array}$} & \multirow{5}{*}{$86(75)$} \\
\hline & L2 & 286 & $1,58(20)$ & & \\
\hline & L3 & 016 & $1,72(21)$ & & \\
\hline & L4 & 016 & $1,03(12)$ & & \\
\hline & L5 & 286 & $1,00(12)$ & & \\
\hline \multirow{5}{*}{ P2 } & L1 & 286 & $1,17(18)$ & \multirow{5}{*}{$\begin{array}{l}0,86 \\
(55)\end{array}$} & \multirow{5}{*}{$91(66)$} \\
\hline & L2 & 335 & $0,77(11)$ & & \\
\hline & L3 & 046 & $0,95(10)$ & & \\
\hline & L4 & 046 & $1,10(10)$ & & \\
\hline & L5 & 106 & $0,38(6)$ & & \\
\hline \multirow{3}{*}{ P3 } & L1 & 046 & $0,66(34)$ & \multirow{3}{*}{$\begin{array}{l}0,81 \\
(64)\end{array}$} & \multirow{3}{*}{$92(62)$} \\
\hline & $\mathrm{L} 2$ & 316 & 1,21 (17) & & \\
\hline & L3 & 316 & 1,03 (13) & & \\
\hline
\end{tabular}

LEGENDA:

${ }^{\#} R Q D_{\text {teórico }}=\mathrm{RQD}$ estimado segundo expressão proposta por PRIEST \& HUDSON (1976), válida para $\lambda \leq 10$ fraturas $/ \mathrm{m}$, definido como: $R Q D_{\min }(\%)=100^{*}\left(1-0,1^{*} \lambda\right)$, onde $\lambda=$ freqüência de fraturas $/ \mathrm{m}$;

\#\# $R Q D_{\text {medido }}=\mathrm{RQD}$ médio obtido através de 6 sondagens horizontais nos pilares onde foram feitos os levantamentos estruturais. O primeiro metro de sondagem foi desconsiderado na computação do $R Q D$, para eliminar a influência dos danos na periferia do pilar devido ao efeito do desmonte por explosivos.

Nota: números entre parênteses = número de fraturas observadas no levantamento. 
Tabela 4.13 - Freqüências aparentes médias de fraturas por metro, individualizadas por direção das linhas de levantamento, nas duas áreas de estudo (Área 14 - pontos 1 e 4; Área 23 - pontos 2 e 3) na camada Bonito, na Mina Fontanella.

\begin{tabular}{|c|c|c|}
\hline \multicolumn{3}{|c|}{ Área 14 de Levantamento } \\
\hline $\begin{array}{l}\text { Linhas de } \\
\text { Levantamento } \\
\text { Agrupadas }\end{array}$ & $\begin{array}{l}\text { Direção das } \\
\text { Linhas de } \\
\text { Levantamento } \\
\text { (o) }\end{array}$ & $\begin{array}{c}\text { Freqüência Aparente } \\
\text { Média de Fraturas, } \lambda \mathrm{a} \\
\text { (fraturas } / \mathrm{m} \text { ) }\end{array}$ \\
\hline $\begin{array}{c}\mathrm{P} 1(\mathrm{~L} 1+\mathrm{L} 2+\mathrm{L} 4) \\
+ \\
\mathrm{P} 4(\mathrm{~L} 1+\mathrm{L} 2+\mathrm{L} 5)\end{array}$ & $106 / 286$ & $1,30(94)$ \\
\hline $\begin{array}{c}\mathrm{P} 1(\mathrm{~L} 3+\mathrm{L} 5) \\
+ \\
\mathrm{P} 4(\mathrm{~L} 3+\mathrm{L} 4)\end{array}$ & 016 / 196 & $1,01(52)$ \\
\hline \multicolumn{3}{|c|}{ Área 23 de Levantamento } \\
\hline $\begin{array}{c}\text { Linha de } \\
\text { Levantamento }\end{array}$ & $\begin{array}{l}\text { Direção das } \\
\text { Linhas de } \\
\text { Levantamento } \\
\text { (o) }\end{array}$ & $\begin{array}{c}\text { Freqüência Aparente } \\
\text { Média de Fraturas, } \lambda a \\
\text { (fraturas } / \mathrm{m})\end{array}$ \\
\hline $\begin{array}{c}\text { P2 }(\mathrm{L} 1+\mathrm{L} 2+\mathrm{L} 5) \\
+ \\
\mathrm{P} 3(\mathrm{~L} 2+\mathrm{L} 3) \\
\end{array}$ & 286 / 316 / 335 & $0,92(64)$ \\
\hline $\begin{array}{c}\mathrm{P} 2(\mathrm{~L} 3+\mathrm{L} 4) \\
+ \\
\mathrm{P} 3(\mathrm{~L} 1) \\
\end{array}$ & 046 & $0,75(53)$ \\
\hline
\end{tabular}

Nota: números entre parênteses = número de fraturas observadas no levantamento.

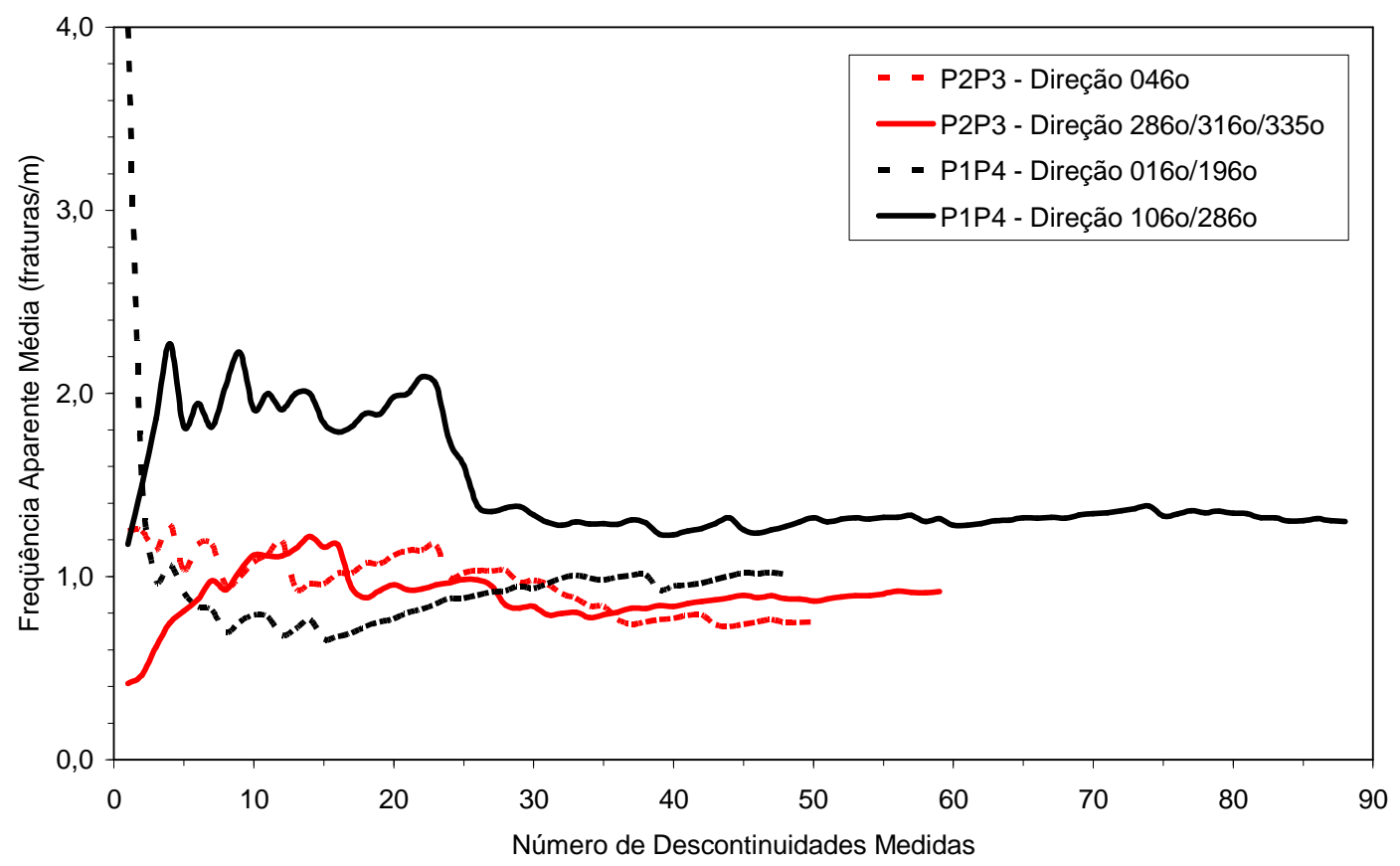

Figura 4.27 - Comportamento da média móvel do espaçamento aparente entre as fraturas, em função da área (pontos agrupados) e da direção das linhas de levantamento na camada Bonito, na Mina Fontanella. 
Tabela 4.14a - Síntese das persistências e freqüências de fraturas por área, computadas em cada linha nos pontos 1 e 4 de levantamento estrutural na camada de carvão Bonito, na Mina Fontanella.

\begin{tabular}{|c|c|c|c|c|c|c|c|c|}
\hline \multicolumn{3}{|c|}{ Localização da Janela } & \multirow{2}{*}{$\begin{array}{l}\text { Direção da } \\
\text { Linha de } \\
\text { Medição } \\
\left({ }^{\circ}\right)\end{array}$} & \multirow{2}{*}{$\begin{array}{l}\text { Número de } \\
\text { Fraturas } \\
\text { Observadas }\end{array}$} & \multirow{2}{*}{$\begin{array}{c}\Sigma \text { das Persistências } \\
\text { das Fraturas } \\
\text { Observadas } \\
(\mathrm{m})\end{array}$} & \multirow{2}{*}{$\begin{array}{l}\text { Área da } \\
\text { Janela } \\
\left(\mathrm{m}^{2}\right)\end{array}$} & \multirow{2}{*}{$\begin{array}{c}\text { Freqüência } \\
\text { Aparente de } \\
\text { Fraturas por Área } \\
\left.\text { (fraturas } / \mathrm{m}^{2}\right)\end{array}$} & \multirow{2}{*}{$\begin{array}{l}\text { Persistência de } \\
\text { Fraturas por Área } \\
\left(\mathrm{m} / \mathrm{m}^{2}\right)\end{array}$} \\
\hline $\begin{array}{l}\text { Pon } \\
\text { de } N\end{array}$ & $\begin{array}{l}\text { inha } \\
\text { dição }\end{array}$ & Endereço na Mina & & & & & & \\
\hline \multirow{6}{*}{ P1 } & $\mathrm{L} 1$ & $\begin{array}{c}\text { Eixo 6NW - G4, entre T2 } \\
\text { e T1, lado esquerdo }\end{array}$ & 106 & 25 & 51,0 & 40,1 & 0,62 & 1,27 \\
\hline & L2 & $\begin{array}{c}\text { Eixo 6NW - G4, entre T2 } \\
\text { e T1, lado esquerdo }\end{array}$ & 106 & 8 & 18,5 & 39,4 & 0,20 & 0,47 \\
\hline & L3 & $\begin{array}{c}\text { Eixo 6NW - T2 entre G4 } \\
\text { e G3, lado esquerdo }\end{array}$ & 196 & 10 & 31,6 & 70,0 & 0,14 & 0,45 \\
\hline & L4 & $\begin{array}{c}\text { Eixo 6NW - G4, entre T3 } \\
\text { e T2, lado esquerdo }\end{array}$ & 106 & 16 & 19,3 & 46,3 & 0,35 & 0,42 \\
\hline & L5 & $\begin{array}{c}\text { Eixo 6NW - T3, entre G4 } \\
\text { e G3, lado esquerdo }\end{array}$ & 196 & 10 & 18,3 & 54,5 & 0,18 & 0,34 \\
\hline & \multicolumn{3}{|c|}{ Totais } & 69 & 138,6 & 250,4 & 0,28 & 0,55 \\
\hline \multirow{6}{*}{ P4 } & $\mathrm{L} 1$ & $\begin{array}{c}\text { Eixo 6NW - Painel 2SW } \\
\text { - T6, entre G0 e G1, lado } \\
\text { esquerdo }\end{array}$ & 286 & 14 & 26,1 & 51,3 & 0,27 & 0,51 \\
\hline & L2 & $\begin{array}{c}\text { Eixo 6NW - Painel 2SW } \\
\text { - T6, entre G1 e G2, lado } \\
\text { direito }\end{array}$ & 286 & 20 & 69,9 & 40,8 & 0,49 & 1,71 \\
\hline & L3 & $\begin{array}{c}\text { Eixo 6NW - Painel 2SW } \\
\text { - G1 entre T6 e T5, lado } \\
\text { direito } \\
\end{array}$ & 016 & 21 & 35,1 & 51,0 & 0,41 & 0,69 \\
\hline & L4 & $\begin{array}{l}\text { Eixo 6NW - Painel 2SW } \\
\text { - G1, entre T5 e T4, lado } \\
\text { esquerdo }\end{array}$ & 016 & 12 & 26,5 & 48,6 & 0,25 & 0,54 \\
\hline & L5 & $\begin{array}{l}\text { Eixo 6NW - Pinel 2SW - } \\
\text { T6, entre G2 e G3, lado } \\
\text { direito }\end{array}$ & 286 & 12 & 33,0 & 37,4 & 0,32 & 0,88 \\
\hline & \multicolumn{3}{|c|}{ Totais } & 79 & 190,7 & 229,2 & 0,34 & 0,83 \\
\hline
\end{tabular}


Tabela 4.14b - Síntese das persistências e freqüências de fraturas por área, computadas em cada linha nos pontos 2 e 3 de levantamento estrutural na camada de carvão Bonito, na Mina Fontanella.

\begin{tabular}{|c|c|c|c|c|c|c|c|c|}
\hline \multicolumn{3}{|c|}{ Localização da Janela } & \multirow{2}{*}{$\begin{array}{l}\text { Direção da } \\
\text { Linha de } \\
\text { Medição } \\
\left({ }^{\circ}\right)\end{array}$} & \multirow{2}{*}{$\begin{array}{l}\text { Número de } \\
\text { Fraturas } \\
\text { Observadas }\end{array}$} & \multirow{2}{*}{$\begin{array}{c}\text { das Persistências } \\
\text { das Fraturas } \\
\text { Observadas } \\
(\mathrm{m})\end{array}$} & \multirow{2}{*}{$\begin{array}{l}\text { Área da } \\
\text { Janela } \\
\left(\mathrm{m}^{2}\right)\end{array}$} & \multirow{2}{*}{$\begin{array}{c}\text { Freqüência } \\
\text { Aparente de } \\
\text { Fraturas por Área } \\
\left(\text { fraturas } / \mathrm{m}^{2}\right)\end{array}$} & \multirow{2}{*}{$\begin{array}{c}\text { Persistência de } \\
\text { Fraturas por Área } \\
\left(\mathrm{m} / \mathrm{m}^{2}\right)\end{array}$} \\
\hline $\begin{array}{l}\text { Pont } \\
\text { de } \mathrm{N}\end{array}$ & $\begin{array}{l}\text { ¿inha } \\
\text { dição }\end{array}$ & Endereço na Mina & & & & & & \\
\hline \multirow{6}{*}{$\mathrm{P} 2$} & L1 & $\begin{array}{c}\text { Eixo 8NW - G2, entre T0 } \\
\text { e T1, lado direito }\end{array}$ & 286 & 18 & 52,6 & 44,9 & 0,40 & 1,17 \\
\hline & L2 & $\begin{array}{c}\text { Eixo 8NW - G2, entre T1 } \\
\text { e T2, lado direito }\end{array}$ & 335 & 11 & 37,4 & 57,7 & 0,19 & 0,65 \\
\hline & L3 & $\begin{array}{c}\text { Eixo 8NW - T0 entre G2 } \\
\text { e G3, lado direito }\end{array}$ & 046 & 10 & 28,2 & 39,4 & 0,25 & 0,72 \\
\hline & L4 & $\begin{array}{c}\text { Eixo 8NW - T0, entre G3 } \\
\text { e G4, lado direito }\end{array}$ & 046 & 10 & 22,5 & 40,0 & 0,25 & 0,57 \\
\hline & L5 & $\begin{array}{c}\text { Eixo 8NW - G4, entre T1 } \\
\text { e T0, lado direito }\end{array}$ & 106 & 6 & 19,0 & 46,5 & 0,13 & 0,41 \\
\hline & \multicolumn{3}{|c|}{ Totais } & 55 & 159,8 & 228,2 & 0,24 & 0,70 \\
\hline \multirow{4}{*}{ P3 } & L1 & $\begin{array}{c}\text { Eixo 7SW - G1, entre T2 } \\
\text { e T1/T0, lado direito }\end{array}$ & 046 & 34 & 92,7 & 155,4 & 0,22 & 0,6 \\
\hline & L2 & $\begin{array}{c}\text { Eixo 7SW - T2, entre G1 } \\
\text { e G2, lado direito }\end{array}$ & 316 & 17 & 41,9 & 40,0 & 0,43 & 1,05 \\
\hline & L3 & $\begin{array}{c}\text { Eixo 7SW - T2 entre G2 } \\
\text { e G3, lado direito } \\
\end{array}$ & 316 & 13 & 31,4 & 56,4 & 0,23 & 0,56 \\
\hline & \multicolumn{3}{|c|}{ Totais } & 64 & 166,0 & 251,8 & 0,25 & 0,66 \\
\hline
\end{tabular}




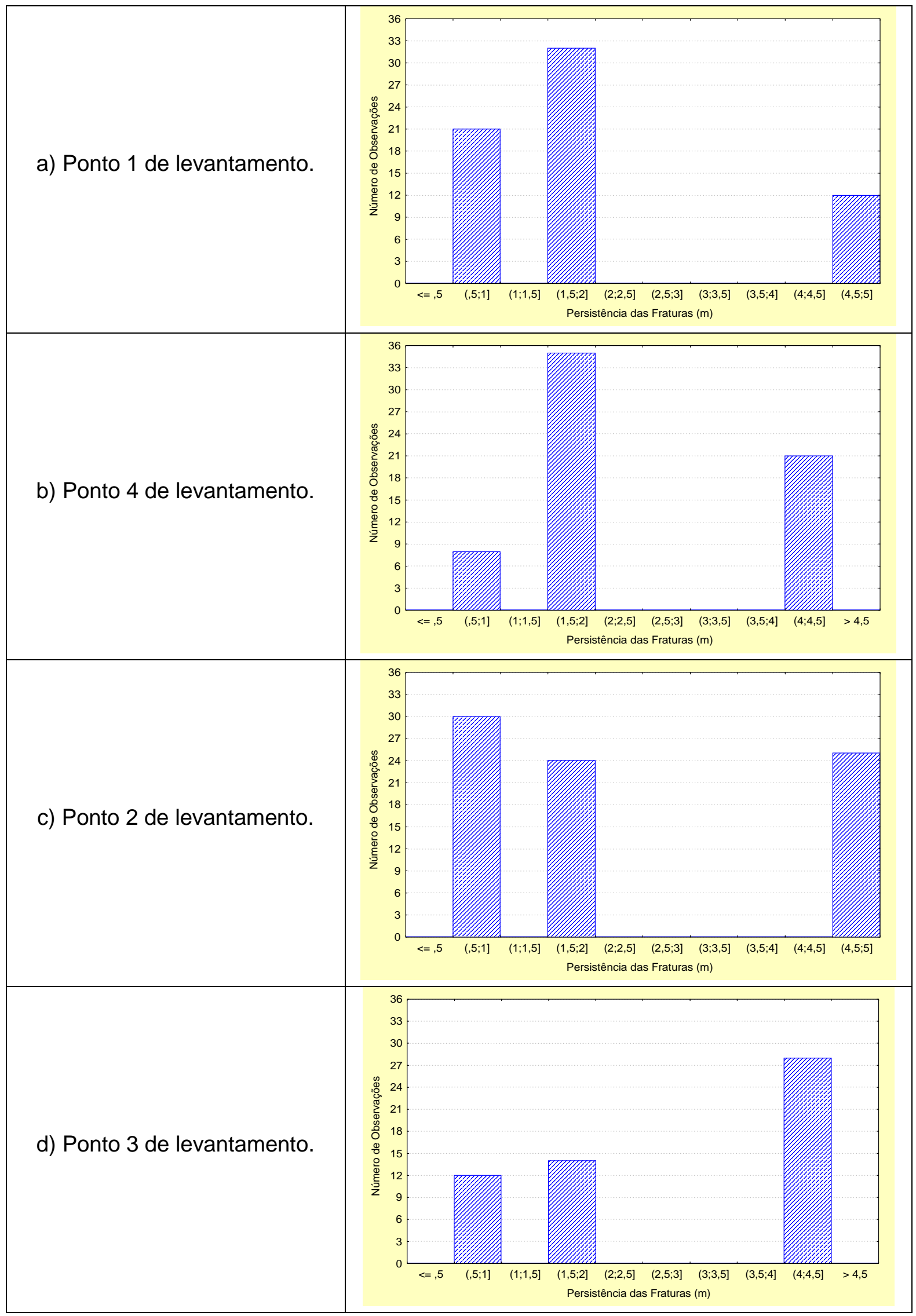

Figura 4.28 - Histogramas de freqüência das persistências de todas as fraturas medidas nos 4 pontos de amostragem. 


\subsubsection{Características dos Contatos Entre os Planos das Fraturas}

As fraturas apresentam características de alteração, abertura e preenchimento semelhante nos diferentes locais mapeados. A análise dos dados foi feita agrupando-se os locais de acordo com a proximidade espacial entre eles dentro da mina (Área 14 - pontos 1 e 4; Área 23 - pontos 2 e 3), analogamente a uma das alternativas aplicadas para o tratamento dos dados relativos ao espaçamento entre fraturas.

Quanto à rugosidade dos planos das descontinuidades, observa-se um JRC médio da ordem de 3 . O grau de alteração varia de "sem alteração" a "levemente alterada". Via de regra, as descontinuidades estão fechadas ou possuem abertura menor que $1 \mathrm{~mm}$. Normalmente não possuem preenchimento, porém, quando preenchidas, o material apresenta-se bastante oxidado. No ponto 4, em especial, observou-se nos testemunhos de sondagens horizontais a presença de fraturas fortemente seladas com preenchimento de carbonato. Não foi observada a presença de água em nenhuma das áreas mapeadas da Mina Fontanella. $\mathrm{Na}$ Figura 4.29 podem ser vistos histogramas de freqüência com os dados das diferentes características das descontinuidades levantados nos diferentes locais de estudo na camada Bonito, na Mina Fontanella.

\subsubsection{Discussão dos Resultados do Mapeamento Estrutural}

Os resultados de obtidos a partir do mapeamento estrutural mostram a existência de duas áreas distintas, em termos de densidade de fraturamento, uma formada pelos pontos de levantamento 1 e 4 (área 14) e outra pelos pontos 2 e 3 (área 23). O mesmo não pode ser dito sobre as demais características estudadas como persistência, abertura das fraturas, preenchimentos, etc.. Ambas as áreas, definidas pelo critério de proximidade espacial dentro da mina, se caracterizam por apresentar pelo menos 3 famílias principais de fraturas. Do ponto de vista do grau de fraturamento, a área 14 se mostra mais fraturada, com freqüência aparente média superior a 1,0 fratura/m, enquanto a área 23 apresenta uma freqüência menor que 1,0 fratura/m. Esse comportamento se mostrou recorrente, independentemente da forma adotada para o tratamento dos dados de campo.

Já sob a ótica da orientação das famílias, definidas como representativas de cada área, são observadas normalmente duas famílias que apresentam direções de mergulho aproximadamente opostas entre si, enquanto uma terceira possui direção de mergulho defasada dessas duas, de aproximadamente $45^{\circ}$ na área 14 e $90^{\circ}$ na área 23. Em termos práticos, o mais importante a observar é a presença de fraturas inclinadas com ângulos de mergulho na faixa entre $40^{\circ}$ e $60^{\circ}$. Essas inclinações são as mais críticas do ponto de vista mecânico e tendem a influenciar negativamente na resistência dos pilares de duas formas distintas:

a) enfraquecendo globalmente a resistência característica da camada, pela presença de planos de fraqueza disseminados no pilar. Algumas evidências desse aspecto podem ser vistas na Figura 4.30, que mostra a relação entre a resistência à compressão uniaxial de laboratório e a densidade média de fraturas observada in situ na camada de carvão;

b) subtraindo parte da área resistiva do pilar, devido ao escorregamento de blocos (cunhas ou "costelas") nas laterais e nos vértices do pilar. 


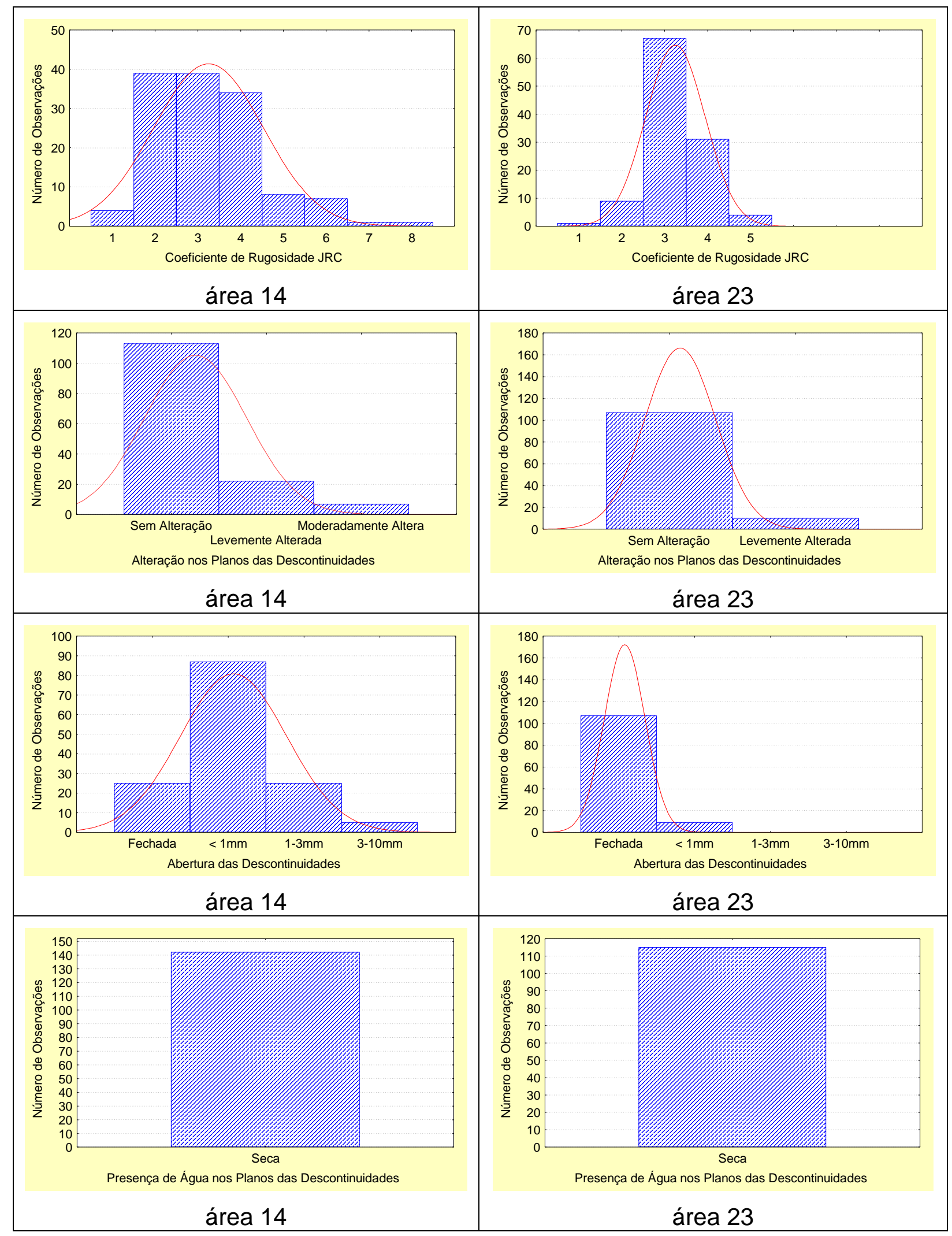

Figura 4.29 - Resultados dos levantamentos efetuados no que se refere à rugosidade (JRC), grau de alteração, abertura e presença de água nos planos de descontinuidades, nas duas áreas de estudo (área $14 \equiv \mathrm{P} 1+\mathrm{P} 4$; área $23 \equiv \mathrm{P} 2+\mathrm{P} 3$ ). 
Outro aspecto que vale ser destacado é o comportamento do índice de qualidade da rocha, $R Q D$, que integra a maioria das classificações geomecânicas de maciços. Dada a sua importância, cabe uma apreciação do porquê da diferença considerável entre o valor calculado teoricamente e o medido diretamente nas sondagens horizontais nos diferentes locais de levantamento na Mina Fontanella, conforme mostra a Figura 4.31.

$O R Q D_{\text {teórico, }}$ estimado a partir da freqüência aparente média de fraturas, $\lambda a$, se mostrou entre $10 \%$ e $60 \%$ superior ao $R Q D_{\text {medido, }}$, determinado nas sondagens (ou $31 \%$ em média). Essa diferença pode ser explicada pelo fato do parâmetro freqüência de fraturas não contemplar aquelas descontinuidades com persistência inferior a $0,5 \mathrm{~m}$, que são os "cleats", cujo espaçamento varia entre $0,10 \mathrm{~m}$ a $0,15 \mathrm{~m}$, aproximadamente. Já as sondagens horizontais atravessaram todas as descontinuidades, incluindo os "cleats" que fraturas verticais, o que explicaria o menor valor do $R Q D_{\text {medido. }}$ Assim, o uso do parâmetro freqüência de fraturas para a estimativa do RQD deve ser feito com cuidado, sob pena de a qualidade do maciço ser superestimada.

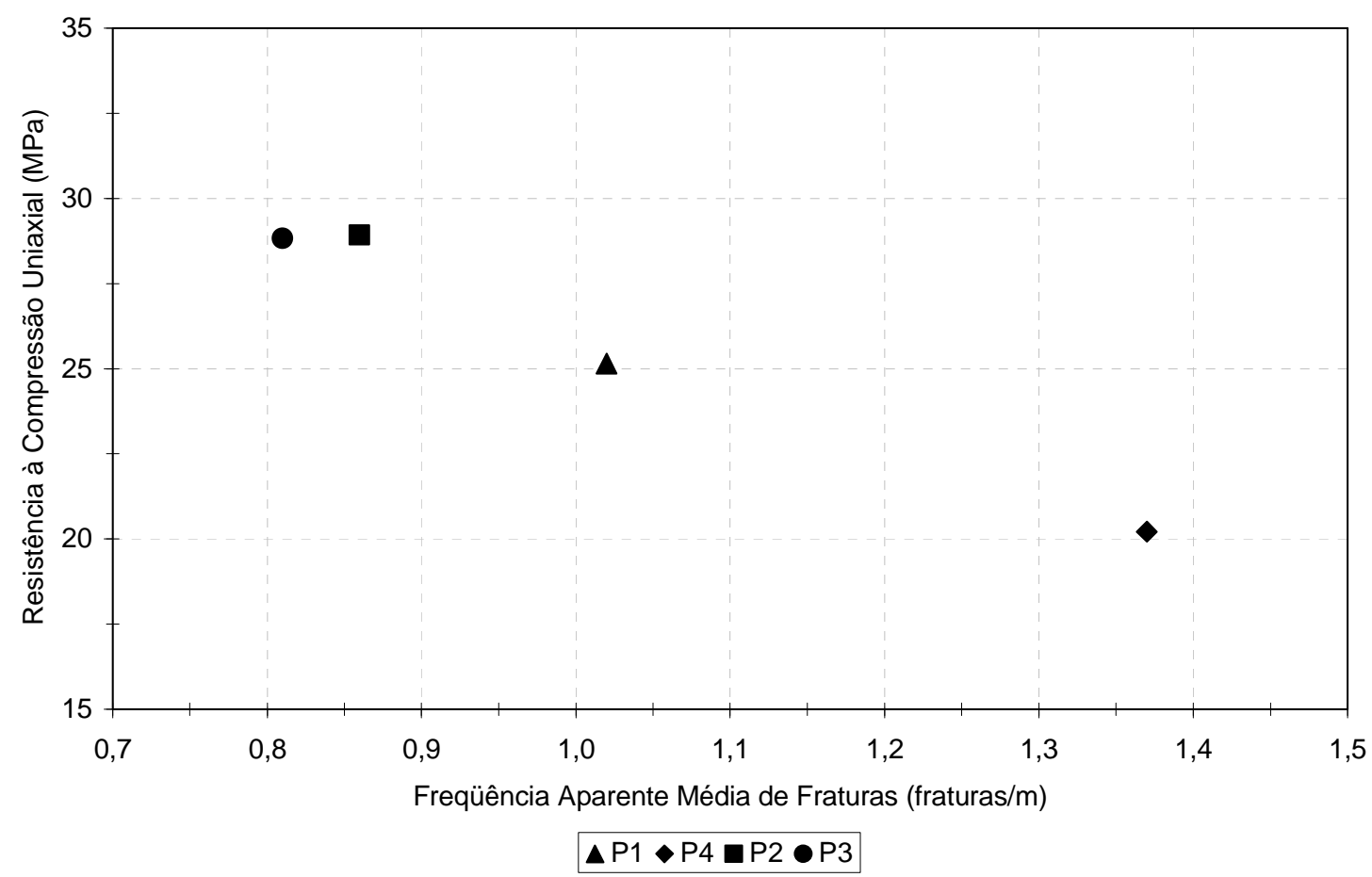

Figura 4.30 - Relação entre a resistência de laboratório (CPs cúbicos com lado entre $5 \mathrm{~cm}$ e $10 \mathrm{~cm}$ ) e a freqüência de fraturas nos diferentes locais de estudo na camada de carvão Bonito, na Mina Fontanella. 


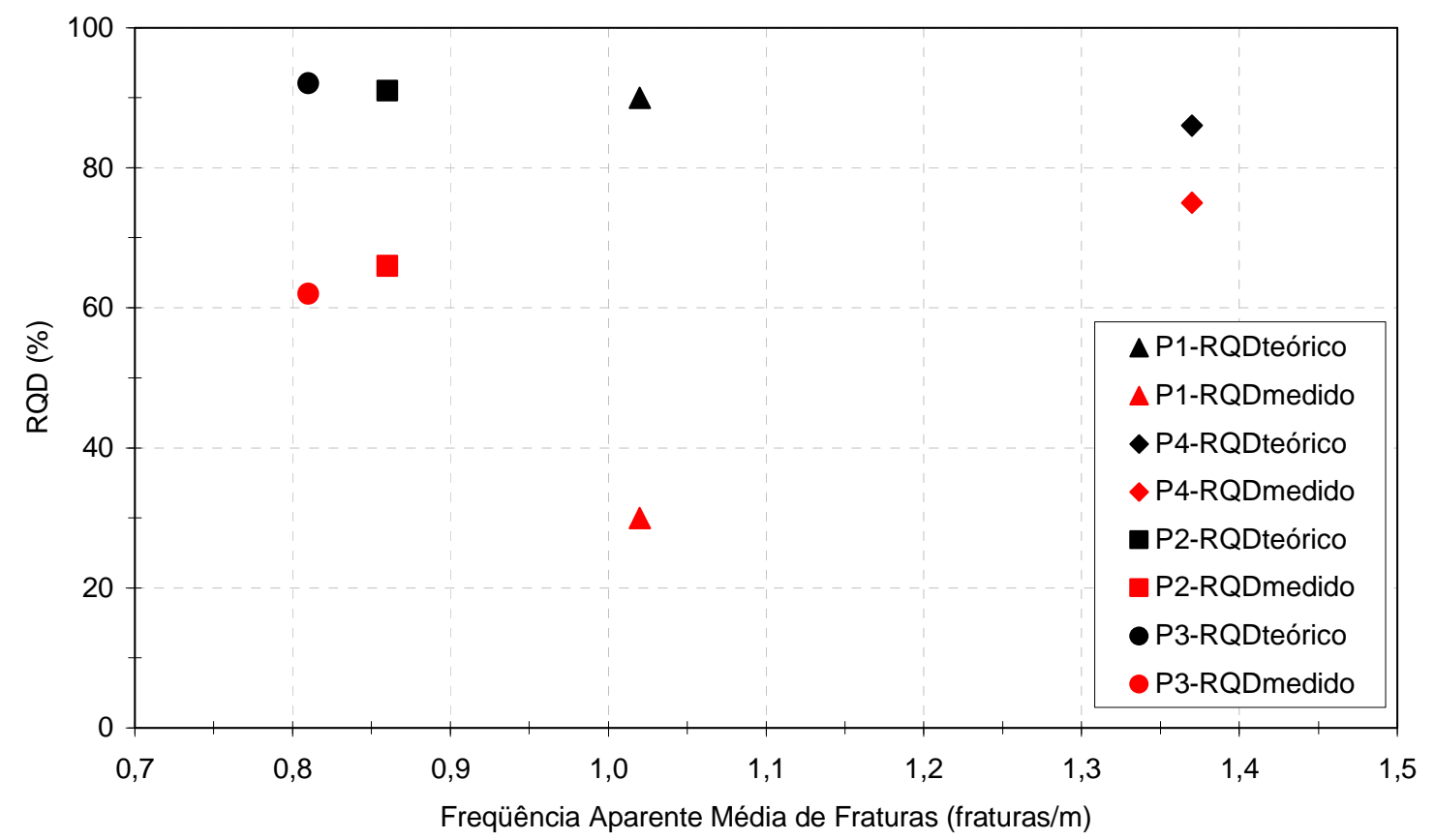

Figura 4.31 - Relação entre os RQDs calculados teoricamente $\left(R Q D_{\text {teórico }}\right)$ e determinados diretamente através de sondagens horizontais $\left(R Q D_{\text {medido }}\right)$, em função da freqüência de fraturas na camada de carvão Bonito, na Mina Fontanella.

\subsection{Investigações In Situ nas Camadas de Carvão Utilizando Geofísica de Refração}

Em todas as minas estudadas os procedimentos adotados foram os sugeridos pela norma ASTM D 5777 (2000) e pelo método da ISRM (2004) para a investigação indireta de subsuperfície utilizando sísmica de refração. Todos os levantamentos foram realizados a partir do acesso direto às camadas de carvão em subsolo.

\subsubsection{Equipamentos Utilizados e Procedimentos de Execução Adotados}

Em ambas as técnicas de levantamento os equipamentos utilizados consistiram de um sismógrafo Geometrics de 24 canais, 12 geofones horizontais com freqüência natural de $14 \mathrm{~Hz}$ para a captação do sismo, um microcomputador laptop para o processamento dos dados em tempo real e uma marreta de $5 \mathrm{~kg}$ para a geração do sismo.

O tratamento dos sismogramas obtidos nos levantamentos foi feito utilizando-se os softwares Geometrics Seismodule Controler, Pickwin e Plotrefa, fornecidos pelo fabricante do equipamento de geofísica. A Figura 4.32 mostra o conjunto de equipamentos utilizados nos levantamentos. 


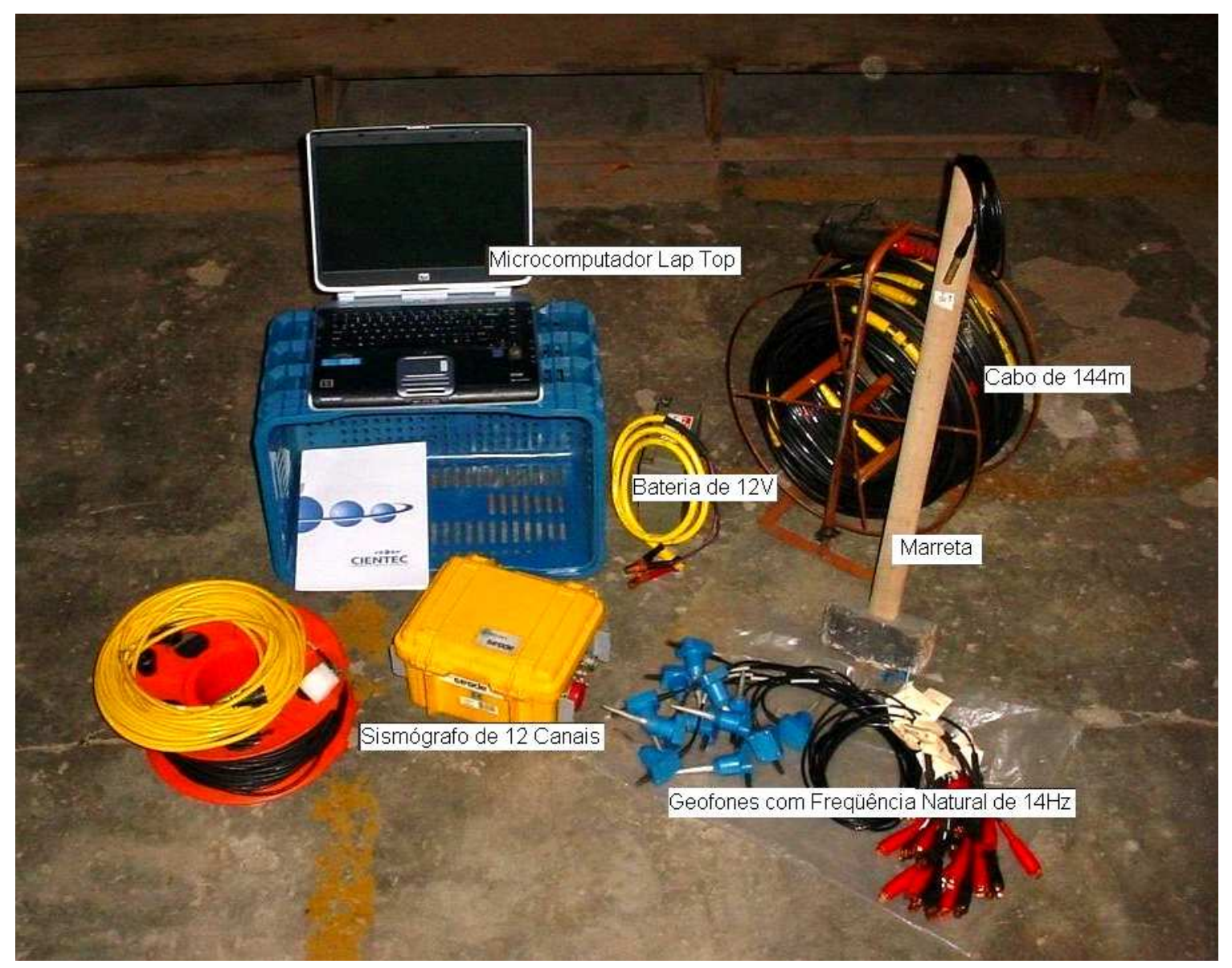

Figura 4.32 - Equipamento utilizado nos levantamentos geofísicos.

A fixação dos geofones foi precedida da marcação da posição no pilar e abertura de pequenas cavidades na parede $(2$ a $5 \mathrm{~cm}$ de profundidade $\times 2 \mathrm{~cm}$ altura $\times 2 \mathrm{~cm}$ de largura). Os geofones, com um pino na ponta com comprimento variando entre 3 e $6 \mathrm{~cm}$, foram solidarizados à parede rochosa através de uma pasta de gesso. Normalmente cerca de 3 a 4 minutos foram suficientes para a pega inicial do gesso. Um período de cerca de 5 minutos foi suficiente para o gesso se tornar uma massa rígida. O consumo do gesso foi de $1 \mathrm{~kg}$ para cada 30 geofones fixados. A Figura 4.33 mostra o geofone solidário na parede do pilar de carvão.

Após a fixação dos geofones na geometria da linha prevista (técnica de perfilagem), foram gerados sismos batendo-se a mareta em parafusos fixados na parede do pilar, como mostra a Figura 4.34, ou na própria rocha.

O tempo dispendido para o levantamento em cada local (2 a 3 linhas através de perfilagem ou dois pilares por radiação) foi de aproximadamente 3 horas, com uma equipe de dois auxiliares e dois técnicos. A tarefa mais demorada está associada à abertura das cavidades na rocha para a fixação dos geofones.

Duas técnicas, distintas pelo arranjo dos geofones, foram utilizadas nos levantamentos geofísicos nos pilares de carvão: a de "perfilagem" e a de "radiação". 


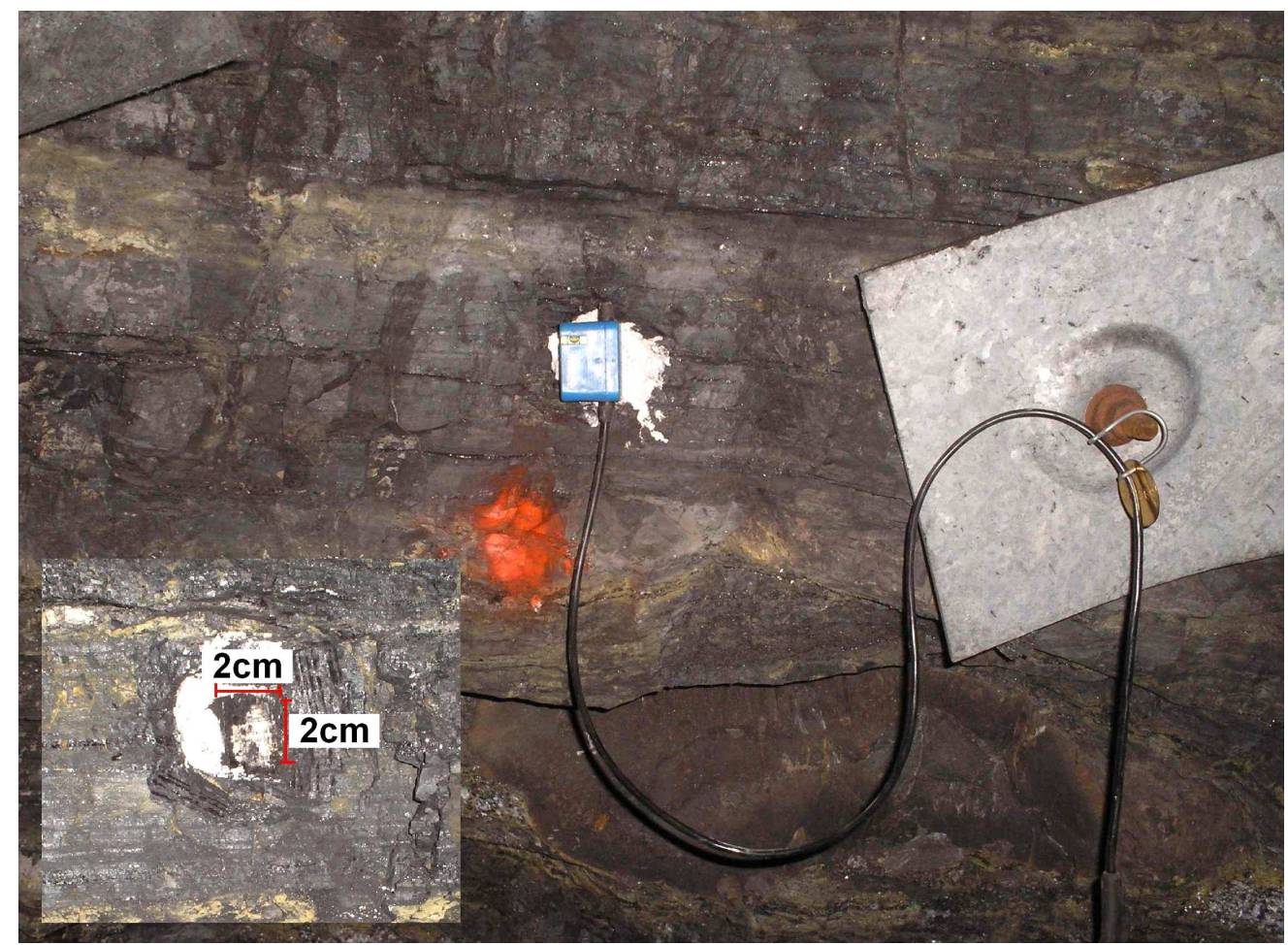

Figura 4.33 - Geofone fixado na rocha. No detalhe, cavidade feita para a inserção do pino com a pasta de gesso para a solidarização do geofone na rocha.

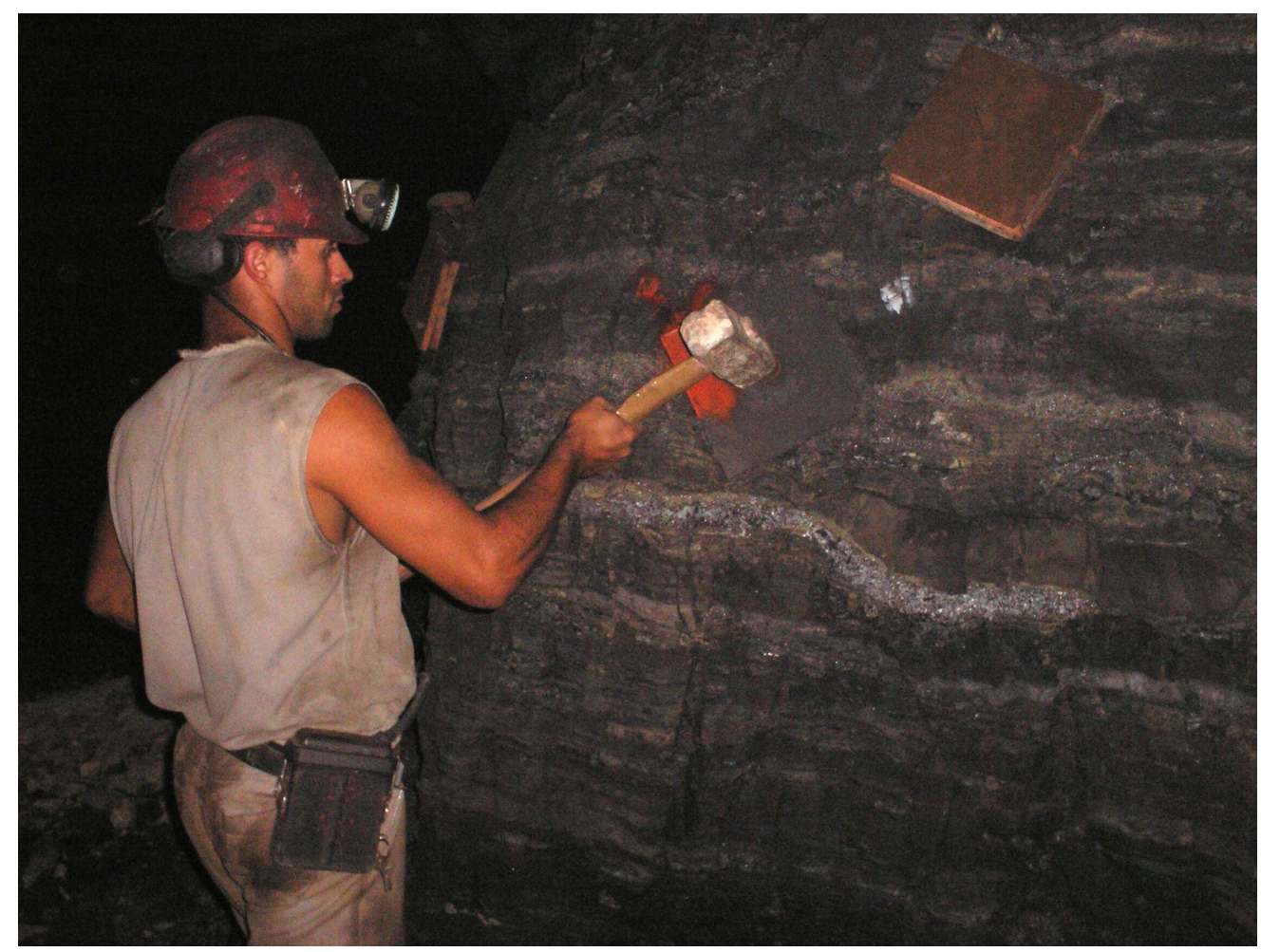

Figura 4.34 - Geração manual do sismo com marreta de 5kg. 


\section{Técnica de Perfilagem}

A técnica de perfilagem foi adotada com o objetivo de determinar pelo menos dois níveis de velocidade sísmica: uma correspondente à velocidade das ondas sísmicas na zona periférica do pilar (região do pilar danificada pelo efeito do desmonte durante a escavação) e outra correspondente à velocidade das ondas sísmicas na região central do pilar (zona de rocha não perturbada pelo desmonte). Nessa técnica de levantamento os geofones são instalados em linha ao longo da parede do pilar. A configuração dos geofones pode ser vista no desenho esquemático da Figura 4.35. Como regra, foram gerados três sismos para a determinação da velocidade em cada linha: um antes do primeiro geofone, um no meio da linha e outro após o último geofone da linha.

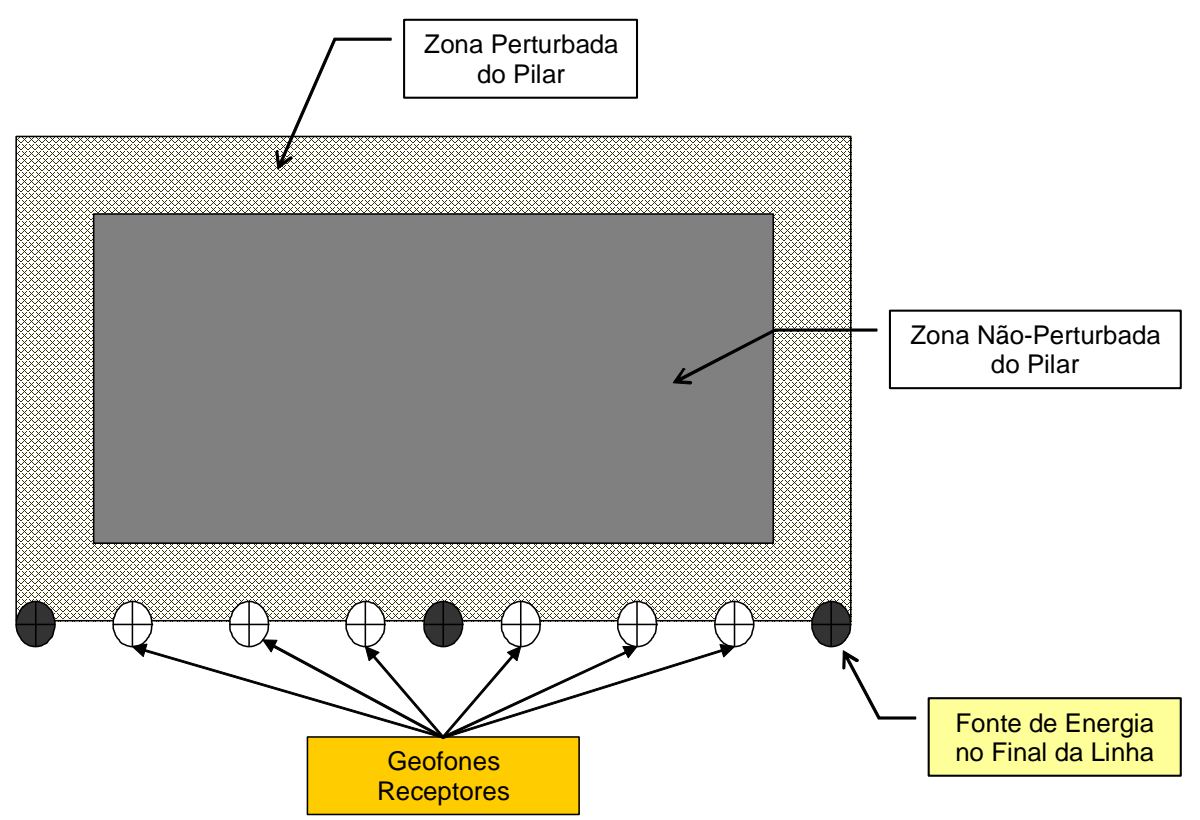

Figura 4.35 - Técnica de perfilagem - Disposição típica dos geofones e dos pontos de geração do sismo no pilar.

\section{Técnica de Radiação}

Esta técnica foi adotada para a medição da velocidade sísmica considerando longos percursos em zona não perturbada do pilar. Esse procedimento permitiu a determinação da velocidade sísmica menos influenciada pela zona perturbada do pilar.

Nessa técnica os geofones foram dispostos em posições nos 4 lados do pilar, circundando-o integralmente. Nessa configuração, o sismo gerado num lado do pilar pode ser captado no outro lado do pilar por mais de um geofone. Os sismos foram gerados em dois lados adjacentes do pilar, normalmente ao lado dos geofones 3 e 12, de forma que as medidas de velocidade pudessem ser tomadas em duas direções ortogonais. A configuração básica dos geofones no pilar é apresentada na Figura 4.36. 


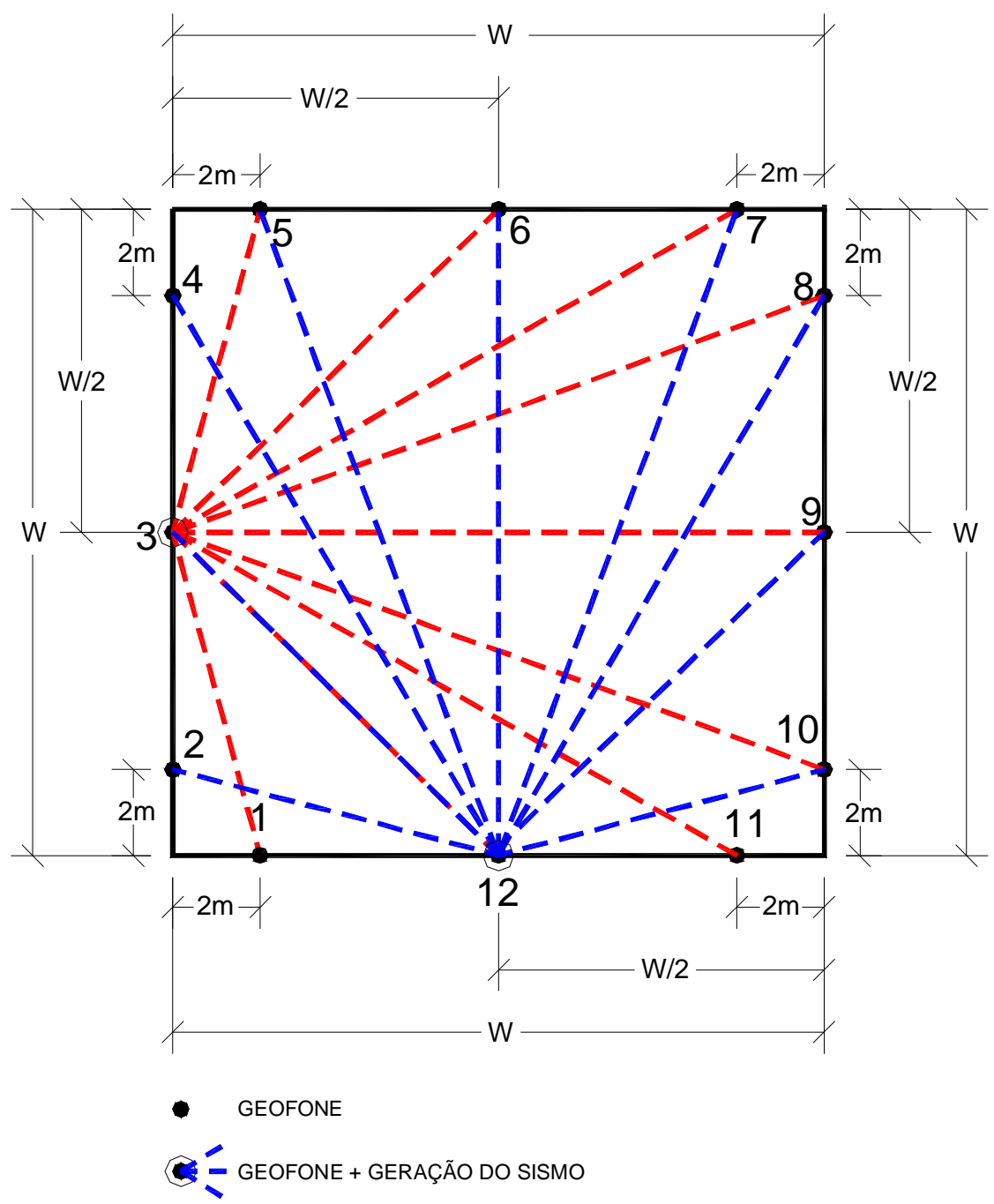

Figura 4.36 - Técnica de radiação - Disposição típica dos geofones e dos pontos de geração dos sismos no pilar de carvão.

\subsubsection{Levantamentos na Mina Fontanella}

$\mathrm{Na}$ Mina Fontanella os levantamentos foram realizados, em duas fases distintas, nos mesmos quatro locais da mina de onde foram coletadas as amostras de carvão para ensaios em laboratório. Na primeira fase foi aplicada a técnica de perfilagem. Na segunda fase a técnica adotada foi a de radiação. Todos os levantamentos foram feitos sob condições de rocha aparentemente seca.

Normalmente, a localização das linhas de geofísica foi a mesma das linhas de levantamento estrutural. Somente no ponto 4 não foi possível a locação sobre as linhas dos levantamentos estruturais devido à impossibilidade de acesso ao local (galeria inundada). Quando foi usada a técnica por radiação, o levantamento foi realizado nos mesmos pilares onde foram localizadas as linhas de perfilagem. 
Em cada local foram feitas pelo menos 2 linhas, dispostas ortogonalmente entre si (uma na galeria, outra no travessão), utilizando em cada linha até 12 geofones horizontais para a formação do perfil. As exceções ficaram por conta do ponto 1 , em que foram feitas duas linhas numa mesma direção, sendo 2 geofones comuns às duas linhas (P1-L1A e P1-L1B), e do ponto 4, em que as linhas foram menores devido às dimensões reduzidas dos pilares (8 geofones na linha P4-L1 e 10 geofones na P4-L2). A localização das linhas de levantamento estão indicadas em azul nos mapas das Figuras 4.24a a 4.24d.

\subsubsection{Resultados Obtidos}

Sismogramas típicos dos levantamentos utilizando a técnica de perfilagem no Ponto 1, onde foi observada a menor velocidade de propagação de ondas sísmicas na camada Bonito, podem ser vistos na Figura 4.37a. A Figura 4.37b mostra o gráfico "distância x tempo de chegada da primeira onda nos geofones" utilizado para o cálculo das velocidades de propagação da onda sísmica na periferia do pilar. Vale ressaltar que nessa região da mina (Ponto 1), as galerias (não os travessões) foram abertas utilizando uma sistemática de desmonte a fogo diferente da técnica de "fogo no duro", empregada no restante da mina. Nesse local, antes do desmonte com explosivos, duas faces do futuro pilar foram previamente conformadas através de cortes verticais, feitos com a cortadeira universal. O resultado do desmonte foi a formação de duas faces do pilar, na direção das galerias, com qualidade "aparente" de desmonte mecânico. As linhas de perfilagem $1 \mathrm{~A}$ e $1 \mathrm{~B}$ foram localizadas nessas faces do pilar. As outras duas faces, na direção dos travessões, foram conformadas com a técnica de desmonte "fogo no duro". Sobre uma das faces de travessão foi localizada a linha de perfilagem 2.

Os sismogramas da Figura 4.38a refletem a propagação da onda no Ponto 3 , onde foram observadas as maiores velocidades na mina. Na Figura $4.38 \mathrm{~b}$ é apresentada a relação "distância $x$ tempo de chegada da primeira onda nos geofones". Nesse local, assim como nos Pontos 2 e 4, a periferia do pilar encontra-se fortemente perturbada pelo desmonte a fogo, conforme representado no desenho esquemático da Figura 4.32. Além disso, a superfície do pilar é muito irregular, não permitindo a configuração de uma linha de geofones perfeitamente reta. Isso tende a introduzir erros na determinação da distância real entre geofones ou entre os geofones e a posição de geração dos sismos.

Os valores de velocidades sísmicas medidas nos diferentes locais, segundo as duas diferentes técnicas de levantamento, são apresentados nas Tabelas $4.15 \mathrm{a}$ (técnica de perfilagem) e 4.15b (técnica de radiação).

$\mathrm{Na}$ aplicação da técnica de perfilagem, um dos objetivos iniciais, o de distinguir a velocidade periférica da velocidade no interior do pilar, não foi alcançado. Aparentemente, isso se deve ao fato de que a transição entre a rocha "fraturada" na periferia do pilar e a rocha não perturbada no interior do pilar, é gradual. Dessa forma, não fica caracterizada claramente a separação entre uma e outra região do pilar e, por conseqüência, não existe um plano de refração bem definido capaz de caracterizar mudança de velocidade. Esse mesmo comportamento foi observado nas outras duas minas onde foram realizados levantamentos geofísicos. 

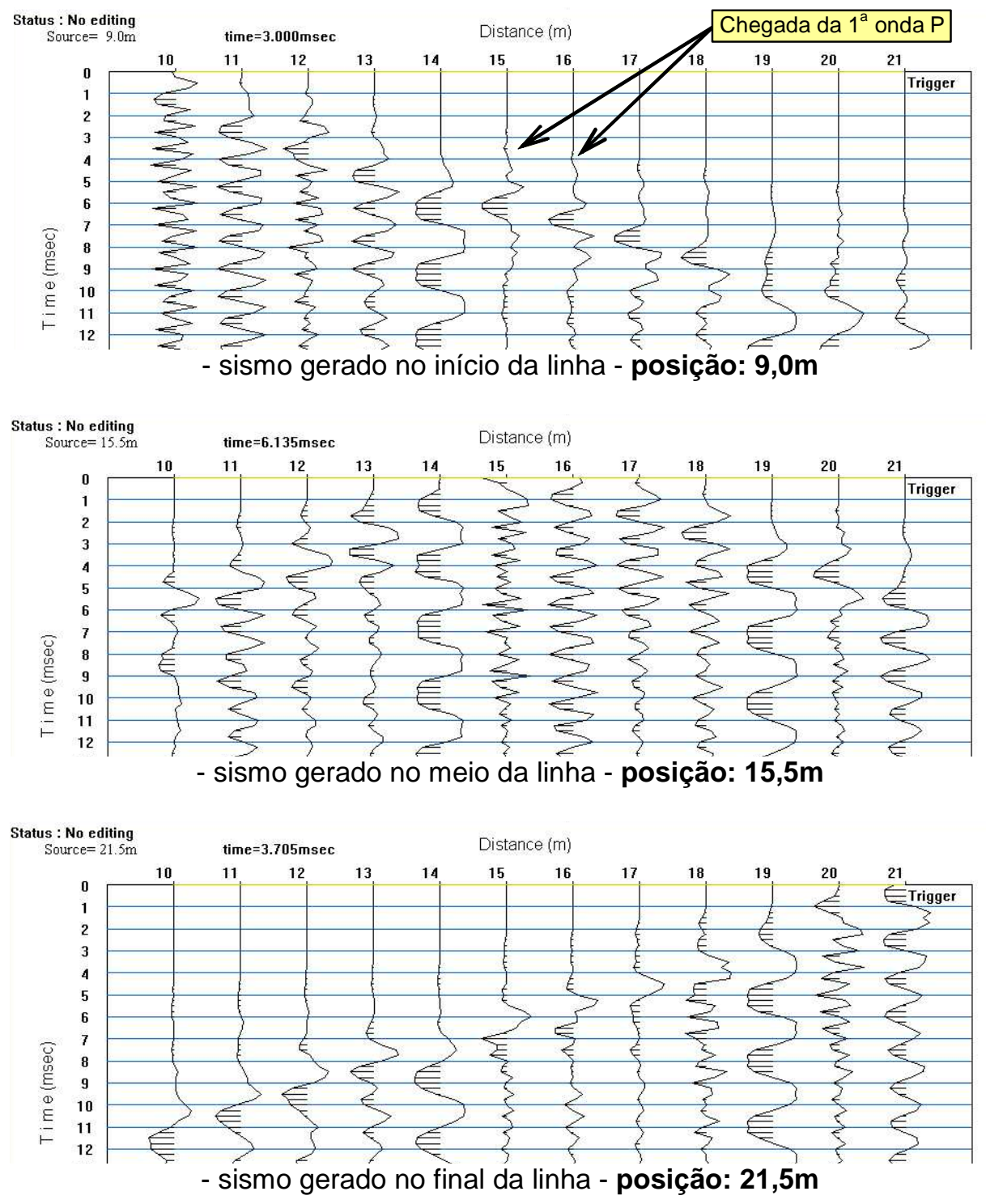

Figura 4.37a - Técnica de perfilagem - Sismogramas obtidos na linha $1 \mathrm{~A}$ do Ponto 1, na Mina Fontanella. Linha com 12 geofones.

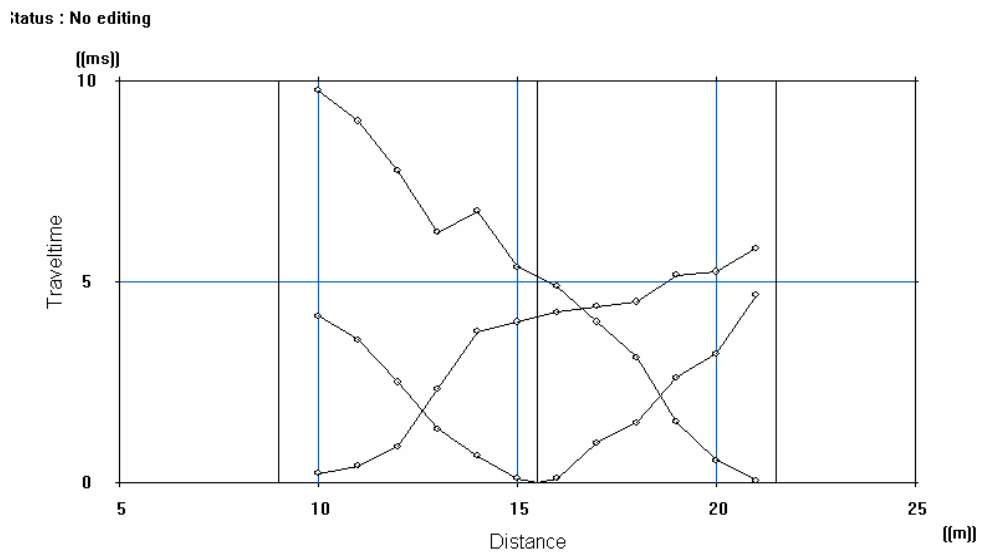

Figura 4.37b - Técnica de perfilagem - Relação "distância x tempo de chegada da primeira onda" composta a partir dos sismogramas obtidos na linha $1 \mathrm{~A}$ do Ponto 1 , na camada Bonito, na Mina Fontanella. 

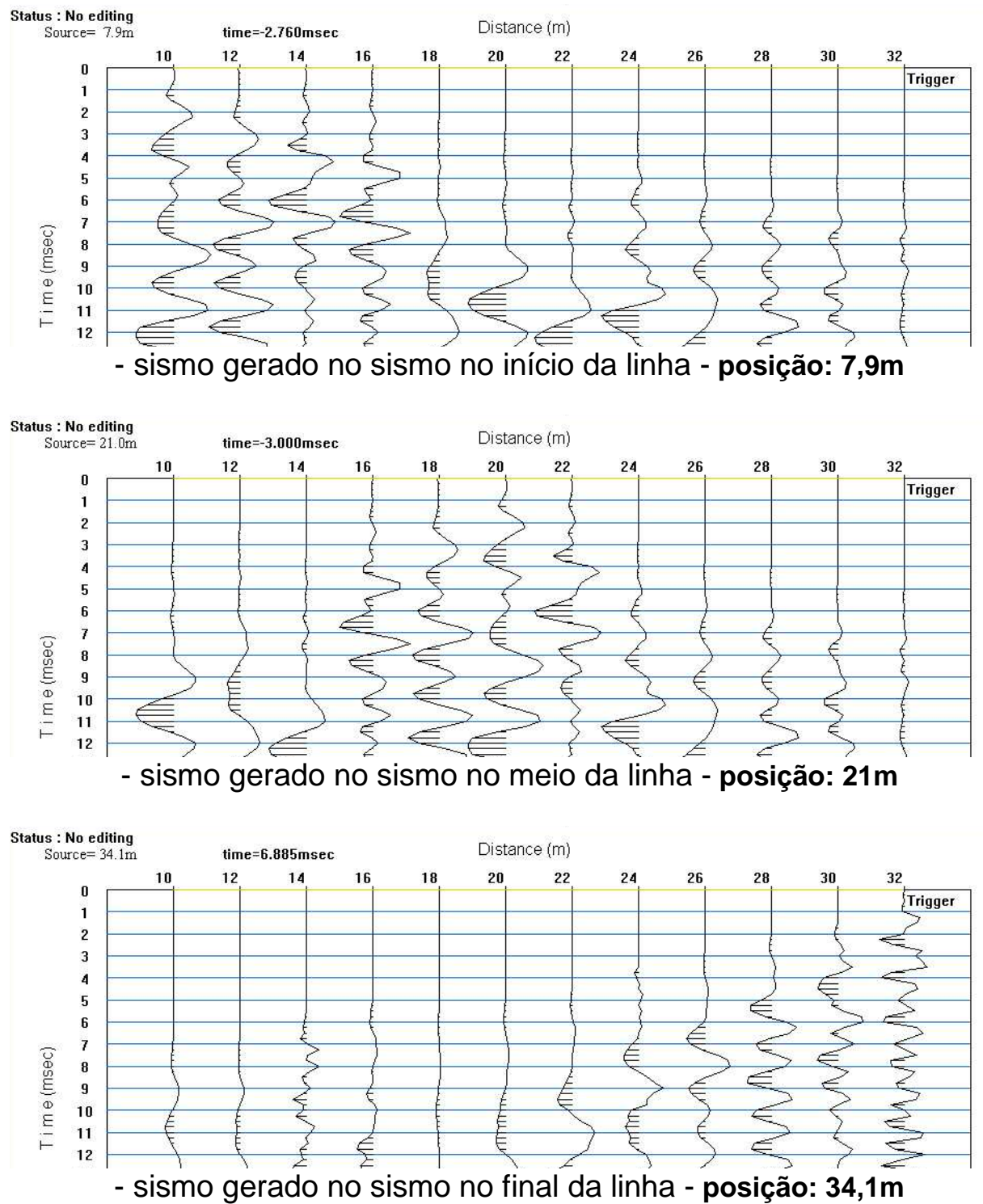

Figura 4.38a - Técnica de perfilagem - Sismogramas obtidos na linha 1 do Ponto 3, na Mina Fontanella. Linha com 12 geofones. Geração do sismo no início da linha (a), no meio da linha (b) e no final da linha (c).

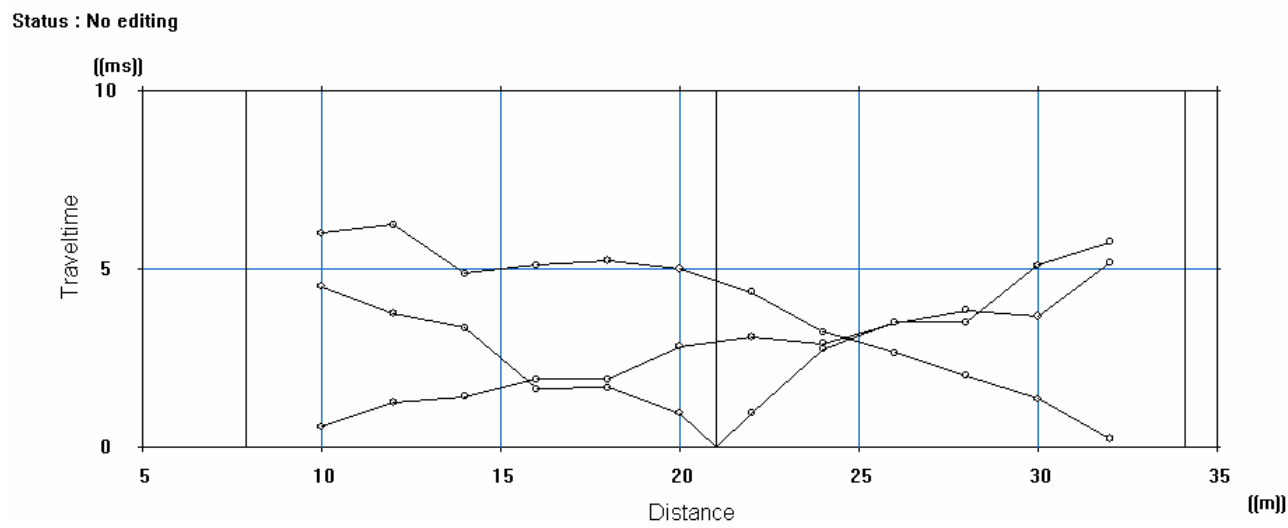

Figura 4.38b - Técnica de perfilagem - Relação "distância x tempo de chegada da primeira onda" composta a partir dos sismogramas obtidos na linha $1 \mathrm{~A}$ do Ponto 3 , na camada Bonito, na Mina Fontanella. 
Tabela 4.15a - Técnica de perfilagem - Velocidades de propagação de ondas sísmicas medidas nos diferentes pontos de levantamento na camada de carvão Bonito, na Mina Fontanella.

\begin{tabular}{|c|c|c|c|c|c|c|c|c|c|c|c|}
\hline \multicolumn{3}{|c|}{ Localização na Mina } & \multirow{2}{*}{$\begin{array}{l}\text { Direção } \\
\text { da Linha } \\
\quad\left({ }^{\circ}\right)\end{array}$} & \multirow{2}{*}{$\begin{array}{l}\text { Comprimento } \\
\text { da Linha } \\
\text { (m) }\end{array}$} & \multirow{2}{*}{$\begin{array}{l}\text { Número } \\
\text { de } \\
\text { Geofones }\end{array}$} & \multirow{2}{*}{$\begin{array}{c}\text { Espaçamento } \\
\text { entre } \\
\text { Geofones } \\
(\mathrm{m}) \\
\end{array}$} & \multirow{2}{*}{$\begin{array}{c}V_{s 1} \\
(\mathrm{~km} / \mathrm{s})\end{array}$} & \multirow{2}{*}{$\begin{array}{c}\mathrm{V}_{\mathrm{s} 2} \\
(\mathrm{~km} / \mathrm{s})\end{array}$} & \multirow{2}{*}{$\begin{array}{c}\mathrm{V}_{s 1}^{\prime}-\mathrm{V}_{\mathrm{s} 2}^{\prime} \\
(\mathrm{km} / \mathrm{s})\end{array}$} & \multirow{2}{*}{$\begin{array}{c}\mathrm{V}_{\mathrm{s}} \\
\text { média } \\
\text { na Linha } \\
(\mathrm{km} / \mathrm{s})\end{array}$} & \multirow{2}{*}{$\begin{array}{l}\mathrm{V}_{\mathrm{s}} \\
\text { média no } \\
\text { Ponto } \\
(\mathrm{km} / \mathrm{s}) \\
\end{array}$} \\
\hline Ponto & Linha & Eixo/Galeria/Travesão & & & & & & & & & \\
\hline \multirow{3}{*}{$\mathrm{P} 1$} & L1A & $\begin{array}{c}\text { Eixo 6NW - G4, entre T3 e } \\
\text { T2, lado direito }\end{array}$ & 106 & 13 & 12 & 1 & 1,80 & 1,13 & $1,15-1,19$ & 1,32 & \multirow{3}{*}{1,79} \\
\hline & L1B & $\begin{array}{c}\text { Eixo 6NW - G4, entre T3 e } \\
\text { T2, lado direito }\end{array}$ & 106 & 13 & 12 & 1 & 2,56 & 2,10 & $1,90-2,43$ & 2,25 & \\
\hline & L2 & $\begin{array}{c}\text { Eixo 6NW - T2 entre G4 e } \\
\text { G3, lado esquerdo }\end{array}$ & 196 & 13 & 12 & 1 & 1,51 & 2,00 & $1,70-2,06$ & 1,82 & \\
\hline \multirow[t]{2}{*}{ P4 } & L1 & $\begin{array}{c}\text { Eixo 6NW - Painel 2SW - } \\
\text { G1, entre T5 e T4, lado } \\
\text { direito }\end{array}$ & 016 & 9 & 8 & 1 & 2,50 & 2,61 & $1,20-2,00$ & 2,08 & \multirow[t]{2}{*}{2,18} \\
\hline & L2 & $\begin{array}{l}\text { Eixo 6NW - Painel 2SW - T5, } \\
\text { entre G1 e G2, lado direito }\end{array}$ & 286 & 11 & 10 & 1 & 2,44 & 2,35 & $2,12-2,18$ & 2,27 & \\
\hline \multirow{2}{*}{ P2 } & L1 & $\begin{array}{c}\text { Eixo 8NW - G2, entre T0 e } \\
\text { T1, lado direito }\end{array}$ & 286 & 13 & 12 & 1 & 1,95 & 2,83 & 1,95-nc & 2,24 & \multirow{2}{*}{2,33} \\
\hline & L2 & $\begin{array}{c}\text { Eixo 8NW - T0, entre G2 e } \\
\text { G3, lado direito }\end{array}$ & 046 & 13 & 12 & 1 & 2,90 & 2,83 & nc- 1,50 & 2,41 & \\
\hline \multirow{2}{*}{ P3 } & L1-A & $\begin{array}{c}\text { Eixo } 7 S W \text { - G1, entre T2 e } \\
\text { T1/T0, lado direito }\end{array}$ & 046 & 25 & 12 & 2 & $5,20^{\#}$ & 3,85 & $1,81-2,30$ & 2,65 & \multirow{2}{*}{2,51} \\
\hline & L2 & $\begin{array}{c}\text { Eixo 7SW - T2, entre G1 e } \\
\text { G2, lado esquerdo }\end{array}$ & 136 & 13 & 12 & 1 & 2,82 & 2,91 & $2,00-1,91$ & 2,41 & \\
\hline
\end{tabular}

LEGENDA:

$\mathrm{V}_{\mathrm{S} 1}=$ velocidade média medida com o sismo gerado no início da linha de levantamento (próximo do geofone 1);

$\mathrm{V}_{\mathrm{s} 2}=$ velocidade média medida com o sismo gerado no final da linha de levantamento (após o último geofone da linha);

$V^{\prime}{ }_{s 1}$ e $V_{s 2}^{\prime}=$ velocidades médias medidas com o sismo gerado no meio da linha de levantamento, nas direções do final da linha ( $\left.V_{1}^{\prime}\right)$ e do início da linha ( $V_{2}{ }_{2}$, respectivamente;

$\mathbf{n c}=$ não calculado devido às características impróprias do sismograma;

\# valor não considerado para efeito de cálculo da média no ponto de levantamento. 
Tabela 4.15b - Técnica de radiação - Velocidades de propagação de ondas sísmicas medidas nos diferentes pontos de levantamento na camada de carvão Bonito, na Mina Fontanella.

\begin{tabular}{|c|c|c|c|c|c|c|c|c|c|c|}
\hline \multicolumn{3}{|c|}{ Localização na Mina } & \multirow[b]{2}{*}{$\begin{array}{l}\text { Dimensões } \\
\text { do Pilar } \\
\text { (m) }\end{array}$} & \multirow[b]{2}{*}{$\begin{array}{c}\text { Direção } \\
\text { Principal de } \\
\text { Interesse de } \\
\text { Propagação } \\
\text { do Sismo } \\
\left(^{\circ}\right)\end{array}$} & \multirow[b]{2}{*}{$\begin{array}{l}\text { Número } \\
\text { de } \\
\text { Geofones }\end{array}$} & \multirow[b]{2}{*}{$\begin{array}{c}\mathrm{V}_{\mathrm{st}} \\
\text { média na } \\
\text { direção } \\
\text { principal de } \\
\text { interesse } \\
(\mathrm{km} / \mathrm{s}) \\
\end{array}$} & \multirow[b]{2}{*}{$\begin{array}{c}\mathrm{V}_{\mathrm{st}} \\
\text { média no } \\
\text { pilar } \\
(\mathrm{km} / \mathrm{s})\end{array}$} & \multirow[b]{2}{*}{$\begin{array}{c}\mathrm{V}_{\mathrm{st}} \\
\text { média no } \\
\text { ponto } \\
(\mathrm{km} / \mathrm{s})\end{array}$} & \multirow[b]{2}{*}{$\begin{array}{c}\mathrm{V}_{\text {sld }} \\
\text { média no } \\
\text { pilar } \\
(\mathrm{km} / \mathrm{s})\end{array}$} & \multirow[b]{2}{*}{$\begin{array}{c}\mathrm{V}_{\text {sld }} \\
\text { média no } \\
\text { ponto } \\
(\mathrm{km} / \mathrm{s})\end{array}$} \\
\hline Ponto & Pilar & Eixo/Galeria/Travesão & & & & & & & & \\
\hline \multirow{4}{*}{ P1 } & \multirow{2}{*}{1} & \multirow{2}{*}{ Eixo 6NW - T3-T2 e G4-G3 } & \multirow{2}{*}{$15 \times 29$} & 106 (SE) & 11 & $2,58(0,44)$ & \multirow{2}{*}{$2,60(0,35)$} & \multirow{4}{*}{$2,59(0,42)$} & \multirow{2}{*}{$2,75(0,24)$} & \multirow{4}{*}{$2,80(0,30)$} \\
\hline & & & & $196(\mathrm{SW})$ & 11 & $2,62(0,25)$ & & & & \\
\hline & \multirow{2}{*}{2} & \multirow{2}{*}{ Eixo 6NW - T2-T1 e G4-G3 } & \multirow{2}{*}{$15 \times 29$} & 106 (SE) & 11 & $2,63(0,63)$ & \multirow{2}{*}{$2,58(0,50)$} & & \multirow{2}{*}{$2,85(0,36)$} & \\
\hline & & & & 196 (SW) & 10 & $2,52(0,31)$ & & & & \\
\hline \multirow{4}{*}{ P4 } & \multirow{2}{*}{7} & \multirow{2}{*}{$\begin{array}{c}\text { Eixo 6NW - Painel 2SW - G1-G0 } \\
\text { e T4-T5 }\end{array}$} & \multirow{2}{*}{$14 \times 14$} & 106 (SE) & 10 & $2,67(0,36)$ & \multirow{2}{*}{$2,69(0,31)$} & \multirow{4}{*}{$2,98(0,42)$} & \multirow{2}{*}{$2,84(0,23)$} & \multirow{4}{*}{$3,09(0,32)$} \\
\hline & & & & $196(\mathrm{SW})$ & 10 & $2,84(0,23)$ & & & & \\
\hline & \multirow{2}{*}{8} & \multirow{2}{*}{$\begin{array}{c}\text { Eixo 6NW - Painel 2SW - G1-G2 } \\
\text { e T5-T4 }\end{array}$} & \multirow{2}{*}{$14 \times 14$} & $296(\mathrm{NW})$ & 10 & $3,24(0,37)$ & \multirow{2}{*}{$3,27(0,32)$} & & \multirow{2}{*}{$3,35(0,17)$} & \\
\hline & & & & 016 (NE) & 10 & $3,29(0,25)$ & & & & \\
\hline & 3 & Fixn 7SW - G5-G4 O T1-T2 & $18 \times 22$ & 106 (SE) & 11 & $2,74(0,39)$ & 1) & & 1) & \\
\hline$e^{-}$ & J & 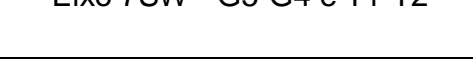 & 10 त & $226(\mathrm{SW})$ & 11 & $2,65(0,44)$ & ) & 1) & 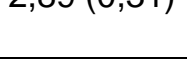 & D) \\
\hline 1 & 4 & Eixo 7SW - G5-Eixo 8NW-T1 e & $18 \times 2 ?$ & $286(\mathrm{NW})$ & 11 & $2,79(0,55)$ & ) & 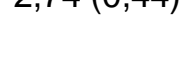 & I) & $c, v 0(0, v<)$ \\
\hline & 4 & Eixo 7SW - T1-Eixo 6NW - G4 & $10 \wedge<2$ & 046 (NE) & 11 & $2,81(0,40)$ & $<, 00(0,41)$ & & $0,00(0,01)$ & \\
\hline & 5 & Fixo 7SW - T2-T1 e G2-G1 & $18 \times 18$ & 046 (NE) & 11 & $3,09(0,37)$ & 1) & & 0) & \\
\hline 3 & r & 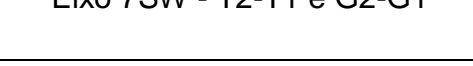 & r & 136 (SE) & 11 & $2,94(0,30)$ & $0,01(0,00)$ & & $0,19(0,00)$ & 5) 1 \\
\hline 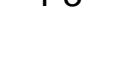 & 6 & Fixn 7SUN - T2-T3 ค G1-G2 & 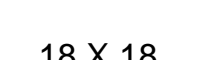 & 226 (SW) & 11 & $3,03(0,37)$ & 3) & $0,00(0,00)$ & 1) & $0,10(U, \angle U)$ \\
\hline & 0 & 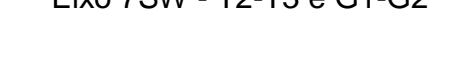 & $10 \times 10$ & $316(N W)$ & 11 & $2,93(0,41)$ & $2,00(0,00)$ & & $0,10(0,21)$ & \\
\hline
\end{tabular}

\section{LEGENDA:}

$\mathrm{V}_{\mathrm{st}}=$ velocidade média considerando todos os geofones localizados a mais de 1,0m de distância do ponto de geração do sismo;

$\mathrm{V}_{\mathrm{sld}}=$ velocidade média computada com a distância de percurso da onda sísmica medida na direção principal de interesse e maior que $75 \%$ da dimensão do lado do pilar; Nota: valores entre parênteses $=$ desvio padrão. 


\subsubsection{Levantamentos na Mina Morozini Norte}

Na Mina Morozini Norte os levantamentos foram realizados num único pilar. Nesta mina utilizaram-se as duas técnicas, perfilagem e radiação, simultaneamente. Os procedimentos de execução adotados foram os mesmos descritos para os levantamentos na Mina Fontanella. A configuração dos geofones utilizada ao redor do pilar pode ser vista na Figura 4.39.

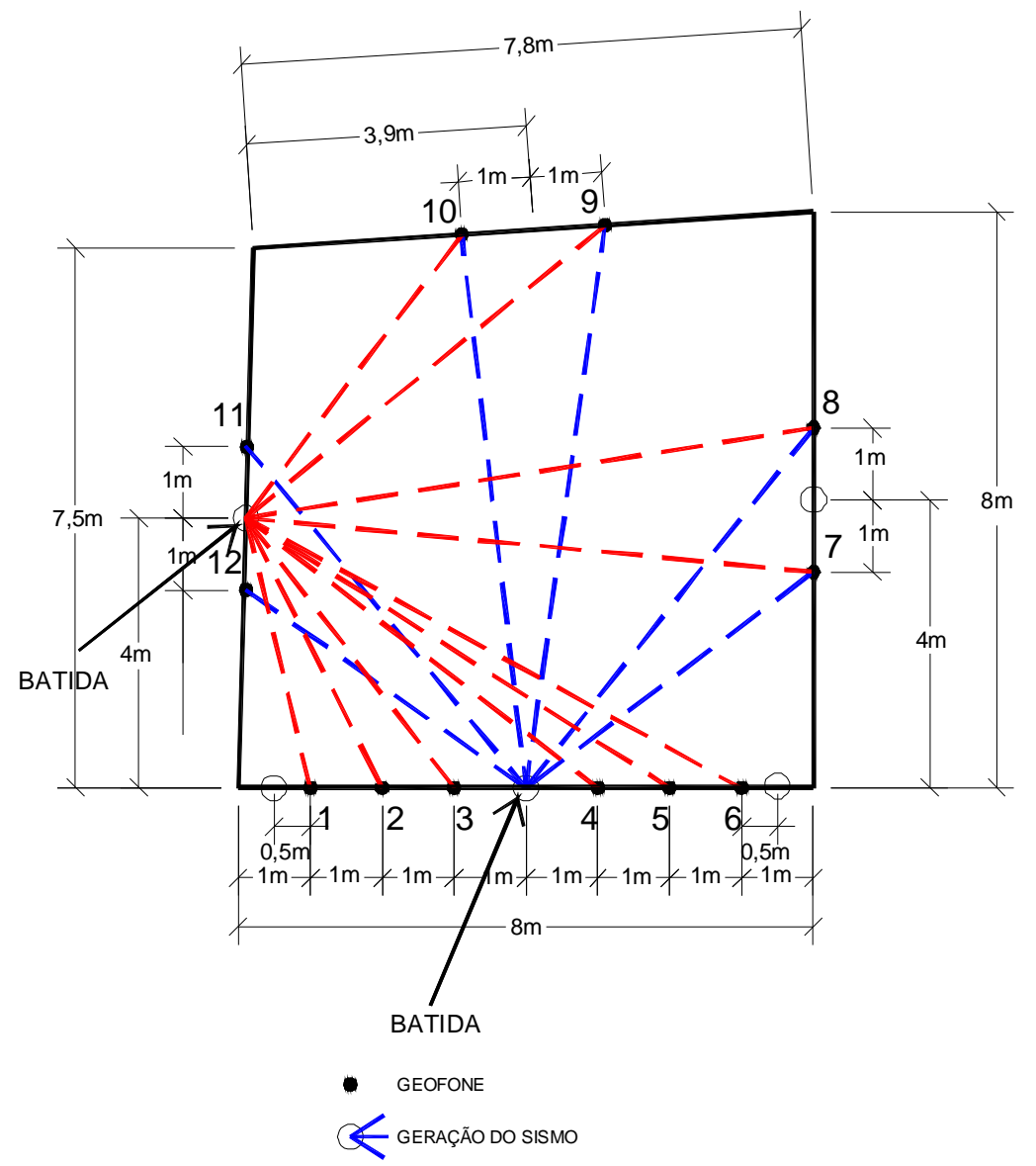

Figura 4.39 - Disposição dos geofones com a indicação dos pontos de geração dos sismos no levantamento por radiação, em pilar de carvão da camada Irapuá, na Mina Morozini Norte.

O local para o levantamento foi definido aleatoriamente ao longo do Eixo NE01, entre as Galerias 6 e 7 e os Travessões 9 e 10. A área estudada apresenta as seguintes condições geométricas:

- dimensões dos lados do pilar: 8m X 8m;

- altura da camada de carvão: 2,5m;

- largura da galeria: 4,5m;

- profundidade: $50 \mathrm{~m}$;

- condições de umidade: rocha aparentemente seca. 


\subsubsection{Resultados Obtidos}

A Figura 4.40a apresenta um dos sismogramas obtidos nos levantamentos utilizando as técnicas de perfilagem e radiação, simultaneamente. Os dados processados na forma "distância x tempo de chegada da primeira onda" nos 6 geofones posicionados para a perfilagem podem ser vistos na Figura 4.40b. Esse sismograma foi obtido na periferia de pilar conformado com desmonte por explosivos, utilizando a técnica de fogo no duro.

Os resultados das velocidades sísmicas medidas podem ser vistos nas Tabelas 16a (técnica de perfilagem) e 16b (técnica de radiação).

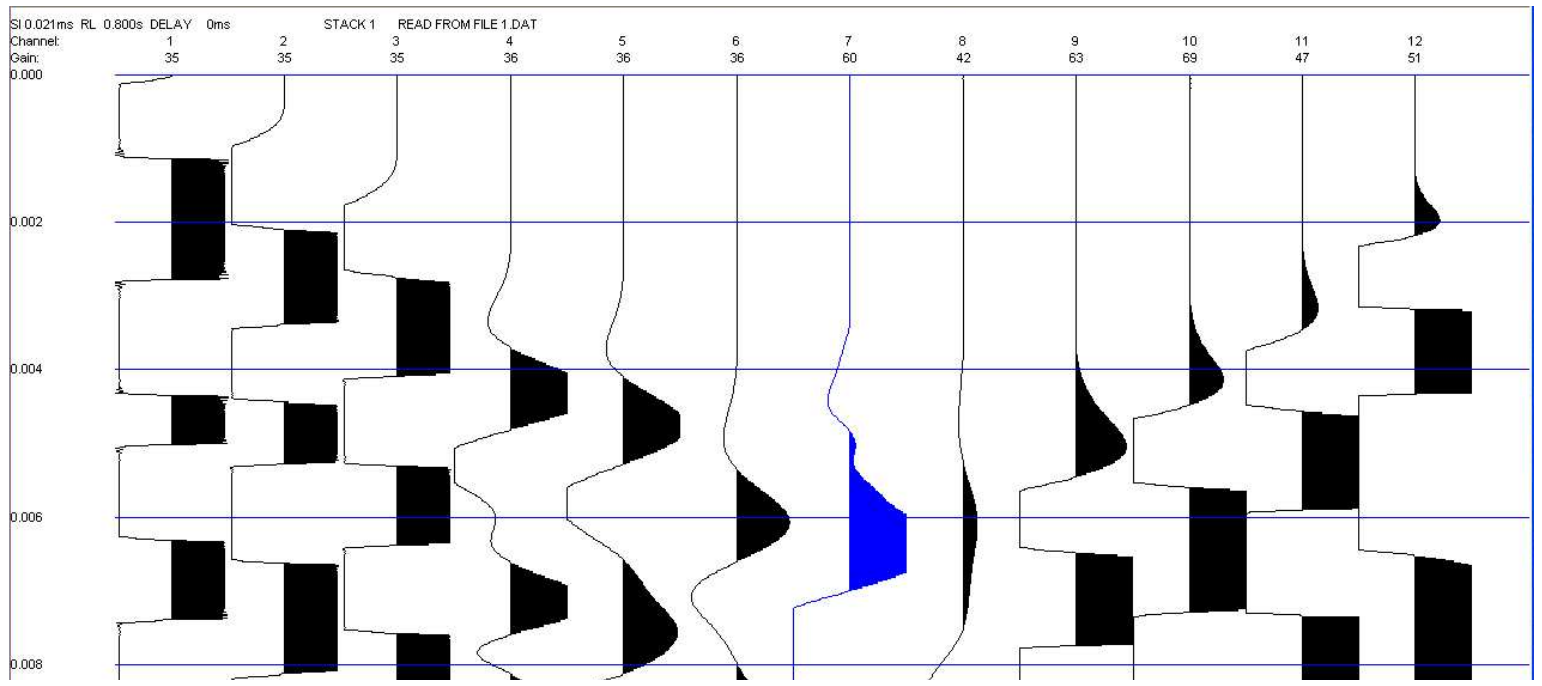

Figura 4.40a - Técnica de perfilagem + radiação - Sismograma obtido na Mina Morozini Norte. Linha de perfilagem com 6 geofones (1 a 6) num lado do pilar. Demais geofones distribuídos nos outros lados do pilar. Geração do sismo no início da linha de perfilagem, ao lado do geofone 1.

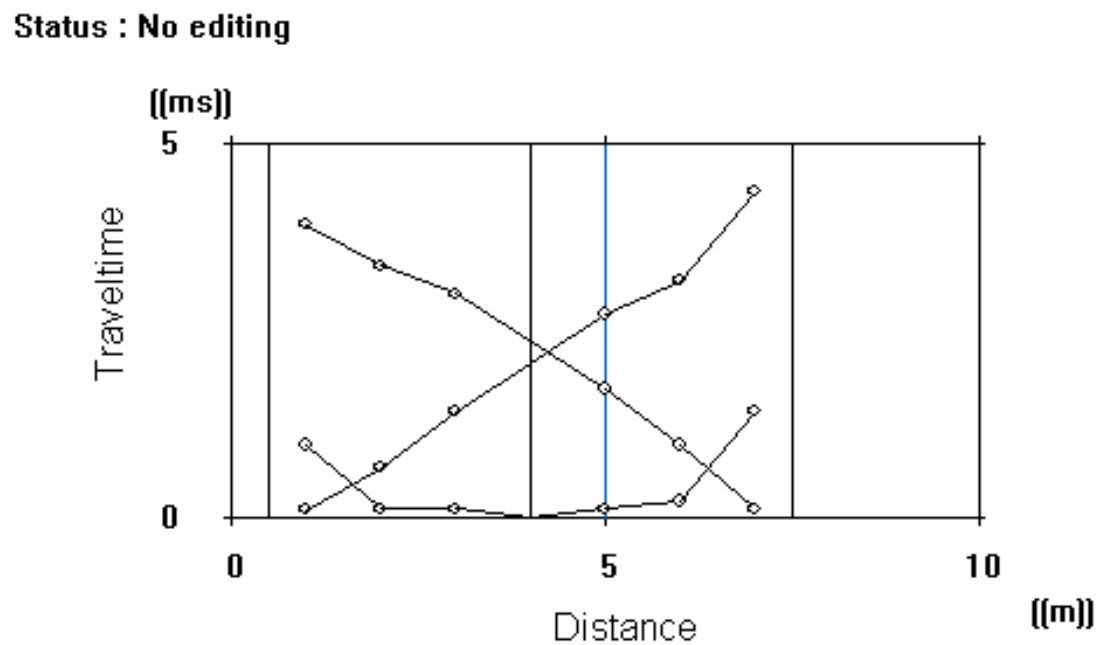

Figura 4.40b - Técnica de perfilagem - Relação "distância x tempo de chegada da primeira onda" composta a partir dos sismogramas obtidos na camada Irapuá, na Mina Morozini Norte. 
Tabela 4.16a - Técnica de perfilagem - Velocidades de propagação de ondas sísmicas medidas na camada de carvão Irapuá, na Mina Morozini Norte.

\begin{tabular}{|c|c|c|c|c|c|c|c|c|c|c|}
\hline \multicolumn{3}{|c|}{ Localização na Mina } & \multirow{2}{*}{$\begin{array}{l}\text { Direção } \\
\text { da Linha } \\
\left(^{\circ}\right)\end{array}$} & \multirow{2}{*}{$\begin{array}{l}\text { Comprimento } \\
\text { da Linha } \\
\text { (m) }\end{array}$} & \multirow{2}{*}{$\begin{array}{c}\text { Número } \\
\text { de } \\
\text { Geofones }\end{array}$} & \multirow{2}{*}{$\begin{array}{c}\text { Espaçamento } \\
\text { entre } \\
\text { Geofones } \\
(\mathrm{m}) \\
\end{array}$} & \multirow{2}{*}{$\begin{array}{c}V_{s 1} \\
(\mathrm{~km} / \mathrm{s})\end{array}$} & \multirow{2}{*}{$\begin{array}{c}V_{\mathrm{s} 2} \\
(\mathrm{~km} / \mathrm{s})\end{array}$} & \multirow{2}{*}{$\begin{array}{c}\mathrm{V}_{\mathrm{s} 1}^{\prime}-\mathrm{V}_{\mathrm{s}}^{\prime}{ }_{\mathrm{s}} \\
(\mathrm{km} / \mathrm{s})\end{array}$} & \multirow{2}{*}{\begin{tabular}{|c|}
$\mathrm{V}_{\mathrm{s}}$ \\
média \\
na Linha \\
$(\mathrm{km} / \mathrm{s})$ \\
\end{tabular}} \\
\hline Ponto & Linha & Eixo/Galeria/Travesão & & & & & & & & \\
\hline $\mathrm{P} 1$ & L1 & $\begin{array}{c}\text { Eixo NE01 - G6 entre T9 e } \\
\text { T10, lado direito }\end{array}$ & $\mathrm{NE}$ & 8 & 6 & 1 & 1,46 & 1,59 & $1,25-1,73$ & 1,51 \\
\hline
\end{tabular}

\section{LEGENDA:}

$\mathrm{V}_{\mathrm{S} 1}=$ velocidade média medida com o sismo gerado no início da linha de levantamento (próximo do geofone 1);

$\mathrm{V}_{\mathrm{s} 2}=$ velocidade média medida com o sismo gerado no final da linha de levantamento (após o último geofone da linha);

$\mathrm{V}_{\mathrm{s} 1}$ e $\mathrm{V}_{\mathrm{s} 2}=$ velocidades médias medidas com o sismo gerado no meio da linha de levantamento, nas direções do final da linha ( $\left.V_{1}{ }_{1}\right)$ e do início da linha $\left(V_{2}{ }_{2}\right)$, respectivamente.

Tabela 4.16b - Técnica de radiação - Velocidades de propagação de ondas sísmicas medidas na camada de carvão Irapuá, na Mina Morozini Norte.

\begin{tabular}{|c|c|c|c|c|c|c|c|c|}
\hline \multicolumn{3}{|c|}{ Localização na Mina } & \multirow[b]{2}{*}{$\begin{array}{l}\text { Dimensões } \\
\text { do Pilar } \\
\text { (m) }\end{array}$} & \multirow{2}{*}{$\begin{array}{c}\text { Direção } \\
\text { Principal de } \\
\text { Interesse de } \\
\text { Propagação } \\
\text { do Sismo } \\
\left({ }^{\circ}\right)\end{array}$} & \multirow[b]{2}{*}{$\begin{array}{l}\text { Número de } \\
\text { Geofones }\end{array}$} & \multirow{2}{*}{$\begin{array}{c}\mathrm{V}_{\mathrm{st}} \\
\text { média na } \\
\text { direção } \\
\text { principal de } \\
\text { interesse } \\
(\mathrm{km} / \mathrm{s}) \\
\end{array}$} & \multirow[b]{2}{*}{$\begin{array}{c}\mathrm{V}_{\mathrm{st}} \\
\text { média no } \\
\text { pilar } \\
(\mathrm{km} / \mathrm{s})\end{array}$} & \multirow[b]{2}{*}{$\begin{array}{c}\mathrm{V}_{\text {sld }} \\
\text { média no } \\
\text { pilar } \\
(\mathrm{km} / \mathrm{s})\end{array}$} \\
\hline Ponto & Pilar & Eixo/Galeria/Travesão & & & & & & \\
\hline \multirow{5}{*}{ P1 } & \multirow{5}{*}{1} & \multirow{5}{*}{ Eixo NE01 - G6-G7 e T9-T10 } & \multirow{5}{*}{$8 \times 8$} & SE & 11 & $2,03(0,33)$ & \multirow{5}{*}{$1,95(0,43)$} & \multirow{5}{*}{$2,03(0,35)$} \\
\hline & & & & SE & 7 & $2,51(0,56)$ & & \\
\hline & & & & SE & 11 & $1,60(0,25)$ & & \\
\hline & & & & NE & 10 & $1,88(0,23)$ & & \\
\hline & & & & NE & 10 & $1,90(0,24)$ & & \\
\hline
\end{tabular}

LEGENDA:

$\mathrm{V}_{\mathrm{st}}=$ velocidade média considerando todos os geofones localizados a mais de 1,0m de distância do ponto de geração do sismo;

$\mathrm{V}_{\text {sld }}=$ velocidade média computada com a distância de percurso da onda sísmica medida na direção principal de interesse e maior que $75 \%$ da dimensão do lado do pilar;

Nota: valores entre parênteses $=$ desvio padrão. 


\subsubsection{Levantamentos na Mina Santa Augusta Norte}

Os levantamentos na Mina Santa Augusta Norte foram realizados na entrada da mina, num pilar com apenas 3 lados conformados. Os levantamentos foram realizados utilizando-se as duas técnicas, perfilagem e radiação, simultaneamente. Os procedimentos de execução adotados foram os mesmos descritos para os levantamentos na Mina Fontanella. A Figura 4.41 apresenta a configuração dos geofones empregada no levantamento.

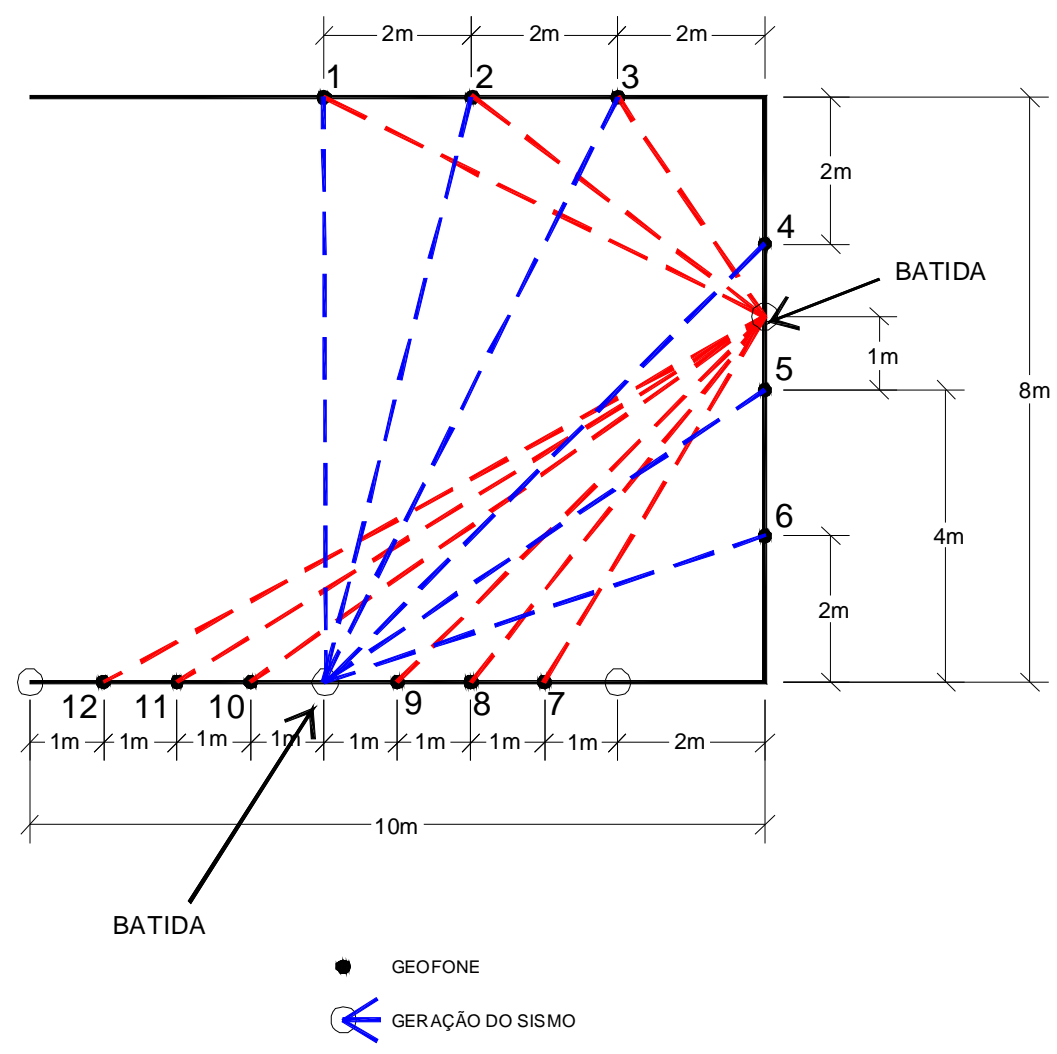

Figura 4.41 - Disposição dos geofones com a indicação dos pontos de geração dos sismos no levantamento por radiação, em pilar de carvão da camada Irapuá, na Mina Santa Augusta Norte.

Como a mina encontra-se na fase inicial de desenvolvimento, selecionou-se um pilar ainda não integralmente conformado nos seus 4 lados, no início do eixo principal. A área estudada possui as seguintes condições geométricas:

- dimensões do lado do pilar: $8 \mathrm{~m} \times 8 \mathrm{~m}$;

- altura da camada de carvão: 2,4m;

- largura da galeria: 4,8m;

- profundidade: $15 \mathrm{~m}$;

- condições de umidade: rocha saturada com água escorrendo continuamente pelas paredes do pilar. 


\subsubsection{Resultados Obtidos}

$\mathrm{Na}$ Figura 4.42a pode ser visto sismograma obtido nos levantamentos utilizando as técnicas de perfilagem e radiação simultaneamente. Os dados da linha de perfilagem organizados na forma "distância $x$ tempo de chegada da onda" podem ser vistos na Figura $4.42 \mathrm{~b}$. Esses sismogramas foram obtidos na periferia de um pilar conformado com desmonte mecânico (minerador contínuo), portanto, sem nenhum tipo de dano aparente na periferia do pilar.

Os resultados das velocidades sísmicas medidas são apresentados nas Tabelas $17 a$ (técnica de perfilagem) e 17b (técnica de radiação).

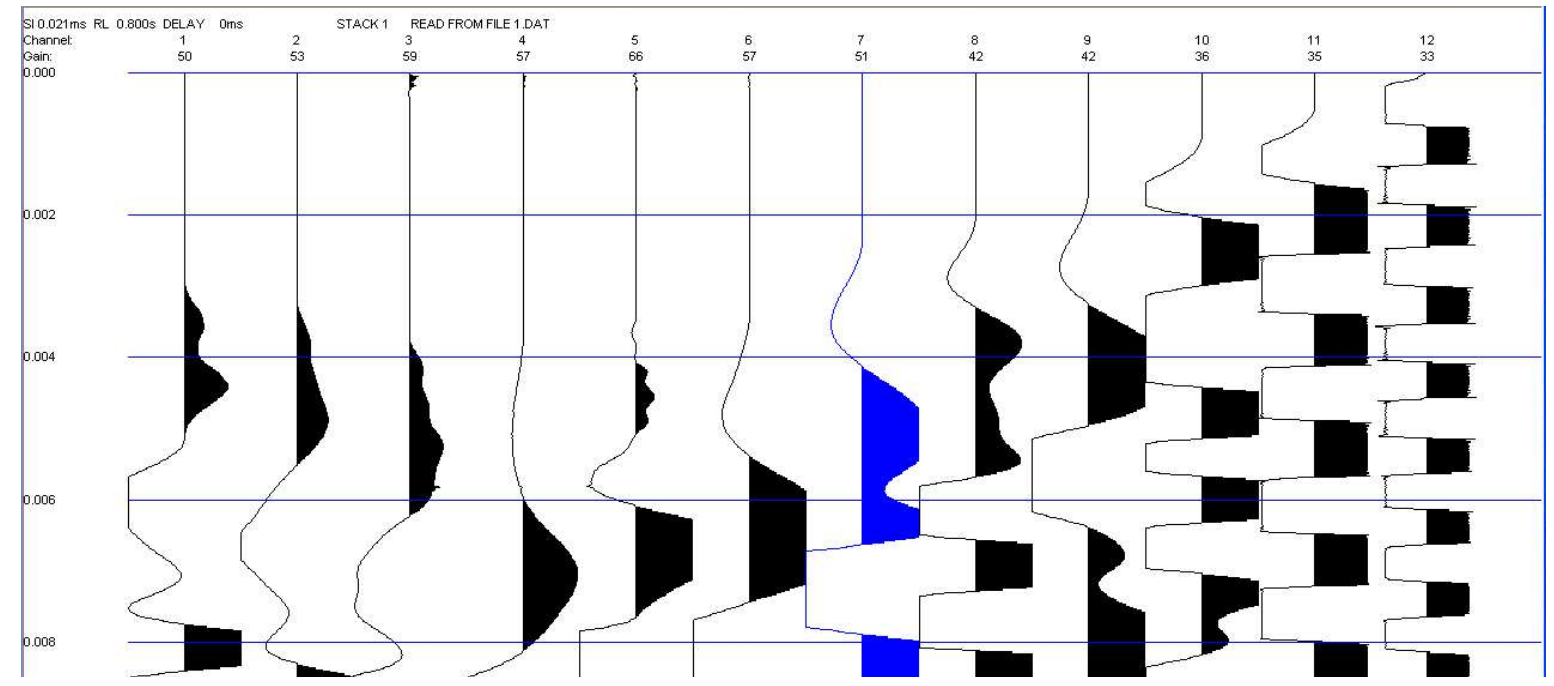

Figura 4.42a - Técnica de perfilagem + radiação - Sismograma obtido na Mina Santa Augusta Norte. Linha de perfilagem com 6 geofones (7 a 12). Demais geofones (1 a 6 ) distribuídos nos outros dois lados do pilar. Geração do sismo no início da linha de perfilagem, ao lado do geofone 12 .

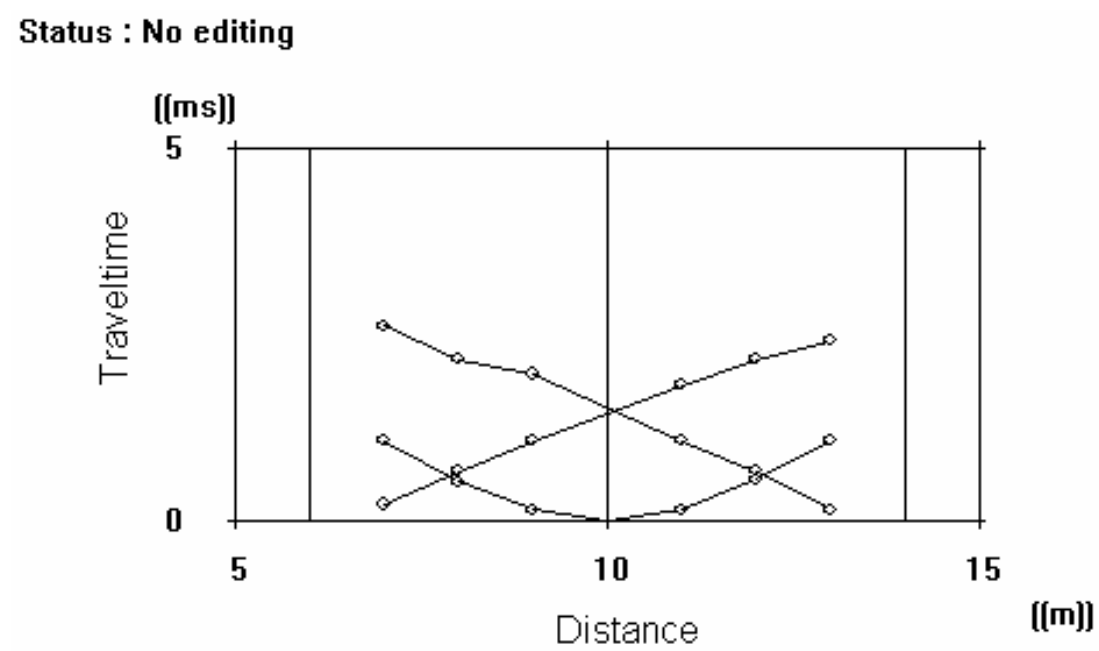

Figura 4.42b - Técnica de perfilagem - Relação "distância x tempo de chegada da primeira onda" composta a partir dos sismogramas obtidos na camada Irapuá, na Mina Santa Augusta Norte. 
Tabela 4.17a - Técnica de perfilagem - Velocidades de propagação de ondas sísmicas medidas na camada de carvão Irapuá, na Mina

\begin{tabular}{|c|c|c|c|c|c|c|c|c|c|c|}
\hline \multicolumn{2}{|c|}{ Localização na Mina } & $\begin{array}{c}\text { Direção } \\
\text { da Linha } \\
\left({ }^{\circ}\right)\end{array}$ & $\begin{array}{c}\text { Comprimento } \\
\text { da Linha } \\
(\mathrm{m})\end{array}$ & $\begin{array}{c}\text { Número } \\
\text { de } \\
\text { Geofones }\end{array}$ & $\begin{array}{c}\text { Espaçamento } \\
\text { entre } \\
\text { Geofones } \\
(\mathrm{m})\end{array}$ & $\begin{array}{c}\mathrm{V}_{\mathrm{s} 1} \\
(\mathrm{~km} / \mathrm{s})\end{array}$ & $\begin{array}{c}\mathrm{V}_{\mathrm{s} 2} \\
(\mathrm{~km} / \mathrm{s})\end{array}$ & $\begin{array}{c}\mathrm{V}_{\mathrm{s1}}^{\prime}-\mathrm{V}_{\mathrm{s} 2}^{\prime} \\
(\mathrm{km} / \mathrm{s})\end{array}$ & $\begin{array}{c}\mathrm{V}_{\mathrm{s}} \\
\mathrm{média} \\
\mathrm{na} \text { Linha } \\
(\mathrm{km} / \mathrm{s})\end{array}$ \\
\hline P1 & L1 & $\begin{array}{c}\text { Eixo de entrada da mina, } \\
\text { segundo pilar a esquerda }\end{array}$ & $\begin{array}{c}\text { Trans- } \\
\text { versal } \\
\text { ao Eixo }\end{array}$ & 7 & 6 & 1 & 2,47 & 2,69 & $2,14-2,14$ & 2,36 \\
\hline
\end{tabular}

\section{LEGENDA:}

$\mathrm{V}_{\mathrm{s} 1}=$ velocidade média medida com o sismo gerado no início da linha de levantamento (próximo do geofone 1);

$\mathrm{V}_{\mathrm{s} 2}=$ velocidade média medida com o sismo gerado no final da linha de levantamento (após o último geofone da linha);

$V^{\prime}{ }_{s 1}$ e $V^{\prime}{ }_{s 2}=$ velocidades médias medidas com o sismo gerado no meio da linha de levantamento, nas direções do final da linha $\left(V^{\prime}{ }_{1}\right)$ e do início da linha $\left(V^{\prime}{ }_{2}\right)$, respectivamente.

Tabela 4.17b - Técnica de radiação - Velocidades de propagação de ondas sísmicas medidas na camada de carvão Irapuá, na Mina

\begin{tabular}{|c|c|c|c|c|c|c|c|c|}
\hline \multirow{2}{*}{\multicolumn{3}{|c|}{ Localização na Mina }} & & & & & & \\
\hline & & & \multirow{2}{*}{$\begin{array}{l}\text { Dimensões } \\
\text { do Pilar } \\
\text { (m) }\end{array}$} & \multirow{2}{*}{$\begin{array}{l}\text { Direção Principal } \\
\text { de Interesse de } \\
\text { Propagação do } \\
\text { Sismo } \\
\left({ }^{\circ}\right)\end{array}$} & \multirow{2}{*}{$\begin{array}{l}\text { Número } \\
\text { de } \\
\text { Geofones }\end{array}$} & \multirow{2}{*}{$\begin{array}{c}\mathrm{V}_{\mathrm{st}} \\
\text { média na } \\
\text { direção principal } \\
\text { de interesse } \\
(\mathrm{km} / \mathrm{s})\end{array}$} & \multirow{2}{*}{$\begin{array}{c}\mathrm{V}_{\mathrm{st}} \\
\text { média no } \\
\text { pilar } \\
(\mathrm{km} / \mathrm{s})\end{array}$} & \multirow{2}{*}{$\begin{array}{l}\mathrm{V}_{\text {sld }} \\
\text { média no } \\
\text { pilar } \\
(\mathrm{km} / \mathrm{s})\end{array}$} \\
\hline Ponto & Pilar & Eixo/Galeria/Travesão & & & & & & \\
\hline \multirow{4}{*}{ P1 } & \multirow{4}{*}{1} & \multirow{4}{*}{$\begin{array}{l}\text { Eixo de entrada da mina, no } \\
\text { segundo pilar a esquerda }\end{array}$} & \multirow{4}{*}{$8 \times 8$} & Paralela ao Eixo & 10 & $2,80(0,15)$ & \multirow{4}{*}{$2,75(0,34)$} & \multirow{4}{*}{$2,75(0,36)$} \\
\hline & & & & Paralela ao Eixo & 8 & $2,99(0,20)$ & & \\
\hline & & & & Paralela ao Eixo & 9 & $2,66(0,23)$ & & \\
\hline & & & & $\begin{array}{c}\text { Transversal ao } \\
\text { Eixo }\end{array}$ & 8 & $2,55(0,56)$ & & \\
\hline
\end{tabular}

\section{LEGENDA:}

$\mathrm{V}_{\mathrm{st}}=$ velocidade média considerando todos os geofones localizados a mais de 1,0m de distância do ponto de geração do sismo;

$\mathrm{V}_{\text {sld }}=$ velocidade média computada com a distância de percurso da onda sísmica medida na direção principal de interesse e maior que $75 \%$ da dimensão do lado do pilar;

Nota: valores entre parênteses = desvio padrão. 


\subsubsection{Dificuldades e Limitações do Método de Levantamento nos Casos Estudados}

Os maiores problemas verificados durante os levantamentos estão associados às irregularidades na periferia dos pilares. Os pilares conformados por explosivos com a técnica fogo no duro, especialmente em camadas de carvão muito fraturadas, como é o caso da camada Bonito, tendem a ficar com as paredes muito irregulares. Como o comprimento das linhas, assim como o espaçamento entre geofones, é relativamente pequeno, comparado com os comprimentos normalmente empregados nos levantamentos superficiais com sísmica de refração, essas irregularidades causam enormes dificuldades para a determinação das distâncias reais entre os geofones e o ponto de geração dos sismos. Esse tipo de problema dificultou sobremaneira a interpretação dos sismogramas e a determinação da velocidade média de propagação da onda sísmica.

Outro aspecto que deve ser considerado quando do levantamento em minas em operação é o ruído no sinal recebido pelo sismógrafo, proveniente das vibrações produzidas pelas atividades mineiras (desmonte do carvão, atividade das correias transportadoras, circulação de máquinas pesadas, funcionamento do sistema de drenagem, etc.). Esses problemas foram contornados através do emprego de filtros, via software, no sinal coletado pelo sismógrafo. Em alguns locais, foi necessário realizar os levantamentos em horários coincidentes com os horários de parada da mina ou dos turnos de manutenção, momento em que as vibrações no maciço são minimizadas.

Talvez a maior dificuldade de ser contornada nessa pesquisa esteja associada a heterogeneidade da camada de carvão. Esse problema foi verificado na camada Irapuá presente na Mina Morozini Norte. Nesta mina, a camada apresenta na sua metade inferior uma composição mais heterogênea (intercalação de carvão e folhelho carbonoso), enquanto na metade superior predomina o carvão, conforme observado no perfil típico da camada Irapuá. O mesmo não ocorre nessa mesma camada na Mina Santa Augusta Norte, que é constituída integralmente por carvão (perfil homogêneo). Em ambas as minas as medições de velocidade sísmica foram feitas no meio da camada. No caso da Mina Morozini Norte, é provável que a velocidade sísmica média não seja representativa da camada como um todo. Esse fato deverá ser considerado quando da aplicação do método proposto para a estimativa da resistência in situ da camada de carvão.

\subsubsection{Discussão dos Resultados dos Levantamentos Geofísicos}

Notadamente as velocidades de ondas que se propagam preferencialmente na periferia dos pilares (técnica de perfilagem) são inferiores às velocidades medidas quando a onda se propaga pelo meio do pilar (técnica de radiação). Considerando as velocidades médias nos pilares, as diferenças observadas variaram entre $17 \%$ e $56 \%$, conforme visto na Tabela 4.18. As maiores diferenças (entre $27 \%$ e $56 \%$ ) são observadas nas minas Fontanella e Morozini Norte. 
Tabela 4.18 - Síntese das velocidades de ondas sísmicas medidas nas diferentes minas estudadas.

\begin{tabular}{|c|c|c|c|c|c|c|}
\hline \multirow{3}{*}{$\begin{array}{l}\text { Técnica de } \\
\text { Levantamento } \\
\text { Empregada }\end{array}$} & \multicolumn{6}{|c|}{$\begin{array}{l}\text { Velocidade Média } \\
(\mathrm{km} / \mathrm{s})\end{array}$} \\
\hline & \multicolumn{4}{|c|}{ Local na Mina Fontanella } & \multirow{2}{*}{$\begin{array}{c}\text { Mina } \\
\text { Morozini } \\
\text { Norte }\end{array}$} & \multirow{2}{*}{$\begin{array}{c}\text { Mina Santa } \\
\text { Augusta } \\
\text { Norte }\end{array}$} \\
\hline & P1 & P4 & P2 & P3 & & \\
\hline Técnica de escavação & E1 & E2 & E2 & E2 & E2 & M \\
\hline $\mathrm{V}_{\mathrm{s}}$ por Perfilagem & 1,79 & 2,18 & 2,33 & 2,51 & 1,51 & 2,36 \\
\hline $\mathrm{V}_{\text {sld }}$ por Radiação & 2,80 & 3,09 & 2,98 & 3,19 & 2,03 & 2,75 \\
\hline Relação $\mathrm{V}_{\text {sld }} / \mathrm{V}_{\mathrm{s}}$ & 1,56 & 1,42 & 1,28 & 1,27 & 1,34 & 1,17 \\
\hline
\end{tabular}

Legenda:

$\mathrm{E} 1$ = desmonte do carvão por explosivos, com pré-corte mecânico em duas faces do pilar antes do desmonte. Técnica de "fogo no duro" (apenas uma face livre) nas outras duas faces;

E2 = desmonte do carvão por explosivos, com técnica de "fogo no duro" (apenas uma face livre) nas quatro faces do pilar;

$\mathrm{M}=$ desmonte do carvão com minerador contínuo.

Pelo menos duas explicações podem ser suscitadas para explicar esse comportamento. A primeira, e possivelmente a mais importante, está associada ao confinamento da região interior do pilar, por onde se propagam as ondas sísmicas quando é utilizada a técnica de radiação. Nessa região do pilar, as descontinuidades e os vazios tendem a estar mais fechados que na periferia, facilitando a propagação das ondas sísmicas. Em menor escala, porém, não desprezível, esse comportamento pode ser atribuído à baixa qualidade da rocha na periferia dos pilares, em função do método de escavação empregado para a extração do carvão. Vale registrar que na Mina Santa Augusta Norte, onde o método de desmonte é mecânico, foi observada a menor diferença entre as velocidades medidas pelas duas técnicas (17\% - Tabela 4.18). No Ponto 1 da Mina Fontanella foi observada a maior diferença entre as velocidades medidas pelas duas técnicas (56\%). Esse número é de certa forma contraditório, porque justamente neste local, dentre os 4 estudados nessa mina, foi adotada a melhor técnica de escavação do carvão.

A observação dos resultados obtidos nas diferentes minas e camadas de carvão estudadas mostra que o carvão da camada Bonito, na Mina Fontanella, é o que apresenta as maiores velocidades de propagação de ondas sísmicas (entre $2,7 \mathrm{~km} / \mathrm{s}$ e $3,0 \mathrm{~km} / \mathrm{s}$ na camada Bonito, contra $1,9 \mathrm{~km} / \mathrm{s}$ a $2,4 \mathrm{~km} / \mathrm{s}$ na camada Irapuá - $V_{\text {sld }}$ já corrigidas pelo efeito da tensão e da água). Esse comportamento, embora pareça contraditório, haja vista a maior densidade de fraturas na camada Bonito em comparação com a camada Irapuá nas minas Morozini Norte (fraturada, porém, menos que na camada Bonito) e Santa Augusta Norte (praticamente sem fraturas), pode ser explicado pela maior densidade do carvão da camada Bonito $\left(\cong 1,80 \mathrm{~g} / \mathrm{cm}^{3}\right)$ em comparação com o carvão da camada Irapuá $\left(\cong 1,55 \mathrm{~g} / \mathrm{cm}^{3}\right)$. 
Outro aspecto a ser destacado é a diferença apreciável entre as velocidades medidas nos pilares 7 e 8, no Ponto 4 da Mina Fontanella (cerca de 18\%, contra no máximo $6,5 \%$ nos demais locais - P1, P2 e P3). Também, do ponto de vista estrutural, não há uma explicação plausível para a elevada velocidade de ondas sísmicas nesse ponto de levantamento (P4), uma vez que dentre os locais de levantamento, neste foi observada a maior densidade de fraturas por metro, conforme mostra a Figura 4.43. Sob o aspecto composicional, não foram observadas variações sensíveis na camada de carvão no Ponto 4 em relação aos demais locais de estudo. Chama a atenção, nas proximidades do local P4, a presença de um dique de diabásio, fato não observado nos outros locais de estudo na Mina Fontanella. Esse tipo de estrutura tende a provocar a perda de matéria volátil da camada de carvão. Já nos testemunhos de sondagens horizontais feitas no local P4, constatou-se o preenchimento das fraturas com carbonatos. Nesse caso, as fraturas, embora presentes em maior quantidade que nos demais locais da mina, podem não estar se constituindo em descontinuidades propriamente ditas e, por esse motivo, não ocasionam redução da velocidade de propagação das ondas sísmicas como era de se esperar. De outra parte, ainda que sejam fraturas fechadas, são planos de fraqueza que reduzem sensivelmente a resistência, como observado em laboratório. A elevada densidade de fraturas presente no P4 parece ter afetado mais a resistência de laboratório do que a velocidade de propagação de ondas sísmicas, em comparação com os outros locais estudados da Mina Fontanella.

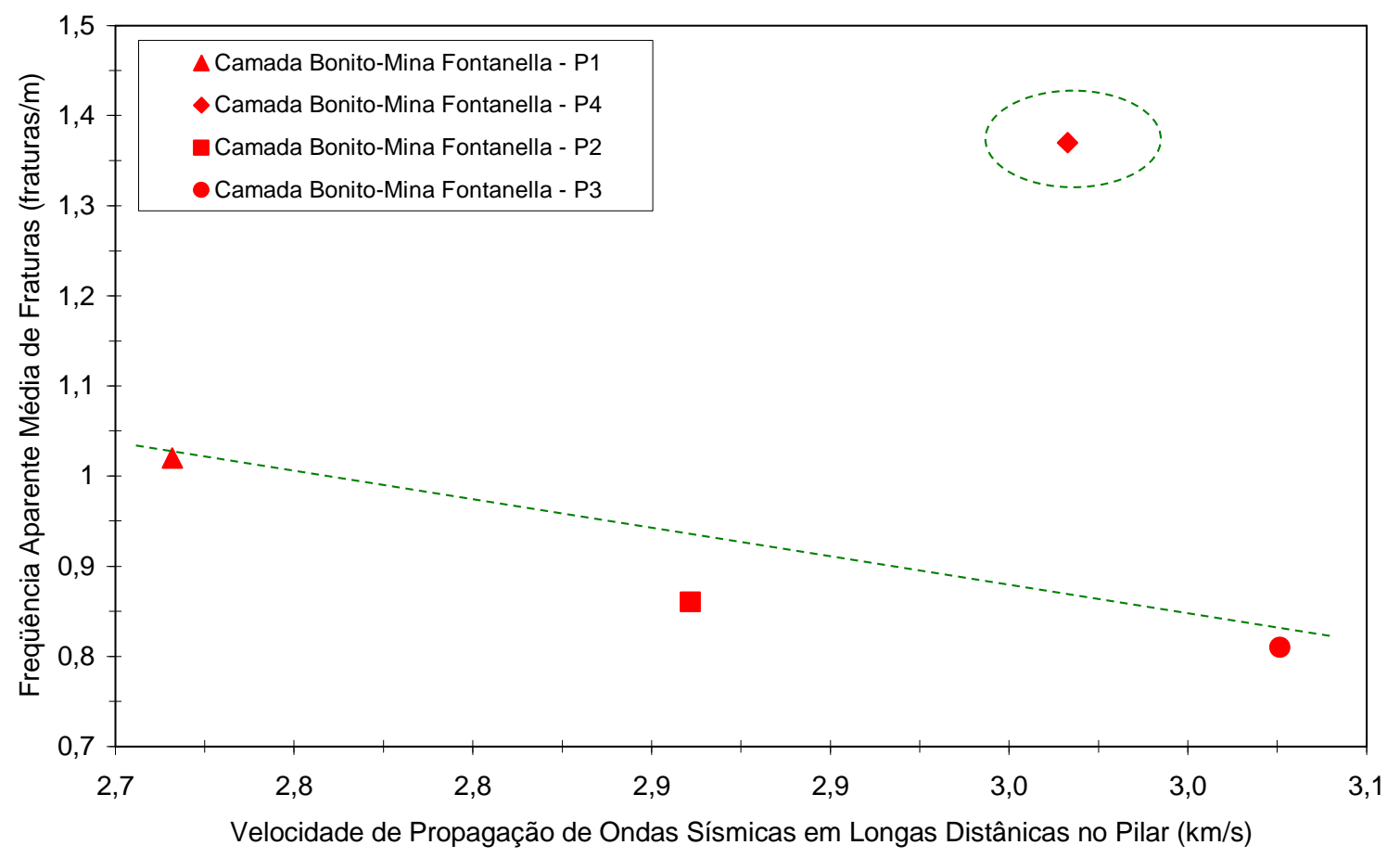

Figura 4.43 - Correlação entre a velocidade de propagação de ondas sísmicas corrigida e a freqüência aparente média de fraturas na camada de carvão Bonito, na Mina Fontanella. 


\subsection{Estudos em Laboratório Sobre a Influência da Tensão e da Água na Velocidade de Propagação de Ondas}

\subsubsection{Introdução}

A realização de ensaios para estudar a influência do nível de tensão na velocidade de propagação da onda ultra-sônica compressional (onda P) visou buscar informações para homogeinizar a velocidade ultra-sônica medida em laboratório e a velocidade de ondas sísmicas medidas in situ. Os materiais utilizados em laboratório foram provenientes das camadas de carvão Bonito Mina Fontanella - e Irapuá - Minas Morozini Norte e Santa Augusta Norte.

Nas condições de ensaio em laboratório, a tensão aplicada à rocha é de $0,1 \mathrm{MPa}$, conforme sugerido pelo método de ensaio (ISRM, 1978a). Já as medições da velocidade das ondas sísmicas são realizadas sob condições de tensão in situ variáveis, em função da cobertura e da geometria das escavações presentes nos diferentes locais estudados.

A presença de água nos poros da rocha também pode exercer influência considerável na velocidade de propagação de ondas. Nas condições de laboratório as determinações da velocidade ultra-sônica foram realizadas na condição de umidade natural. Já as velocidades de ondas sísmicas foram medidas in situ sob diferentes condições de saturação da rocha (condição "seca" ou de umidade natural, equivalente ao grau de saturação $\cong 0 \%$ - Minas Fontanella e Morozini Norte - e condição saturada ou grau de saturação $\cong 100 \%$ - Mina Santa Augusta Norte).

Os fatores $F_{1}$ (influência da tensão) e $F_{2}$ (influência da água), definidos nesses estudos, deverão corrigir as velocidades sísmicas para as seguintes condições de laboratório: - tensão $\cong 0$ e; - umidade natural (grau de saturação $\cong 0$ ).

\subsubsection{Ensaios para a Determinação da Influência da Tensão na Velocidade de Propagação da Onda Ultra-Sônica}

A configuração ideal dos ensaios em laboratório para simular as condições em que foram feitas as medições da velocidade de propagação de ondas sísmicas pela técnica de radiação (ondas sísmicas se propagando pelo interior do pilar) é a seguinte:

- ensaios na condição triaxial, com tensões confinantes (tensão principal menor) similares às tensões horizontais in situ no pilar;

- ensaios na condição triaxial, com aplicação da tensão principal maior na direção perpendicular aos planos de estratificação do carvão e medição da velocidade de propagação das ondas ultra-sônicas na direção paralela aos planos de estratificação.

Essas condições, porém, não puderam ser atendidas por dois motivos operacionais:

- a impossibilidade de obtenção de corpos-de-prova cilíndricos com dimensões apropriadas para ensaios triaxiais, em número razoável para a realização dos estudos; 
- o tipo de câmara triaxial disponível (câmara de Hoek) e dimensões dos geofones.

Assim, os estudos foram limitados à determinação da variação da velocidade ultra-sônica em função da variação da tensão apenas na condição uniaxial, com o carregamento aplicado na direção perpendicular aos planos de estratificação do carvão. Essa condição de tensão representa aproximadamente o que ocorre em termos de tensões in situ na periferia dos pilares de carvão.

$\mathrm{Na}$ primeira fase dos estudos foram utilizadas amostras do carvão da camada Bonito provenientes do ponto 3 de amostragem, na Mina Fontanella. Esse material foi escolhido por apresentar boa qualidade e permitir a preparação de uma quantidade de espécimens razoável para o estudo. $\mathrm{Na}$ segunda etapa utilizaram-se amostras de carvão da camada Irapuá, procedentes das Minas Morozini Norte (Amostras - Fase 1, utilizadas exclusivamente para esses estudos) e Santa Augusta Norte.

\subsubsection{Execução dos Ensaios}

$\mathrm{Na}$ primeira fase dos estudos, a aplicação da tensão uniaxial foi feita com o sistema de ensaio MTS 816, equipado com uma célula de carga de $100 \mathrm{kN}$ e sensibilidade de $10 \mathrm{~N}$. Nesse sistema de carga, tensões acima de aproximadamente $40 \%$ da tensão de ruptura tornaram praticamente impossível a determinação da velocidade da onda ultra-sônica, devido ao forte ruído eletrônico e instabilidade do sinal emitido/recebido pelos geofones.

$\mathrm{Na}$ segunda fase, com o intuito de eliminar os ruídos ocasionados pelo servocontrole do sistema MTS observados durante os ensaios com o material da camada Bonito, foi utilizada uma prensa mecânica, com capacidade para aplicação de cargas até o limite de $50 \mathrm{kN}$ e resolução de $10 \mathrm{~N}$. Durante o carregamento a prensa foi desligada nos níveis de carga previamente definidos, para que as medições do tempo de percurso da onda ultra-sônica fossem efetuadas. Com esse procedimento, em alguns casos as medições foram feitas até a ruptura do corpo-de-prova.

A medição da velocidade da onda ultra-sônica foi feita com o mesmo equipamento PUNDIT utilizado nos estudos de laboratório anteriores e de acordo com o método da ISRM, 1978a. Dois tipos de geofones foram empregados, dependendo da direção de medição da onda ultra-sônica no corpo-de-prova:

- percurso da onda perpendicular aos planos de estratificação do carvão: geofones com freqüência de ressonância de $1 \mathrm{MHz}$, interpostos entre os pratos da prensa e o corpo-de-prova, conforme Figura 4.44a, capazes de suportar tensões de até 50MPa;

- percurso da onda paralelo aos planos de estratificação do carvão: geofones de $200 \mathrm{kHz}$ instalados nas faces laterais do corpo-de-prova, como mostra a Figura 4.44b.

Independente da direção de medição do percurso da onda, a aplicação da carga sempre foi feita perpendicularmente aos planos de estratificação do carvão.

O ensaio consistiu na aplicação de incrementos de tensão até o limite máximo estabelecido em 16MPa. As medições de velocidade ultra-sônica foram feitas a partir do nível de tensão 0,2MPa. Em muitos corpos-de-prova não foi possível a 
medição da velocidade já sob tensões bem inferiores ao patamar máximo previsto, devido à deterioração do sinal lido pelo PUNDIT. Em outros casos, os corpos-de-prova romperam antes de ser atingido o patamar máximo de tensão desejado. As leituras de tensão e do tempo de percurso da onda foram feitas pontualmente, sempre após os sucessivos incrementos de tensão.

Os parâmetros de interesse foram calculados pelas seguintes expressões:

Variação $V_{\text {perp }}=\frac{V_{\text {tensão.variävel }}-V_{\text {perp }}}{V_{\text {perp }}} * 100$

e

Variação $V_{p a r}=\frac{V_{\text {tensão. variável }}-V_{p a r}}{V_{p a r}} * 100$

onde: Variação $\mathrm{V}_{\text {perp }}$ = variação da velocidade de propagação da onda ultra-sônica longitudinal medida na direção perpendicular aos planos de estratificação do carvão (\%);

Variação $\mathrm{V}_{\text {par }}=$ variação da velocidade de propagação da onda ultra-sônica longitudinal medida na direção paralela aos planos de estratificação do carvão (\%);

$\mathrm{V}_{\text {perp }}=$ velocidade de propagação da onda ultra-sônica longitudinal medida na direção perpendicular aos planos de estratificação do carvão, na condição de tensão uniaxial de ensaio $\cong 0(\mathrm{~km} / \mathrm{s})$;

$\mathrm{V}_{\mathrm{par}}=$ velocidade de propagação da onda ultra-sônica longitudinal medida na direção paralela aos planos de estratificação do carvão, na condição de tensão uniaxial de ensaio $\cong 0(\mathrm{~km} / \mathrm{s})$;

$\mathrm{V}_{\text {tensãovvariável }}=$ velocidade de propagação da onda ultra-sônica longitudinal medida nas diferentes tensões uniaxiais de ensaio $(\mathrm{km} / \mathrm{s})$.

\subsubsection{Resultados Obtidos}

\section{Carvão Bonito - Mina Fontanella}

As características geométricas e físicas dos corpos-de-prova, a velocidade da onda ultra-sônica determinada na condição de tensão de ensaio e a resistência à compressão uniaxial podem ser vistas nas Tabelas 4.19a e 4.19b.

As Figuras 4.45a e 4.45b apresentam curvas de variação da velocidade ultrasônica nas direções perpendicular e paralela à estratificação, respectivamente, em função do aumento da tensão uniaxial. 


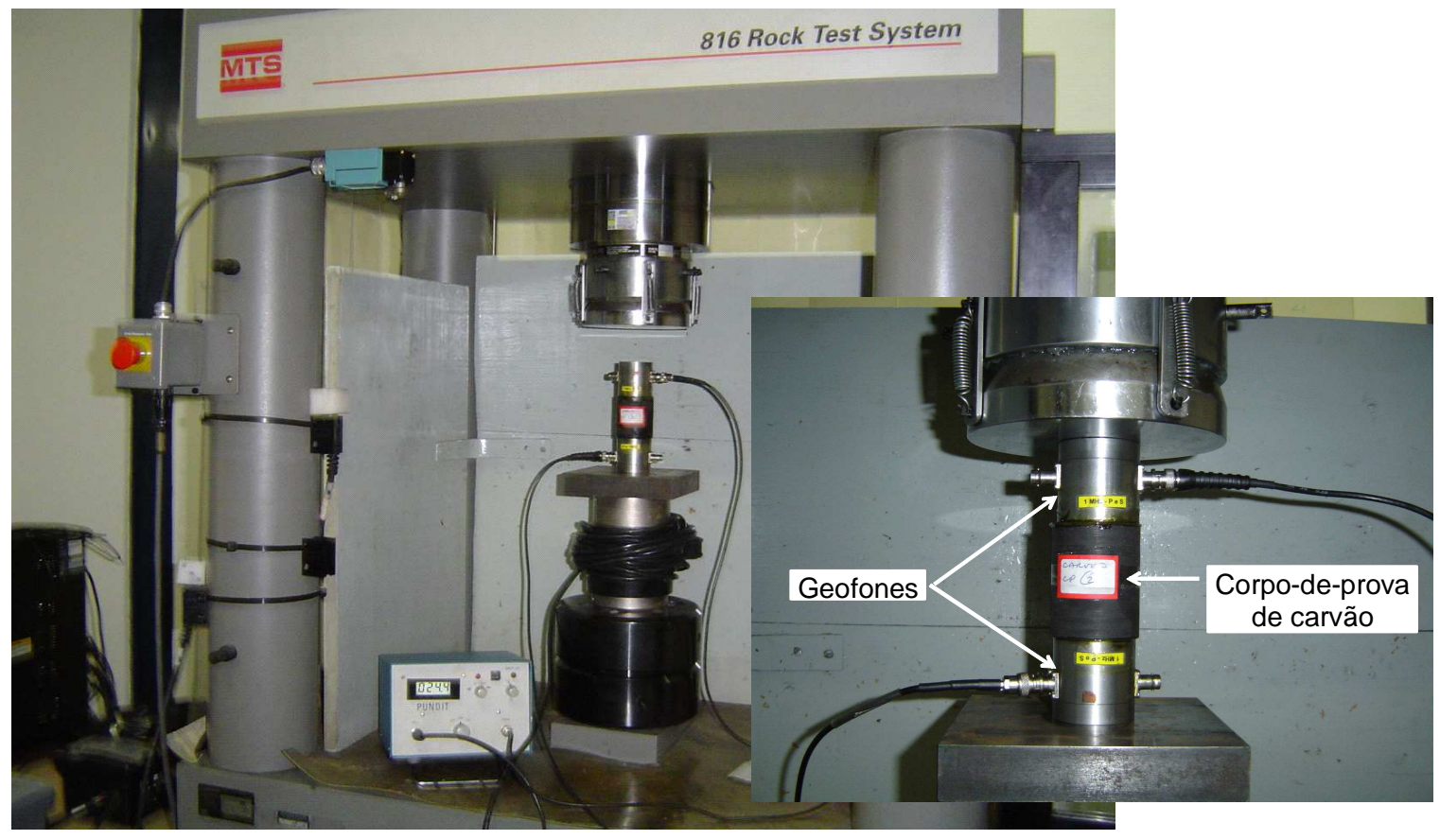

Figura 4.44a - Configuração do ensaio com aplicação da carga e medição da velocidade de propagação da onda ultra-sônica na direção perpendicular aos planos da estratificação do carvão. No detalhe, geofones de $1 \mathrm{MHz}$ acoplados ao corpo-de-prova.

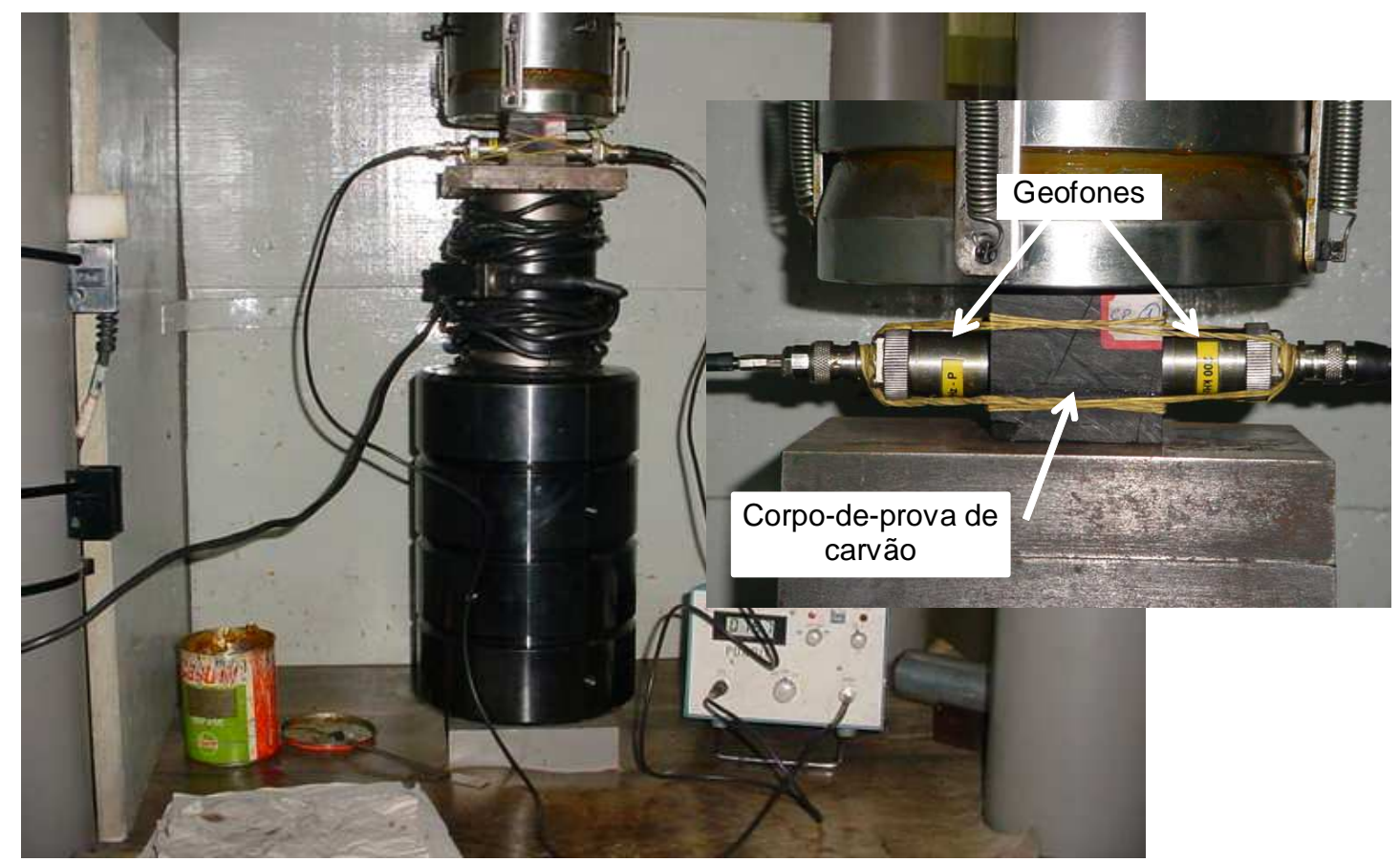

Figura 4.44b - Configuração do ensaio com aplicação da carga na direção perpendicular aos planos de estratificação do carvão e medição da velocidade de propagação da onda ultra-sônica na direção paralela. No detalhe, geofones de $200 \mathrm{kHz}$ acoplados ao corpo-deprova. 
Tabela 4.19a - Características dos corpos-de-prova para estudo da influência da tensão uniaxial na velocidade de propagação da onda ultra-sônica medida na direção perpendicular aos planos de estratificação, no carvão da camada Bonito, na Mina Fontanella.

\begin{tabular}{|c|c|c|c|c|c|c|}
\hline $\mathrm{CP}$ & $\begin{array}{c}\mathrm{D} \\
(\mathrm{cm})\end{array}$ & $\begin{array}{c}\mathrm{H} \\
(\mathrm{cm})\end{array}$ & $\begin{array}{c}\rho_{\mathrm{a}} \\
\left(\mathrm{g} / \mathrm{cm}^{3}\right)\end{array}$ & $\begin{array}{c}\mathrm{V}_{\text {perp (tensão } 00)} \\
(\mathrm{km} / \mathrm{s})\end{array}$ & $\begin{array}{c}\mathrm{W} \\
(\%)\end{array}$ & $\begin{array}{c}\sigma_{\mathrm{c} . \text { cilindro }} \\
(\mathrm{MPa})\end{array}$ \\
\hline 7 & 5,41 & 5,96 & 1,85 & 2,43 & 1,1 & 19,57 \\
\hline 8 & 5,40 & 6,85 & 1,87 & 2,37 & 1,0 & 24,33 \\
\hline 9 & 5,41 & 6,09 & 1,84 & 2,39 & 1,1 & 26,22 \\
\hline 10 & 5,41 & 7,64 & 1,90 & 2,42 & 1,0 & 28,37 \\
\hline 11 & 5,41 & 6,13 & 1,87 & 2,45 & 1,0 & 21,41 \\
\hline 12 & 5,39 & 5,69 & 1,84 & 2,06 & 1,0 & 21,78 \\
\hline 13 & 5,41 & 6,78 & 1,93 & 2,51 & 1,0 & 24,20 \\
\hline
\end{tabular}

$\sigma_{\text {c.ilindro }}=$ resistência à compressão uniaxial de corpo-de-prova cilíndrico com carregamento na direção perpendicular aos planos de estratificação do carvão, corrigida para a relação altura/diâmetro $=1$ segundo a ASTM C 170: $\sigma_{\text {c.cilindro }}=\sigma_{\text {c.ensaio }} /(0,778+0,222 * D / H) ; \mathrm{CP}=$ corpo-de-prova; $\mathrm{D}$ e $\mathrm{H}=$ diâmetro $\mathrm{e}$ altura do corpo-de-prova, respectivamente; $\rho_{\mathrm{a}}=$ massa específica aparente; $V_{\text {perp }}$ (tensão $\left.\simeq_{0}\right)=$ velocidade de propagação da onda ultra-sônica longitudinal medida na direção perpendicular aos planos de estratificação do carvão, na condição de tensão uniaxial de ensaio $\cong 0 ; \mathrm{W}=$ umidade da amostra após o ensaio.

Tabela 4.19b - Características dos corpos-de-prova para estudo da influência da tensão uniaxial na velocidade de propagação da onda ultra-sônica medida na direção paralela aos planos de estratificação, no carvão da camada Bonito.

\begin{tabular}{|c|c|c|c|c|c|c|c|}
\hline $\mathrm{CP}$ & $\begin{array}{c}\mathrm{L} \\
(\mathrm{cm})\end{array}$ & $\begin{array}{c}\mathrm{P} \\
(\mathrm{cm})\end{array}$ & $\begin{array}{c}\mathrm{H} \\
(\mathrm{cm})\end{array}$ & $\begin{array}{c}\rho_{\mathrm{a}} \\
\left(\mathrm{g} / \mathrm{cm}^{3}\right)\end{array}$ & $\begin{array}{c}\mathrm{V}_{\text {par (tensão } \cong 0)} \\
(\mathrm{km} / \mathrm{s})\end{array}$ & $\begin{array}{c}\mathrm{W} \\
(\%)\end{array}$ & $\begin{array}{c}\sigma_{\text {c.cubo }} \\
(\mathrm{MPa})\end{array}$ \\
\hline 1 & 5,34 & 5,19 & 5,01 & 1,68 & 2,89 & 1,1 & - \\
\hline 2 & 5,43 & 5,06 & 4,39 & 1,69 & 2,97 & 1,0 & 18,42 \\
\hline 3 & 5,24 & 5,34 & 4,79 & 1,63 & 2,99 & 1,0 & 8,15 \\
\hline 4 & 5,18 & 5,39 & 5,05 & 1,67 & 2,73 & 0,9 & 21,31 \\
\hline 5 & 5,46 & 5,24 & 5,07 & 1,65 & 3,02 & 1,1 & 14,61 \\
\hline 6 & 5,32 & 5,48 & 5,05 & 1,63 & 2,89 & 1,0 & 19,76 \\
\hline
\end{tabular}

$\sigma_{\mathrm{c} . \text { cubo }}=$ resistência à compressão uniaxial de corpo-de-prova cúbico com carregamento na direção perpendicular aos planos de estratificação do carvão; L, P e H = largura, profundidade e altura do corpo-de-prova, respectivamente; $\mathrm{V}_{\text {par (tensão } \cong 0)}=$ velocidade de propagação da onda ultra-sônica longitudinal medida na direção paralela aos planos de estratificação do carvão, na condição de tensão uniaxial de ensaio $\cong 0$. 
Velocidade da Onda Ultra-Sônica Medida na Direção da ALTURA

- Perpendicular à Estratificação -

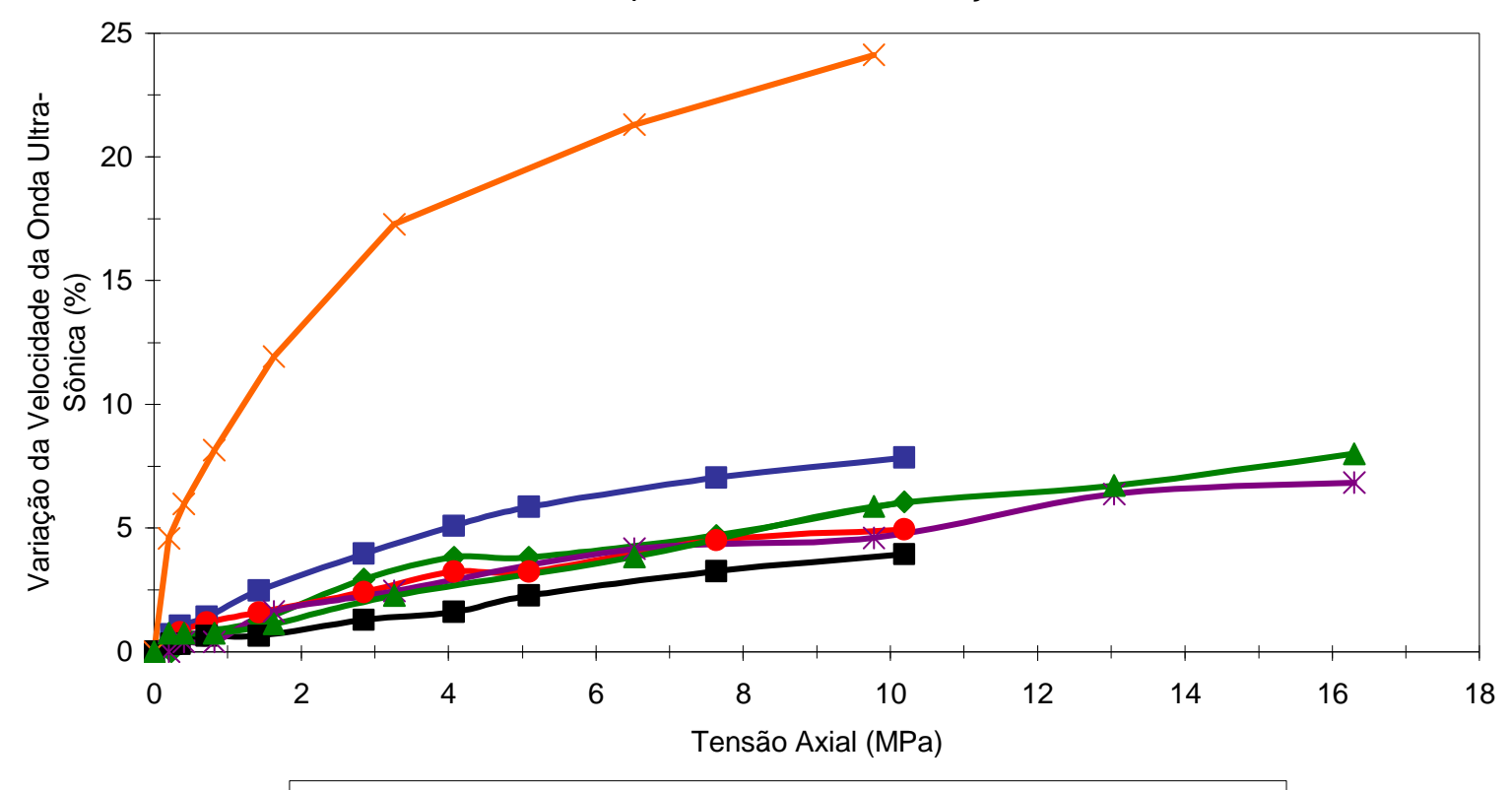

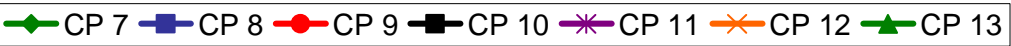

Figura 4.45a - Variação percentual da velocidade de propagação da onda ultra-sônica em função da variação da tensão uniaxial - Carvão da camada Bonito da Mina Fontanella.

Velocidade da Onda Ultra-Sônica Medida na Direção da PROFUNDIDADE ou LARGURA - Paralela à Estratificação -

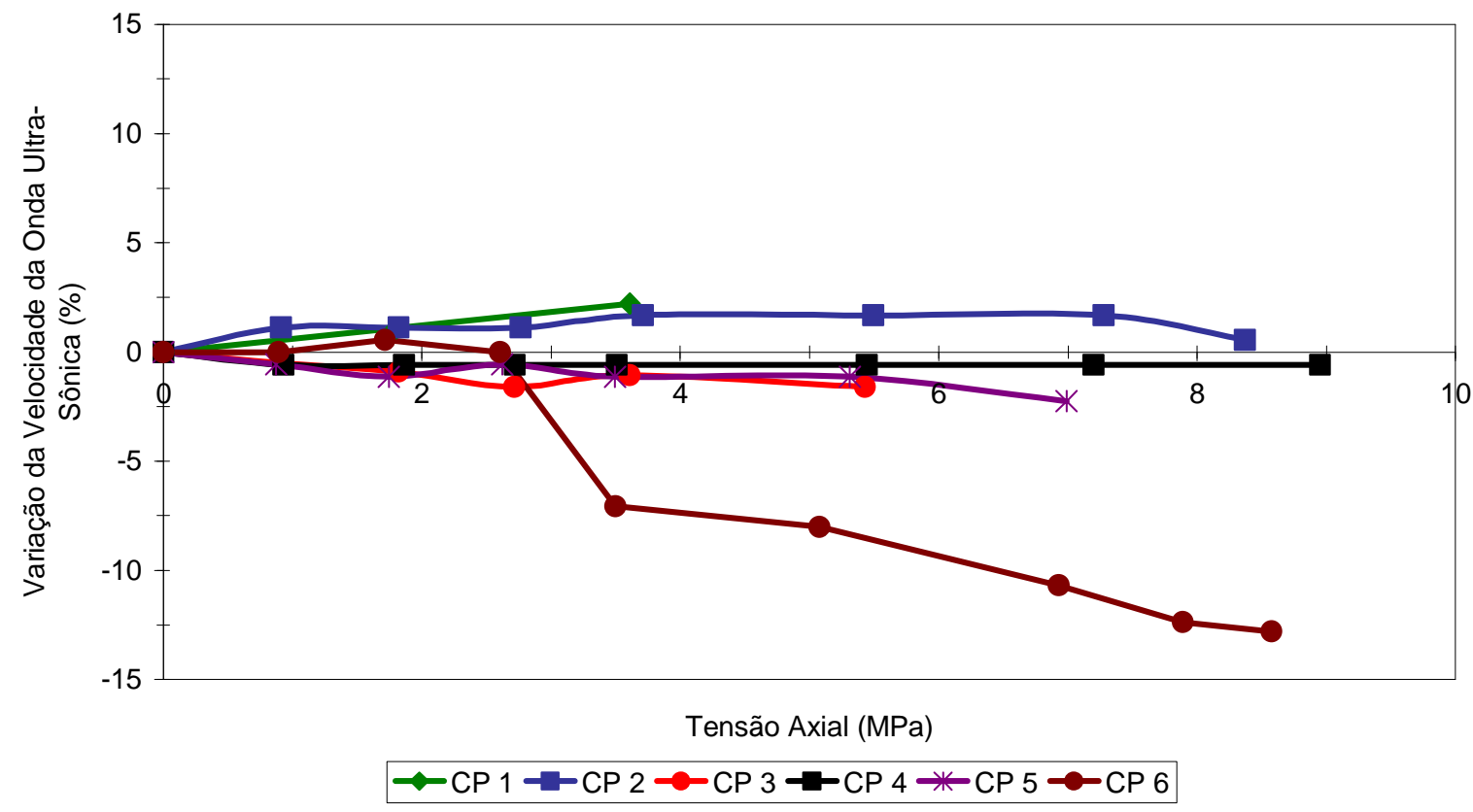

Figura 4.45b - Variação percentual da velocidade de propagação da onda ultra-sônica em função da variação da tensão uniaxial - Carvão da camada Bonito da Mina Fontanella. 


\section{Carvão Irapuá - Mina Morozini Norte}

$\mathrm{Na}$ Tabela 4.20 podem ser vistas as características geométricas e físicas dos corpos-de-prova ensaiados, a velocidade da onda ultra-sônica determinada na condição sob tensão uniaxial zero e a resistência à compressão uniaxial.

Nas Figuras 4.46a e 4.46b são apresentadas as curvas de variação da velocidade ultra-sônica em função da tensão axial aplicada nas amostras.

Tabela 4.20 - Características dos corpos-de-prova usados nos estudos da influência da tensão uniaxial na velocidade de propagação da onda ultra-sônica medida nas direções paralela e perpendicular aos planos de estratificação, no carvão da camada Irapuá da Mina Morozini Norte (Amostras - Fase 1).

\begin{tabular}{|c|c|c|c|c|c|c|c|c|}
\hline $\mathrm{CP}$ & $\begin{array}{c}\mathrm{L} \\
(\mathrm{cm})\end{array}$ & $\begin{array}{c}\mathrm{P} \\
(\mathrm{cm})\end{array}$ & $\begin{array}{c}\mathrm{H} \\
(\mathrm{cm})\end{array}$ & $\begin{array}{c}\rho_{\mathrm{a}} \\
\left(\mathrm{g} / \mathrm{cm}^{3}\right)\end{array}$ & $\begin{array}{c}\mathrm{V}_{\text {perp (tensão=0) }} \\
(\mathrm{km} / \mathrm{s})\end{array}$ & $\begin{array}{c}\mathrm{V}_{\text {par (tensão00) }} \\
(\mathrm{km} / \mathrm{s})\end{array}$ & $\begin{array}{c}\mathrm{W} \\
(\%)\end{array}$ & $\begin{array}{c}\sigma_{\text {c.cubo }} \\
(\mathrm{MPa})\end{array}$ \\
\hline 1 & 6,00 & 5,83 & 5,97 & 1,57 & 2,11 & - & 1,0 & 12,81 \\
\hline 2 & 6,10 & 6,03 & 5,97 & 2,00 & 1,97 & 1,92 & 0,7 & 7,25 \\
\hline 3 & 6,04 & 6,11 & 5,97 & 1,97 & 1,77 & - & 0,7 & 8,51 \\
\hline 4 & 5,95 & 6,01 & 6,00 & 1,70 & 2,03 & - & 1,4 & 3,58 \\
\hline 5 & 5,76 & 6,00 & 5,89 & 1,53 & - & 2,46 & 1,0 & 3,13 \\
\hline 7 & 5,49 & 5,45 & 5,24 & 1,43 & - & 2,33 & 0,9 & 9,70 \\
\hline 8 & 5,46 & 5,47 & 5,24 & 1,60 & 1,98 & 2,98 & 1,3 & 15,32 \\
\hline 9 & 5,57 & 5,05 & 5,34 & 1,45 & 1,98 & 1,77 & 0,9 & 3,73 \\
\hline 10 & 5,60 & 5,61 & 5,41 & 1,51 & 1,91 & 2,17 & 1,0 & 9,78 \\
\hline 12 & 5,63 & 5,73 & 5,44 & 1,92 & 1,65 & 2,87 & 0,8 & 4,86 \\
\hline
\end{tabular}

$\sigma_{\text {c.cubo }}=$ resistência à compressão uniaxial de corpo-de-prova cúbico com carregamento na direção perpendicular aos planos de estratificação do carvão; CP = corpo-de-prova; L, P e H = largura, profundidade e altura do corpo-de-prova, respectivamente; $\rho_{a}=$ massa específica aparente; $V_{\text {perp }}$ (tensão@0) e $\mathrm{V}_{\text {par (tensão@0) }}=$ velocidade de propagação da onda ultra-sônica longitudinal medida nas direções perpendicular e paralela aos planos de estratificação do carvão, respectivamente, na condição de tensão uniaxial de ensaio $\cong 0 ; W=$ umidade da amostra após o ensaio. 
Velocidade da Onda Ultra-Sônica Medida na Direção da ALTURA

- Perpendicular à Estratificação -

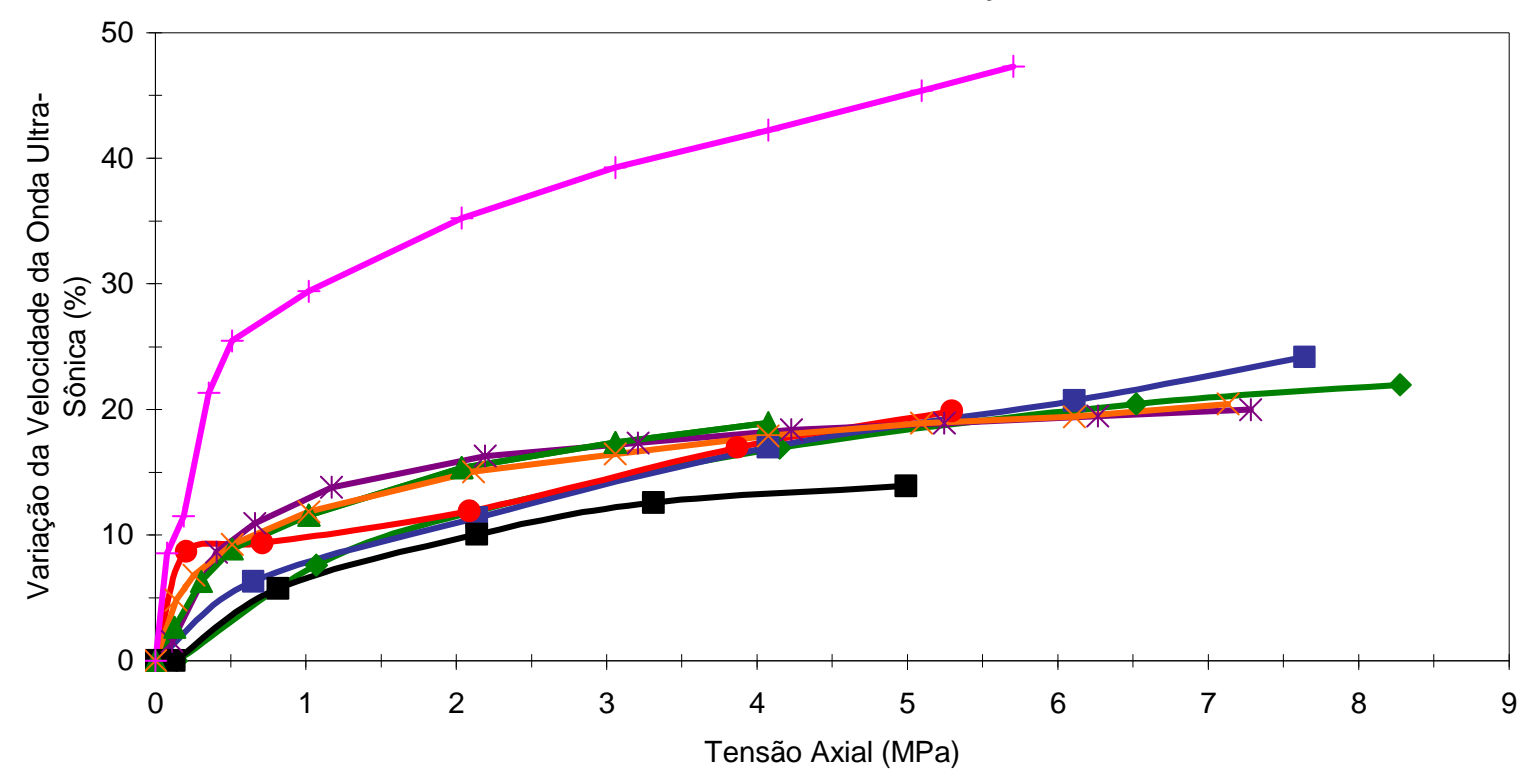

$\sim \mathrm{CP} 1-\mathrm{CP} 2-\mathrm{CP} 3-\mathrm{CP} 4 \div \mathrm{CP} 8 \div \mathrm{CP} 9 \div \mathrm{CP} 10 \div \mathrm{CP} 12$

Figura 4.46a - Variação percentual da velocidade de propagação da onda ultra-sônica em função da variação da tensão uniaxial - Carvão da camada Irapuá da Mina Morozini Norte.

Velocidade da Onda Ultra-Sônica Medida na Direção da PROFUNDIDADE ou LARGURA - Paralela à Estratificação -

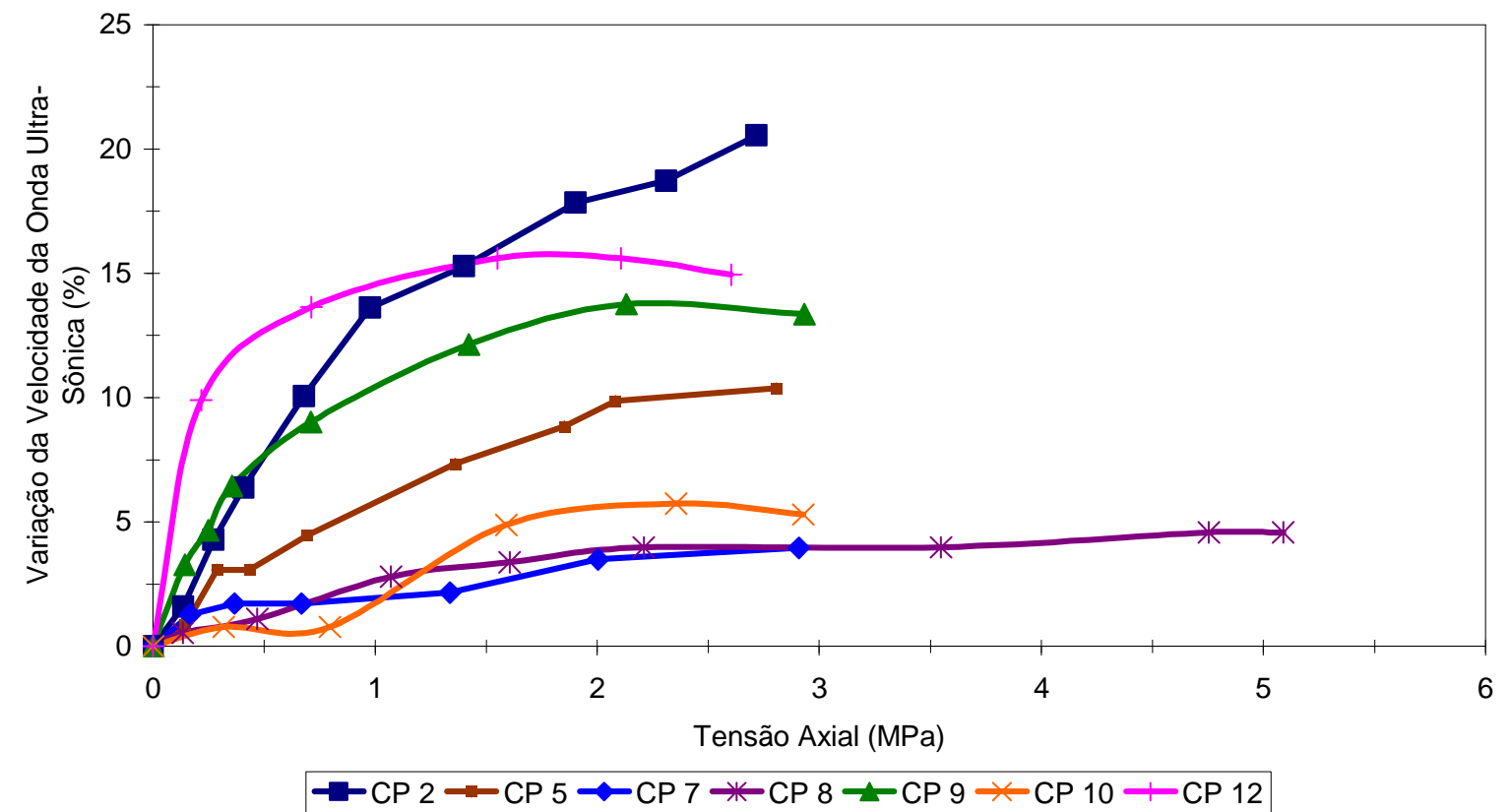

Figura 4.46b - Variação percentual da velocidade de propagação da onda ultra-sônica em função da variação da tensão uniaxial - Carvão da camada Irapuá da Mina Morozini Norte. 


\section{Carvão Irapuá - Mina Santa Augusta Norte}

A Tabela 4.21 apresenta as características geométricas e físicas dos corpos-deprova, a velocidade da onda ultra-sônica determinada na condição sob tensão uniaxial zero e a resistência à compressão uniaxial.

As curvas de variação da velocidade ultra-sônica em função da tensão axial das amostras ensaiadas são apresentadas nas Figuras 4.47a e 4.47b.

Tabela 4.21 - Características dos corpos-de-prova usados nos estudos da influência da tensão uniaxial na velocidade de propagação da onda ultra-sônica medida nas direções paralela e perpendicular aos planos de estratificação, no carvão da camada Irapuá da Mina Santa Augusta Norte.

\begin{tabular}{|c|c|c|c|c|c|c|c|c|}
\hline $\mathrm{CP}$ & $\begin{array}{c}\mathrm{L} \\
(\mathrm{cm})\end{array}$ & $\begin{array}{c}\mathrm{P} \\
(\mathrm{cm})\end{array}$ & $\begin{array}{c}\mathrm{H} \\
(\mathrm{cm})\end{array}$ & $\begin{array}{c}\rho_{\mathrm{a}} \\
\left(\mathrm{g} / \mathrm{cm}^{3}\right)\end{array}$ & $\begin{array}{c}\mathrm{V}_{\text {perp (tensão00) }} \\
(\mathrm{km} / \mathrm{s})\end{array}$ & $\begin{array}{c}\mathrm{V}_{\text {par (tensão00) }} \\
(\mathrm{km} / \mathrm{s})\end{array}$ & $\begin{array}{c}\mathrm{W} \\
(\%)\end{array}$ & $\begin{array}{c}\sigma_{\mathrm{c} . \text { cubo }} \\
(\mathrm{MPa})\end{array}$ \\
\hline $5 \mathrm{C}$ & 5,60 & 5,65 & 5,53 & 1,54 & 1,95 & 2,68 & 0,8 & 30,10 \\
\hline $5 \mathrm{D}$ & 5,57 & 5,64 & 5,45 & 1,52 & 1,90 & 2,63 & 0,9 & 31,75 \\
\hline $5 \mathrm{E}$ & 5,62 & 5,62 & 5,44 & 1,47 & 2,23 & 2,72 & 0,8 & 36,61 \\
\hline $5 \mathrm{~F}$ & 5,61 & 5,71 & 5,38 & 1,48 & 2,15 & 2,60 & 0,4 & 36,62 \\
\hline $5 \mathrm{G}$ & 5,63 & 5,67 & 5,52 & 1,48 & 2,26 & 1,98 & 0,7 & 31,39 \\
\hline $5 \mathrm{H}$ & 5,64 & 5,64 & 5,31 & 1,56 & 2,27 & 2,85 & 0,9 & 28,87 \\
\hline
\end{tabular}

$\sigma_{\text {c.cubo }}=$ resistência à compressão uniaxial de corpo-de-prova cúbico com carregamento na direção perpendicular aos planos de estratificação do carvão; CP = corpo-de-prova; L, P e H = largura, profundidade e altura do corpo-de-prova, respectivamente; $\rho_{a}=$ massa específica aparente; $V_{\text {perp }}$ (tensão@0) e $\mathrm{V}_{\text {par (tensão@0) }}=$ velocidade de propagação da onda ultra-sônica longitudinal medida nas direções perpendicular e paralela aos planos de estratificação do carvão, respectivamente, na condição de tensão uniaxial de ensaio $\cong 0 ; W=$ umidade da amostra após o ensaio. 
Velocidade da Onda Ultra-Sônica Medida na Direção da ALTURA

- Perpendicular à Estratificação -

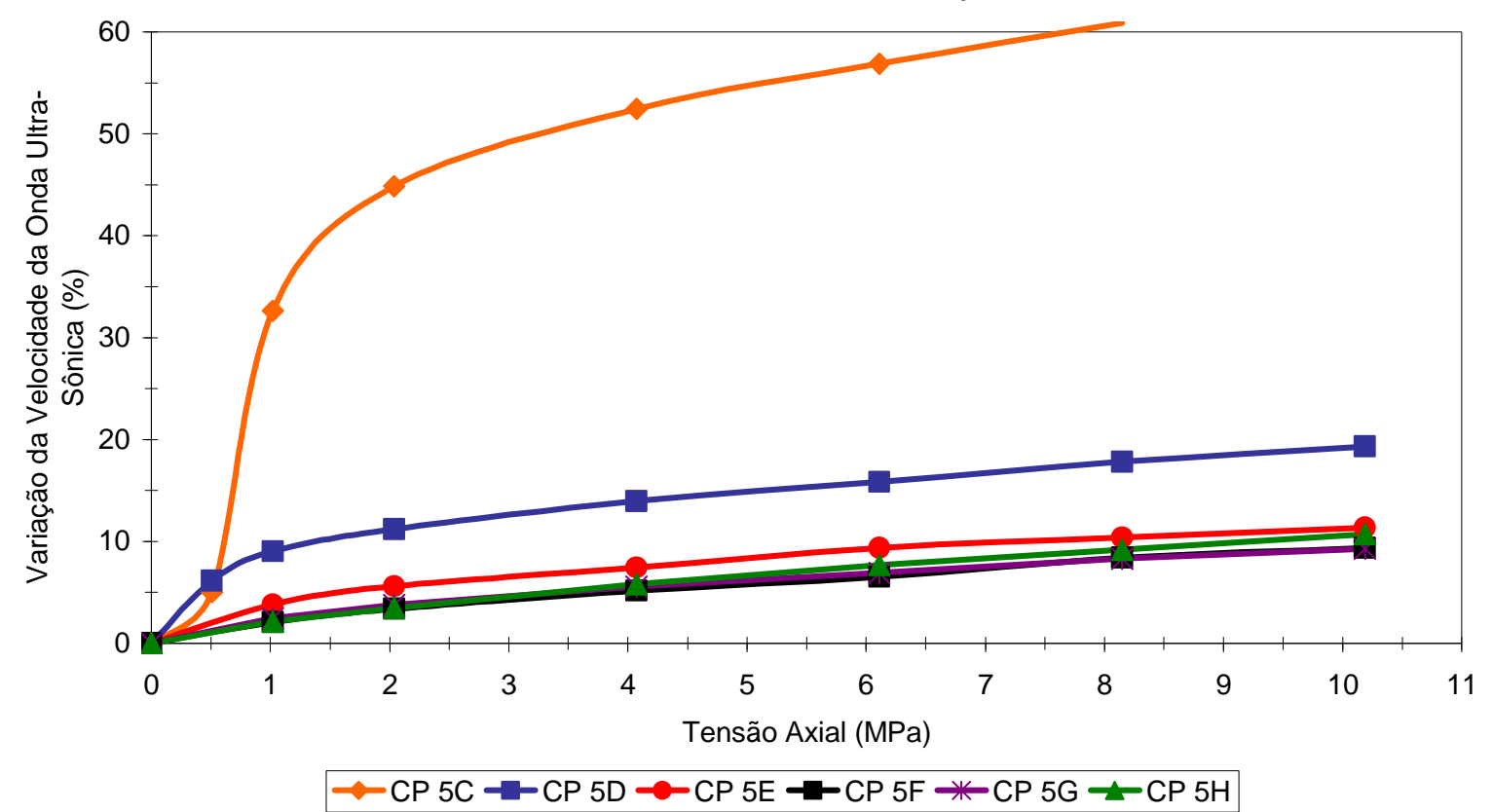

Figura 4.47a - Variação percentual da velocidade de propagação da onda ultra-sônica em função da variação da tensão uniaxial - Carvão da camada Irapuá da Mina Santa Augusta Norte.

Velocidade da Onda Ultra-Sônica Medida na Direção da PROFUNDIDADE ou LARGURA - Paralela à Estratificação -

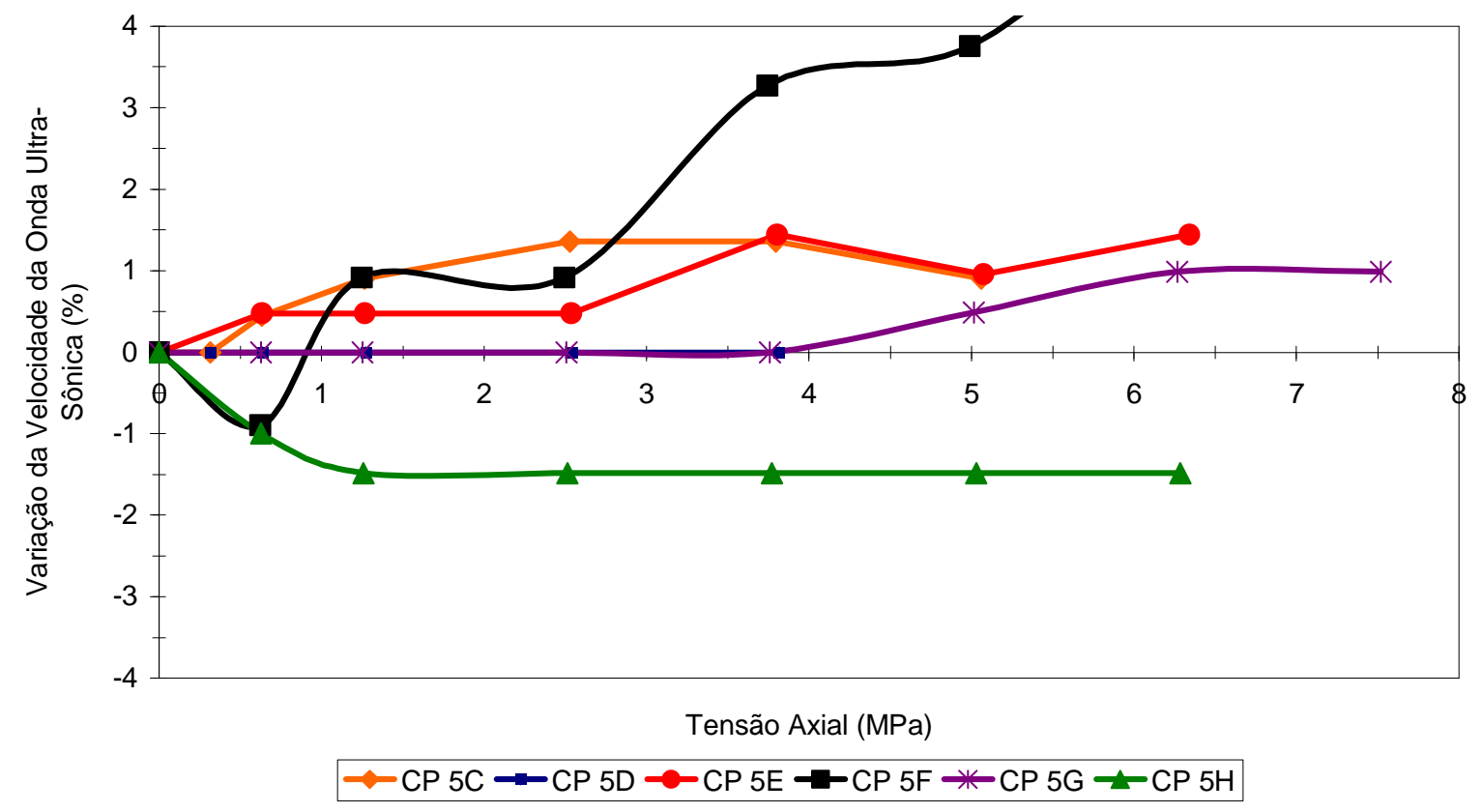

Figura 4.47b - Variação percentual da velocidade de propagação da onda ultra-sônica em função da variação da tensão uniaxial - Carvão da camada Irapuá da Mina Santa Augusta Norte. 


\subsubsection{Discussão dos Resultados}

\section{Percurso da onda paralelo aos planos de estratificacão do carvão}

Tanto no carvão da camada Bonito, como no da camada Irapuá da Mina Santa Augusta Norte, observou-se variação desprezível na velocidade medida na direção paralela à estratificação (perpendicular à direção de carregamento) em função da variação da tensão. Em muitos casos, inclusive, constatou-se o decréscimo na velocidade com o aumento da tensão axial. Já no carvão da Mina Morozini Norte, a variação máxima da velocidade situou-se entre $2 \%$ e $15 \%$. Porém, não foi possível estabelecer um padrão de variação da velocidade com a variação da tensão.

Esse comportamento era de certa forma esperado, devido à tendência de abertura das fraturas pré-existentes ou aberturas de novas descontinuidades (fraturas de tração) no plano ortogonal à direção de medição da velocidade.

\section{Percurso da onda perpendicular aos planos de estratificação do carvão}

A velocidade da onda ultra-sônica medida na direção perpendicular aos planos de estratificação (mesma direção do carregamento) mostra variações máximas entre $8 \%$ (em amostras do carvão Bonito) e 22\% (em amostras do carvão Irapuá). Em cada grupo de ensaios um único corpo-de-prova mostrou variação discrepante do comportamento médio (CP 12 - Bonito da Mina Fontanella; CP 12 - Irapuá da Mina Morozini Norte; 5C - Irapuá da Mina Santa Augusta Norte). Nos dois primeiros casos observa-se que os corpos-de-prova são os que apresentaram a menor velocidade da onda ultra-sônica na condição tensão axial $\cong 0$. Os resultados desses ensaios foram desconsiderados para efeitos de estabelecimento das curvas típicas de variação da velocidade em função da tensão de cada amostra. A Figura 4.48 apresenta as curvas médias de variação da velocidade da onda ultra-sônica para as diferentes amostras de carvão estudadas (curva 1 - carvão Bonito da Mina Fontanella; curva 2 - carvão Irapuá da Mina Santa Augusta Norte; curva 5 - carvão Irapuá da Mina Morozini Norte), além de outras duas curvas estimadas (curva 3 e curva 4).

A diferença marcante na variação da velocidade no carvão Irapuá da Mina Morozini, comparada com a que ocorre no carvão da camada Bonito, pode ser associada à grande diferença de deformabilidade na direção perpendicular aos planos de estratificação, entre esses dois carvões. Na média, as amostras utilizadas do carvão Irapuá da Mina Morozini são cerca de 2 vezes mais deformáveis que o carvão da camada Bonito.

Em se tratando de rocha carbonosa, com forte marcação dos planos de estratificação, é de se esperar uma forte influência da tensão uniaxial na velocidade de propagação de ondas ultra-sônicas já sob baixas tensões. Observando-se as curvas típicas "tensão x variação da velocidade sônica" das diferentes amostras estudadas, nota-se que a variação da velocidade se estabiliza a partir de tensões acima de $10 \mathrm{MPa}$, aproximadamente. Esse comportamento pode ser explicado porque nesse patamar de tensão as deformações, devidas ao fechamento dos planos de estratificação do carvão, praticamente cessam. Assim, os planos dessas descontinuidades não mais 
constituem barreiras para a propagação das ondas ultra-sônicas, à medida que o nível de tensão cresce, até o patamar em que a rocha começa se desintegrar.

A variação máxima esperada para a velocidade ultra-sônica medida na direção perpendicular aos planos de estratificação do carvão, quando a rocha é submetida à elevadas tensões uniaxiais, foi correlacionada com a velocidade ultra-sônica medida na condição tensão $\cong 0$ e com a resistência à compressão uniaxial. Os resultados podem ser vistos nas Figuras 4.49 e 4.50.

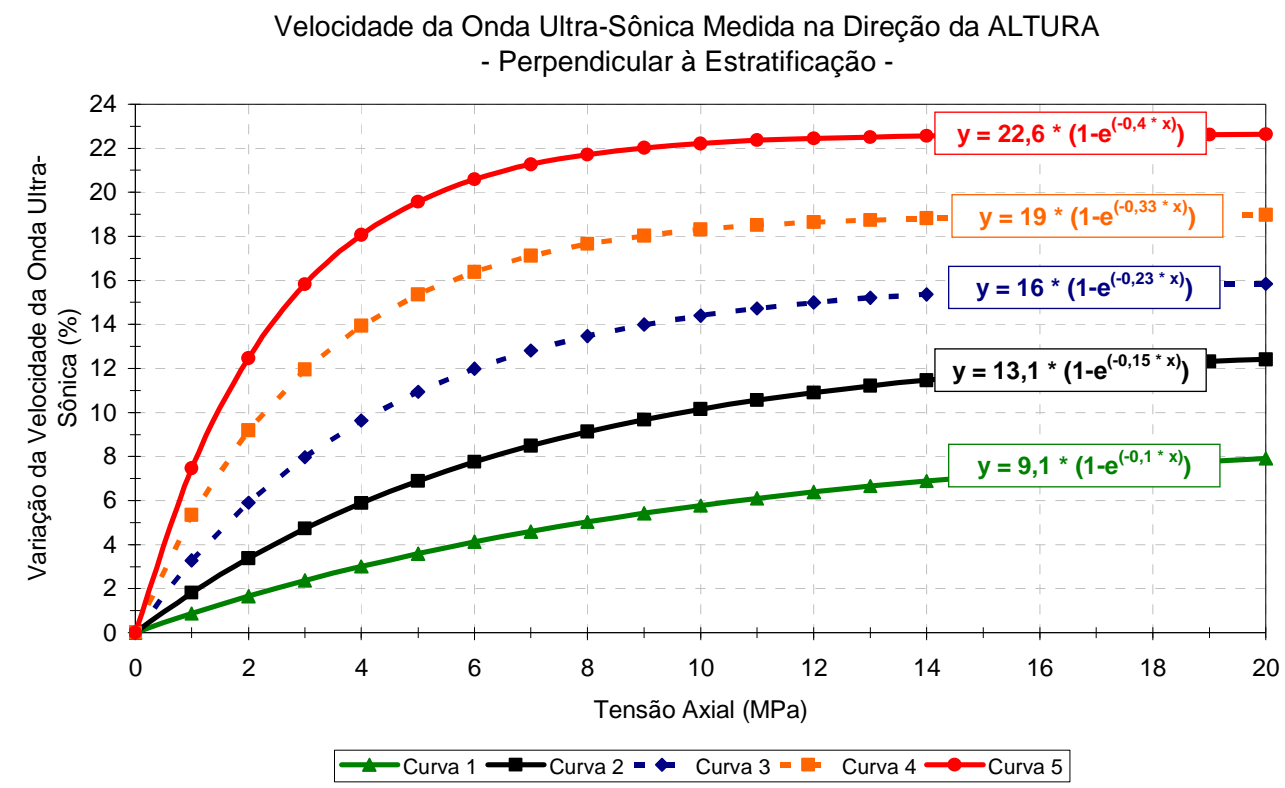

Figura 4.48 - Curvas típicas de variação percentual da velocidade ultra-sônica em função da variação da tensão uniaxial aplicada na rocha.

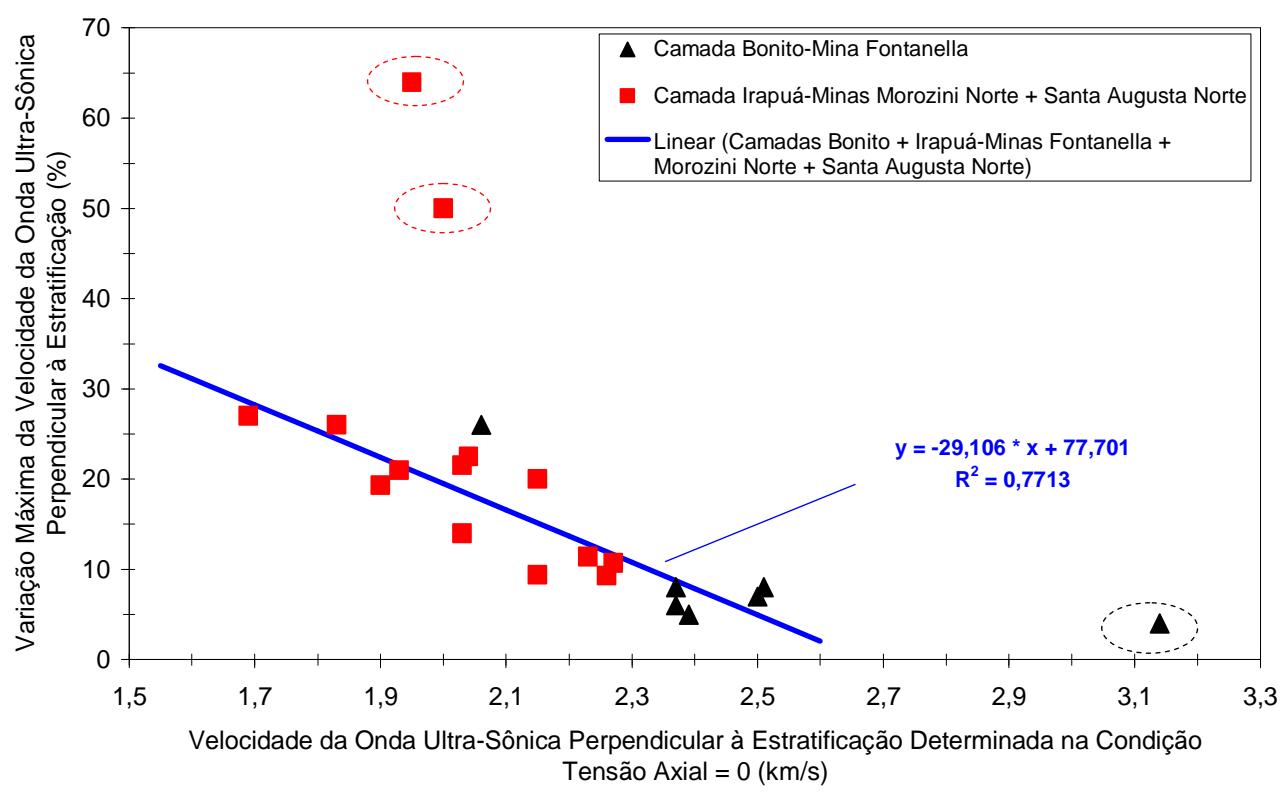

Figura 4.49 - Variação máxima esperada para a velocidade ultra-sônica quando a rocha é submetida a tensões uniaxiais elevadas, para carvões com diferentes velocidades ultrasônicas determinadas sob tensão $\cong 0$. Nota: os dados com elipse não foram considerados na regressão. 


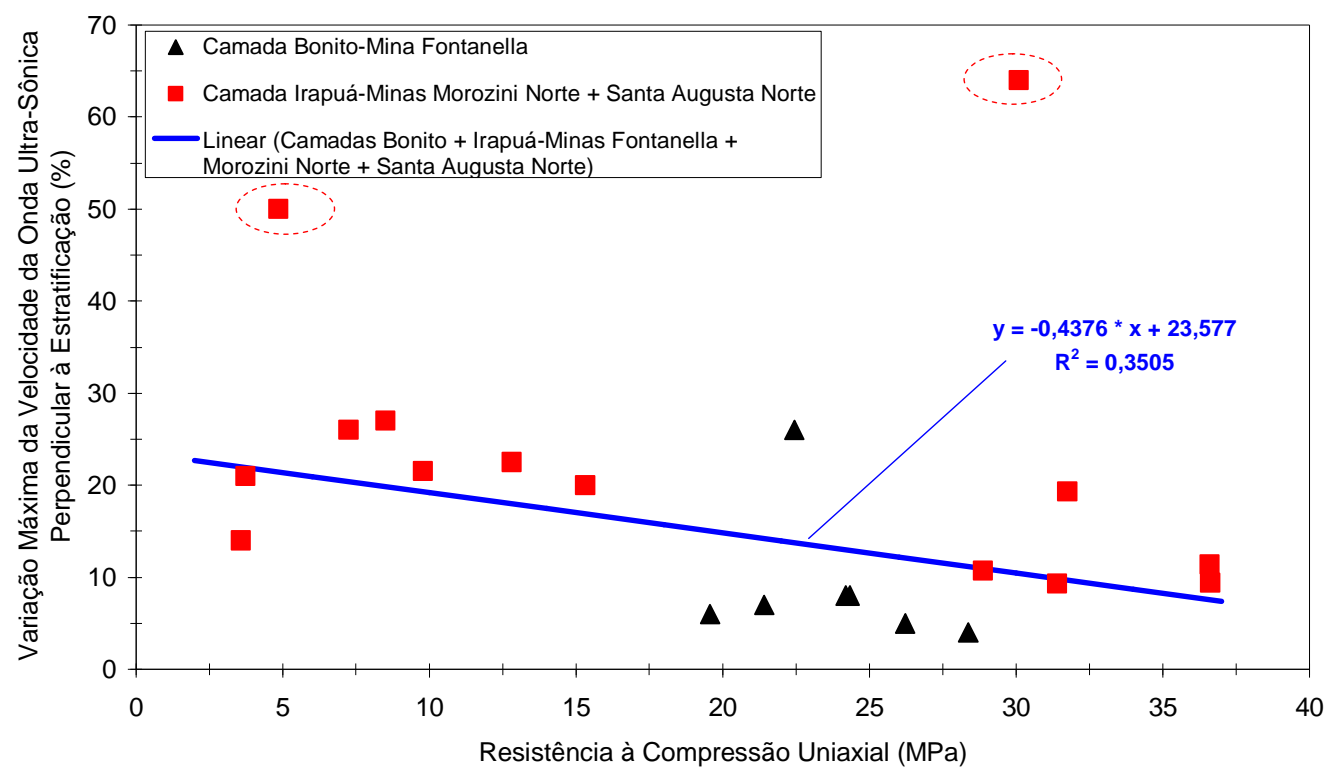

Figura 4.50 - Variação máxima esperada para a velocidade ultra-sônica em função da resistência à compressão uniaxial. Nota: os dados com elipse não foram considerados na regressão.

\subsubsection{Fator de Correção da Velocidade de Ondas Sísmicas Medidas In Situ para a Condição de Tensão de Ensaio em Laboratório (Tensão $\cong 0$ )}

Ainda que conhecidas as limitações da configuração dos ensaios de laboratório em relação à condição idealizada inicialmente para representar as condições in situ de tensão e direção de medição da velocidade de propagação das ondas sísmicas, as curvas de variação da velocidade em função da tensão, estabelecidas na Figura 4.48, serão utilizadas para determinar o fator de correção da velocidade de ondas sísmicas determinadas sob diferentes níveis de tensão vertical in situ, para a condição de laboratório (tensão $\cong 0$ ).

Quando não há estudos de laboratório sobre o comportamento da velocidade de ondas ultra-sônicas em função da tensão, deve ser adotado o seguinte procedimento:

- determinar em laboratório a velocidade média da onda ultra-sônica medida na direção perpendicular aos planos de estratificação do carvão;

- com base na relação expressa na Figura 4.49, estimar a variação máxima esperada para a velocidade ultra-sônica em função da velocidade média da camada, medida na direção perpendicular aos planos de estratificação do carvão, em laboratório;

- na Figura 4.48, selecionar a função $y(x)$ de variação da velocidade em função da tensão que melhor expresse a variação máxima esperada para a velocidade ultra-sônica; 
- calcular o fator de correção da velocidade de propagação de ondas sísmicas $\left(F_{1}\right)$ em função da tensão vertical in situ $\left(\sigma_{v}\right)$ onde foi feita a medição da velocidade sísmica, utilizando a seguinte expressão:

$F_{1}=1-\frac{\mathrm{y}\left(\mathrm{x}=\sigma_{v}\right)}{100}$

A Tabela 4.22 apresenta os fatores de correção $\left(\mathrm{F}_{1}\right)$ para as velocidades sísmicas medidas in situ de acordo com as diferentes curvas de variação obtidas em laboratório (Figura 4.48).

Tabela 4.22 - Valores do fator $F_{1}$ a serem utilizados para correção da velocidade de propagação de ondas sísmicas medidas in situ sob diferentes níveis de tensão, para a condição de tensão de ensaio em laboratório (tensão $\cong 0$ ).

\begin{tabular}{|c|c|c|c|c|c|}
\hline $\begin{array}{c}\text { Faixa de } \\
\text { Tensão } \\
\text { Vertical In } \\
\text { Situ } \\
(\mathrm{MPa})\end{array}$ & $\begin{array}{c}\text { Carvão Bonito } \\
\text { Mina Fontanella } \\
\text { (Curva 1) }\end{array}$ & $\begin{array}{c}\text { Carvão Irapuá } \\
\text { Mina Santa } \\
\text { Augusta Norte } \\
\text { (Curva 2) }\end{array}$ & Curva 3 & Curva 4 & $\begin{array}{c}\text { Carvão Irapuá } \\
\text { Mina Morozini } \\
\text { Norte } \\
\text { (Curva 5) }\end{array}$ \\
\hline $0-2$ & 0,98 & 0,97 & 0,94 & 0,91 & 0,88 \\
\hline $2-4$ & 0,97 & 0,94 & 0,90 & 0,86 & 0,82 \\
\hline $4-6$ & 0,96 & 0,92 & 0,88 & 0,84 & 0,79 \\
\hline $6-8$ & 0,95 & 0,91 & 0,87 & 0,82 & 0,78 \\
\hline $8-10$ & 0,94 & 0,90 & 0,86 & 0,82 & 0,78 \\
\hline$>10$ & 0,92 & 0,88 & 0,84 & 0,81 & 0,77 \\
\hline
\end{tabular}

\subsubsection{Ensaios para a Determinação da Influência do Grau de Saturação na Velocidade de Propagação da Onda Ultra-Sônica}

\subsubsection{Execução dos Ensaios}

A saturação das amostras foi baseada na norma da ABNT NBR 12766 (1992). Os seguintes procedimentos foram adotados durante o ensaio:

- medição da velocidade da onda ultra-sônica na condição de umidade natural, ou, subsaturada;

- imersão dos corpos-de-prova em água destilada durante 72 horas, à temperatura ambiente (aproximadamente $22^{\circ} \mathrm{C}$ ), conforme mostra a Figura 4.51. Medição da velocidade ultra-sônica na condição saturada após 24,48 e 72 horas de imersão, aproximadamente;

- secagem em estufa a $60^{\circ} \mathrm{C}$ até constância de massa. Medição da velocidade ultra-sônica na condição seca. 


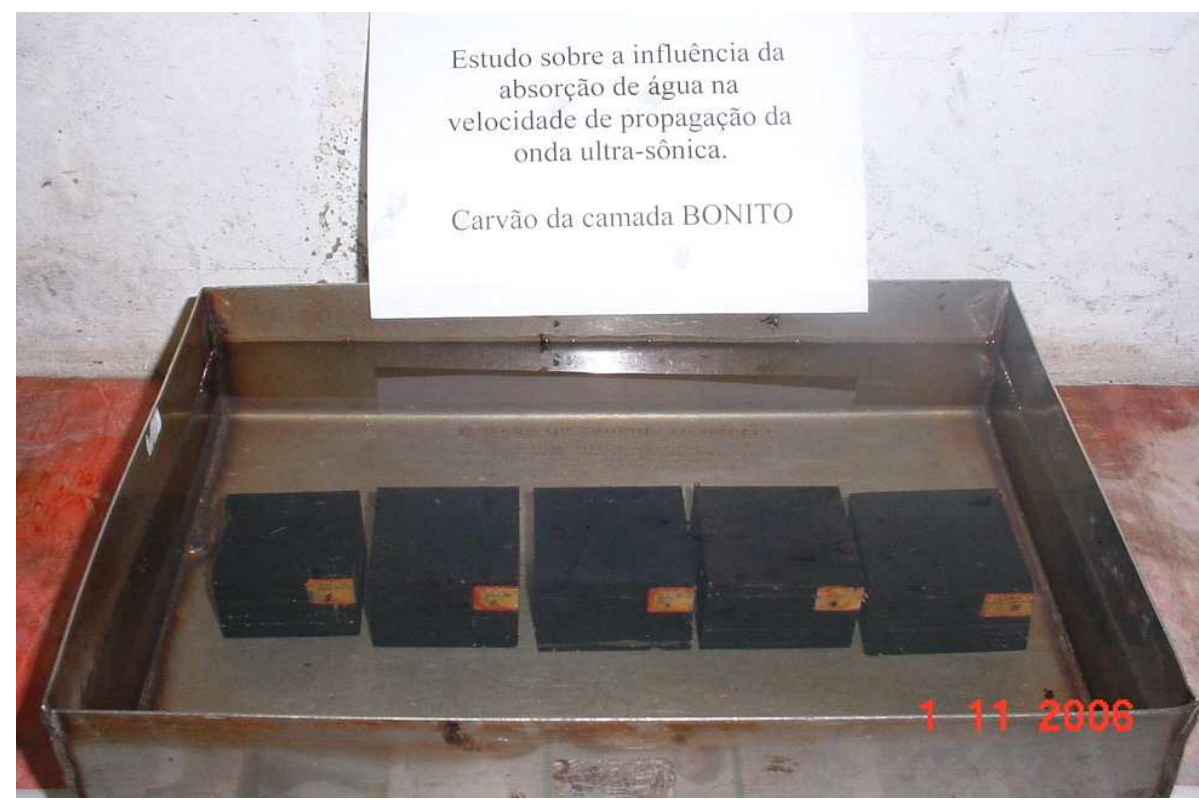

Figura 4.51 - Imersão dos corpos-de-prova de carvão em água à temperatura ambiente, durante o estudo da influência do grau de saturação na velocidade da onda ultra-sônica no carvão da camada Bonito da Mina Fontanella.

Os parâmetros de interesse foram calculados pelas seguintes expressões:

$$
\begin{aligned}
& S_{i}=\frac{\text { Absorção }_{i}}{\text { Absorção }_{\max }} * 100 \\
& \text { Variaçãao } V_{\text {pond.par }}=\frac{V_{\text {pond.par.Si }}-V_{\text {pond.par.sec } a}}{V_{\text {pond.par.seca } a}} * 100
\end{aligned}
$$

onde: $S_{i}=$ grau de saturação aparente ao longo do tempo de imersão (\%);

Variação $_{\text {pond.par }}=$ variação da velocidade de propagação da onda ultrasônica longitudinal ponderada nas direções de determinação paralelas aos planos de estratificação do carvão (\%);

Absorção $\mathrm{i}_{\mathrm{i}}=$ Absorção de água ao longo do tempo de imersão (\%);

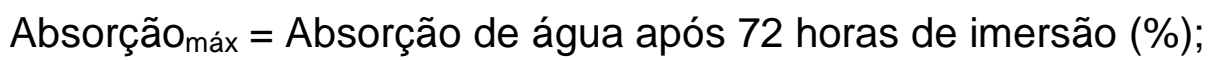

$\mathrm{V}_{\text {pond.par.Si }}=$ velocidade de propagação da onda ultra-sônica longitudinal ponderada nas direções de determinação paralelas aos planos de estratificação do carvão com o corpo-de-prova sob diferentes graus de saturação aparente $S_{i}(\mathrm{~km} / \mathrm{s})$;

$\mathrm{V}_{\text {pond.par.seca }}=$ velocidade de propagação da onda ultra-sônica longitudinal ponderada nas direções de determinação paralelas aos planos de estratificação do carvão com o corpo-de-prova na condição seca $(\mathrm{km} / \mathrm{s})$. 


\subsubsection{Resultados Obtidos}

Nos corpos-de-prova individualmente, os resultados mostraram que, com o aumento do grau de saturação, os vazios permeáveis preenchidos com água $\left(V_{\text {água }} \cong 1,5 \mathrm{~km} / \mathrm{s}\right)$ favorecem mais a propagação das ondas do que quando preenchidos somente com ar $\left(\mathrm{V}_{\mathrm{ar}} \cong 0,34 \mathrm{~km} / \mathrm{s}\right)$, aumentando assim a velocidade de propagação das ondas. Uma vez atingido o grau de saturação máximo, a velocidade se estabiliza.

A Figura 4.52 apresenta graficamente os resultados de variação da velocidade de ondas medidas paralelamente aos planos de estratificação do carvão em função do grau de saturação da amostra, individualizados para cada uma das camadas de carvão estudadas (Bonito e Irapuá). Aos dados agrupados por camada foram associados modelos de regressão exponencial.

Os resultados mostram um comportamento da variação da velocidade ultra-sônica paralela à estratificação muito disperso, especialmente para o carvão da camada Bonito (ver $r^{2}$ dos modelos de regressão). Isso pode ser explicado pela diferença de velocidade entre os corpos-de-prova ensaiados, devido à presença de fraturas no carvão, em maior ou menor quantidade num e noutro corpo-de-prova. $\mathrm{Na}$ prática, para o período de imersão considerado (72 horas), a percolação da água tende a ser maior nas fraturas do que na matriz da rocha carbonosa (e das rochas em geral). Assim, o mesmo grau de saturação em dois corpos-de-prova, um sem fraturas e outro com fraturas abertas, pode estar associado a variações de velocidade da onda ultra-sônica diferentes.

Outro aspecto bem caracterizado no comportamento da variação da velocidade ultra-sônica paralela à estratificação está associado à velocidade medida na condição seca. Quanto maior a velocidade na condição seca (grau de saturação, $\left.S_{i}=0 \%\right)$, menor é a variação máxima da velocidade na condição saturada $\left(S_{i}=\right.$ 100\%), conforme mostra Figura 4.53.

\subsubsection{Discussão dos Resultados}

Os resultados obtidos nos estudos com diferentes amostras de carvão das camadas Bonito e Irapuá mostram que há influência da presença de água na velocidade de propagação de ondas. Ainda que com baixa representatividade estatística, é possível observar a tendência e o patamar máximo de variação da velocidade sônica em função da presença de água na rocha. Na condição extrema (grau de saturação $=100 \%$ ), uma variação média de cerca de $4 \%$ foi observado para o carvão da camada Bonito, enquanto que $12 \%$ para o carvão Irapuá.

Embora a influência não seja tão grande, é desejável a adoção de fatores de correção das velocidades de ondas sísmicas medidas sob diferentes condições de umidade. 


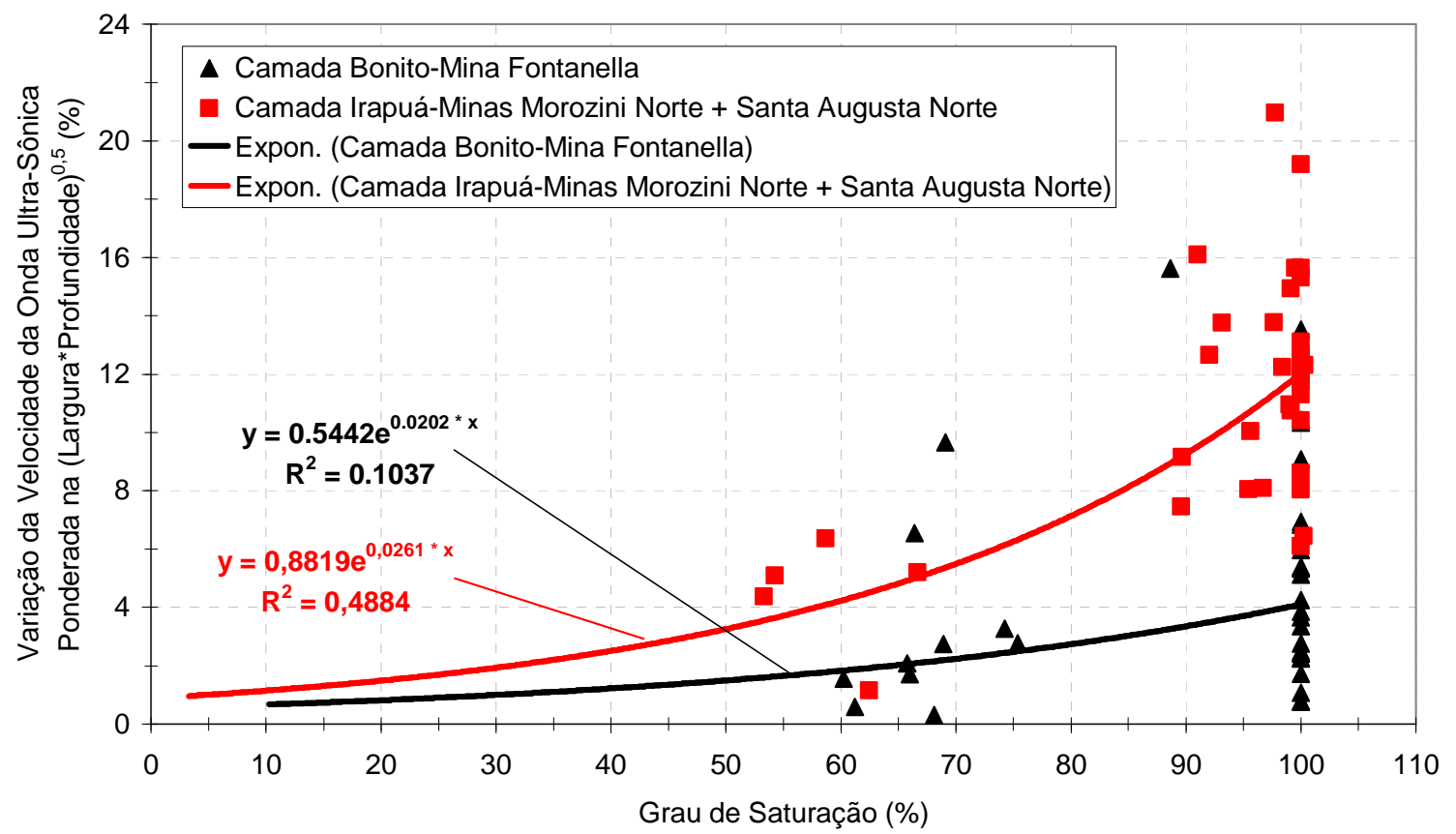

Figura 4.52 - Variação percentual da velocidade de propagação da onda ultra-sônica, medida na direção paralela aos planos de estratificação do carvão, em função do grau de saturação do carvão.

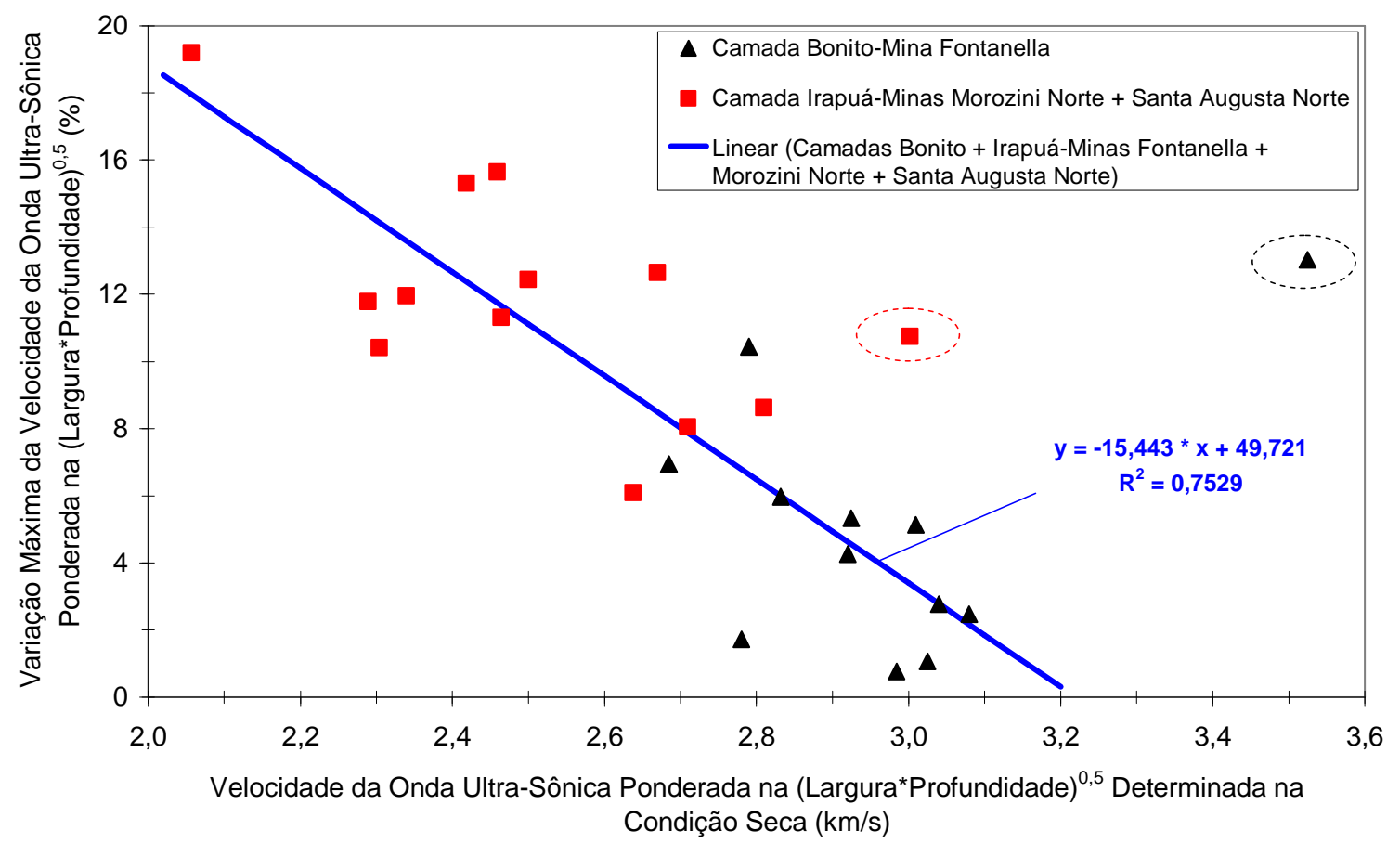

Figura 4.53 - Variação percentual máxima da velocidade de propagação da onda ultrasônica na condição saturada $\left(S_{i}=100 \%\right)$, em função da velocidade medida no corpo-deprova na condição seca $\left(S_{i}=0 \%\right)$. Nota: os dados com elipse não foram considerados na regressão. 


\subsubsection{Fator de Correção da Velocidade de Ondas Sísmicas Medidas In Situ para a Condição de Umidade Natural em Laboratório (Grau de Saturação $\cong 0$ )}

Com base nos resultados de laboratório, deverão ser adotados fatores de correção distintos para cada umas das camadas de carvão estudadas, Bonito e Irapuá, os quais contempla as diferentes condições de umidade vigentes nos locais onde foram feitas as medições de velocidade de propagação de ondas sísmicas.

Os valores sugeridos para três diferentes condições de umidade são apresentados na Tabela 4.23.

Tabela 4.23 - Valores do fator $F_{2}$ a serem utilizados para correção da velocidade de propagação de ondas sísmicas medidas in situ sob diferentes condições de umidade, para a condição de umidade natural em laboratório (grau de saturação $\cong 0$ ).

\begin{tabular}{|l|c|c|}
\hline \multirow{2}{*}{\multicolumn{1}{|c|}{ Condição de Umidade }} & \multicolumn{2}{|c|}{$\mathrm{F}_{2}$} \\
\cline { 2 - 3 } & $\begin{array}{c}\text { Carvão Bonito } \\
\text { Mina Fontanella }\end{array}$ & $\begin{array}{c}\text { Carvão Irapuá } \\
\text { Minas Morozini } \\
\text { Norte e Santa } \\
\text { Augusta Norte }\end{array}$ \\
\hline $\begin{array}{l}\text { Rocha "seca" ou na umidade natural } \\
\text { (nenhuma água visível nas paredes do pilar) }\end{array}$ & 1,00 & 1,00 \\
\hline $\begin{array}{l}\text { Rocha úmida } \\
\text { (parede do pilar molhada) }\end{array}$ & 0,99 & 0,97 \\
\hline $\begin{array}{l}\text { Rocha saturada } \\
\text { (água escorrendo nas paredes do pilar) }\end{array}$ & 0,96 & 0,88 \\
\hline
\end{tabular}




\section{Estimativa da Resistência In Situ da Camada de Carvão Bonito na Mina Fontanella Utilizando Diferentes Técnicas}

\subsection{Introdução}

A escolha da técnica mais adequada para a estimativa da resistência in situ $\left(S_{1}\right)$ utilizada pelos métodos empíricos de dimensionamento de pilares em minas de carvão depende de uma série de fatores distintos, que podem ser de ordem econômica, operacional e tecnológica. Merecem destaque os seguintes aspectos dentre as técnicas mais conhecidas:

- a técnica de ensaios em laboratório, com pequenas amostras, está entre as menos custosas do ponto de vista econômico, porém, com limitações devido à baixa representatividade das variações litológicas e das características estruturais do maciço rochoso;

- a técnica direta de execução de ensaios in situ em grandes amostras. Essa técnica possui como inconvenientes as dificuldades de acesso à camada minerada, problemas operacionais, baixa representatividade devido ao pequeno número de ensaios e os altos custos de execução;

- outra técnica muito empregada é a análise estatística de casos de ruptura/sucesso de pilares, ou seja, baseia-se na experiência prática da mineração. As maiores dificuldades residem na escasses de casos para a retro-análise, associado ao fato de que nem sempre é possível determinar com segurança e fidelidade as condições em que ocorreu o colapso;

- em se tratando de rochas carbonosas, técnicas empíricas, como o uso de classificações geomecânicas, vem ganhando mais atenção nos últimos anos. Essa técnica possui como atrativo a incorporação de um número de parâmetros maior do que a simples determinação da resistência à compressão uniaxial da rocha em laboratório. De outra parte, o provimento desses parâmetros requer acesso direto ao local e grande quantidade de tempo para o levantamento e processamento dos dados, dificultando sobremaneira a sua aplicação dentro da dinâmica de produção de uma mina de carvão.

As classificações geomecânicas associadas ou não a algum critério de ruptura, constituem-se em métodos empíricos desenvolvidos com base na experiência prática dos seus proponentes. Normalmente utilizam um ou mais parâmetros da rocha intacta e do maciço que, ponderados, são capazes de prover informações quantitativas sobre a resistência e deformabilidade de determinado maciço rochoso. Dentre as várias classificações geomecânicas associadas a critério de ruptura propostas ao longo das últimas décadas, algumas parecem ser mais 
adequadas para a estimativa da resistência in situ de camadas de carvão. São as que possuem entre os parâmetros de saída a resistência a compressão uniaxial do maciço $\left(\sigma_{\mathrm{cm}}\right)$, que para maciços de rochas carbonosas pode ser traduzido como a resistência in situ da camada de carvão $\left(S_{1}\right)$.

Para a estimativa da resistência in situ da camada Bonito, na Mina Fontanella, serão utilizados os seguintes métodos ou critérios, julgados os mais apropriados para maciços carbonosos:

a) aplicação dos critérios de ruptura de Hoek-Brown (HOEK et al., 2002), SHEOREY et al. (1997), RAMAMURTHY (1986), Bieniawski genérico (KALAMARAS \& BIENIAWSKI, 1993) e Kalamaras (KALAMARAS, 1993);

b) aplicação dos métodos empíricos de WILSON (1983) e PALMSTR $\varnothing \mathrm{M}$ (1995);

c) aplicação da lei do efeito escala proposta por GADDY (1956), utilizando os resultados de laboratório obtidos com corpos-de-prova cúbicos de dimensões variáveis, entre $5 \mathrm{~cm}$ e $30 \mathrm{~cm}$;

d) retro-análise de caso de ruptura de pilares ocorrido na Mina Fontanella em 1997.

\subsection{Aplicação dos Diferentes Métodos para a Estimativa da Resistência In Situ}

\subsubsection{Critério de Ruptura de Hoek-Brown}

Para a aplicação desse critério de ruptura foram utilizados os parâmetros da envoltória de resistência do carvão proveniente do local de amostragem P3. Esses mesmos parâmetros foram extrapolados para os demais locais de amostragem (P1, P2 e P4).

As informações provenientes dos levantamentos estruturais do maciço rochoso nos 4 locais de estudo serviram de base para a estimativa do Geological Strength Index (GSI) na faixa entre 40 e 55 e o fator perturbação do maciço, $D=0$. O programa RocLab 1.0 foi utilizado para a estimativa da resistência in situ considerando os resultados de laboratório apresentados no Capítulo 4.

Os parâmetros do critério de ruptura para o maciço rochoso e os valores estimados de resistência in situ para a camada de carvão Bonito são apresentados na Tabela 5.1.

\subsubsection{Critério de Wilson}

Para a aplicação do critério proposto por WILSON (1983) foram utilizadas as informações estruturais e a resistência à compressão uniaxial determinadas distintamente para os 4 locais da Mina Fontanella. As características estruturais do maciço carbonoso nos locais estudados sugerem a adoção de um fator $F$ entre 4 e 5. As resistências in situ estimadas $\left(S_{1}\right)$ são apresentadas na Tabela 5.2. 
Tabela 5.1 - Resistência in situ $\left(S_{1}\right)$ da camada de carvão Bonito, na Mina Fontanella, estimada segundo o critério de ruptura de Hoek-Brown (HOEK et al., 2002).

\begin{tabular}{|c|c|c|c|c|c|c|c|}
\hline $\begin{array}{c}\text { Local de } \\
\text { Levantamento }\end{array}$ & GSI & $\mathrm{m}_{\mathrm{b}}$ & $\mathrm{s}$ & $\mathrm{a}$ & $\begin{array}{c}\mathrm{c}^{\prime} \\
(\mathrm{MPa})\end{array}$ & $\begin{array}{c}\phi^{\prime} \\
(\mathrm{o})\end{array}$ & $\begin{array}{c}\mathrm{S}_{1} \\
(\mathrm{MPa})\end{array}$ \\
\hline \multirow{2}{*}{$\mathrm{P} 1+\mathrm{P} 4$} & 40 & 1,049 & 0,0013 & 0,511 & 1,26 & 26,6 & 4,08 \\
\cline { 2 - 8 } & 45 & 1,254 & 0,0022 & 0,508 & 1,37 & 28,1 & 4,56 \\
\hline \multirow{2}{*}{$\mathrm{P} 2+\mathrm{P} 3$} & 50 & 1,499 & 0,0039 & 0,506 & 1,49 & 29,6 & 5,10 \\
\cline { 2 - 8 } & 55 & 1,792 & 0,0067 & 0,504 & 1,61 & 31,0 & 5,71 \\
\hline
\end{tabular}

LEGENDA:

$\mathrm{GSI}=$ Geological Strength Index; $\mathrm{m}_{\mathrm{b}}, \mathrm{s}, \mathrm{a}=$ constantes do critério de ruptura de Hoek-Brown para o maciço rochoso; $c^{\prime}, \phi^{\prime}=$ coesão e ângulo de atrito interno, respectivamente, estimados para o maciço rochoso.

Tabela 5.2 - Resistência in situ $\left(\mathrm{S}_{1}\right)$ da camada de carvão Bonito, na Mina Fontanella, estimada segundo WILSON (1983).

\begin{tabular}{|c|c|c|c|}
\hline $\begin{array}{c}\text { Local de } \\
\text { Levantamento }\end{array}$ & $\begin{array}{c}\text { Resistência à } \\
\text { compressão uniaxial } \\
(\mathrm{MPa})\end{array}$ & $\mathrm{F}$ & $\begin{array}{c}\text { Faixa de } \mathrm{S}_{1} \\
(\mathrm{MPa})\end{array}$ \\
\hline P1 & 25,15 & $5-4$ & $5,03-6,29$ \\
\hline P4 & 20,22 & $5-4$ & $4,04-5,06$ \\
\hline P2 & 28,92 & $5-4$ & $5,78-7,23$ \\
\hline P3 & 28,82 & $5-4$ & $5,76-7,21$ \\
\hline
\end{tabular}

LEGENDA:

$F=$ fator de correção da resistência de laboratório para a condição in situ.

\subsubsection{Critérios de Ruptura de Ramamurthy, Bieniawski Genérico e Sheorey}

Os pesos atribuídos a cada parâmetro da classificação de Bieniawski foram definidos utilizando as respectivas versões da classificação sugeridas pelos autores dos diferentes critérios. Para efeito de cálculo do índice Rock Mass Rating da camada de carvão ( $\left.R M R_{\text {camada }}\right)$, o $R Q D$ utilizado foi o teórico $\left(R Q D_{\text {teórico }}\right)$.

Os resultados da aplicação de cada um dos critérios e os valores estimados para a resistência in situ da camada de carvão Bonito podem ser vistos nas Tabelas 5.3a e 5.3b (critério de Ramamurthy), 5.4a e 5.4b (critério Bieniawski genérico) e $5.5 a$ e $5.5 b$ (critério de Sheorey). 
Tabela 5.3a - RMR da camada de carvão Bonito segundo BIENIAWSKI (1974).

\begin{tabular}{|c|c|c|c|c|}
\hline \multirow[t]{2}{*}{ Parâmetro } & \multicolumn{4}{|c|}{$\begin{array}{l}\text { Pesos em Função do Local de } \\
\text { Levantamento na Mina Fontanella }\end{array}$} \\
\hline & P1 & P4 & P2 & P3 \\
\hline 1 - Resistência à compressão uniaxial & 1 & 0 & 1 & 1 \\
\hline 2 - Índice de Qualidade da Rocha, RQD teórico & 18 & 17 & 20 & 20 \\
\hline 3 - Espaçamento entre descontinuidades & 20 & 20 & 25 & 25 \\
\hline 4 - Orientação das descontinuidades & 5 & 5 & 5 & 5 \\
\hline 5 - Condições das descontinuidades & 10 & 10 & 10 & 10 \\
\hline 6 - Fluxo de água & 10 & 10 & 10 & 10 \\
\hline $\mathrm{RMR}_{\text {camada }}$ & 64 & 62 & 71 & 71 \\
\hline
\end{tabular}

Tabela 5.3b - Resistência in situ $\left(S_{1}\right)$ da camada de carvão Bonito, na Mina Fontanella, estimada utilizando o critério de ruptura de RAMAMURTHY (1986).

\begin{tabular}{|c|c|c|c|}
\hline $\begin{array}{c}\text { Local de } \\
\text { Levantamento }\end{array}$ & $\mathrm{RMR}_{\text {camada }}$ & Função de Cálculo & $\begin{array}{c}\mathrm{S}_{1} \\
(\mathrm{MPa})\end{array}$ \\
\hline $\mathrm{P} 1$ & 64 & $S_{1}=25,15^{*} \exp ^{\left(\frac{64-100}{18,75}\right)}$ & 3,69 \\
\hline P4 & 62 & $S_{1}=20,22 * \exp ^{\left(\frac{62-100}{18,75}\right)}$ & 2,66 \\
\hline P2 & 71 & $S_{1}=28,92 * \exp ^{\left(\frac{71-100}{18,75}\right)}$ & 6,16 \\
\hline P3 & 71 & $S_{1}=28,82 * \exp ^{\left(\frac{71-100}{18,75}\right)}$ & 6,14 \\
\hline
\end{tabular}

Tabela 5.4a - RMR da camada de carvão Bonito segundo BIENIAWSKI (1989).

\begin{tabular}{|c|c|c|c|c|}
\hline \multirow[t]{2}{*}{ Parâmetro } & \multicolumn{4}{|c|}{$\begin{array}{l}\text { Pesos em Função do Local de } \\
\text { Levantamento na Mina Fontanella }\end{array}$} \\
\hline & $\mathrm{P} 1$ & P4 & P2 & P3 \\
\hline 1 - Resistência à compressão uniaxial & 4 & 2 & 4 & 4 \\
\hline 2 - Índice de Qualidade da Rocha, $R Q D_{\text {teórico }}$ & 18 & 17 & 20 & 20 \\
\hline 3 - Espaçamento entre descontinuidades & 15 & 15 & 15 & 15 \\
\hline 4 - Orientação das descontinuidades & -11 & -11 & -11 & -11 \\
\hline 5 - Condições das descontinuidades & 25 & 25 & 25 & 25 \\
\hline 6 - Fluxo de água & 15 & 15 & 15 & 15 \\
\hline $\mathrm{RMR}_{\text {camada }}$ & 66 & 63 & 68 & 68 \\
\hline
\end{tabular}

Tabela 5.4b - Resistência in situ $\left(S_{1}\right)$ da camada de carvão Bonito, na Mina Fontanella, estimada utilizando o critério de ruptura "Bieniawski genérico".

\begin{tabular}{|c|c|c|c|}
\hline $\begin{array}{c}\text { Local de } \\
\text { Levantamento }\end{array}$ & RMR $_{\text {camada }}$ & Função de Cálculo & $\begin{array}{c}\mathrm{S}_{1} \\
(\mathrm{MPa})\end{array}$ \\
\hline P1 & 66 & $S_{1}=25,15 * \exp ^{\left(\frac{66-100}{24}\right)}$ & 6,10 \\
\hline P4 & 63 & $S_{1}=20,22 * \exp ^{\left(\frac{63-100}{24}\right)}$ & 4,33 \\
\hline P2 & 68 & $S_{1}=28,92 * \exp ^{\left(\frac{68-100}{24}\right)}$ & 7,62 \\
\hline P3 & 68 & $S_{1}=28,82 * \exp ^{\left(\frac{68-100}{24}\right)}$ & 7,60 \\
\hline
\end{tabular}


Tabela 5.5a - RMR da camada de carvão Bonito segundo BIENIAWSKI (1976).

\begin{tabular}{|l|c|c|c|c|}
\hline \multirow{2}{*}{ Parâmetro } & \multicolumn{4}{c|}{ Pesos em Função do Local de } \\
& Levantamento na Mina Fontanella \\
\cline { 2 - 5 } & $\mathrm{P} 1$ & $\mathrm{P} 4$ & $\mathrm{P} 2$ & $\mathrm{P3}$ \\
\hline 1 - Resistência à compressão uniaxial & 4 & 2 & 4 & 4 \\
\hline 2 - Índice de Qualidade da Rocha, RQD teórico & 18 & 17 & 20 & 20 \\
\hline 3 - Espaçamento entre descontinuidades & 20 & 20 & 25 & 25 \\
\hline 4 - Condições das descontinuidades & 9 & 9 & 9 & 9 \\
\hline 5 - Fluxo de água & 10 & 10 & 10 & 10 \\
\hline \multicolumn{1}{|c|}{ RMR $_{\text {camada }}$} & 61 & 58 & 68 & 68 \\
\hline
\end{tabular}

Tabela 5.5b - Resistência in situ $\left(\mathrm{S}_{1}\right)$ da camada de carvão Bonito, na Mina Fontanella, estimada utilizando o critério de ruptura de SHEOREY (1997).

\begin{tabular}{|c|c|c|c|}
\hline $\begin{array}{c}\text { Local de } \\
\text { Levantamento }\end{array}$ & $\mathrm{RMR}_{\text {camada }}$ & Função de Cálculo & $\begin{array}{c}\mathrm{S}_{1} \\
(\mathrm{MPa})\end{array}$ \\
\hline P1 & 61 & $S_{1}=25,15 * \exp ^{\left(\frac{61-100}{20}\right)}$ & 3,58 \\
\hline P4 & 58 & $S_{1}=20,22 * \exp ^{\left(\frac{58-100}{20}\right)}$ & 2,48 \\
\hline P2 & 68 & $S_{1}=28,92 * \exp ^{\left(\frac{68-100}{20}\right)}$ & 5,84 \\
\hline P3 & 68 & $S_{1}=28,82 * \exp ^{\left(\frac{68-100}{20}\right)}$ & 5,82 \\
\hline
\end{tabular}

Com o intuito de avaliar a sensibilidade das estimativas da resistência in situ em função da diferença constatada entre o $R Q D_{\text {teórico e }}$ o $R Q D_{\text {medido, a Tabela }} 5.6$ apresenta os valores de $S_{1}$ recalculados levando em consideração os RQDs medidos nas sondagens horizontais nos pilares de carvão (valores entre $30 \%$ e $75 \%$ ). Para efeitos práticos, todos os pontos de amostragem foram enquadrados na mesma classe de RQD, entre $50 \%$ e $75 \%$.

Tabela 5.6 - Resistências in situ $\left(S_{1}\right)$ da camada de carvão Bonito, na Mina Fontanella, estimadas utilizando os critérios de ruptura de RAMAMURTHY (1986), "Bieniawski

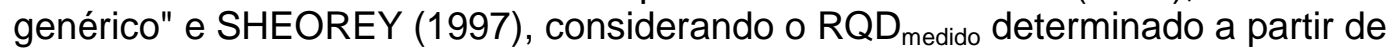
sondagens horizontais.

\begin{tabular}{|c|c|c|c|}
\hline \multirow{2}{*}{$\begin{array}{c}\text { Local de } \\
\text { Levantamento }\end{array}$} & $\begin{array}{c}|c| \\
\text { RAMAMURTHY } \\
(1986)\end{array}$ & "Bieniawski genérico" & SHEOREY (1997) \\
\hline P1 & 2,98 & 5,16 & 2,93 \\
\hline P4 & 2,27 & 3,82 & 2,13 \\
\hline P2 & 4,47 & 5,94 & 4,33 \\
\hline P3 & 4,46 & 5,92 & 4,31 \\
\hline
\end{tabular}




\subsubsection{Critério de Kalamaras}

Os parâmetros utilizados para a classificação do maciço rochoso de carvão são os propostos por KALAMARAS (1993) e KALAMARAS \& BIENIAWSKI (1993, 1995). Vale destacar que nessa classificação, a resistência à compressão uniaxial deve estar associada à rocha intacta, ou seja, sem a presença de fraturas.

Os valores de RQD foram determinados na direção horizontal da camada de carvão. Não foram incluídos, portanto, os planos horizontais de estratificação da camada carbonosa. Por outro lado, duas situações distintas de cálculo da resistência in situ foram consideradas: uma com o $R Q D_{\text {teórico }}$ calculado em função da freqüência de fraturas obtida através de levantamentos estruturais nos diferentes locais de levantamento e outra com o $R Q D_{\text {medido }}$ determinado a partir de sondagens horizontais. $O$ critério de ruptura utilizado para o cálculo de $S_{1}$ é o proposto por KALAMARAS \& BIENIAWSKI (1995):

$$
S_{1}=0,5 * \frac{R M R_{\text {camada }}-15}{85} * \sigma_{c}
$$

onde: $\sigma_{\mathrm{c}}=$ resistência à compressão uniaxial de laboratório;

$$
\begin{aligned}
R M R_{\text {camada }}=\sum_{i=1}^{5} \text { Peso }_{i}= & \text { Rock Mass Rating da camada de carvão ou índice } \\
& \text { de classificação da camada de carvão. }
\end{aligned}
$$

Os pesos utilizados para representar cada um dos parâmetros da classificação nos diferentes locais amostrados na mina podem ser vistos na Tabela 5.7a. Já a Tabela 5.7b apresenta os valores de resistência in situ estimados a partir da classificação geomecânica, para cada uma dos locais de estudo na Mina Fontanella.

\begin{tabular}{|c|c|c|c|c|}
\hline \multirow[t]{2}{*}{ Parâmetro } & \multicolumn{4}{|c|}{$\begin{array}{c}\text { Pesos em Função do Local de } \\
\text { Levantamento na Mina } \\
\text { Fontanella }\end{array}$} \\
\hline & P1 & P4 & P2 & P3 \\
\hline 1 - Resistência à compressão uniaxial & 4 & 2 & 4 & 4 \\
\hline 2 - Índice de Qualidade da Rocha, $\mathrm{RQD}_{\text {teórico }}$ & 18 & 17 & 20 & 20 \\
\hline 3 - Condições das descontinuidades & 22 & 22 & 22 & 22 \\
\hline 4 - Deformabilidade dos estratos & 15 & 15 & 15 & 15 \\
\hline $\begin{array}{l}5 \text { - Ajuste em função da orientação das } \\
\text { descontinuidades em relação à parede do } \\
\text { pilar }\end{array}$ & -5 & -5 & -5 & -5 \\
\hline $\mathrm{RMR}_{\text {camada }}$ & 54 & 51 & 56 & 56 \\
\hline
\end{tabular}

Tabela 5.7a - RMR da camada de carvão Bonito segundo a classificação geomecânica de KALAMARAS (1993). 
Tabela 5.7b - Resistência in situ $\left(S_{1}\right)$ da camada de carvão Bonito, na Mina Fontanella, estimada utilizando a classificação geomecânica de KALAMARAS (1993).

\begin{tabular}{|c|c|c|c|c|}
\hline $\begin{array}{c}\text { Local de } \\
\text { Levantamento }\end{array}$ & $\mathrm{RMR}_{\text {camada }}$ & Função de Cálculo & $\begin{array}{c}\mathrm{S}_{1 \text { f(RQDteórico) }} \\
(\mathrm{MPa})\end{array}$ & $\begin{array}{c}\mathrm{S}_{1 \text { f(RQDmedido })} \\
\text { (MPa) }\end{array}$ \\
\hline P1 & 54 & $S_{1}=0,5 * \frac{(54-15)}{85} * 25,15$ & 5,77 & 5,03 \\
\hline P4 & 51 & $S_{1}=0,5 * \frac{(51-15)}{85} * 20,22$ & 4,28 & 3,81 \\
\hline P2 & 56 & $S_{1}=0,5 * \frac{(56-15)}{85} * 28,92$ & 6,97 & 5,78 \\
\hline P3 & 56 & $S_{1}=0,5 * \frac{(56-15)}{85} * 28,82$ & 6,95 & 5,76 \\
\hline
\end{tabular}

\subsubsection{Critério de Palmstrøm}

Os diferentes parâmetros estruturais utilizados pelo método de Palmstrøm foram determinados considerando as informações obtidas no mapeamento geotécnico da camada de carvão. Para o cálculo do volume dos blocos (Vb) foram utilizadas três formas distintas sugeridas por PALMSTR $\varnothing \mathrm{M}$ (1995):

a) baseada na freqüência média de fraturas por metro $(\lambda)$ das famílias individualizadas;

b) baseada na freqüência aparente média de fraturas por metro $(\lambda a)$ determinada unidirecionalmente;

c) baseada na freqüência de fraturas por volume (Jv).

Para a computação do fator forma dos blocos $(\beta)$ foram utilizadas as freqüências ponderadas médias de fraturas das famílias representativas de cada local de levantamento. Para efeito do cálculo do ângulo formado entre as famílias de juntas foram utilizadas as orientações médias representativas das famílias observadas nos locais de levantamento agrupados dois a dois - P1+P4 e P2+P3. Os fatores que representam a persistência $(\mathrm{jL})$, rugosidade $(\mathrm{jR})$ e grau de alteração (jA) das juntas foram quantificados da seguinte forma:

$\mathrm{jL}=1$ - persistência das juntas entre 1,5m e 3,0m, contínuas;

$\mathrm{jR}=1$ - juntas polidas numa escala pequena e onduladas numa escala grande;

$\mathrm{j} A=2$ - juntas levemente alteradas, sem preenchimento.

As Tabelas 5.8a, 5.8b e 5.8c apresentam os resultados dos diversos parâmetros estimados segundo cada uma das técnicas de cálculo do $\mathrm{Vb}$, para cada local de levantamento, juntamente com os valores estimados para a resistência do maciço (RMi) - designado neste trabalho como $S_{1}$ da camada de carvão. Já a Tabela 5.8d apresenta a média dos valores de $S_{1}$ obtidos a partir de diferentes técnicas de cálculo do $\mathrm{Vb}$, considerando os locais de levantamento individualizados ou agrupados. 
Tabela 5.8a - Estimativas da resistência in situ $\left(\mathrm{S}_{1}\right)$, com Vb calculado a partir da freqüência média de fraturas por metro das famílias.

\begin{tabular}{|c|c|c|c|c|c|c|}
\hline $\begin{array}{c}\text { Local de } \\
\text { Levantamento }\end{array}$ & $\begin{array}{c}\lambda_{1} \\
(\text { frat/m) }\end{array}$ & $\begin{array}{c}\lambda_{2} \\
(\mathrm{frat} / \mathrm{m})\end{array}$ & $\begin{array}{c}\lambda_{3} \\
(\mathrm{frat} / \mathrm{m})\end{array}$ & $\begin{array}{c}\mathrm{Vb} \\
\left(\mathrm{m}^{3}\right)\end{array}$ & $\mathrm{JP}$ & $\begin{array}{c}\mathrm{S}_{1} \\
(\mathrm{MPa})\end{array}$ \\
\hline $\mathrm{P} 1$ & 0,83 & 1,95 & 1,48 & 0,74 & 0,12 & 3,12 \\
\hline $\mathrm{P} 4$ & 1,37 & 1,56 & 1,61 & 0,51 & 0,11 & 2,15 \\
\hline $\mathrm{P} 1+\mathrm{P} 4$ & 1,15 & 1,72 & 1,54 & 0,58 & 0,11 & 2,52 \\
\hline $\mathrm{P} 2$ & 1,57 & 1,37 & 1,15 & 0,48 & 0,10 & 2,99 \\
\hline $\mathrm{P} 3$ & 0,41 & 0,92 & 0,80 & 3,93 & 0,25 & 7,29 \\
\hline $\mathrm{P} 2+\mathrm{P} 3$ & 0,90 & 1,13 & 0,95 & 1,23 & 0,15 & 4,44 \\
\hline
\end{tabular}

LEGENDA:

$\lambda_{1}, \lambda_{2}$ e $\lambda_{3}=$ freqüência média de fraturas por metro das famílias representativas dos locais de levantamento (F1m, F1m'), (F2m, F2m'), (F3m e F3m'), respectivamente; Vb = volume dos blocos; JP = fator de redução da resistência.

Tabela 5.8b - Estimativas da resistência in situ $\left(\mathrm{S}_{1}\right)$, com $\mathrm{Vb}$ calculado com base na freqüência aparente média de fraturas por metro determinada unidirecionalmente.

\begin{tabular}{|c|c|c|c|c|c|c|c|}
\hline $\begin{array}{c}\text { Local de } \\
\text { Levantamento }\end{array}$ & $\lambda \mathrm{a}$ & $\mathrm{kl}$ & $\begin{array}{c}\mathrm{Jv} \\
\left(\mathrm{frat} / \mathrm{m}^{3}\right)\end{array}$ & $\beta$ & $\begin{array}{c}\mathrm{Vb} \\
\left(\mathrm{m}^{3}\right)\end{array}$ & $\mathrm{JP}$ & $\begin{array}{c}\mathrm{S}_{1} \\
(\mathrm{MPa})\end{array}$ \\
\hline $\mathrm{P} 1$ & 1,02 & 2 & 2,0 & 32,3 & 6,70 & 0,32 & 7,98 \\
\hline P4 & 1,37 & 2 & 2,7 & 27,2 & 2,33 & 0,20 & 4,10 \\
\hline P2 & 0,86 & 2 & 1,7 & 27,7 & 6,54 & 0,31 & 9,03 \\
\hline P3 & 0,81 & 2 & 1,6 & 32,0 & 8,93 & 0,36 & 10,34 \\
\hline
\end{tabular}

LEGENDA:

$\lambda \mathrm{a}=$ freqüência aparente média de fraturas por metro; $\mathrm{kl}$ = fator de correlação entre a freqüência de juntas unidimensional e tridimensional; $\mathrm{Jv}=$ densidade de fraturas por volume; $\beta=$ fator forma dos blocos; $\mathrm{Vb}=$ volume dos blocos; $\mathrm{JP}=$ fator de redução da resistência.

Tabela 5.8c - Valores estimados para a resistência in situ $\left(S_{1}\right)$, com Vb calculado a partir do índice Jv.

\begin{tabular}{|c|c|c|c|c|c|c|c|c|}
\hline $\begin{array}{c}\text { Local de } \\
\text { Levantamento }\end{array}$ & $\begin{array}{c}\lambda_{1} \\
\text { (frat/m) }\end{array}$ & $\begin{array}{c}\lambda_{2} \\
\text { (frat } / \mathrm{m})\end{array}$ & $\begin{array}{c}\lambda_{3} \\
\text { (frat/m) }\end{array}$ & $\begin{array}{c}\mathrm{JV} \\
\left(\mathrm{frat} / \mathrm{m}^{3}\right)\end{array}$ & $\beta$ & $\begin{array}{c}\text { Vb } \\
\left(\mathrm{m}^{3}\right)\end{array}$ & $\mathrm{JP}$ & $\begin{array}{c}\mathrm{S}_{1} \\
(\mathrm{MPa})\end{array}$ \\
\hline $\mathrm{P} 1$ & 0,83 & 1,95 & 1,48 & 4,3 & 32,3 & 0,74 & 0,12 & 3,12 \\
\hline $\mathrm{P} 4$ & 1,37 & 1,56 & 1,61 & 4,5 & 27,2 & 0,51 & 0,11 & 2,15 \\
\hline $\mathrm{P} 2$ & 1,57 & 1,37 & 1,15 & 4,1 & 27,7 & 0,48 & 0,10 & 2,99 \\
\hline $\mathrm{P} 3$ & 0,41 & 0,92 & 0,80 & 2,1 & 32,0 & 3,93 & 0,25 & 7,29 \\
\hline
\end{tabular}

LEGENDA:

$\lambda_{1}, \lambda_{2}$ e $\lambda_{3}=$ freqüência média de fraturas por metro das famílias representativas dos locais de levantamento ( $F 1 \mathrm{~m}$, F1m'), (F2m, F2m'), (F3m e F3m'), respectivamente; Jv = densidade de fraturas por volume; $\beta=$ fator forma dos blocos; $\mathrm{Vb}=$ volume dos blocos; JP = fator de redução da resistência. 
Tabela 5.8d - Média dos valores de resistência in situ $\left(S_{1}\right)$, segundo o critério de Palmstrøm, obtidos para os diferentes locais de estudo na camada Bonito, na Mina Fontanella.

\begin{tabular}{|c|c|c|c|}
\hline $\begin{array}{c}\text { Local de } \\
\text { Levantamento }\end{array}$ & \multicolumn{3}{|c|}{$\begin{array}{c}\text { S1 } \\
\text { (MPa) }\end{array}$} \\
\cline { 1 - 2 } P1 & 4,19 & \multirow{2}{|c|}{3,46} & \multirow{2}{*}{4,78} \\
\cline { 1 - 2 } P4 & 2,73 & \\
\cline { 1 - 2 } P2 & 4,86 & \multirow{2}{*}{6,10} & \\
\hline P3 & 7,34 & & \\
\hline
\end{tabular}

\subsubsection{Lei do Efeito Escala de GADDY}

Dos diferentes modelos de regressão aplicados aos resultados de laboratório, nenhum deles pode ser considerado de boa qualidade do ponto de vista estatístico. A extrapolação dos resultados de laboratório para a condição in situ, neste caso, deve ser feita com base no bom senso, no conhecimento das características geológico-estruturais da camada de carvão e no conhecimento das condições de segurança vigentes na Mina Fontanella, nas áreas estudadas.

O modelo de variação da resistência inversamente proporcional ao quadrado da dimensão da amostra, proposto por GADDY (1956), apesar de também não aderir fortemente aos dados de laboratório, parece ser o mais razoável para uma primeira aproximação da resistência in situ da camada Bonito. Pelo menos dois aspectos concorrem para a sua aplicação neste estudo: - a camada de carvão Bonito apresenta-se muito fraturada; - o modelo produz os valores de resistência in situ mais condizentes com a realidade das camadas de carvão do sul do Brasil já estudadas, cujos valores médios variam entre 5,0MPa e 7,0MPa, aproximadamente.

As funções utilizadas foram as seguintes:

- locais de levantamento P1 + P4 agrupados: $S_{1}(M P a)=58,33^{*} L(\mathrm{~cm})^{-0,5}$;

- locais de levantamento P2 + P3 agrupados: $S_{1}(M P a)=79,69 * L(\mathrm{~cm})^{-0,5}$.

Considerando essas duas funções distintas e um tamanho crítico equivalente a $150 \mathrm{~cm}$, a resistência in situ $\left(S_{1}\right)$ da camada Bonito na Mina Fontanella, pode ser estimada entre $4,8 \mathrm{MPa}$ e $6,5 \mathrm{MPa}$. A menor resistência a priori poderia ser associada às regiões mais perturbadas da mina (proximidades das zonas de falhas ou de intrusões de diabásio, por exemplo), enquanto à resistência de maior valor para condições de camada estruturalmente menos comprometida.

A Figura 5.1 mostra o modelo de GADDY para explicar o efeito escala da camada de carvão Bonito na Mina Fontanella, utilizando os resultados obtidos em laboratório sobre corpos-de-prova com dimensão do lado entre $5 \mathrm{~cm}$ e $30 \mathrm{~cm}$. Para efeitos de ilustração, nessa mesma figura são apresentados valores médios de resistência in situ sugeridos para outras camadas brasileiras do RS e SC. 


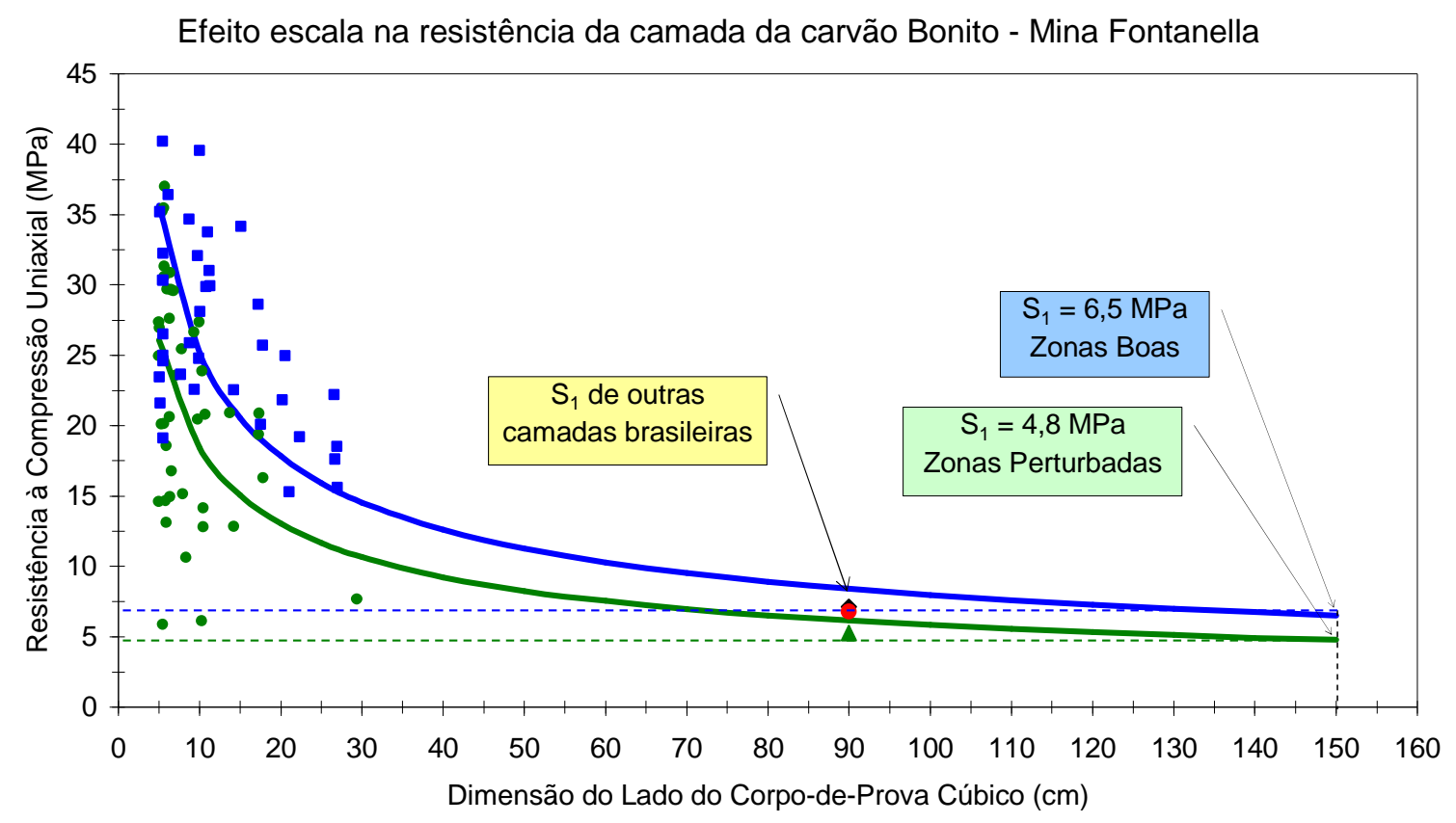

- Dados P1+P4 -Ajuste P1+P4 - Dados P2+P3 - Ajuste P2+P3 • S1 - Barro Branco • S1 - I1F $\Delta$ S1 - Irapuá

Figura 5.1 - Ajuste do modelo de GADDY (1956) aos resultados de laboratório para a estimativa da resistência in situ da camada Bonito na Mina Fontanella. Notar os valores sugeridos para a resistência in situ para outras camadas de carvão brasileiras.

\subsubsection{Retro-Análise de Caso de Ruptura de Pilares na Mina Fontanella}

Um único caso de ruptura de pilares na Mina Fontanella ocorreu em 1997 no início das operações da mina. O processo de ruptura se deu em área com as seguintes condições geométricas de projeto:

- dimensões dos lados do pilar: $11 \mathrm{~m} \times 11 \mathrm{~m}$;

- altura da camada de carvão: $3,75 \mathrm{~m}$;

- largura da galeria: 6,0m;

- profundidade: $80 \mathrm{~m}$.

O método de dimensionamento de pilares da CIENTEC (ZORZI et al., 1991) foi utilizado para a retro-análise desse caso de ruptura. A geometria das estruturas em subsolo na área colapsada, associada às informações fornecidas por técnicos da Carbonífera Metropolitana sobre o processo de ruptura, propriamente dito, apontam para valores de resistência in situ da camada Bonito, na área do colapso, entre $4,2 \mathrm{MPa}$ e $5,4 \mathrm{MPa}$.

\subsection{Discussão dos Resultados de $S_{1}$ Obtidos Segundo as Diferentes Técnicas para a Estimativa da Resistência In Situ}

Os parâmetros estruturais utilizados pela maior parte das classificações geomecânicas para o cálculo da resistência in situ representam quase $90 \%$ no 


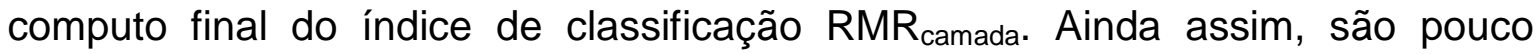
sensíveis à variação da qualidade estrutural do maciço nos diferentes locais estudados na Mina Fontanella. Contraditoriamente, o parâmetro de menor peso

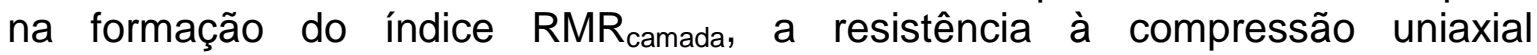
determinada em laboratório, é a que mais influencia na diferenciação da resistência in situ estimada.

Entre os 4 pontos de amostragem, do ponto de vista da qualidade do maciço e resistência laboratorial, podem ser identificadas duas áreas distintas. Os pontos P1 e P4 se caracterizam por maior densidade de fraturas e menor resistência de laboratório, enquanto em P2 e P3 ocorre o contrário, caracterizando esses dois últimos como maciços de melhor qualidade estrutural e de resistência. Esses resultados podem ser traduzidos pela boa correlação entre a densidade de fraturas e a resistência de laboratório (ver Figura 4.30).

Cabe sempre ressaltar, no entanto, que o parâmetro freqüência aparente de fraturas apresentou grande variação entre as linhas em um mesmo local de levantamento (ver Tabela 4.12). Isso ocorre devido à forte influência tanto da orientação da linha de levantamento como do seu comprimento. A utilização desse tipo de correlação deve sempre ser amparada numa boa amostragem das estruturas presentes, sendo imprescindível a realização de levantamentos em linhas tanto na direção das galerias como na dos travessões. Também, é de fundamental importância que o comprimento das linhas seja no mínimo equivalente às dimensões laterais dos pilares e, sempre que possível, sejam feitos levantamentos em pelo menos dois pilares adjacentes.

A grande variação observada entre as estimativas de $S_{1}$ feitas pelos diferentes métodos mostra que não existe um método único capaz de prover uma estimativa razoável para as condições geológico-estruturais da camada de carvão Bonito na Mina Fontanella. De outra parte, é possível observar que alguns métodos possuem uma melhor adequação para estimar a resistência in situ de rochas carbonosas, seja pelos parâmetros usados na classificação do maciço, seja pela simplicidade de aplicação.

Dos critérios utilizados, o de Ramamurthy e o de Sheorey são os que produziram os valores mais conservadores, especialmente nas condições de maciço menos favoráveis. Ainda, esses dois critérios e o de "Bieniawski genérico" são os mais sensíveis às variações do RQD. Na prática, os três critérios são baseados em versões da classificação de Bieniawski desenvolvidas para a classificação de maciços em geral. Nos casos estudados, as estimativas da resistência in situ diferem entre $16 \%$ e $38 \%$, num mesmo ponto de levantamento, quando são utilizados o $R Q D_{\text {teórico }}$ e $0 R \mathrm{RD}_{\text {medido }} \mathrm{O}$ mesmo não ocorre com o critério de Kalamaras e Bieniawski, onde as diferenças são inferiores a $20 \%$. Dos três critérios, o de Kalamaras é o único que foi desenvolvido com propósitos para a estimativa da resistência in situ de camadas carbonosas.

O critério de ruptura de Hoek e Brown, desenvolvido com base em maciços não carbonosos, produz valores razoáveis para a estimativa da resistência in situ do carvão da camada Bonito na Mina Fontanella. Os valores estimados por esse método são levemente inferiores aos obtidos pelos critérios de Kalamaras e o de Wilson. Todos os três critérios, no entanto, possuem particularidades que os diferenciam entre si, seja pelos parâmetros estruturais e de resistência 
considerados, seja pela complexidade do método com que esses parâmetros são integrados para a estimativa da resistência in situ.

Como uma primeira aproximação, o critério de Wilson, pela sua simplicidade, não deve ser descartado como técnica para a estimativa da resistência in situ da camada Bonito. Para o seu uso, no entanto, é desejável ter-se como base para a definição do fator escala, informações estruturais obtidas a partir de mapeamento geotécnico criterioso.

Os valores estimados a partir do emprego da lei de Gaddy, apoiada nos resultados de laboratório divididos em dois grupos (P1 + P4 e P2 + P3), estão nos mesmos patamares dos valores obtidos segundo os diferentes critérios empíricos para as condições de melhor e pior qualidade do maciço. Também estão de acordo com os valores sugeridos pela CIENTEC (2006), onde as análises foram baseadas exclusivamente nos ensaios de laboratório e os 4 pontos de amostragem analisados individualmente.

As estimativas feitas a partir do único caso de retro-análise de ruptura de pilares na própria Mina Fontanella, contemplam a faixa intermediária de variação dos valores obtidos segundo os outros diferentes métodos. Esses valores, no entanto, devem ser tomados com reserva, haja vista às incertezas para a definição da real geometria das escavações no local onde se deu o início do processo de ruptura.

O critério proposto por Palmstrøm parece ser o menos indicado para estimar a resistência de camadas carbonosas. Os valores de $S_{1}$, obtidos segundo as diferentes formas de determinação do parâmetro volume dos blocos (Jv), mostram que o método é muito sensível ao tipo de tratamento dado às informações estruturais do maciço. Uma quarta alternativa de cálculo de Vb chegou a ser experimentada, tendo como base a freqüência de fraturas por área. As estimativas de $S_{1}$ resultaram em valores muito elevados, completamente fora do contexto esperado para o maciço em estudo e foram desprezadas. Assim, os resultados provenientes da aplicação desse critério devem ser tomados com certa reserva, utilizando-se, na melhor das hipóteses, o valor médio de todas as áreas estudadas como um indicativo para essa camada de carvão na Mina Fontanella.

Não obstante as limitações da aplicação dos diferentes métodos utilizados para a estimativa da resistência in situ, os resultados obtidos para a camada de carvão Bonito parecem estar coerentes com a realidade das camadas de carvão da bacia carbonífera Sul-Catarinense. Os valores obtidos situam-se próximos da resistência média sugerida para a camada Irapuá de 5,27MPa (ZORZI et al., 1991), ora um pouco inferiores, ora um pouco superiores. As camadas Bonito e Irapuá têm em comum estruturas de pequeno porte ("cleats") e uma relativa homogeneidade litológica ao longo do perfil da camada. Porém, possuem diferenças de resistência de laboratório, normalmente superior na camada Bonito, e nas características estruturais, melhores na camada Irapuá. Comparada com a resistência para as condições médias da camada Barro Branco, de 7,12MPa, a da camada Bonito apresenta na maior parte das estimativas, valores inferiores. Esse comportamento parece coerente e pode ser explicado pela existência, na camada Bonito, de estruturas extremamente negativas para a sua resistência, fato não observado na camada Barro Branco. 


\section{Metodologia para a Estimativa da Resistência In Situ de Camadas de Carvão Utilizando Geofísica}

\subsection{Introdução}

Como visto ao longo do desenvolvimento deste trabalho, determinar a resistência in situ de camadas de carvão não se constitui em tarefa fácil. Os estudos desenvolvidos sobre a camada de carvão Bonito na Mina Fontanella, na jazida Sul-Catarinense, e as diferentes técnicas aplicadas para estimar a sua resistência característica, mostram que não existe um caminho único capaz de suprir essa necessidade dos projetistas dos pilares de sustentação das minas subterrâneas nessa camada. Nessa mesma mina, com base na observação dos resultados de diferentes estudos, nota-se que a resistência in situ da camada de carvão, como de resto outras variáveis, não é constante ao longo da jazida.

Também os resultados de laboratório e in situ em duas minas na camada de carvão Irapuá mostraram que a resistência dessa camada não parece assumir um valor único nas diferentes jazidas (minas).

Para atender as necessidades de determinação da resistência in situ de camadas de carvão, buscou-se uma alternativa capaz de estimar a resistência de maneira objetiva, menos complexa e mais econômica do que várias técnicas disponíveis. Também, deveria levar em conta as particularidades das diferentes camadas de carvão presentes nas jazidas brasileiras, em especial as da camada Bonito. Dois aspectos nortearam o seu desenvolvimento:

- a possibilidade de uso da técnica para prover informações sobre a resistência da camada de carvão antes da implantação de uma nova mina, ou seja, ainda na fase da pesquisa mineral;

- a objetividade e exeqüibilidade necessárias para atender às necessidades das minas, no que tange ao conhecimento da resistência in situ da camada, durante o desenvolvimento das operações de lavra.

Uma nova técnica quando proposta, deve ter como pressupostos básicos a clareza na definição dos parâmetros envolvidos, a existência ou o estabelecimento de métodos para a geração dos parâmetros e a sua exeqüibilidade dentro das condições tecnológicas e operacionais disponíveis. Assim, a sua aplicação, bem como o seu aperfeiçoamento, tendem a ser facilitados e os resultados aproveitados sob condições de segurança aceitáveis. 


\subsection{Descrição da Metodologia}

A técnica proposta para estimar a resistência in situ de camadas de carvão baseia-se em parâmetros conhecidos, como a resistência à compressão uniaxial e a velocidade de propagação de ondas ultra-sônicas, determinadas em laboratório, e a velocidade de propagação de ondas sísmicas, determinada in situ.

A resistência à compressão e a velocidade ultra-sônica contemplam as características da rocha na condição "quase intacta" em pequena escala, não incluindo, portanto, estruturas de grande porte presentes nos maciços carbonosos (falhas, diques de diabásio, inclusões de pirita, calcário, etc.). Ambos os parâmetros são conhecidos e possuem métodos de ensaio sugeridos pela ISRM.

Já a velocidade das ondas sísmicas é determinada sobre um volume de maciço mais próximo do que se convenciona chamar de "Volume Elementar Representativo". Contempla todas as condições presentes nas amostras utilizadas em laboratório, além de incluir aquelas estruturas de grande porte que influenciam sensível e negativamente na resistência do maciço rochoso. Também esse parâmetro é conhecido e possui procedimento de levantamento normatizado segundo a ASTM ou método sugerido pela ISRM. As particularidades observadas na determinação da velocidade de propagação de ondas sísmicas nas camadas de carvão estudadas foram detalhadamente descritas no Capítulo 4, item 4.5.

Para a computação da resistência in situ da camada de carvão $\left(S_{1}\right)$ propõe-se a seguinte expressão:

$$
S_{1}=\frac{\left(\frac{V_{\text {sld }} * F_{1} * F_{2}}{V_{\text {pond. par }}}\right)^{0,5}-0,3}{3} * \sigma_{\text {c.cubo }}
$$

onde: $\mathrm{V}_{\text {sld }}=$ velocidade de ondas sísmicas medidas nos pilares de carvão na direção paralela aos planos de estratificação do carvão, computadas em distâncias de percurso da onda maiores que $75 \%$ da dimensão do lado do pilar $(\mathrm{km} / \mathrm{s})$;

$\mathrm{V}_{\text {pond.par }}=$ velocidade de propagação da onda ultra-sônica, ponderada nas direções de determinação paralelas aos planos de estratificação do carvão. Deve ser medida em laboratório em corpos-de-prova cúbicos com a dimensão do lado entre $5 \mathrm{~cm}$ e $10 \mathrm{~cm}$, sob condições de tensão $\cong 0$, com a rocha "seca" ou na umidade natural (grau de saturação $\cong 0 \%)(\mathrm{km} / \mathrm{s})$;

$F_{1}=$ fator de correção da velocidade de ondas sísmicas devido ao efeito da tensão vertical in situ. $F_{1}$ corrige a velocidade sísmica para a condição de tensão $\cong 0$;

$F_{2}=$ fator de correção da velocidade de ondas sísmicas devido ao efeito da presença de água in situ. $F_{2}$ corrige a velocidade sísmica para a condição "seca" ou de umidade natural (grau de saturação $\cong 0 \%$ );

$\sigma_{\text {c.cubo }}=$ resistência á compressão uniaxial, determinada em laboratório sobre corpos-de-prova cúbicos com a dimensão do lado menor ou igual a $10 \mathrm{~cm}$, na condição "seca" ou de umidade natural (MPa). 
Essa expressão foi definida embasada nas seguintes premissas:

- que os valores estimados para a resistência in situ sejam coerentes com os valores obtidos pelos métodos empíricos já conhecidos, ensaios de laboratório e retro-análise de caso de ruptura, para a camada de carvão Bonito, e com o valor médio sugerido por ZORZI et al. (1991), para a camada de carvão Irapuá;

- que os valores estimados para a resistência in situ nas diferentes minas/camadas de carvão estudadas, quando aplicados nos métodos de dimensionamento de pilares normalmente empregados no Brasil, produzam fatores de segurança muito próximos dos valores mínimos recomendados pelos respectivos métodos;

- que os fatores de segurança resultantes sejam compatíveis com as condições de estabilidade constatadas nos pilares das três minas objeto dessa pesquisa.

A relação entre as velocidades in situ e de laboratório - $\left(\frac{V_{\text {sld }} * F_{1} * F_{2}}{V_{\text {pond.par }}}\right)$ - válida para a expressão 6.1 pode variar entre 0,1 e 1 , embora valores menores que 0,4 aproximadamente, tendam a ser irreais. Na prática, essa relação representa 0 "fator geofísico" indicador da qualidade geofísica do maciço em relação à rocha intacta. A parcela da expressão 6.1 que multiplica $\sigma_{\text {c.cubo }}$ pode ser traduzida como o fator de correção da resistência de laboratório para as condições in situ (resistência do maciço). O comportamento desse fator de correção da resistência, em função da variação do "fator geofísico", pode ser visto na Figura 6.1 (linha cheia). Nessa mesma figura, os símbolos indicam os valores do fator de correção da resistência calculados para cada um dos casos estudados.

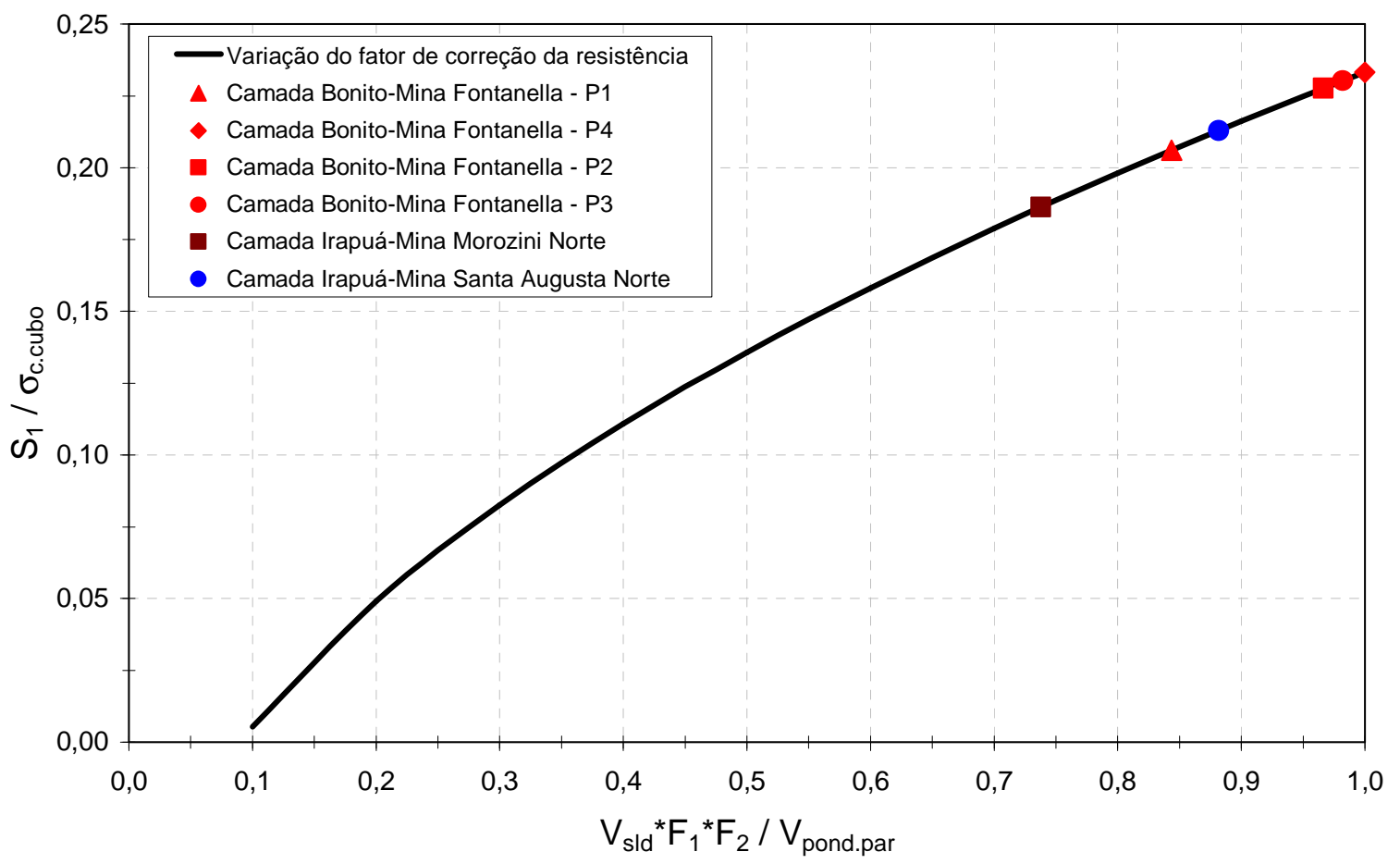

Figura 6.1 - Comportamento do fator de correção da resistência de laboratório para a condição in situ (linha cheia), em função da variação do "fator geofísico". 
A aplicação do modelo pode ser feita nas diferentes fases do empreendimento mineiro. Na fase de operação da jazida (mina já em operação), o provimento dos parâmetros de entrada deve ser feito seguindo os procedimentos adotados nesta pesquisa.

$\mathrm{Na}$ fase de pesquisa da jazida de carvão, sugere-se a adoção da seguinte sistemática para a determinação dos valores médios das variáveis requeridas pelo modelo:

- coletar amostras da camada de carvão, através de testemunhos de sondagem com diâmetro mínimo NX (54mm), com o emprego de barrilete duplo-móvel;

- determinar a velocidade de propagação de ondas ultra-sônicas e a resistência à compressão uniaxial médias em laboratório para os diferentes locais amostrados na jazida;

- determinar a velocidade de ondas sísmicas in situ, utilizando geofísica de refração e a técnica de tomografia.

\subsection{Estimativas das Resistências In Situ $\left(\mathrm{S}_{1}\right)$ para os Casos Estudados}

Para a aplicação da metodologia proposta foram utilizadas as condições geométricas de profundidade, dimensão dos pilares e galerias presentes nas 4 áreas de estudos na Mina Fontanella (camada Bonito) e nas duas minas em atividade na camada Irapuá - Morozini Norte e Santa Augusta Norte.

Os fatores de correção da velocidade sísmica $\left(F_{1}\right.$ e $\left.F_{2}\right)$ foram definidos a partir das informações geométricas das escavações e de umidade observadas nos locais de levantamentos, conforme sintetizado na Tabela 6.1. As estimativas da resistência in situ $\left(S_{1}\right)$ para cada um dos locais estudados da camada Bonito, na Mina Fontanella, e para a camada Irapuá, presente nas minas Morozini Norte e Santa Augusta Norte, podem ser vistas na Tabela 6.2.

Tendo como parâmetro de entrada a resistência $\left(S_{1}\right)$ estimada pelo modelo proposto e as variáveis geométricas de cada mina, foram calculados os fatores de segurança (FS) para as condições de projeto. O cálculo dos mesmos, em cada um dos locais considerados, foi feito utilizando-se 2 diferentes métodos de dimensionamento de pilares para a lavra segundo o método de "câmaras e pilares", quais sejam:

- o método proposto pela CIENTEC em 1991 (ZORZI et al., 1991) para as camadas de carvão do sul do Brasil;

- o método de SALAMON (1967), e a sua versão mais recente (SALAMON et al., 1996), proposto com base nas condições Sul-Africanas.

Independente do método utilizado, a tensão média nos pilares foi computada com base na teoria da área tributária.

Os resultados obtidos segundo cada um dos diferentes métodos utilizados são apresentados na Tabela 6.3. 
Tabela 6.1 - Condições geométricas das escavações e de umidade observadas nos locais de levantamentos nas diferentes minas estudadas.

\begin{tabular}{|l|c|c|c|c|c|}
\hline \multicolumn{1}{|c|}{ Mina } & $\begin{array}{c}\mathrm{H}_{\text {cam }} \\
(\mathrm{m})\end{array}$ & $\begin{array}{c}\mathrm{B}_{\text {gal }} \\
(\mathrm{m})\end{array}$ & $\begin{array}{c}\mathrm{h}_{\text {cam }} \\
(\mathrm{m})\end{array}$ & $\begin{array}{c}\mathrm{W}_{1} \times \mathrm{W}_{2} \\
(\mathrm{~m})\end{array}$ & $\begin{array}{c}\text { Condições de } \\
\text { Umidade }\end{array}$ \\
\hline Fontanella - P1 & 83 & 6 & 3,4 & $15 \times 29$ & seca \\
\hline Fontanella - P4 & 116 & 6 & 3,4 & $14 \times 14$ & seca \\
\hline Fontanella - P2 & 127 & 6 & 3,1 & ${ }^{\#} 18 \times 22$ & seca \\
\hline Fontanella - P3 & 159 & 6 & 3,0 & $18 \times 18$ & seca \\
\hline Morozini Norte & 50 & 4,5 & 2,4 & $8 \times 8$ & seca \\
\hline Santa Augusta Norte & 15 & 4,8 & 2,4 & $8 \times 8$ & saturada \\
\hline
\end{tabular}

LEGENDA:

$\mathrm{H}_{\mathrm{cam}}=$ profundidade da camada minerada; $\mathrm{B}_{\text {gal }}=$ largura da galeria; $\mathrm{h}_{\mathrm{cam}}=$ altura da camada minerada; $\mathrm{W}_{1} \mathrm{e}$ $\mathrm{W}_{2}$ = dimensões de projeto do lado menor e do lado maior do pilar, respectivamente;

\# pilar com formato de paralelogramo, onde o menor ângulo interno entre $W_{1}$ e $W_{2}$ é igual a $60^{\circ}$.

Tabela 6.2 - Resistências in situ $\left(S_{1}\right)$ estimadas para as camadas de carvão Bonito, na Mina Fontanella, e Irapuá, nas Minas Morozini Norte e Santa Augusta Norte.

\begin{tabular}{|c|c|c|c|c|c|c|}
\hline \multirow{2}{*}{ Mina } & \multicolumn{2}{|c|}{$\begin{array}{l}\text { Parâmetros de } \\
\text { Laboratório }\end{array}$} & \multicolumn{3}{|c|}{ Parâmetros In Situ } & \multirow{2}{*}{$\begin{array}{c}\mathrm{S}_{1} \\
(\mathrm{MPa})\end{array}$} \\
\hline & $\begin{array}{l}\sigma_{\text {c.cubo }} \\
(\mathrm{MPa})\end{array}$ & $\begin{array}{l}V_{\text {pond.par }} \\
(\mathrm{km} / \mathrm{s})\end{array}$ & $\begin{array}{c}\mathrm{V}_{\text {sld }} \\
(\mathrm{km} / \mathrm{s})\end{array}$ & $F_{1}$ & $F_{2}$ & \\
\hline Fontanella - P1 & 25,15 & 3,22 & 2,80 & 0,97 & 1,00 & 5,18 \\
\hline Fontanella - P4 & 20,22 & 2,95 & 3,09 & 0,96 & 1,00 & 4,74 \\
\hline Fontanella - P2 & 28,92 & 2,96 & 2,98 & 0,96 & 1,00 & 6,59 \\
\hline Fontanella - P3 & 28,82 & 3,08 & 3,19 & 0,95 & 1,00 & 6,64 \\
\hline Morozini Norte & ${ }^{\#} 17,47$ & 2,65 & 2,03 & 0,94 & 1,00 & 3,26 \\
\hline Santa Augusta Norte & 28,33 & 2,69 & 2,75 & 0,98 & 0,88 & 6,03 \\
\hline
\end{tabular}

LEGENDA:

$\sigma_{\text {c.cubo }}=$ resistência á compressão uniaxial, determinada em laboratório sobre corpos-de-prova cúbicos com a dimensão do lado menor ou igual a $10 \mathrm{~cm}$; $V_{\text {pond.par }}=$ velocidade de propagação da onda ultra-sônica, ponderada nas direções de determinação paralelas aos planos de estratificação do carvão; $V_{\text {sld }}=$ velocidade de ondas sísmicas medidas nos pilares de carvão na direção paralela aos planos de estratificação do carvão, computadas em distâncias de percurso da onda maiores que $75 \%$ da dimensão do lado do pilar; $F_{1}$ e $F_{2}=$ fatores de correção da velocidade de ondas sísmicas devido ao efeito da tensão vertical in situ e das condições de umidade.

\# Valor determinado a partir da ponderação pela proporção de carvão ( $60 \%)$ e de folhelho carbonoso ( 40\%) na camada total da camada Irapuá. 
Tabela 6.3 - Fatores de segurança calculados segundo os diferentes métodos de dimensionamento para as condições presentes na camada de carvão Bonito, na Mina Fontanella, e Irapuá, nas Minas Morozini Norte e Santa Augusta Norte.

\begin{tabular}{|c|c|c|c|c|}
\hline \multirow{3}{*}{ Mina } & \multicolumn{4}{|c|}{ Fator de Segurança } \\
\hline & \multicolumn{2}{|c|}{ Método CIENTEC } & \multirow{2}{*}{$\begin{array}{c}\text { Método SALAMON } \\
(1967)\end{array}$} & \multirow{2}{*}{$\begin{array}{c}\text { Método SALAMON } \\
\text { et al. (1996) }\end{array}$} \\
\hline & $\mathrm{Ft}=0,8$ & $\mathrm{Ft}=1$ & & \\
\hline Fontanella - P1 & 2,12 & 2,65 & 2,58 & 2,47 \\
\hline Fontanella - P4 & 0,90 & 1,12 & 1,20 & 1,16 \\
\hline Fontanella - P2 & 1,68 & 2,10 & 2,14 & 2,05 \\
\hline Fontanella - P3 & 1,36 & 1,70 & 1,71 & 1,63 \\
\hline Morozini Norte & 0,92 & 1,14 & 1,52 & 1,48 \\
\hline Santa Augusta Norte & 7,63 & 9,53 & 9,17 & 8,90 \\
\hline
\end{tabular}

Notas: 1) no método CIENTEC, o pilar quadrado equivalente foi calculado de acordo com a função:

$$
W_{e q}=\frac{2 * W_{1} * W_{2} * \operatorname{sen} \theta}{W_{1}+W_{2}}
$$

onde, $W_{1}$ e $W_{2}$ são os lados menor e maior do pilar, respectivamente, e $\theta$ o menor ângulo interno entre $W_{1}$ e $W_{2}$. Demais condições de dimensionamento: desmonte por explosivos com fogo no duro; vida útil dos pilares: $\mathrm{Ft}=0,8$ (longo prazo) e $\mathrm{Ft}=1$ (curto prazo); esbeltez do pilar não variável ao longo do tempo; encaixantes mais resistentes que a camada de carvão; sem recuperação de pilares;

2) nos métodos de SALAMON (1967) e SALAMON et al. (1996), o pilar quadrado equivalente foi calculado com base na mesma função utilizada pelo método CIENTEC;

3) independente do método de dimensionamento utilizado, a tensão média no pilar foi calculda de acordo com a teoria da área tributária.

\subsection{Análise dos Resultados}

\subsubsection{Camada de Carvão Bonito - Mina Fontanella}

Os valores de resistência in situ $\left(S_{1}\right)$ da camada Bonito, na Mina Fontanella, obtidos com a aplicação da nova metodologia situam-se muito próximos aos valores aceitáveis computados segundo outras diferentes técnicas disponíveis, descritas no Capítulo 5. Na Figura 6.2 são apresentados os valores estimados para a resistência in situ da camada Bonito pela metodologia proposta, assim como pelas diferentes técnicas utilizadas, com exceção das estimativas feitas por retro-análise. Nessa figura, a resistência foi relacionada com a densidade de fraturas observada nos diferentes locais estudados na Mina Fontanella. A coerência entre os valores obtidos pela metodologia proposta e as outras técnicas utilizadas, especialmente as de Hoek-Brown, Wilson e Kalamaras, baseadas em classificação geomecânica, e de Gaddy (ensaios laboratoriais), pode ser observada, inclusive, nas variações de resistência que ocorrem dentro da Mina Fontanella. As estimativas de $S_{1}$ feitas pela metodologia proposta também são amparadas na faixa de variação $(4,2 \mathrm{MPa}$ a $5,4 \mathrm{MPa})$ estimada para o caso de retro-análise estudado nessa mesma mina. 


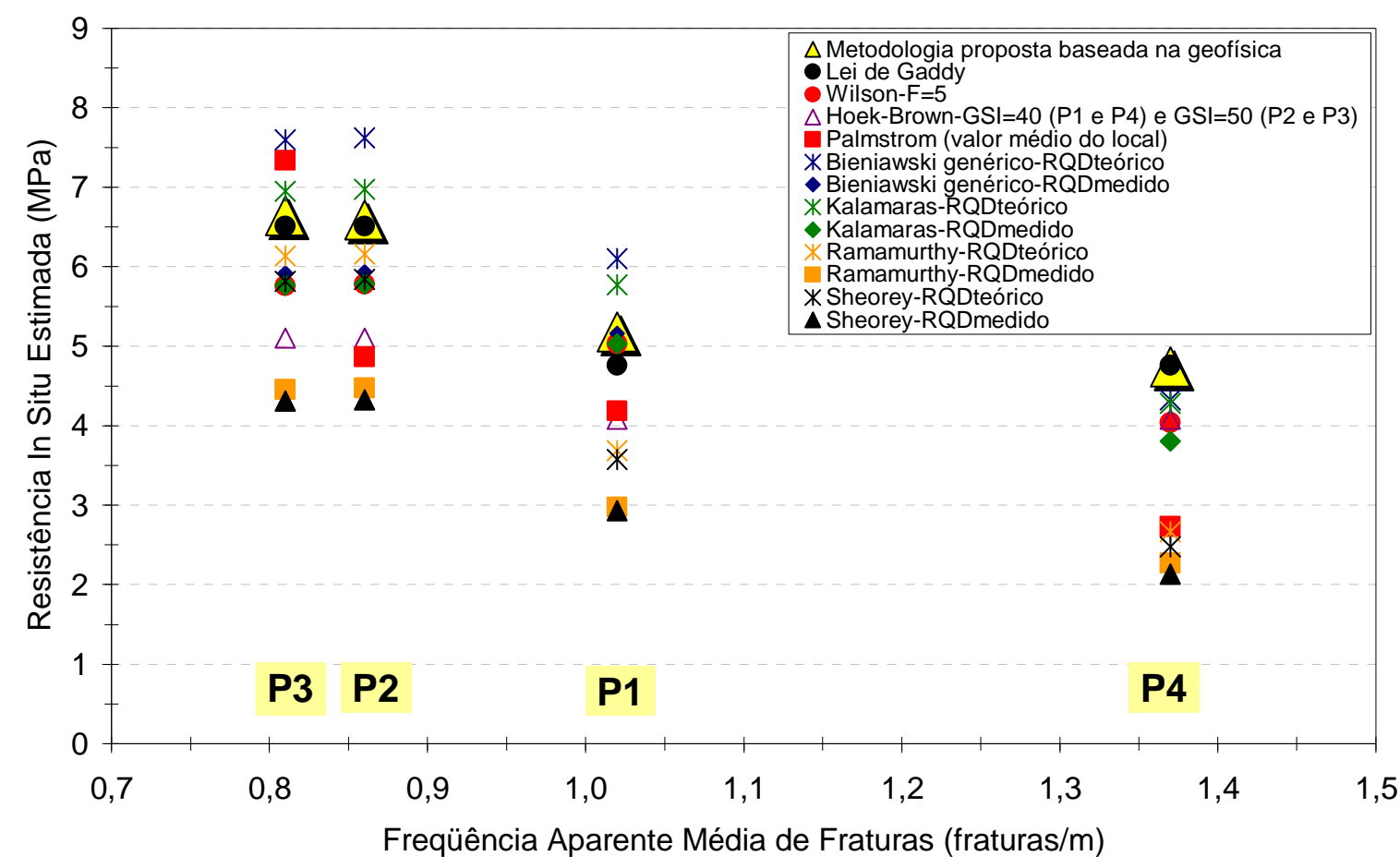

Figura 6.2 - Valores de resistência in situ estimados para a camada de carvão Bonito, de acordo com as diferentes técnicas utilizadas, em função da densidade de fraturas observada nos diferentes locais (P1, P2, P3 e P4) estudados na Mina Fontanella.

Os valores de resistência in situ estimados, associados aos fatores de segurança computados e às condições de segurança observadas nos pilares, sugerem que as 3 variáveis utilizadas pelo modelo proposto, contemplam relativamente bem as características de composição e estruturais que influenciam diretamente na resistência in situ da camada de carvão. Alguns dos outros métodos necessitam até o dobro de variáveis e uma quantidade considerável de trabalho adicional para chegar a resultados semelhantes ou piores. Pelo menos a metade deles produziu estimativas totalmente fora da realidade, se levarmos em conta as condições de estabilidade vigentes nos pilares existentes na mina.

Dos locais avaliados, o P4 na Mina Fontanella e a Mina Morozini Norte são os que apresentam os menores fatores de segurança. Segundo o método CIENTEC, em ambos os casos os pilares possuem fatores de segurança abaixo do recomendado, ou seja, $F S \geq 1,3$. Esse mesmo tipo de previsão também se verifica quando são utilizados os métodos Sul-Africanos. Para esses métodos, os fatores de segurança sugeridos são de 1,6 para pilares de painel convencionais e 1,7 para zonas geologicamente perturbadas.

Notadamente, o local designado por P4, na Mina Fontanella, poderia ser caracterizado com uma área geologicamente perturbada, haja vista a presença de um dique de diabásio nas proximidades do ponto de coleta das amostras. Adicionalmente, neste local foi constatada a maior densidade de fraturas por metro, comparada com os demais locais estudados na Mina Fontanella. Outro 
indicativo de anomalia no local é o fato de que foi o único que apresentou velocidade de propagação de ondas sísmicas fora dos padrões esperados, quando relacionado com a resistência de laboratório ou com a freqüência de fraturas (Figura 4.43).

\subsubsection{Camada de Carvão Irapuá - Minas Morozini Norte e Santa Augusta Norte}

A Figura 6.3 apresenta uma síntese dos valores estimados para a resistência in situ da camada de carvão Irapuá, segundo a nova proposta baseada na geofísica, juntamente com o valor médio sugerido na literatura.

No que tange à estimativa de resistência in situ feita para a Mina Morozini Norte no município de Treviso - SC, cujo valor está bastante abaixo (-38\%) do único valor médio conhecido para esta camada $(5,27 \mathrm{MPa})$, vários aspectos devem considerados.

Em primeiro lugar, a qualidade das amostras fornecidas para ensaios de laboratório pode não ter sido a desejável, uma vez que foram coletadas da borda dos pilares, na região periférica ainda afetada pelo desmonte por explosivos. Outro aspecto diz respeito às medições de velocidade de ondas sísmicas. Uma análise mais detalhada do perfil da camada Irapuá nessa mina (ver perfil na Figura 3.5) sugere que a medição da velocidade de propagação das ondas sísmicas seja feita em mais de um nível da camada, e não somente na meia altura do pilar como foi executado. Com isso, seriam contemplados tanto os extratos de carvão, na parte superior da camada, como os de folhelho carbonoso, na parte inferior. Do ponto de vista estrutural, trata-se de uma camada que apresenta perturbações estruturais bem evidentes na escala in situ (fraturas inclinadas atravessando a camada e dobramentos ao longo da calha de deposição). Essas características são marcantes, negativamente em termos de resistência, quando comparadas com o que se observa na camada Irapuá presente na região de Criciúma, na Mina Santa Augusta Norte. Todos esses aspectos elencados sobre a Mina Morozini Norte tendem a contribuir para 0 rebaixamento da estimativa da resistência in situ da camada e, por conseqüência, para a obtenção de um FS relativamente baixo.

O elevado fator de segurança calculado para a Mina Santa Augusta Norte, a partir da estimativa de resistência in situ feita pela nova proposta, não deve sugerir que a resistência in situ esteja superestimada. Por orientação do órgão fiscalizador da mineração no Brasil (DNPM), a relação W/H (largura do pilar/altura da camada) deve ser maior ou igual a 3 . Como a mina se encontra a uma profundidade relativamente pequena (cerca de $15-20 \mathrm{~m}$ ), mesmo que a dimensão lateral do pilar necessária para atender ao FS mínimo requerido pelos métodos de dimensionamento pudesse ser inferior a $8 \mathrm{~m}$, a sua dimensão deve ser mantida em $8 \mathrm{~m}$ para atender a relação geométrica da forma do pilar. Nessa mina, o melhor parâmetro para balizar a estimativa feita pela nova metodologia proposta é o valor médio recomendado por ZORZI et al. (1991), igual a 5,27MPa. Esse valor foi obtido com base em estudos na Mina A-Sangão, distante cerca de $4 \mathrm{~km}$ da Mina Santa Augusta Norte. O valor de 6,03MPa estimado pela metodologia ora apresentada, portanto, não parece fora de contexto. 


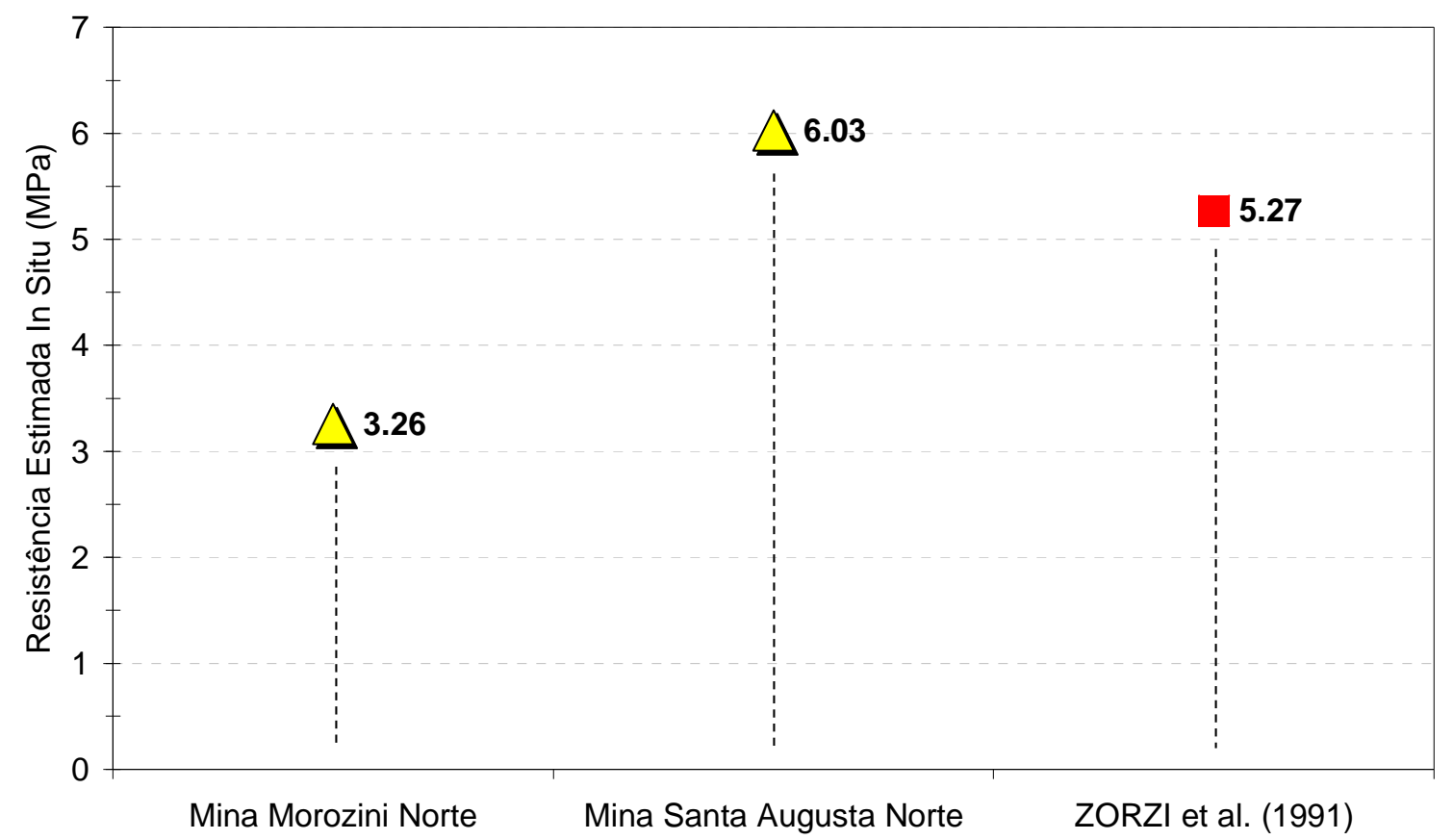

Figura 6.3 - Valores de resistência in situ estimados para a camada de carvão Irapuá, de acordo com a nova metodologia (Minas Morozini Norte e Santa Augusta Norte), e o valor médio sugerido por ZORZI et al. (1991). 


\section{Conclusão}

Os esforços desenvolvidos durante a pesquisa bibliográfica, na direção do conhecimento das diferentes técnicas empregadas para o estudo e definição das características geomecânicas de maciços carbonosos, mostraram que inexiste um caminho único capaz de fornecer todos os elementos necessários para o entendimento do comportamento da rocha, no que tange à sua resistência in situ.

Também é objeto de muita discussão qual a melhor forma de determinar o valor da resistência in situ do carvão, já que muitas variáveis estão envolvidas e nem sempre é possível explicá-las conjuntamente.

A avaliação dos resultados obtidos nesta pesquisa com materiais da camada de carvão Irapuá e, principalmente, da camada Bonito na Mina Fontanella, parecem corroborar as afirmações acima.

Dentro desse contexto, a proposta ora apresentada para a estimativa da resistência in situ de camadas de carvão, atendeu plenamente aos propósitos da pesquisa. $O$ produto final constitui-se numa ferramenta prática que vai ao encontro das necessidades das empresas mineradoras, no sentido de prover informações antecipadas e mais rápidas sobre a resistência in situ do maciço carbonoso. Pela sua objetividade, pode contribuir para a otimização da recuperação das reservas e melhoria da segurança das atividades em subsolo durante a lavra do carvão.

O modelo proposto para estimativa da resistência in situ de camadas de carvão possui como vantagens em relação a outras tantas técnicas disponíveis os seguintes aspectos:

- possibilita a estimativa da resistência já na fase de pesquisa, intento que para muitas das técnicas disponíveis (classificações geomecânicas e outros métodos empíricos simplificados) é praticamente impossível, dado ao número e características das variáveis utilizadas;

- utiliza-se de um número de variáveis menores que a maioria das outras técnicas, tornando o trabalho de geração de dados menos custoso e mais rápido. Assim, mais amostras podem ser trabalhadas, tornando os resultados mais representativos dos maciços estudados;

- baseia-se num conjunto de variáveis cuja determinação em laboratório e in situ é objetiva. 
No que se refere à camada de carvão Bonito, na Mina Fontanella cabem as seguintes considerações:

- os resultados obtidos pela aplicação da nova proposta no carvão da camada Bonito, na Mina Fontanella, mostraram que a resistência in situ não é constante ao longo da jazida. Isso significa dizer que a busca de informações sobre a resistência mais próxima da realidade dessa camada deve ser constante ao longo do desenvolvimento da lavra, sob pena das estruturas de sustentação (pilares) estarem ora superdimensionadas, ora subdimensionadas, quando é assumido um valor único para a resistência in situ da camada;

- no atual estágio do conhecimento da camada Bonito, na Mina Fontanella, e com base na aplicação da nova metodologia, balizada pelos resultados de outras diferentes técnicas, valores entre $4,7 \mathrm{MPa}$ e $6,6 \mathrm{MPa}$ são sugeridos para a resistência in situ nessa mina. Esses valores se mostraram compatíveis com a estabilidade e o comportamento dos pilares de sustentação presentes até o momento nos locais estudados. Por outro lado, não deve ser esquecido que esses resultados são representativos de uma área restrita da mina, com cerca de $1 \mathrm{~km}^{2}$;

- os resultados dos levantamentos estruturais e a observação dos pilares na mina após algum tempo de vida, mostram que pode ocorrer perda de área resistiva do pilar devido ao deslocamento (queda de "costelas") de blocos para dentro da galeria. A resistência in situ estimada pela proposta apresentada não contempla esse tipo de perda de resistência global do pilar. A aplicação de suporte artificial na lateral do pilar sistemático, semelhante ao que vem sendo feito atualmente, e/ou considerar já na fase de projeto uma perda de área resistiva do pilar, através da introdução de fator de correção nos métodos de dimensionamento dos pilares, são alternativas que devem ser consideradas no dimensionamento dos pilares, independentemente da resistência in situ utilizada.

No que tange à camada de carvão Irapuá, cuja resistência média in situ já era conhecida, os resultados obtidos com a aplicação da proposta ora apresentada, para a estimativa da resistência in situ de camadas de carvão, tornam pertinentes os seguintes comentários:

- as mesmas considerações sobre a inconstância da resistência in situ, feitas para a camada Bonito, parecem valer para a camada Irapuá, haja vista a diferença apreciável entre os valores estimados para a minas Morozini Norte $(-40 \%)$ e Santa Augusta Norte (+15\%), em relação ao valor médio de 5,27MPa sugerido por ZORZI et al. (1991);

- o valor de $S_{1}=5,27 \mathrm{MPa}$ proposto em 1991, e até então utilizado pelas mineradoras, expressa uma condição média da camada de carvão Irapuá, tendo como fonte de informações a Mina A-Sangão em Criciúma - SC. A proximidade entre o valor estimado nesta pesquisa para a Mina Santa Augusta Norte $(6,03 \mathrm{MPa})$ e o valor já conhecido parece coerente, haja vista as minas estarem localizadas muito próximas entre si (aproximadamente $4 \mathrm{~km}$ de distância) e a camada de carvão nas duas minas ser muito semelhante litológica e estruturalmente; 
- com relação ao valor da resistência in situ estimado com a nova metodologia para a camada da Mina Morozini Norte (3,26MPa), os aspectos apontados no Capítulo 6, que concorrem para a redução da resistência, explicam com razoável segurança a diferença para menos em relação ao valor até então conhecido para a camada Irapuá.

Não deve ser desconsiderado, portanto, também para a camada de carvão Irapuá, a necessidade de estudos adicionais para a implantação de novas minas ou mesmo para as minas que estão em operação nesta camada de carvão.

Para efeitos práticos, apesar dos resultados positivos, a proposta ora apresentada deve ser tomada como uma primeira aproximação para a estimativa da resistência in situ. Como toda nova proposição e, dada a heterogeneidade presente nos maciços carbonosos que vem sendo observada nas camadas presentes na Bacia Sul-Catarinense, é desejável que seja utilizada, sempre que possível, associada com outras técnicas conhecidas e capazes de serem aplicadas para as condições presentes nos locais de interesse.

Em especial na camada Bonito, nunca deve ser deixado de lado o fato de que é necessário o monitoramento contínuo das estruturas dimensionadas a partir do uso da resistência in situ determinada com o uso do modelo ora proposto. Características como a grande altura da camada comparada com as camadas que vinham sendo mineradas, a presença de estruturas de fraqueza até então não observadas em camadas de carvão no Brasil e os graves problemas já ocorridos de colapso integral ou parcial de minas, justificam os cuidados acima. A técnica ora proposta, assim como outras tantas técnicas, não é capaz de contemplar todas as variáveis que intervém no processo de determinação da resistência in situ de maciços rochosos.

A consolidação dessa proposta também passa pelo uso da experiência prática de engenharia e do bom senso dos técnicos envolvidos no projeto dos pilares de sustentação das minas, onde a resistência in situ se constitui num dos vários parâmetros necessários ao dimensionamento dos pilares. 


\section{Recomendações}

Com o intuito de melhorar a performance da metodologia proposta para a estimativa da resistência in situ de camadas carbonosas, alguns aspectos intervenientes na resistência e na velocidade de propagação de ondas justificam estudos adicionais no futuro, quais sejam:

- inclusões de carbonatos na camada de carvão: esse tipo de material caracterizase por apresentar velocidades de propagação de ondas bem mais elevada em relação à velocidade média do carvão. $O$ fato de não serem representadas nas determinações da velocidade de ondas ultra-sônicas em laboratório $\left(\mathrm{V}_{\text {pond.par }}\right)$, pode resultar em valores na relação $\left(\frac{V_{\text {sld }} * F_{1} * F_{2}}{V_{\text {pond.par }}}\right)$ maiores que 1 , fato que em teoria não é esperado;

- tipos de preenchimento e condições das fraturas: esses aspectos podem mascarar parcialmente as determinações da velocidade de propagação de ondas sísmicas in situ. Aparentemente é o que ocorreu na determinação da velocidade de ondas sísmicas no carvão Bonito presente no P4 de amostragem (fraturas preenchidas por carbonatos e bem seladas). Nas condições de ensaio em laboratório, essas mesmas fraturas mesmo preenchidas tendem a interferir negativamente, tanto na velocidade de propagação das ondas ultra-sônicas (devido ao desconfinamento da rocha) como na resistência (presença de planos de fraqueza), reduzindo ambas. A interferência sobre a velocidade ultrasônica tende a produzir valores na relação $\left(\frac{V_{s l d} * F_{1} * F_{2}}{V_{\text {pond.par }}}\right)$ também maiores do 1 , da mesma maneira que acima, não esperado;

- heterogeneidade da camada de carvão: a intercalação de carvão com outras litologias (siltitos, folhelhos) no perfil da camada de carvão, sugere que as determinações da velocidade de propagação de ondas sísmicas sejam feitas com os geofones posicionados em mais de um patamar dentro do perfil da camada, como forma de melhor representar a velocidade sísmica da camada de carvão. O mesmo deve ser feito em laboratório, a partir da coleta de amostras em diferentes posições do perfil na camada. Nesse caso, pode ser adotada alguma forma de ponderação dos resultados, tanto da velocidade de ondas ultra-sônicas como da resistência, em função da proporção das diferentes litologias no perfil da camada de carvão;

- influência da tensão e da água na velocidade de propagação de ondas: a influência desses dois fatores ainda é pouco conhecida na prática, especialmente em rochas sedimentares, onde é observada anisotropia na 
velocidade. No contexto desta pesquisa, esses dois aspectos foram avaliados independentemente, quando na prática, é razoável esperar que atuem conjuntamente. Estudos adicionais poderão ajudar no refinamento dos fatores de correção da velocidade de ondas sísmicas in situ. 


\section{Referências Bibliográficas}

ABNT NBR 8289 (1983) - Carvão mineral - Determinação do teor de cinzas.

ABNT NBR 12766 (1992) - Rochas para revestimento - Determinação da massa específica aparente, porosidade aparente e absorção d'água aparente.

ABORRAGE, A. M \& LOPES, R. DA C. (1986). Projeto Borda Leste da bacia do Paraná: Integração geológica e avaliação econômica. Relatório Final, CPRM - Companhia de Pesquisa de Recursos Minerais. Volumes 1, 10 e 13.

AGOSTINI, M. I; ZORZI, L.; GONZATTI, C. (2002). Ensaios de compressão uniaxial in situ em grandes amostras de carvão. In.: Simpósio Brasileiro de Mecânica das Rochas, III $^{\circ}$. Proceedings. São Paulo, SP, Brasil. São Paulo, ABMS - Associação Brasileira de Mecânica dos Solos. XII COBRAMSEG, trabalho 406, 9p..

ANON (1977). The description of rock masses for engineering purposes. Report by the Geological Society Engineering Group Working Party. The Quartely Journal of Engineering Geology, v. 10, p. 355-388.

ASTM D 5777 (2000). Standard guide for using the seismic refraction method for subsurface investigation. $14 \mathrm{p}$.

ATKINSON, R. H. \& KO, HON-YIM (1977). Strength characteristics of U.S. coals. In.: Symposium on Rock Mechanics, $18^{\text {th }}$. Proceedings. Keystone, CO, USA, p. 2B3-1-2B3-6.

ATKINSON, T. \& CASSAPI, V. B. (1983). The preparation of laboratory-cored specimens from friable rock. The Mining Engineer, April, p. 541-547.

BABCOCK, C.; MORGAN, T.; HARAMY, K. (1981). Review of pillar design equations including the effects of constraint. In.: Conference on Ground Control in Mining, $\mathbf{1}^{\text {st }}$. Proceedings. Morgantown, WV, USA, p. 23-34.

BANDIS, S. C. (1990). Scale effects in the strength and deformability of rocks and rock joints. In.: International Workshop on Scale Effects in Rock Masses, $1^{\text {st }}$. Proceedings. Loen, Noruega, p. 59-76. Balkema, Rotterdam. 
BARRON, K. \& YANG, T. (1992). Influence of specimen size and shape on strength of coal. Part 1: Size effects of uniaxial strength of coal. Part 2: An approach to evaluation of intact and mass strengths of coal from triaxial tests on laboratory-size specimens. Part 3: Laboratory test results. Part 4: Influence of coal rank. In.: Workshop on Coal Pillar Mechanics and Design. Proceedings. United States Department of the Interior, USBM, Pittsburgh, PA, USA. IC 9315, p. 5-24.

BARRON, K. (1983). An analytical approach to the design of pillars in coal. Part 2: Apllication of the model to case histories. Final Report, phase 2. Canada Centre for Mineral Energy Technology. Alberta, Canada, Coal Mining Research Center. 207p..

BARTON, N. (1990). Scale effects or sampling bias? In.: International Workshop on Scale Effects in Rock Masses, $1^{\text {st }}$. Proceedings. Loen, Noruega, p. 3155. Balkema, Rotterdam.

BARTON, N. (2000). TBM Tunneling in jointed and faulted rock. A. A. Balkema, Rotterdam. 172p..

BARTON, N.; LIEN, R.; LUNDE, J. (1974). Engineering classification of rock masses for the design of tunnel support. Rock Mechanics, v. 6, $n^{\circ} 4$, p. 189 236. Springer-Verlag Wien, New York.

BHATTACHARYYA, A. K. \& BELLEZA, G. V. (1986). A seismic study of pheriferical fractured zones in coal pillas in an underground coal mine in N.S.W.. In.: Australian Coal Science Conference. Newcastle, NSW, Austrália, v. 1, p. 198-203.

BIENIAWSKI, Z. T. \& BAUER, J. (1982). Discussão (do artigo de HOEK, E. \& BROWN, E. T. (1980). Empirical strength criterion for rock masses. Journal of the Geotecnical Engineering Division. ASCE, September (GT9), p. 10131035). Journal of the Geotecnical Engineering Division. ASCE, April (GT4), p. 670-671.

BIENIAWSKI, Z. T. \& VAN HEERDEN, W. L. (1975). The significance of in situ tests on large rock specimens. International Journal of Rock Mechanics and Mining Sciences, v. 12, $\mathrm{n}^{\circ} 4$, p. 101-113.

BIENIAWSKI, Z. T. (1968a). In situ strength and deformation characteristics of coal. Engineering Geology, v. 2, $n^{\circ} 5$, p. 325-340.

BIENIAWSKI, Z. T. (1968b). The effect of specimen size on compressive strength of coal. International Journal of Rock Mechanics and Mining Sciences, $v$. 5 , p. 325-335.

BIENIAWSKI, Z. T. (1968c). Note on in situ testing of the strength of coal pillars. Journal of the South African Institute of Mining and Metallurgy, v. 68, p. 455-465. 
BIENIAWSKI, Z. T. (1969). In situ large scale testing of coal. In.: Conference on In Situ Investigations on Soils and Rocks. Proceedings. London, UK. British Geotechnical Society, p. 67-74.

BIENIAWSKI, Z. T. (1973). Engineering classification of jointed rock masses. Transactions of South African Institution of Civil Engineers, v. 15, $\mathrm{n}^{\circ} 12$, p. 335-344.

BIENIAWSKI, Z. T. (1974). Estimating the strength of rock materials. Journal of the South African Institute of Mining and Metallurgy, March, p. 312-320.

BIENIAWSKI, Z. T. (1976). Rock mass classifications in rock engineering. In.: Symposium on Exploration for Rock Engineering. Proceedings. Johannesburg, África do Sul, v. 1, p. 97-105.

BIENIAWSKI, Z. T. (1977). Discussão (do artigo de HUSTRULID, W. A. (1976). A review of coal pillar strength formulas. Rock Mechanics, v. $8, n^{\circ} 2$, p. $115-$ 145). Rock Mechanics, v. 10, $n^{\circ} 1-2$, p. 107-110. Springer-Verlag Wien, New York.

BIENIAWSKI, Z. T. (1981). Improved design of coal pillars for U.S. mining conditions. In.: Conference on Ground Control in Mining, $1^{\text {st }}$. Proceedings. Morgantown, WV, USA, p. 13-22.

BIENIAWSKI, Z. T. (1982). Improved design of room-and-pillar coal mines for U.S. conditions. In.: International Conference on Stability in Underground Mining, $1^{\text {st }}$. Proceedings. Vancouver, BC, Canadá. Society of Mining Engineers of AIME. New York, USA, cap. 2, p. 19-49.

BIENIAWSKI, Z. T. (1983). New design approach for room-and-pillar coal mines in the U.S.A.. In.: International Congress on Rock Mechanics, $5^{\text {th }}$. Proceedings. Melbourne, Austrália, v. 2, p. E27-E36. Balkema, Rotterdam.

BIENIAWSKI, Z. T. (1984). Rock mechanics design in mining and tunneling. Balkema, Rotterdam, 271p..

BIENIAWSKI, Z. T. (1989). Engineering rock mass classifications. Balkema, Rotterdam, 251p..

BRACE, W. F. (1981). The effect of size on mechanical properties of rock. Geophysical Research Letters, v. 8, $n^{\circ}$ 7, p. 651-652.

BROWN, E. T. \& HOEK, E. (1988). Discussão (do artigo de UCAR, R. (1986). Determination of shear failure envelope in rock masses. Journal of the Geotecnical Engineering Division. ASCE, March, v. 112, $\left.\mathrm{n}^{\circ} 3,303-315\right)$. Journal of the Geotecnical Engineering Division. ASCE, v. 114, $n^{\circ} 3,371$ 373.

BROWN. E. T. (1971). Strength-size effects in rock material. In.: International Symposium on Rock Mechanics. Nancy, França, artigo II-11. 
BUNTING, D. (1911). Chamber-pillars in deep anthracite-mines. Transactions of AIME, v. 42, p. 236-245.

CARTER, B. J.; SCOTT DUNCAN, E. J.; LAJTAI, E. Z. (1991). Fitting strength criteria to intact rock. Geotecnical and Geological Engineering. V. 9, 73-81.

CIENTEC - FUNDAÇÃO DE CIÊNCIA E TECNOLOGIA (1990). Projeto: Dimensionamento de Pilares em Minas de Carvão. Coord. Luiz Zorzi. Porto Alegre, 2v..

CIENTEC - FUNDAÇÃO DE CIÊNCIA E TECNOLOGIA (1996). Projeto: Lavra Subterrânea de Camadas Múltiplas de Carvão - Estudo Geomecânico. Coord. Luiz Zorzi. Porto Alegre, 2v..

CIENTEC - FUNDAÇÃO DE CIÊNCIA E TECNOLOGIA (1998). Mina Fontanella: Relatório de Ensaios de Compressão Uniaxial e Compressão Triaxial em Laboratório. Porto Alegre, 38p..

CIENTEC - FUNDAÇÃO DE CIÊNCIA E TECNOLOGIA (2002). Projeto Reforço Reforço de Pilares em Minas de Carvão. Coord. Luiz Zorzi. Porto Alegre, v. 2, 208p..

CIENTEC - FUNDAÇÃO DE CIÊNCIA E TECNOLOGIA (2006). Projeto: Bonito Mina Fontanella. Equipe técnica: Luiz Zorzi; Ivone M. Agostini \& Clovis Gonzatti. Porto Alegre, Relatório Técnico N 1285/65526, 37p..

COOK, N. G. W.; HODGSON, K.; HOJEM, J. P. M. (1970). A 100-MN jacking system for testing coal pillars underground. Chamber of Mines of South Africa. Johannesburg, África do Sul. 40p. (Reseach Report $n^{\circ}$ 48/70).

COON, R. F. \& MERRITT, A. H. (1970). Predicting in situ mudulus of deformation iusing rock quality indexes. In: Determination of the In Situ Modulus of Deformation of Rock, ASTM STP 477, American Society for Testing and Materials, p. 154-173.

COSTA, J. F. C. L. (2000). Avaliação de reservas de carvão - Projeto Fontanella - Carbonífera Metropolitana S.A.. Departamento de Engenharia de Minas, Universidade Federal do Rio Grande do Sul. Porto Alegre, Volume 1.

CUNHA, A. P. (1990). Scale effect in rock mechanics. In.: International Workshop on Scale Effects in Rock Masses. Loen, Noruega, v. 1, p. 3-27. Balkema, Rotterdam.

CUNHA, A. P. (1992). Efeito de escala na determinação de características mecânicas de fracturas e maciços rochosos fracturados. Geotecnia, $n^{\circ} 65, p$. 3-19. 
CYRUL, T. (1984). A large scale in-situ compression test on a 1,5m coal cube. In.: International Conference on Stability in Underground Mining, $2^{\text {nd }}$. Proceedings. Lexington, KE, USA. Society of Mining Engineers of AIME. New York, USA, cap. 11, p. 171-188.

DANIELS, J. \& MOORE, L. D. (1907). The ultimate crushing strength of coal. The Engineering and Mining Journal, August 10, v. LXXXIV, n. 6, p. 263-268.

DARRACOTT, B. W. \& ORR, C. M. (1976). Geophysics and rock engineering. In.: Symposium on Exploration for Rock Engineering. Proceedings. Johannesburg, África do Sul, v. 1, p. 159-164.

DEERE, D. U. \& DEERE, D. W. (1988). The Rock Quality Designation (RQD) index in practice. In.: Rock Classification Systems for Engineering Purposes, ASTM STP 984, Luis Kirkaldie, Ed., American Society for Testing and Materials, Philadelphia, 1988, p. 91-101.

DEERE, D. U. \& HENDRON, A. J. Jr.; PATTON, F. D.; CORDING, E. J. (1967). Design of surface and near surface construction in rock. In.: Charles Fairhurst (ed.). Failure and Breakage of Rock. Society of Mining Engineers of AIME, New York, USA, p. 237-302.

DEERE, D. U. (1963). Technical description of rock cores for engineering purposes. Rock Mechanics Engineering Geology, v. 1, p. 16-22.

DENKHAUS, H. G. (1962). A critical review of the present state of scientific knowledge related to the strength of mine pillars. Journal of the South African Institute of Mining and Metallurgy, September, v. 63, p. 59-75.

EINSTEIN, H. H.; BAECHER, G. B.; HIRSCHFELD, R. C. (1970). The effect of size on strength of a brittle rock. In.: International Congress on Rock Mechanics, $2^{\text {nd }}$. Proceedings. Belgrado, luguslávia, paper 3-2, p. 7-13.

ESTERHUIZEN, G. S. (1995). Rock engineering evaluation of jointing in South African coal seams and its potential effect on coal pillar strength. In.: International Conference on the Mechanics of Jointed and Faulted Rock, $2^{\text {nd }}$. Proceedings. Viena, Áustria, p. 807-812. Balkema, Rotterdam.

ESTERHUIZEN, G. S. (2000). Jointing effects on pillar strength. In.: International Conference on Ground Control in Mining, 19 ${ }^{\text {st }}$. Proceedings. Morgantown, WV, USA, p. 286-290.

EVANS, I. \& POMEROY, C. D. (1958). The strength of cubes of coal in uniaxial compression. In.: Mechanical Properties of Non-metallic and Brittle Materials. London, Butterworth Scientific Publications, W. H. Walton, p. 5-28.

EVANS, I.; POMEROY, C. D.; BERENBAUM, R. (1961a). The compressive strength of coal. Colliery Engineering, v. 38, February, p. 75-80.

EVANS, I.; POMEROY, C. D.; BERENBAUM, R. (1961b). The compressive strength of coal. Colliery Engineering, v. 38, March, p. 123-127. 
EVANS, I.; POMEROY, C. D.; BERENBAUM, R. (1961c). The compressive strength of coal. Colliery Engineering, v. 38, April, p. 172-178.

FAIRHURST, C. (1973). Laboratory testing of rock and its relevance to mine design. SME Mining Engineering Handbook, v. 1, p. 13-36 e 13-51.

GADDY, F. L. (1956). A study of the ultimate strength of coal as related to the absolute size of the cubical samples tested. Virginia Polytechnic Institute. Blacksburg, Virginia, USA, 57p.. (Dissertação de Mestrado).

GALVIN, J. M.; HEBBLEWHITE, B. K.; SALAMON, M. D. G. (1999). University of New South Wales coal pillar strength determinations for Australian and South African mining conditions. In.: Workshop on Coal Pillar Mechanics and Design, $2^{\text {nd }}$. Proceedings. NIOSHI, Pittsburgh, PA, USA. IC 9448, p. 63-71.

GOMES, M. J. L. (1993). Rock mass sampling conditions needed to overcome the scale effect. In.: International Workshop on Scale Effects in Rock Masses, $2^{\text {nd }}$. Proceedings. Lisboa, Portugal, p. 199-204. Balkema, Rotterdam.

GREENWALD, H. P.; HOWARTH, H. C.; HARTMANN, I. (1939). Experiments on strength of small pillars of coal in the Pittsburgh bed. United States Department of the Interior, USBM, USA. Technical Paper 605, 12p..

GREENWALD, H. P.; HOWARTH, H. C.; HARTMANN, I. (1941). Experiments on strength of small pillars of coal in the Pittsburgh bed. United States Department of the Interior, USBM, USA. R. I. 3575, 10p..

HARPALANI, S. (1988). Specimen preparation for testing coal properties. International Journal of Rock Mechanics and Mining Sciences, v. 25, $n^{\circ} 5$, p. 327-330. Technical Note.

HEDLEY, D. G. F. \& GRANT, F. (1972). Stope-and-pillar design for Elliot Lake Uranium Mine. CIM Transactions, v. LXXV, p. 121-128.

HEUZE, F. E. (1980). Scale effects in the determination of rock mass strength and deformability. Rock Mechanics, v. 12, p. 167-192. Springer-Verlag Wien, New York.

HOBBS, D. W. (1960). The strength and the stress-strain characteristics of Oakdale coal under triaxial compression. Geology Magazine, v. 97, $n^{\circ} 5$, p. 421-435.

HOBBS, D. W. (1964). The strength and the stress-strain characteristics of coal in triaxial compression. Journal of Geology, v. 72, p. 214-231.

HODGSON, K. \& COOK, N. G. W. (1970). The effects of size and stress gradiente on the strength of rock. In.: International Congress on Rock Mechanics, $2^{\text {nd }}$. Proceedings. Belgrado, luguslávia, paper 3-5, p. 31-34. 
HOEK, E. \& BROWN, E. T. (1980a). Empirical strength criterion for rock masses. Journal of the Geotecnical Engineering Division. ASCE, September, v. 106, nº GT9, p. 1013-1035.

HOEK, E. \& BROWN, E. T. (1980b). Underground escavations in rock. Inst. Min. and Metall. London.

HOEK, E. \& BROWN, E. T. (1982). Fechamento (do artigo de HOEK, E. \& BROWN, E. T. (1982). Empirical strength criterion for rock masses. Journal of the Geotecnical Engineering Division. ASCE, April (GT4), p. 672-673). Journal of the Geotecnical Engineering Division. ASCE, April (GT4), p. 672-673.

HOEK, E. \& BROWN, E. T. (1988). The Hoek-Brown failure criterion - A 1988 update. In: Canadian Rock Mechanics Symposium, 15 ${ }^{\text {th }}$. Proceedings. Toronto, Canadá, p. 31-38.

HOEK, E. \& BROWN, E. T. (1997). Practical estimates of rock mass strength. International Journal of Rock Mechanics and Mining Sciences, v. $34, n^{\circ} 8$, p. 1165-1186.

HOEK, E. (1983). Strength of jointed rock masses. Géotechnique, v. 33, $n^{\circ} 3, p$. 187-223 (The Rankine Lecture).

HOEK, E. (1990). Estimating Mohr-Coulomb friction and cohesion values from the Hoek-Brown failure criterion. International Journal of Rock Mechanics and Mining Sciences, v. 27, $n^{\circ} 3$, p. 227-229.

HOEK, E. (1994). Strength of rock and rock masses. ISRM News Journal. , v. 2, $\mathrm{n}^{0} 2$, p. 4-16.

HOEK, E.; WOOD, D. F.; SHAH, S. (1992). A modified Hoek-Brown failure criterion for jointed rock masses. In: ISRM Symposium: Eurock'92 - Rock Characterization. Chester, UK, p. 209-214. London, UK, Imperial College of Science, Technology \& Medicine.

HOEK, E.; CARRANZA-TORRES, C.; CORKUM, B. (2002). Hoek-Brown failure criterion - 2002 edition. In.: North American Rock Mechanics Symposium, $5^{\text {th }}$. Proceedings. Toronto, Canadá, p. 267-273.

HOLLAND, C. T. (1962a). Design pillars for overburden support - Part I. Mining Congress Journal, March, p. 24-32.

HOLLAND, C. T. (1962b). Design pillars for overburden support - Part II. Mining Congress Journal, April, p. 66-71.

HOLLAND, C. T. (1964). The strength of coal in mine pillars. In.: Symposium on Rock Mechanics, $6^{\text {th }}$. Proceedings. Rolla, MO, USA, p. 450-466. 
HOLLAND, C. T. (1973). Pillar design for permanent and semi-permanent support of the overburden in coal mines. In.: Canadian Rock Mechanics Sympsium, $\mathbf{9}^{\text {th }}$. Proceedings. Montreal, Canadá, p. 113-135.

HUSTRULID, W. A. (1976). A review of coal pillar strength formulas. Rock Mechanics, v. 8, $n^{\circ}$ 2, p. 115-145. Springer-Verlag Wien, New York.

ISRM (1978a) - Suggested methods for determining sound velocity. Int. Journal of Rock Mech. and Min. Scienc. \& Geomech. Abstr.. Vol. 15, oㅡ 2, p. 53-58.

ISRM (1978b). Suggested methods for determining tensile strength of rock material. Int. Journal of Rock Mech. and Min. Scienc. \& Geomech. Abstr.. Vol. 15, no 3, p. 99-103.

ISRM (1978c). Suggested methods for the quantitative description of discontinuities in rock masses. International Journal of Rock Mechanics and Mining Sciences, v. 15, p. 319-368. Commission on Standardization of Laboratory and Field Tests, BARTON, N. (coord.).

ISRM (1979a) - Suggested methods for determining water content, porosity, density, absorption and related properties and swelling and slake-durability index properties. Int. Journal of Rock Mech. and Min. Scienc. \& Geomech. Abstr.. Vol. 16, № 2, p. 141-156.

ISRM (1979b). Suggested methods for determining the uniaxial compressive strength and deformability of rock materials. Int. Journal of Rock Mech. and Min. Scienc. \& Geomech. Abstr.. Vol. 16, no 2, p. 135-140.

ISRM (1983). Suggested methods for determining the strength of rock materials in triaxial compression: revised version. Int. Journal of Rock Mech. and Min. Scienc. \& Geomech. Abstr.. Vol. 20, oㅡ 6, p. 283-290.

ISRM (1999) - Suggested methods for the complete stress-strain curve for intact rock in uniaxial compression. Int. Journal of Rock Mech. and Min. Scienc. \& Geomech. Abstr.. Vol. 36, p. 279-289.

ISRM (2004). Suggested methods for land geophysics in rock engineering. International Journal of Rock Mechanics and Mining Sciences, v. 41, p. 885-914, TAKAHASHI, T. (coord.).

JAEGER, J. C. \& COOK, N. G. W (1977). Fundamental of rock mechanics. Chapman and Hall, London, cap. 18, p. 485-490.

KAHRAMAN, S. (2001). A correlation between P-wave velocity, number of joints and schmidt hammer rebound number. International Journal of Rock Mechanics and Mining Sciences, v. 38, p. 729-733.

KALAMARAS, G. S. \& BIENIAWSKI. Z. T. (1993). A rock mass concept for coal seams. In.: International Conference on Ground Control in Mining, $\mathbf{1 2}^{\text {st }}$. Proceedings. Morgantown, WV, USA, p. 274-283. 
KALAMARAS, G. S. \& BIENIAWSKI. Z. T. (1995). A rock mass concept for coal seams incorporating the effect of time. In.: International Congress on Rock Mechanics, $8^{\text {th }}$. Proceedings. Tokyo, Japão, v. 1, p. 295-302.

KING, M. S. (1966). Wave velocities in rocks as a function of changes in overburden pressure and pore fluid saturants. Geophysics, v. 31, $n^{0} 1$, p. $50-$ 73.

KING, M. S. (1983). Static and dynamic elast properties of rocks from canadian shield. International Journal of Rock Mechanics and Mining Sciences, v. $20, n^{\circ} 5$, p. 237-241.

KING, M. S. (1984). Elastic-wave velocities in quartz monzonite at different levels of water saturation. International Journal of Rock Mechanics and Mining Sciences, v. 21, $n^{0} 1$, p. 35-38.

KLIMENTOS, T. (1991). The effects of porosity-permeability-clay content on the velocity of compressional waves. Geophysics, v. 56, n 12 , p. 1930-1939.

KUSTER, G. T. \& TOKSOZ, M. N. (1974). Velocity and attenuation of seismic waves in two-phase media: Part I. Theoretical formulations. Geophysics, v. $39, n^{\circ} 5$, p. 587-606.

LAMA, R. D. (1966). A comparison of the in situ mechanical properties of coal seams. Colliery Engineering, January, v. 1, p. 20-25.

LAMA, R. D. (1970). In-situ and laboratory strength of coal. In.: Symposium on Rock Mechanics, 12 $^{\text {th }}$. Proceedings. Rolla, MO, USA, cap. 14, p. 265-300.

LAROCQUE, G. E. (1964). A sonic unit for the determination of 'in situ' dynamic properties and for outlining of fracture. In.: Symposium on Rock Mechanics, $6^{\text {th }}$. Proceedings. Rolla, USA, 358-390. The University of Missouri at Rolla, USA.

LAUBSCHER, D. H. (1984). Design aspects and effectiveness of support systems in different mining condititons. Transactions of Institution of Mining and Metallurgy, section A, v. 93, p. A70-A81.

LAVALL, C. E. \& HOLLAND, C. T. (1937). Some physical characteristics of West Virginia coals. Research Bulletin of Engineering Experiment Station, West Virginia University. Morgantown, WV, USA. Bulletin $n^{0} 17,50 p$..

LOGIE, C. \& MATHESON, G. M. (1983). A critical review of the current state-ofthe-art design of mine pillars. In.: International Conference on Stability in Underground Mining, $\mathbf{1}^{\text {st }}$. Proceedings. Vancouver, BC, Canadá. Society of Mining Engineers of AIME. New York, USA, cap. 16, p. 359-382.

LONDE, P. (1988). Discussão (do artigo de UCAR, R. (1986). Determination of shear failure envelope in rock masses. Journal of the Geotecnical Engineering Division. ASCE, March, v. 112, $\left.\mathrm{n}^{\circ} 3,303-315\right)$. Journal of the Geotecnical Engineering Division. ASCE, v. 114, $n^{\circ} 3,374-376$. 
MADDEN, B. J. (1991). A re-assessment of coal-pillar design. Journal of the South African Institute of Mining and Metallurgy, January, v. 91, $n^{\circ} 1, p$. 27-37.

MARION, D. \& NUR, A. (1991). Pore-filling material and its effect on velocity in rocks. Geophysics, v. 56, n ${ }^{\circ}$ 2, p. 225-230.

MARK, C. \& BARTON, T. (1996). The uniaxial compressive strength of coal: should it be used to design pillars?. In.: International Conference on Ground Control in Mining, $1^{\text {th }}$. Proceedings. Golden, CO, USA, p. 61-78.

MARK, C. \& BARTON, T. (1997). Pillar design and coal strength. In.: New Technology for Ground Control in Retreat Mining. Proceedings. United States Department of the Interior, USBM, Pittsburgh, PA, USA. IC 9446, p. 4959.

MARTIN, C. D. \& MAYBEE, W. G. (2000). The strength of hard-rock pillars. International Journal of Rock Mechanics and Mining Sciences, v. $37, n^{\circ} 8$, p. $1239-1246$.

MEDHURST, T. P. \& BROWN, E. T. (1996). Large scale laboratory testing of coal. In.: Australia-New Zeland Conference on Geomechanics, $7^{\text {th }}$. Proceedings. Canberra, Austrália, p. 203-207.

MEDHURST, T. P.; TRUEMAN, R.; BROWN, E. T. (1995). Experimental studies on the effect of scale on strength of coal. In.: International Congress on Rock Mechanics, $8^{\text {th }}$. Proceedings. Tokyo, Japão, v. 1, p. 347-351.

MIDÉA, N. F.; YOSHIKAWA, N. K.; MARCHI, A. J. (1985). Dimensionamento de pilares - Um exemplo do papel da mecânica de rochas. In.: Congesso

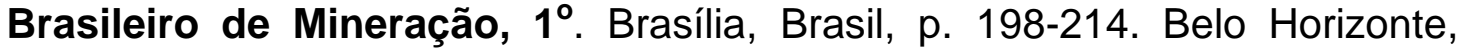
IBRAM.

MILLARD, D. J.; NEWMAN, P. C.; PHILLIPS, J. W. (1955). The apparent strength of extensively cracked materials. In.: Proceedings of The Physical Society. Section B, v. LXVIII, p. 723-728.

MOHAN, G. M.; SHEOREY, P. R.; KUSHWAHA, A. (2001). Numerical estimation of pillar strength in coal mines. International Journal of Rock Mechanics and Mining Sciences, v. 38, p. 1185-1192.

NATAU, O. (1990). Scale effects in the determination of the deformability and strength of rock masses. In.: International Workshop on Scale Effects in Rock Masses, $\mathbf{1}^{\text {st }}$. Proceedings. Loen, Noruega, p. 77-88. Balkema, Rotterdam.

OBERT, L. \& DUVALL, W. I. (1967). Rock mechanics and the design of structures in rock. John Wiley \& Sons, New York, cap. 17, p. 542-545.

OJIMA, L. M. (1982). Metodologia de classificação geomecânica de maciços rochosos aplicáveis a túneis. São Paulo, ABGE. 
ONODERA, T. F. (1963). Dynamic investigation of foundation rocks in situ. In.: Symposium on Rock Mechanics, $5^{\text {th }}$. Proceedings. Minesota, USA, p. 517533.

PAKALNIS, R. \& VONGPAISAL, S. (????). Empirical design methods - UBC geomechanics. University of British Columbia, Geomechanisc Group. Artigo disponível em: http://www.mining.ubc.ca/rock/publications/Empirical.html.

PALMSTR $\varnothing M, A$. (1982). The volumetric joint count - a useful and simple measure of the degree of rock mass jointing. In.: International Congress of International Association of Engineering Geology, $4^{\text {nd }}$. Proceedings. New Delhi, Índia, v. V, tema 2, p. V.221-V.228.

PALMSTR $\varnothing \mathrm{M}$, A. (1985). Application of the volumetric joint count as a measure of rock mass jointing. In.: International Symposium on Fundamentals of Rock Joints. Proceedings. Björkliden, Suécia, p. 103-110.

PALMSTR $\varnothing M, A$. (1995). RMi - a rock mass characterization system for engineering purposes. Tese de Doutorado, Universidade de Oslo, Noruega. 400p..

PALMSTR $\varnothing \mathrm{M}$, A. (1996a). The volumetric joint count as a measure of rock mass jointing. In.: Conference on Fracture, Fragmentation and Flow. Jerusalém, Israel, 18p..

PALMSTR $\varnothing M, A$. (1996b). Characterizing rock masses by RMi for use in practical rock engineering. Part 1: the development of Rock Mass index. Tunnelling and Underground Space Technology, v. 11, $n^{\circ} 2$, p. 175-188.

PALMSTR $\varnothing \mathrm{M}$, A. (1996c). Characterizing rock masses by RMi for use in practical rock engineering. Part 2: some practical applications of Rock Mass index (RMi). Tunnelling and Underground Space Technology, v. 11, $n^{\circ} 3$, p. 287303.

PALMSTR ØM, A. (1997). Collection and use of geological data in rock engineering. ISRM News Journal, v. 4, $\mathrm{n}^{\circ} 2$, p. 21-25.

PANEK, L. A. (1980). Estimating mine pillar strength from compression tests. Society of Mining Engineers of AIME, Transactions, v. 268, p. 1749-1761.

PARISEAU, W. G. (1975). Limit design of mine pillars under uncertainty. In.: Symposium on Rock Mechanics, $16^{\text {th }}$. Proceedings. Design Methods in Rock Mechanics. Minneapolis, MI, USA, p. 287-301. Minneapolis, University of Minnesota.

POTVIN, Y.; HUDYMA, M.; MILLER, H. D. S. (1989). Rib pillar design in open stope mineng. CIM Bulletin, v. 82, no 927, p. 31-36. 
PRATT, H. R.; BLACK, A, D.; BROWN, W. S.; BRACE, W. F. (1972). The effect of specimen size on the mechanical properties of unjointed diorite. International Journal of Rock Mechanics and Mining Sciences, v. 9, p. 513-529.

PRIEST, S. D. \& HUDSON, J. A. (1976). Discontinuity spacing in rock. International Journal of Rock Mechanics and Mining Sciences, v. 13, p. 135-148.

PRIEST, S. D. \& HUDSON, J. A. (1981). Estimation of discontinuity spacing and trace legth using scanline survey. International Journal of Rock Mechanics and Mining Sciences, v. 18, $n^{\circ}$ 3, p. 183-197.

PROTODIAKONOV, M. M. \& KOIFMAN, M. I. (1967). The scale effect in investigations of rock and coal. South African Council for Scientific and Industrial Research, Pretoria, 25p. Separata de Deutsche Akademie der Wissenschaften, Berlin, Alemanha, $n^{\circ} 3$, p. 97-108, 1964. (CSIR Tanslation Section, ref. 628).

PROTODYAKONOV, M. M. (1965). Methods of evaluating the cracked state and strength of rocks in situ. In.: International Conference on Strata Control and Rock Mechanics, $4^{\text {th }}$. Proceedings. New York, NY, USA, 1964, 30p. (DR FMP 65/11-MRL).

RAMAMURTHY, T. (1986). Stability of rock mass. Indian Geotechnical Journal, v. $16, n^{\circ} 1$, p. $1-74$

REDDISH, D. J. \& STACE, L. R. (1999). A UK coal mining based rock mass classification system for determining input parameters for numerical model. International Mining and Minerals. January, p. 19-25.

Relatório de Ensaio 19997/66354 - MINAGEO LTDA. Relatório emitido pela CIENTEC - FUNDAÇÃO DE CIÊNCIA E TECNOLOGIA em 25 de outubro de 2006.

Relatório de Ensaio 19774/66293 - CARBONÍFERA BELLUNO LTDA. Relatório emitido pela CIENTEC - FUNDAÇÃO DE CIÊNCIA E TECNOLOGIA em 26 de outubro de 2006.

RICE, G. S. (1929). Tests of strength of roof supports used in anthracite mines of Pennsylvania. United States Department of the Interior, USBM, USA. Bulletin 303, 44p..

SALAMON, M. D. G. \& MUNRO, A. H. (1967). A study of the strength of coal pillars. Journal of the South African Institute of Mining and Metallurgy, September, v. 67, p. 55-67.

SALAMON, M. D. G. (1967). A method of designing bord and pillar workings. Journal of the South African Institute of Mining and Metallurgy, September, v. 68, p. 68-78. 
SALAMON, M. D. G.; GALVIN, J. M.; HOCKING, G.; ANDERSON, I. (1996). Coal pillar strength from back-calculation. The University of New South Wales, Department of Mining Engineering. October, Progress Report n ${ }^{\circ}$ 1/96, 62p..

SHEOREY, P. R. (1992). Pillar strength considering in situ stresses. In.: Workshop on Coal Pillar Mechanics and Design. Proceedings. United States Department of the Interior, USBM, Pittsburgh, PA, USA. IC 9315, p. 122-127.

SHEOREY, P. R.; DAS, M. N.; BARAT, D.; PRASAD, R. K; SINGH, B. (1987). Coal pillar strength estimation from failed and stable cases. International Journal of Rock Mechanics and Mining Sciences, v. 24, n 6, p. 347-355.

SHEOREY, P. R.; DAS, M. N.; BORDIA, S. K.; SINGH, B. (1986). Pillar strength strength approaches based on a new failure criterion for coal seams. International Journal of Mining and geological Engineering, v. 4, p. 273290.

SHEOREY, P. R. (1997). Empirical rock failure criteria. Balkema, Rotterdam, cap. 2 e 3.

SILVA, L. A. A. \& BORN, H. (1993). The definition of intact rock and its application to the determination of the smallest spacing between discontinuities in rock masses. In.: International Workshop on Scale Effects in Rock Masses, $2^{\text {nd }}$. Proceedings. Lisboa, Portugal, p. 211-216. Balkema, Rotterdam.

SILVA, L. A. A. \& HENNIES, W. T. (1993). A methodology for rock compressive strength characterization from laboratory tests. In.: International Workshop on Scale Effects in Rock Masses, $2^{\text {nd }}$. Proceedings. Lisboa, Portugal, p. 217-224. Balkema, Rotterdam.

SINGH, B. (1980). Rock mechanics investigation in India - Practical application in coal mines \& tunnels. In.: Symposium on Rock Mechanics, $21^{\text {th }}$. Proceedings. Rolla, MO, USA, p. 806-819.

SJOGREN, B.; OFSTHUS, A.; SANDBERG, J. (1979). Seismic classification of rock mass qualities. Geophysical Prospecting, v. 27, n² 2, p. 409-442.

SKELLY, W. A.; WOLGAMOTT, J.; WANG, F. D. (1977). Coal mine pillar strength and deformation prediction through laboratory sample testing. In.: U. S. Symposium on Rock Mechanics, $\mathbf{1 8}^{\text {th }}$. Proceedings. Keystone, CO, USA, p. 2B5-1-2B5-5. Golden, CO, Colorado School of Mines.

Software CurveExpert, versão 1.38. registro $n^{0} \# 93494326687$.

St GEORGE, J. D. (1995). Strength of New Zeland coals in relation to pillar stability. In.: New Zeland Coal Conference, $6^{\text {th }}$. Proceedings. Wellington, New Zeland, p. 365-372. 
St GEORGE, J. D. (1997). Structural effects on the strength of New Zeland coal. International Journal of Rock Mechanics and Mining Sciences, v. 34, $\mathrm{n}^{\circ}$ 3/4, paper $n^{0} 299$.

STEART, F. A. (1954). Strength and stability of pillars in coal mines. Journal of the Metallurgical and Mining Society of South Africa, March, p. 309-325.

TANIMOTO, C. \& IKEDA, K. (1983). Acoustic and mechanical properties of jointed rock. In.: International Congress on Rock Mechanics, $5^{\text {th }}$. Proceedings. Melbourne, Austrália, v. 1, p. A15-A18. Balkema, Rotterdam.

TRUEMAN, R. \& MEDHURST, T. P. (1994). The influence of scale effects on the strength and deformability of coal. In.: ISRM International Symposium on Integral Approach to Applied Rock Mechanics. Proceedings. Sociedad Chilena de Geotecnia, Santiago, Chile, v. 1, p. 103-114.

TRUEMAN, R.; THIN, I. G. T.; TYLER, D. B. (1992). Rock mass classification as an aid to estimating the strength of coal pillars. In.: International Conference on Ground Control in Mining, $11^{\text {th }}$. Proceedings. Wollongong, NSW, Austrália, p. 22-29.

TSUR-LAVIE, Y. \& DENEKAMP, S. A. (1982a). Size and shape effect in pillar design. In.: Symposium on Strata Mechanics. Proceedings. Newcastle upon Tyne, England. Developments in Geotechnical Engineering, v. 32, p. 245-248. Elsevier, Amsterdam. Newcastle upon Tyne, England, Department of Mining Engineering, The University of New Castle upon Tyne.

TSUR-LAVIE, Y. \& DENEKAMP, S. A. (1982b). Comparison of size effect for different types of strength tests. Rock Mechanics, v. 15, p. 243-254. SpringerVerlag Wien, New York.

TUCKER Jr., J. (1945). Effect of dimensions of specimens upon the precision of strength data. In.: American Society for Testing and Materials. Proceedings. Philadelphia, USA, v. 45, p. 952-960.

UCAR, R. (1986). Determination of shear failure envelope in rock masses. Journal of the Geotecnical Engineering Division. ASCE, March, v. 112, $\mathrm{n}^{\circ}$ 3, 303-315.

UNRUG, K. F.; NADY, S.; THOMPSON, E. (1986). Evaluation of the coal strength for pillar calculations. Society of Mining Engineers of AIME, Transactions, preprint $85-314,9 p .$.

VAN der MERWE, J. N. (1993). Revised strength factor for coal in the Vaal basin. Journal of the South African Institute of Mining and Metallurgy, v. 93, $n^{\circ}$ 3, p. 71-77.

VAN der MERWE, J. N. (1999). New strength formula for coal pillars in South Africa. In.: Workshop on Coal Pillar Mechanics and Design, $2^{\text {nd }}$. Proceedings. NIOSHI, Pittsburgh, PA, USA. IC 9448, p. 163-171. 
VAN der MERWE, J. N. (2002). A linear coal pillar strength formula for South African coal. In.: International Conference on Ground Control in Mining, $21^{\text {th }}$. Proceedings. Morgantown, WV, USA, p. 98-104.

VAN HEERDEN, W. L. (1975). In situ complete stress-strain characteristics of large coal specimens. Journal of the South African Institute of Mining and Metallurgy, v. $75, n^{\circ} 8$, p. 207-217.

VAN HEERDEN, W. L. (1976). In situ rock mass property tests. In.: Symposium on Exploration for Rock Engineering. Proceedings. Johannesburg, África do Sul, v. 1, p. 147-158.

VARGA, A. (1993). Scale factor in rock masses as affected by geological conditions. In.: International Workshop on Scale Effects in Rock Masses, $2^{\text {nd }}$. Proceedings. Lisboa, Portugal, p. 183-189. Balkema, Rotterdam.

WAGNER, H. (1974). Determination of the complete load-deformation characteristics of coal pillars. In.: ISRM Congress, $3^{\text {rd }}$. Proceedings. Denver, CO, USA, v. 2, p. 1076-1081.

WANG, F. D.; SKELLY, W. A.; WOLGAMOTT, J.; (1976). In-situ coal pillar strength study. Excavation Engineering and Earth Mechanics Institute. 241p.. Golden, CO, USA, Colorado School of Mines. USBM contract No. H0242022.

WEILBULL, W. (1952). A survey of "statistical effects" in the field of material failure. Applied Mechanics Reviews, v. 5, n 11, p. 449-451.

WILSON, A. H. (1972). Research into the determination of pillar size. Part 1 - An hypothesis concerning pillar stability. The Mining Engineer. June, v. 131, p. 409-417.

WILSON, A. H. (1983). The stability of underground workings in the soft rocks of the coal measures. International Journal of Mining Engineering, v. 1, $\mathrm{n}^{\circ} 2$, p. 91-187. London, Chapman and Hall.

WINKLER, K. W. (1986). Estimates of velocity dispersion between seismic and ultrasonic frequencies. Geophysics, v. $51, n^{\circ} 1$, p. 183-189.

WOOD, D. F. (1991). Estimating Hoek-Brown rock mass strength parameters from rock mass classification. Transportation Research Record 1330, p. 22-29.

WU, B.; KING, M. S.; HUDSON, J. A. (1991). Stress-induced ultrasonic wave velocity anisotropy in a sandstone. International Journal of Rock Mechanics and Mining Sciences, v. 28, $n^{\circ} 1$, p. 101-107.

YANG, T. (1991). Influence of specimen size and shape on the strength of coal. Department of Mining, Metallurgy and Petroleum Engineering, University of Alberta. Edmonton, Canadá, 297p. (Dissertação de Mestrado). 
YASAR, E. \& ERDOGAN, Y. (2004). Correlating sound velocity with density, compressive strength and Young's modulus of carbonate rocks. International Journal of Rock Mechanics and Mining Sciences, v. 41, p. 871-875.

YOUNG, R. P. \& HILL, J. J. (1986). Seismic attenuation spectra in rock mass characterization; a case study in open-pit mining. Geophysics, v. 51, $\mathrm{n}^{\circ} 2$, p. 302-332.

ZORZI, L.; AGOSTINI, I. M. ; GONZATTI, C. (1998). O desenvolvimento da mecânica de rochas no Rio Grande do Sul. In.: SCHNAID, F. \& CERATTI, J. A. (eds). Anais do Simpósio de Prática de Engenharia Geotécnica da Região Sul, GEOSUL'98, p. 199-237. Editora Palotti, Porto Alegre.

ZORZI, L.; AGOSTINI, I. M.; GONZATTI, C. (1991). Metodologia para dimensionamento de pilares em minas de carvão do Sul do Brasil. CIENTEC - FUNDAÇÃO DE CIÊNCIA E TECNOLOGIA, Porto Alegre, 23p. (Boletim Técnico $n^{\circ} 23$ ). 


\section{ANEXO 1}

Detalhes dos Procedimentos Adotados nos Ensaios para a Determinação do Efeito Escala na Resistência à Compressão Uniaxial do Carvão da Camada Bonito - Mina Fontanella 


\section{Sumário}

$\begin{array}{llc}\text { A1.1 } & \text { Extração das Amostras } & \text { Página } \\ \text { A1.2 } & \text { Preparação dos Corpos-de-Prova } & 199 \\ \text { A1.3 } & \text { Execução dos Ensaios } & 206 \\ \text { A1.4 } & \text { Dificuldades Encontradas para a Realização dos Ensaios } & 216\end{array}$




\section{A1.1 Extração das Amostras}

A Mina Fontanella, da Carbonífera Metropolitana S/A, principal campo experimental desta pesquisa, está localizada no município de Treviso-SC. Essa mina possui uma área relativamente grande para o acesso direto à camada de carvão Bonito e encontra-se atualmente em explotação a profundidades entre 100 e $150 \mathrm{~m}$ aproximadamente.

A coleta de amostras de carvão foi coordenada pelo autor e executada em conjunto pela empresa Carbonífera Metropolitana S/A, proprietária da mina, e pela CIENTEC, parceira no desenvolvimento dos estudos geomecânicos.

O mapa da Figura 4.1 (Capítulo 4) contém a indicação dos pontos de amostragem dentro da mina. A localização dos pontos amostrados é a seguinte:

a) PONTO 1 - situa-se no Eixo 6NW, na Galeria 4, entre os Travessões 1 e 2 (área minerada em 1999);

b) PONTO 2 - situa-se no Eixo 8NW, Galeria 1, Travessão 1 (área minerada em 1999);

c) PONTO 3 - situa-se no Eixo 7SW, Galeria 1, Travessão 2 (área em lavra);

d) PONTO 4 - situa-se no Eixo 6NW, Painel 2, Travessão 6, entre as Galerias 0 e 1 (área em lavra).

Em todas as operações de corte dos blocos foi utilizada uma cortadeira universal, equipada com uma lança de 2,7m de comprimento.

$O$ processo de extração obedeceu às seguintes operações básicas, conforme ilustrado na Figura A1.1:

- execução dos cortes 1 e 2 ;

- execução dos cortes 3 e 4 para a individualização do material a ser desprezado e isolamento do futuro bloco de carvão a ser extraído;

- marcação dos futuros blocos em função da posição dos mesmos no perfil da camada;

- realização de cortes horizontais para a separação dos blocos com cerca de $80 \mathrm{~cm}$ de altura cada um;

- remoção dos blocos, com volume da ordem de $1,0 \mathrm{~m}^{3}$, para a superfície e parafinamento imediato para evitar a ação da umidade.

Em cada ponto amostrado foram dispendidos, em média, 2 turnos de 6 horas, com uma equipe de 4 pessoas. As Figuras A1.2, A1.3, A1.4 e A1.5 mostram aspectos das operações durante a extração das amostras. Nas Figuras A1.6a a A1.6d são apresentados os perfis da camada de carvão Bonito nos locais amostrados na Mina Fontanella. 


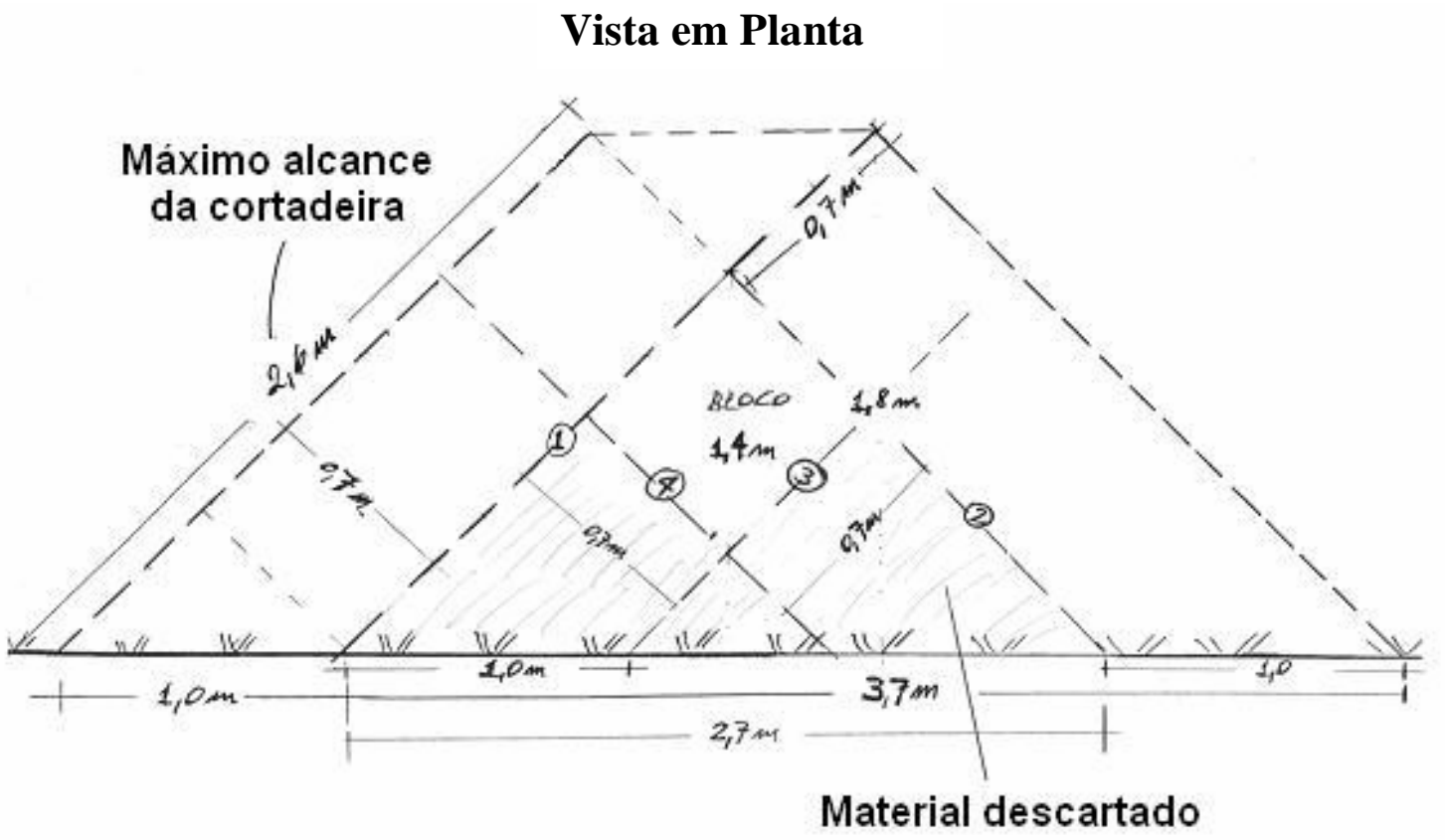

Figura A1.1 - Detalhe da execução dos cortes para a extração dos blocos de carvão na camada Bonito, na Mina Fontanella.

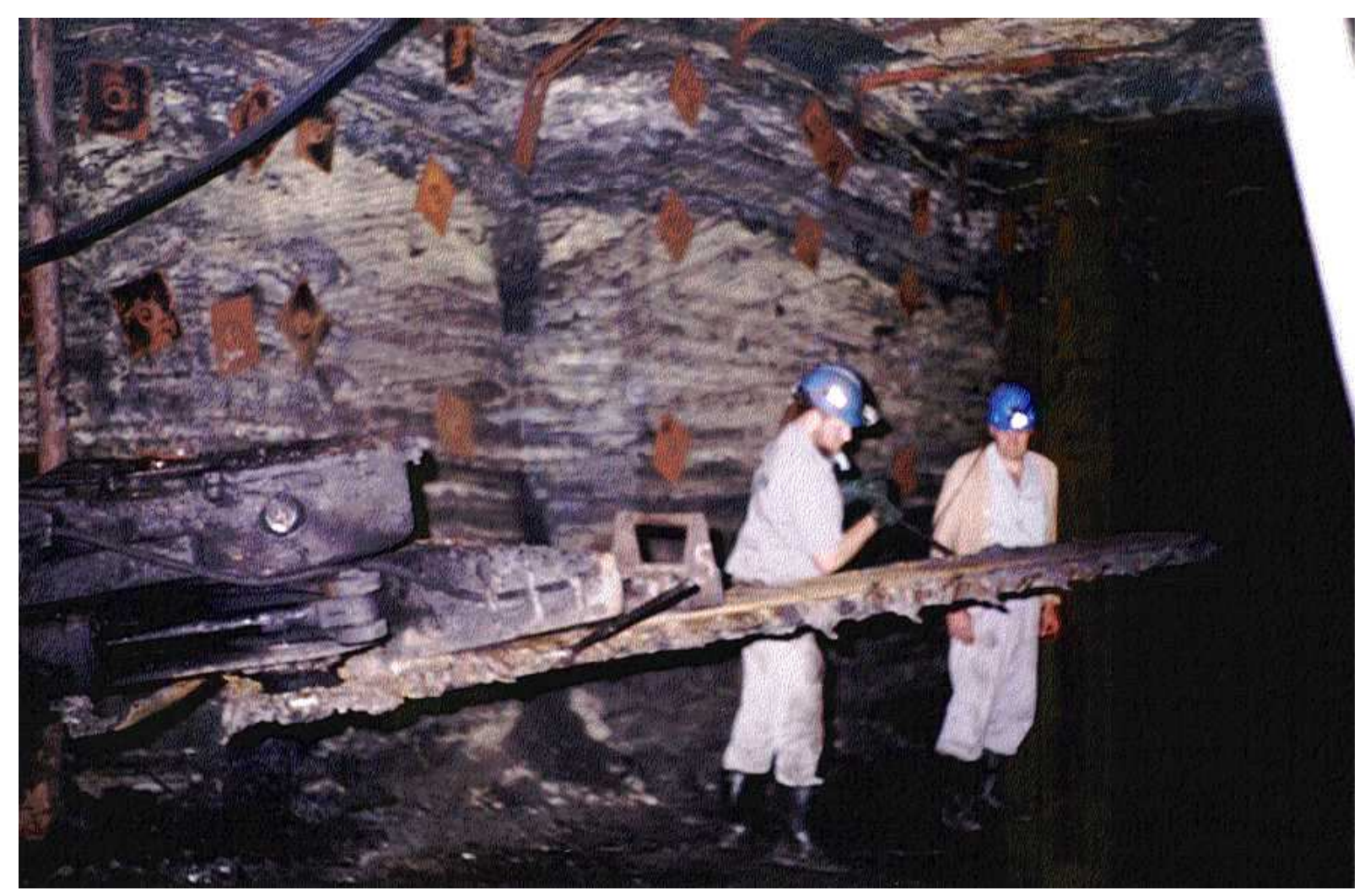

Figura A1.2 - Cortadeira universal utilizada para o corte do carvão na Mina Fontanella. 


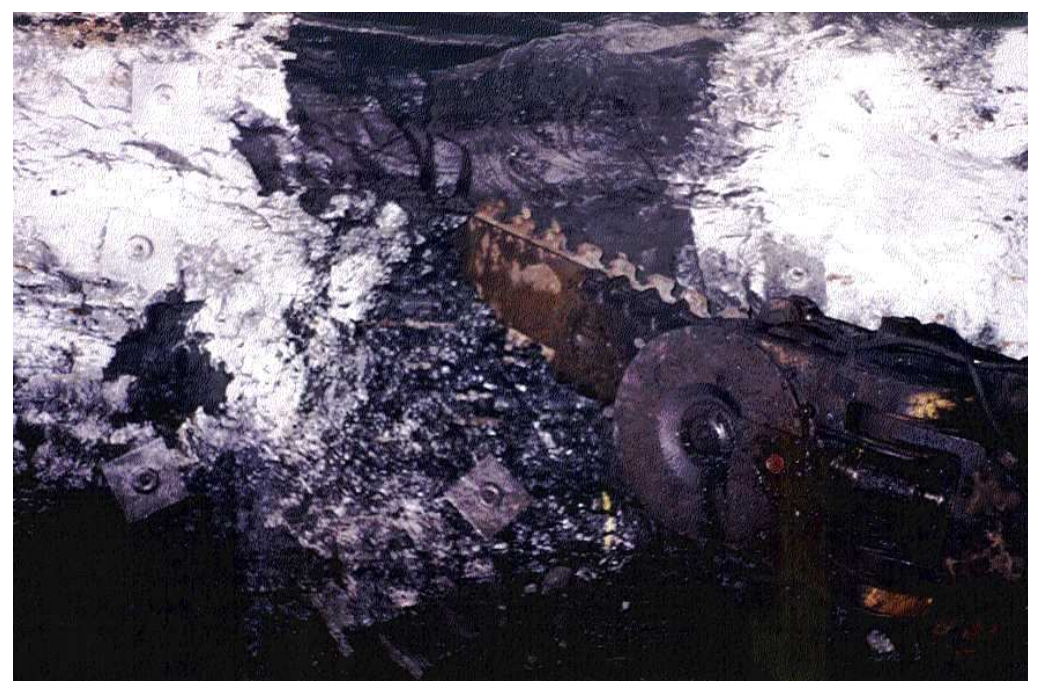

Figura A1.3 - Cortadeira em operação no corte do carvão na camada Bonito.

Figura A1.4 - Detalhe do bloco separado da camada lateralmente na parte superior da camada de carvão Bonito.
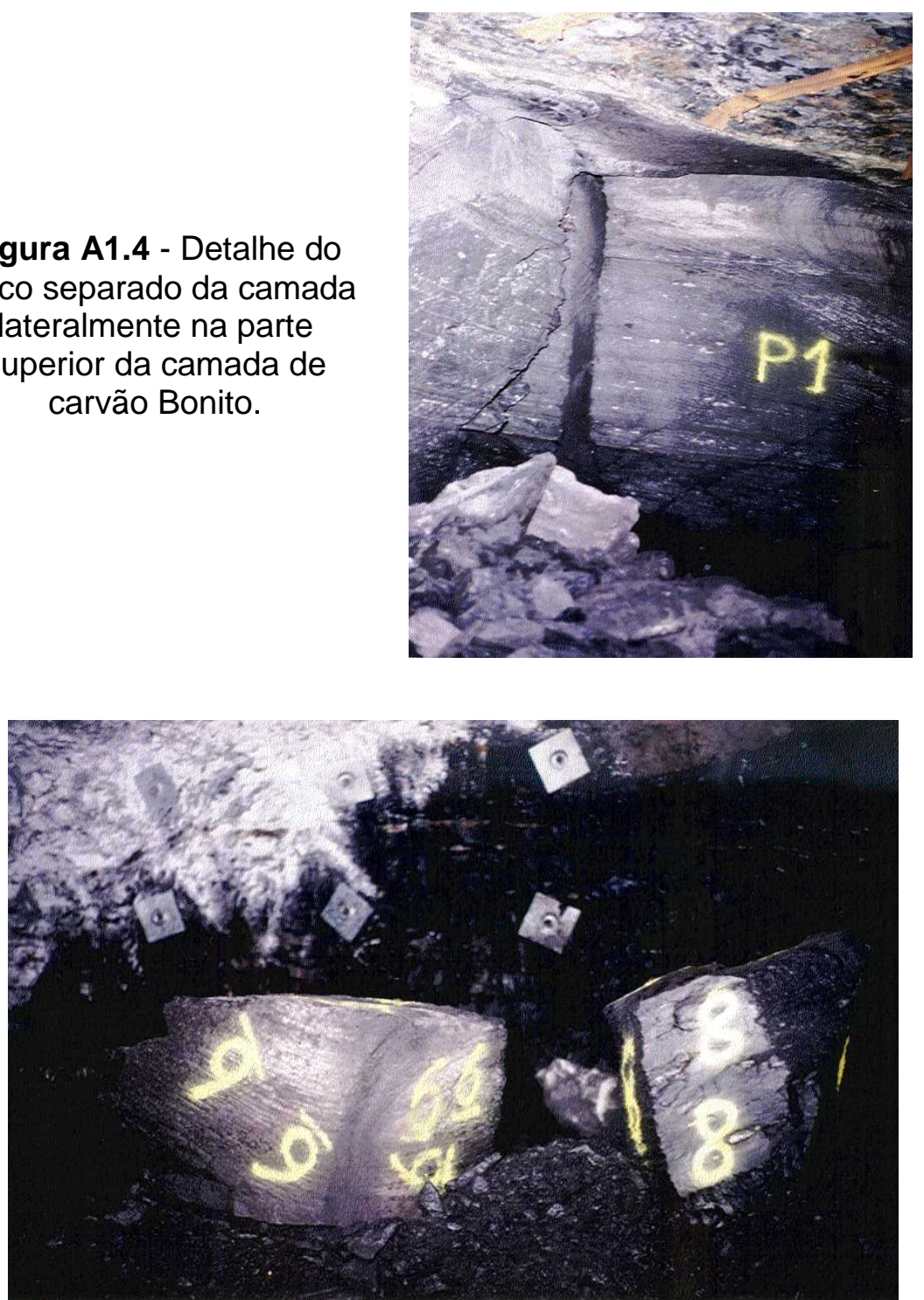

Figura A1.5 - Blocos de carvão, com cerca de $1 \mathrm{~m}^{3}$, da camada Bonito coletados no Ponto 2. 


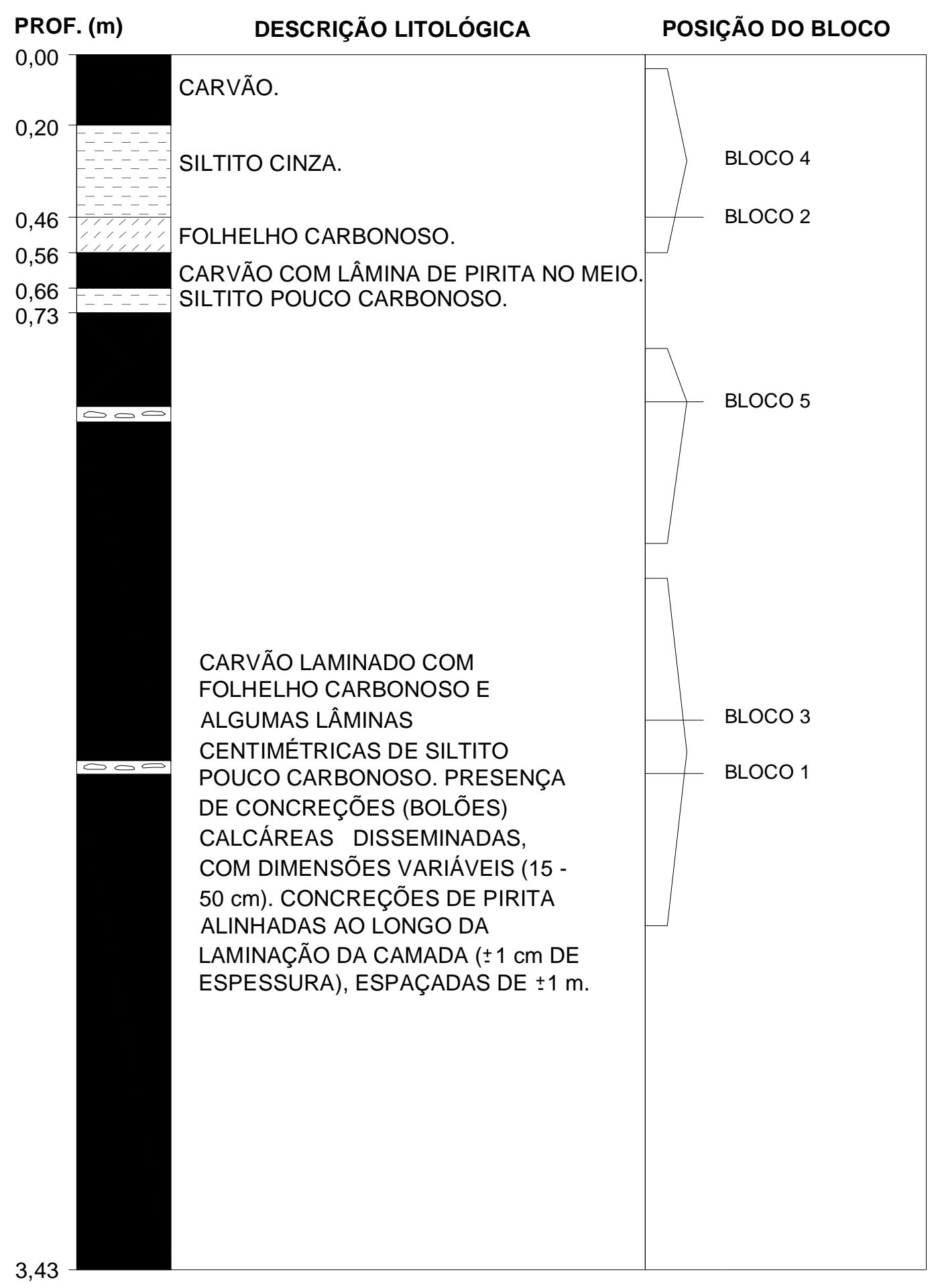

Figura A1.6a - Perfil da camada de carvão Bonito no ponto 1 de amostragem com a indicação da posição dos blocos coletados. 


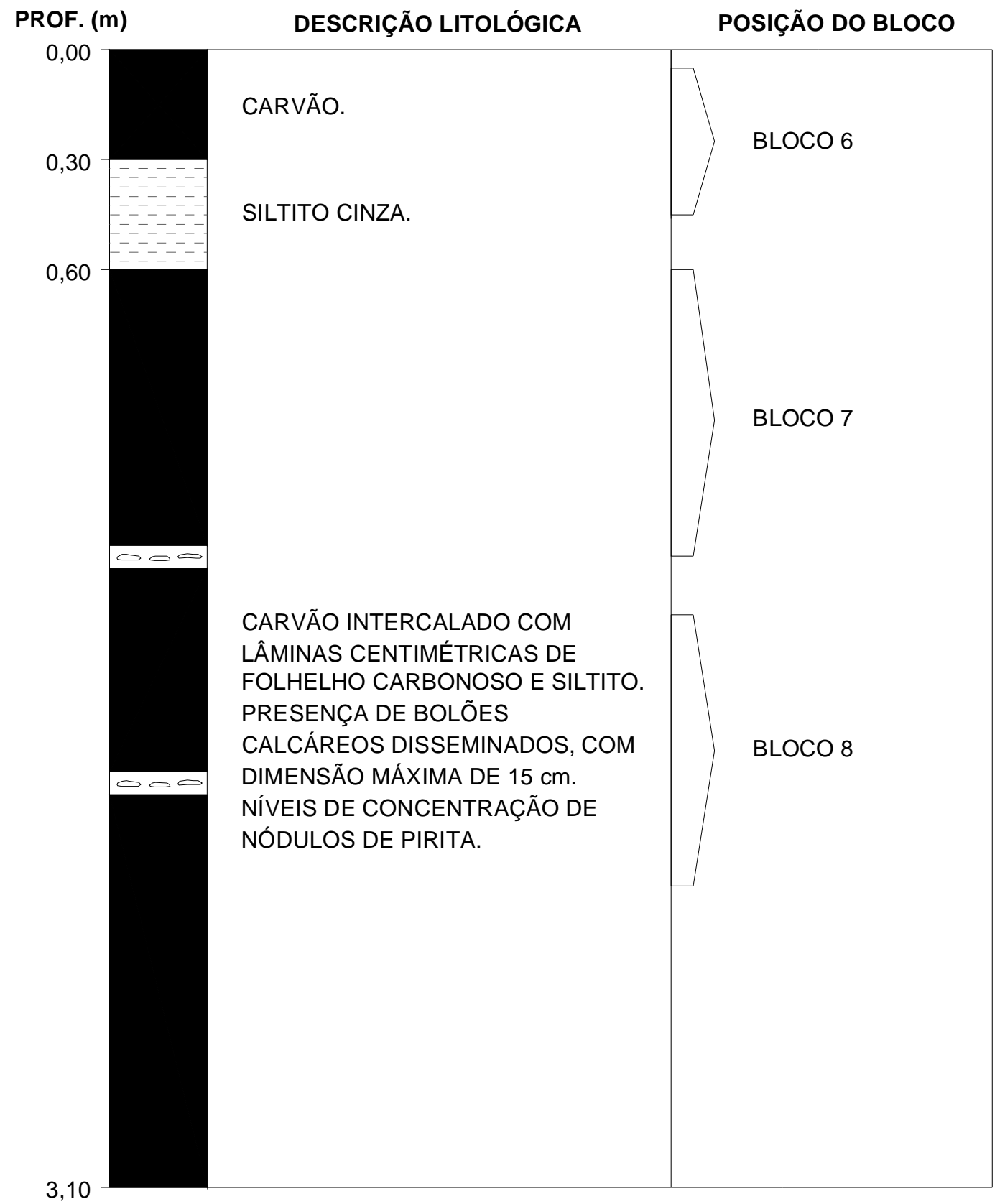

Figura A1.6b - Perfil da camada de carvão Bonito no ponto 2 de amostragem com a indicação da posição dos blocos coletados. 


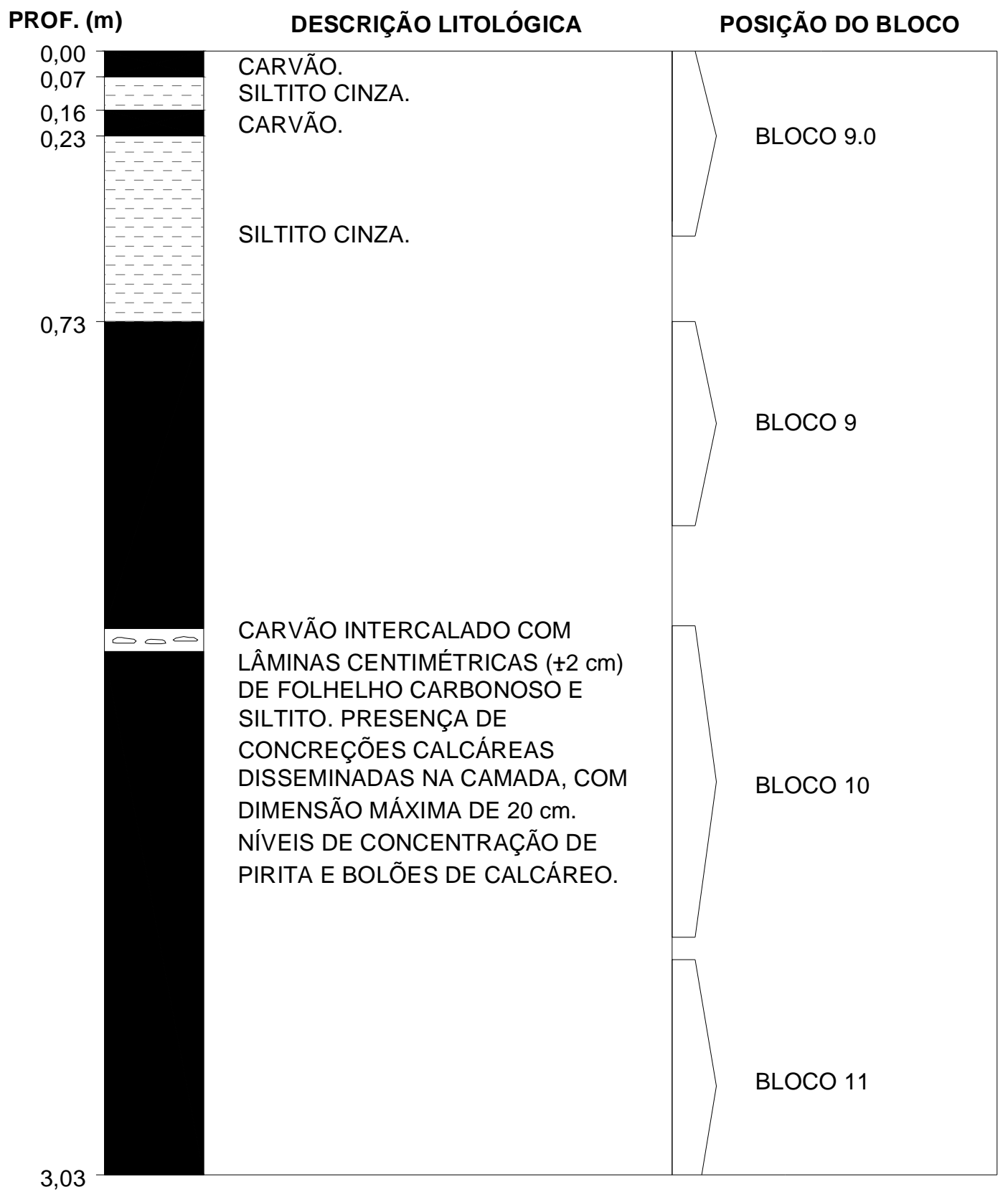

Figura A1.6c - Perfil da camada de carvão Bonito no ponto 3 de amostragem com a indicação da posição dos blocos coletados. 


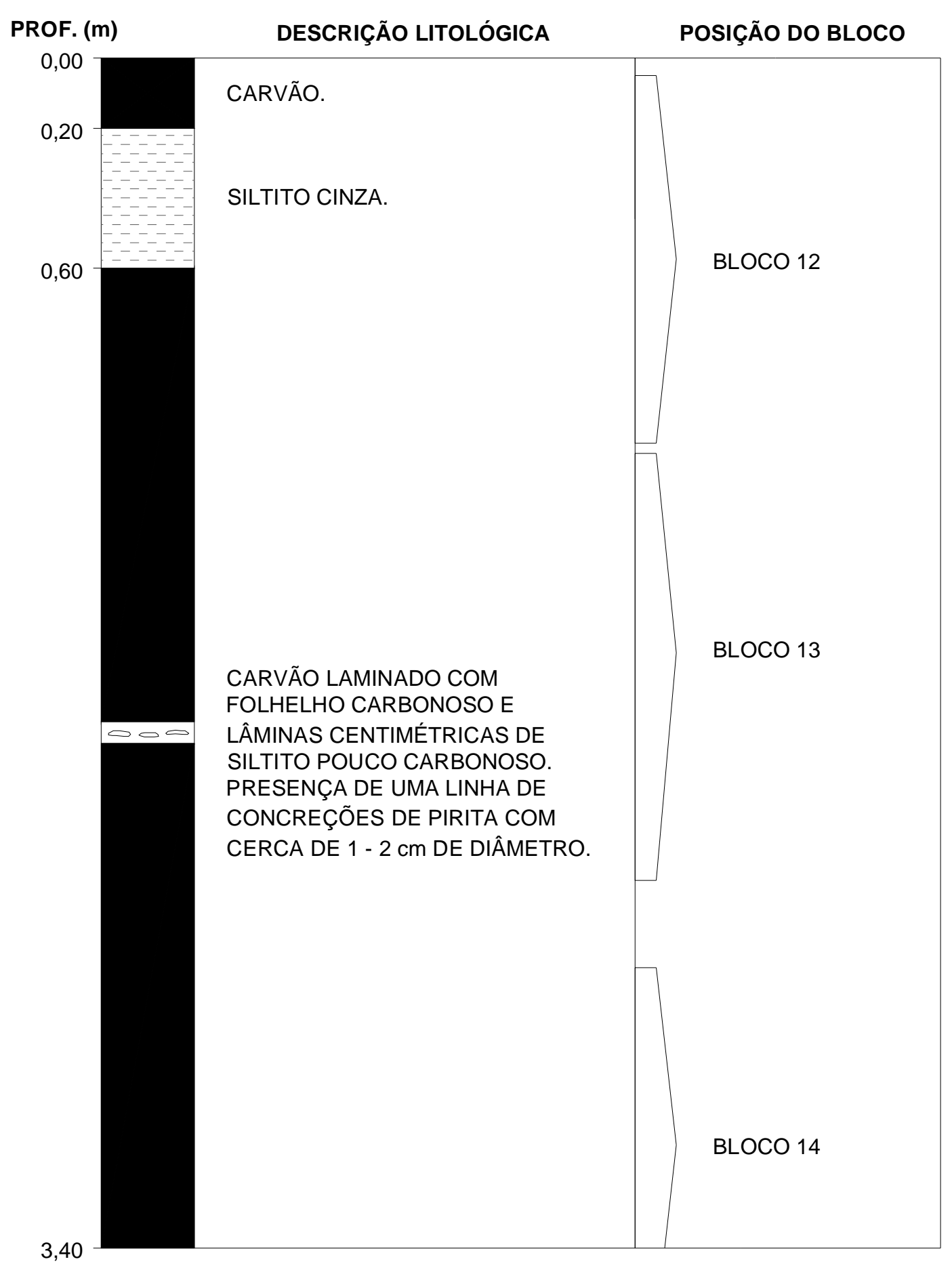

Figura A1.6d - Perfil da camada de carvão Bonito no ponto 4 de amostragem com a indicação da posição dos blocos coletados. 


\section{A1.2 Preparação dos Corpos-de-Prova}

O processo de preparação e acabamento dos corpos-de-prova, assim como a ruptura, seguiu as orientações do método sugerido pela ISRM (1999) para ensaios de compressão uniaxial com determinação da curva "tensão $x$ deformação" pós-ruptura. Para o corte foram utilizadas serras diamantadas, enquanto o acabamento das faces de aplicação das cargas final foi feito com o emprego de uma retífica de superfícies planas, conforme ilustrado nas Figuras A1.7 e A1.8.

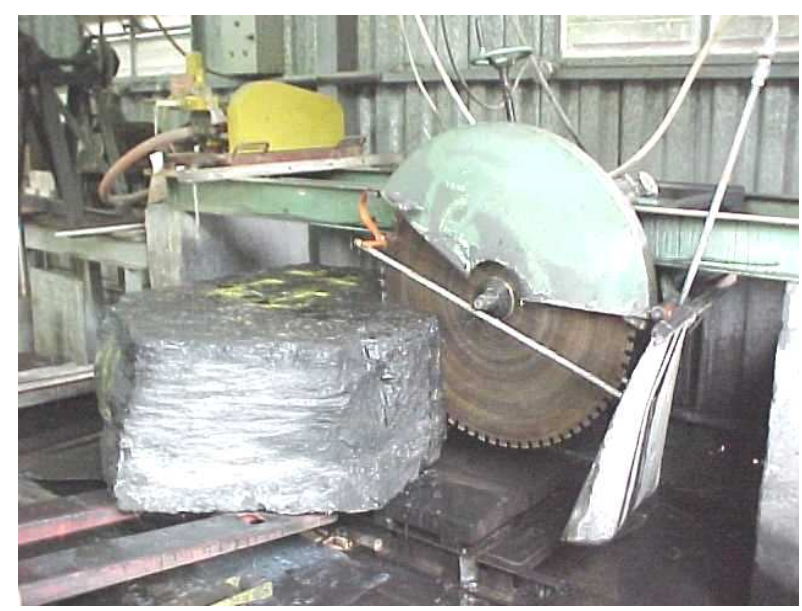

a)

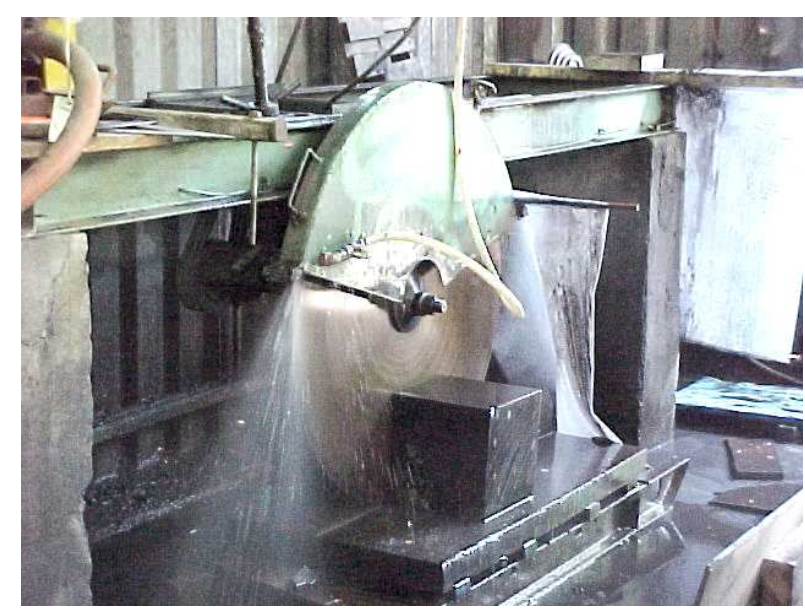

b)

Figura A1.7 - a) Serra de grande porte utilizada para o desmembramento dos blocos de carvão amostrados; b) Corte final em cubo com lado de $30 \mathrm{~cm}$.

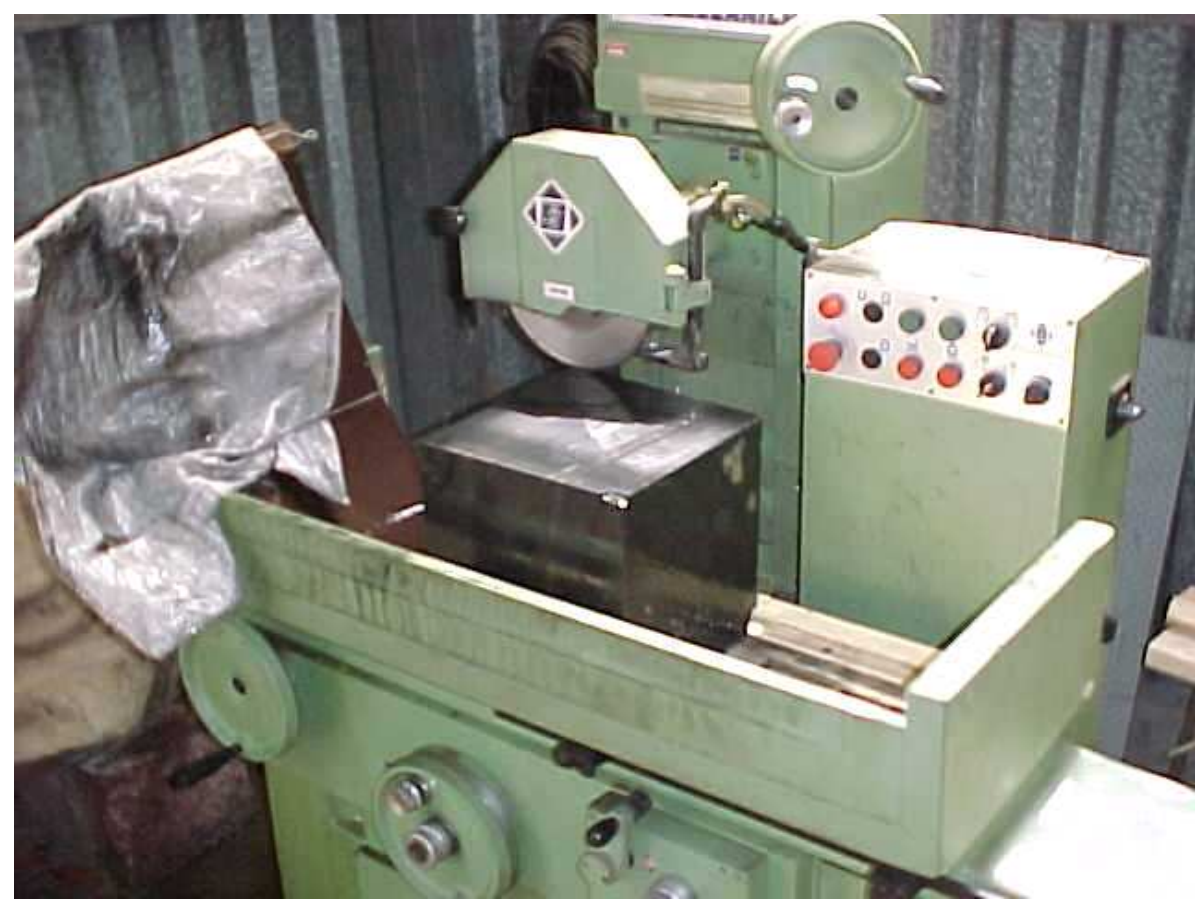

Figura A1.8 - Retífica de superfícies planas utilizada para o acabamento das faces de aplicação das cargas. 
O plano de trabalho com as quantidades de ensaios previstas nas diferentes dimensões de corpo-de-prova pode ser visto na Tabela A1.1.

Tabela A1.1 - Quantidades de ensaios previstas para as amostras de carvão em cada ponto de amostragem na camada Bonito, na Mina Fontanella.

\begin{tabular}{|l|c|}
\hline \multicolumn{1}{|c|}{ Dimensões dos Corpos-de-Prova } & Quantidade \\
\hline CUBOS de $30 \mathrm{~cm} \times 30 \mathrm{~cm} \times 30 \mathrm{~cm}$ & 7 \\
\hline CUBOS de $20 \mathrm{~cm} \times 20 \mathrm{~cm} \times 20 \mathrm{~cm}$ & 7 \\
\hline CUBOS de $10 \mathrm{~cm} \times 10 \mathrm{~cm} \times 10 \mathrm{~cm}$ & 10 \\
\hline CUBOS de $5 \mathrm{~cm} \times 5 \mathrm{~cm} \times 5 \mathrm{~cm}$ & 10 \\
\hline
\end{tabular}

As quantidades efetivamente realizadas, porém, nem sempre puderam ser atingidas durante o processo de preparação. $O$ material de alguns pontos de amostragem (pontos 1 e 4 , principalmente) se mostrou muito frágil, devido à presença de grande quantidade de descontinuidades, como pode ser observado nas Figuras A1.9 e A1.10, o que acabou ocasionando freqüentes quebras durante o processo de preparação. Em alguns casos, um bloco inteiro de amostra não permitiu a preparação de nenhum corpo-de-prova.

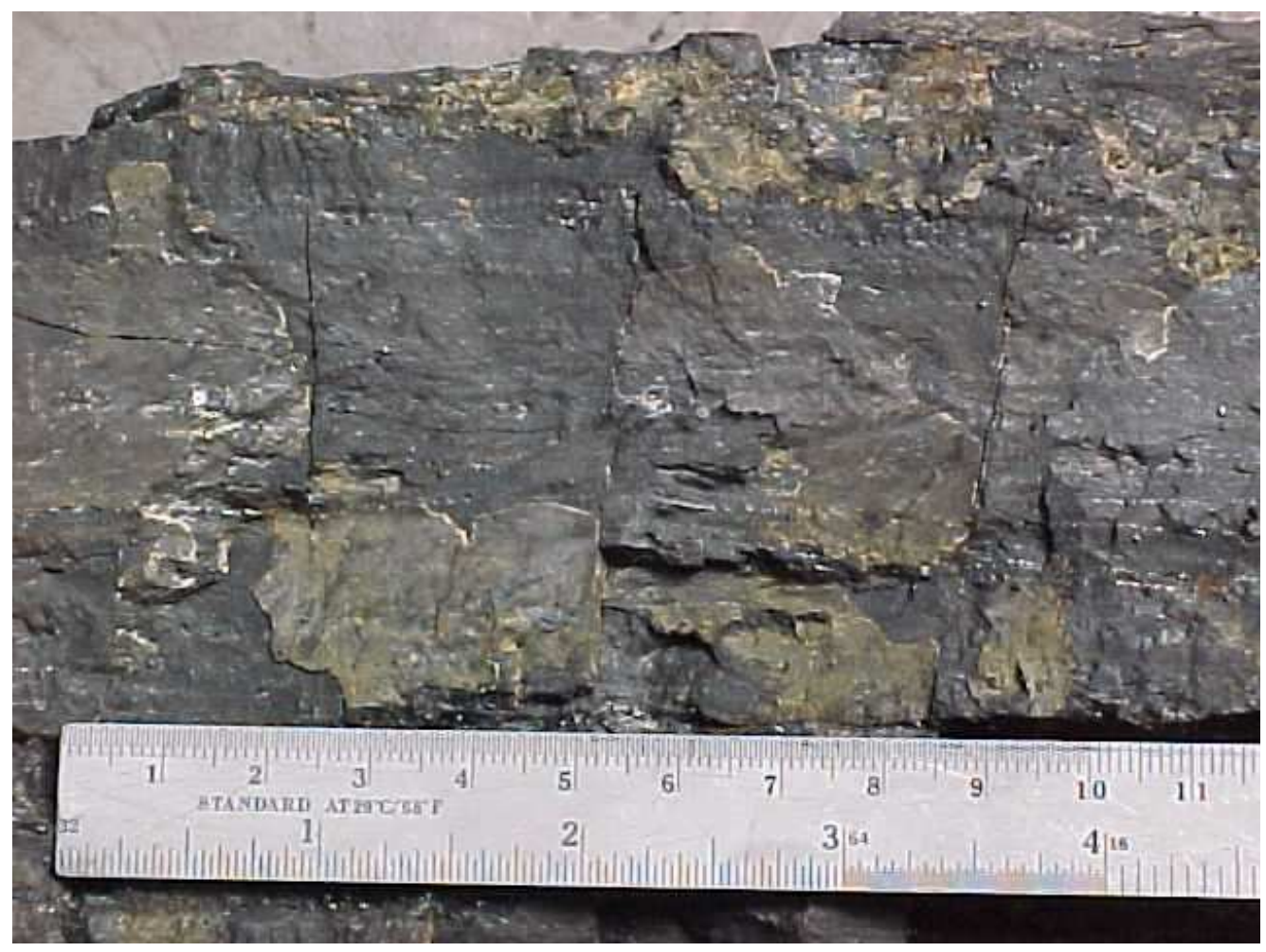

Figura A1.9 - Detalhe das fraturas (cleats) com espaçamento inferior a $10 \mathrm{~cm}$, presentes nas amostras do ponto 4. 


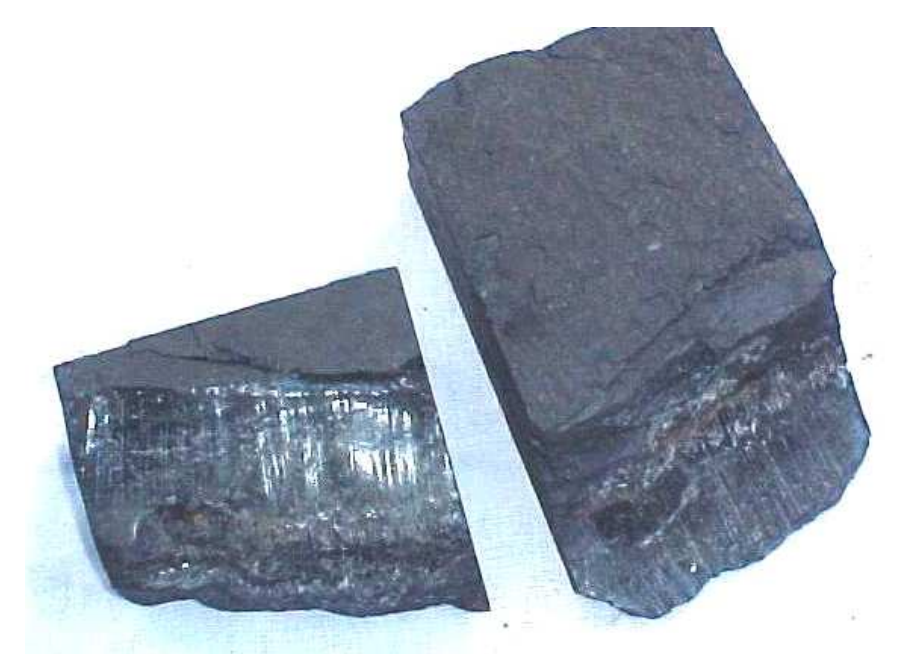

Figura A1.10 - Fratura tipo "slikenside" presente nas amostras coletadas para ensaios em laboratório.

Após o processo de acabamento e identificação dos corpos-de-prova, foram determinados a geometria, a massa e o tempo de percurso da onda ultra-sônica compressional (onda P) na direção dos três eixos do corpo-de-prova (largura, profundidade e altura), conforme mostra 0 desenho esquemático da Figura A1.11a. Para a medição do tempo de percurso da onda ultra-sônica foi utilizado um equipamento PUNDIT - Portable Ultrasonic Non-Destructive Digital Indicating Tester, modelo Mark V da C. N. S. Eletronics LTD, seguindo-se os procedimentos de ensaio recomendados pela ISRM (1978a). Geofones com diferentes freqüências de ressonância $(54 \mathrm{kHz}, 200 \mathrm{kHz}, 500 \mathrm{kHz}$ e $1 \mathrm{MHz})$ foram utilizados para atender as especificações de extensão infinita de percurso da onda em relação ao seu comprimento, em função dos diferentes tamanhos de corpos-deprova ensaiados. Para a medição do tempo de percurso da onda $\mathrm{P}$, os geofones foram posicionados no centro da face, adotando-se a técnica de transmissão do pulso, ou seja, com os geofones localizados em faces opostas do corpo-de-prova cúbico, como mostra a Figura A1.11b. Já a massa específica aparente natural e a umidade (medida após o ensaio) dos corpos-de-prova foram determinadas segundo o método sugerido pela ISRM (1979a). A determinação do teor de cinzas também foi feita após o ensaio, segundo procedimentos previstos na norma ABNT NBR 8289 (1983).

Antes da ruptura, os corpos-de-prova foram submetidos a uma investigação criteriosa, sendo descritas, detalhadamente, as descontinuidades e inclusões de outros materiais, além do material carbonoso. $O$ roteiro com os critérios utilizados na descrição é apresentado na Tabela A1.2. A visualização dos diferentes aspectos codificados foi feita utilizando-se como base o diagrama de um cubo com as 6 faces abertas. Sobre cada uma das faces foram desenhadas as principais estruturas observadas (fraturas, inclusões de pirita, lâminas de vitrênio, etc.).

As Figuras A1.12a a A1.12d apresentam descrições típicas de corpos-de-prova representativos dos diferentes tamanhos ensaiados. A Tabela A1.3, por sua vez, apresenta a descrição codificada de todos os corpos-de-prova que foram levados à ruptura. Já a Figura $\mathrm{A} 1.13$ mostra um conjunto de corpos-de-prova cúbicos com dimensões entre $5 \mathrm{~cm}$ e $30 \mathrm{~cm}$ prontos para ensaio. 


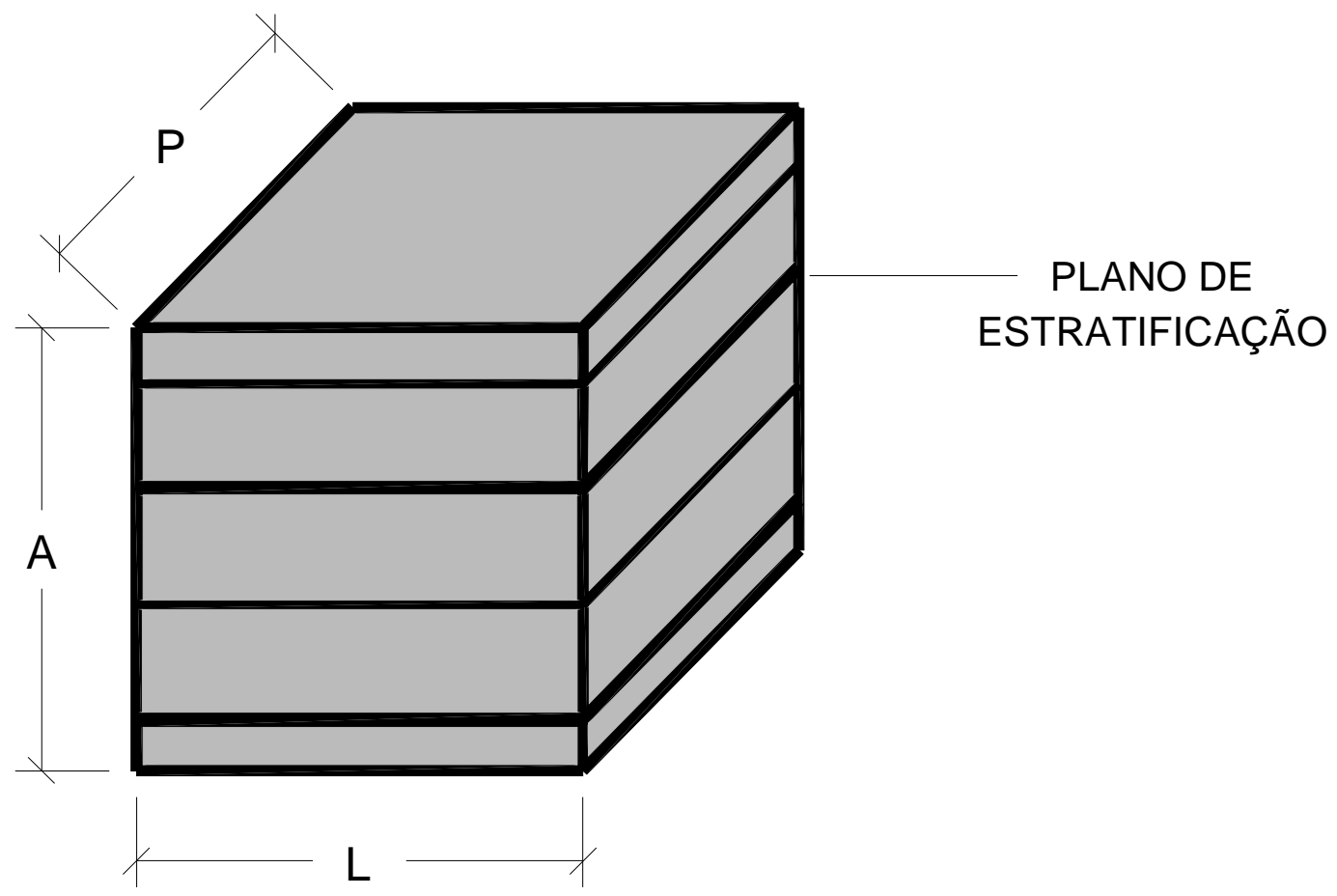

Figura A1.11a - Direções de medição da velocidade de ondas ultra-sônicas nos corposde-prova cúbicos de carvão (A - direção de propagação da onda perpendicular aos planos de estratificação; $\mathbf{L}$ e $\mathbf{P}$ - direção de propagação da onda paralela aos planos de estratificação).

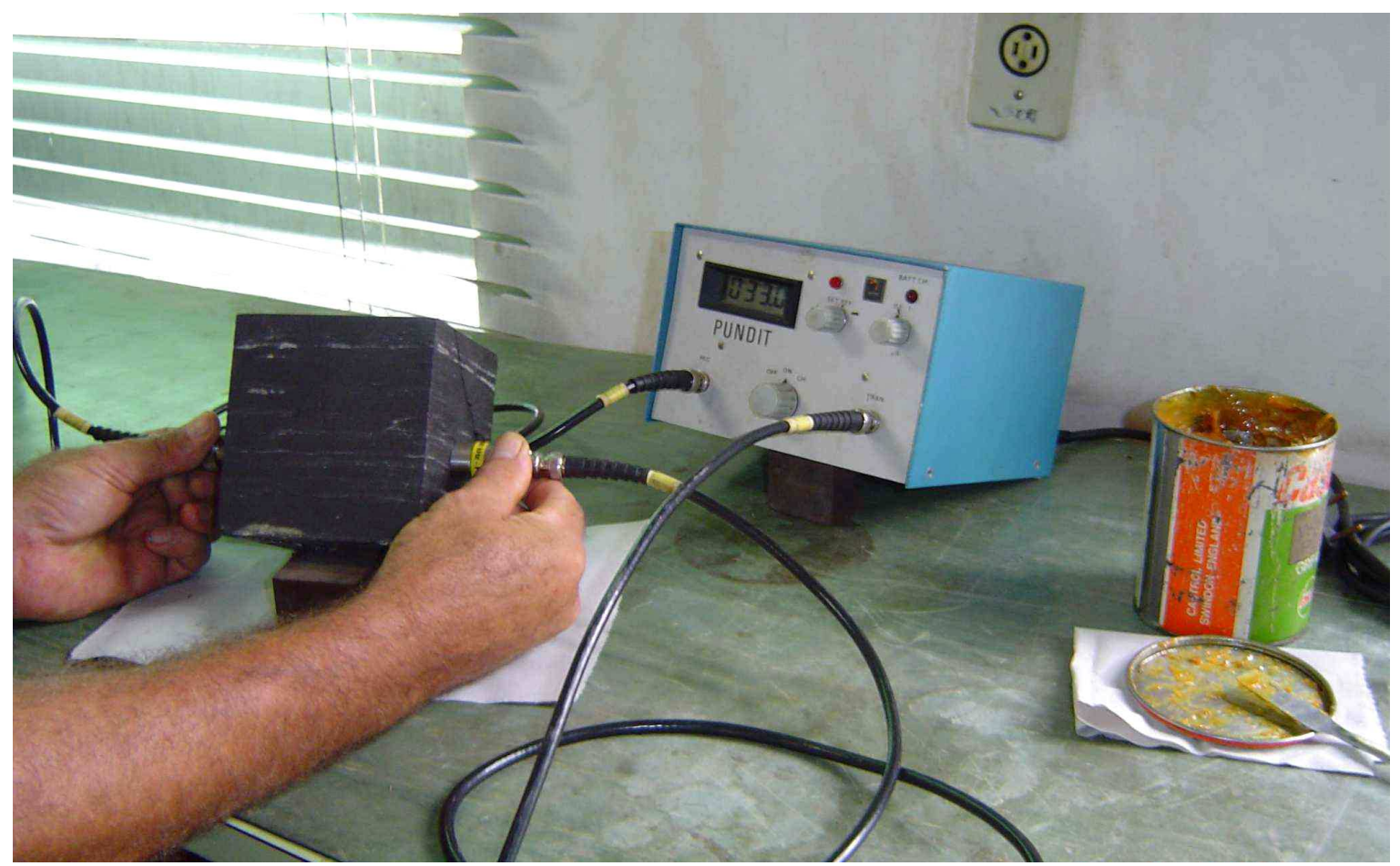

Figura A1.11b - Equipamento PUNDIT utilizado para a medição da velocidade ultrasônica. No detalhe, determinação da velocidade da onda $P$ na direção da largura do corpo-de-prova utilizando geofone com freqüência de $200 \mathrm{kHz}$ - direção de propagação da onda paralela aos planos de estratificação da camada de carvão. 


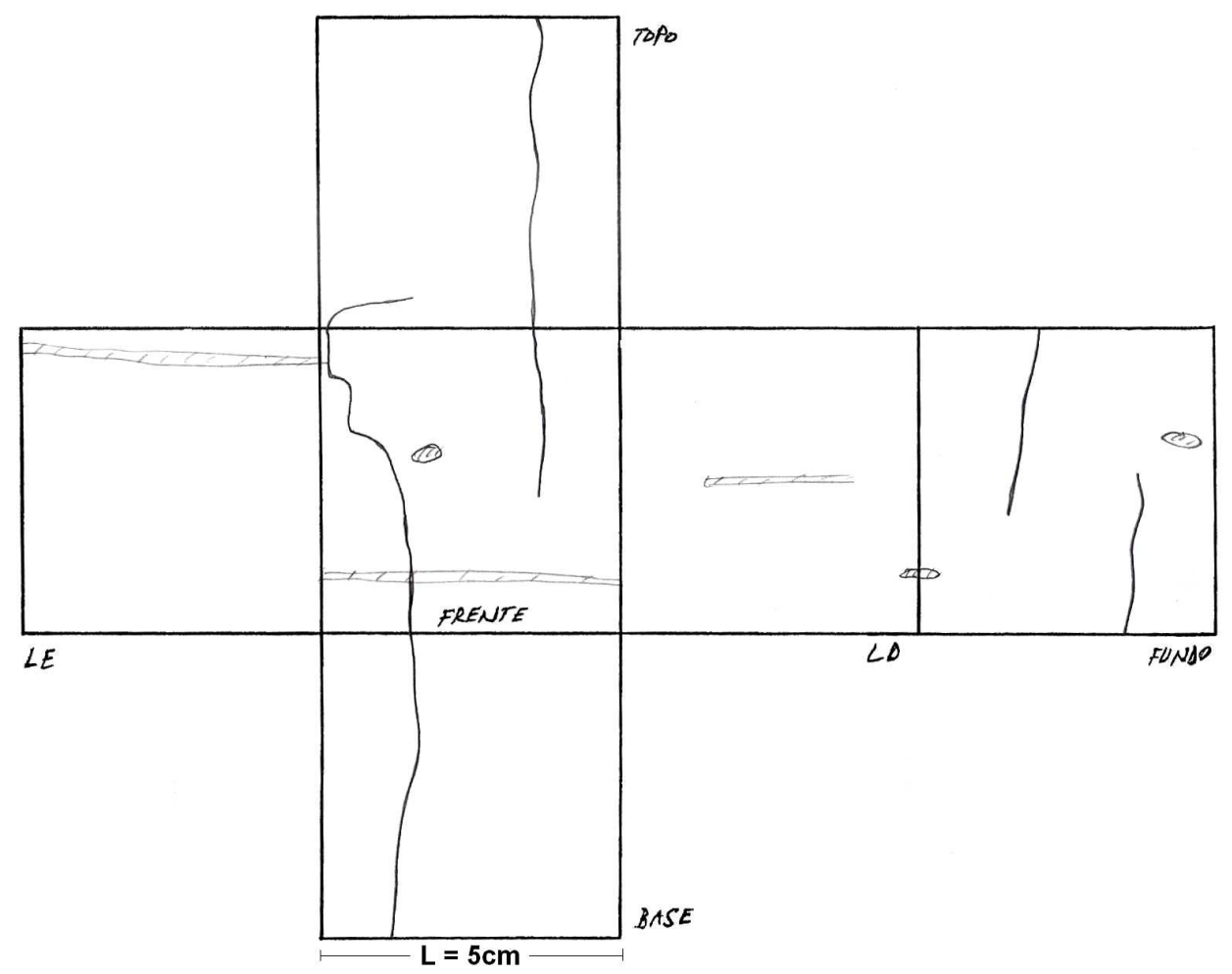

Figura A1.12a - llustração das fraturas e inclusões presentes no corpo-de-prova 15 (código de descrição macroscópica: D2----G1121G3337H4332033I0J0).

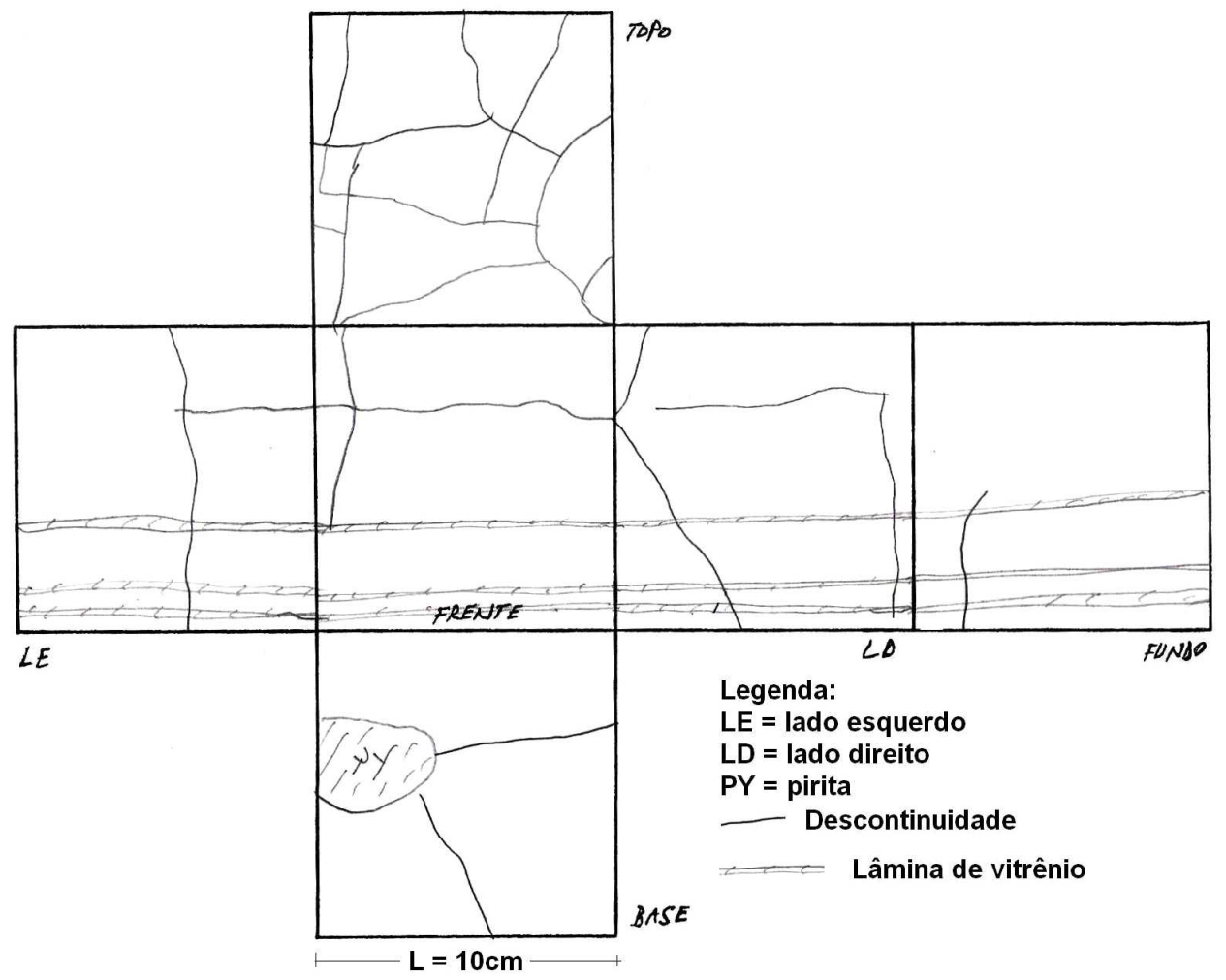

Figura A1.12b - llustração das fraturas e inclusões presentes no corpo-de-prova 32 (código de descrição macroscópica: D2---43G1121G3351H4434033I0J0). 


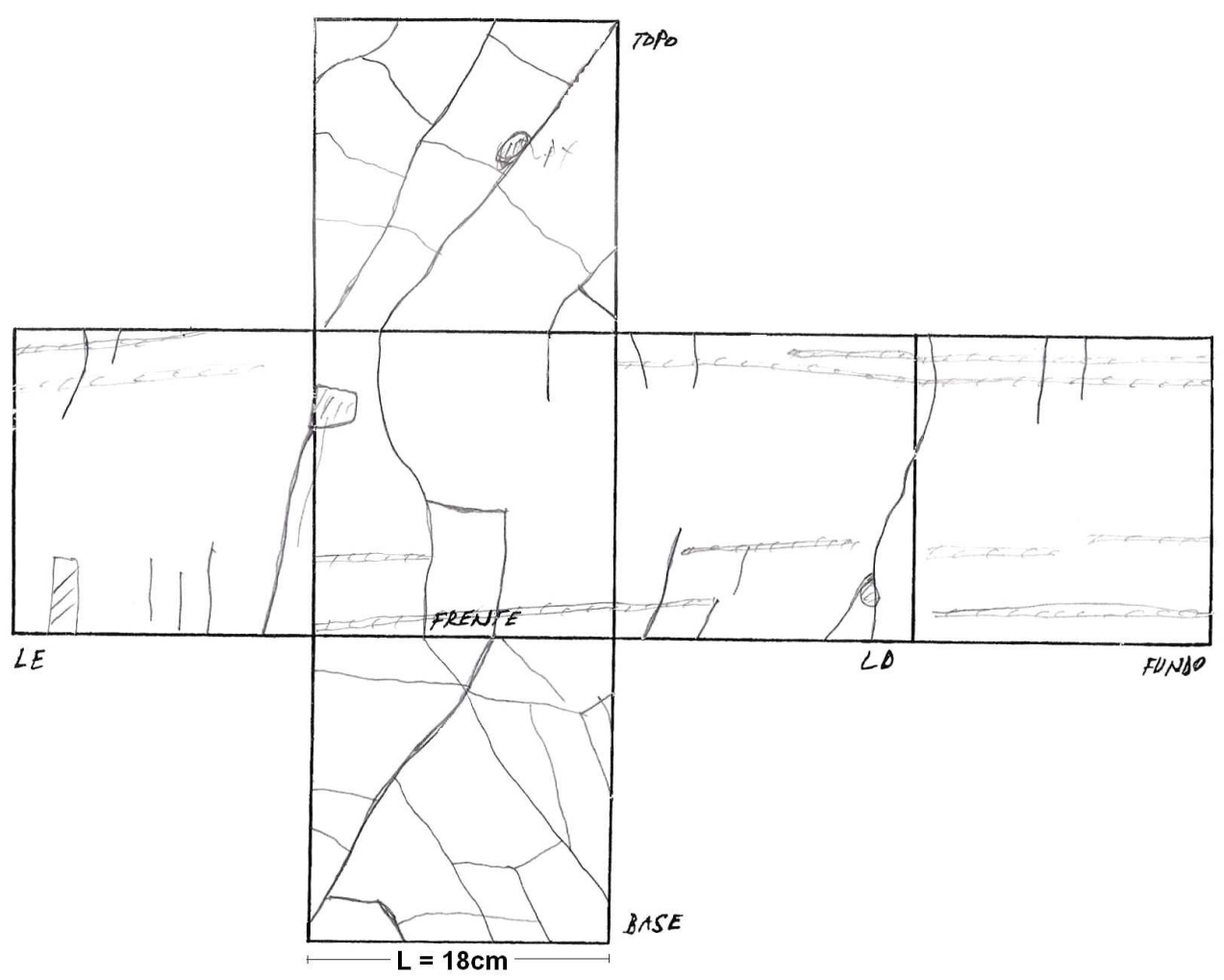

Figura A1.12c - Ilustração das estruturas presentes no corpo-de-prova 60 (código de descrição macroscópica: D2---53G1121G3346H4332041H4315032I43120J0).

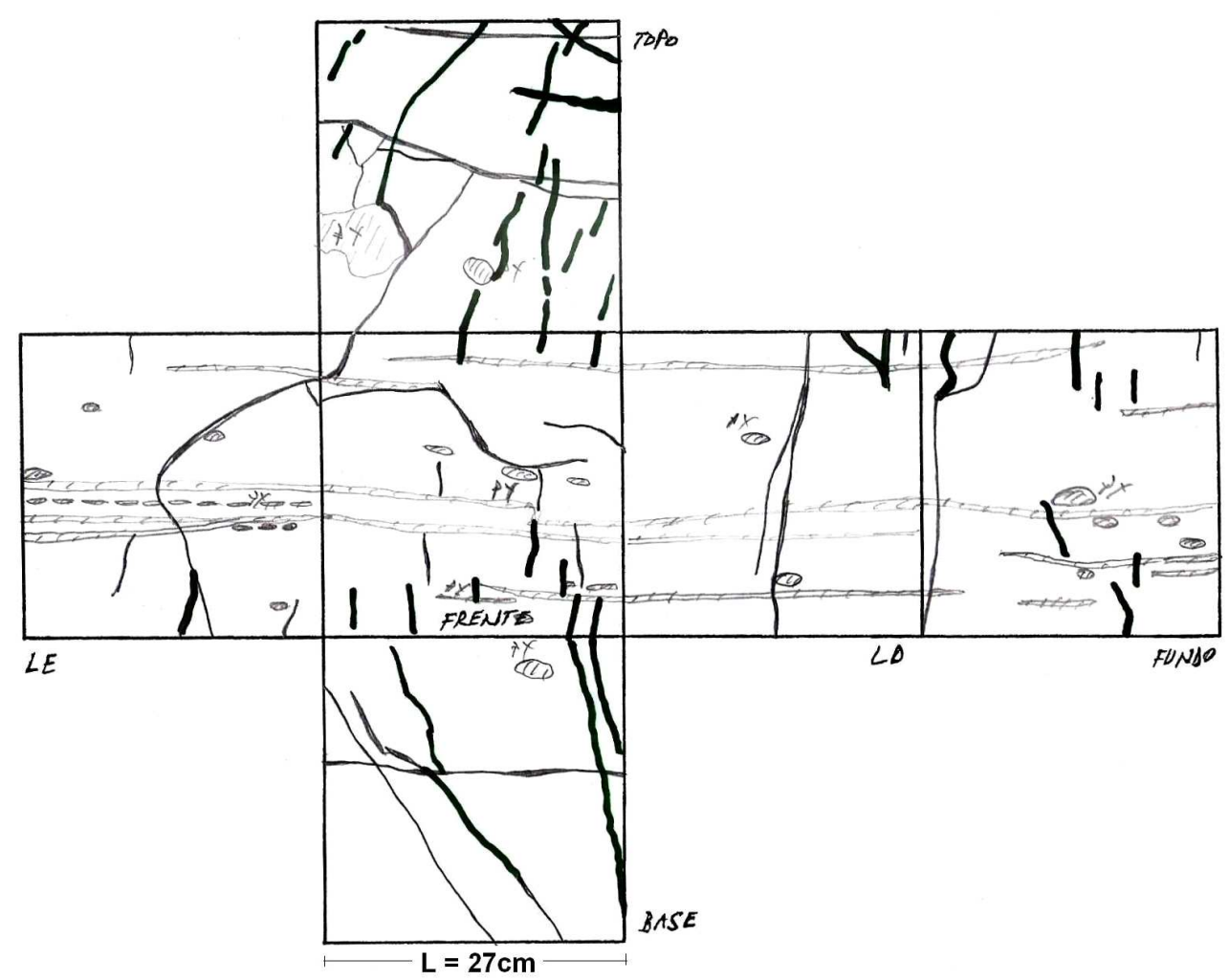

Figura A1.12d - llustração das fraturas e inclusões presentes no corpo-de-prova 18 (código de descrição macroscópica: D2---53G1121G3357H4331041H1315133I0J0). 
Tabela A1.2 - Critérios utilizados para a descrição macroscópica dos corpos-de-prova de carvão (ZORZI et al., 1990).

\begin{tabular}{|c|c|c|c|c|c|c|}
\hline & & & $\begin{array}{c}\text { CARVÃO } \\
\text { DETRÍTICO }\end{array}$ & & D & $\begin{array}{l}\text { 2. FOSCO - MACICO } \\
\text { 4. BRILHANTE - ESTRATIFICADO }\end{array}$ \\
\hline & & TIPO & ESTÉRIL & $E$ & TIPO & \begin{tabular}{|l|} 
1. FOLHELHOO \\
2. SILTITO \\
3. ARENITO \\
\end{tabular} \\
\hline & & & & & QUALIDADE & $\begin{array}{l}\text { 1. NAO CARBONOSO } \\
\text { 3. CARBONOSO }\end{array}$ \\
\hline & MATRIZ & ESP & $\begin{array}{r}\text { SURA DO CC } \\
\text { BAN } \\
\text { carvão entre }\end{array}$ & $\begin{array}{l}\mathrm{RPC} \\
\mathrm{A} N \\
\text { s lâ }\end{array}$ & $\begin{array}{l}\text { DE-PROVA OU DA } \\
\text { EIA } \\
\text { inas de vitrênio) }\end{array}$ & $\begin{array}{l}1.1,0 \mathrm{a} 2,0 \mathrm{~cm} \\
\text { 2. } 2,1 \mathrm{a} 4,0 \mathrm{~cm} \\
3.4,1 \mathrm{a} 6,0 \mathrm{~cm} \\
4.6,1 \mathrm{a}, 0 \mathrm{~cm} \\
5.8,1 \mathrm{a} 10,0 \mathrm{~cm} \\
6.10,1 \mathrm{a} 15,0 \mathrm{~cm} \\
7.15,1 \mathrm{a} 20,0 \mathrm{~cm} \\
8 .>20,0 \mathrm{~cm} \\
\end{array}$ \\
\hline & & & BAND & EAN & NTO & $\begin{array}{l}\text { 1. ESPARSO } \leq 15 \% \\
\text { 2. MODERAD } 16 \text { a } 30 \% \\
\text { 3. ABUNDANTE } 31 \text { a } 50 \%\end{array}$ \\
\hline $\begin{array}{l}\text { COMPOSIÇÃO } \\
\text { DOS LEITOS }\end{array}$ & & & & & TIPO & $\begin{array}{l}\text { 1. VITRENIO } \\
\text { 2. PULSENIO } \\
\text { 3. PIRTA } \\
\text { 4. CARBONATO } \\
\text { 5. SILICATO } \\
\text { 6. ARGILA } \\
\text { 7. MATERIA CARBONOSA }\end{array}$ \\
\hline & & & & & FORMA & $\begin{array}{l}\text { 1. LÁMINAS } \\
\text { 2. LENTES } \\
\text { 3. NÓDULOS } \\
\text { 5. IRREGULAR } \\
\end{array}$ \\
\hline & & INCLUS & ES & $G$ & ESPESSURA & $\begin{array}{l}\text { 1. }<0,5 \mathrm{~mm} \\
\text { 2. } 0,5 \mathrm{a} 2,0 \mathrm{~mm} \\
\text { 3. } 2,1 \text { a } 5,0 \mathrm{~mm} \\
\text { 4. } 5,1 \mathrm{a} 10,0 \mathrm{~mm} \\
5.10,1 \mathrm{a} 20,0 \mathrm{~mm} \\
6.20,1 \mathrm{a} 60,0 \mathrm{~mm} \\
\end{array}$ \\
\hline & & & & & CONCENTRAÇÃO & $\begin{array}{l}\text { 1. RARAS }<5,0 \% \\
\text { 2. ESPARSA } 5,0 \text { a } 15 \% \\
\text { 3. MODERADAS } 15,1 \% \text { a } 30 \% \\
\text { 4. ABUNDATES } 30,1 \% \% \text { a } 60 \% \\
\text { 5. DOMINANTES }>60 \%\end{array}$ \\
\hline & & & & & $\begin{array}{l}\text { CONCENTRAÇÃO } \\
\text { PARA PIRITAS }\end{array}$ & $\begin{array}{l}\text { 6. OCASIONAL <6\% } \\
\text { 7. DISSEMINADA ESPARSA } \\
\text { 8. DISSEMINADA CONCENTRADA } \\
\text { 9. ZONEADA }\end{array}$ \\
\hline & & & & & TIPO & $\begin{array}{l}\text { 1. CLEAT } \\
\text { 2. FISSURA } \\
\text { 4. FRATURA } \\
\text { 5. SLIKENSIDE }\end{array}$ \\
\hline & & & & & ORIENTAÇÃO & $\begin{array}{l}\text { 1. HORIZONTAL } \\
\text { 2. OBLIOUA } \\
\text { 3. VERTICAL } \\
\text { 4. IRREGULAR }\end{array}$ \\
\hline & & & & & PERSISTÊNCIA & $\begin{array}{l}\text { 1. AREA/4 } \\
\text { 2. AREA/2 } \\
\text { 3. AREA }\end{array}$ \\
\hline & & ZATURA & ENTO & $\mathrm{H}$ & QUANTIDADE & $\begin{array}{ll}1 \text { a } 8 \\
9+\text { de } 8 \\
\end{array}$ \\
\hline & & & & & PREENCHIMENTO & $\begin{array}{l}\text { 0. NĀO TEM } \\
\text { 1. CARBONATOS } \\
\text { 2. ARGILAS } \\
\text { 3. PIRITAS }\end{array}$ \\
\hline & & & & & ESPAÇAMENTO & $\begin{array}{l}\text { 1. PEQUENO <10mm } \\
\text { 2. MODERADO } 10 \mathrm{a} 20 \mathrm{~mm} \\
\text { 3. GRANDE } 20,1 \mathrm{a} 60 \mathrm{~mm} \\
\text { 4. MUITO GRANDE }>60 \mathrm{~mm}\end{array}$ \\
\hline REGULARIDADE & & & & & ABERTURA & $\begin{array}{l}\text { 1. MARCANTE }>0,5 \mathrm{~mm} \\
\text { 2. EVIDENTE } 0,25 \text { a } 0,5 \mathrm{~mm} \\
\text { 3. PERCEPTIVEL }<0,25 \mathrm{~mm}\end{array}$ \\
\hline $\begin{array}{c}\text { DO CORPO-DE- } \\
\text { PROVA }\end{array}$ & & & & & LOCALIZAÇÃO & $\begin{array}{l}\text { 0. NAOO TEM } \\
\text { 1. VERTICE } \\
\text { 2. ARESTA VERTICAL } \\
\text { 3. ARESTA HORIZONTAL } \\
\text { 4. LADOS } \\
\text { 5. BASES }\end{array}$ \\
\hline & & & & & PROFUNDIDADE & $\begin{array}{l}\text { 1. } \leq 2,0 \mathrm{~mm} \\
\text { 2. } 2,1 \text { a } 5,0 \mathrm{~mm} \\
\text { 3. } 5,1 \text { a } 10,0 \mathrm{~mm} \\
\text { 4. } \geq 10,1 \mathrm{~mm}\end{array}$ \\
\hline & & ASCAN & NTO & 1 & ÁREA & $\begin{array}{l}\text { 1. AREA/32 } \\
\text { 2. ÁREA/16 } \\
\text { 3. ÁREA } / 8 \\
\text { 4. ÁREA/4 } \\
\text { 5. ÁREA/2 } \\
\text { 6. ÁREA } \\
\end{array}$ \\
\hline & & & & & QUANTIDADE & $\begin{array}{l}1 \text { a } 8 \\
9+\text { de } 8 \\
\end{array}$ \\
\hline & & & & & PREENCHIMENTO & $\begin{array}{l}\text { 0. NÃO TEM } \\
\text { 1. PRÓPRIO MATERIAL } \\
\text { 2. DUREPOXI/ARALDITE } \\
\end{array}$ \\
\hline & & A I & ? & 1 & TIPO & $\begin{array}{l}\text { 0. NÁO TEM } \\
\text { 1. ENXOFRE } \\
\end{array}$ \\
\hline & & JAF & NIO & $\mathrm{J}$ & LOCALIZAÇÃO & $\begin{array}{l}\text { 1. BASE } \\
\text { 2. BASE E TOPO }\end{array}$ \\
\hline
\end{tabular}


Tabela A1.3 - Descrição macroscópica codificada de todos os corpos-de-prova ensaiados.

\begin{tabular}{|c|c|c|}
\hline $\begin{array}{l}\mathrm{N}^{\circ} \\
\mathrm{CP}\end{array}$ & Codificação & Observações \\
\hline 1 & D2---43G1121G3249G3349H4232041I53120J0 & Ponto 1 \\
\hline 2 & D2---23G3359H433204110J0 & Ponto 1 \\
\hline 4 & D2---31G1121H2231043I0J0 & Ponto 1 \\
\hline 5 & D2---31G1122H4331043H4221043IOJ0 & Ponto 1 \\
\hline 6 & D2---31G1121H2222043I0J0 & Ponto 1 \\
\hline 32 & D2---43G1121G3351H4434033I0J0 & Ponto 1 \\
\hline 33 & D2---43G1121G3357H4334032I0J0 & Ponto 1 \\
\hline 34 & D2---33G1121G3158H4223032I13120J0 & Ponto 1 \\
\hline 35 & D2---43G1121G3366H4233031H4331041153210J0 & Ponto 1 \\
\hline 36 & D2---33G3357H4422033I0J0 & Ponto 1 \\
\hline 38 & D2---33G1121H4330143I0J0 & Ponto 1 \\
\hline 39 & D2---33G1121G3231H4311043I53110J0 & Ponto 1 \\
\hline 40 & D2---33G1121G3348H4331043I0J0 & Ponto 1 \\
\hline 41 & D2---31G1121G3239H4221043I51110 & Ponto 1 \\
\hline 42 & D2---23G1121G3236I0J0 & Ponto 1 \\
\hline 43 & D2---23G1121G3336I0J0 & Ponto 1 \\
\hline 44 & D2---21G1131G3149I0J0 & Ponto 1 \\
\hline 45 & D2---23G1121G3149H4331342I0J0 & Ponto 1 \\
\hline 46 & D2---33G1131G3138H4332031I0J0 & Ponto 1 \\
\hline 47 & D2---33G1131G3149H333303210J0 & Ponto 1 \\
\hline 48 & D2---31G3336H4231032I0J0 & Ponto 1 \\
\hline 49 & D2---41G3346H4231043I0J0 & Ponto 1 \\
\hline 50 & D2---23G1121H4311043I0J0 & Ponto 1 \\
\hline 51 & D2---23G1121H4231043I0J0 & Ponto 1 \\
\hline 52 & D2---31H4321043I0J0 & Ponto 1 \\
\hline 53 & D2---23G1121H4232333I0J0 & Ponto 1 \\
\hline 54 & D2---73G1131G3346H4331043H4321043I0J0 & Ponto 2 \\
\hline 55 & D2---81G1121G3366H4332042H2323043I0J0 & Ponto 2 \\
\hline 56 & D2---61G1121G3236H4321043I0J0 & Ponto 2 \\
\hline 57 & D2---61G1121H2331043I0J0 & Ponto 2 \\
\hline 58 & D2---31G1121H4331042I0J0 & Ponto 2 \\
\hline 59 & D2---31G1121G3346H4331042I12110J0 & Ponto 2 \\
\hline 60 & D2---53G1121G3346H4332041H4315032I43120J0 & Ponto 2 \\
\hline 61 & D2E2143G1121G3356H4331041H4313033I14110J0 & Ponto 2 \\
\hline 62 & D2---61G1111H423204110J0 & Ponto 2 \\
\hline 63 & D2---61G1121H4231031I0J0 & Ponto 2 \\
\hline 64 & D2---51G1121G3346H4322043153120J0 & Ponto 2 \\
\hline 65 & D2---51H4332042I42110J0 & Ponto 2 \\
\hline
\end{tabular}

Continua . . . 
Continuação . . .

\begin{tabular}{|c|c|c|}
\hline $\begin{array}{l}\mathrm{N}^{0} \\
\mathrm{CP}\end{array}$ & Codificação & Observações \\
\hline 7 & D2---43G1121G3347H4333042I22130J0 & Ponto 3 \\
\hline 8 & D2---43G1121G3357H4233042H2222143I0J0 & Ponto 3 \\
\hline 9 & D2---43G1121G3229H2319133I0J0 & Ponto 3 \\
\hline 10 & D2---23G1121G3357H1326123H4332042I0J0 & Ponto 3 \\
\hline 11 & D2---23G1121G3346H1331143H4332041I0J0 & Ponto 3 \\
\hline 12 & D2---63G1121G3347H1116133H4232042I0J0 & Ponto 3 \\
\hline 13 & D2---31G1121I0J0 & Ponto 3 \\
\hline 14 & D2---31G1121H1323123I0J0 & Ponto 3 \\
\hline 15 & D2---31G1121G3337H4332033I0J0 & Ponto 3 \\
\hline 16 & D2---31G1121H1332143H2332033I0J0 & Ponto 3 \\
\hline 17 & D2---43G1121G3356H1318133H4232041I33110I13110I23110J0 & Ponto 3 \\
\hline 18 & D2---53G1121G3357H4331041H1315133I0J0 & Ponto 3 \\
\hline 19 & D2---33G1131G1121G3346H1315133H4331041I13110J0 & Ponto 3 \\
\hline 20 & D2---23G1121G3236H1223133H4322042I11110J0 & Ponto 3 \\
\hline 21 & D2---43G1121G3358H1313133H4331041H4131042I0J0 & Ponto 3 \\
\hline 22 & D2---51G1121G3346H4331141I0J0 & Ponto 3 \\
\hline 23 & D2---61G3236H3132023I0J0 & Ponto 3 \\
\hline 24 & D2---43G1121G3236H4231133H4214133I0J0 & Ponto 3 \\
\hline 25 & D2---33G1121H2221043I0J0 & Ponto 3 \\
\hline 26 & D2---33G1121G3358H4332033I0J0 & Ponto 3 \\
\hline 27 & D2---23G1121H4211043/12110J0 & Ponto 3 \\
\hline 28 & D2---23G1121H1221143H4332031I0J0 & Ponto 3 \\
\hline 29 & D2---23G1121G3338H4221043H1211143I0J0 & Ponto 3 \\
\hline 30 & D2---23G1121H4221143I0J0 & Ponto 3 \\
\hline 31 & D2---23G1121G4331G4321H1231133H4321043IOJ0 & Ponto 3 \\
\hline 100 & D2---72G1121G3246H4321042I0J0 & Ponto 4 \\
\hline 101 & D2---71G1131G3352H4231041H2321143I52110J0 & Ponto 4 \\
\hline 102 & D2---61G1121G3238H433104110J0 & Ponto 4 \\
\hline 103 & D2---61G1121G3246H4331042H2222033I0J0 & Ponto 4 \\
\hline 104 & D2---61G1121G3236H4231141H2331043I0J0 & Ponto 4 \\
\hline 105 & D2---51G1121G3346H4322033I0J0 & Ponto 4 \\
\hline 106 & D2---51G1121H2323133I0J0 & Ponto 4 \\
\hline 107 & D2---41G1121G3356H423114110J0 & Ponto 4 \\
\hline 109 & D2---41G11111H4312043I0J0 & Ponto 4 \\
\hline 110 & D2---41G1121H4331041I0J0 & Ponto 4 \\
\hline 111 & D2---41G11111H2331043I0J0 & Ponto 4 \\
\hline 112 & D2---31G1111H2331043I0J0 & Ponto 4 \\
\hline 113 & D2---31G1121G3236H4332042I0J0 & Ponto 4 \\
\hline 114 & D2---G1121G3537H4231342I52240J0 & Ponto 4 \\
\hline
\end{tabular}




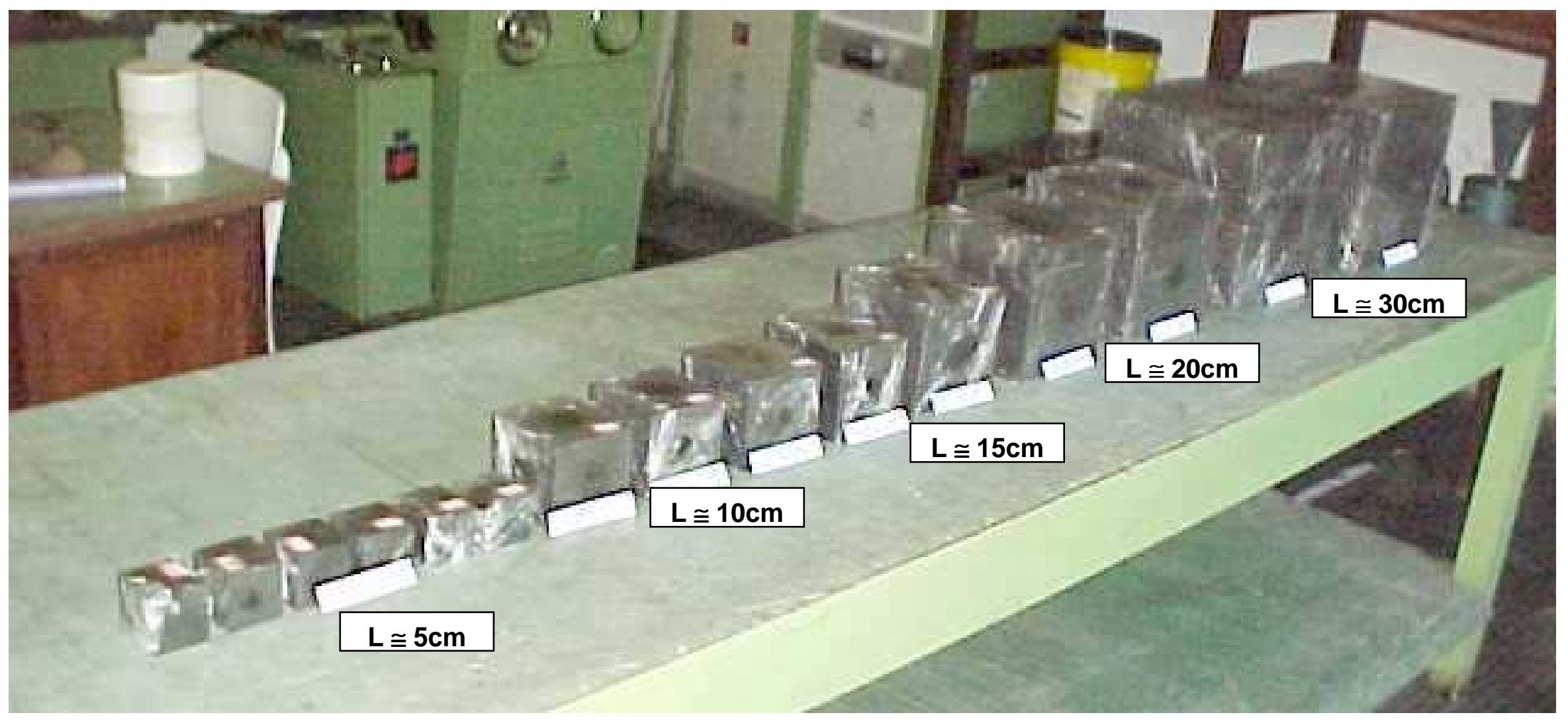

Figura A1.12 - Corpos-de-prova cúbicos de carvão da camada Bonito da Mina Fontanella, com a dimensão do lado (L) variando entre $5 \mathrm{~cm}$ e $30 \mathrm{~cm}$, prontos para ensaio de compressão uniaxial. 


\section{A1.3 Execução dos Ensaios}

Para a ruptura à compressão uniaxial dos corpos-de-prova foi utilizado um sistema de carregamento MTS 816 servo-controlado, com capacidade de carga de 2,0MN. Para o ensaio dos corpos-de-prova de grandes dimensões (acima de $15 \mathrm{~cm}$ de lado) foram feitas adaptações no sistema de transferência de carga, como mostra a Figura A1.12a. Já para os de menor dimensão, o sistema de medição das cargas foi adequado com o uso de uma célula de carga com capacidade para $100 \mathrm{kN}$ e resolução de $10 \mathrm{~N}$ (Figura $\mathrm{A} 1.12 \mathrm{~b}$ ).

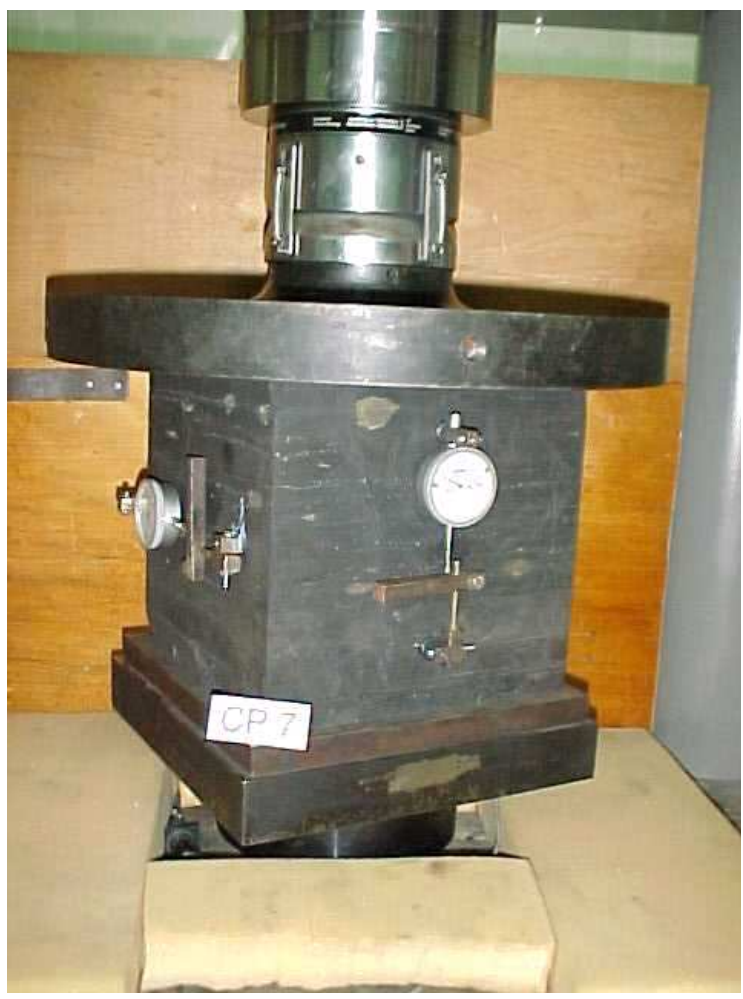

a)

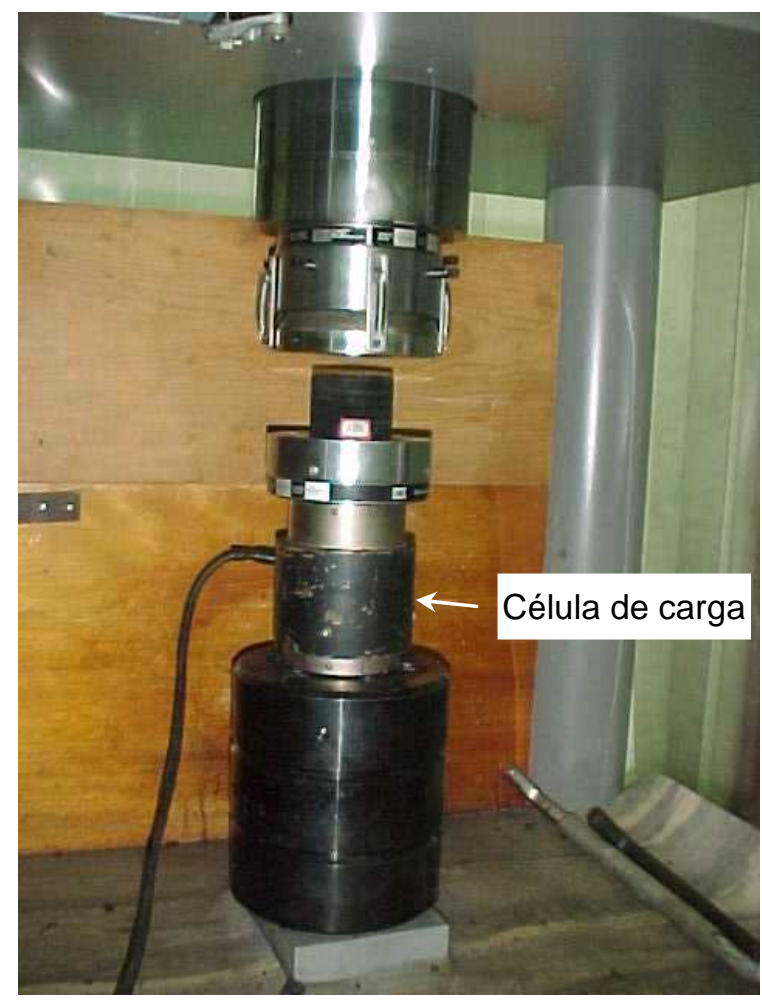

b)

Figura A1.12 - a) No topo e na base, detalhe das placas de transferência de carga em ensaio de corpo-de-prova cúbico com $\mathrm{L}=30 \mathrm{~cm}$. No corpo-de-prova, detalhe da instrumentação (relógios comparadores com resolução de $0,001 \mathrm{~mm}$ ) utilizada para a medição das deformações axiais e transversais durante a ruptura; b) Célula com capacidade de carga de $100 \mathrm{kN}$ e resolução $10 \mathrm{~N}$.

A medição das deformações nos corpos-de-prova durante os ensaios foi feita utilizando-se diferentes tipos de instrumentos. Foi necessária, tanto a adequação da faixa de medição como da resolução dos instrumentos, em função das diferentes dimensões dos corpos-de-prova ensaiados. Como regra, sensores tipo relógio comparador e réguas resistivas com capacidade de medição de até $10 \mathrm{~mm}$ e resolução de $0,001 \mathrm{~mm}$ foram utilizados nos corpos-de-prova com lado entre $20 \mathrm{~cm}$ e $30 \mathrm{~cm}$. Sensores tipo régua resistiva e defletômetros a base de "strain gages" (modelos MTS) foram usados nos ensaios de corpos-de-prova com 
dimensões entre $10 \mathrm{~cm}$ e $20 \mathrm{~cm}$. Nos corpos-de-prova com lado menor que $10 \mathrm{~cm}$ foram utilizadas células "strain gages" de $20 \mathrm{~mm}$ de comprimento, $1200 \mathrm{mhs}$ de resistência e fator gage de 2,09. Nas Figuras A1.13, A1.14 e A1.15 são apresentados os diferentes tipos de instrumentos utilizados e a disposição dos mesmos na face dos corpos-de-prova.

$\mathrm{Na}$ Tabela A1.4 são apresentados os quantitativos de ensaios realizados com os materiais de cada um dos locais amostrados na Mina Fontanella. Nas Figuras A1.16 a A1.21 podem ser vistos diferentes aspectos observados nos corpos-deprova ensaiados, como os diferentes tamanhos trabalhados, modos de ruptura e características estruturais e/ou inclusões comuns que tendem a influenciar na resistência do carvão.

Tabela A1.4 - Dimensões dos corpos-de-prova e quantidades de ensaios efetivamente realizadas com amostras de cada um dos pontos de amostragem.

\begin{tabular}{|c|c|c|}
\hline $\begin{array}{c}\text { Ponto de } \\
\text { Amostragem }\end{array}$ & $\begin{array}{l}\text { Dimensão do Lado dos } \\
\text { Corpos-de-Prova Cúbicos }\end{array}$ & Quantidade \\
\hline \multirow{4}{*}{1} & $5 \mathrm{~cm}$ a $10 \mathrm{~cm}$ & 20 \\
\hline & $10 \mathrm{~cm}$ a $20 \mathrm{~cm}$ & 5 \\
\hline & $20 \mathrm{~cm}$ a $30 \mathrm{~cm}$ & 1 \\
\hline & Total de ensaios no ponto 1 & 26 \\
\hline \multirow{4}{*}{2} & $5 \mathrm{~cm}$ a $10 \mathrm{~cm}$ & 6 \\
\hline & $10 \mathrm{~cm}$ a $20 \mathrm{~cm}$ & 4 \\
\hline & $20 \mathrm{~cm}$ a $30 \mathrm{~cm}$ & 2 \\
\hline & Total de ensaios no ponto 2 & 12 \\
\hline \multirow{4}{*}{3} & $5 \mathrm{~cm}$ a $10 \mathrm{~cm}$ & 12 \\
\hline & $10 \mathrm{~cm}$ a $20 \mathrm{~cm}$ & 7 \\
\hline & $20 \mathrm{~cm}$ a $30 \mathrm{~cm}$ & 6 \\
\hline & Total de ensaios no ponto 3 & 25 \\
\hline \multirow{4}{*}{4} & $5 \mathrm{~cm}$ a $10 \mathrm{~cm}$ & 10 \\
\hline & $10 \mathrm{~cm}$ a $20 \mathrm{~cm}$ & 5 \\
\hline & $20 \mathrm{~cm}$ a $30 \mathrm{~cm}$ & - \\
\hline & Total de ensaios no ponto 4 & 15 \\
\hline \multicolumn{2}{|c|}{ Total de Ensaio na Camada Bonito } & 78 \\
\hline
\end{tabular}




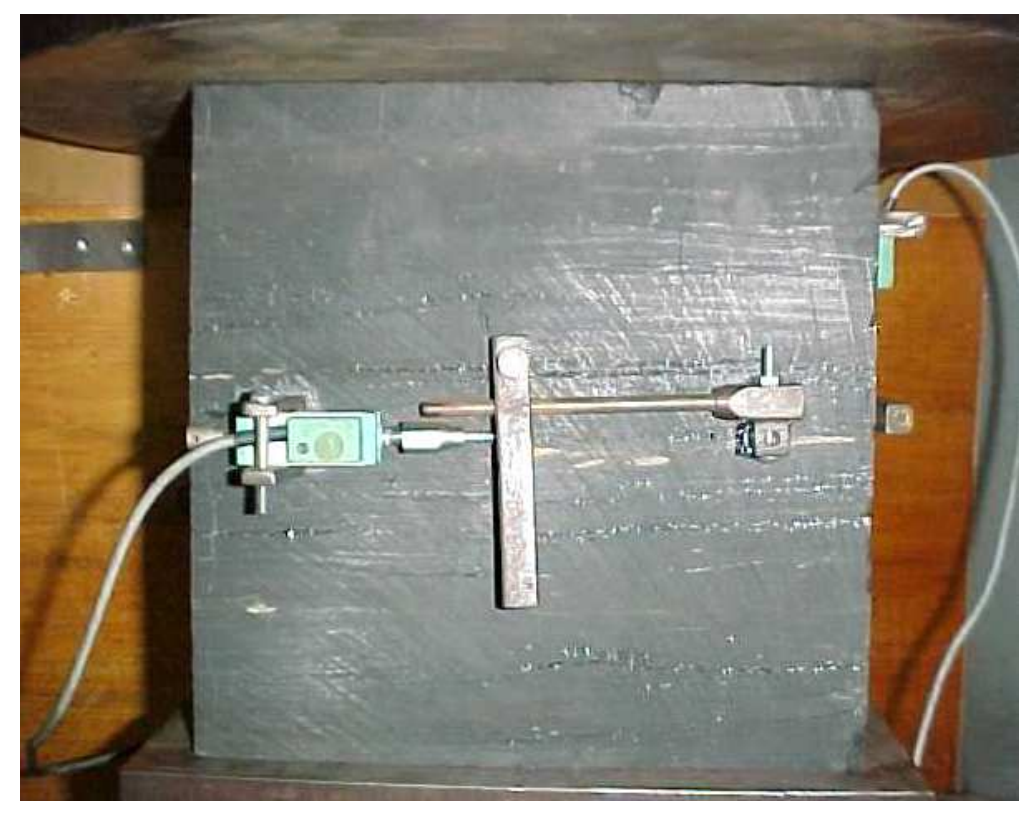

a)

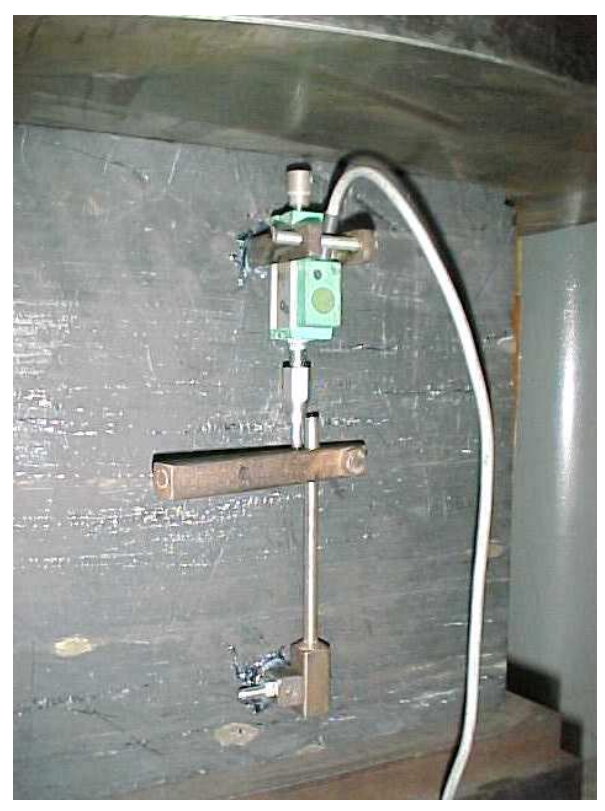

b)

Figura A1.13 - Detalhe da instrumentação (réguas resistivas) utilizada para a medição de deformações (a) transversais e (b) axiais durante a ruptura de corpo-de-prova ( $L=26 \mathrm{~cm})$.

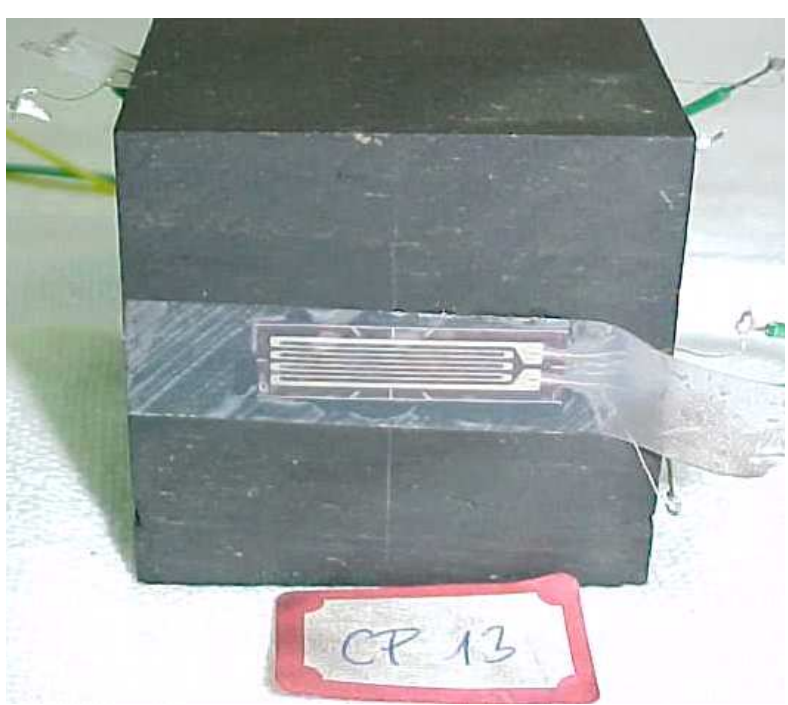

a)

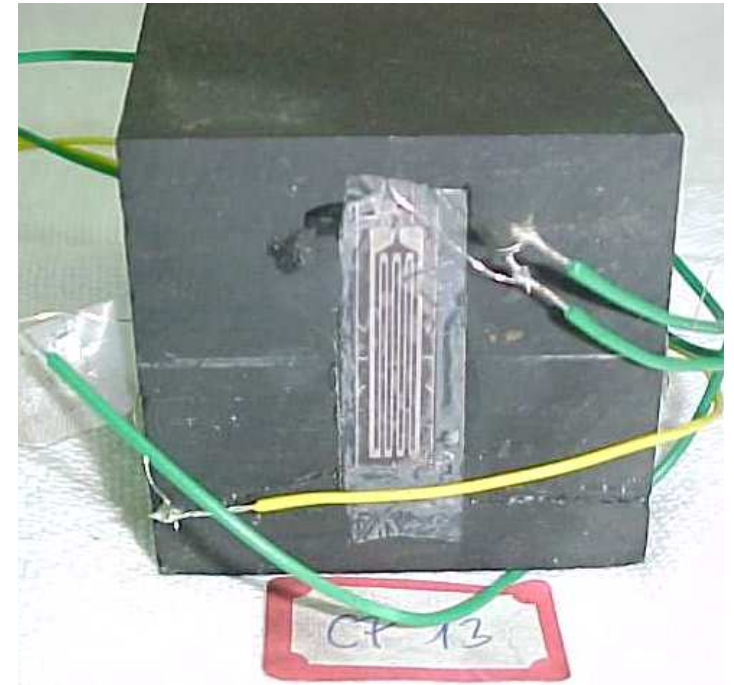

b)

Figura A1.14 - Detalhe da instrumentação ("strain gages") utilizada para a medição de deformações (a) transversais e (b) axiais em corpo-de-prova com lado igual a $5 \mathrm{~cm}$. 


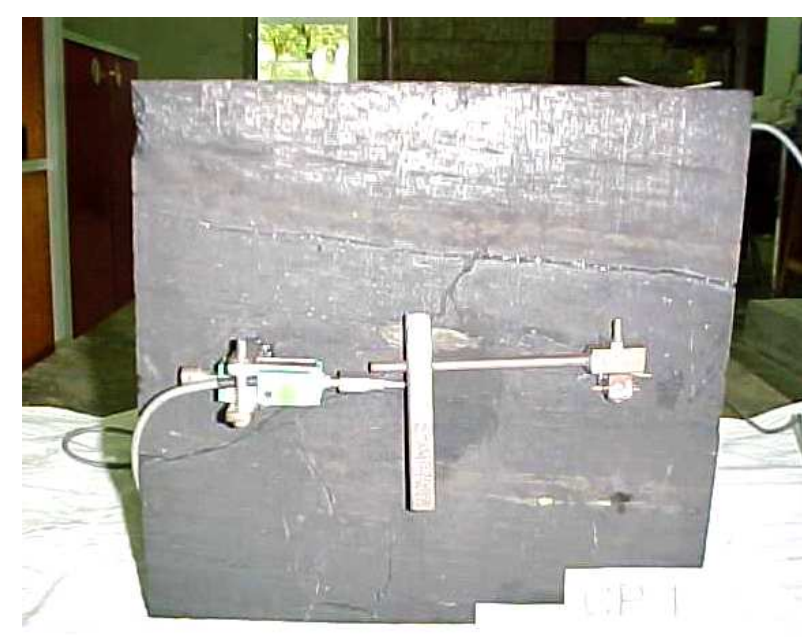

a)

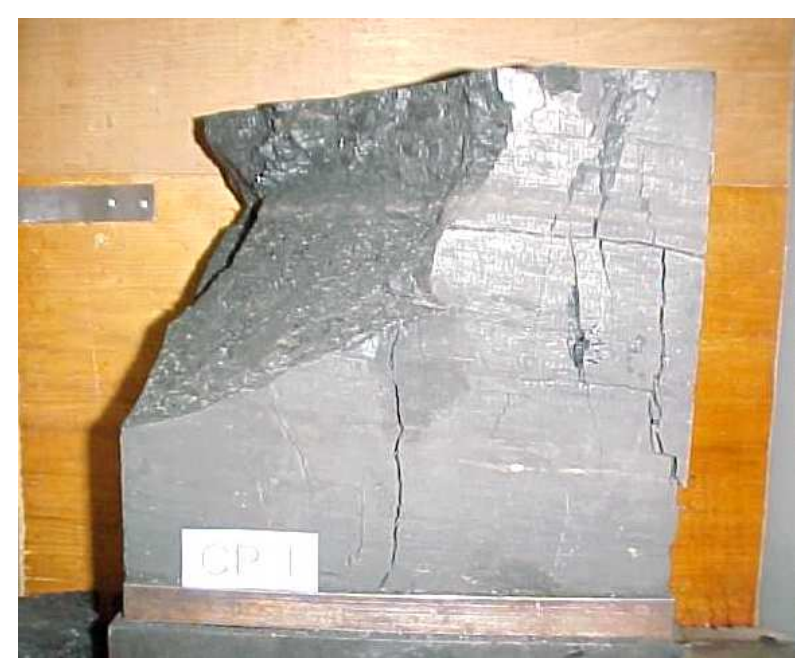

b)

Figura A1.15 - a) Detalhe de fratura inclinada e lâmina de vitrênio $( \pm 2 \mathrm{~mm})$ na face lateral de corpo-de-prova com $L=30 \mathrm{~cm}$; b) Vista do plano de ruptura passando pela fratura pré-existente.

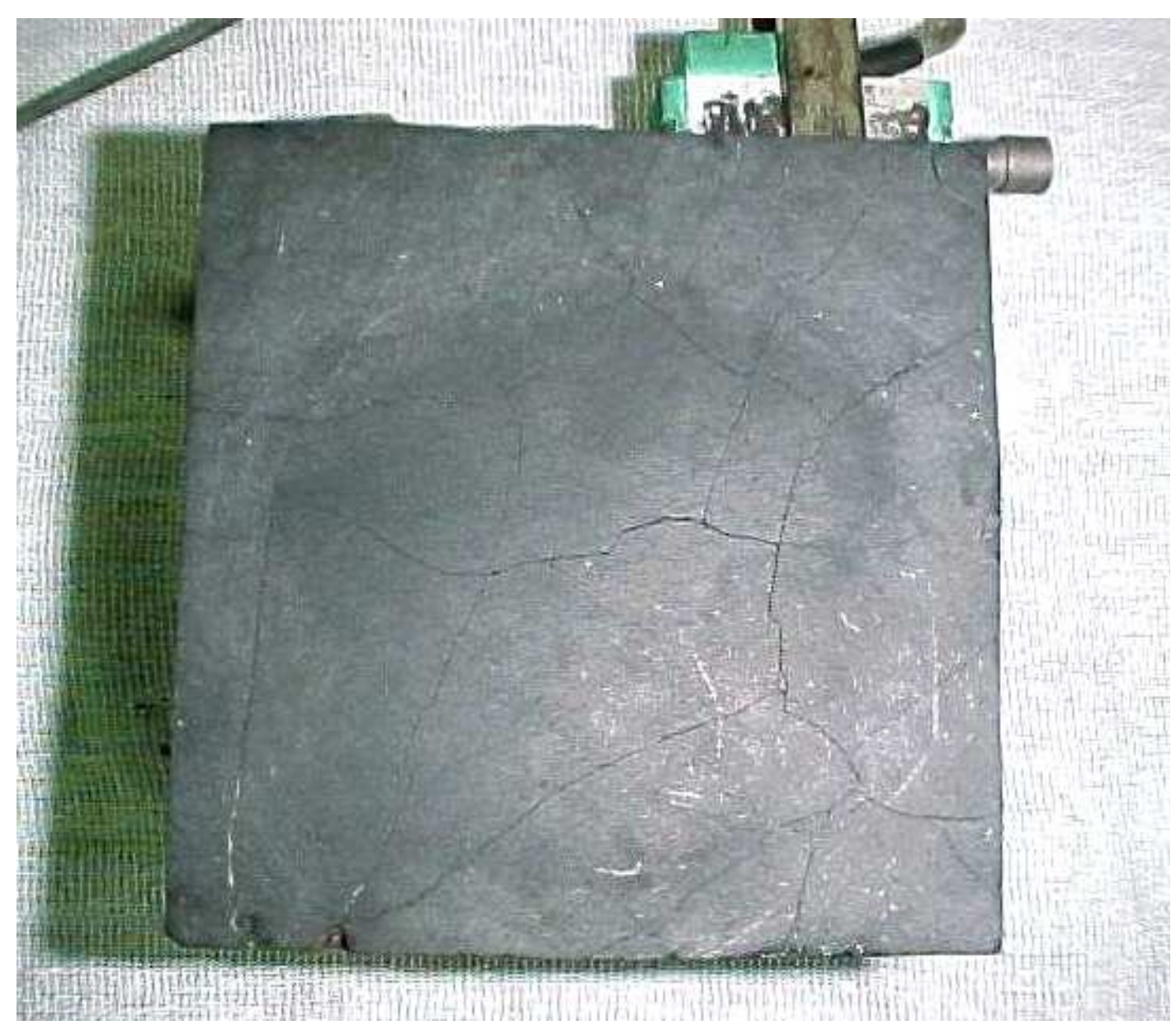

Figura A1.16 - Detalhe das fraturas observadas no topo do corpo-de-prova ( $L=10 \mathrm{~cm})$. 


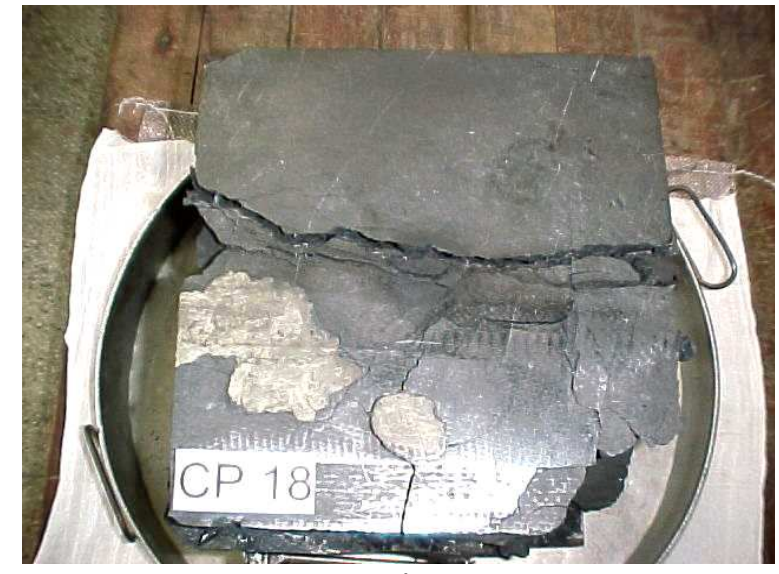

a)

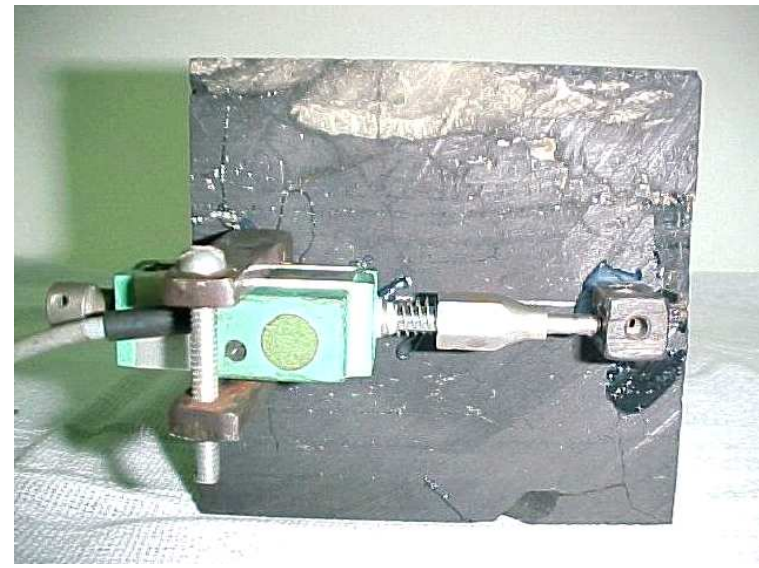

b)

Figura A1.17 - a) Nódulos de pirita observados no topo do corpo-de-prova $(L=27 \mathrm{~cm})$; b) Nódulos de pirita observados na face lateral do corpo-de-prova $(L=11 \mathrm{~cm})$.

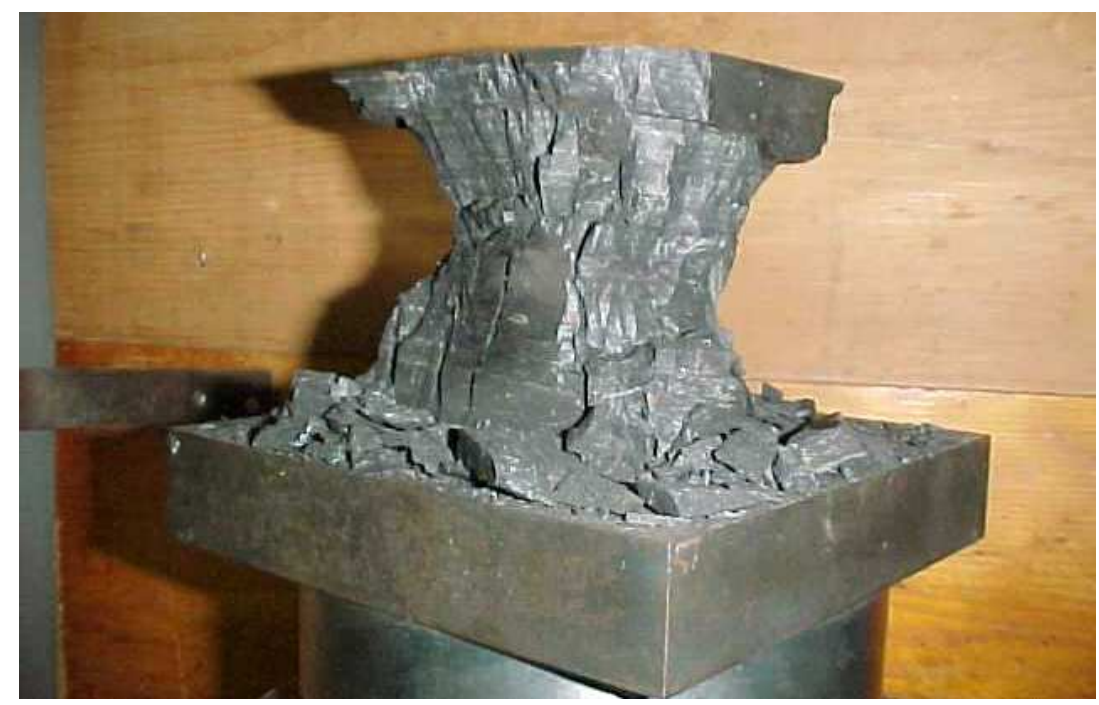

Figura A1.18 - Detalhe de ruptura bipiramidal em corpo-de-prova com $L=10 \mathrm{~cm}$.

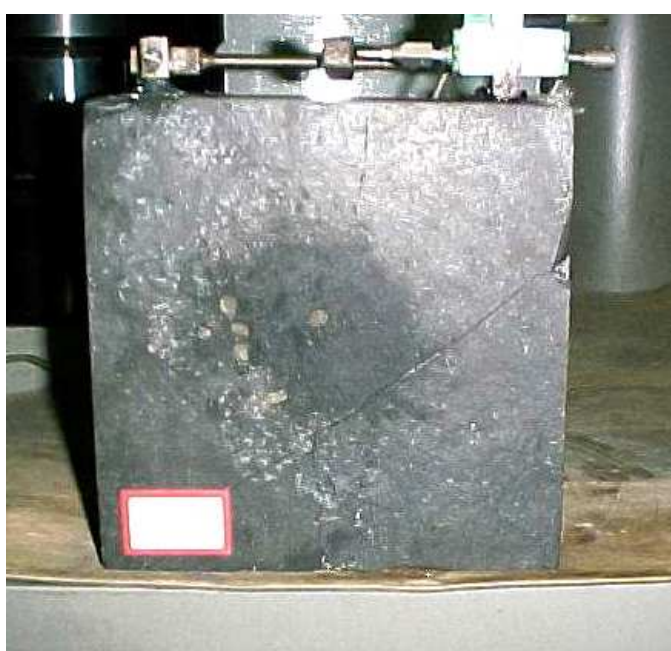

a)

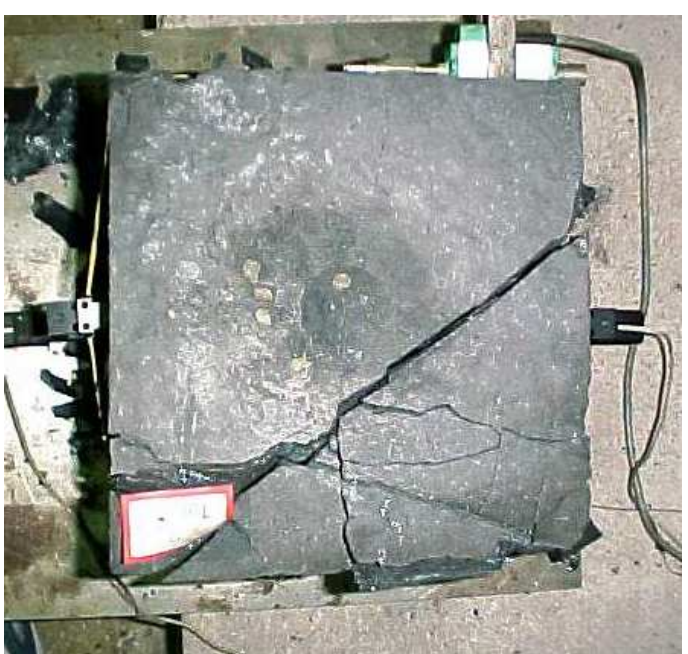

b)

Figura A1.19 - a) Detalhe de fratura na base do corpo-de-prova, paralela à direção de carregamento; b) Superfície de ruptura sobre a fratura pré-existente (corpo-de-prova com $\mathrm{L}=27 \mathrm{~cm})$. 


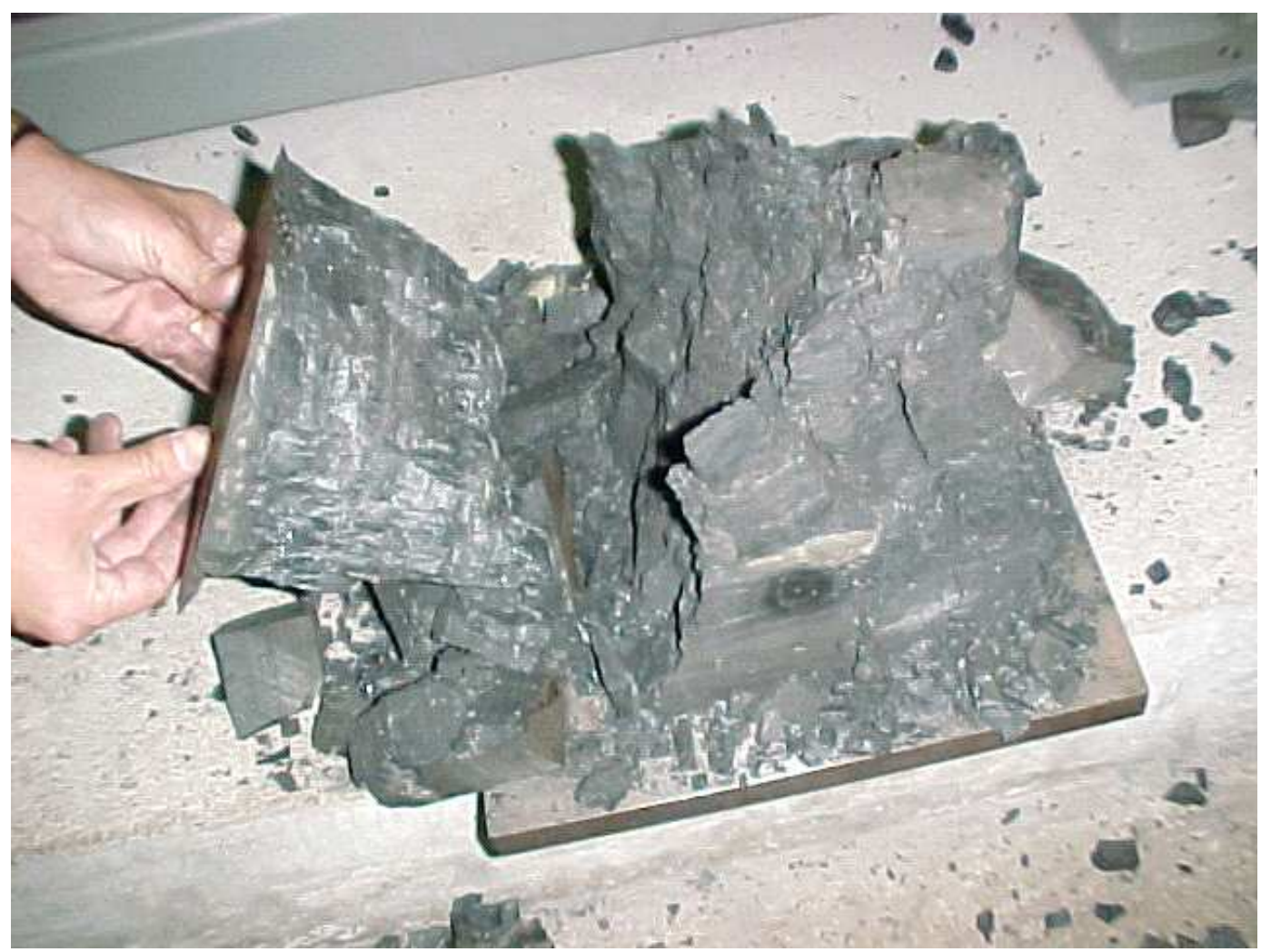

Figura A1.20 - Detalhe da superfície de ruptura por cisalhamento em corpo-de-prova com lado igual a $20 \mathrm{~cm}$.

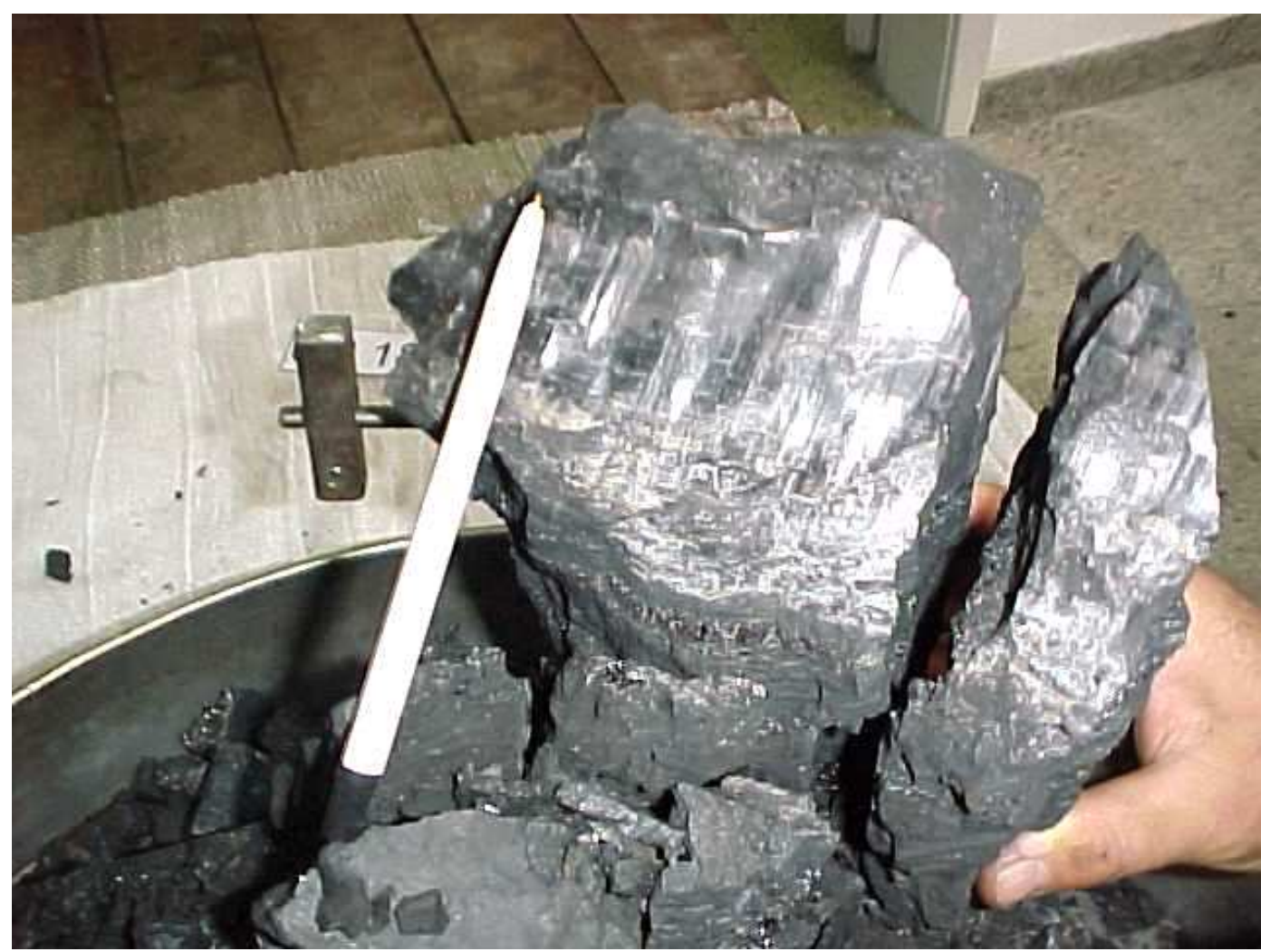

Figura A1.21 - Detalhe da superfície de ruptura sobre "slikenside", em corpo-de-prova com lado igual a $27 \mathrm{~cm}$. 


\section{A1.4 Dificuldades Encontradas para a Realização dos Ensaios}

A avaliação dos resultados obtidos não pode desconsiderar as inúmeras dificuldades no que se refere à trabalhabilidade da rocha carbonosa. A preparação dos espécimens para os ensaios de laboratório é uma atividade fundamental para o sucesso ou insucesso da pesquisa em laboratório.

Quando tratamos da trabalhabilidade, estamos nos referindo aos problemas de quebras durante o desmembramento dos grandes blocos de carvão, amostras julgadas representativas do maciço. Os fatores que concorrem negativamente para o aproveitamento do material são a grande quantidade de descontinuidades presentes na rocha, a fragilização da rocha devido ao desconfinamento que ocorre quando os blocos são separados do maciço e a forte tendência de alteração desse tipo de rocha. Os esforços impostos à rocha durante o trabalho de corte e acabamento são outros fatores que acabam danificando grande parte do material disponível. O resultado é a freqüente quebra da rocha, gerando um aproveitamento muito baixo do material disponível. Tais problemas geralmente não permitem a obtenção das quantidades necessárias de espécimens para dar representatividade estatística à amostra ensaiada. Pior do que isso, em geral somente materiais de "boa qualidade" chegam ao processo final de preparação e ensaio propriamente dito. Isso significa dizer que, mesmo os materiais que eventualmente tenham sido ensaiados em número estatisticamente representativo, podem não necessariamente refletir as propriedades mecânicas do universo de onde foram extraídos.

Enquanto a proposta inicial foi a de estudar o efeito escala na resistência do carvão utilizando corpos-de-prova cúbicos com até $30 \mathrm{~cm}$ de lado, os materiais provenientes dos pontos de amostragem 1 e 4 praticamente não permitiram a preparação de corpos-de-prova com dimensões acima de $15 \mathrm{~cm}$. A estratégia adotada durante a preparação foi a de conformar primeiro os espécimens de maior dimensão. Porém, os materiais desses locais se mostraram não resistentes ao processo de corte e acabamento, ocorrendo quebras freqüentes, a ponto de chegarem para ensaio de compressão uniaxial, nas dimensões acima de $15 \mathrm{~cm}$, apenas 4 corpos-de-prova. Qualitativamente, isso já é um indício, comparativamente com os materiais dos pontos 2 e 3 , da maior fragilidade da rocha nesses locais (pontos 1 e 4 ).

Outro aspecto importante diz respeito ao tempo de execução do trabalho de preparação e ensaio. Devido aos problemas elencados acima, foram necessários cerca de 8 meses de trabalho, com uma equipe de dois laboratoristas e um engenheiro. Embora as amostras tenham sido mantidas nas melhores condições possíveis em laboratório (longe de variações de temperatura e isolamento da umidade do ambiente), não pode ser descartada a influência do tempo de estoque dessas amostras na determinação das propriedades mecânicas da rocha. 


\section{ANEXO 2}

Tratamento dos Dados dos Levantamentos Estruturais Realizados na Camada de Carvão Bonito - Mina Fontanella 


\section{Sumário}

$\begin{array}{llc}\text { A2.1 } & \text { Orientação das Descontinuidades } & \text { Página } \\ \text { A2.2 } & \text { Freqüência das Descontinuidades } & 225 \\ & 236\end{array}$




\section{A2.1 Orientação das Descontinuidades}

As medidas de orientação das fraturas (direção do mergulho e mergulho) são apresentadas em projeções esféricas através dos seguintes conjuntos de figuras:

- Ponto 1: Figuras A2.1a (diagrama de rosetas), A2.1b (diagrama de isolinhas), A2.1c (diagrama de densidade de pólos);

- Ponto 4: Figuras A2.2a, A2.2b e A2.2c;

- Ponto 2: Figuras A2.3a, A2.3b e A2.3c;

- Ponto 3: Figuras A2.4a, A2.4b e A2.4c.

A definição das principais famílias de fraturas presentes em cada ponto de amostragem foi feita adotando-se os seguintes procedimentos:

a) plotagem do diagrama de rosetas para a observação da direção de mergulho preferencial dos planos das fraturas;

b) plotagem do diagrama de isolinhas dos pólos das fraturas para a observação das zonas de maior concentração de pólos e identificação das principais famílias;

c) plotagem do diagrama de densidade de pólos e definição da orientação das principais famílias. Cada uma das famílias foi definida a partir do traçado de um cone de influência de $15^{\circ}$, normalmente com centro nas zonas cuja concentração de pólos fosse no mínimo superior a $2 \%$. Como regra, a orientação da família deveria representar pelo menos 10\% das medidas levantadas no campo.

Em alguns casos, no entanto, as famílias foram definidas mesmo representando menos de $10 \%$ das medidas realizadas. Porém, nesses casos observou-se que se tratam de variações da orientação de determinada família representada por mais de $10 \%$ dos pólos.

$\mathrm{Na}$ Tabela A2.1 é apresentada uma síntese dos resultados relativos às principais famílias de fraturas identificadas nos diferentes locais mapeados.

Após a avaliação global das famílias mapeadas, foram definidas 3 famílias para representar o conjunto das descontinuidades nas duas áreas formadas pelo agrupamento dos pontos de levantamento mais próximos entre si. Embora numa das áreas uma quarta família pudesse ser considerada, com mergulho vertical, para efeitos práticos julgou-se oportuno agrupá-la a uma das famílias inclinadas que também apresenta grande representatividade na camada.

Nas Figuras A2.5 e A2.6 podem ser vistas todas as famílias de descontinuidades identificadas nessas áreas de estudo, assim como as famílias representativas das descontinuidades nesses locais. A Tabela A2.2 apresenta a orientação dessas famílias. 


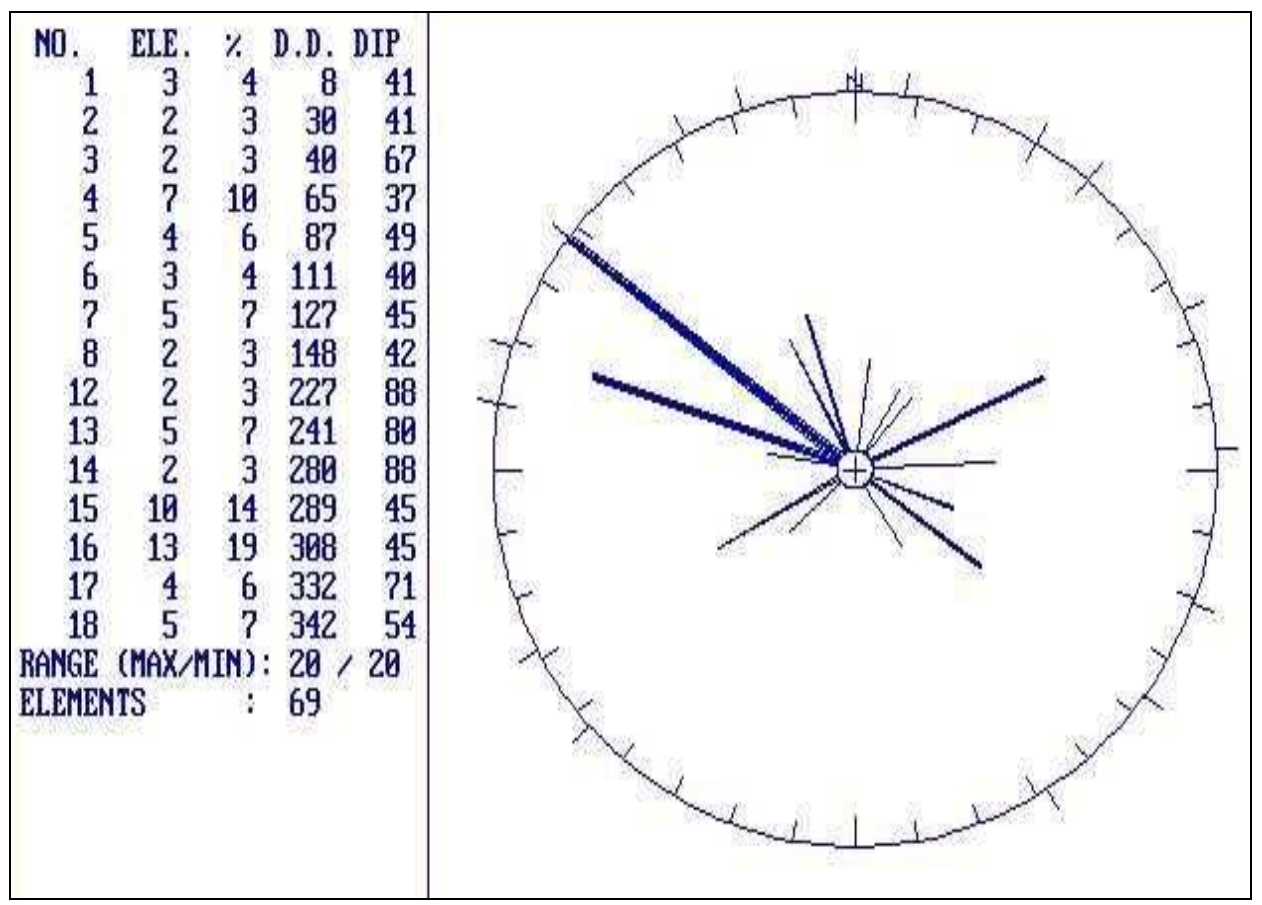

Figura A2.1a - Diagrama de roseta dos planos das fraturas levantadas no Ponto 1.

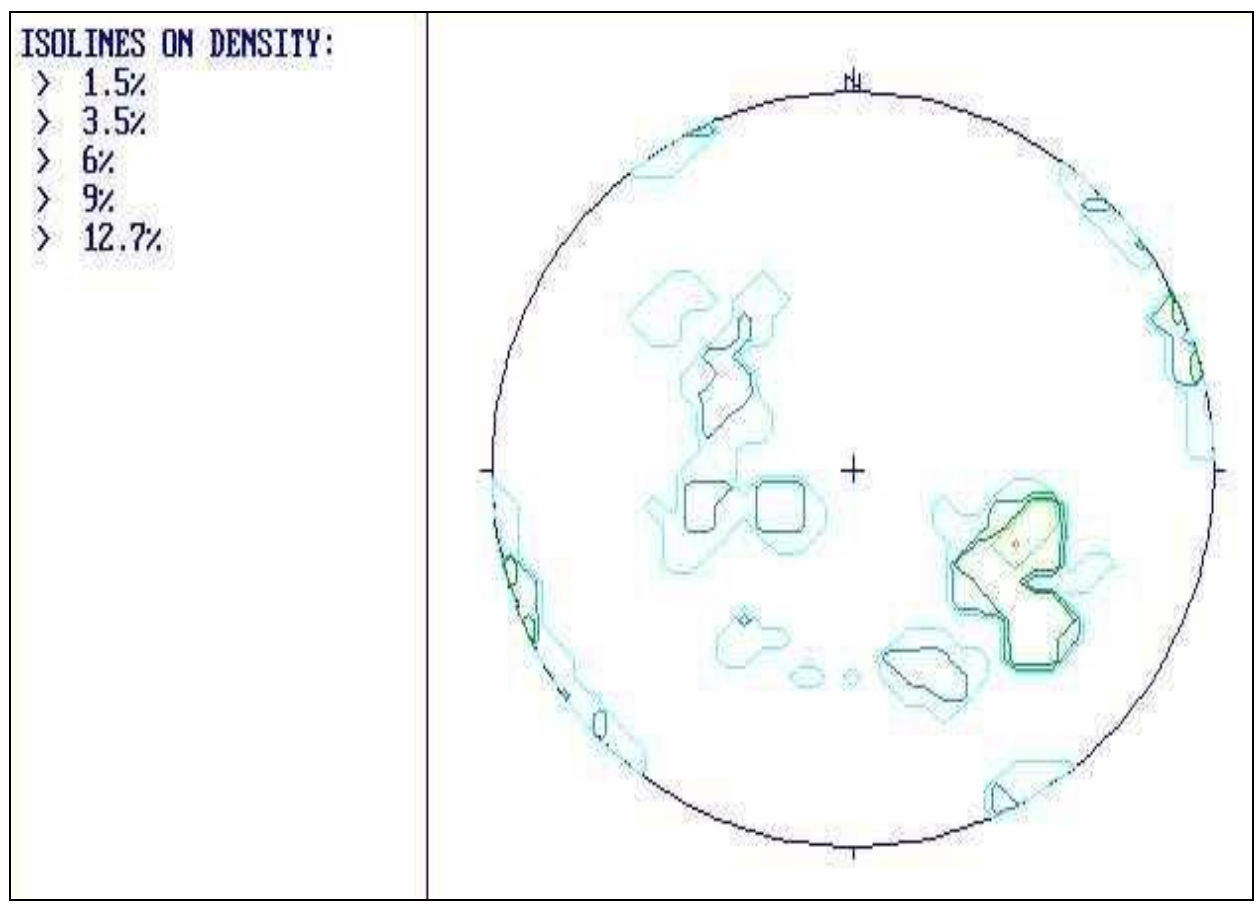

Figura A2.1b - Diagrama de isolinhas dos pólos das fraturas levantadas no ponto 1. Projeção no hemisfério inferior. 


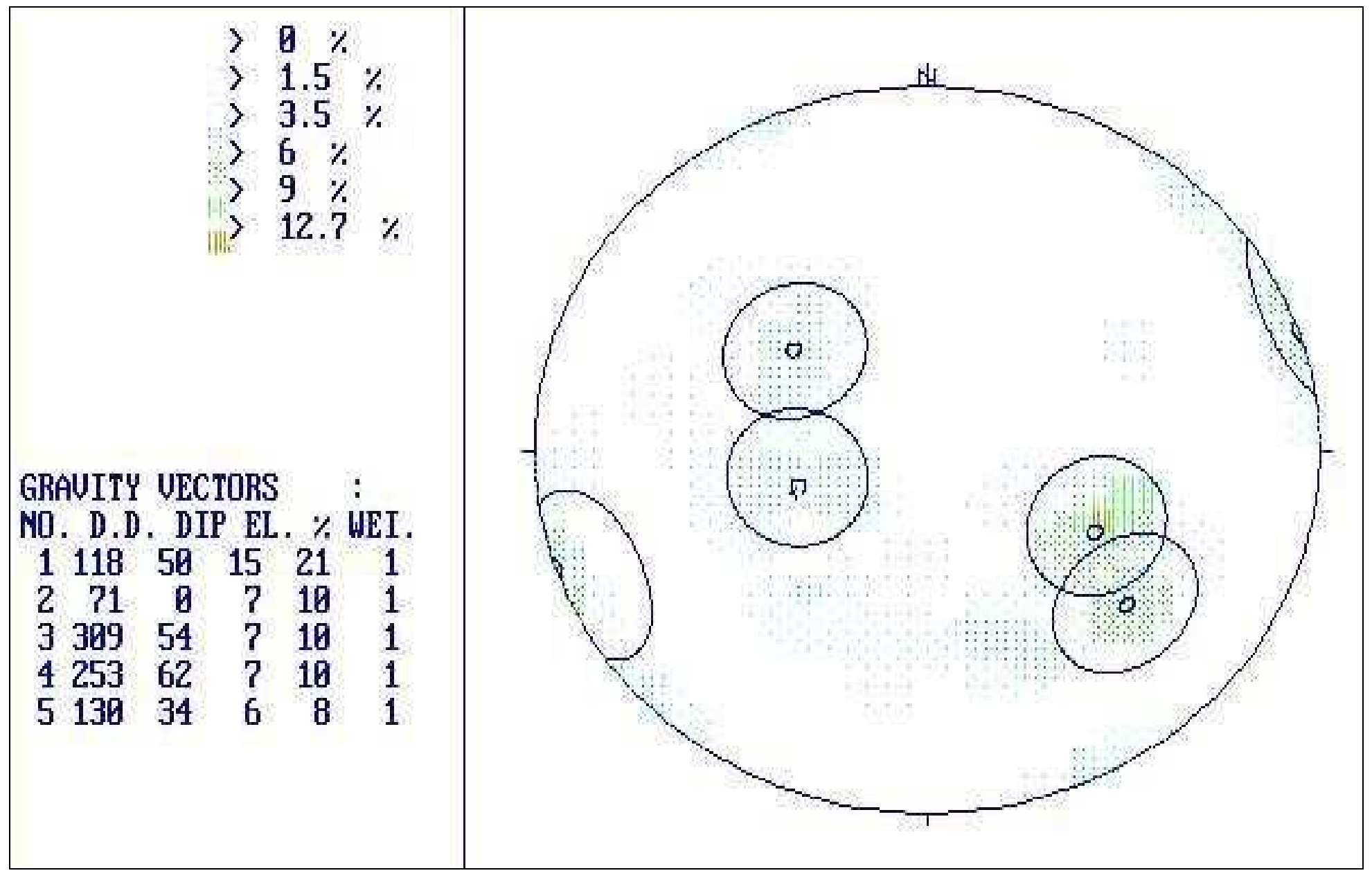

Figura A2.1c - Diagrama de densidade com a definição dos pólos das principais famílias de fraturas presentes no Ponto 1 (cones de influência $=15^{\circ}$ ). Projeção no hemisfério inferior. 


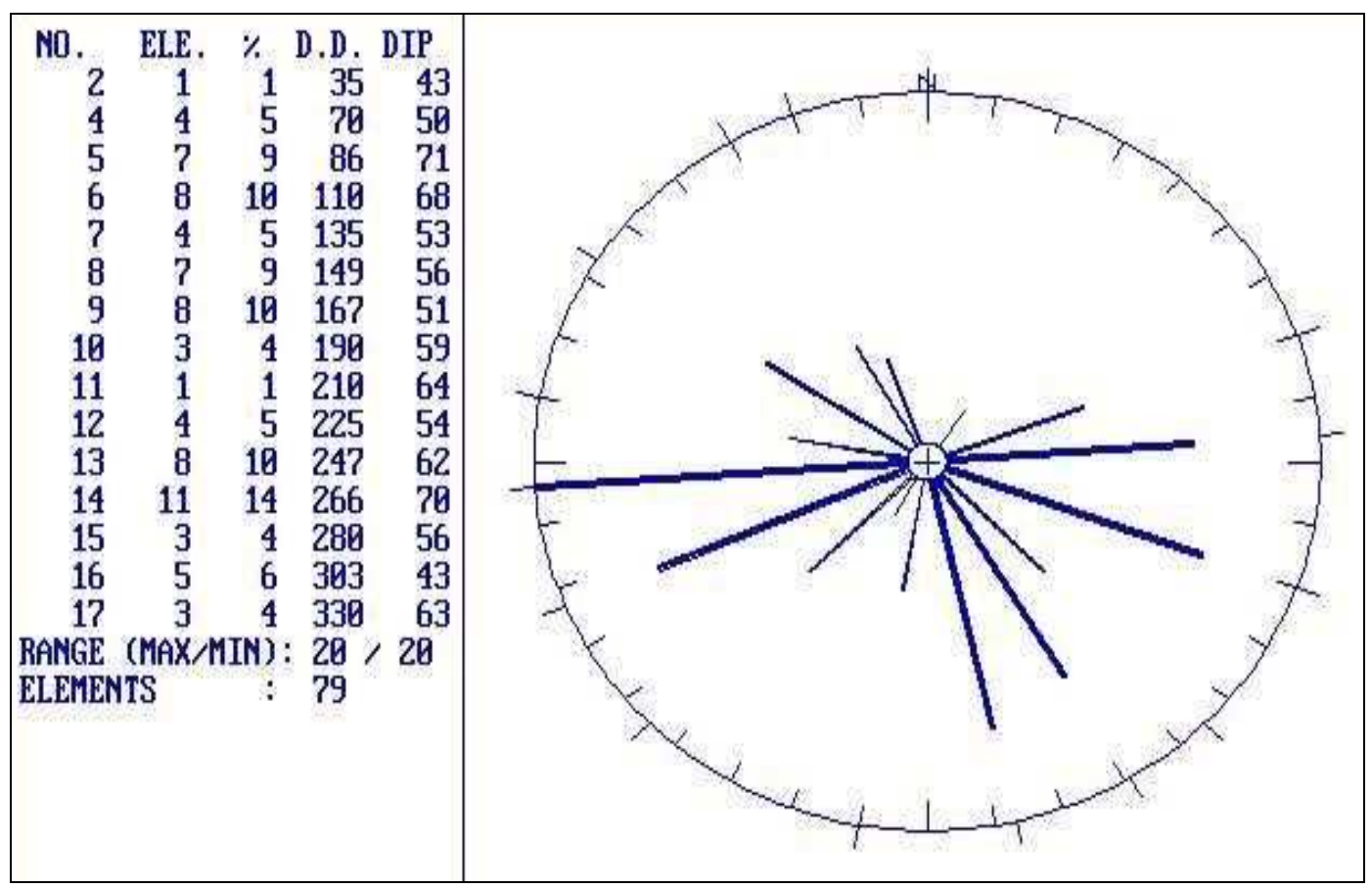

Figura A2.2a - Diagrama de roseta dos planos das fraturas levantadas no Ponto 4.

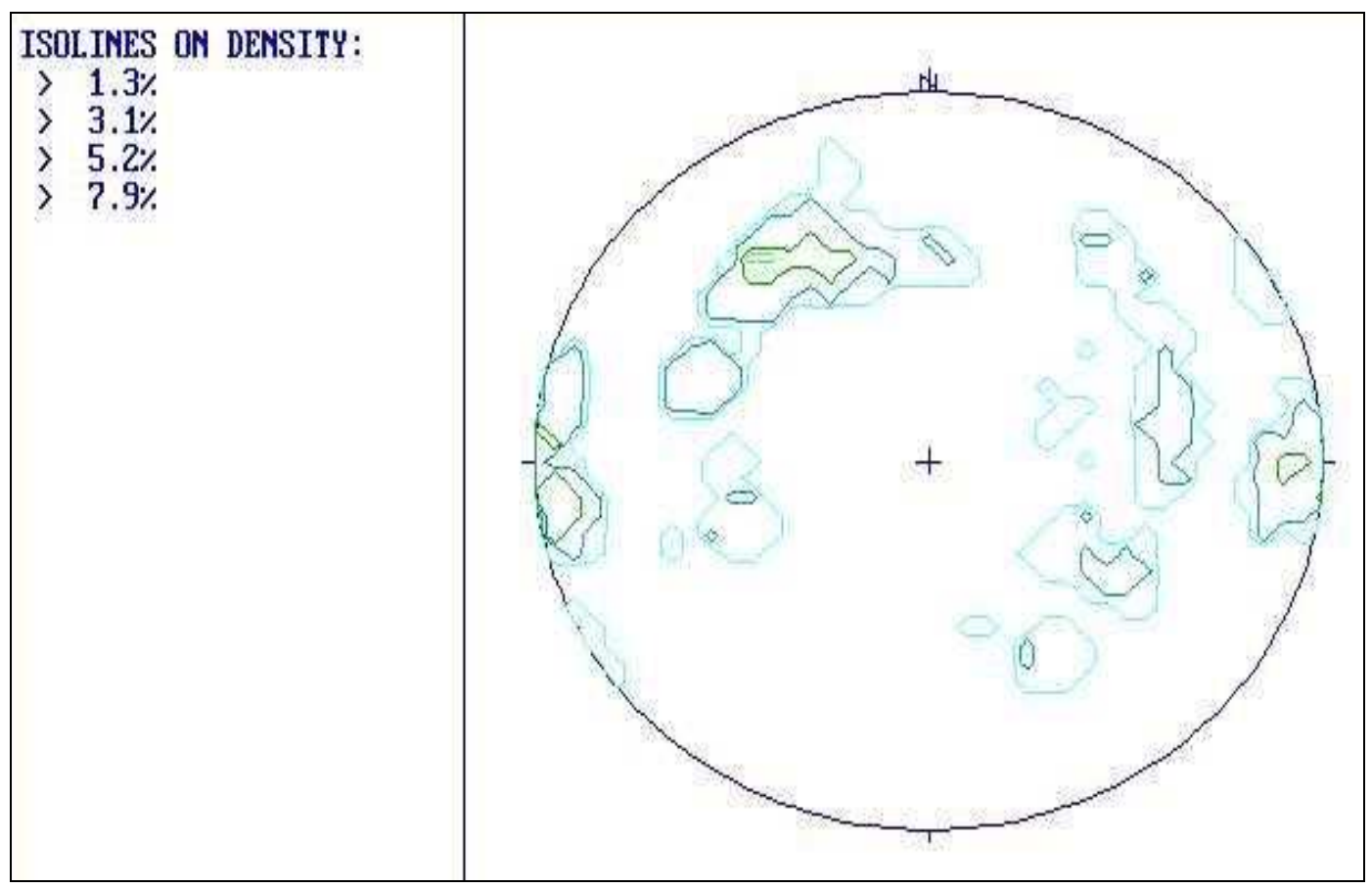

Figura A2.2b - Diagrama de isolinhas dos pólos das fraturas levantadas no ponto 4 . Projeção no hemisfério inferior. 


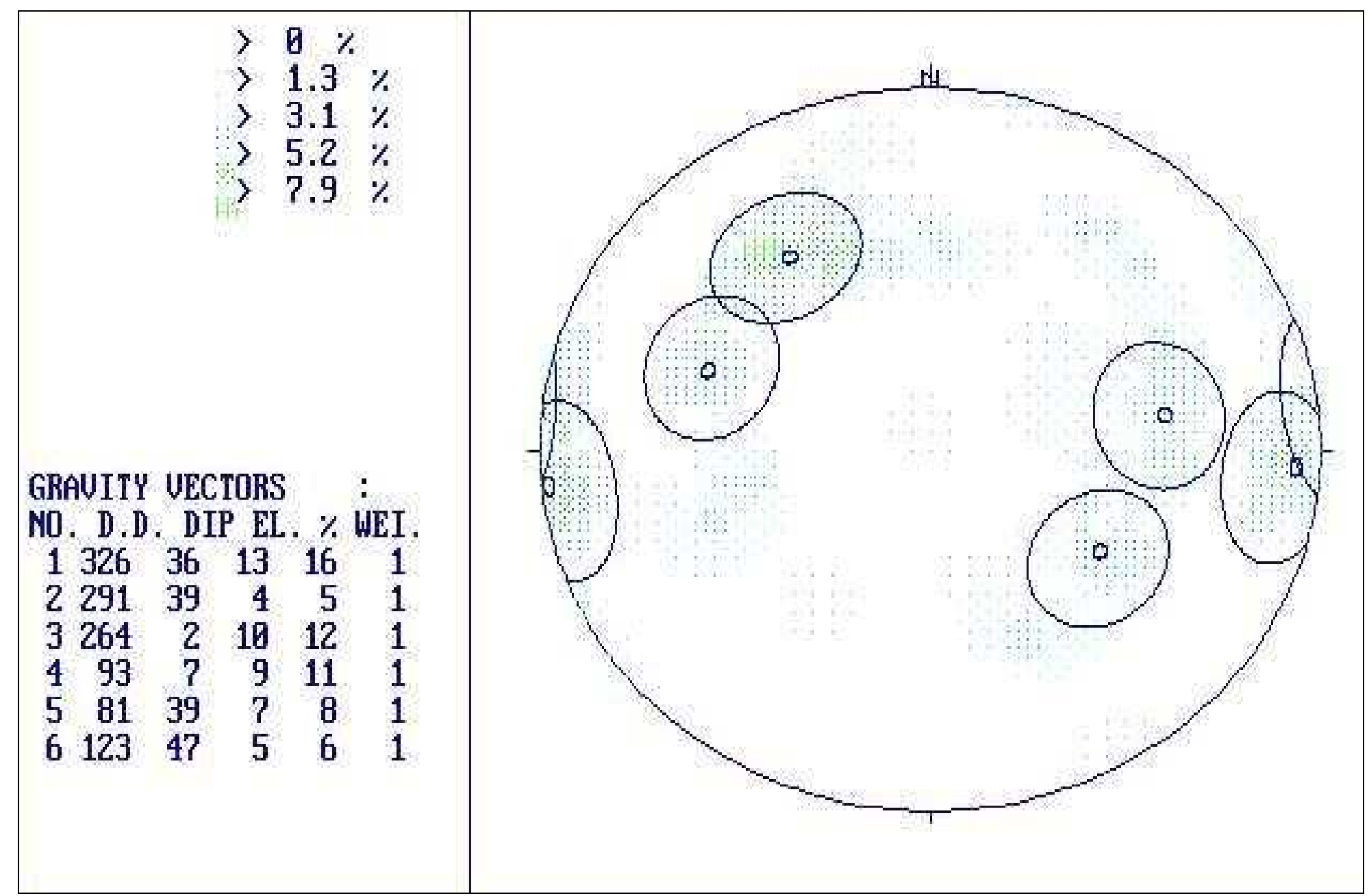

Figura A2.2c - Diagrama de densidade com a definição dos pólos das principais famílias de fraturas presentes no Ponto 4 - (cones de influência $=15^{\circ}$ ). Projeção no hemisfério inferior. 


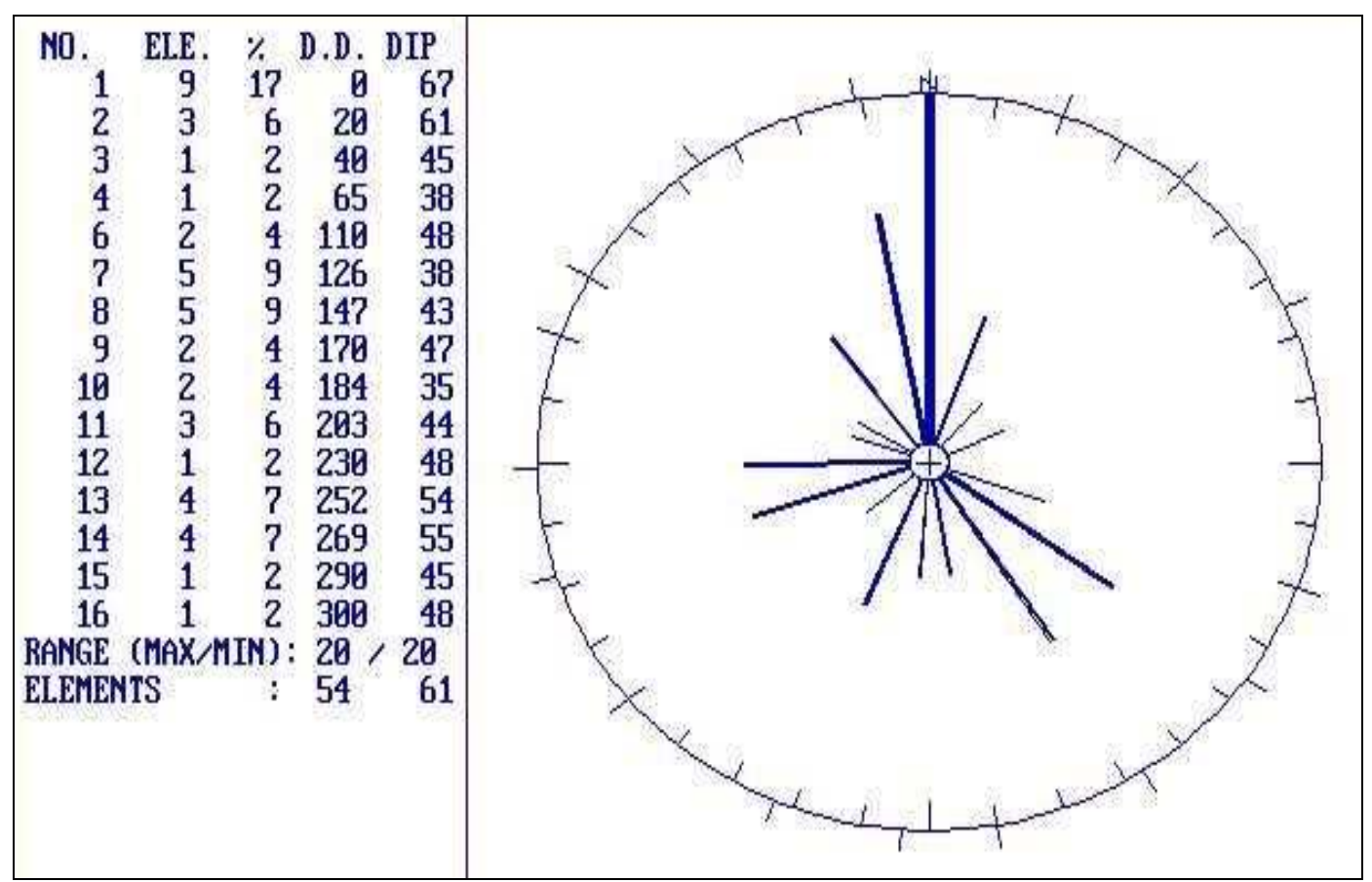

Figura A2.3a - Diagrama de roseta dos planos das fraturas levantadas no Ponto 2.

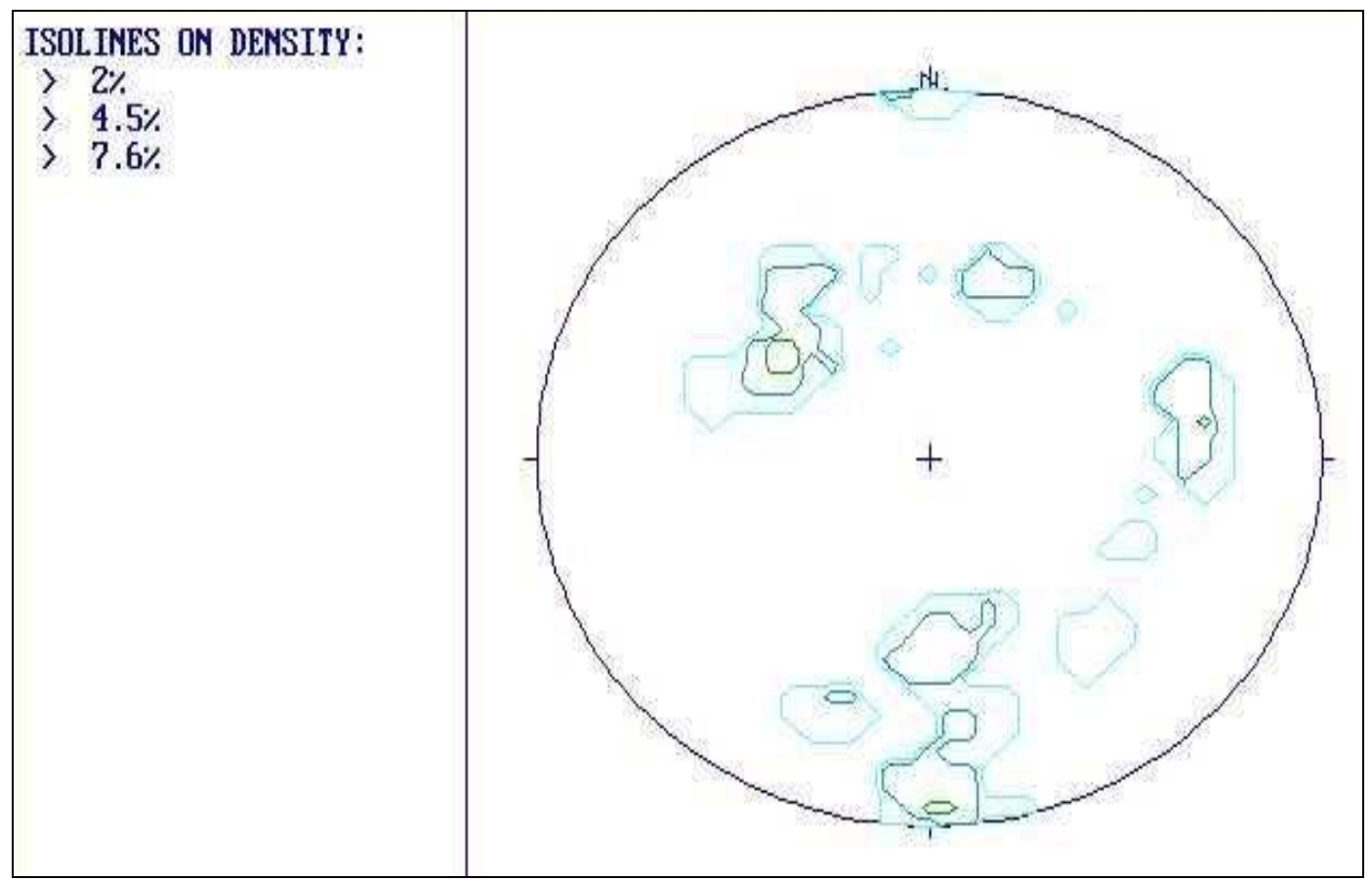

Figura A2.3b - Diagrama de isolinhas dos pólos das fraturas levantadas no ponto 2. Projeção no hemisfério inferior. 


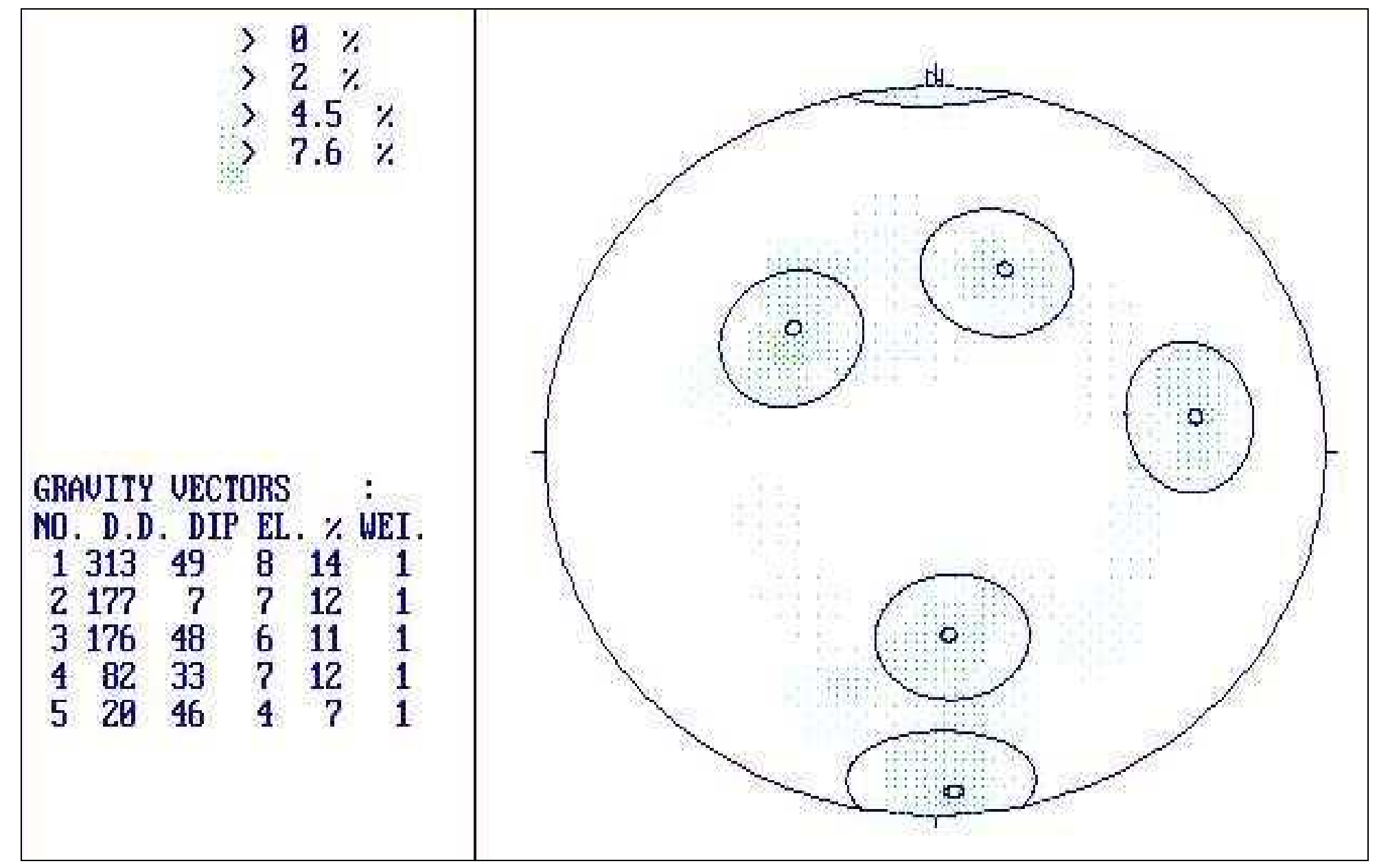

Figura A2.3c - Diagrama de densidade com a definição dos pólos das principais famílias de fraturas presentes no Ponto 2 (cones de influência $=15^{\circ}$ ). Projeção no hemisfério inferior. 


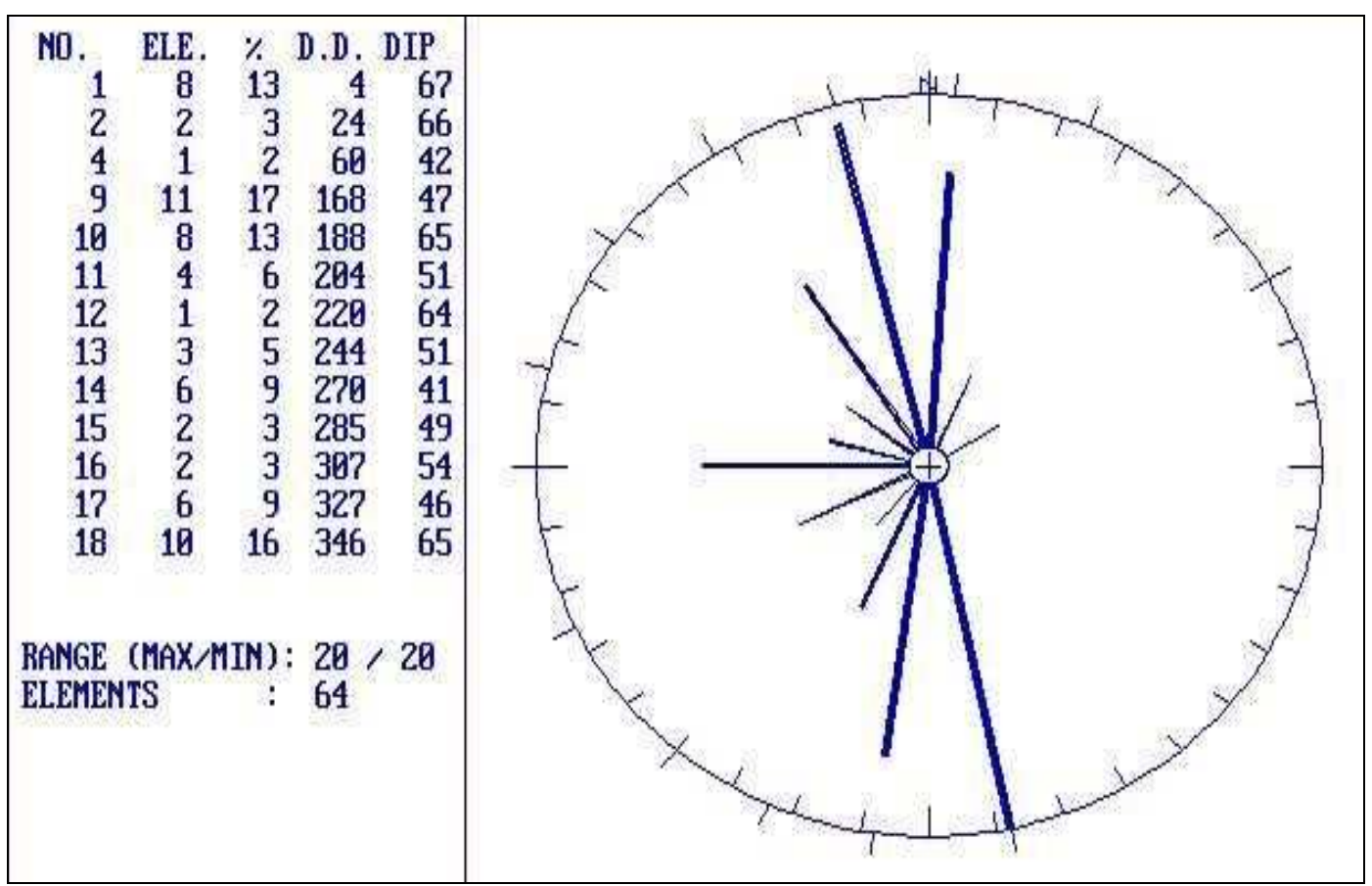

Figura A2.4a - Diagrama de roseta dos planos das fraturas levantadas no Ponto 3.

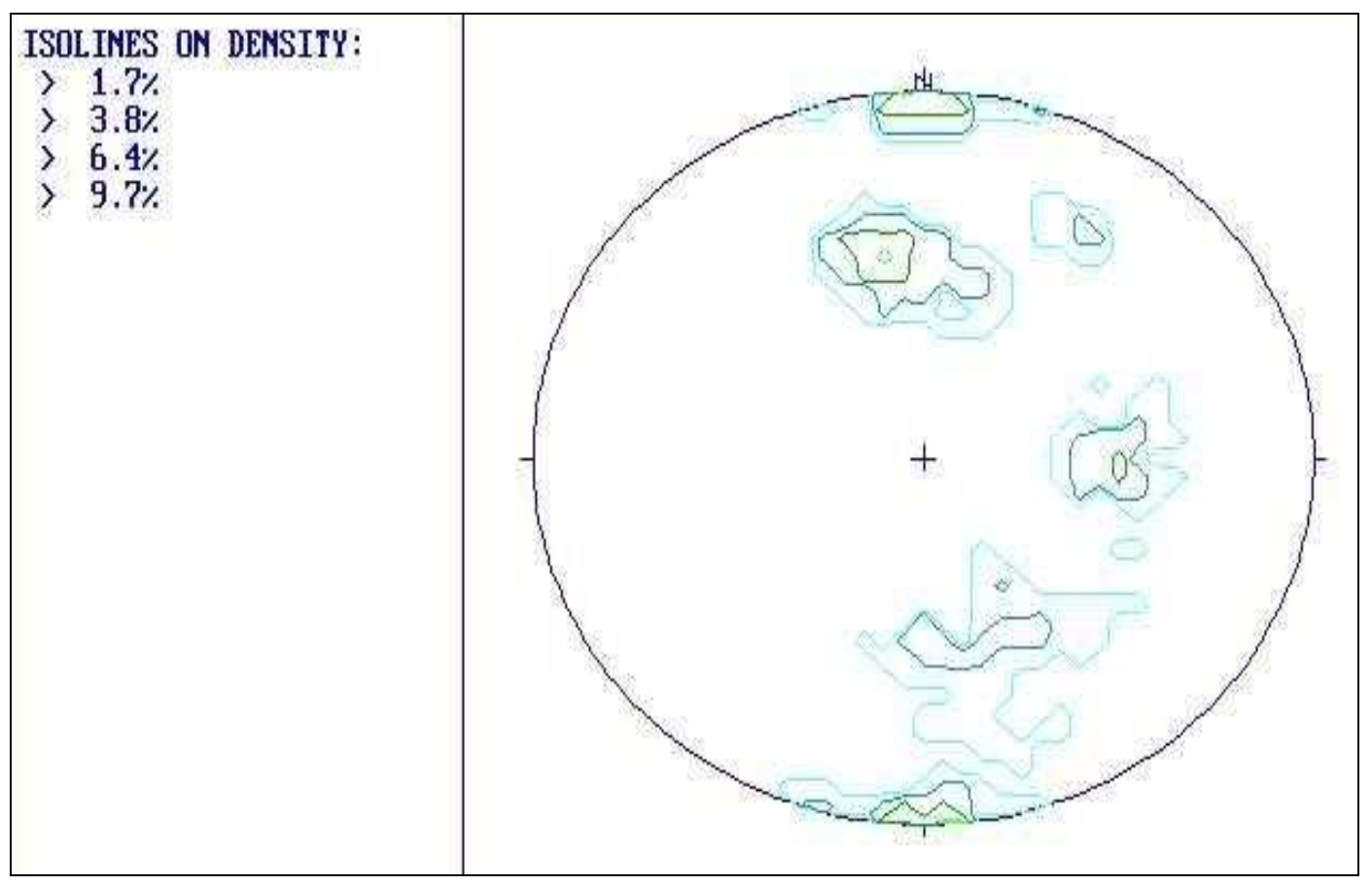

Figura A2.4b - Diagrama de isolinhas dos pólos das fraturas levantadas no ponto 3. Projeção no hemisfério inferior. 


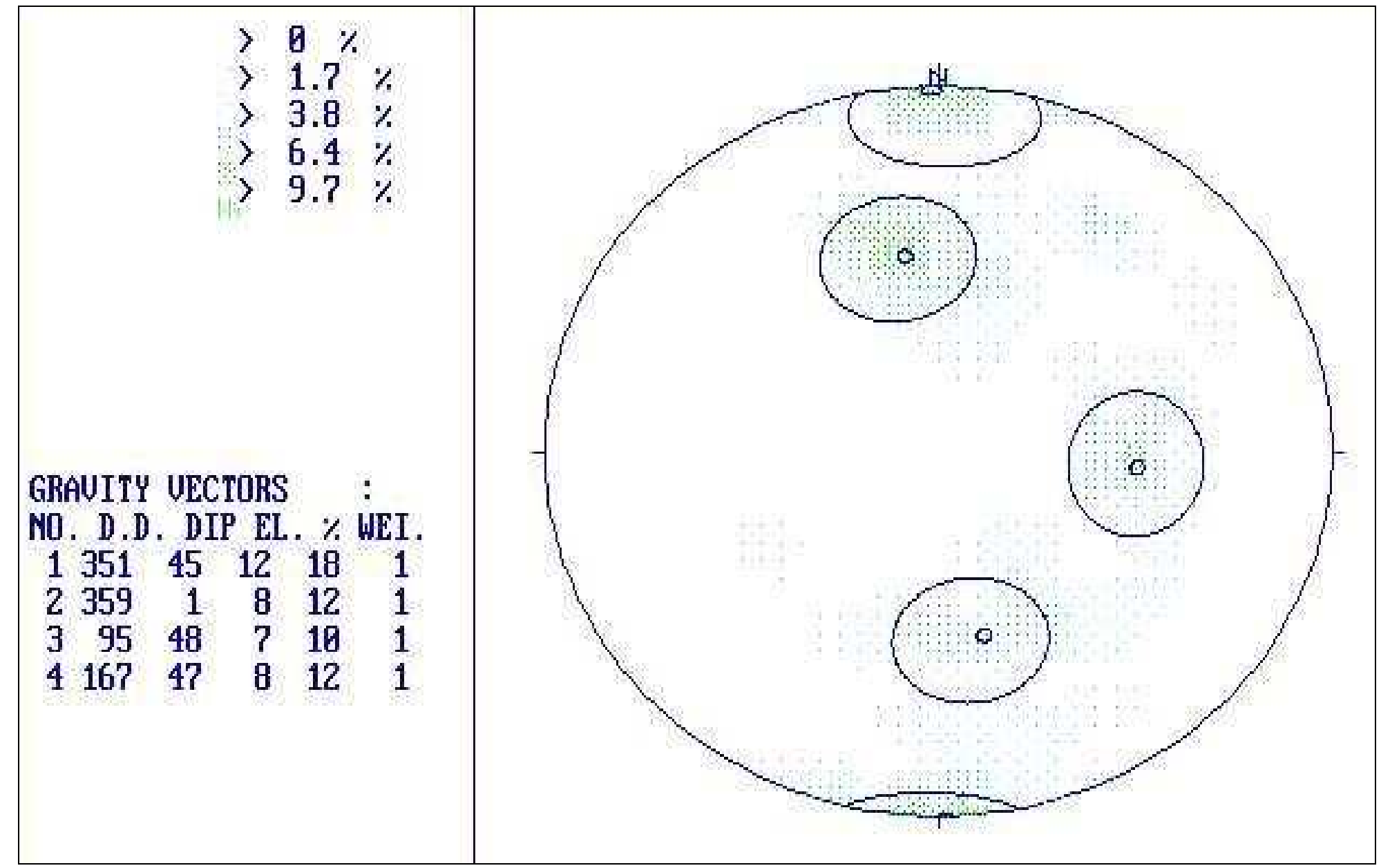

Figura A2.4c - Diagrama de densidade com a definição dos pólos das principais famílias de fraturas presentes no Ponto 3 - (cones de influência $=15^{\circ}$ ). Projeção no hemisfério inferior. 
Tabela A2.1 - Síntese das orientações das principais famílias de fraturas identificadas nos 4 pontos de levantamento estrutural.

\begin{tabular}{|c|c|c|c|c|c|}
\hline \multicolumn{6}{|c|}{ Ponto 1 de Levantamento } \\
\hline \multicolumn{2}{|c|}{ Pólo do Plano da Fratura } & \multicolumn{2}{|c|}{ Plano da Fratura } & \multirow[b]{2}{*}{$\begin{array}{l}\mathrm{N}^{0} \mathrm{da} \\
\text { Família }\end{array}$} & \multirow[b]{2}{*}{$\begin{array}{l}\text { \% de Pólos } \\
\text { Representados } \\
\text { pela Família }\end{array}$} \\
\hline $\begin{array}{l}\text { Direção do } \\
\text { Mergulho } \\
\text { (o) }\end{array}$ & $\begin{array}{l}\text { Mergulho } \\
\text { (0) }\end{array}$ & $\begin{array}{l}\text { Direção de } \\
\text { Mergulho } \\
\text { (o) }\end{array}$ & $\begin{array}{l}\text { Mergulho } \\
\text { (o) }\end{array}$ & & \\
\hline 253 & 62 & 73 & 28 & 4 & 10 \\
\hline 309 & 54 & 129 & 36 & 3 & 10 \\
\hline 71 & 0 & 251 & 90 & 2 & 10 \\
\hline 118 & 50 & 298 & 40 & 1 & 21 \\
\hline 130 & 34 & 310 & 56 & 5 & 8 \\
\hline \multicolumn{6}{|c|}{ Ponto 4 de Levantamento } \\
\hline \multicolumn{2}{|c|}{ Pólo do Plano da Fratura } & \multicolumn{2}{|c|}{ Plano da Fratura } & \multirow[b]{2}{*}{$\begin{array}{c}\mathrm{N}^{0} \text { da } \\
\text { Família }\end{array}$} & \multirow[b]{2}{*}{$\begin{array}{c}\text { \% de Pólos } \\
\text { Representados } \\
\text { pela Família }\end{array}$} \\
\hline $\begin{array}{l}\text { Direção do } \\
\text { Mergulho } \\
\text { (o) }\end{array}$ & $\begin{array}{l}\text { Mergulho } \\
\text { (o) }\end{array}$ & $\begin{array}{l}\text { Direção de } \\
\text { Mergulho } \\
\text { (o) }\end{array}$ & $\begin{array}{l}\text { Mergulho } \\
\text { (o) }\end{array}$ & & \\
\hline 264 & 2 & 84 & 88 & 3 & 12 \\
\hline 291 & 39 & 111 & 51 & 2 & 5 \\
\hline 326 & 36 & 146 & 54 & 1 & 16 \\
\hline 81 & 39 & 261 & 51 & 5 & 8 \\
\hline 93 & 7 & 273 & 83 & 4 & 11 \\
\hline 123 & 47 & 303 & 43 & 6 & 6 \\
\hline \multicolumn{6}{|c|}{ Ponto 2 de Levantamento } \\
\hline \multicolumn{2}{|c|}{ Pólo do Plano da Fratura } & \multicolumn{2}{|c|}{ Plano da Fratura } & \multirow[b]{2}{*}{$\begin{array}{c}\mathrm{N}^{\circ} \mathrm{da} \\
\text { Família }\end{array}$} & \multirow[b]{2}{*}{$\begin{array}{c}\text { \% de Pólos } \\
\text { Representados } \\
\text { pela Família }\end{array}$} \\
\hline $\begin{array}{l}\text { Direção do } \\
\text { Mergulho } \\
\text { (o) }\end{array}$ & $\begin{array}{l}\text { Mergulho } \\
\text { (o) }\end{array}$ & $\begin{array}{l}\text { Direção de } \\
\text { Mergulho } \\
\text { (o) }\end{array}$ & $\begin{array}{l}\text { Mergulho } \\
\text { (o) }\end{array}$ & & \\
\hline 313 & 49 & 133 & 41 & 1 & 14 \\
\hline 20 & 46 & 200 & 44 & 5 & 7 \\
\hline 82 & 33 & 262 & 57 & 4 & 12 \\
\hline 176 & 48 & 356 & 42 & 3 & 11 \\
\hline 177 & 7 & 357 & 83 & 2 & 12 \\
\hline \multicolumn{6}{|c|}{ Ponto 3 de Levantamento } \\
\hline \multicolumn{2}{|c|}{ Pólo do Plano da Fratura } & \multicolumn{2}{|c|}{ Plano da Fratura } & \multirow[b]{2}{*}{$\begin{array}{c}\mathrm{N}^{\circ} \mathrm{da} \\
\text { Família }\end{array}$} & \multirow[b]{2}{*}{$\begin{array}{l}\text { \% de Pólos } \\
\text { Representados } \\
\text { pela Família }\end{array}$} \\
\hline $\begin{array}{l}\text { Direção do } \\
\text { Mergulho } \\
\text { (o) }\end{array}$ & $\begin{array}{l}\text { Mergulho } \\
\text { (o) }\end{array}$ & $\begin{array}{l}\text { Direção de } \\
\text { Mergulho } \\
\text { (o) }\end{array}$ & $\begin{array}{l}\text { Mergulho } \\
\text { (o) }\end{array}$ & & \\
\hline 351 & 45 & 171 & 45 & 1 & 18 \\
\hline 359 & 1 & 179 & 89 & 2 & 12 \\
\hline 95 & 48 & 275 & 42 & 3 & 10 \\
\hline 167 & 47 & 347 & 43 & 4 & 12 \\
\hline
\end{tabular}




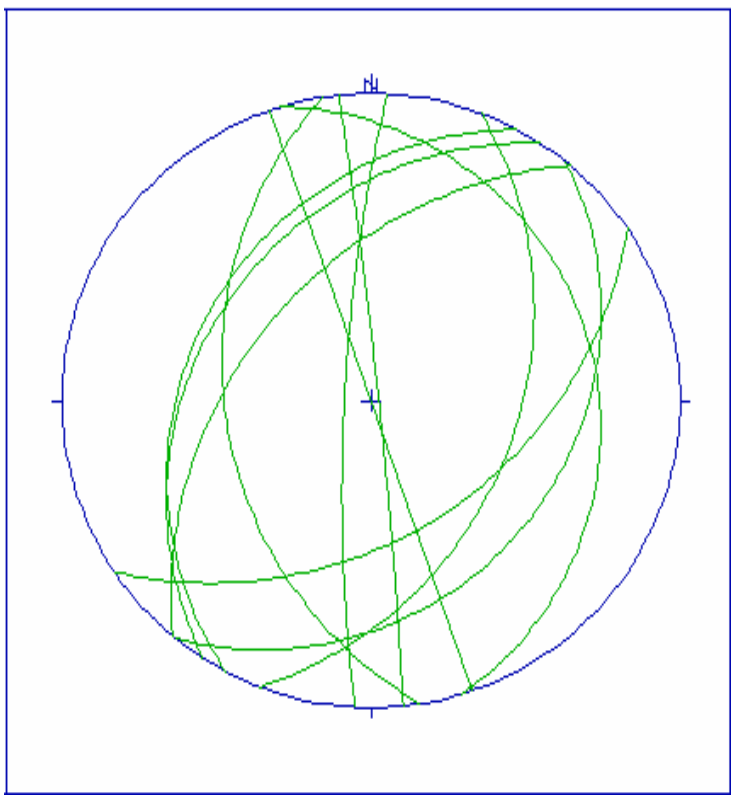

a)

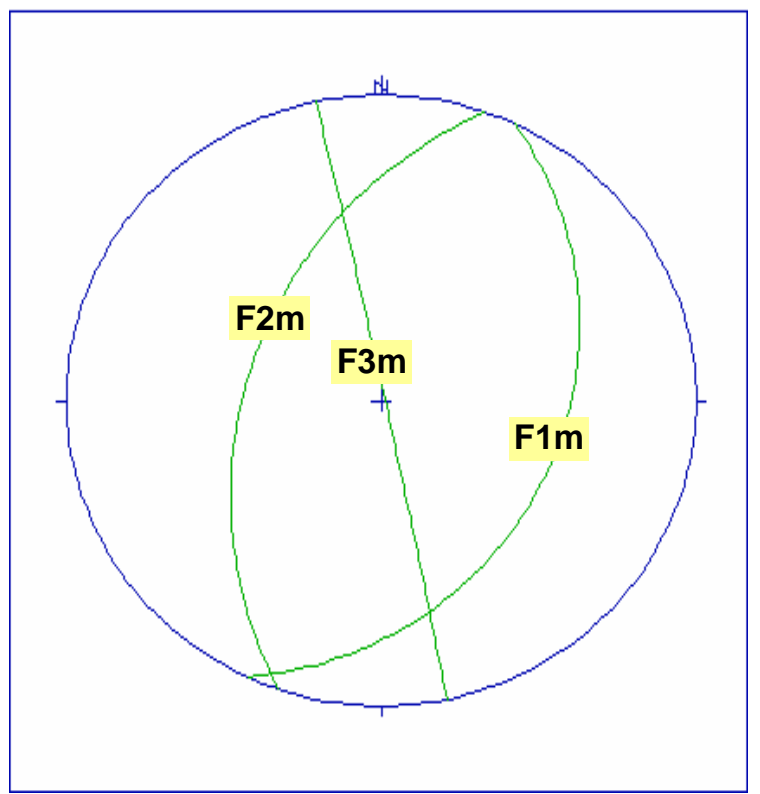

b)

Figura A2.5 - a) Orientações das famílias presentes nos locais P1 e P4; b) Orientação média dos planos que representam as famílias presentes nos locais P1 + P4 agrupados Projeção no hemisfério inferior.

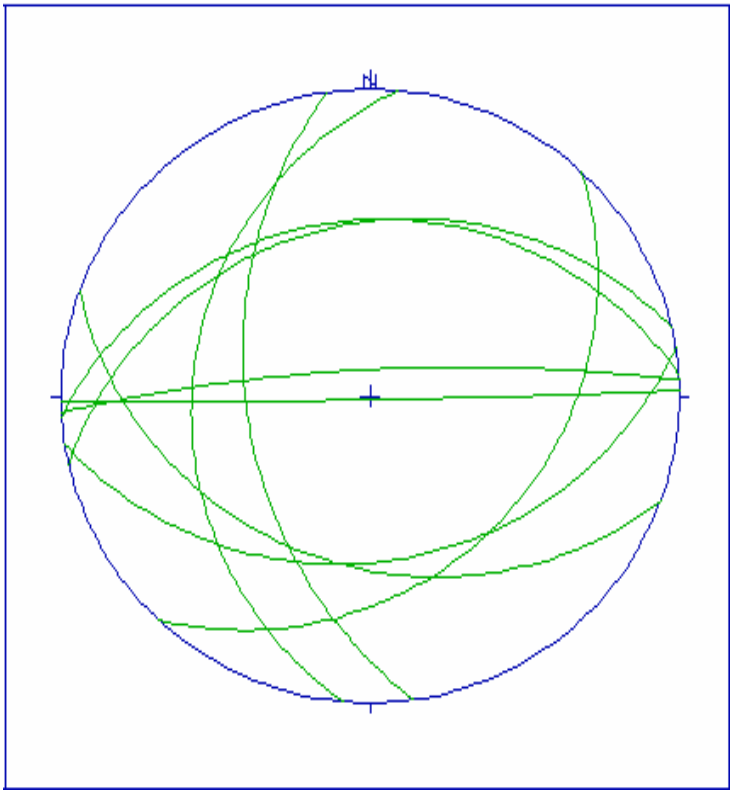

a)

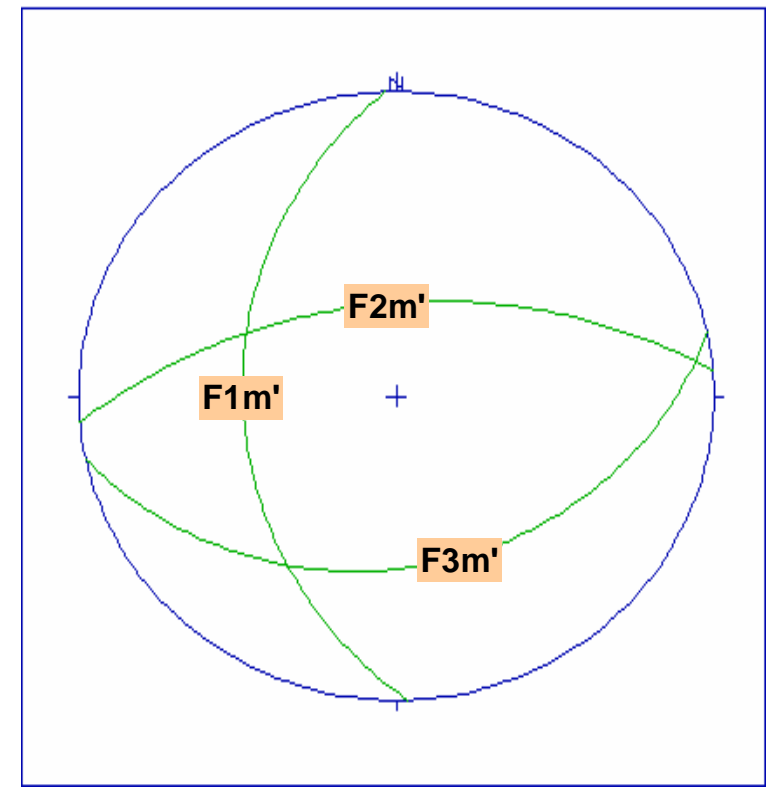

b)

Figura A2.6 - a) Orientações das famílias presentes nos locais P2 e P3; b) Orientação média dos planos que representam as famílias presentes nos locais P2 + P3 agrupados Projeção no hemisfério inferior. 
Tabela A2.2 - Orientações médias definidas para representar as famílias de descontinuidades presentes nas duas áreas de levantamento na camada de carvão Bonito, na Mina Fontanella.

\begin{tabular}{|c|c|c|c|c|}
\hline $\begin{array}{c}\text { Área de } \\
\text { Levantamento }\end{array}$ & Família & $\begin{array}{l}\text { Direção do } \\
\text { Mergulho } \\
\text { (o) }\end{array}$ & $\begin{array}{c}\text { Mergulho } \\
\text { (o) }\end{array}$ & $\begin{array}{l}\text { Ângulo Formado } \\
\text { entre as Famílias } \\
\text { (o) }\end{array}$ \\
\hline \multirow{3}{*}{$\begin{array}{c}14 \\
(\mathrm{P} 1+\mathrm{P} 4)\end{array}$} & $\mathrm{F} 1 \mathrm{~m}$ & 115 & 42 & \multirow{3}{*}{$\begin{array}{l}F 1 m \text { e } F 2 m=103 \\
F 1 m \text { e } F 3 m=54 \\
F 2 m \text { e } F 3 m=134\end{array}$} \\
\hline & $\mathrm{F} 2 \mathrm{~m}$ & 289 & 55 & \\
\hline & F3m & 078 & 89 & \\
\hline \multirow{3}{*}{$\begin{array}{c}23 \\
(P 2+P 3)\end{array}$} & $\mathrm{F} 1 \mathrm{~m}^{\prime}$ & 268 & 50 & \multirow{3}{*}{$\begin{array}{l}F 1 m^{\prime} \text { e } F 2 m^{\prime}=73 \\
F 1 m^{\prime} \text { e } F 3 m^{\prime}=68 \\
F 2 m^{\prime} \text { e } F 3 m^{\prime}=108\end{array}$} \\
\hline & $\mathrm{F} 2 \mathrm{~m}^{\prime}$ & 355 & 65 & \\
\hline & F3m' & 168 & 43 & \\
\hline
\end{tabular}

\section{A2.2 Freqüência das Descontinuidades}

Além da alternativa descrita no Capítulo 4, outras duas alternativas distintas foram adotadas para a computação do espaçamento médio e da sua recíproca, a freqüência média de fraturas por metro, das diferentes famílias identificadas.

A definição do espaçamento médio de cada família de fraturas foi precedida pela correção da distância medida in situ (distância aparente), considerando-se a orientações da linha de levantamento e da descontinuidade (direção do mergulho e mergulho). Por conveniência, será utilizado como parâmetro indicativo da densidade de fraturas a recíproca do espaçamento, ou seja, a freqüência média de fraturas por metro $(\lambda)$, calculada segundo a expressão proposta por PRIEST \& HUDSON (1981):

$$
\left.\lambda=\frac{\frac{1}{\sum_{i=1}^{N-1} X_{i}}}{N-1} \text { (fraturas } / \mathrm{m}\right)
$$

onde: $\frac{\sum_{i=1}^{N-1} X_{i}}{N-1}=$ espaçamento médio entre fraturas de uma mesma família;

$\mathrm{X}_{\mathrm{i}}=$ distância (corrigida) medida ortogonalmente entre duas fraturas adjacentes $(\mathrm{m})$;

$\mathrm{N}=$ número de fraturas pertencentes à família ou grupo de famílias com orientação semelhante.

\section{Alternativa 1}

O cálculo do espaçamento médio entre fraturas e da freqüência média de fraturas por metro, de cada família ou grupo de famílias, foi feito considerando cada uma das linhas, em cada ponto de levantamento, individualmente. Após a correção da distância aparente medida, as freqüências médias foram computadas. Os resultados podem ser vistos no Tabela A2.3. 
Tabela A2.3 - Freqüências médias de fraturas por metro das principais famílias identificadas em cada linha nos 4 pontos de levantamento na camada de carvão Bonito na Mina Fontanella.

\begin{tabular}{|c|c|c|c|c|}
\hline \multicolumn{5}{|c|}{ Ponto 1 de Levantamento } \\
\hline \multirow{2}{*}{$\begin{array}{l}\text { Linha de } \\
\text { Levantamento }\end{array}$} & \multirow{2}{*}{$\begin{array}{c}\text { Direção da } \\
\text { Linha de } \\
\text { Levantamento } \\
\text { (o) }\end{array}$} & \multicolumn{3}{|c|}{$\begin{array}{l}\text { Freqüência Média de Fraturas, } \lambda \\
\text { (fraturas } / \mathrm{m} \text { ) }\end{array}$} \\
\hline & & Famílias 3 e 4 & Famílias 1 e 5 & Família 2 \\
\hline L1 & 106 & $1,16(9)$ & $2,18(15)$ & NP \\
\hline L2 & 106 & $0,20(2)$ & $2,12(4)$ & $0,69(2)$ \\
\hline L3 & 196 & $0,96(2)$ & $\mathrm{NP}$ & $4,63(2)$ \\
\hline L4 & 106 & $0,18(3)$ & $1,98(7)$ & $1,09(3)$ \\
\hline L5 & 196 & $0,81(3)$ & $0,46(3)$ & $0,29(3)$ \\
\hline \multicolumn{2}{|c|}{$\begin{array}{l}\text { Freqüência Média Ponderada } \\
\text { da(s) Família(s) }\end{array}$} & 0,83 & 1,95 & 1,48 \\
\hline \multicolumn{5}{|c|}{ Ponto 4 de Levantamento } \\
\hline \multirow{2}{*}{$\begin{array}{l}\text { Linha de } \\
\text { Levantamento }\end{array}$} & \multirow{2}{*}{$\begin{array}{c}\text { Direção da } \\
\text { Linha de } \\
\text { Levantamento } \\
\text { (o) }\end{array}$} & \multicolumn{3}{|c|}{$\begin{array}{c}\text { Freqüência Média de Fraturas, } \lambda \\
\text { (fraturas } / \mathrm{m})\end{array}$} \\
\hline & & Famílias 1 e 2 & Famílias 4, 5 e 6 & Família 3 \\
\hline $\mathrm{L} 1$ & 286 & $1,33(9)$ & $0,64(3)$ & NP \\
\hline L2 & 286 & $0,96(5)$ & $1,04(12)$ & $0,65(3)$ \\
\hline L3 & 016 & $0,47(3)$ & $2,55(14)$ & $1,34(4)$ \\
\hline L4 & 016 & $1,45(4)$ & $0,97(4)$ & $2,59(4)$ \\
\hline L5 & 286 & $1,96(8)$ & $0,91(4)$ & NP \\
\hline \multicolumn{2}{|c|}{$\begin{array}{l}\text { Freqüência Média Ponderada } \\
\text { da(s) Família(s) }\end{array}$} & 1,37 & 1,56 & 1,61 \\
\hline \multicolumn{5}{|c|}{ Ponto 2 de Levantamento } \\
\hline \multirow{2}{*}{$\begin{array}{l}\text { Linha de } \\
\text { Levantamento }\end{array}$} & \multirow{2}{*}{$\begin{array}{c}\text { Direção da } \\
\text { Linha de } \\
\text { Levantamento } \\
\text { (o) }\end{array}$} & \multicolumn{3}{|c|}{$\begin{array}{l}\text { Freqüência Média de Fraturas, } \lambda \\
\text { (fraturas } / \mathrm{m} \text { ) }\end{array}$} \\
\hline & & Família 4 & Famílias 2 e 3 & Famílias 1 e 5 \\
\hline $\mathrm{L} 1$ & 286 & $0,37(2)$ & $1,80(8)$ & $1,47(8)$ \\
\hline L2 & 335 & NP & $0,21(3)$ & $1,16(8)$ \\
\hline L3 & 046 & NP & $0,85(5)$ & $0,64(5)$ \\
\hline L4 & 046 & $1,97(6)$ & $2,34(4)$ & $\mathrm{NP}$ \\
\hline L5 & 106 & NP & $1,12(5)$ & NP \\
\hline \multicolumn{2}{|c|}{$\begin{array}{l}\text { Freqüência Média Ponderada } \\
\text { da(s) Família(s) }\end{array}$} & 1,57 & 1,37 & 1,15 \\
\hline \multicolumn{5}{|c|}{ Ponto 3 de Levantamento } \\
\hline \multirow{2}{*}{$\begin{array}{l}\text { Linha de } \\
\text { Levantamento }\end{array}$} & \multirow{2}{*}{$\begin{array}{c}\text { Direção da } \\
\text { Linha de } \\
\text { Levantamento } \\
\text { (o) }\end{array}$} & \multicolumn{3}{|c|}{$\begin{array}{l}\text { Freqüência Média de Fraturas, } \lambda \\
\text { (fraturas } / \mathrm{m} \text { ) }\end{array}$} \\
\hline & & Família 3 & Famílias 2 e 4 & Família 1 \\
\hline $\mathrm{L} 1$ & 046 & $0,36(8)$ & $0,58(15)$ & $0,54(11)$ \\
\hline L2 & 316 & NP & $1,29(9)$ & $0,59(7)$ \\
\hline L3 & 316 & $0,54(3)$ & $1,34(4)$ & $1,43(6)$ \\
\hline \multicolumn{2}{|c|}{$\begin{array}{l}\text { Freqüência Média Ponderada } \\
\text { da(s) Família(s) }\end{array}$} & 0,41 & 0,92 & 0,80 \\
\hline
\end{tabular}

Nota 1: Números entre parênteses = número de fraturas observadas.

Nota 2: NP - família(s) de fraturas não presente(s) na linha de levantamento. 


\section{Alternativa 2}

A determinação do espaçamento médio e da freqüência média de cada família foi feita considerando os pontos de levantamento agrupados dois a dois, em função da proximidade na área de estudo. Adicionalmente, como nas linhas de levantamento mais curtas algumas famílias não foram suficientemente representadas e, considerando que algumas famílias definidas inicialmente constituem-se em variações de uma mesma família, duas ou mais famílias foram agrupadas e consideradas como uma única família. O resultado desse agrupamento ficou assim definido:

- Área 14 - formada pelos pontos 1 e 4 de levantamento e as famílias agrupadas da seguinte forma:

- P1 - famílias 3 e 4 D 4 - famílias 1 e 2;

-P1 - famílias 1 e $5 \equiv P 4$ - famílias 4,5 e 6 ;

- P1 - família $2 \equiv \mathrm{P} 4$ - família 3 .

- Área 23 - formada pelos pontos 2 e 3 de levantamento e as famílias agrupadas da seguinte forma:

- P2 - família $4 \equiv P 3$ - família 3;

- P2 - famílias 2 e 3 झ P3 - famílias 2 e 4;

- P2 - família 1 e 5 इP3 - família 1.

Da mesma forma que na análise por linha de levantamento, as distâncias foram corrigidas e as freqüências médias de fraturas por metro foram calculadas.

A Tabela A2.4 apresenta as freqüências médias ponderadas das famílias representativas das áreas 14 e 23.

Já os resultados de freqüência média das principais famílias nos pontos de levantamento agrupados são apresentados nas Tabelas A2.5a e A2.5b, juntamente com os histogramas de espaçamentos entre fraturas e a curva da distribuição exponencial de probabilidade ajustada aos dados de campo.

Tabela A2.4 - Freqüências médias de fraturas por metro das famílias representativas das duas áreas de levantamento na camada Bonito, na Mina Fontanella.

\begin{tabular}{|c|c|c|c|}
\hline $\begin{array}{c}\text { Área de } \\
\text { Levantamento }\end{array}$ & \multicolumn{3}{|c|}{ Freqüência Média Ponderada de Fraturas, $\lambda$} \\
(fraturas/m)
\end{tabular}


Quadro A2.5a - Freqüências médias de fraturas por metro das principais famílias, agrupadas por ponto de levantamento, identificadas na área 14 na camada Bonito, na Mina Fontanella. Nos histogramas, distribuição da freqüência de espaçamento entre fraturas e a função da distribuição exponencial de probabilidade ajustada.

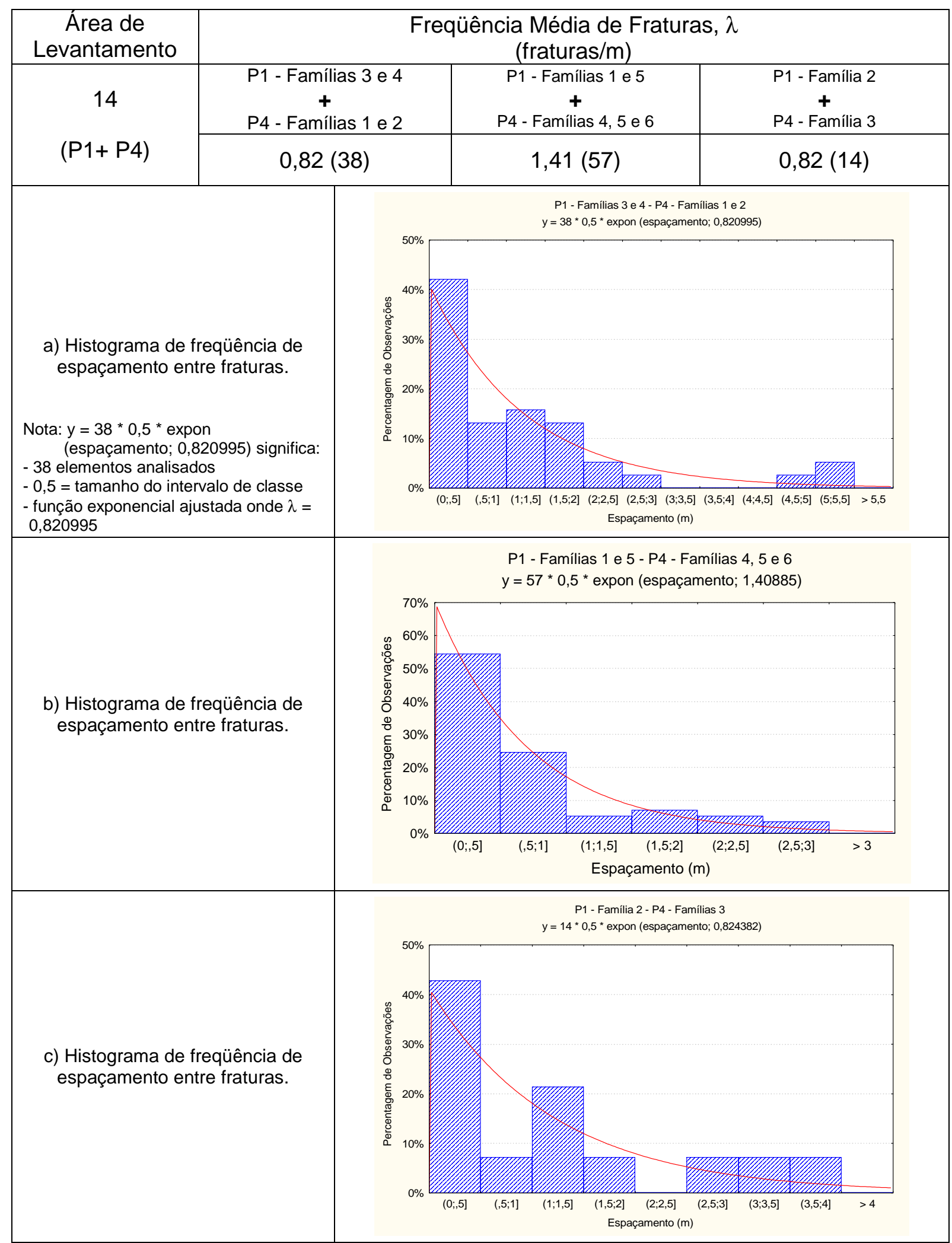

Nota: Números entre parênteses = número de fraturas observadas. 
Quadro A2.5b - Freqüências médias de fraturas por metro das principais famílias, agrupadas por ponto de levantamento, identificadas na área 23 na camada Bonito, na Mina Fontanella. Nos histogramas, distribuição da freqüência de espaçamento entre fraturas e a função de distribuição exponencial de probabilidade ajustada.

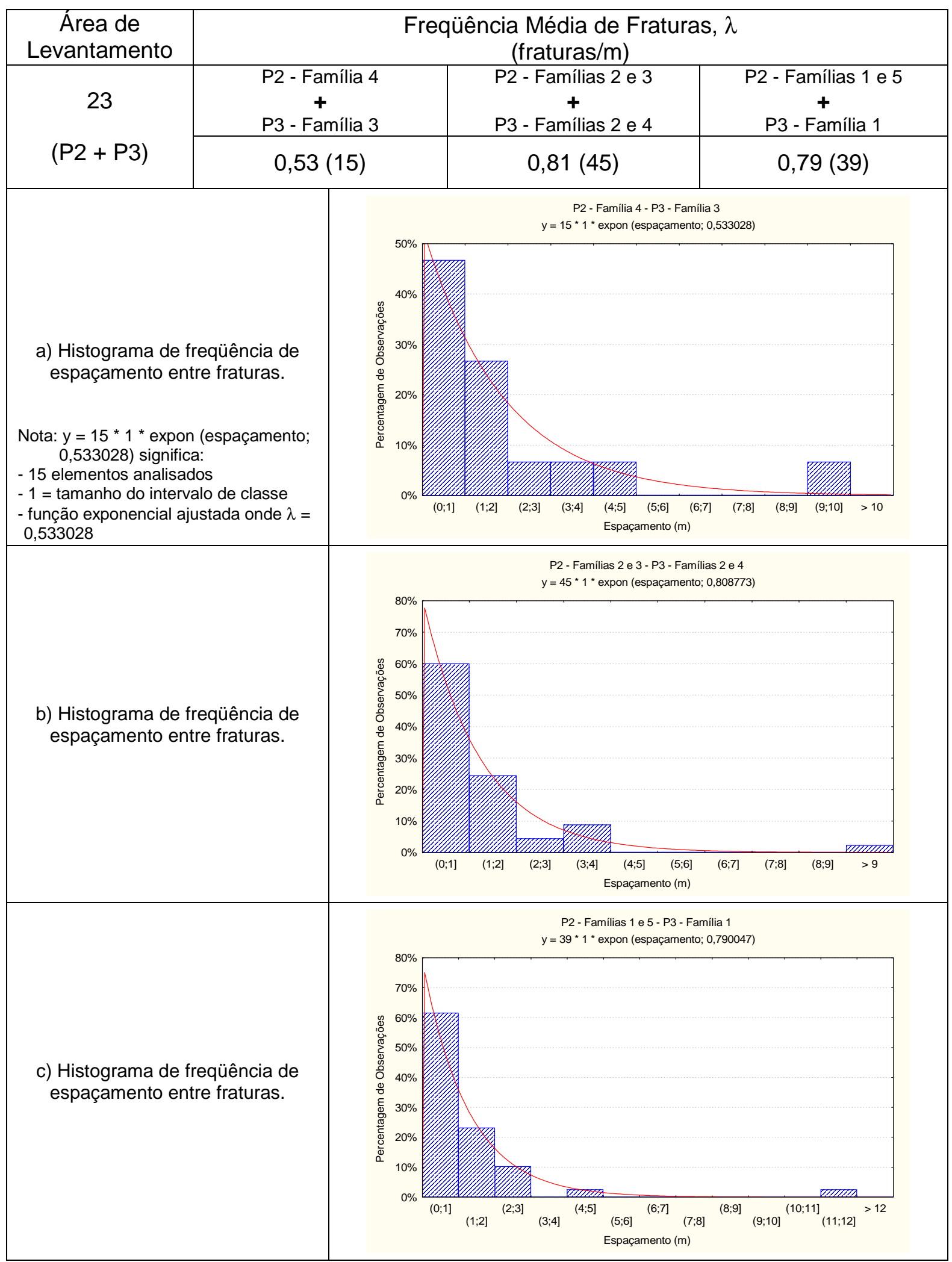

Nota: Números entre parênteses = número de fraturas observadas. 